\title{
SEISMIC SAFETY GUIDE
}

\author{
Compiled and Edited by \\ Donald G. Eagling \\ Plant Manager \\ Lawrence Berkeley Laboratory \\ Engineering and Technical Services Division
}

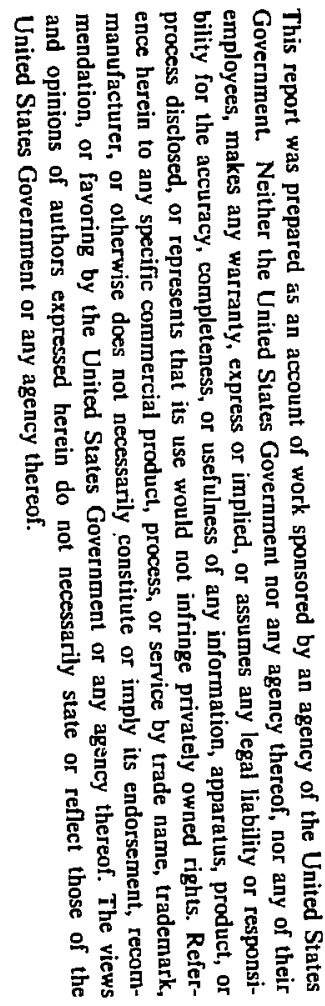

Jack R. Benjamin

Jack R. Benjamin and

Associates, Inc.

Consulting Engineers

Wendell S. Bril

International

Conference of

Building Officials

John J. Earle

Shapiro, Okino, Hom

and Associates

Engineers

Consultants

\section{MOTIEE \\ PORTIONS OF THIS REPORT ARE ILLEGIRLE. \\ It has been reproduced from the best \\ availab!e copy to permit possible availability.}

Harold M. Engle, Jr.

Engle and Engle

Structural Engineers

Stephen R. Korbay

and

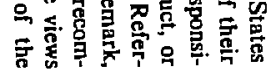

Lyle E. Lewis

Harding Lawson Associates

Engineers, Geologists and

Geophysicists

Roland L. Sharpe

Engineering Decision

Analysis Company, Inc.

James L. Stratta

Consulting Engineer

\section{Lawrence Berkeley Laboratory \\ University of California \\ Berkeley, California 94720}

\section{MASTER}

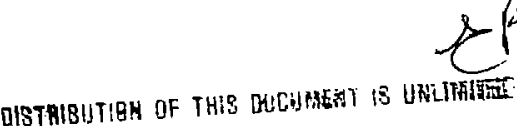

Prepared for the Office of Nuclear Safety, Assistant Secretary for Environmental Protection, Safety, and Emergency

Preparedness, U. S. Department of Energy under Contract DE-AC03-76SF00098. 


\section{CONTENTS}

Preface

Page

Chapter 1

Introduction

Donald G. Eagling

Chapter 2

Donald G. Eagling

The Operator-Manager's Role in

Earthquake Safety

Chapter 3

James L. Stratta

Earthquake Damage

Foreword

3-1

Chapter 4

Stephen R. Korbay and

L.yle E. Lewis

Site-Use Planning for Earthquake Safety

Foreword 4-1

Appendices
A. Earthquake Measurement
B. Maximum Credible and Maximum Probable Earthquakes
C. Seismicity of the United States

Chapter 5

Roland L. Sharpe

Design of New Facilities for Earthquake Safety Appendices

A. Excerpts from Uniform Building
Code (UBC), 1982 Edition

B. "Discontinuities in Strength of Vertical Resisting System."

C. "Ductile Concrete Space Frames."

D. Excerpt fron? ATC-3-06, "Tentative Provisions for the Development of Seismic Regulations for Buildings."

Chapter 6

Harold M. Engle, Jr.

Evaluation of Existing Buildings

Foreword

Appendices

A-D. Inspection Reports

6-16

E. Design Summary

6-20

Chapter 7

John J. Earle

Rehabilitation of Buildings for

Foreword

Earthquake Resistance

Chapter 8

James L. Stratta

Evaluation of Operations and

Foreword

8-1

Building Contents

8-5 
Chapter 9

Donald G. Eagling

Chapter 10

Jack R. Benjamin

Chapter 11

John J. Earle

Chapter 12

Wendell S. Bril
Emergency Planning for Earthquake Safety

$9-1$

Foreword 10-1

Risk Management

$10-5$

Design of Concrete Shielding

Foreword $\quad 11-1$

Blocks for Earthquake Safety

$11-3$

Foreword

$12-1$

Model Code and Related Services 


\section{PREFACE}

Author Donald Eagling writes: "Often the process of studying the seismology of an area, selecting design earthquakes, and developing priorities and analysis techniques becomes so complex and bound up with sophisticution that the (seismic) program's practical oojectives are lost in the cracks between experts." How true!

As a person who has been part of the earthquake engineering profession for over 40 years I have observed the rapid growth of sophisticated earthquake engineering analysis and design practices. As a former educator I applaud the great progress brought about by this thrust. Sophisticated "state of the art" analyses accomplished with understanding have brought about better earthquake resistive construction and have the potential to continue to do so. However, it is my personal opinion that the complexities of today's most advanced anslytical techniques have outstripped the capabilities of the majority of structural engineering's practitioners. While many can manipulate the mathematics, most do not understand the results in physical terms. Over the last few decades public debate about the safety of nuclear facilities has intensified this problem. In the eyes of many, the potential intervenor is "demon god," and to appease this "god" an even increasing complexity of investigations, analyses and design practices have been served to it in the name of increased safety. Various proposals for appeasement have been to no avail. Opposing arguments have always favored more sophisticated and costly engineering practices and usually more studies have been required. Too often the result has been to put off relatively simple solutions to seismic problems. Where new construction is involved, costs increase with time but the hazard does not. Where existing poor construction is involved, hazards as well as costs grow with time. When the nitigation of serious seismic hazards is delayed by overly sophisticated reviews or studies, the practical objectives of seismic safety are simply not realized in timely way.

During these times when socio-political issues often dominate public discussion of seismic safety, it is more important than ever to move ahead with practical and corrective action where the consequences of damaging earthquakes can be serious.

The authors of this Seismic Safety Guide represent a cross section of the earthquake engineering profession, from state of the art to practitioner. I recommend their counsel in the chapters that follow for a practical course to seismic safety. 


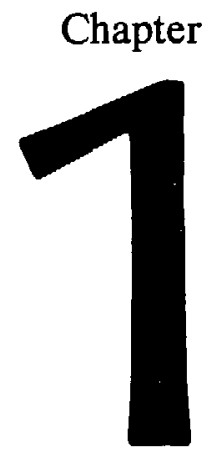

\title{
Introduction
}

\author{
Donald G. Eagling \\ Civil Engineer \\ Plant Manager \\ Lawrence Berkeley Laboratory
}

Mr. Eagling joined the University of California's Lawrence Berkeley Laboratory (LBL) in 1963, after eight years as Structural and Soils Engineer for Libbey-Owens-Ford Glass Co., and five years with the California Division of Highways. In his new position at LBL he was responsible for the conceptual design of physical plant facilities for a 200 billion electron volt accelerator, then estimated to cost 350 million dollars.

In 1967 he was appointed Plant Manager in charge of Plant Engineering. Construction Management, and Construction and Maintenance departments. He is responsible for planning, design, construction, maintenance and operations of LBL physical plant facilities.

Mr. Eagling is a Registered Civil Engineer in California, a member of the Structural Engineers Association of Northern California, and of the Earthquake Engineering Research Institute; he also is a Class A Member of the International Conference of Building Officials, representing LBL. He holds a Master of Engineering degree from the University of Michigan, where he majored in structures and soils engineering.

This Seismic Safety Guide provides managers of U.S. Department of Energy (DOE) facilities with practical guidelines for administering a comprehensive earthquake safety program. Because of an increasing awareness of seismic risk, such a guide is badly needed. Often the approach to reviewing existing facilities for seismic safety is so overly sophisticated that the actual abatement of obvious deficiencies is delayed, costly, and often legalistic rather than objective. Furthermore, it is widely observed that still today buildings are generally being constructed without benefit of a seismic plan check, a simple process that has proved so effective in actual experience with earthquakes in California.

Significantly. structural engineers who have observed and studied damaged buildings in the aftermath of earthquakes are generally able to diagnose hazardous deficiencies in existing buildings rather easily and efficiently. It is seldom necessary to carry out elaborate analyses to evaluate the seismic resistance of structures. The process of review does not have to be expensive or complex. Often, the problems found in construction and design are simply the results of failure to implement what has been known and observed about earthquake engineering for many years.

The objective of this Seismic Safety Guide is to provide practical advice about earthquake safety and engineerin, to Managers of DOE facilities so that they can get the job done without falling into common pitfalls and prolonged diagnosis. This Guide provides the Manager with basic guidelines and methodology, but is intended neither as a textbook nor as a substitute for the use of competent consultants.

The Guide is comprehensive with respect to earthquakes in that it covers the most important aspects of 
natural hazards, site planning, evaluation and rehabilitation of existing buildings, design of new facilities, operational safety, emergency planning, special considerations related to shielding blocks, non-structural elements, lifelines, fire protection and emergency facilities. Management of risk and liabilities are also covered. Nuclear facilities per se are not dealt with specifically. The principles covered in the Guide also apply generally to nuclear facilities but the design and construction of such structures vre subject to special regulations and legal controls.

Each section of the Guide was written by a professional with solid design and field experience in his subject. Conment and advice from the OperatorManager's point of view is also provided in the Foreword to each consultant-authored section to bridge the gap between earihquake engineering and operational reality.

\section{Seismic Review of LBL Facilities}

Lawrence Berkeley Laboratory (LBL) is a multipurpose DOE facility operated by the University of California, engaged in large-scale fundamental research and applied science. It is located in the San Francisco Bay Area in "earthquake country." In February 197I, following the destructive San Fernando earthquake in Southern California, LBL initiated a comprehensive review of its existing facilities and operations to improve earthquake safety.

The experience was enlightening. At LBL, all except a few old buildings were designed by professional architects and engineers, licensed in California, using the Uniform Building Code. All structures had received construction inspection. In spite of these procedures, the earthquake safety survey revealed that significant structural deficiencies, stemming from many sources, were present in over $50 \%$ of the buildings reviewed. Several old buildings had no formal lateral-forceresisting system. In other buildings, deficiencies were related to modifications after construction that inadvertently altered the lateral-force-resisting system. Design deficiencies, relatively few in number, were usually due to the lack of a clear, comprehensive design philosophy rather than to design error. Generally, not enough consideration for non-structural elements in buildings and life line services was given by the designer.

Significantly, most hazardous deficiencies in existing buildings were relatively simple to diagnose. They were quickly found by practical techniques used by structural engineers specializing in earthquake safety. Sophisticated analysis techniques were not required and in fact would have complicated and slowed the entire process of deteclion and, consequently, correction.

Sixty buildings, as well as critical site-utilities and emergency facilities, were inspected. Non-structural elements and operational conditions were also inspected and analyzed in order to minimize unnecessary hazards.
The site proper was studied to identify, delineate and evaluate natural seismic hazards such as possible fault displacement and earthquake-triggered subsidence and landslides. Special facilities such as shielding blocks. storage for hazardous materials, communications centers, medical" services and emergency generators received careful attention. The order of inspection was based on a priority system which considered life safety. emergency recovery capacity, off-site consequences, program continuity and property value. The order of subscquent projects to abate hazards and improve earthquake safety was based on a separate priority system. This included consideration of the probability of earthquake occurrence. the structure's probable response, the severity of human exposure and property damage, and the possibility of off-site consequences. The system also evaluated the relative priority of projects to abate other types of risk such as fire, pollution. industrial hazards and radiation.

These priority sys!ems were simplistic and judgmental. Although due process was followed, the level of sophistication and complexity was minimized in favor of decisiveness and practicality. Structural deficiencies and operational hazards which could be easily corrected were promptly abated. When more complex hazards were identified, interim action was undertaken to reduce risks until the process of full abatement could take place. Over 30 buildings at LBL were strengthened; four were evacuated and later demolished. Projects to repair or strengthen structural systems, non-structural elements and lifelines were carried out on a priority basis over several years.

The cost of the earthquake safety survey by LBL's specialized consultants amounted to $\$ 50,000$ or $0.06 \%$ of the replacement value of all buildings surveyed, not including contents. Costs for all building corrections totaled about $1.0 \%$ of replacement value. Throughout the earthquake safety survey and subsequently during the design and construction of projects for strengthening buildings, LBL used services of consultants specializing in all phases of earthquake science and engineering, including seismology, geology, soils, dynamics, earthquake risk analysis, and structural design. LBL also conducted shaking-table research with concrete shielding blocks in conjunction with the University of California's Earthquake Engineering Research Center. The International Conference of Building Officials, publishers of the Uniform Building Code, provided advice and consultation at various stages of the program.

The earthquake safety survey and improvement program at LBL has been a comprehensive experience in practical risk management. From this perspective it has been our observation that some earthquake safety programs elsewhere have tended to become too sophisticated, complex, and expensive for expeditious achievement of desired results. Often the process of studying the seismology of an area, selecting "design" earthquakes, and developing priorities and analysis tech- 
niques, becomes so complex and bound up with sophistication that the program's practical objectives are lost in the cracks between experts.

Fortunately, the consultants and specialists who have assisted LBL with its earthquake safety program counseled a practical course which achieved early results and minimized costs. It was with their advice and support that the concept for this Seismic Safery Guide was developed, Its emphasis, then, is on the practical application of earthquake safety rather than the state-of-theart.

\section{Acknowledgements}

The LBL. Seismic Safety Program has come a long way since early 1971 when the San Fernando Earthquake provided stimulus for the Laboratory to embark on a complete review of its facilities. During the year before the 197 I earthquake, Kari V. Steinbrugge, Chief Structural Engineer for Pacific Fire Rating Bureau (predecassor to Insurance Services Office), volunteered to visit our Laboratory and make an informal and cursory assessment of the nature of damage that might take place as the result of an intense earthquake. Karl was then Professor of Structural Design, Department of Architecture (now Professor Emeritus) at UC Berkeley and one of the most respected earthquake engineers in the profession. His wealth of experience in reviewing earthquake damage throughout the world led us to seek his advice. Karl's informal assessment in 1970 of the probable damage to $\mathrm{LBL}$ if an intense earthquake should occur was 30 to 40 million dollars. This news was rather shocking and prompted us, with Karl's help. to plan and outline a program for a complete seismic review of $\mathrm{LBL}$ facilities by independent earthquake engineers. Our proposal was under review by LBL Management when the San Fernando Earthquake took place; it was accepted one day later.

Much of Karl's energy over the years had been directed to improving public policy and safety in the face of the inevitable great earthquake. His contributions, which have been enormous, cannot be adequately described in this short space. They include, however, Chairmanship of the President's Task Force on Earthquake Hazard Reduction, the Seismic Safety Commission of the State of California, and the U.S. National Committee on Earthquake Engineering. $\mathrm{He}$ has also been President of the Earthquake Engineering Research Institute and the Seismological Society of America. As a consultant, he served the Nuclear Regulatory Commission Advisory Committee on Reactor Safeguard: the National Oceanic and Atmospheric Administration and the U.S. Geological Survey. Karl's recent book, Earthquakes, Volcanoes, and Tusunamis, Scandia America Group, 280 Park Avenue, New York, NY 10017,1982 , is a valuable reference document based on his writings, including previously unpublished papers. His voluntary contribution to our Seismic Safety Program is deeply appreciated by the Lawrence Berkeley Laboratory.
With Karl's counsel, LBL selected Engle and Engle, Structural Engineers, to carry out an independent review of LBL facilities. The late Harold M. Engle, Senior, was a true pioneer in earthquake engineering as well as a rugged individualist with very high professional standards. He also possessed a rare practical aptitude for confronting the basic issues in a way that enabled us to get the most seismic safety within the time and money available. Great strides were made in spite of the tight budgets of those times. Harold's sage advice and support kept LBL from being entangled in the endless and expensive studies and controversies that have plagued many seismic safety programs. Harold and his son, Harold Engle, Jr., who now carries on the work of the firm, were extremely effective in gettirig the job done efficiently and expeditiously, protecting people and property and avoiding sericus pitfalls in risk management.

LBL is indebted to the University of California Berkeley (UCB) for the contributions of many of its professional staff. Professor Bruce Bolt, Seismologist and Director of the Seismographic Station at UC Berkeley, provided design earthquake input for dynamic analysis where required. Professor Joseph Penzein, of the UC Civil Engineering Department and Director of Earthquake Engineering Research Center, also provided counsel for dynamic analyses and made recommendations with respect to complex seismic engineering problems. Professor William Godden, of the UCB Civil Engineering Department, collaborated with LBL's Dr. Theodore Scalice to carry out original research with concrete shielding blocks on UC Berkeley's 100 ton shaking table facility, and provided consultation to LBL's Seismic Safety Committee for special design reviews.

Frank E. McCiure, well known earthquake engineer, joined the LBL Plant Engineering staff in 1978 as Chief Structural Engineer. In Frank, LBL is fortunate to have a highly professional and experienced in-house capability in seismic engineering. His professional career includes long public service with the State of California's Seismic Safety Commission, the Field $\mathrm{Act}$ Advisory Board to the State Architect, the Earthquake Engineering Research Institute, and the Seismology Code Development Committee of the International Conference of Building Officials. Frank has provided key support and guidance for the LBL Seismic Safety Program. His encouragement and technical consultation in support of the development of this Seismic Safery Guide is greatly appreciated by the author

The Seismic Safety Program at LBL is carefully monitored by an in-house Seismic Safety Committee which recommends policy and participates in design reviews when state-of-the-art projects are involved and the design carries an assumption of risk which should be an institutional responsibility rather than that of an individual. Dr, Theodore Scalice, Chairman of the Seismic Safety Committee, has contributed heavily to LBL's Seismic Safety Program. In addition to this leadership 
roie, he has carried out original research in collaboration with UCB Professor William Godden. Their work has significantly contributed to the development of analysis and design procedures now used at LBL for the seismic restraint of shielding block systems and is described in Chapter 11 of this Guide.

Daniel Shapiro and John Earle of Shapiro, Okino, Hom and Associates, Structural Engineers; Harold Engle. Jr., of Engle and Engle, Structural Engineers; and James Stratta, Consulting Enginecr, all contributed heavily to the LBL Seismic Safety Program as well as to the Seismic Safety Guide. Each gave the author strong support for the concept that a seismic safety guide with practical advice would be a valuable reference for the Manager-Operator of DOE facilities.

Finally, James R. Hill, Project Manager for the Seismic Safety Guide, Oflice of Nuclear Safety, Assistant Secretary for Environmental Protection, Safety, and Emergency Preparedness, U. S. Department of Energy, Washington D. C., provided the vital sponsorship which made this publication feasible. Without his strong continuous support the Seismic Safety Guide would not exist. 


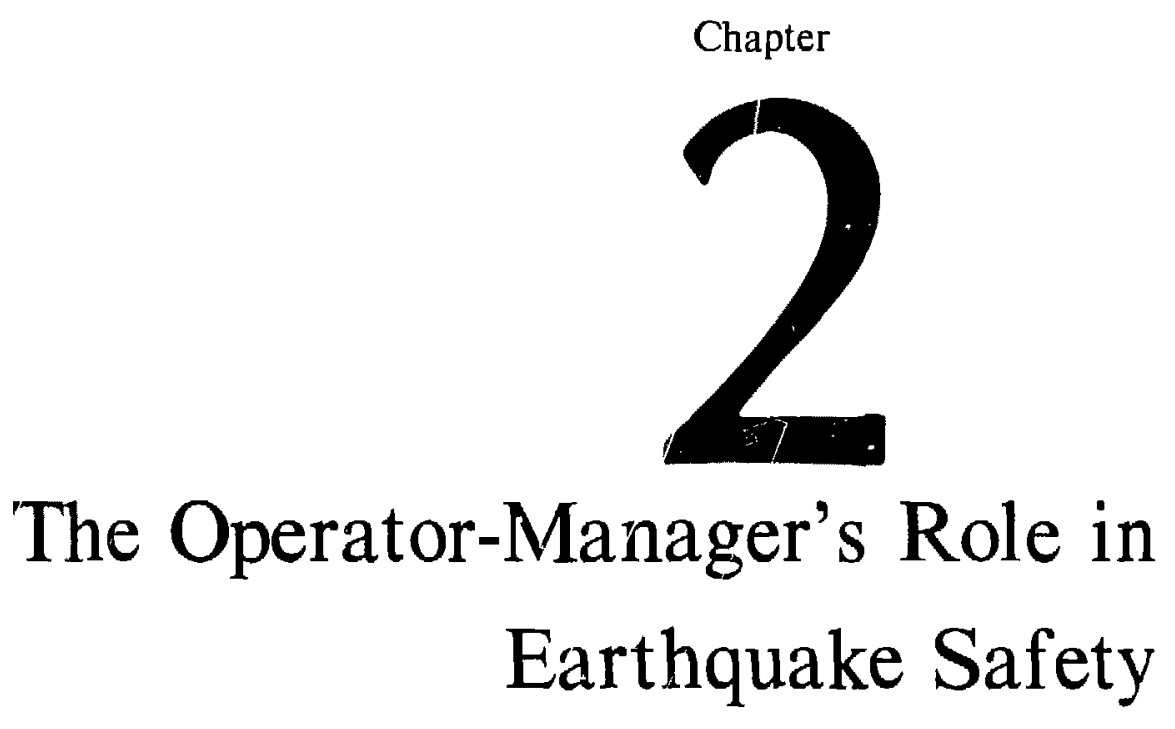

Donald G. Eagling

A comprehensive earthquake safety program can cover a lot of territory, certainly all of the elements covered in this Seismic Safety Guide. The scope, depth and focus required to carry out a satisfactory program will vary considerably with the age of a facility, the risk involved and the quality of design which was applied during its construction history. For a new and growing facility the focus will be on design and construction. For an older facili:; the need to evaluate existing conditions and prioritize projects for abatement of seismic hazards will receive most attention. For the majority of sites, however, a balanced program will be most effective in preventing further development of new hazards while reducing the backlog of old ones.

Those structural engineers who are experienced in earthquake engineering and have reviewed a number of facilities, both in government and private enterprise, have found a wide variety of serious seismic deficiencies that tile operator-managers were unaware existed. It is par for the course, even in areas of the country where seismic design provisions have been part of the building code for many years.

East of California, few conventional buildings in the United States have been designed for earthquakes, even where there has been a history of earthquakes of sufficient intensity to damage buildings. At those sites where the potential for seismic destruction exists along with a legacy of hazardous buildings and contents, the prospect of carrying out a comprehensive earthquake safety program is indeed challenging.

The operator-manager who is responsible for a facility is usually unfamiliar with earthquake engineering and may tend to look for answers in techniques that are more sophisticated than are required to solve the actual problems in earthquake safety. The approach to solutions of these problems can become so academic, ponderous, and expensive that the job of abatement of the seismic hazards simply doesn't get done in a timely manner.

In recent years, the state-of-the-art in seismology, geo-technical theory, and the dynamic analysis of structures has progressed tremendously. Spurred on by the need to resolve questions in seismic safety for nuclear pnwer plants, the field has become very compartmentalized and specialized. The great strides made in these specialties have contributed significantly to the field of earthquake engineering and public safety. Unfortunately, it is easy for the responsible manager, plant engineer, or administrator to "fall into a crack" between these experts who quite naturally tend to resolve seismic questions in compartmentalized, complex solutions based on their own specialties.

Often more time and money are expended on analyzing the problems in earthquake safety than would be needed to design practical solutions to these same problems. The situation is analogous to deploying a cannon to shoot a rabbit; the tools are not matched to the job. To gain a better perspective it is important to understand that most problems found in existing construction are a result of not implementing what is known and has been observed about earthquake-resistant construction. Structural engineers who have observed and studied earthquake-damaged buildings are able to diagnose hazardous deficiencies in existing buildings rather 
easily and efficiently, often without complex calculations. These experienced earthquake investigators know which types of construction can cause problems. They also know standard methods for strengthening hazardous conditions in existing buildings.

\section{Selecting a Consultant}

The most important thing the operator-nanager can do to initiate an effective and economical carthquake safely program is to hire an experienced carthquake engineer who is strong on design and tends to keep analysis straight-forward and simple. Occasionally, there is good reason to apply structural dynamics to provide a better understanding of a complex problem, but not very often. Beware of the potential consultant who sells professional services primarily on the basis of dynamic analysis. The earthquake engineer, working clesely with the operator-manager, should advise on selection of other consultants, define their ssope of work, and coordinate their work with the overall program.

A similar warning should be issued about one's choice of geo-technical consultants. The level of sophistication in state-of-the-art techniques and their application for predicting the intensity of ground shaking is intimidating. There is a strong tendency for both consultants and clients to believe the predictions to be more accurate than history shows they are. This tendency may lead participants to spend more money and time than the exercise is worth. The illusion of security thus developed is apt to be in direct proportion to the degree of sophistication ar-lied.

Really, it should be ie consultant (the project manager of the design team) who should ensure that the client (the operator-manager) is not victimized by overly specialized consultants. Too often, however, in their search for highly specialized consultants to compete for Architect-Engineer appointments, project design managers themselves become overwhelmed by the sophistication of the specialists' jargon.

During a recent conference on seismic safety a geotechnical expert was expounding or the sophisticatad techniques his firm had used to predict site specific earthquake ground motion for his client. His study had been the last of a series by various consultants and agencies covering the same geographical area. These analyses had absorbed almost ten years. A well known earthquake design engineer asked, "Haven't we analyzed this site enough? Isn't it time to design corrective reseasures to upgrade the seismic resistance of the unsafe buildings at this site?" The consultant's answer was, "Well, no, not really, because the state-ofthe-art is changing all the time." Obviously, the specialist was more interested in analysis for its own sake than he was in solving the problem of earthquake safety.
Selecting the right structural engineering firm to counsel a practical way through the complexities and pitfalls which can befall earthquake safety programs is certainly the most important decision the operatormanager can make. To repeat, the best advice for this decision is to hire an experienced earthquake engineer who is strong on design and tends to keep analysis straight forward and simple.

Again, the watchword is ro keep the site investigution straighr-forward and simple, and rely more heavily on design than prediction.

Even when structural dynamics is to be employed. the selection of an effective ground-motion input can be a relatively simple matter. There ; no sense in making a "federal case" over the input because the record shows that the prediction of ground molion is indeed an inaccurate science. The inaccuracies of input often can is accommodated in good structural design.

Fortunately, there have been a number of excellent studies by qualified engineers and geologists which enable the operator-manager to look to history and oast clients of prospective consultants when sclecting professional help for an earthquake safety program. The right questions should be asked, such as, "How much did the study cost? How long did it take? What kinds of projlems occurred? What techniques were employed? What werc the results? What is the ratio of the cost of studies to review the site and existing buildings, to the replacement value of the buildings reviewed? How much money was spent on studies as compared to the cost of rehabilitation? Was anything practical accomplished?"

Potential earthquake engineering and geo-technical consultants should be asked to explain in simple terms how they expect to approach the project, what techniques will be applied and what they expect to find. Ask for examples of previous work, names of clients, and cost history. Satisfy yourself that the lead consultant selected is a structural engineer who has strong design experience and has made field investigations of earthquake damage.

\section{The Balanced Program}

An effective earthquake safety program is analogous to an effective lateral-force-resisting system: il should have no weak links. Several basic precautions should be taken in establishing your program: of primary importance are the following five:

First, make certain that planned new buildings are not being inadequately designed while the process of earthquake safety review of existing building is underway. This is a profound admonition, but the possibility of its happening is real. It can be avoided by using plan-check or third-party review, prior to start of construction. to ensure that the calculations and designs of new structures and rehabilitation projerts are done 
properly to resist earthquakes. It is embarrassing for a manager to find that a newly designed and constructed building is worse than an old one.

Design criteria should be clearly defined and simple to use. Standards and model codes are readily available and should be used. Complex approaches or criteria should not be applied unless the need is clearly established; the criteria should be practical. At most sites, many building modifications, experimental setups, equipment installations, cabinetry, and other nonstructural components and projects are designed regularly by architects, mechanical engineers, designers, and other non-structural engineers who do not have a background in seismic analysis and oesign. If the criteria are simple and straight-forward these minor projects will be designed and built with adequate earthquake resistance. The significant structural problems should be handied by registered structural engineers. A professional engineer's stamp and signature and a third-party review should be required.

Second, the site should be reviewed for geologic and likely seismic hazards. Potential conditions that are inherently hazardous in ground shaking should be identified. These can include the following:

1. Unstable slopes and existing landslides;

2. Areas of low-density saturated granular soils subject to densification and subsidence;

3. Areas of low-density saturated granular soils subject to liquefaction;

4. Areas where sensitive clays may be subject to strength loss under heavy ground shaking;

5. Areas where flooding would occur due to failure of an up-slope levee or dam.

Active faults should be identified and a geologic map of the site developed.

The site review need not be rigorous in detail unless the potential hazards pose a high risk for an existing building or lifeline. If a new building or improvement is planned, the specific siting can be examined in more detail. The main thing is to flag potential hazards and take them into account. For example, it would be folly to permit the typical one-third increase in allowable soil bearing capacity for seismic loading in an area of sensitive clays subject to strength loss under ground shak ing. The initial review should be quite broad and superficial in character. It is important that it be carried out by a geologist or soils engineer who understands the nature of soil dynamics, preferably from a perspective of experience with earthquakes. Generally, except for fault rupture, each of the potential hazards that may exist can be mitigated through standard stabilization practices, or by simply avoiding them in the case of new construction. Sometimes fault movement can be accommodated, or the effect of fault movement mitigated, if it is known where surface ruptures are likely to occur.

Third, survey and evaluate ail existing buildings and structures to determine their earthquake safety ratings. If possible, a structural engineer experienced in earthquake investigation should do the job. The assessment should be kept simple. A basic requirement is to determine the necessary work to insure that each building has a predictable lateral force-resisting system. The job of rehabilitation should be started one step at a time, reducing liability on a priority basis.

Given a limited budget it is important to determine which buildings will have the greatest payoffs per dollar spent for improvements in life-safety and property damage. For life-safety, the procedures found in "Evaluating the Seismic Hazard of State Owned Buildings," California Seismic Safety Commission, SSC 79-01, by McClure, Degenkolb, Steinbrugge, and Olson, are recommended. For property damage, refer to Figure 10 and its supporting text in the report entitled "Estimation of Earthquake Losses to Buildings (Except Single Family Dwellings)," by Algermissen, Steinbrugge, and Largorio, USGS Open-file Report 78-441. Thest references provide practical rationale for a general approach to cost effectiveness. Of course, practical risk management must also address those socio-political issues which encompass and plague earthquake safety piograms and pose questions of public and personal liability. These aspects of risk management are discussed in the foreword to Chapter 10.

Fourth, make an earthquake-hazards survey of each building for types of operations, equipment and other contents, hazardous materials storage. and nonstructural building elements. Obvious hazards, such as loose-item overhead storage, should be corrected by building managers or supervisors. Most operational hazards are obvious to onc simpiy observing the scene and imagining an earthquake taking place. Tipping hazards, such as storage cabinets, tall files, library shelving, and similar furnishings, should be braced or anchored. Tie-downs should be installed on plant equipment such as transformers, emergency generators, tanks, elevator irives, fans. moturs, and similar units. Apply a simple and judgmental priority system to use limited resources economically.

Fifth, develop an emergency plan to recover from a des:ructive earthquake. Apply the scenario technique to develop a realistic model for the aftermain of an intense earthquake. Use those department heads who will have to handle the recovery to spearhead the planning. Reduce the obstacles to recovery by eliminating obvious hazards and ensuring that the supplies and equipment that will be needed will in fact be available. Lifelines, such as water supply lines, power systems, storm and sanitary sewers, transportation and communications systems also should be surveyed with earthquakes in mind. The consequences of possible facility losses can be mitigated by careful emergency planning, and the potential for loss of a given facility reduced by "hardening" the lifelines that would likely be in jeopardy during an earthquake. 
Self-help planning, preparation, and training should be key elements in any emergency response plan for earthquake safety. Make sure that building managers and supervisors understand this fact and let them take part in the preparation of local emergency plans.

In the chapters that follow, each facet of a balanced earthquake safety program is discussed by engineers who have a great deal of experience and concern with earthquakes. Each has considerable knowledge about ail of the subjects covered so that parts of chapters tend to oveilap. As one might expect, there is sometimes a healthy difference of opinion expressed. These differences reflect the perspectives of experts and tend to give the operator-manager some insight into the practical state-of-the-art. It also reminds us that there often is more than one answer to a given problem. When a problem is particularly "sticky" and costs, risks, or priorities are high, it is unquestionably worthwhile to get more than one opinion.

The question arises, how does the operator-manager resolve technical differences of opinion between two consultants on subject-matter about which the operatormanager feels inadequate.

The best answer lies in the operator-manager's usual role, that of managing the multi-disciplinary functions of a technical complex such as a majoi research and development laboratory or a sophisticated production facility. The development of good communication and mutual trust with a practical earthquake engineering consultant will provide the operator-manager with an extension of expertise in this specialized field much as it does in any other specialized field under the supervision and management of the operator-manager. In the end the responsibility must lie with the operatormanager and it is important to realize ahead of time that technical differences of opinion are apt to arise about earthquake safety management. The earthquake engineering consultant should be interested in the goal of practical earthquake safety rather than earthquake engineering for its own sake. This extension of expertise through selection of wise counsel is a challenge that most operator-managers face in other facets of their responsibilities.

$W^{\prime}$ ?n questions regarding technical differences of opinion or criteria persist, it is important that they are resolved by some due process within a technical framework that will stand the test of future technical and legal review. The designer and the operator-manager should be reasonably protected by the due process involved assuming each fulfills his design responsibilities satisfactorily. This subject involves considerations in risk management which are discussed more thoroughly in Chapter 10. 


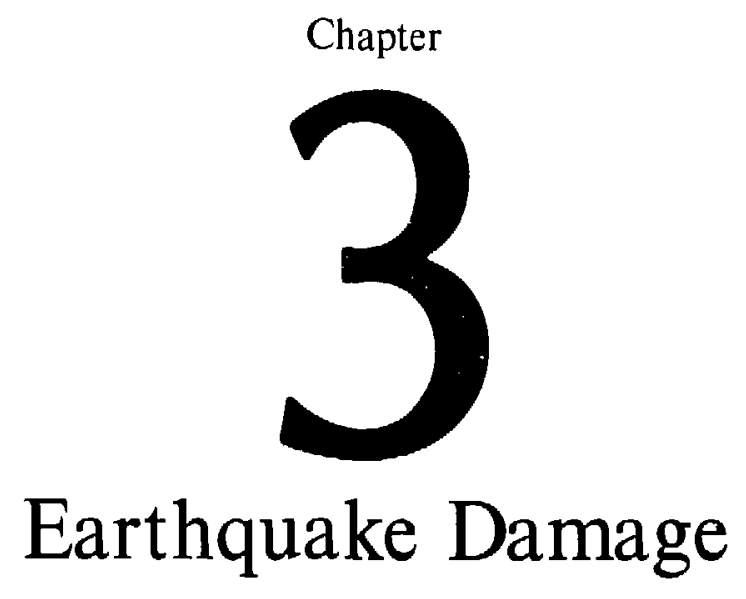

\section{FOREWORD: Operator-Manager's Point of View (Donald G. Eagling)}

In the aftermath of an intense earthquake one can observe many obvious and convincing lessons that are almost impossible to describe later to the many people that will be involved in an earthquake safety program. Management, plant and safety engineers, administrators, and in particular, the operators and occupants of buildings and facilities must couperate if such a progiam is to be successful. The earthquake experience is hard to imagine and without some understanding of the devastation that can result from the combination of hazardous buildings and intense earthquakes, the motivation for cooperation is minimal. People also have short memories with respect to accounts of damage from earthquakes that happened somewhere else.

The best way to get attention focused on earthquake safety is to have all persons concerned view the results of a damaging earthquake first hand. Failing in that, a presentation of earthquake damage by a structural engineer experienced in earthquake investigation is the next best thing. The use of ample photographs to illustrate the effects of heavy shaking on buildings, contents, and other types of facilities that art familiar to the audience can be very effective in promoting an understanding of the requirements for earthquake safety and providing motivation for action and cooperation.
This Chapter of the Guide provides the reader with the "earthquake chasers" point of view. Typical failures and problems one must face in the aftermath of damaging earthquakes are described with ample photos to illustrate the lessons available there. Subsequent Chapters of the Guide will focus on solutions to the problems illustrated in this Chapter to provide continuity for the reader.

Generally, United States experience has more impact on the American engineer than foreign experience. In the Chapter that follows, however, James Stratta has used many examples of earthquake damage which occurred in foreign countries. American engineers tend to discount foreign experience because they believe the structures are less well designed and constructed and they are unfamiliar with the foreign codes used for analysis. For the most part, however, the lessons illustrated with foreign examples are rather common to United States experience. In a way, the foreign examples tend to reinforce an important point of this publication. That is that most problems in earthquake damage are simply the result of not impiementing what has been known and observed about earthquake engineering for many years, and are not the result of lack of sophistication in analysis. We still need to understand and avoid the failures identified in the old lessons. 


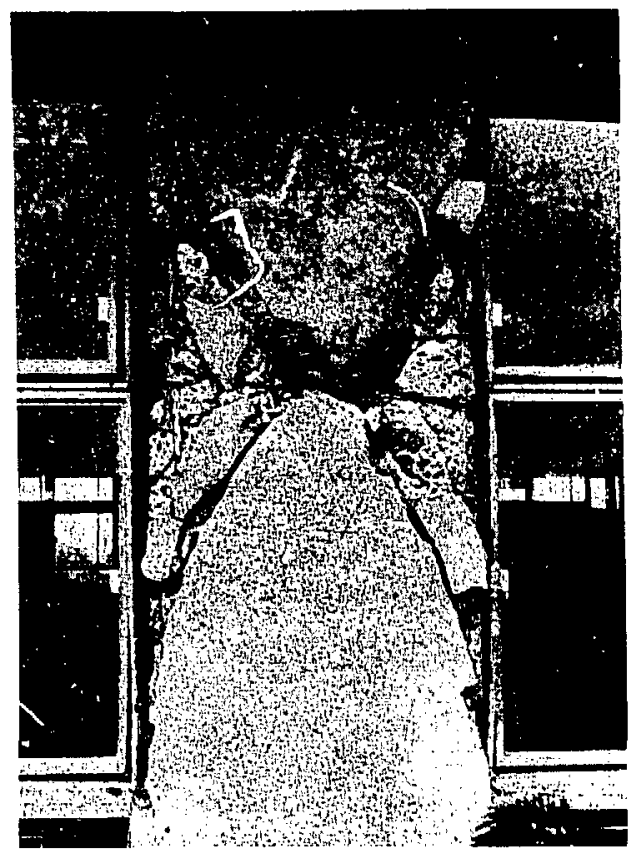

Misawa Commerce High School. Damage to a reinfored concrete column in the 1968 Tokachi-Oki earthquake.

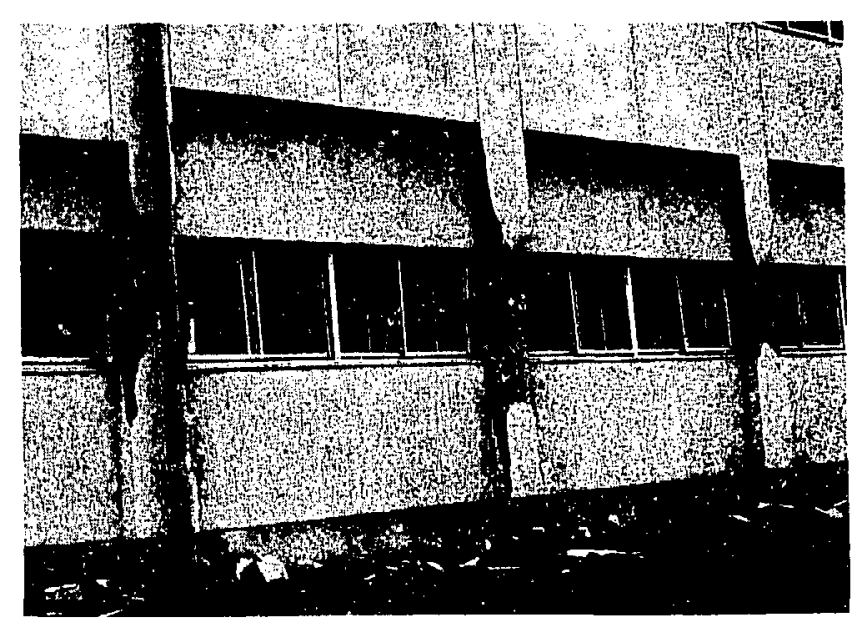

Hachinohe Technical College. Damage to reinforced concrete columns in the 1968 Tokachi-Oki earthquake.

Shown are classic failures in non-ductile reinforced concrete columns with insufficient transverse reinforcement. Non-ductile reinforced concrete window piers framed with heavy spandrel walls typically exhibit classic brittle shear failures. 


\title{
Chapter
}

\author{
3 \\ Earthquake Damage \\ James L. Stratta \\ Civil Engineer \\ Structural Engineer
}

Mr. Stratta has been a consulting civil and structural engineer since his graduation from the University of California at Berkeley in 1943. In 1952 he joined a partnership for architecture and engineering, with special emphasis on seismic analysis and design. He began his private consulting practice in 1978.

Mr. Stratta served in 1962 as president of the Structural Engineers Association of Northern California, and in 1967 as president of the Consulting Engineers Association of California. He was a director of the American Consulting Engineers Council, 1968, and is a member of the Earthquake Engineering Research Institute. He is a fellow of both the American Society of Civil Engineers, and the American Consulting Engineers Council. He has taken part in world-wide earthquake conferences and surveyed numerous quake sites. James L. Stratta is located in Menlo Park, California.

Mr. Stratta has co-authored reports on the following seismic events:

$\begin{array}{ll}1964 & \begin{array}{l}\text { Anchorage, Alaska Earthquake. } \\ 1970 \text { \& 1974 }\end{array} \\ 1971 & \begin{array}{l}\text { Peru Earthquakes. } \\ \text { Interaction of Infill Walls and Concrete } \\ \text { Frames During Earthquakes. }\end{array} \\ 1976 & \text { Rotation of Footings Due to Surface Waves. } \\ 1977 & \text { Mindanao, Philippines Earthquakes. } \\ 1979 & \text { Friuli Earthquake, Italy 1976. } \\ 1980 & \text { Compania-Basilicnta Earthquake, Italy. }\end{array}$

\section{Introduction}

Laboratory testing of materials has long been the engineer's best means of determining or predicting the physical properties of materials used for design purposes. Furthermore, full-scale assemblies of materials such as structurai joints and wall sections are of ten tested to enable the engineer to predict more accurately their behavior and rely upon certain assumptions necessary for design. Complete building structures, however, are very difficult and expensive to test, and it is virtu- ally impossible to introduce realistic earthquake ground motions into such tests.

There is no substitute for real earthquakes. They provide the ultimate in full-scale testing of large structures such as buildings, dams, bridges, roads, tanks and utilities systems. Also, geologic phenomena such as faulting, liquefaction, heaving, subsidence and grabens can be carefully observed and studied in the aftermath of an earthquake. 
There is an old saying that "a picture is worth a thousand words." We propose a new saying: "A visit to the scene of a damaging earthquake is worth a thousand lectures." It is a profound experience for a structural engineer to observe earthquake damage first-hand. He can see what is good construction, what is bad, and study the actual mode of failures. The experience improves and develops his judgment for structural detailing, selection of building configurations, and generally upgrades the overall quality of his work. Unfortunately, few structural enginetrs have the opportunity to visit an areat damaged by an carthquake, so they must study reports and pictures of carthquake damage in order to learn these lessons. The pictures and descriptions that follow are intended to communicate the earthquake investigator's point of view about earthquake danage.

The discussion will be broken down into several categorics. The reader should keep in mind that seismic design is not a science, but an art. In many cases varying reasons may be given, or varying assumptions made, as to the cause of earthquake damage. This is a healthy situation, because from many of these controversies have come answers that we are looking for. If the reader should find what he considers to be con- tradictory statements hercin, he should remember that we are dealing with an art.

\section{Building}

The interest of the structural engineer lies predominantly in the building. Why has the building failure occurred? Why did other buildings not fail"? What have been the most common or consistent types of failures? What force levels would cause damage? These and many more questions race through the structural enginecr's mind during an inspection trip.

Certainly one of the most important considerations in seismic design relates to the relative rigidities of the elements taking the lateral load and their capabilities to resist load. Lack of consideration for relative rigidities is exemplificd in the type of construction utilizing infilled walls with concretc frames, which is used predominantly in many countries throughout the world. The infill matcrial is usually hollow tile, block or brick; very brittle but not reinforced and usually not capable of resisting the load attracted by such rigid construction.

Figure 1 shows the Marionist School in Chimbote. in

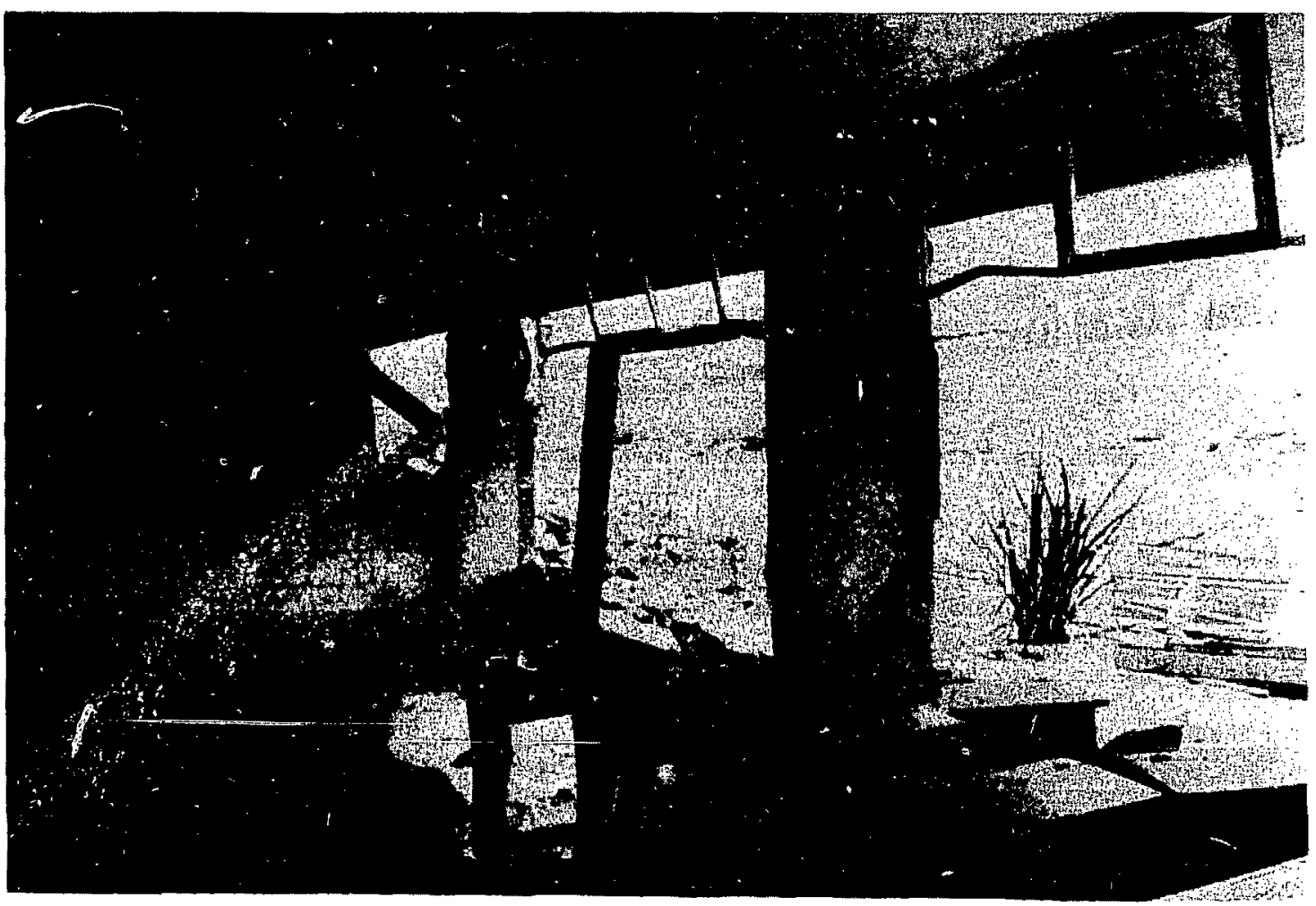

Photo Courtesy Jack F. Meehan, SSS/OSA

Fig. 1 - Marionist School, Chimbote, Peru, May 31, 1970 earthquake. 


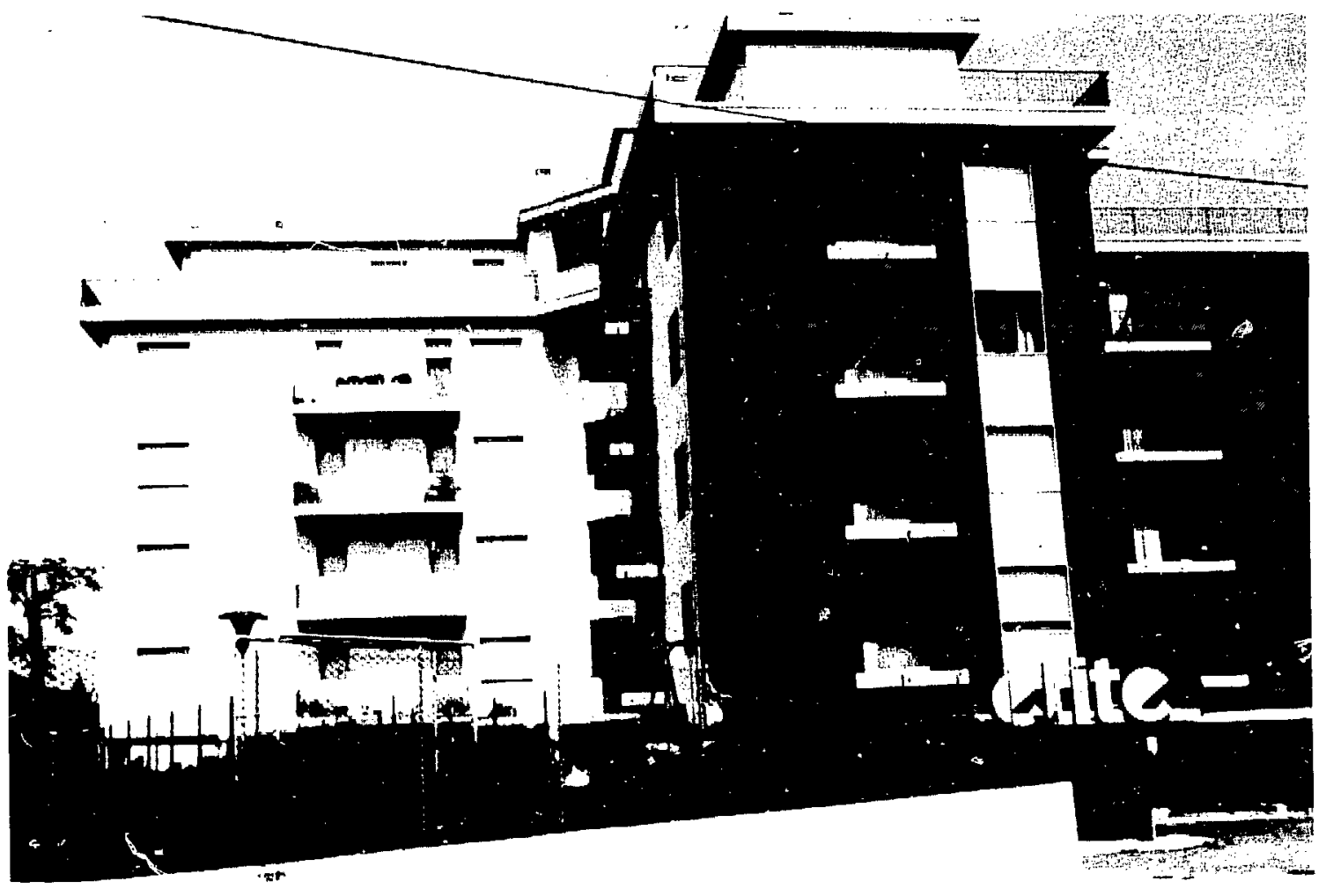

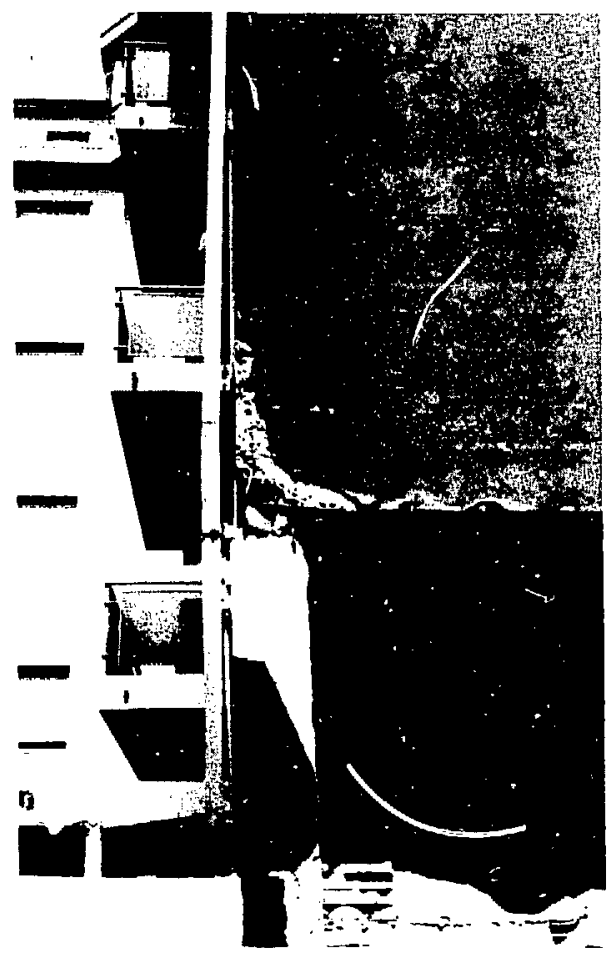

Fig. 3 - Lack of ductile reinforcing in first-story end-wall column, Elite condominium.
Fig. 2 - Elite condominium, northern Italy, May 6, 1976 earthquake.

the Peru earthquake of May $31,1970^{\prime}$ Since a relatively rigid transverse partition was located every third column, each attracted a large part of the load but was unable to resist it. Note the severe damage to the column at the infill wall relative to the column between walls. It is quite probable that the intermediate column failed only after failure of the column at the infilled Trame.

Figure 2 shows little discernible damage in the Elite condominium after the Northern Italian earthquake of May 6, 1976, ${ }^{2}$ but Figure 3 shows otherwise in a closeup of the end wall column at the first story. Note that the end frame once ald a tile infilled wall, most of which has been destroyed. The rigid infill attracted the lateral load and caused the column failure. The interaction of the rigid infill and the less-rigid column was very damaging to the column. The entire structure totally collapsed in a later after shock. Fortunately, all of the tenants had moved out.

In Fig. 3, note the lack of ductile reinforcing in the column. (Ductility is the ability to deform inelastically without abruptly failing.) Early on, it was noted that ductility is necessary in concrete frames in order to develop toughness. In 1960 the Portland Cement Asso- 


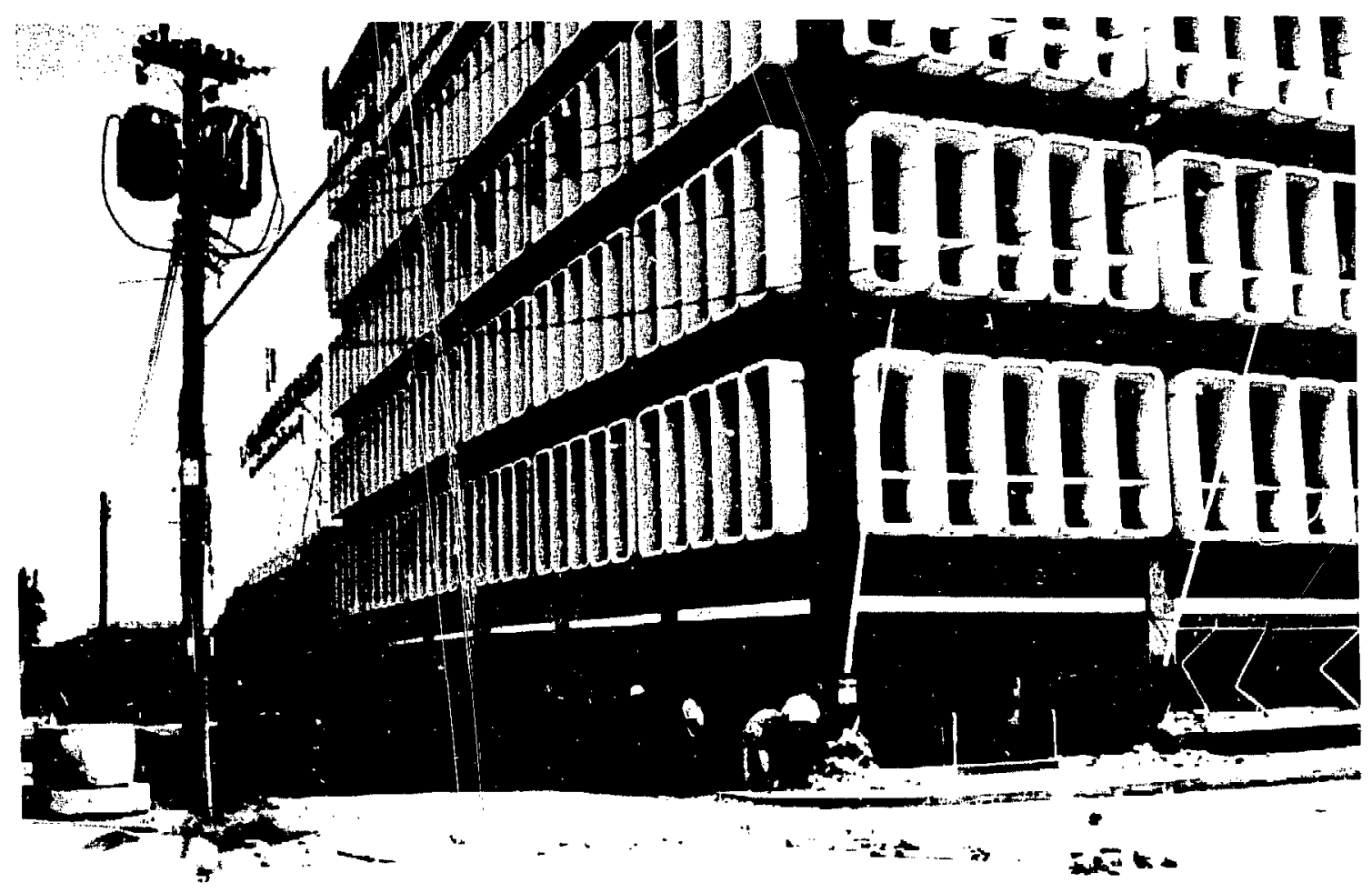

Fig. 4-Philippine Bar Association building, Manila, 1968 earthquake.

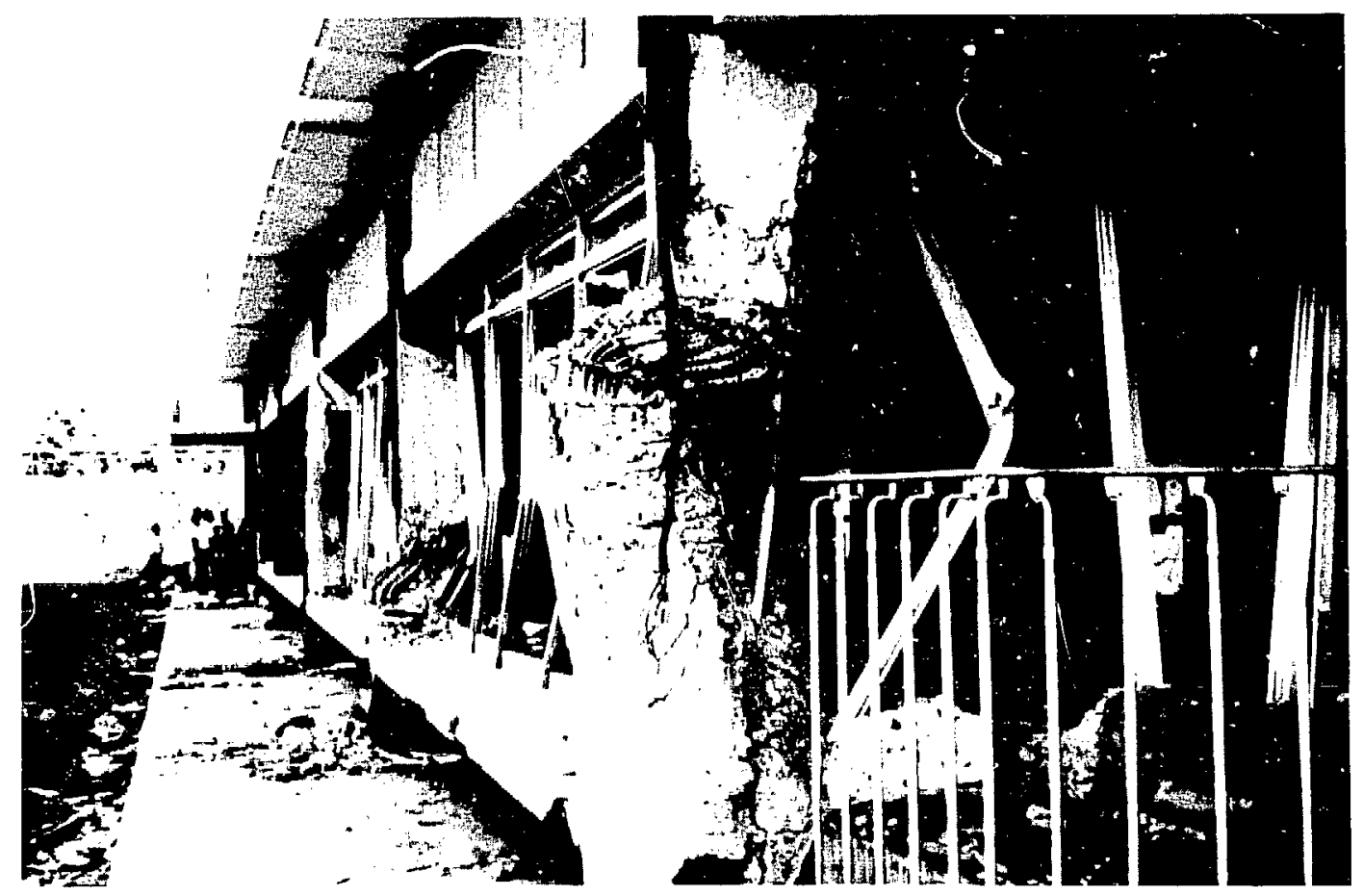

Fig. 5- Spirally reinforced column in Philippine Bar Association building. 
ciation published a book by Blume, Newmark and Corning $^{3}$ demonstrating how to achieve ductility in concrete. Design for ductility and ductile reinforcing is a highly technical specialty. The designer who wishes to become proficient in earthquake engineering must understand how buildings respond, deflect, and distort, considering the effect of relative rigidities and other factors, and be able to cope with them in the design process.

The Philippine Bar Association Building (Fig. 4), damaged in the Manila earthquake of 1968, dramatically illustrates the role of ductility. Figure 5 shows a spirally reinforced column, and Fig. 6 shows a tied column. Note the obvious capability of the spiral reinforcing to confine the concrete so the column can deform and continue to take load, ultimately failing in a ductile manner. On the other hand, in the tied column, the concrete has shattered and "flowed out" from between ties in abrupt failure.

Another of the many lessons learned from observation is the effect of torsion on buildings and how it may be introduced into a structure by the unsymnetrical location of load resisting clements. Figure 7 shows the J. C. Penney building after the May 27, 1964 earthquake in Anchorage, Naska. ${ }^{4}$ Torsion was certainly an important factor contributing to damage.

It is not necessary to inspect large structures to understand what actually happens to buildings. The

Fig. 6-Tied column in the Philippine Bar Association building.
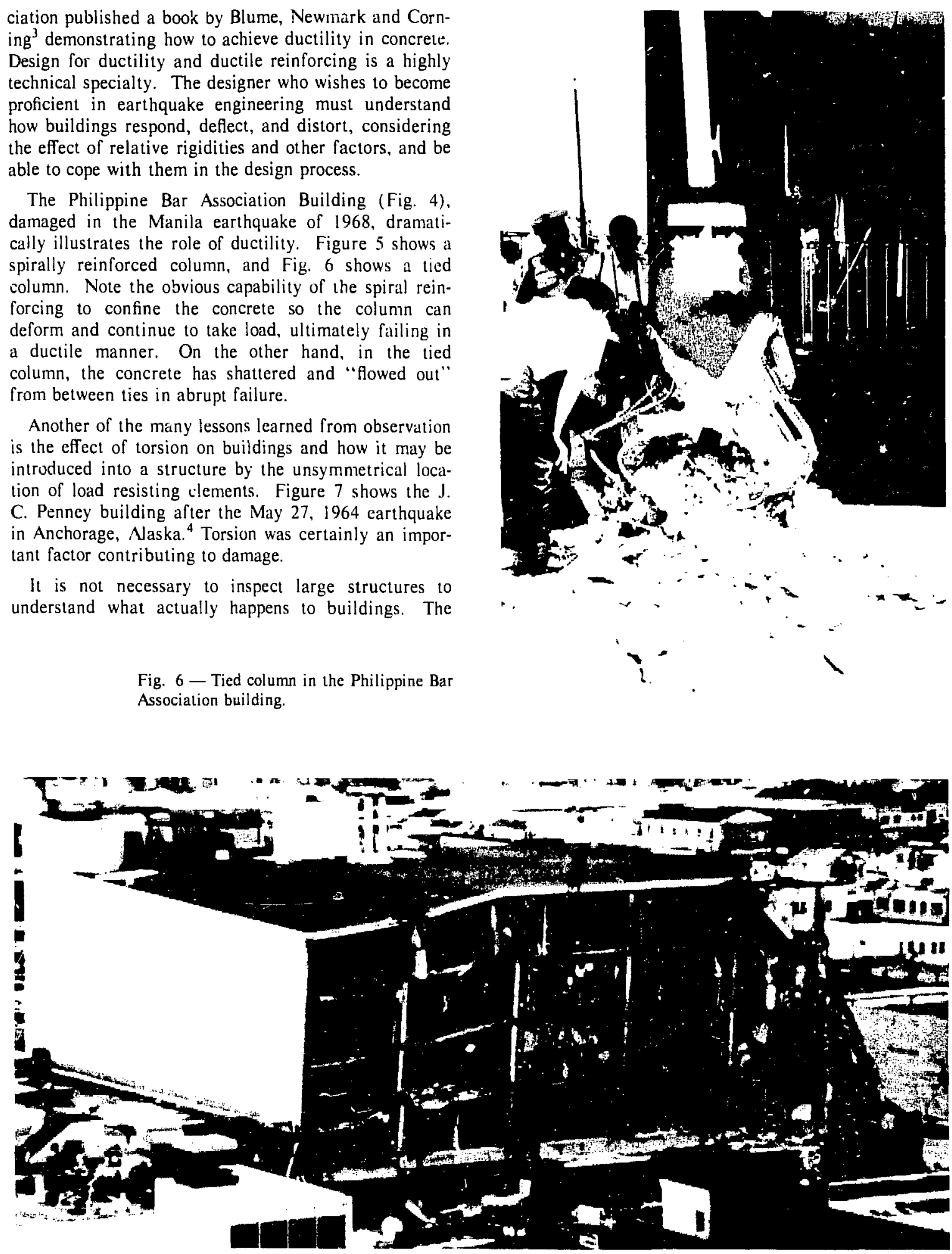

Fig, 7 - J. C. Penney building, Anchorage, Alaska, May 27, 1967 earthquake. 


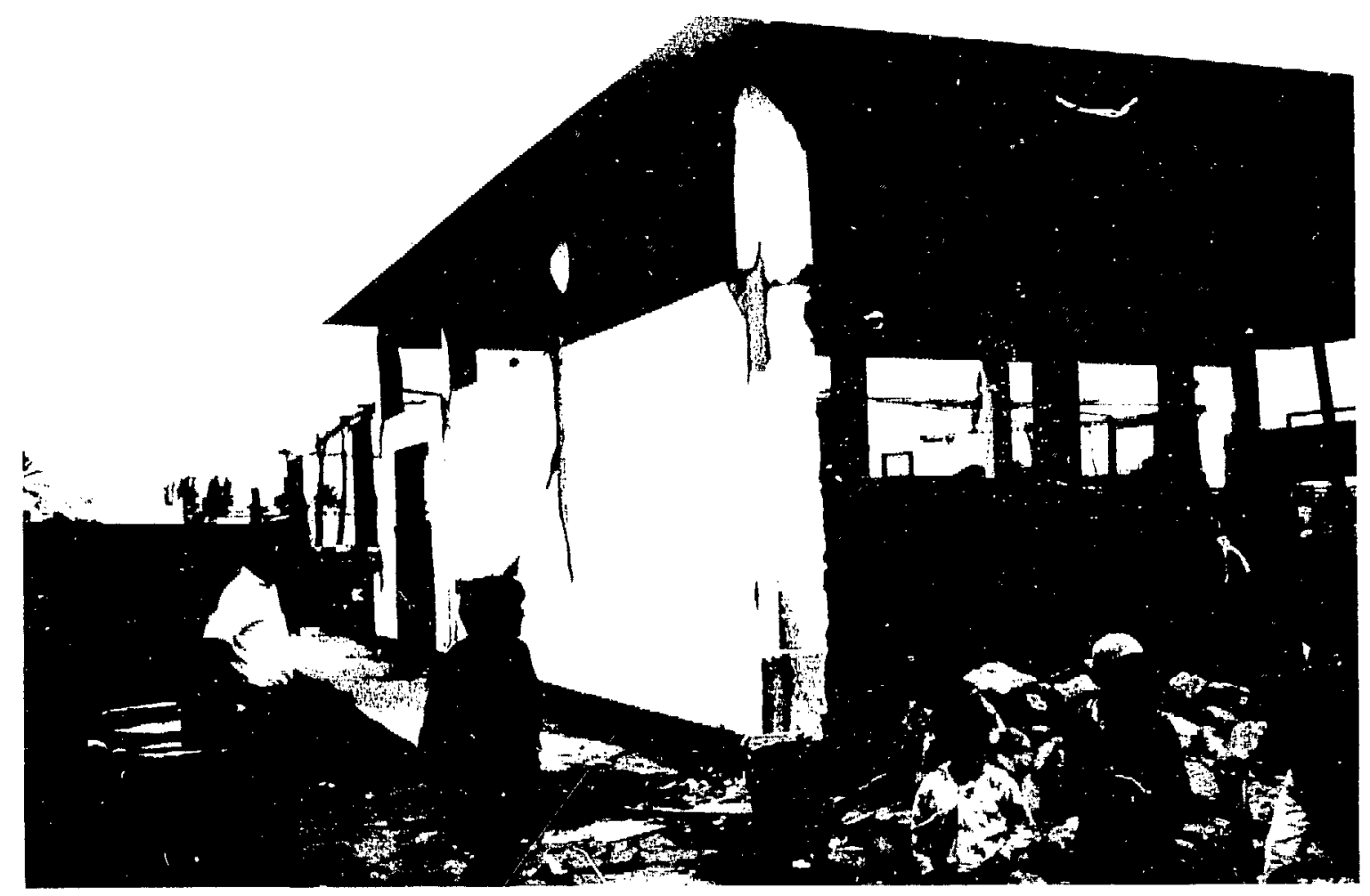

Figs. 8 and 9 - Mercado Modelo, Huarmey, Peru, May 31, 1970 earthquake.

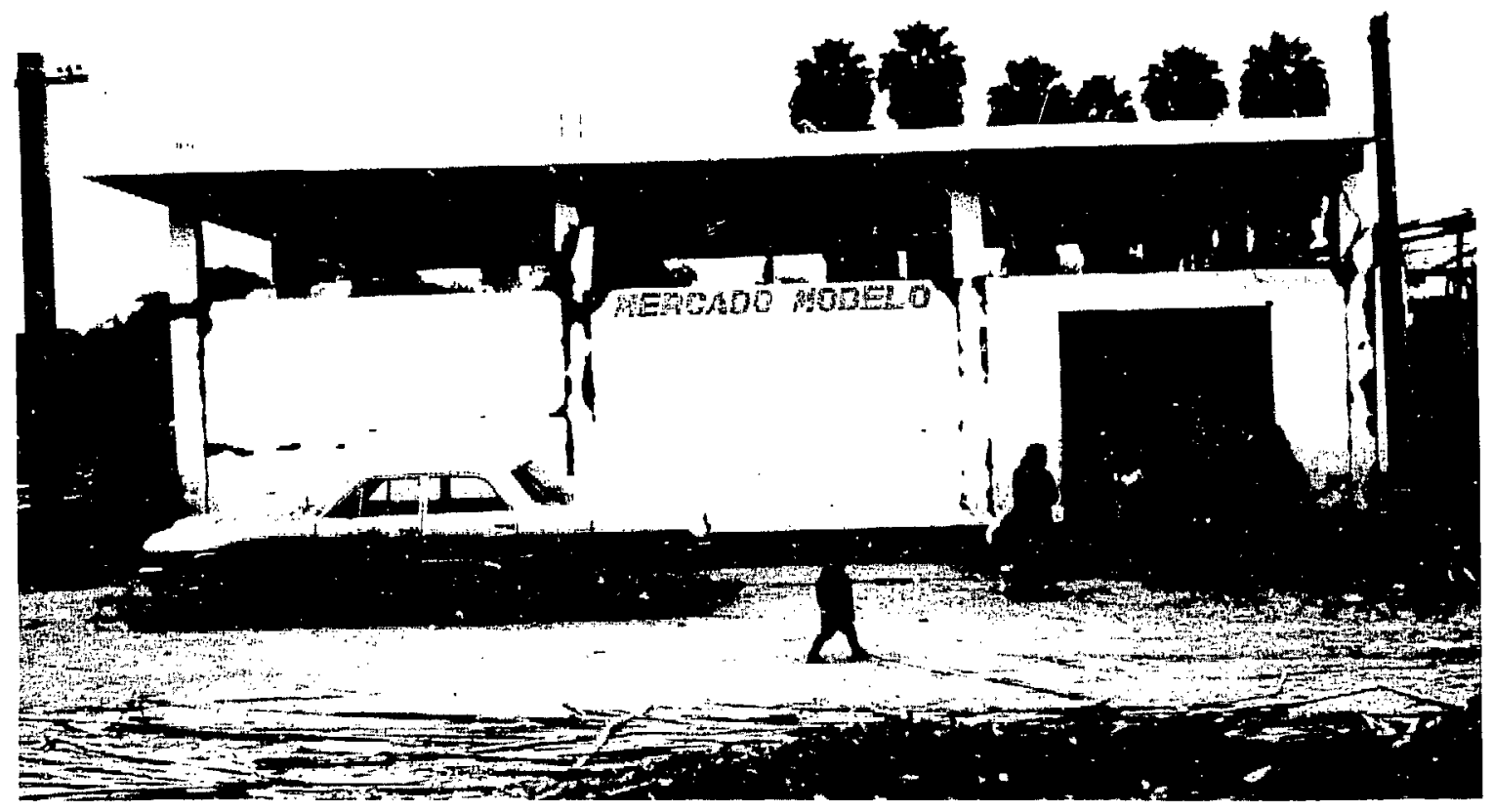



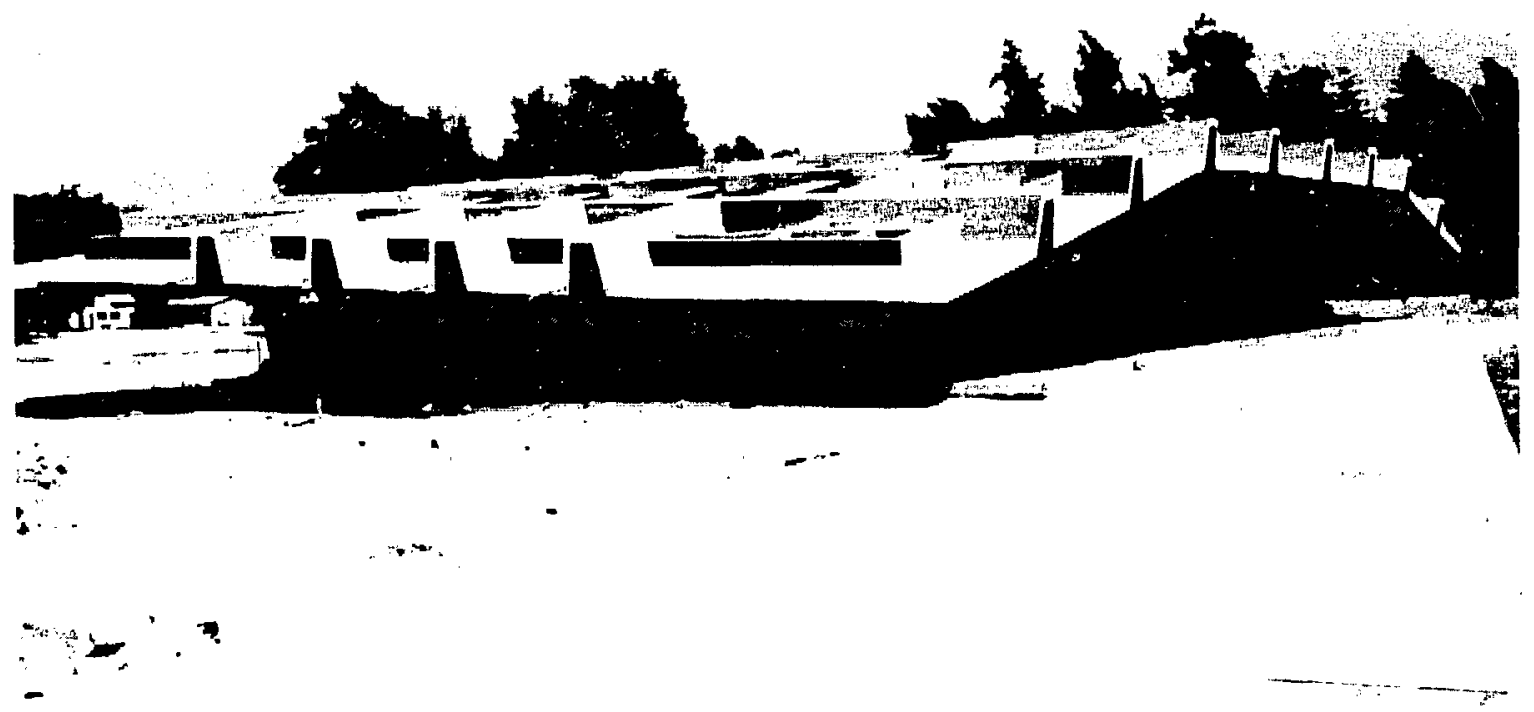

Fig. 10 - One-story classroom structure at the Agricultural University, Lima, Peru, October 3, 1974 earthquake.

Mercado Modelo (Figs. 8 and 9) in Huarmey, Peru shown after the May 31, 1970 earthquake' is a classic example of the effects of varying rigidities cumbined with the effects of torsion and lack of ductile reinforcing. Reference (1) includes calculations for this structure.

Figure 10 shows the one-story classroom structure at the Agricultural University in Lima, Peru after the October 3, 1974 earthquake. ${ }^{5}$ Here the structural combination of elements with different relative rigidities, and a site situated in a localized area of high intensity shaking (a microseismic area to be discussed later), were the chief causes of damage. Figure 11 pinpoints the failure at the columns just below the zone of closely spaced ties (ductile reinforcing) in this classroom building.

Information can be learned from undamaged elements as well as from those that failed. In the Mindanao, Philippines earthquake of August 17, 1976, ${ }^{6}$ the New Society Hotel (Fig. 12) rotated and collapsed. The Harvardian College (Fig. 13) collapsed. However, the Tison Building (Fig. 14), designed by Filipino engineers using the California Code (exact year not known) suffered no structural damage. Flower pots on the roof (Fig. 15) moved approximately 8 centimeters ( 3 inches), indicating that the building experienced a peak acceleration of about $40-50 \%$ or more at the roof.

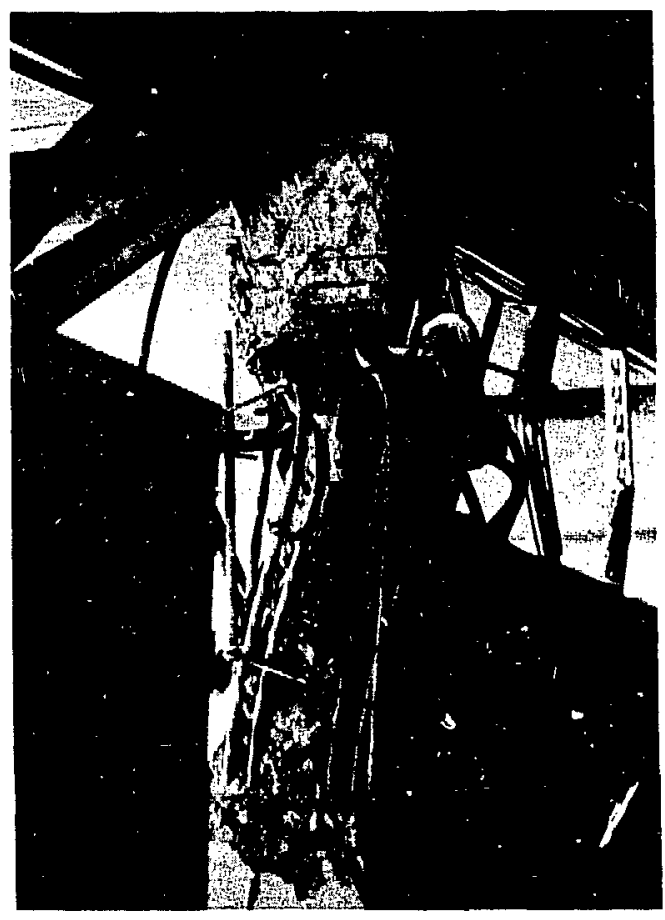

Fig. 11 - Column failure in Agricultural University classroom structure of Fig. 10. 


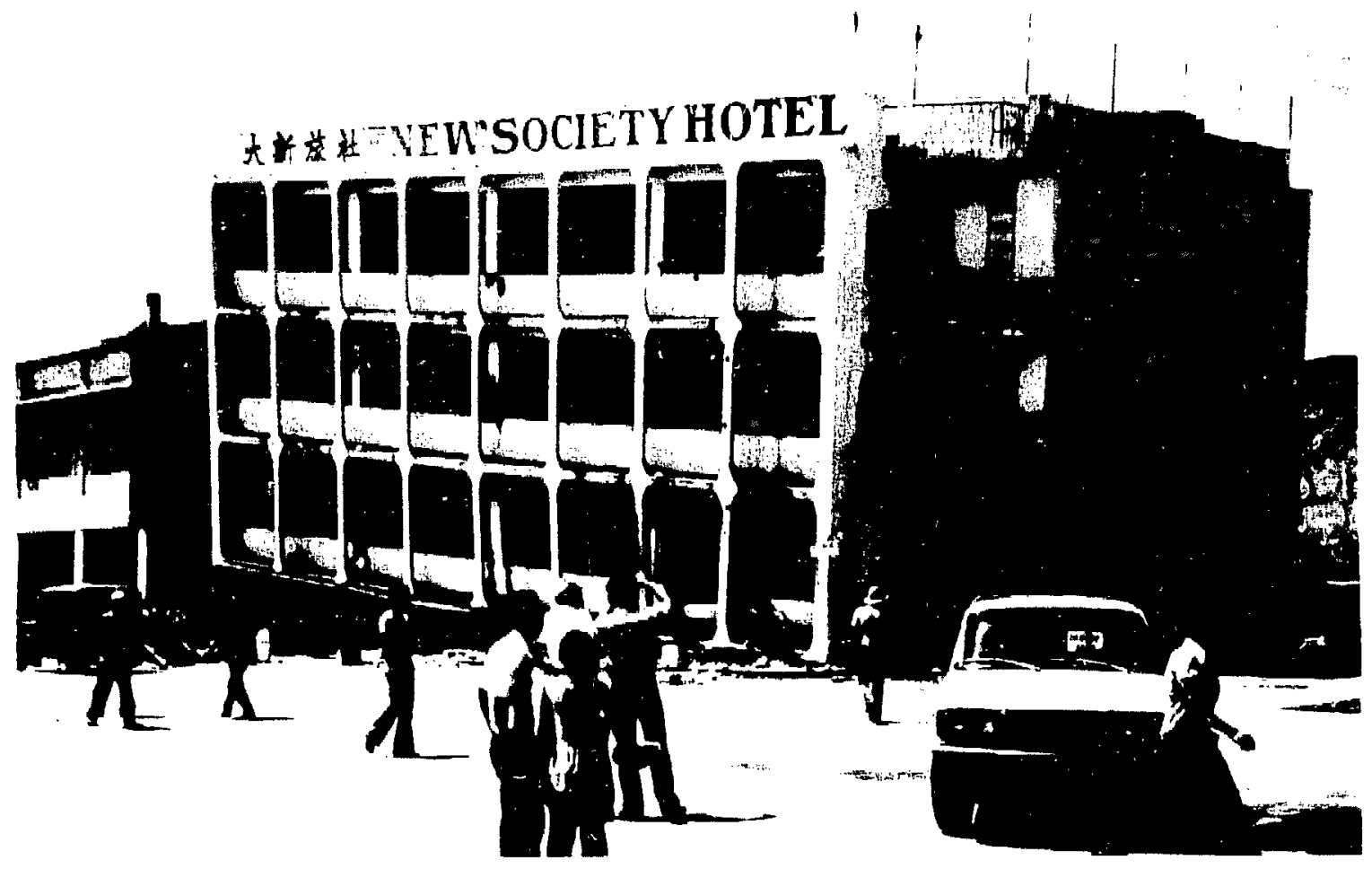

Fig. 12 - New Society Hotel, Mindanao, Philippines, August, 17, 1976 earthquake.

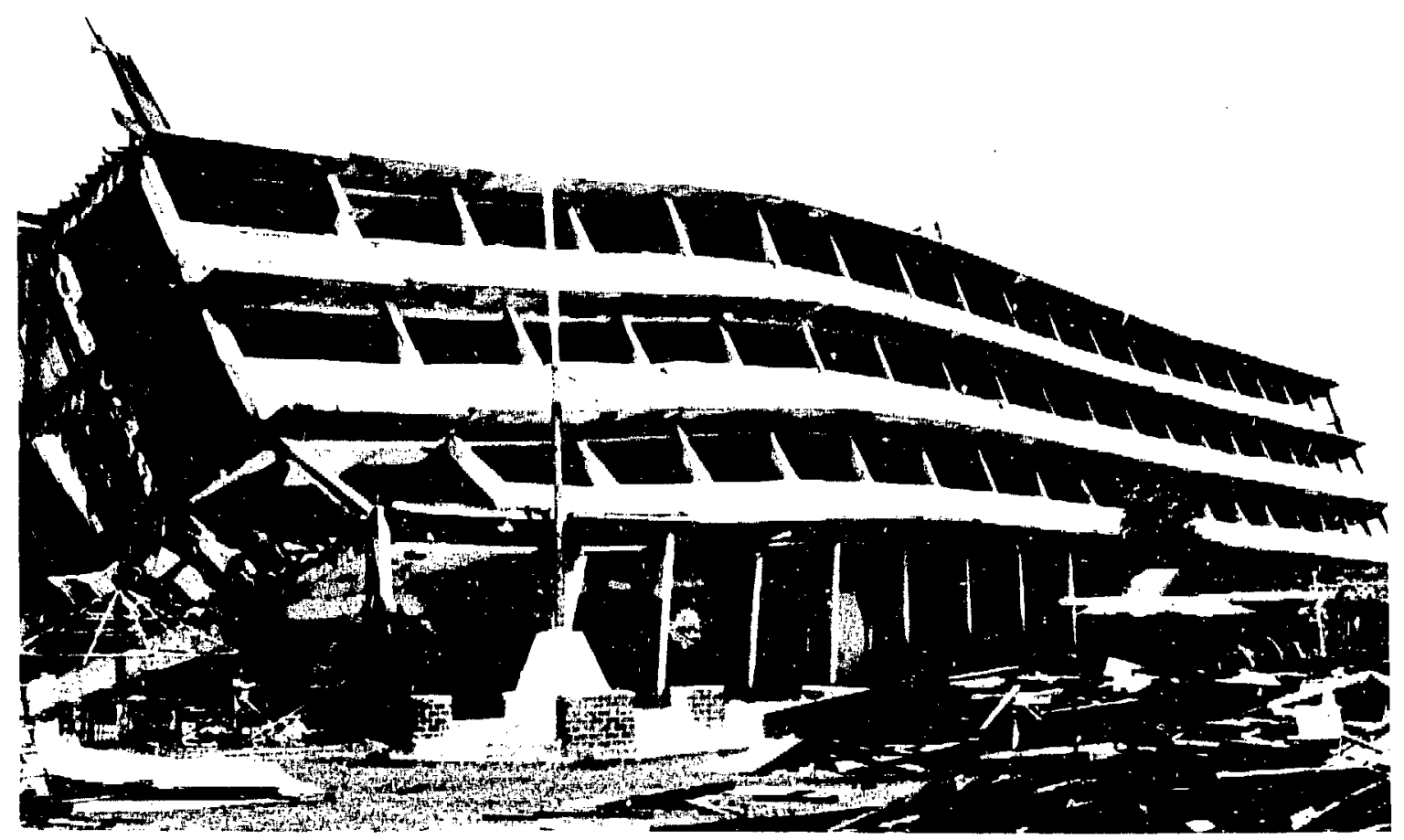

Fig. 13 - Harvardian College building, Mindanao. 


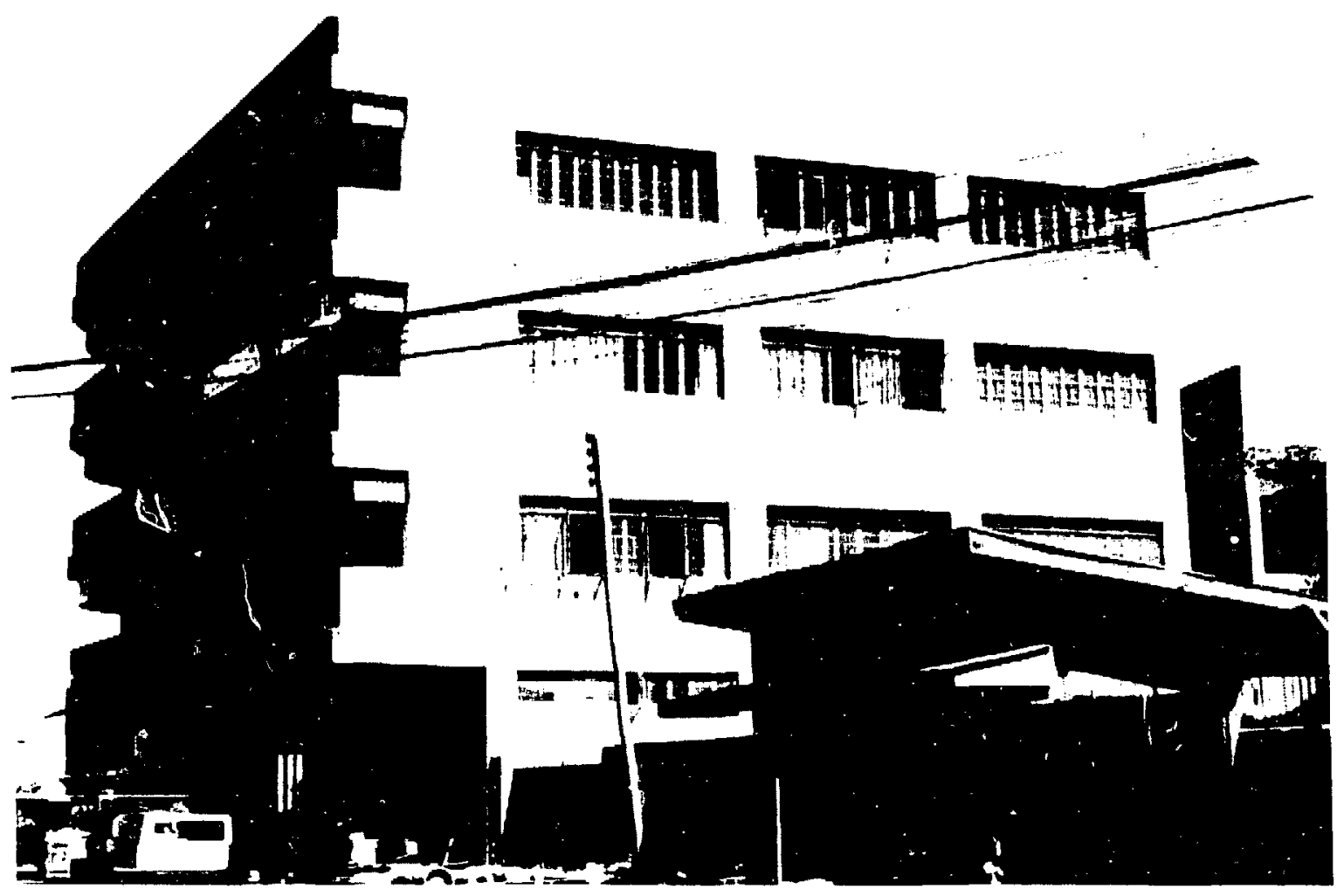

Fig. 14 - Tison building, Mindanao.

This does not mean that a lateral force coefficient of $40 \%$ or more should have been used in the design because the building was designed for a much lower static lateral load, sustained no serious damage from the earthquake.

Earthquake engineers are not agreed on the proper "force coefficients" to be used in design. Some feel the coeflicients specified in the newest codes are higher than necessary, while others feel they are too low. Some feel dynamic analyses should be used for all structures, and others feel that knowledge about earthquakes has not progressed sufficiently to warrant this type of mathematical accuracy. Still others believe that we do not have all of the necessary and proper input for computer analyses.

"Force coefficients" and damage sustairied during earthquakes are not always directly related to the magnitude or peak acceleration of an earthquake. The Earthquake Engineering Research Institute sent reconnaissance teams to both the $1970^{1}$ and $1974^{5}$ earthquakes in Peru. Each earthquake gave a surface wave magnitude (Ms) of about 7.5, yet the damage diflered

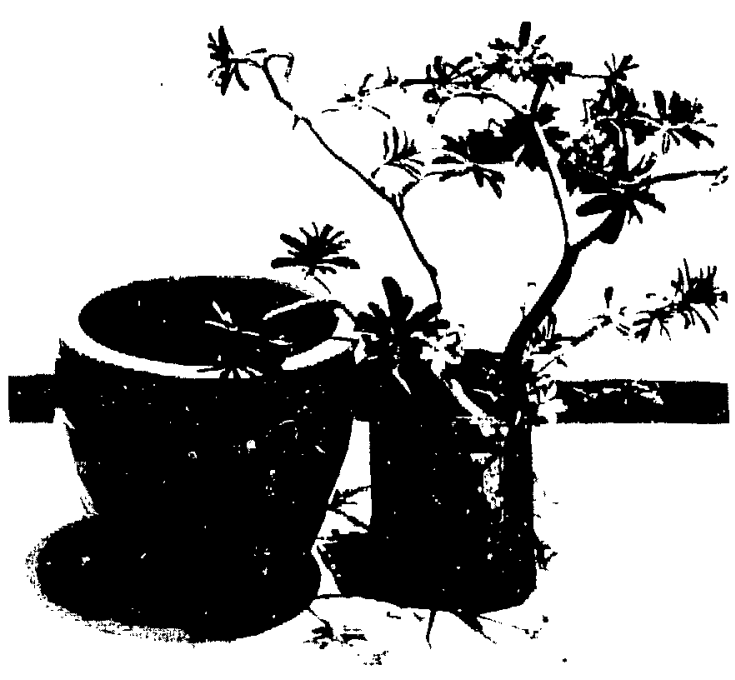

Fig. $15-$ Flower pots on roof of Tison building. 


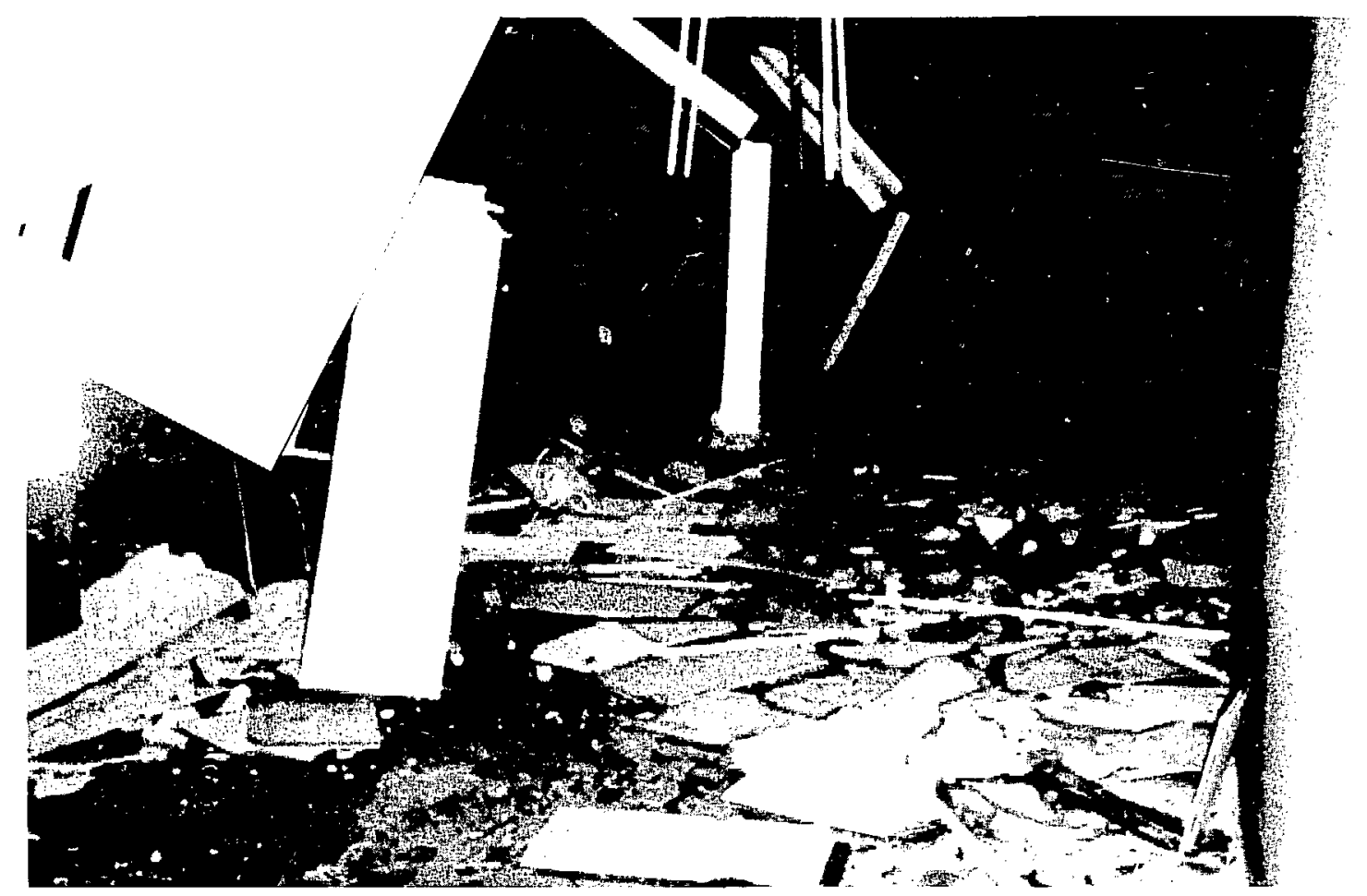

fig. 16 - Corridor in Olive View Hospite:, San Fernando, California, 1971 earthquake.

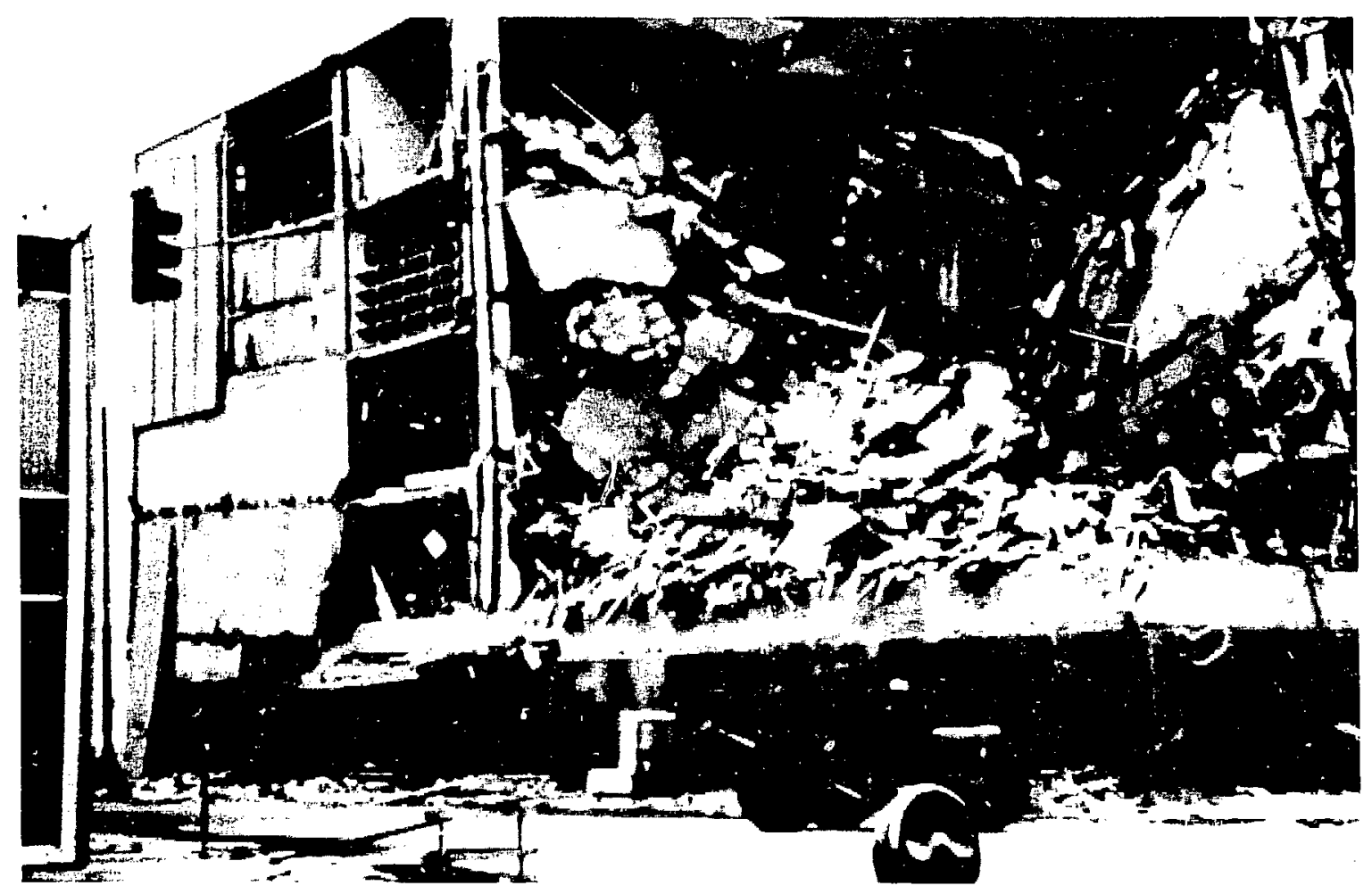

Fig. 17 - Two exterior walls, J. C. Penney building. 
vastly. This difference was presented to Dr. Bruce A. Bolt, seismologist at the University of California at Berkeley, for explanation. He responded with a paper at the Earthquake Engineering Research Institute's Annual Meeting on February 8, 1975, which is published as Appendix A of Reference 5. This paper is strongly recommended to those interested.

In this paper, Dr. Bolt stated that, "the evidence is growing that there is no strong correlation, at least in the near field, between magnitude and peak acceleration." Thus, such questions as: Will this building withstand a 7.0 magnitude earthquake? Or, to what magnitude should we design this structure? are not very useful.

There are many facets of earthquake damage, and to determine methods for preventing such damage, rxperienced and well-qualified consultants should be engaged. Furthermore, some kind of review procedure should be adopted to check plans before implementation. While some cities and some governmental agencies have excellent review procedures, othe's have procedures that are almost meaningless. Usualiy, the task of making certain that plans are properly checked seems to fall to the operator-manager.

\section{Building Components}

Not all damage to buildings is of a structural nature. Much damage usually occurs to architectural, mechanical and electrical features. Figure 16 shows a corridor in the basement of the Olive View Hospital ${ }^{7}$ after the Sari Fernando earthquake of 1971 . The extensive damage ciearly indicated that ceilings and light fixtures must be properly anchored and braced to prevent collapse. Exterior facades shouid also be carefully suppórted. Figure 17 shows two exterior, precast concrete walls that completely collapsed on the J. C. Penney Building. $^{8}$

Mechanical and electrical systems including equipment and components should be carefully reviewed for compliance with good seismic standards. The degree of care taken should be commensurate with the occupancy and usage of the structure. Figure 18 shows the four modes of equipment failure: sliding, overturning. inability of the equipment itself to withstand shaking; and pulling away from anchorage.

Figure 19 shows a boiler at the Olive View Hospital ${ }^{7}$ which moved in excess of four feet, sliding into the exterior wall and causing considerable damage. The air conditioning chillers also slid, breaking cast-iron valves and piping. The cost of "down time" and repairs was considerable, yet, a few relatively inexpensive anchors and snubbers could have prevented this motion. Figure

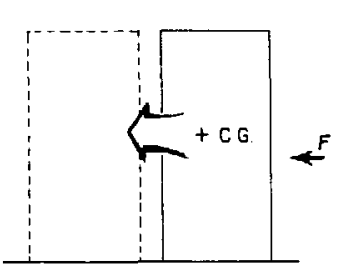

SLIDIING
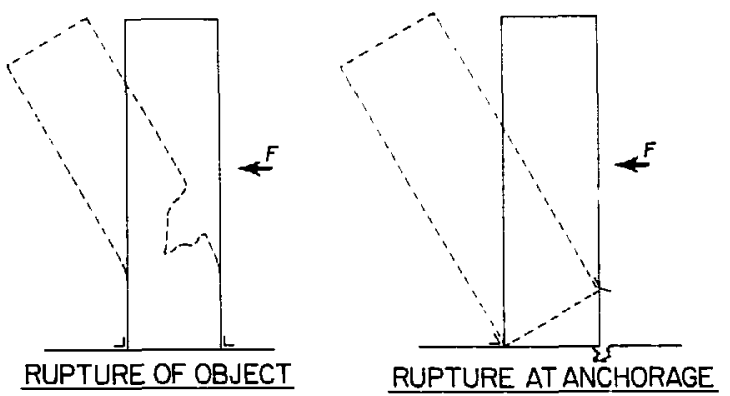

Fig. 18 - Modes of equipment failure.

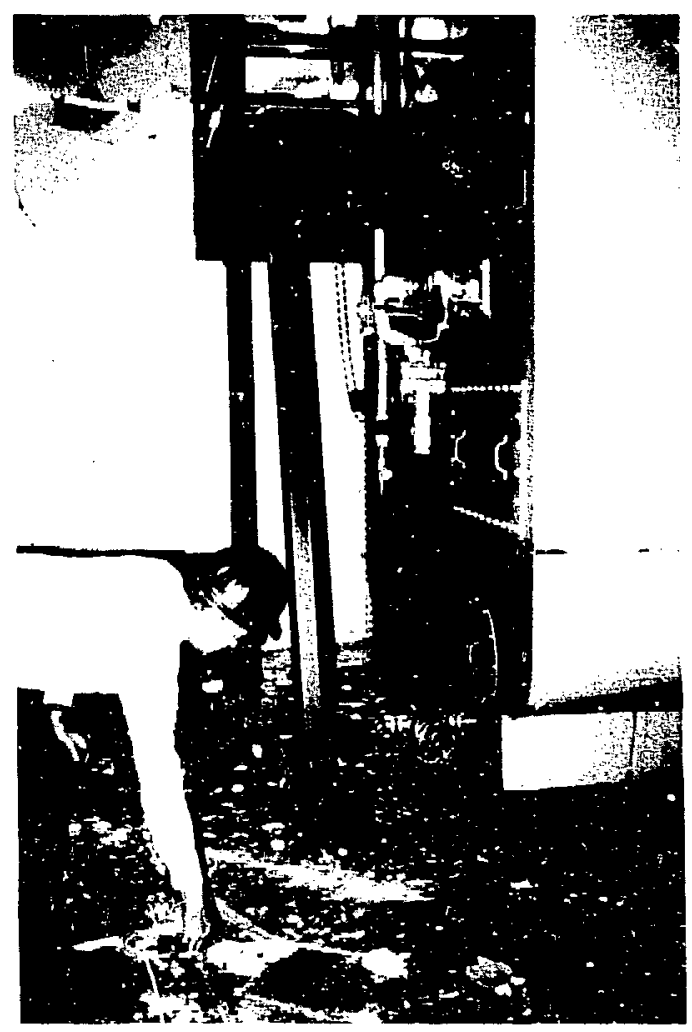

Fig. 19 - Boiler at Olive View Hospital. 
20 shows the motor control center unit, which nearly overturned. It was restrained only by cable trays.

Sliding is the mode of failure illustrated in Fig. 21. The emergency power generator tore away from its feeder cable, rendering it useless.

Figure 22 also illustrates failure due to sliding. The main transformer at the sub station tore away from its feeder. With both sub-station and emergency power generator out, no power was available to the Olive View Hospital. $^{7}$

\section{Site Conditions}

Although site conditions are more appropriately described by geologists, there are some site problems that qualified foundation engineers consider when investigating a potential site. No site should evei be selected without prior investigation by qualified foundation engineers.

In the Peru 1970, northern Italy 1976, and Mindanao 1976 earthquakes, numerous slides were visible in the hilly and mountainous areas. The most dramatic was the Braulins slide in northern Italy, shown in Figure 23. Fig. 24 shows boulders the size of two-story houses which came to rest at the toe of the slide. This slide

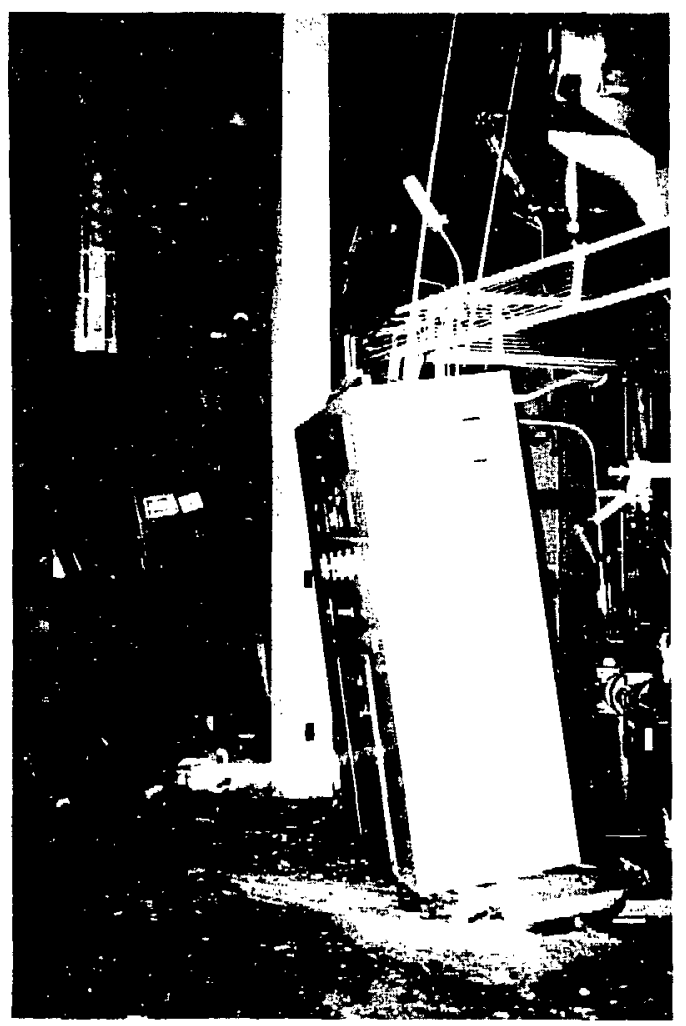

Fig. 20-Motor control units in Olive View Hospi 1. completely buried several homes constructed at the base of the mountain side. It occurred during an aftershock two days after the initial earthquake and subsequent torrential rainfalls. The heavy, wet earth simply failed. Studies st unld have been made to assess such possibilities. Not only are slides dangerous in themselves, they can do double damage if, for example, they block an access road to a hospital. A well designed hospital that has withstood an earthquake is of limited value if its access road is impassable.

Figure 25 shows the effect of a combination of soil liquefaction and rising water table. The soil has consolidated and subsided, squeezing water out of the pores of the soil up to the surface. The building has also subsided into the soil. This occurred in Chimbote, Peru in 1970. ${ }^{\prime}$

One of the strange phenomena evidenced in many earthquakes is the occurrence of small areas of much more intensive shaking than other areas in the same earthquake. These areas could be considered as microseismic areas where ground waves seem to concentrate or focus to amplify the intensity of ground shaking. For example, Fig. 26 shows the Solari Watch Works in northern Italy in 1976 . Ground shaking was so intense that the side precast panels were thrown approximately one meter away from the base. All

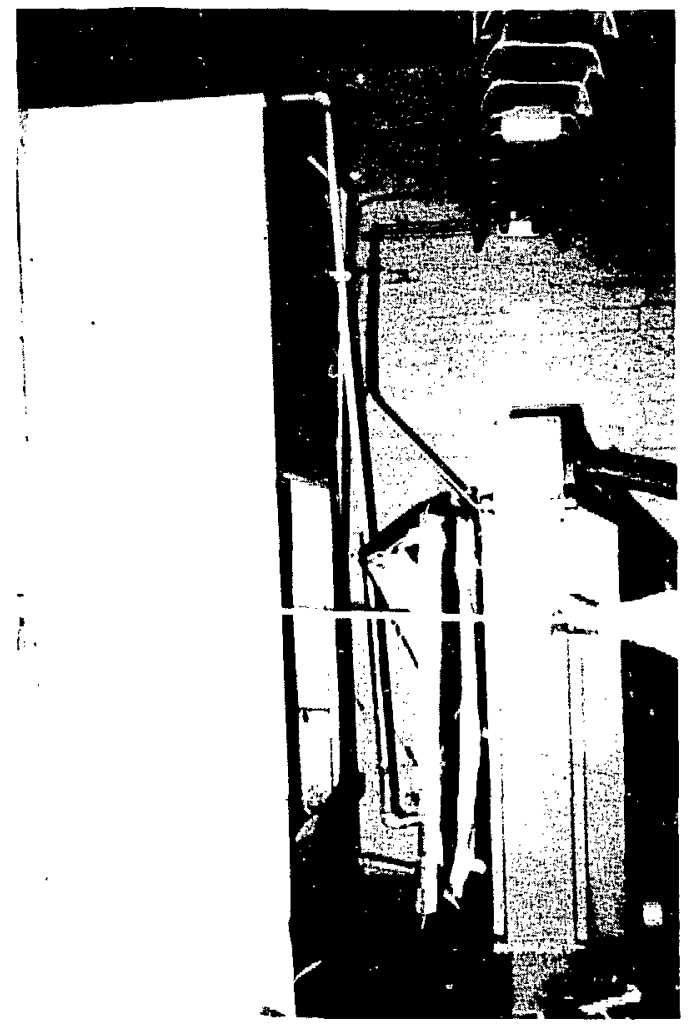

Fig. 21 - Emergency power generator at Olive View Hospital, torn away from feeder cable. 


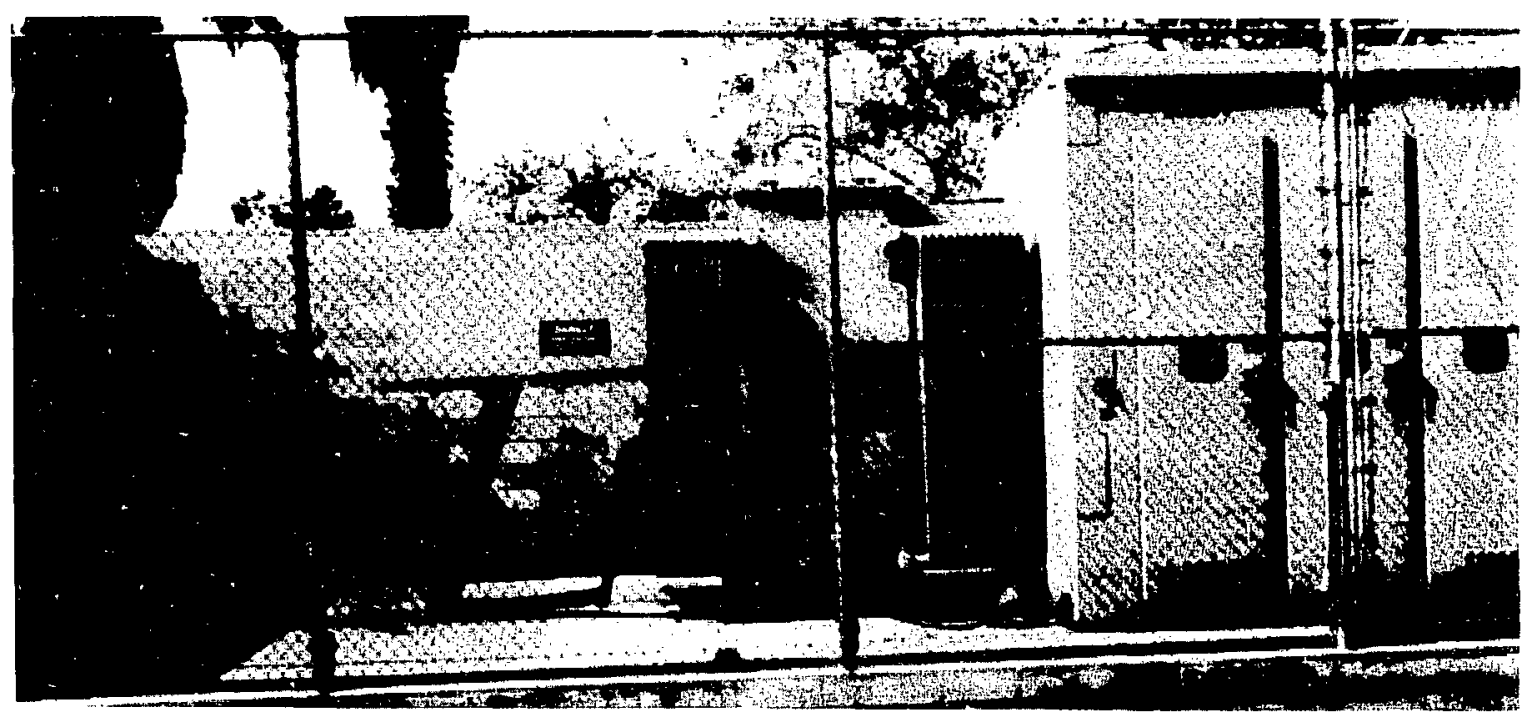

Fig. 22 - Olive View Hospital substation main transformer torn away from feeder cable.

Fig. 23 - Aerial view of Braulins slide in northern Italy, May 6, 1976 earthquake.

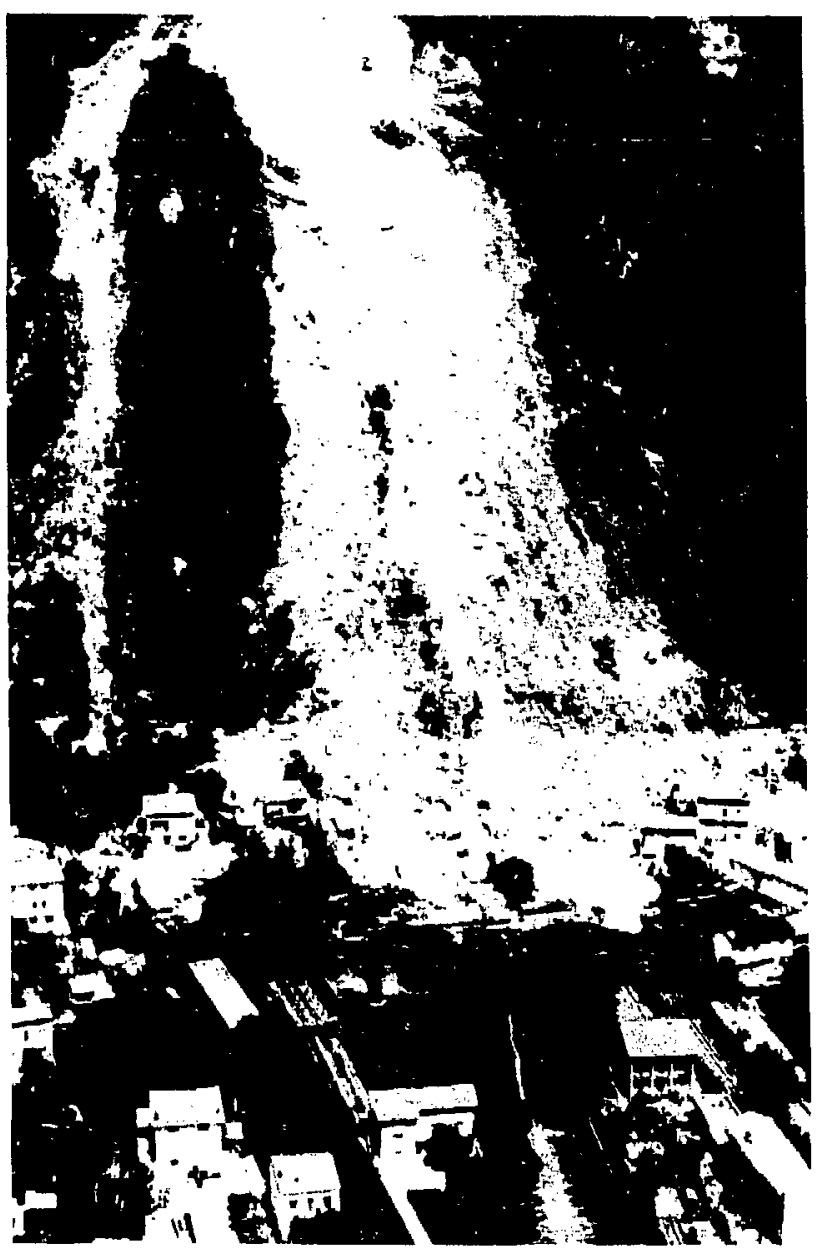




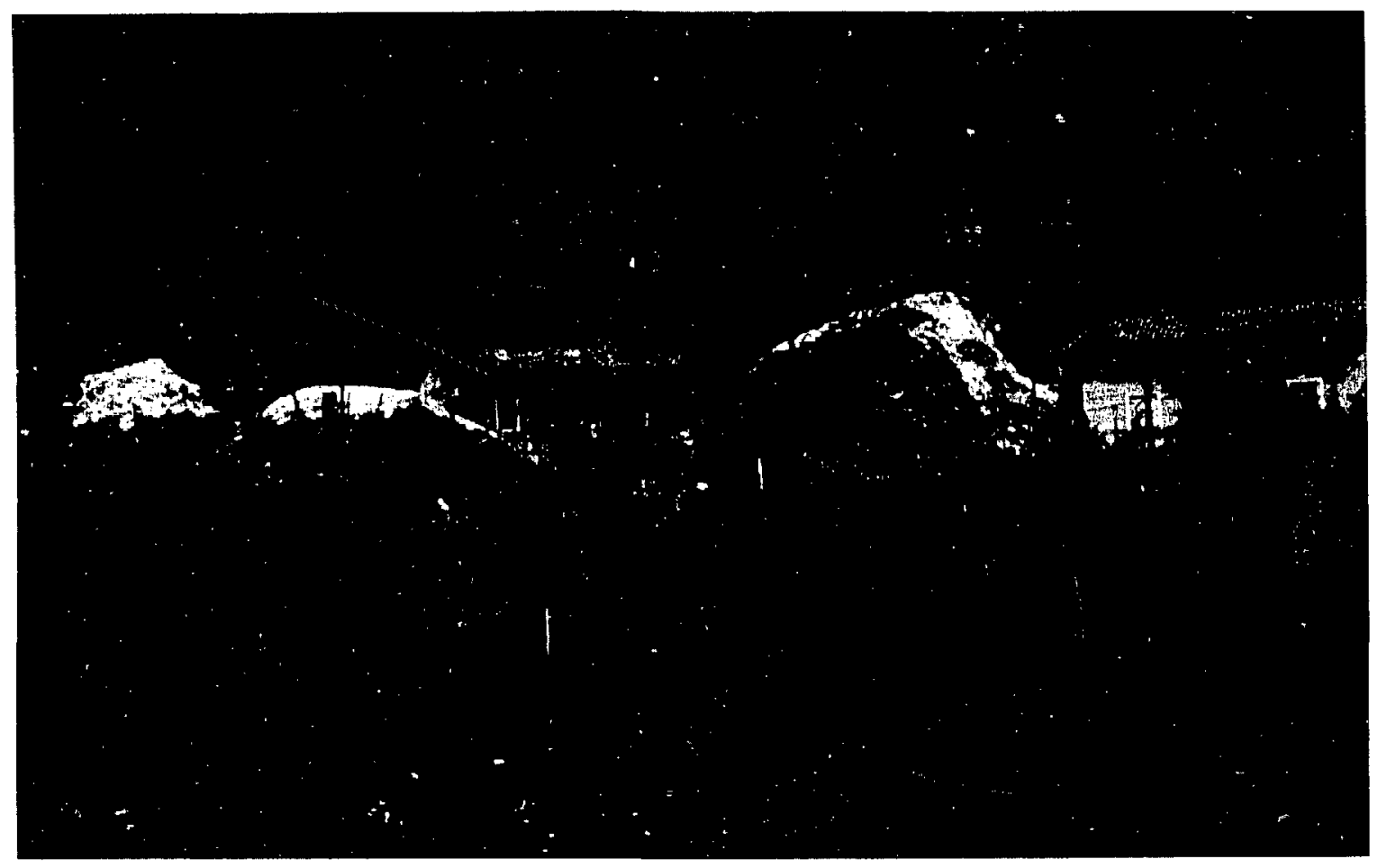

Fig. 24 - Two-story boulders came to rest at base of Braulins slide.

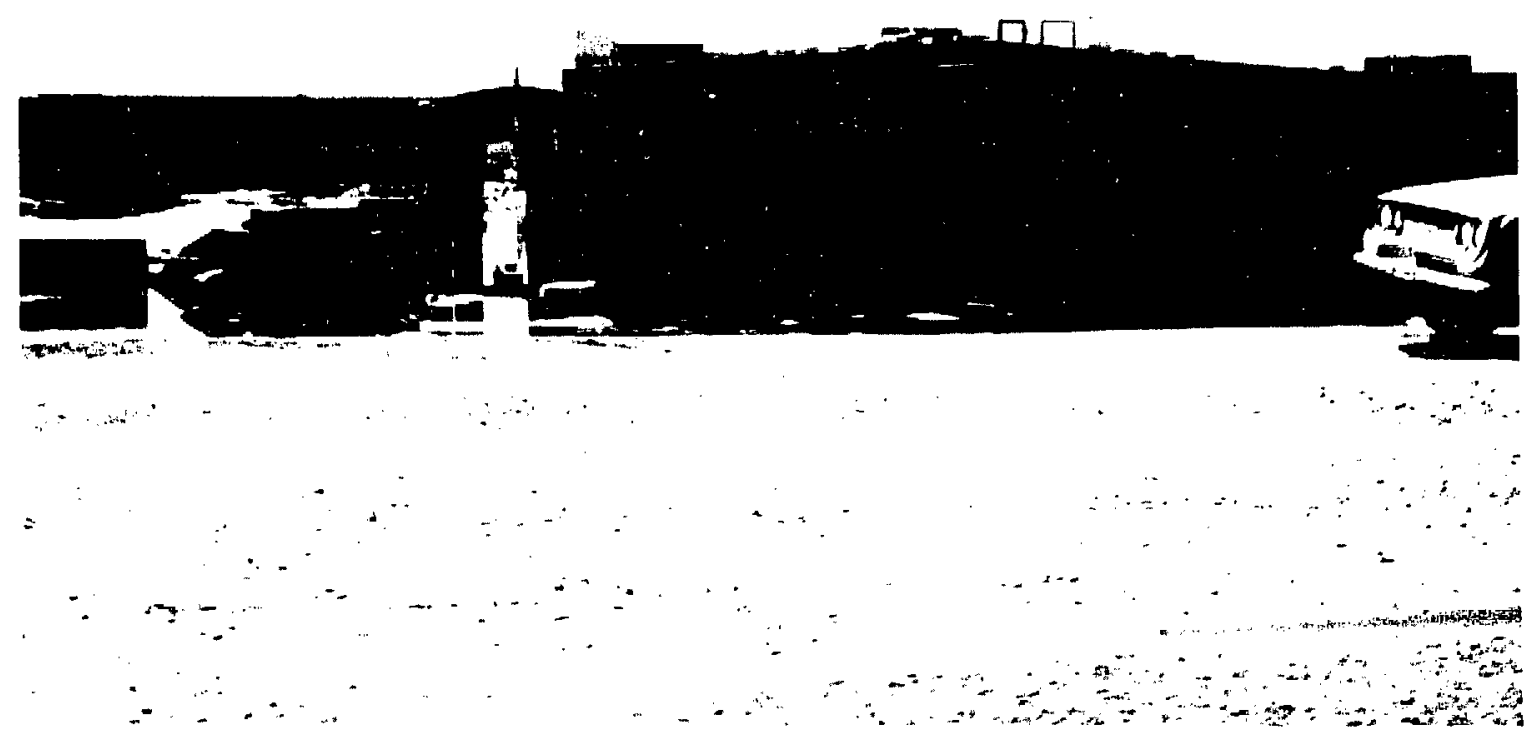

Fig. 25 - Effects of combination of soil liquefaction and rising water table, Chimbote, Peru, May 31, 1970 earthquake. 
equipment on the floor moved between 0.5 meter (1.6 feet) and 1.0 meter (3.3 feet) in the same direction. No similar intensity was noted elsewhere in this earthquake. A similar situation occurred in the Lima, Peru earthquake ${ }^{5}$ in which the University classroom building failed (Fig. 10), yet within 1.5 kilometers ( 1 mile), adobe dwellings suffered no damage. Most of these microseismic areas seem to lie in lowlands, with high water tables.

\section{Contents}

The cfficcts of earthquakes on the contents of buildings can be devastating, depending on usage and contents. Figure 27 (San Fernando earthquake of 1971$)^{7}$ illustrates the overturning of equipment, and Fig. 28 shows the spillage of materials from shelving. These in themselves are relatively minor kinds of earthquake damage. In other situations, the damage has ramifications that pose more serious problems.

For example, damage to computer rooms involves more than equipment damage. In gencral, computers are placed on raised floors that allow cables and, frequently, air-conditioned air to pass under the various components to serve them. These computer floors are usually not laterally braced for seismic loads as shown in Fig. 29, a view showing the underside of the computer floor. If floors collapse, computers will overturn and fall to the sub-floor, causing severe damage to the computer plus loss of stored data. In some computer centers millions of dollars worth of equipment and

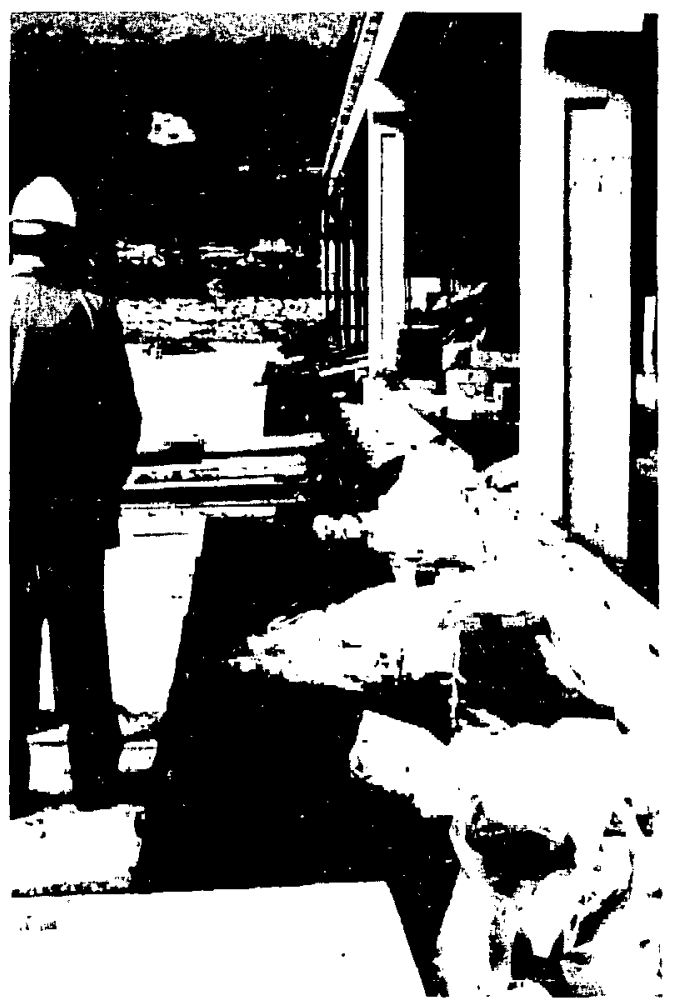

Fig. 26 - Solari Watch Works, northern ltaly, May 6, 1976 earthquake.

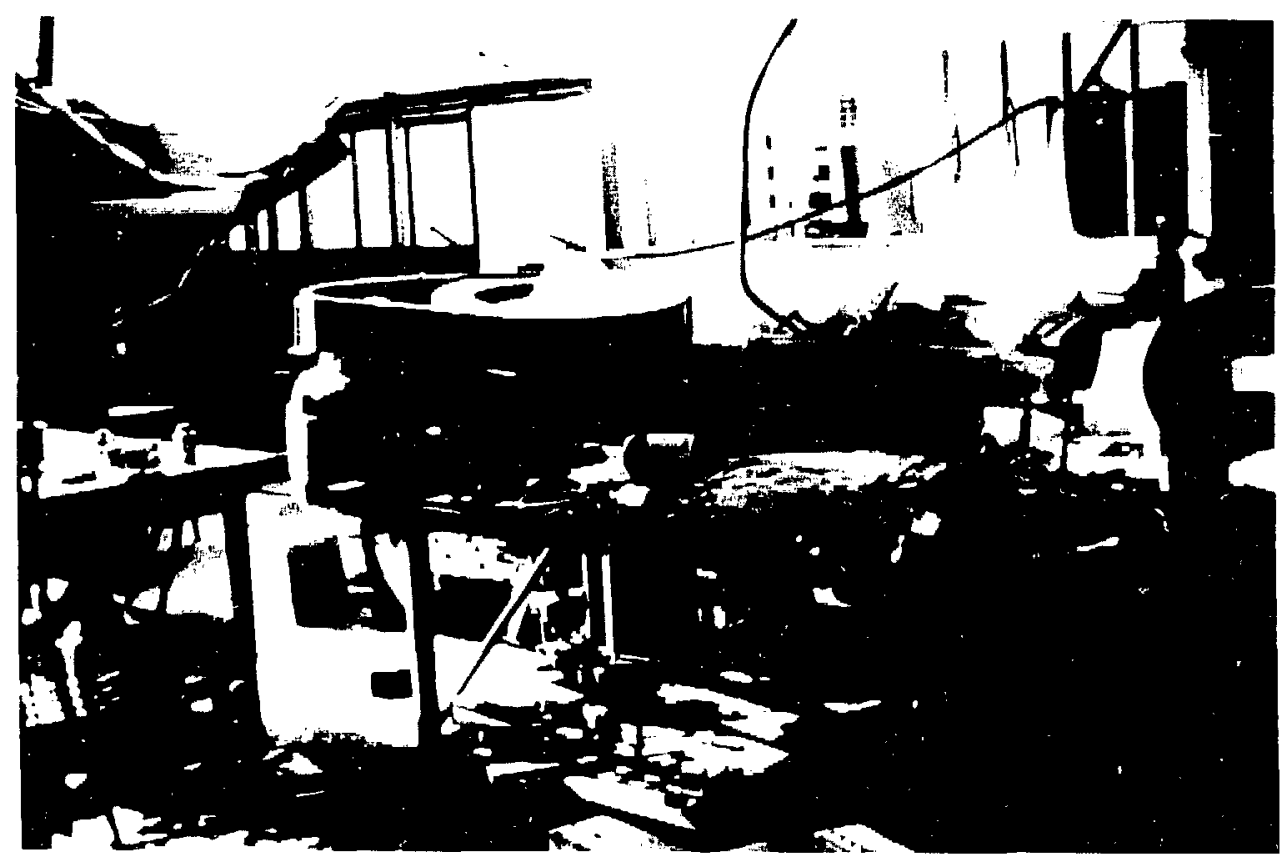

Fig. 27 -- Overturned equipment, San Fernando earthquake, 1971. 


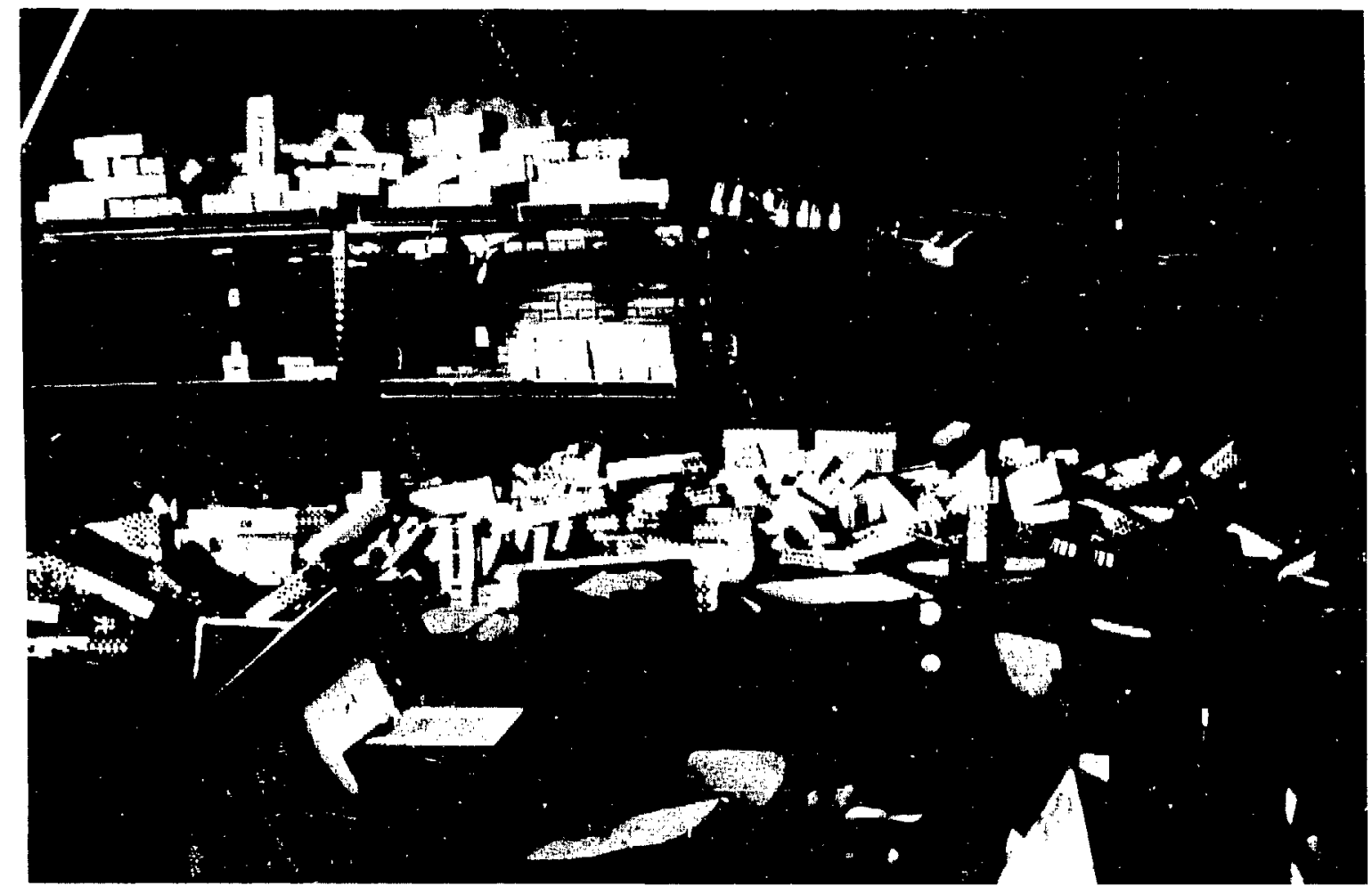

Fig. 28 - Spillage of materials from sheiving, San Fernando earthquake, 1971.

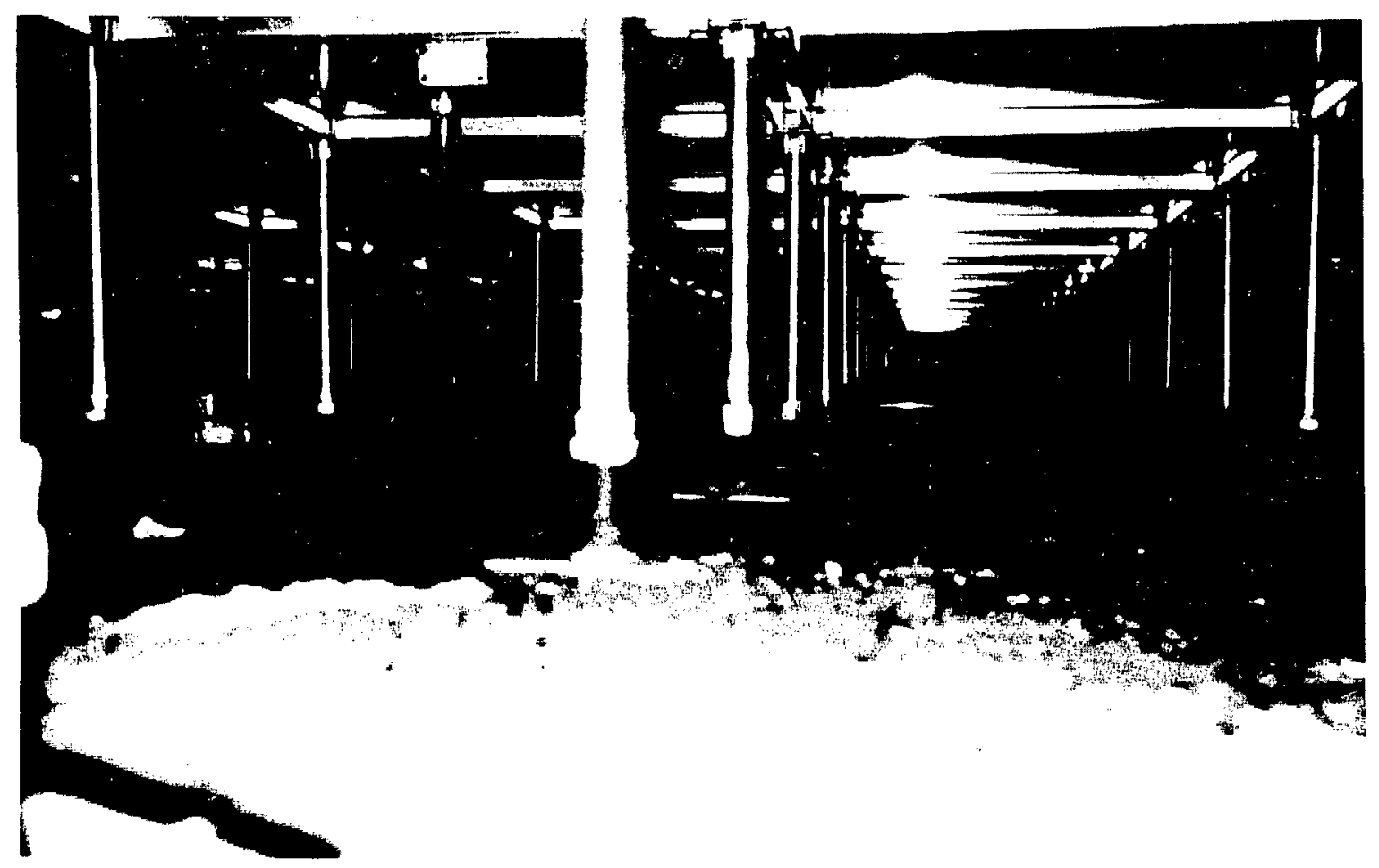

Fig. 29 - Underside of a computer-room floor. 
stored data could be lost, as well as the time necessary to restore the data and equipment.

In research and development centers and electronic facilities, large amounts of costly equipment are utilized on tables and benches. This equipment will probably fall to the floor during a mild shock. A severe shock could force some facilities to close for several months until damaged equipment can be replaced. Where integrated circuits and semi-conductor chips are stored on shelving, all could be lost.

Plating facilities also pose hazardous problems with the chemicals they store. The cyanide tank is usually four tanks removed from the acid tank. During an earthquake, sloshing and spillage will occur. If the cyanide and acid are combined, hydrogen cyanide, a deadly poisonous gas, is produced. A similar situation exists in chemistry laboratories where chemical compounds are often stored in bottles in glass door cabinets above the benches. Generally, both cyanide compounds and acids are stored there. If the earthquake shakes these bottles off the shelves, a situation similar to that in plating facilities could develop.

A related problem occurred in the Mindanao earthquake of August 17, $1976 .^{6}$ When the reconnaissance team for the Earthquake Engineering Research Institute reached Cotobato City in Mindanao, they went to the Notre Dame University to study the damage there. Figure 30 shows the Notre Dame Science Wing before the earthquake. Figure 31 shows the collapsed structure as seen by the reconnaissance team. and although the structure was blackened by fire it was assumed the earthquake had caused the collapse. However, a local photographer produced Fig. 32 showing that immediately after the earthquake, the structure, although severely damaged, had remained erect. A fire had broken out due presumably to a mixture of chemicals that caused a flammable or explosive compound to be formed. This fire burned fiercely and caused the already weakened structure to collapse. The lesson to be learned is obviously to store chemicals so that a mixture of any two will not create toxic. flammable or explosive conditions.

A similar situation arises when gases are stored in tanks serving a building. Figures 33 and 34 show a small tank outside the Olive View Hospital. Note how the tank slid and attempted to overturn, but was restrained by the fence. Such tanks should be properly anchored to reduce the possibility of damage.

Wherever toxic, flammable or explosive gases are piped into a building, serious consideration should be given to the use of earthquake valves located outside the building. These valves are mechanical devices designed to shut off all supply to the building upon sensing earthquake motions above a set level. In this manner, only gases in the lines within the building confines will escape into the building in the event of a break in the lines, and the effects of toxic gases and possibilities for fires will be greatly reduced if not eliminated. Earthquake valves may also be used for !iquids when desirable.

In one case an earthquake valve was used to actuate a solenoid valve to open a water main under a plating

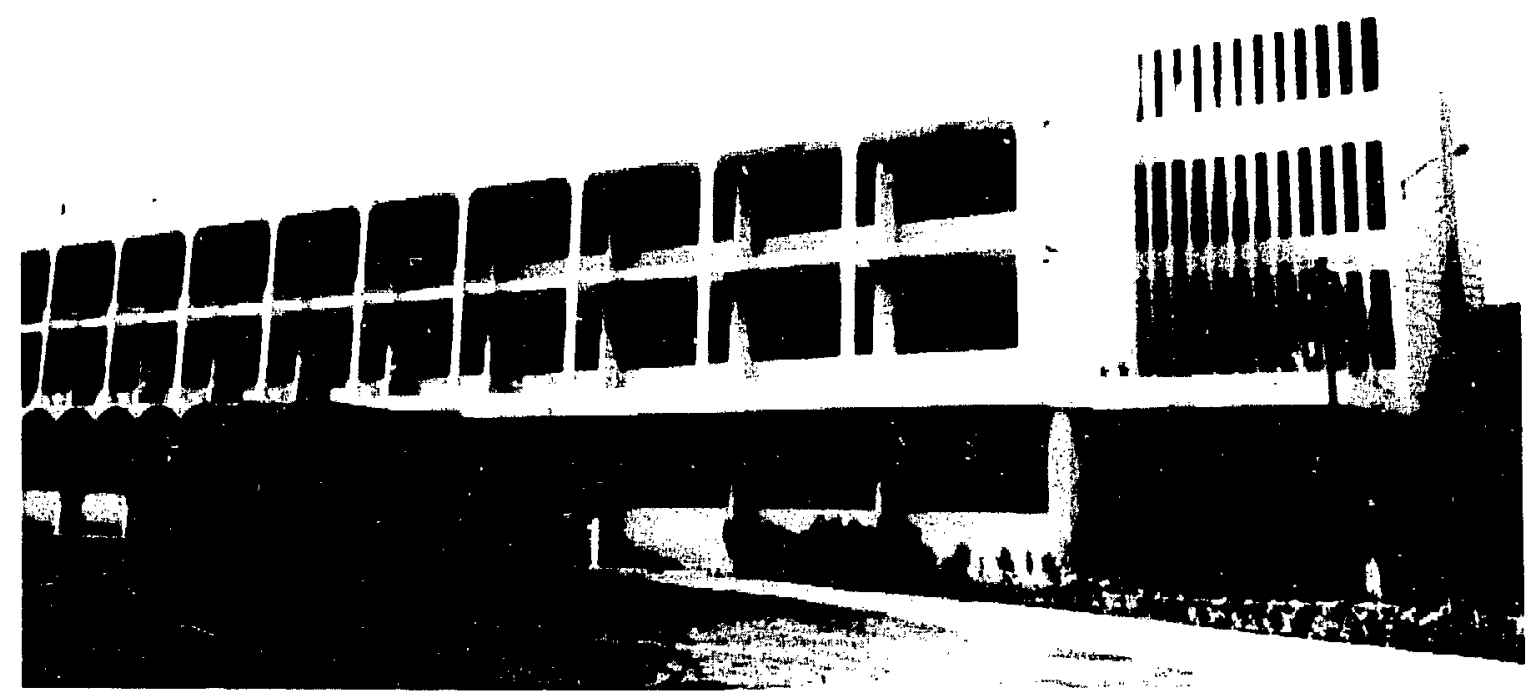

Fig. 30 - Notre Dame Science wing, Cotobato City, Mindanao, PI, prior to August 17, 1976 earthquake. 


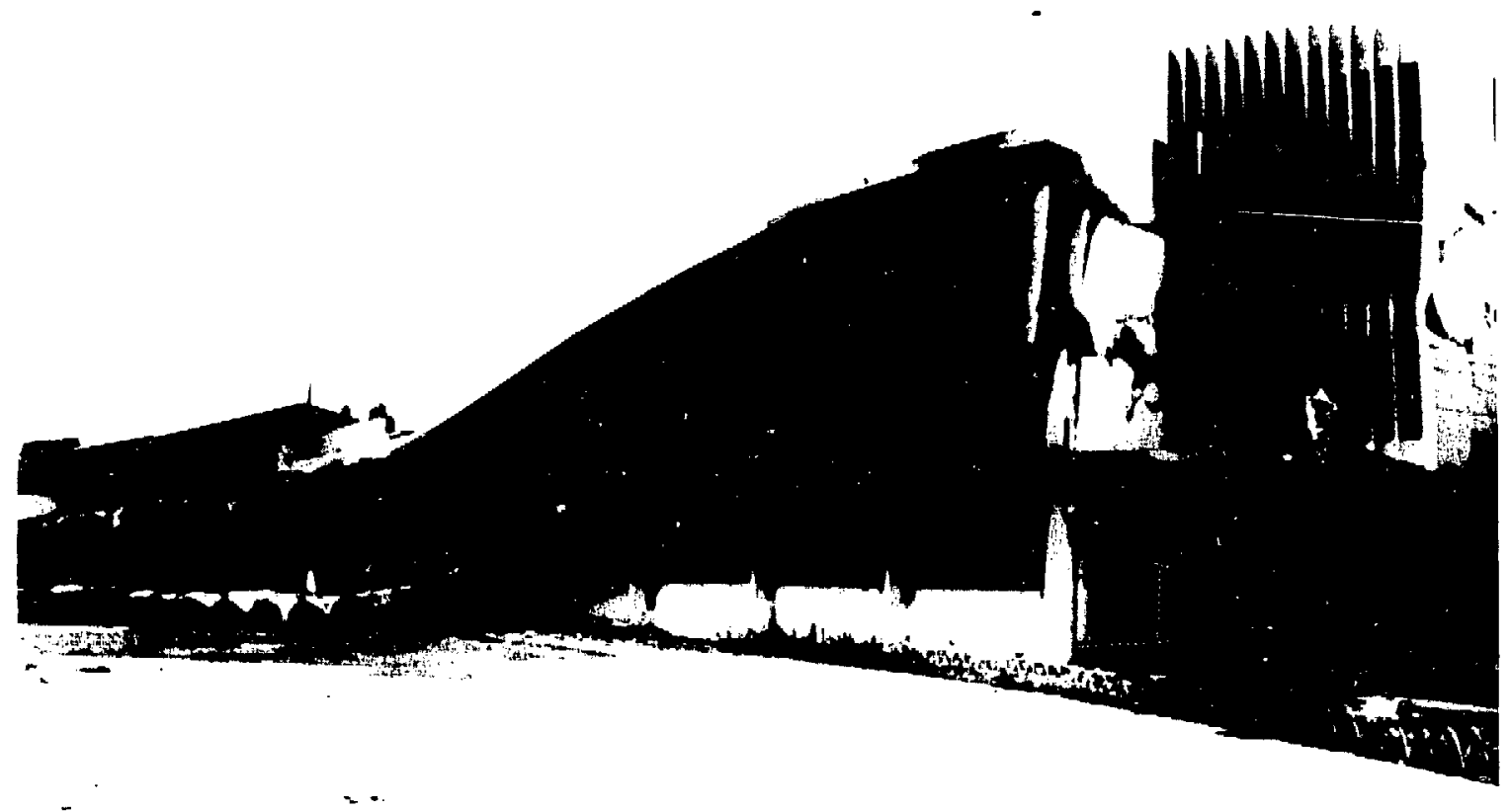

Fig. 31 - Notre Dame Science wing, blackened by fire. Photo taken a day or two after the earthquake.

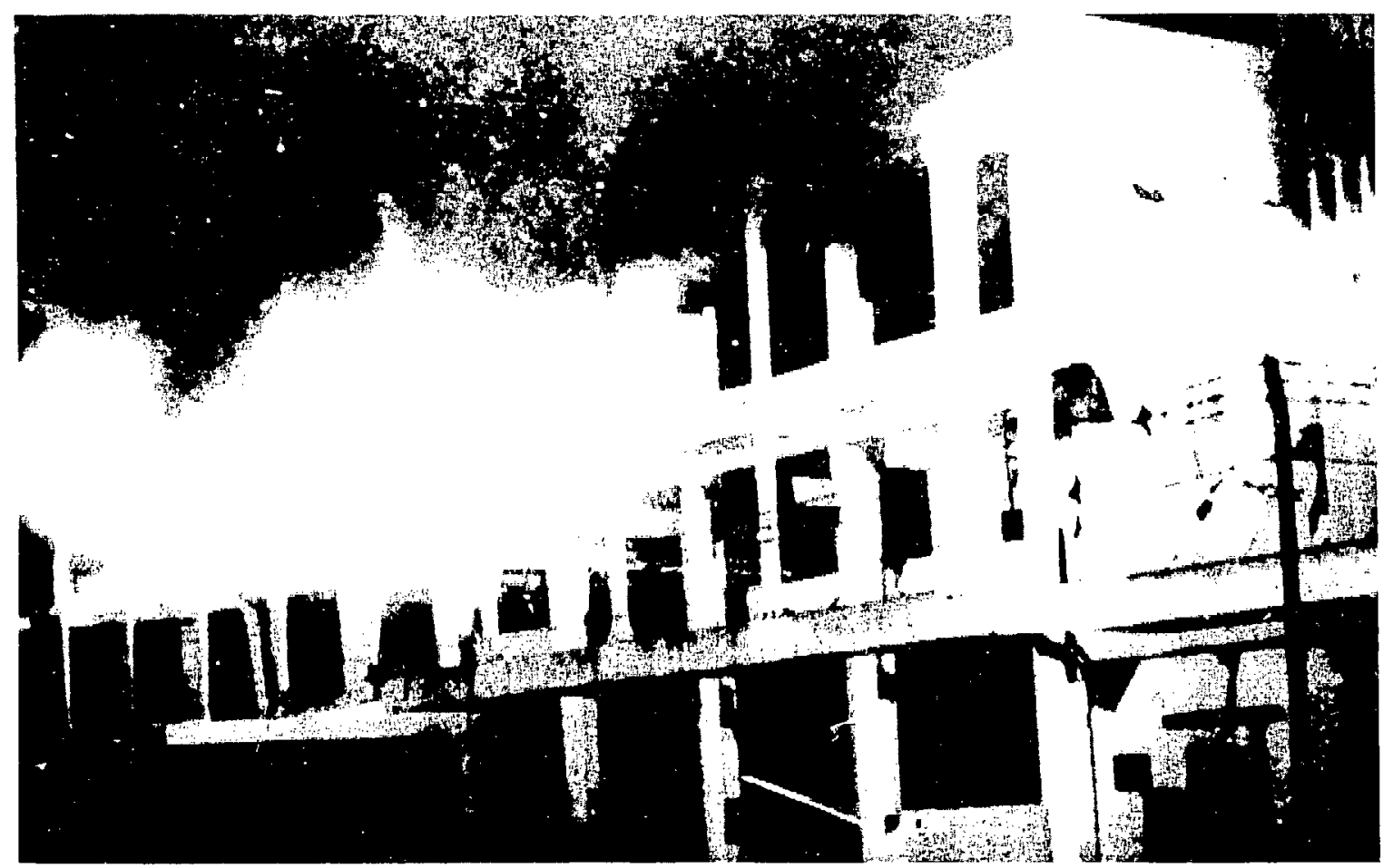

Fig. 32 - Notre Dame Science wing during fire, photo taken immediately after the earthquake. 

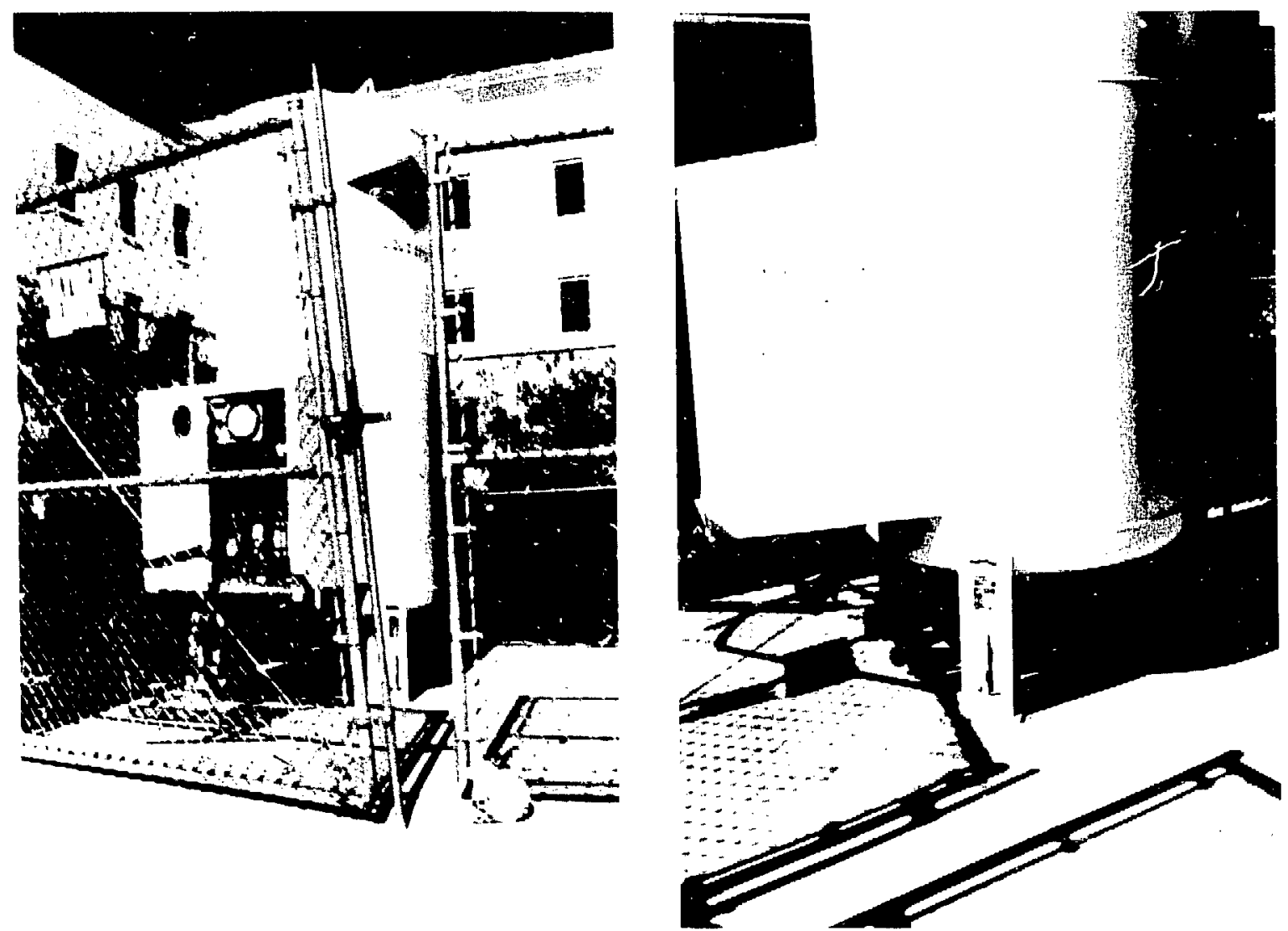

Figs. 33 and 34 - Tank outside Olive View Hospital slid during earthquake and was restrained only by the fence from overturning.

facility and flush the area in order to prevent the concentration of dangerous mixtures created by spillage.

\section{Supervision}

The necessity for good field oversight by the design engineer cannot be overemphasized. It is not of much value to go through painstaking calculations, detailed drawings and specifications and then allow the construction work to be carried out improperly. After every damaging earthquake, lack of proper inspection is very noticeable. It is not possible to categorize this lack because it seems to occur in all areas. One specific cxample, however, will point out the problem. In the Philippine Bar Association Building failure, one of the columns literally exploded during the earthquake. Whether this was a cause or result of the damage that occurred can only be surmised. However, what actually occurred is interesting. The plumbing contractor realized that he had forgotten to place a downspout in a column as required. The column reinforcing, however, was already in place, including the spirals from top to bottom of the column. The contractor opened up the column reinforcing by cutting with a torch, inserted a downspout, neatly closed the column reinforcing and tack-welded the spirals occasionally to maintain the steel in place. Consequently, during the earthquake "the most artistically sculptured failure yet was developed," (see Fig. 35).

Some owners and governmental agencies of ten remove this overseeing requirement frons engineering agreements. This action can certainly be deemed as "penny wise and pound foolish." It is strongly recommended that overseeing of the project be made an integral part of the contract with design engineers.

\section{Conclusion}

It should be apparent that a complete dissertation on earthquake damage would require several volumes. It is hoped. however, that the few examples and discussions 
Fig. 35 - Exploded column in Philippine Bar Association building. An overseer to check all details of construction is strongly recommended.

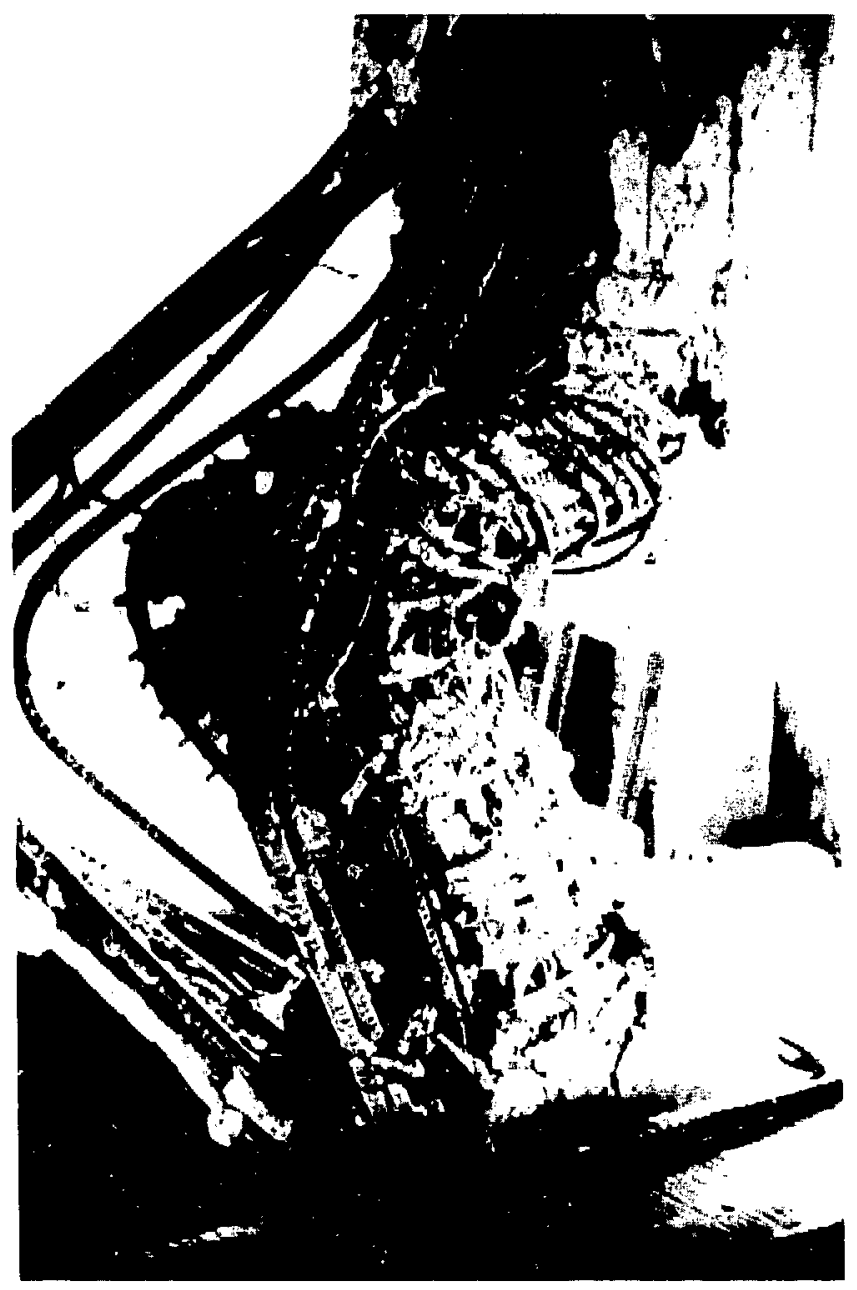

given here will serve to develop a sense of urgency for proper seismic design and construction.

The following references are recommended reading for a more detailed understanding of earthquake damage.

\section{REFERENCES}

\section{Chapter 3}

1. Peru Earthquake of May 31, 1970. Earthquake Engineering Research Institute, 1970, Berkeley, California.

2. Friuli, Italy Earthquake of 1976, Earthquake Engineering Research Institute, August 1979, Berkeley, California.

3. Design of Multi-Stored Reinforced Concrete Buildings for Earthquake Motion, Blume, J. A. Newmark, N. M. and Corning, L. H., 1961, Portland Cement Association, Chicago.
4. Earthquakes, American Iron and Steel Institute, 1975, Washington, D.C.

5. The Lima. Peru Earthquake of October 3. 1974. Earthquake Engineering Research Institute, 1975. Berkeley, California.

6. Mindanao, Philippines Earthquake of August 17, 1976. Earthquake Engineering Research Institute, 1977, Berkeley, California.

7. San Fernando, California, Earthquake of February 9, 1971, Volume I, Parts A and B, Leonard M. Murphy, Scientific Coordinator, U. S. Department of Commerce, 1973.

8. The Prince William Sound, Alaska, Earthquake of 1964 and Aftershocks. Volume I, Part A, Fergus J. Wood, Editor-in-Chief, U. S. Department of Commerce, 1967.

9 Learning From Earthquakes - Planning and Field Guides, Earthquake Engineering Research Institute, 1977, Berkeley, California. 


\section{Chapter

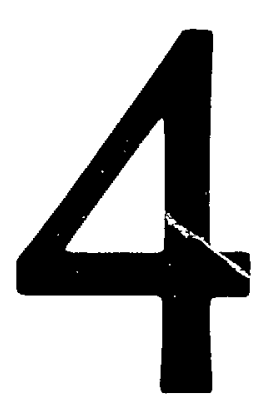

\section{Site-use Planning for Earthquake Safety}

\section{FOREWORD: Operator-Manager's Point of View (Donald G. Eagling)}

The extent to which a site should be investigated varies with the degree of natural hazard present and the possible consequences of damage, whether it is a new site to be developed or a site with existing improvements to be protected. It will also vary directly with the complexity of the geology, that is, with the difficulty of the diagnosis. One important point to keep in mind is that it is easy to dissipate funds in site investigation work before the problems, priorities and direction of the broader earthquake safety program are fully understood. Detailed work should always be carried out after the other facets of earthquake safety have been considered and the objectives of further work are more clearly defined.

The important practical goal of a site investigation for ea hquake safety is to identify potential natural hazards such as unstable slopes and existing landslides, areas subject to dynamic subsidence, liquefaction or strength loss under ground shaking and of course fault movement. The object of the investigation is to avoid the hazard if possible and to mitigate it if it is not practical to avoid it.

The development of site-specific criteria for seismic design is one of the more sensitive processes that must be carefully managed to avoid technical and political pitfalls. Usually, the pressure to devclop site-specific criteria relates to criteria required for dynamic analysis rather than static lateral force analysis. Unfortunately, there is persistent misunderstanding and confusion about the meaning and use of ground-surface acceleration as a measure of the earthquake resistance of build- ings. This applies not only to the public perception but also to most operator-managers and engineers who do not have the technical insight and experience of the earthquake engineer. This confusion is amplified through continued misrepresentation of the issue by public communication media. The following example illustrates the problem:

A low-rise building having a ductile lateral forceresisting system analyzed for a $0.2 \mathrm{~g}$ static lateral force, and having been well-designed and constructed to code, should resist actual ground accelerations of $0.8 \mathrm{~g}$ without collapse. ${ }^{*}$ In this case, the equivalent staticdesign procedure requires a base shear force of 0.2 times the weight of the building to be fully resisted by allowable code stresses in the members of the lateral force-resisting system only.

An analysis using structural dynamics in conjunction with $0.8 \mathrm{~g}$ ground acceleration assumes that all forms of structural work will act to resist earthquake forces, including kinetic energy inducing vibration of the building mass, strain energy causing elastic and inelastic deflections, and damping energy causing friction between moving parts and internal molecular friction within the materials of construction. In effect, earthquake-resistant design using dynamic analysis balances the ultimate resistance of the building against the

\footnotetext{
'An explanation for this apparent paradox is contained in "Earthquake Design Criteria," Housner, G. W., and Jennings, P. C., Division of Engincering and Applied Science, California Institute of Technology: a monograph published by the Earthquake Engineering Research Institute, September 1982.
} 
earthquake input forces. Many assumptions or decisions made by the engineer responsible for the analysis and design may be more or less conservative with respect to the actual resistance of the building. The competence of the engineer responsible for the analysis and design is much more important than the specification of input criteria.

In spite of the fact that site-specific earthquake ground motions are not predictable in an engineering sense, ${ }^{\dagger}$ there seems to be a compulsion to study and attempt to predict accurately the maximum credible earthquake and the maximum ground acceleration a site might experience. Possibly this is influenced by technical "spin-off" from the nuclear power industry, where the determination of a maximum credible carthquake for cach reactor site is a regulatory requirement. For whatever reason - political, academic, or psychological - a lot of time and money goes into estimating and predicting the size of the earthquake and the maximum ground acceleration, even though it may be an unrewarding and impractical exercise.

There is a growing number of earthquake engineers who do not consider the maximum greund acceleration or effective peak ground accsleration as the key predictor-variable in site-specific seismic design criteria. If one looks at actual experience with damaging earthquakes, it is indeed rare to find that the predicted size of the earthquake was the major deficiency revealed by the damage. The reality is that most problems are found to be the result of structural deficiencies, such as a missing or brittle link in the lateral-force-resisting system, or simply the lack of a formal, predictable lateral-force-resisting system. The point is that excessive time and money should not be spent on guessing the size of a future earthquake and its ground motion. For the operator-manager this is an important pitfall to be avided. The money can be more wisely spent on fixing buildings before the earthquake strikes.

When site-specific seismic criteria must be specified, the work should be carried out by an experienced geotechnical specialist working in close coordination with the structural engineer who will use the results. Generally, seismologists and geologists have limited understanding and little control over how the site spe zific criteria will be utilized for structural design. It is impossible for them to take this into account if they must set criteria in a structural vacuum. Worse, when this happens, the structural enginecr may bc saddled with unrealistic criteria that will make the results of the analysis unrealistic or the resulting design solution impractical if not unusable.

Public arguments over seismic crileria arc commonplace with respect to facilities that house hazardous miterials. Because the estimate of earthquake size is at best an educated guess, these arguments make an ideal battleground for political forces. It's a poor place to take a stand. The cost to provide extra strenoth and ductility for an earthquakc-resistant structure to resist a major earthquakc, versus that required for a moderate earthquake, is of ten small; perhaps 2 or $3 \%$ of the cost of most buiidings. It is not worth arguing about if this cost is balanced against the high costs that are usually required to develop data to support site-specific criteria for an event smaller than a major earthquake. As a practical matter, the cost of inflation due to sevcral month's delay is apt to be more than the cost of providing extra strength for the larger earthquake.

Politically, the costs of prolonged public debate are significant and damaging. It does not m:r., zonomic or technical sense to undertake extensive ....uits that have the object or possibility of establishirg les. stringent site criteria in an arca wherc potentially damaging earthquakes have been part of recent geological time and can be anticipated in the future.

This subject is further discussed in the Foreword to Chapter 5. 


\title{
Chapter
}

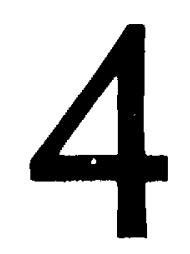

\section{Site-use Planning for Earthquake Safety}

\author{
Stephen R. Korbay \\ Geologist, \\ Engineering Geologist
}

and

Lyle E. Lewis

Civil Engineer

\begin{abstract}
Mr. Korbay has extensive experience in geologic investigations for earthfill dams, subdivisions, nuclear power plants, pipeline and transmission line routes, and geothermal steam well sites. He has performed geologic hazards assessments and is experienced in geologic and hydrologic studies for environmental impact reports. He also has conducted water resource evaluations and construction materials searches for numerous sites in California, Nevada, Texas and Guam. Mr. Korbay has special expertise in geologic/seismic site investigations for hospitals and schools. A Registered Geologist and a Certified Engineering Geologist in California, he is an Associate Geologist with Harding Lawson Associates, Novato, California.

Mr. Lewis has been consulting in soil mechanics, instrumentation, and all phases of laboratory testing of soils for the past 20 years, with extensive experience in dams and tailings piles in the Western United States. He also has considerable experience with solid waste disposal sites and projects, landslide repair and dredging technology. $\mathrm{He}$ is a Registered Civil Engineer in California and an Associate Engineer in the firm of Harding Lawson Associates.
\end{abstract}

Facilities located in most regions of the United States will experience some degree of earthquake shaking at some time. Maps of seismic zones in the United States are shown in Figs. 1, 2, and 3; these zone maps illustrate the expected seismic risks for particular broad geographic areas and are based, essentially, on the earthquake history and geology of these regions.
Site use planning for a particular site within one of these seismic zones should include an estimate of the probable frequency and severity of earthquakes to which the site will be subject. This information can be used to develop design criteria for buildings and other facilities that will enable these structures to survive the potential earthquakes and continue to function safely. 


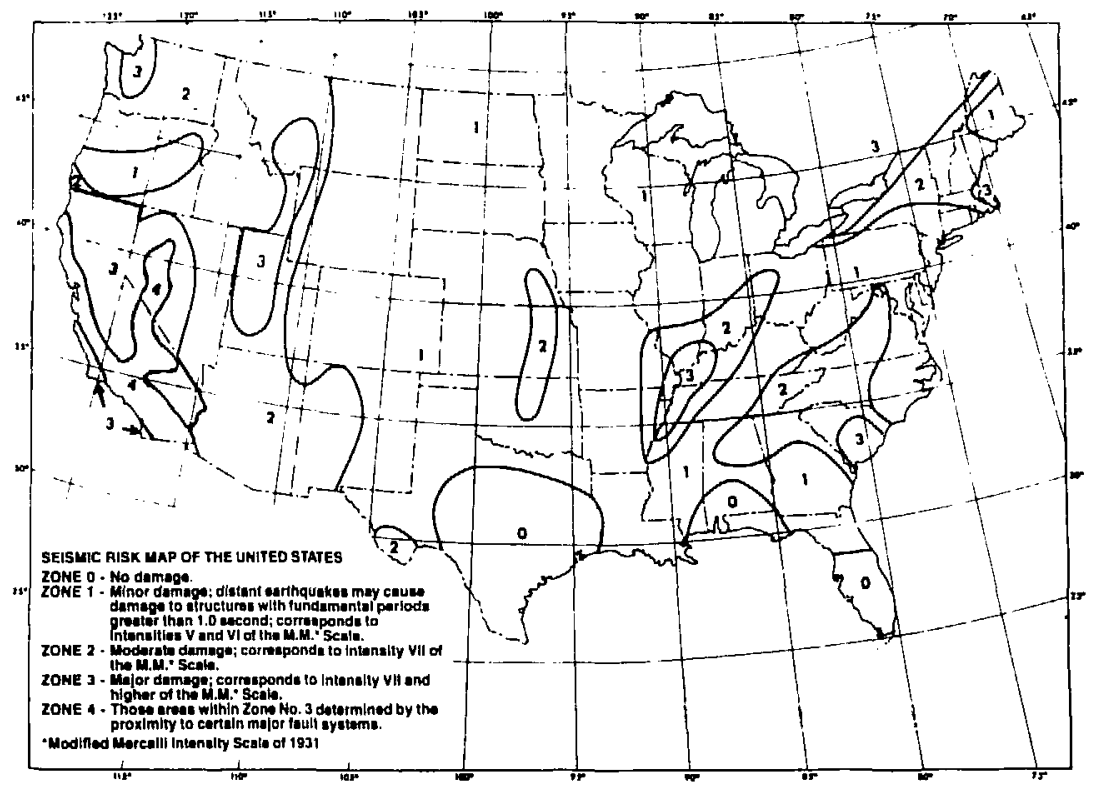

Fig. 1 - United States, Mainland

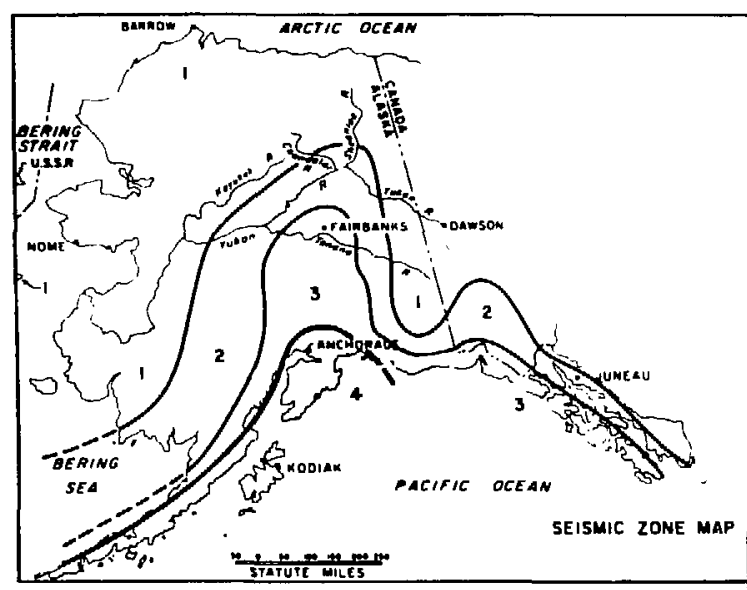

Fig. 3 - United States, Hawaii

Fig. 2 - United States, Alaska

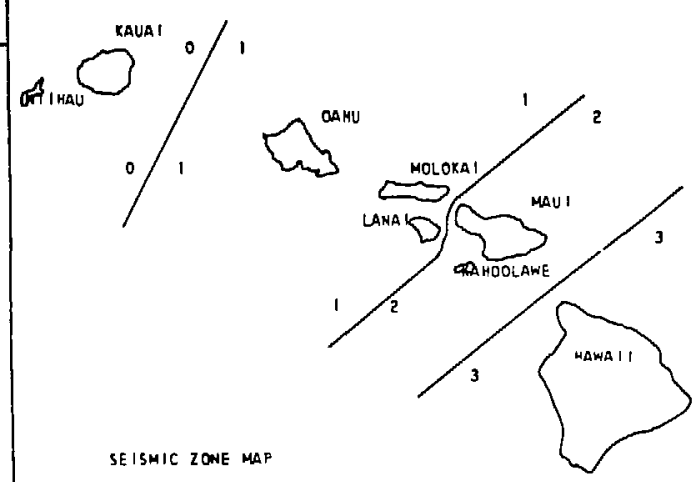

Figs. 1, 2 and 3 - Seismic maps of the United States (Uniform Building Code, 1982, International Conference of Building Officials.) 


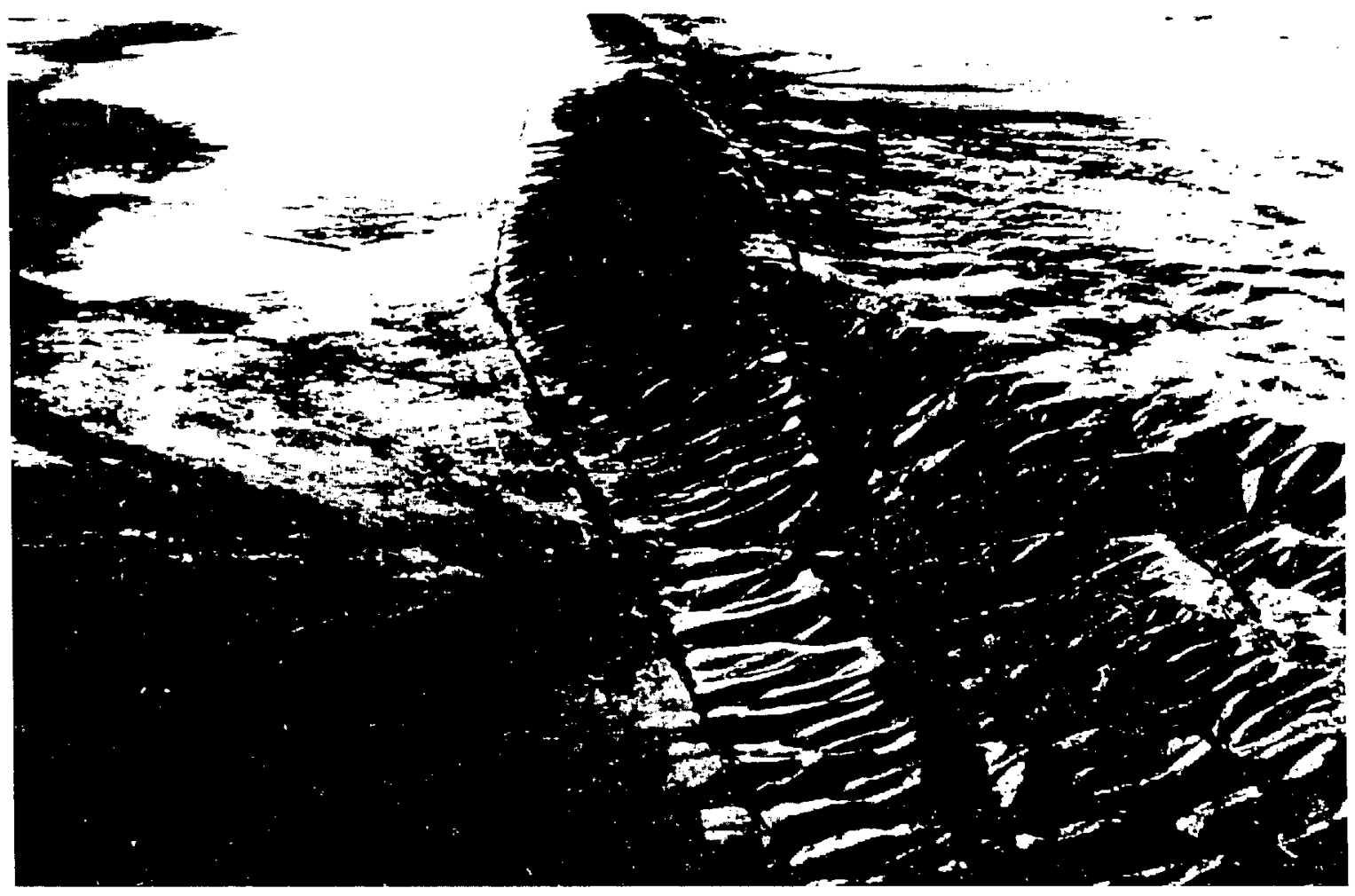

Fig. 4 - San Andreas fault, southern California (National Oceanic and Atmospheric Administration, U.S. Department of Commerce.)

\section{Seismicity}

The seismicity of a region, and of a site within a region, should be investigated from both historical and technical standpoints. A review of seismic zone maps will provide preliminary information. Evaluation of the seismicity of a specific site will also require study of the following:

1. Regional and site geology

2. Tectonic and/or structural history

3. History of seismic activity

4. Location of active faults (Photographs of active faults are shown in Figs. 4 and 5.)

5. Types and lengths of significant faults or faults that occur within a radius of at least 100 kilometers.

The magnitude and the occurrence date of previous earthquakes should be investigated. Both the maximum credible earthquake and the maximum probable earthquake should be determined by a seismologist or a geologist experienced in this field. The maximum credible earthquake is the largest magnitude earthquake that appears possible within the known tectonic framework. The maximum probable earthquake is the largest mag. nitude earthquake that is likely to occur either during a 100-year interval or the expected life of the project. It is also helpful to determine the recurrence interval for earthquakes of all magnitudes, including those that are more frequent but of lower magnitude, in establishing basic seismic design criteria.

A discussion of methods for measuring the severity of earthquakes is presented in Appendix A. Criteria for determinimg maximum credible and maximum probable earthquakes are provided in Appendix B. A brief description of the seismicity of the United States is presentec in Appendix C. 


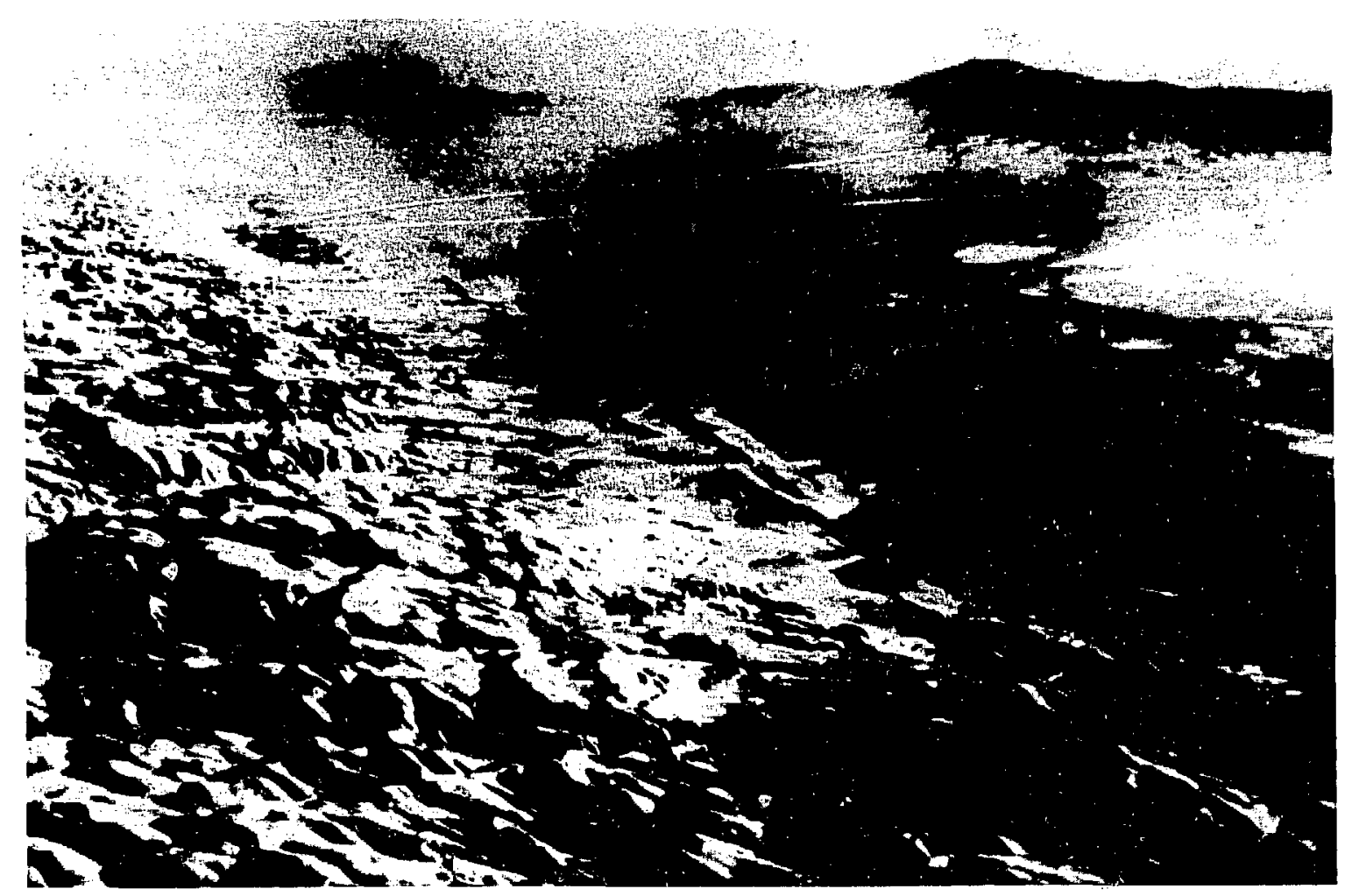

Fig. 5 - San Andreas fault, Carrizo Plain, southern California (National Oceanic and Atmospheric Administration, U.S. Department of Commerce.)

\section{SEISMIC HAZARDS}

Geotechnical and topographic data should be studied as part of site use planning to assess the potential effects of ground shaking on subsurface conditions at a site and to determine whether conditions are present that could become hazardous during an earthquake. Hazardous conditions may directly influence the effective use of a site, and the economic feasibility of hazard mitigation must be determined as a part of site use planning. Potential seismic hazards that should be considered are:

1. Surface rupture

2. Slope failure

3. Soil densification and liquefaction

4. Ground lurching

5. Water wave generation (tsunamis and seiches).

Each type of hazard is discussed in sections that follow, and suggested mitigation measures are described. A more detailed description is presented in Seismic Hazards and Land Use Planning, U. S. Geological Survey Circular 690.

\section{Surface Rupture}

The location of active faults relative to the site and the magnitude of the maximum probable earthquake at the site should be studied to determine the likelihood of a significant surface rupture during the operating life of the facility. Examples of fault rupture are pictured in Figs. 6 and 7. If fault rupture is possible, the amount and direction of displacement should be estimated and the building or facility should be located outside of the rupture zone. The safe distance from the rupture zone depends on many factors, including the nature and use of the facility, the type and length of the fault, and the soil and geologic conditions present.

\section{Slope Failure}

Earthquake ground shaking can cause mud flows, rock avalanches, and rotational slides in soil and 


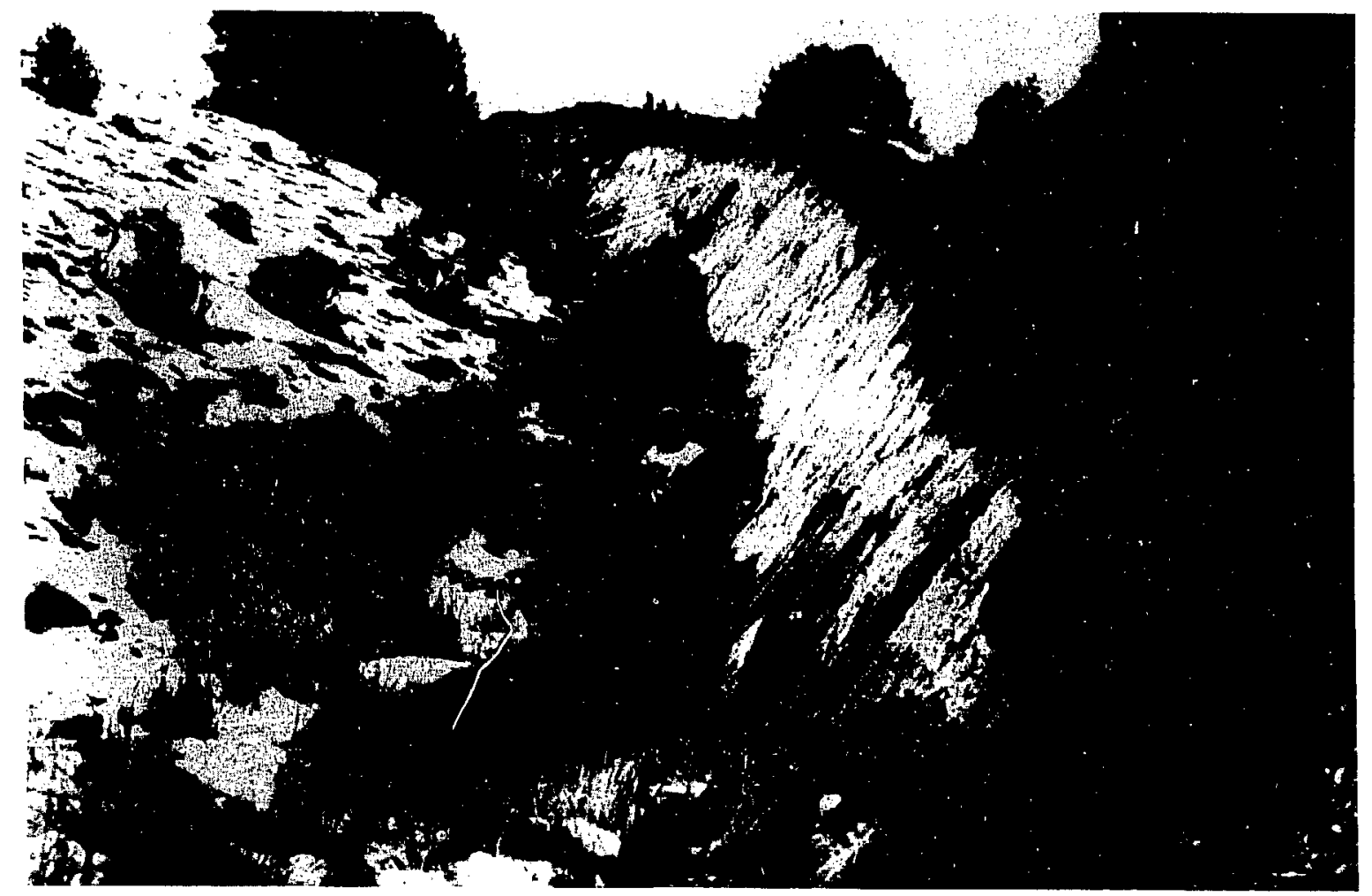

Fig. 6 - Fault rupture with vertical displacement, Fairview Peak, Nevada, earthquake of December 16, 1954 (National Oceanic and Atmospheric Administration. U.S. Department of Commerce.)

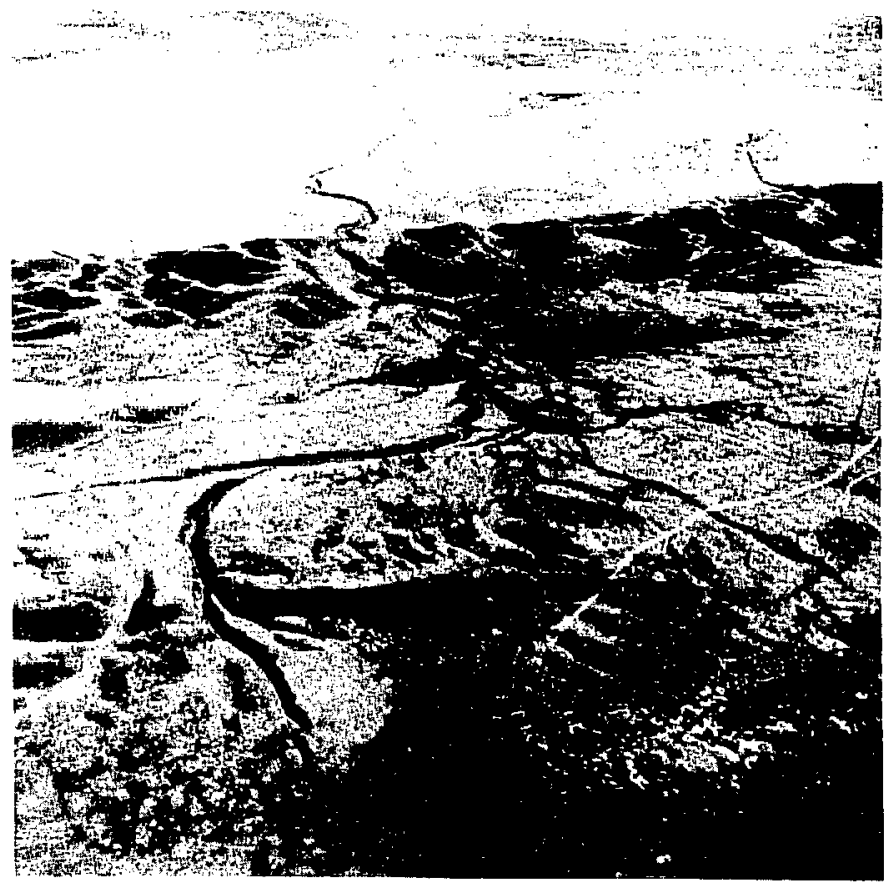

Fig. 7 - Fault trace with horizontal displacement. San Andreas fault near the Carrizo Plain, southern California (U.S. Geological Survey Professional Paper 941-A.) 


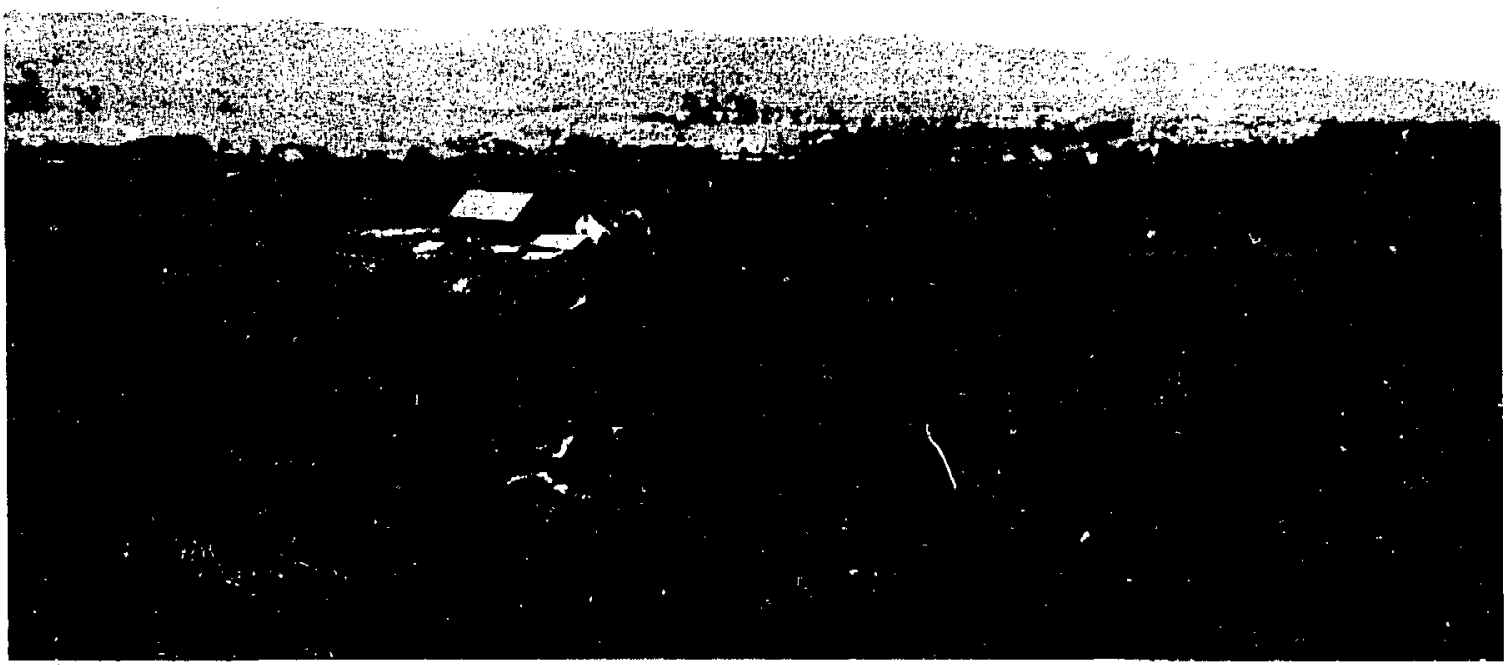

A. Earth-10w at Mount Oliret Cemetery. Bonrce of flow, looking down, A. O. L.

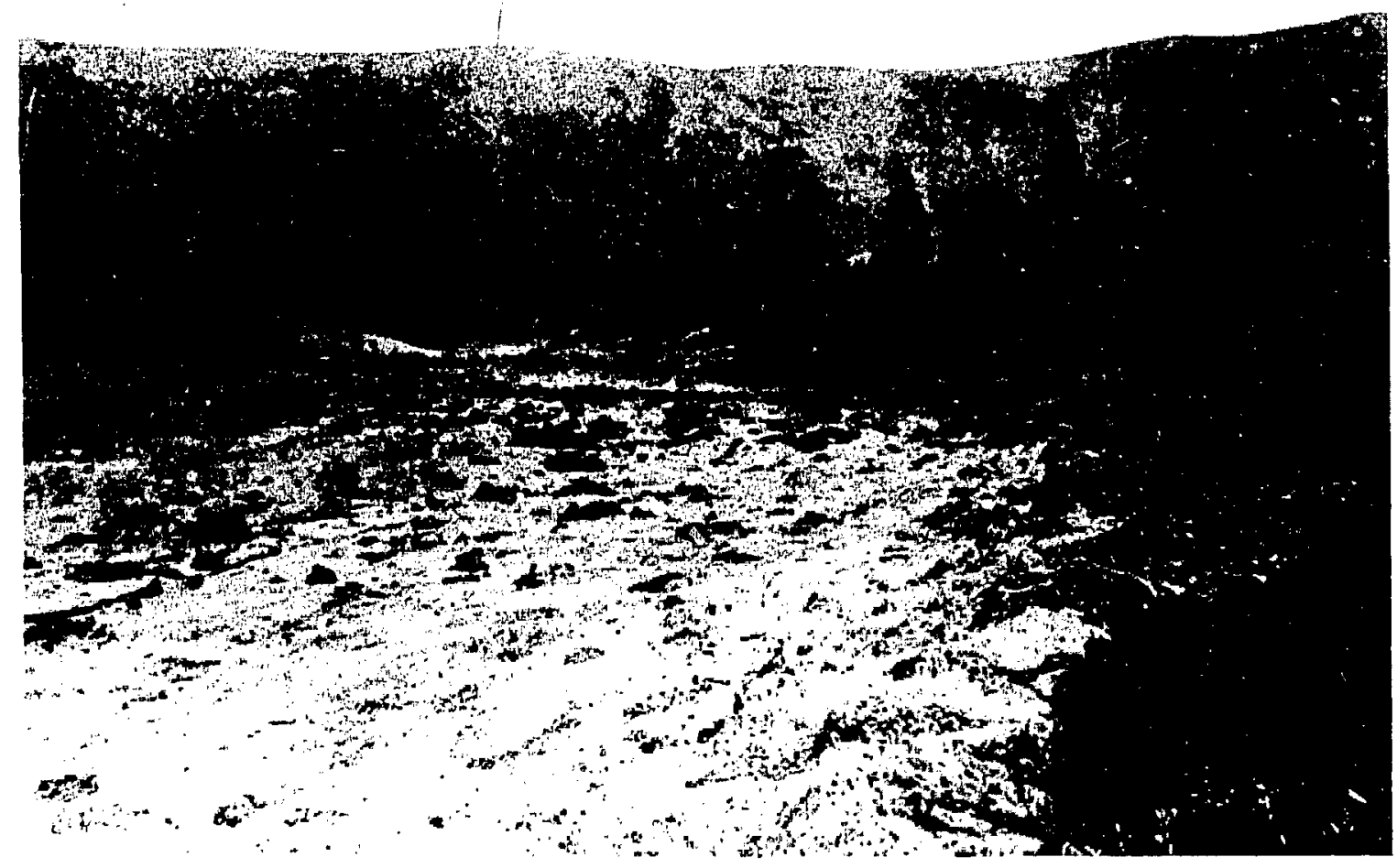

B. Earth-flow at Mount Olivet Oemetery. Path of flow, looking up. A, O, L,

Fig. 8 - Mudflow near Mount Olivet Cemetry, San Francisco, California, earthquake of April 18, 1906 (Report of the State Earthquake Investigation Commission, Carnegie Institution of Washington, D.C., Publication No. 87.) 


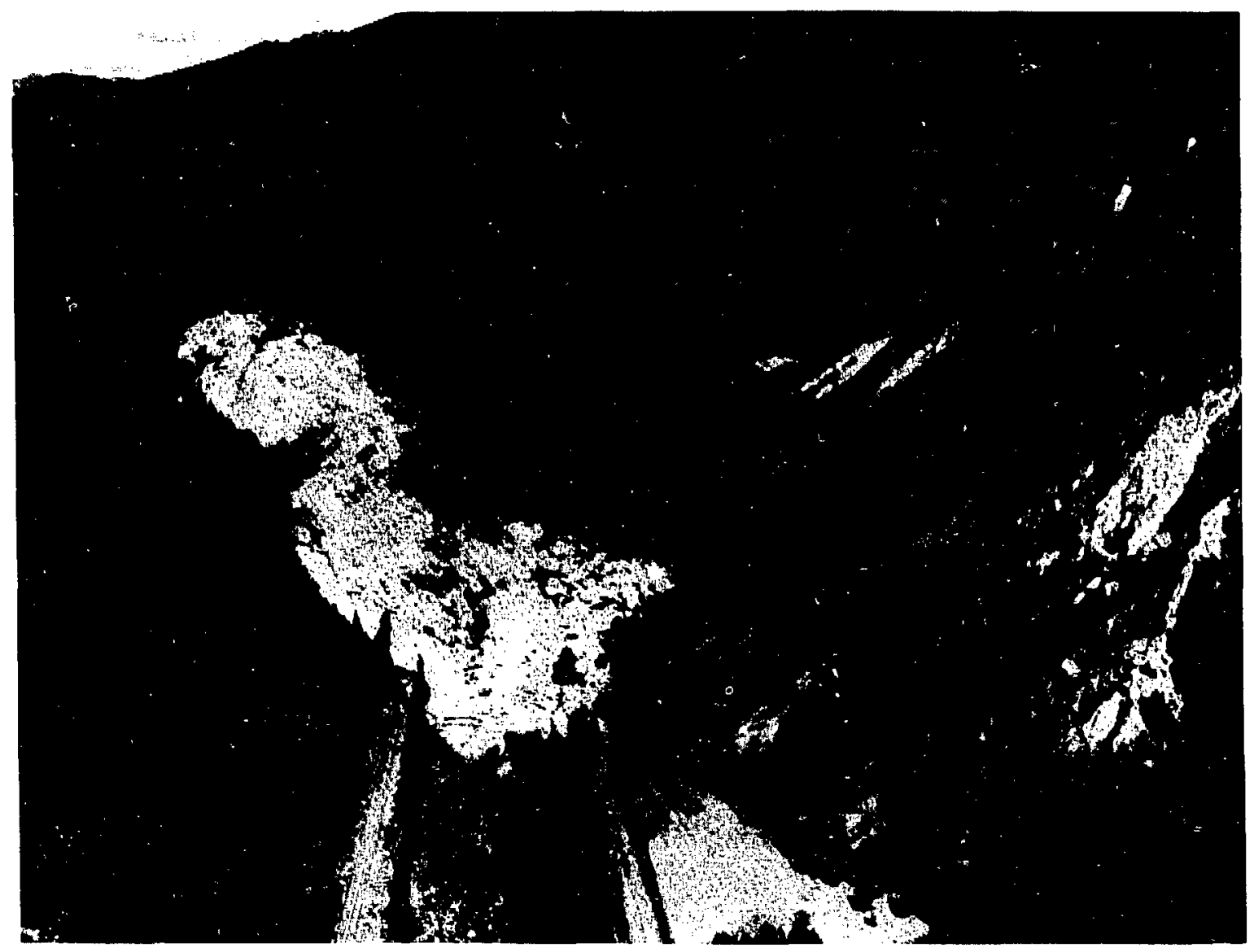

Fig. 9 - Rock avalanche, Madison slide, Hebgen Lake, Montana, earthquake of August 18, 1959 (U.S. Geological Survey Professional Paper 435.)

bedrock. Examples are shown in Figs. 8 through 10. Dormant landslides are frequently reactivated by earthquake shaking.

Slopes should be considered potentially unstable until geotechnical investigation establishes their stability. Avoiding a potentially unstable slope is a mitigating measure; however, in many cases, this is not economically feasible. If facilities, including lifelines, are to be located on or adjacent to slopes, a detailed investigation should be performed to evaluate slope stability during a design earthquake. The investigation should include consideration of all adverse geotechnical conditions and produce methods of improving slope stability to achieve a desired factor of safety against failure. Common stabilization methods include surface and subsurface drainage, buttressing, and slope flattening. Although utility lifelines may be routed across potentially unstable areas, clearly marked locations and appropriate design can permit rapid shut-off and repair in the event of displacement or rupture.

\section{Soil Densification and Liquefaction}

Soils should be investigated early in a site use study to determine their potential for densification or liquefaction.

Densification occurs when low density, unsaturated, granular soils are subjected to ground shaking that causes the soil grains to move closer together. As a result of densification, the ground surface and objects supported above the densified layer will settle. This differential behavior can produce severe damage to buildings and other facilities. An example is shown in Fig. 11.

The amounts of settlement within relatively small areas can vary significantly as a result of differences in soil properties and thicknesses of critical materials. Factors affecting the potential extent of densification include the initial relative density" of the soil, the

"Relative density is determined by comparing the natural density of the soil
with the maximum density of the same material in accordance with the ASTM D2049-69 laboratory test procedure. 


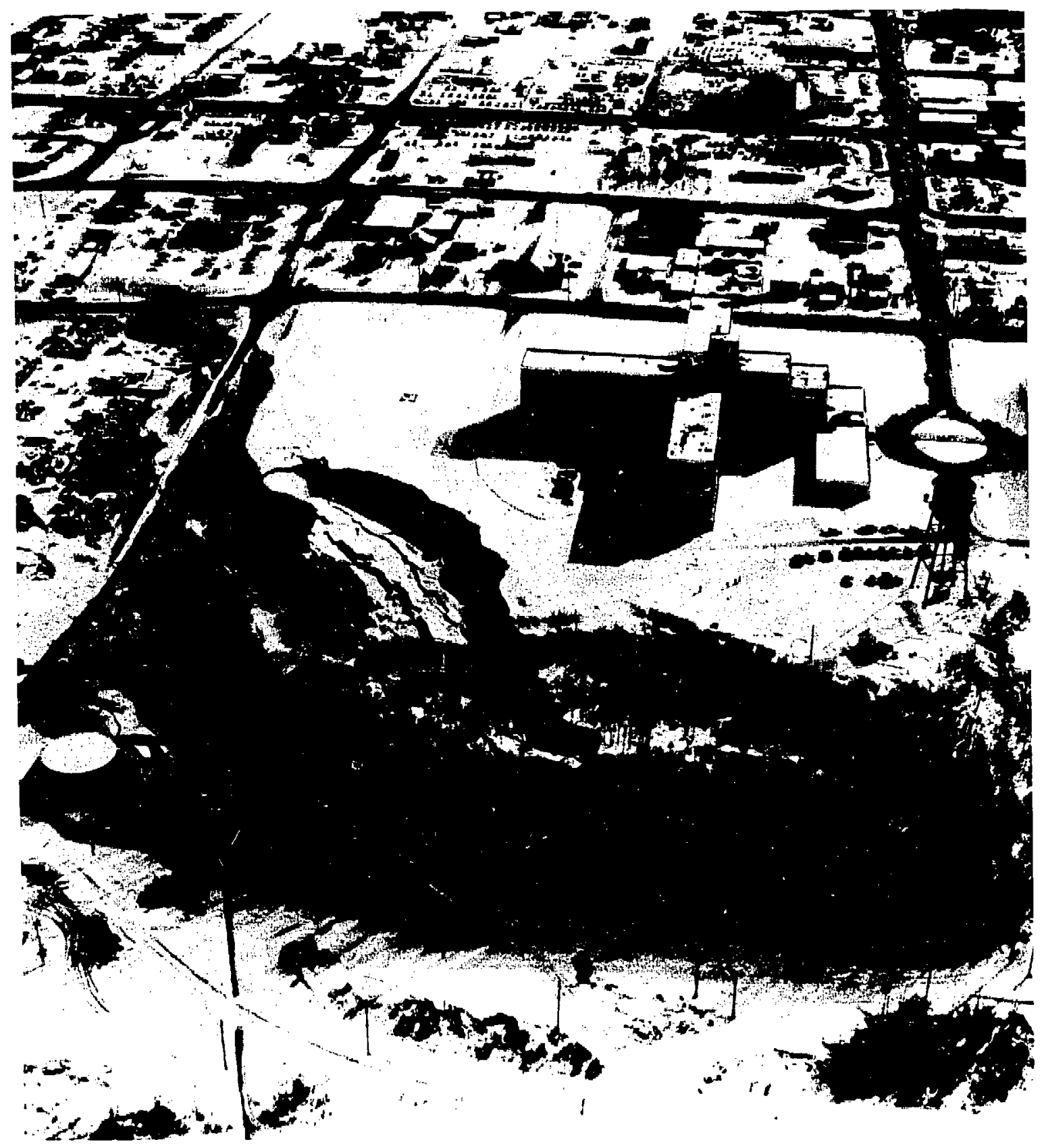

Fig. 10 - Rotational landslide, Native Hospital, Anchorage, Alaska, earthquake of March 27, 1964 (National Academy of Sciences, 1971.)

shape and size of the individual grains in the soil mass, the intensity and duration of the shaking, and the amount of surcharge (the weight of soil or other loads) above the granular layer in question.

When low density sandy or silty soils below the water table are subjected to ground shaking, liquefaction can result. Liquefaction occurs when soil grains move closer together during shaking and the pressure of the pore water between and around the grains increases until it equals or exceeds the confining pressure. $\mathrm{At}$ this point, the water moves upward and may emerge at the surface. The soil becomes "quick," or fluid, and 


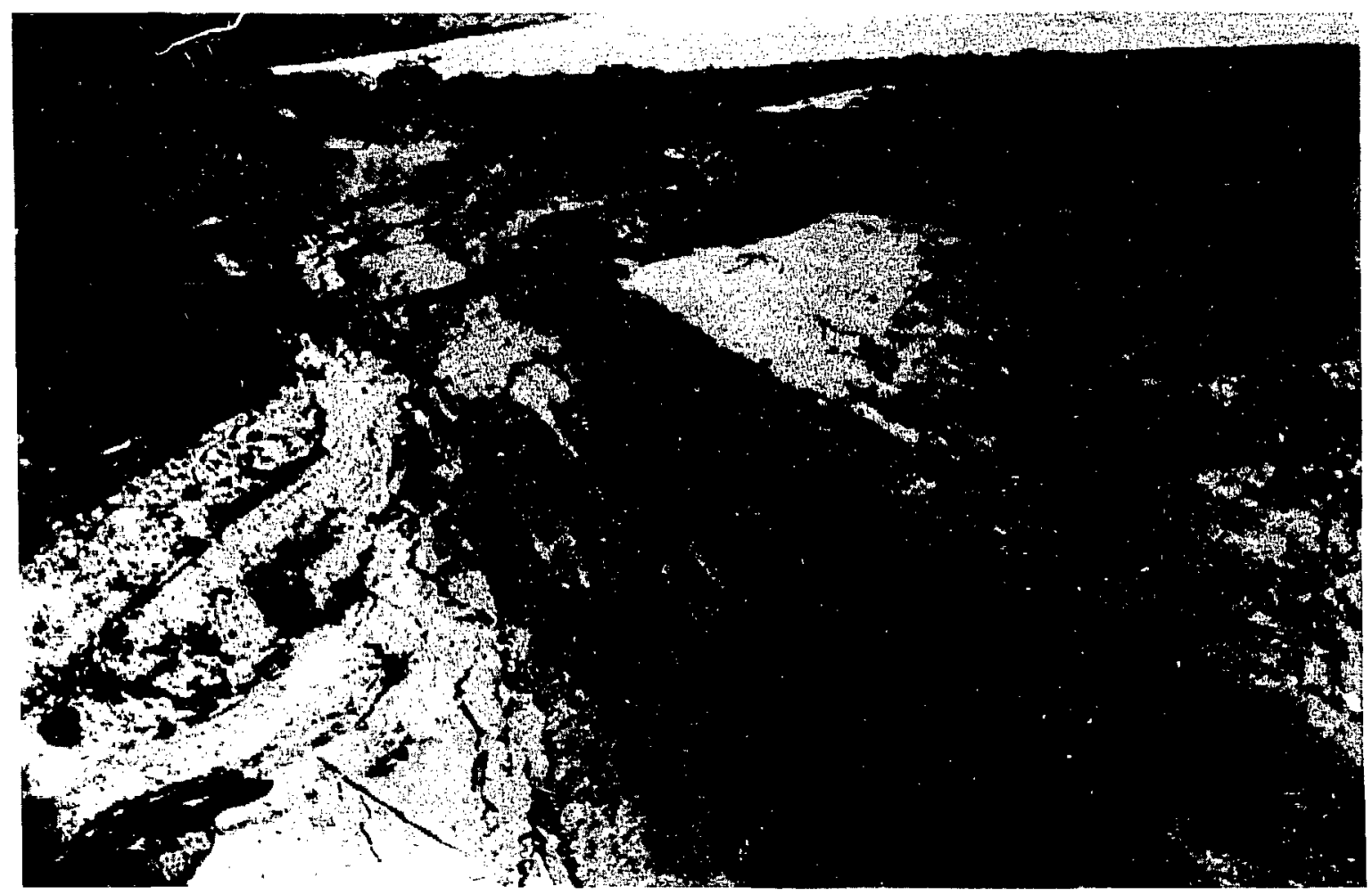

Fig. 11 - Soil densification and lateral spreading, Copper River Highway, Alaska; earthquake of March 27, 1964 (National Academy of Sciences, 1971.)

temporarily loses its strength and supporting capacity. The differential settlement and loss of foundation support that can result from liquefaction can cause severe structural damage. Settlement amounts can range up to several feet. Figure 12 illustrates the results of extreme liquefaction.

Liquefaction can be an important factor in slope instability, as well. Relatively flat slopes composed of saturated cohesionless soils may slide or flow during an earthquake. Furthermore, soils not susceptible to liquefaction (such as clays or even dense sands) sometimes contain lenses of loose sand or silt that may liquefy and cause low angle sliding.

The risk of densification and liquefaction can be reduced by compacting critical soils to densities that are high enough to prevent further densification or, in the case of liquefaction, by lowering the water table if drainage is feasible. In some cases, pressure grouting can be used or critical soils can be removed and replaced with compacted fill. Vibratory techniques can be used to increase densification, as well; however, such measures can be costly and are not always feasible. For some structures, deep foundations can be established below susceptible soil zones. The alternative of locating structures and critical facilities away from vulnerable areas may be preferable to these methods.

\section{Ground Lurching}

Ground lurching that results from earthquake shaking can produce damage not associated with the seismic hazards previously discussed. This is particularly true for facilities constructed over fill.

Filled areas underlain by relatively soft foundation soils can be affected by earthquake shaking in several ways. The soils along the perimeter of a filled area of this type may crack and settle for some distance inward from the toe of the fill slope, resulting in danage to structures and facilities. A geotechnical investigation of the site would be required to determine the setback distances from the zones subject to cracking and setthing. Roads and other embankments constructed of fill over soft soils may crack or settle and embankments may sprcad as the result of earthquake shaking. An example is presented in Fig. 13. Random or previously unrecognized fill areas may settle and crack. The variable and relatively poor physical properties of fill can produce a combination of densification, void collapse, and shearing action in response to earthquake shaking.

Background information on prior fill placement should be obtained early in site use studies. Sources of this information include: persons with long-term 


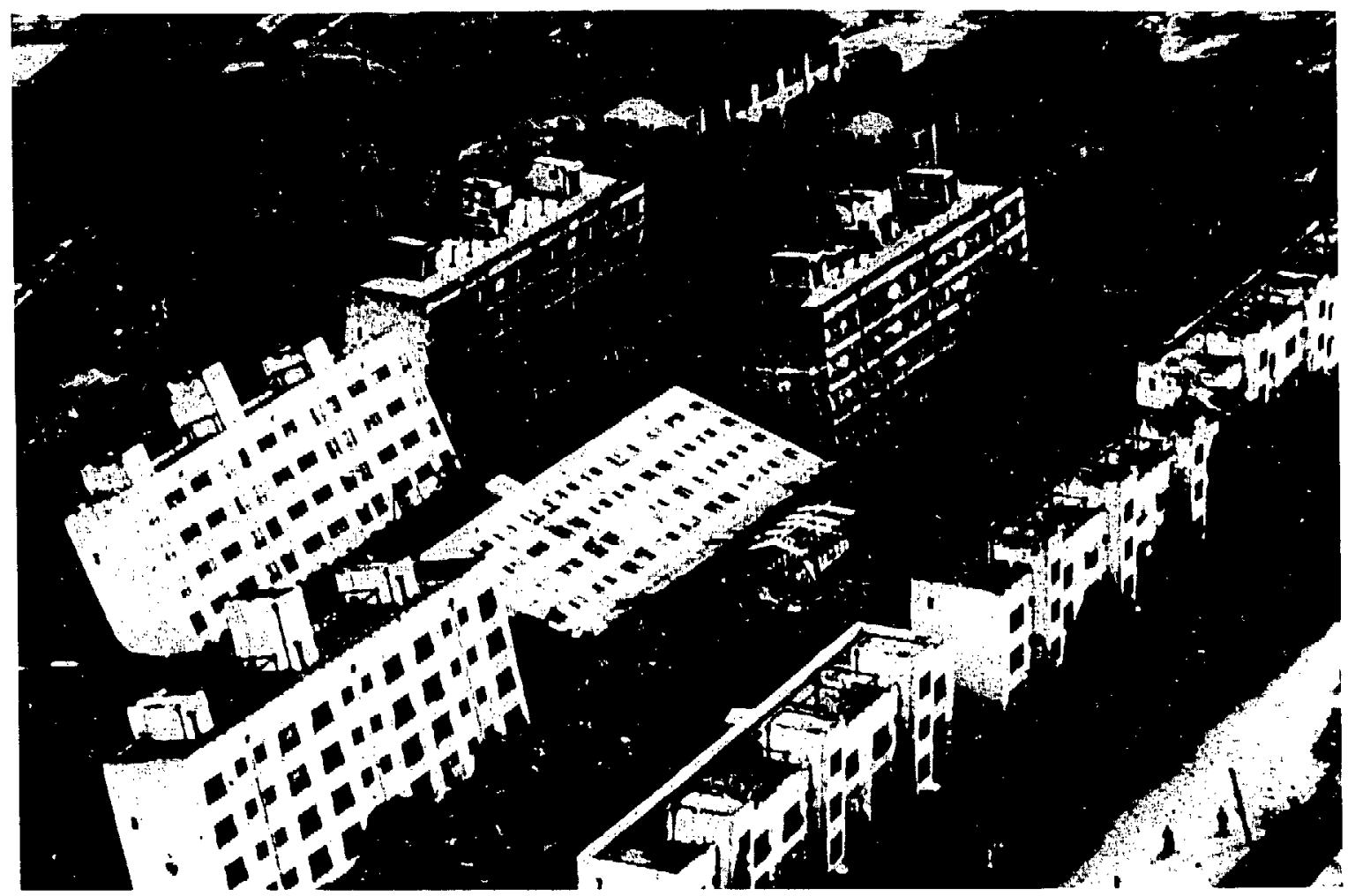

Fig. 12 - Ground failure due to liquefaction, Nigata, Japan, earthquake of June 16, 1964 (Natiunal Oceanic and Atmospheric Administration, U.S. Department of Commerce.)

knowledge about the site; old and current maps; and public records. Geotechnical test borings should be drilled in areas of suspected or known fill, and logging and sampling of borings should include the identification of fill materials.

Fill of poor quality within a site should be removed and replaced with properly compacted fill in areas where buildings and other facilities susceptible to damage from differential settlement will be founded. Where removal is not feasible, building foundations can be established on competent materials below the fill. In this case, however, it is important to recognize that adjacent structures not so supported, including utilities or paved areas, will be vulnerable to settlement at all times and especially during carthquake shaking.

\section{Water Wave Generation}

Two types of water waves can be generated as the result of earthquake shaking: tsunamis, which travel at high speeds across oceans, and seiches, which are oscillating waves in inland bodies of water. Both tsunamis and seiches have caused severe flooding and structural damage in low-lying areas adjacent to bodies of water
Tsunamis usually are generated by distant earthquakes: seiches are usually the result of more localized earthquake shaking. An example of a tsunami is shown in Fig. 14.

"A tsunami, or seismic ocean wave. maly be generated by quake-accompanying changes in the elevation of the sea bottom, or by submarine landslides. Such a wave may be tens of feet high when it approilches certain types of shorelines. The generated waves reach velocities of 500 to 600 miles per hour in the deep ocean, where they are only a few feet in height. Tsunamis can affect areas several thousands of miles from their origin, and warning systems have been developed to predict their impending approach so that vulnerable areas can be evacuated. However, the existence of such warning systems does not preclude lives from being lost. Despite 6 hours of warning given, 61 lives were lost in Hilo, Hawaii, in 1960 due to the tsunami that originated off the coast of Chile after a major earthquake there in May of that year."

\footnotetext{
'Learning from Earthquakes; Planning and Field Guide, p. 5. Earthquake Engineering Institute. Berkeley, Califomia, 1977.
} 


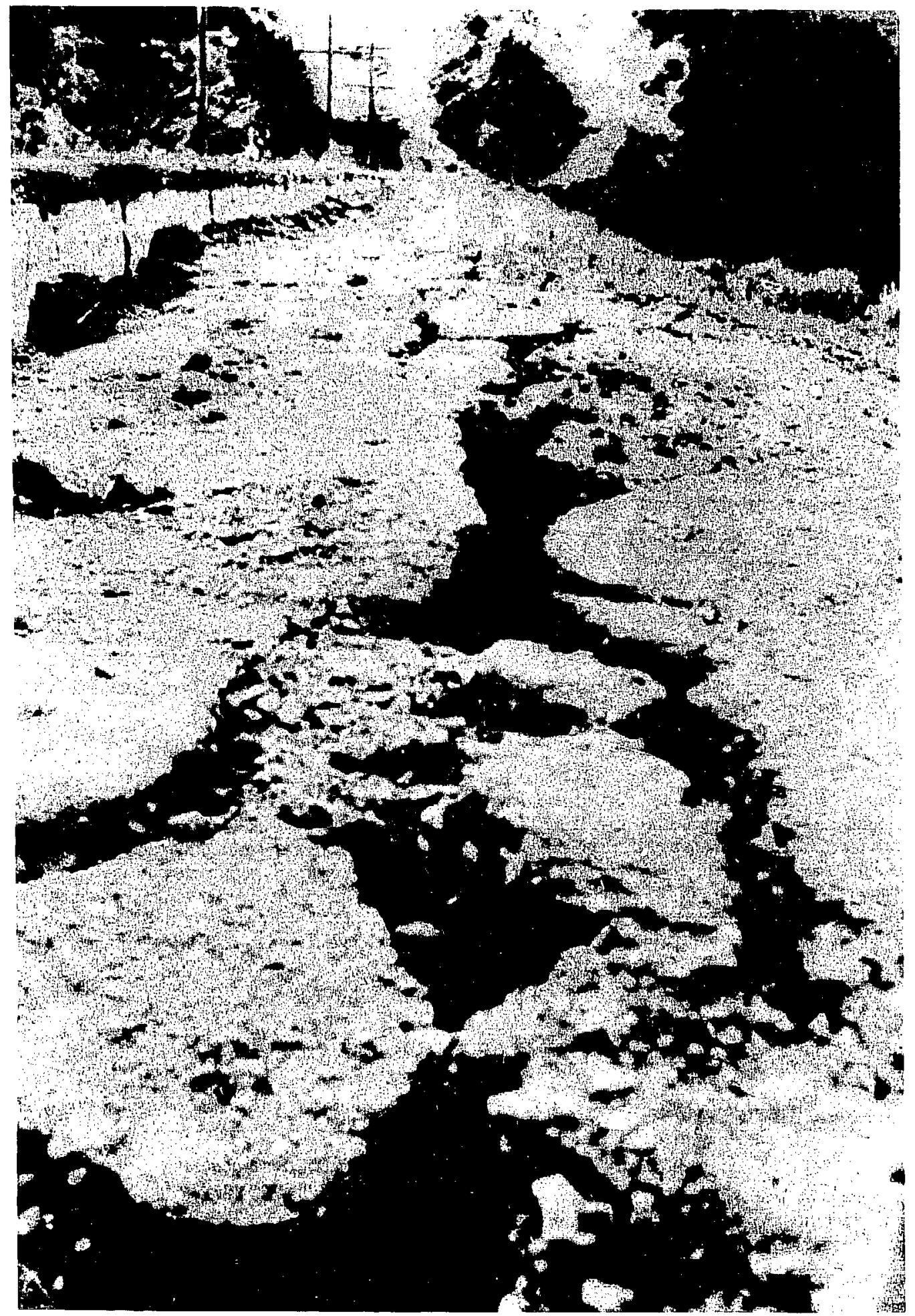

Fig. 13-Ground failure and settlement of embankment, Hebgen Dam, Montana, earthquake of August 18, 1959 (U.S. Geological Survey Professional Paper 435.) 


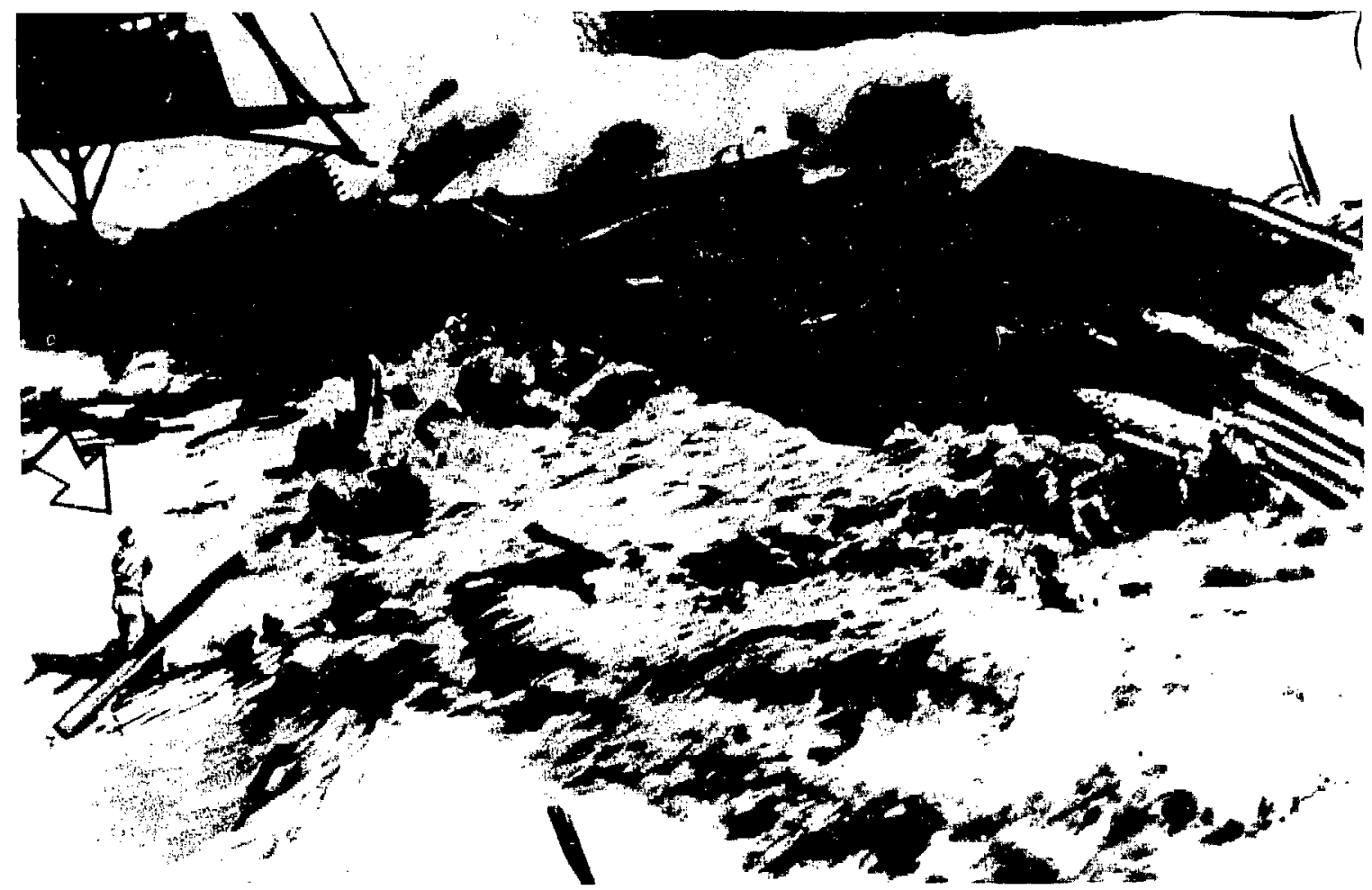

Fig. 14 - Tsunami hitting Hawaii Island, Hawaii, earthquake of April 1, 1946, Aleutian Islands (National Oceanic and Atmospheric Administration, U.S. Department of Commerce.)

The vulnerability of a water-side site to these waves can be evaluated by reviewing historical data and using analytical procedures. Tsunamis and their effects on U.S. coastal areas have been studied in considerable detail; the degree of exposure or protection afforded by various shoreline configurations has been correlated with the degree of damage resulting from different wave

\section{REFERENCES}

\section{Chapter 4}

Geology, Seismicity and Environmental Impact, Association of Engineering Geologists, Oct. 1973. AEG Special Publication. Los Angeles.

Recommended Guidelines for Determining the Maximum Credible and Maximum Probable Earthqual.

California Division of Mines and Geology, Feb. 19/3. CDMG Note No. 43. Sacramento, Califo, nia.

"Earthquake Measurements," California Gewi'ggy, pp. heights.

Site studies should include the determination of the run-up for the highest anticipated seismic wave, and facilities should be constructed at site elevations above the anticipated flood level. Adequate protection may also be provided by properly designed and constructed dikes or levees.
35-37, California Division of Mines and Geology, Feb. 1979.

Learning from Earthquakes - Planning and Field Guides, Earthquake Engineering Research Institute. 1977. Berkeley, California.

Uniform Building Code, International Conference of Building Officials. 1982 ed., Whittier, California.

Seismic Hazards and Land-Use Planning, U.S. Geological Survey, 1974. Geological Survey Circular 690.

Earthquake Engineering, Wiegel, R. L. 1970. Prentice-Hall, Inc., Englewood Cliffs, New Jersey. 
Chapter 4

\section{APPENDICES}

A

B

C

Maximum Credible and Maximum Probable Earthquakes

Seismicity of the United States

$4-22$ 
Chapter 4

\section{APPENDIX A}

\section{EARTHQUAKE MEASUREMENT}

Earthquake vibrations are recorded and measured by seismographs, which are capable of amplifying ground motion and transcribing it onto seismograms. From a seismogram, the time, epicenter, and focal depth of an earthquake can be determined, and its relative size and the amount of energy released can be estimated. The size of an earthquake is generally described in terms of magnitude and intensity.

The magnitude of an earthquake is commonly expressed in terms of the Richter scale; magnitudes usually range between 1 and 10 , but the scale is openended. Richter scales are derived from the maximum trace amplitude registered on a Wood-Anderson torsion seismograph. When an earthquake is recorded, the highest point on the trace is measured and compared with that of a standard reference earthquake corrected to the same epicenter-to-station distance. The standard reference earthquake is defined in such a way that an earthquake of magnitude 0 produces a maximum trace amplitude of 0.001 nullimeter at a distance of 100 kilometers. With distance corrections, the magnitude is constant; this produces an effective method of size classification. Figure 15 illustrates how earthquake magnitude is determined from a seismogram.

Earthquake intensity is comunonly expressed in terms of the Modified Mercalli intensity scale, which is based on the amount and type of damage that occurs at a particular location as a result of ground shaking or distortion.

\section{Richter Magnitude Scale}

The widely recognized Richter magnitude scale is named after Dr. Charles R. Richter, Professor Emeritus of the California Institute of Technology. On this scale, an earthquake's magnitude is expressed in whole numbers and decimals. The magnitude varies logarithmically with the wave amplitude of the quake recorded by the seismograph; each whole number on the scale represents an increase of 10 times the measured wave amplitude. The amplitude of an 8.0 magnitude earthquake is not twice that of an earthquake of magnitude 4.0, therefore, but 10,900 times the amplitude.

Earthquake magnitude can also be expressed as an estimate of the amount of energy released during an earthquake. For every unit increase in magnitude, there is a 32 -fold increase in energy release. Therefore, an earthquake of magnitude 8.0 releases almost $1 \mathrm{mil}$ lion times more energy than an earthquake of magnitude 4.0. An example of the vast difference in energy released by various earthquakes is presented on the accompanying chart, Fig. 16, which compares magnitude with energy.

Normally, an earthquake of magnitude 2 is the smallest earthquake humans will feel. The Richter magnitude scale has no fixed maximum or minimum; however, observations have placed the largest recorded earthquakes in the world at about 8.9 and the smallest at about -3. Richter magnitudes have been used in attempts to estimate damage; it is apparent, however, that earthquakes of equal magnitude cause varying degrees of damage, depending upon their locations.

\section{Modified Mercalli Intensity Scale}

The Modified Mercalli intensity scale measures the intensity of an earthquake by categorizing the amount and severity of the damage it produces in any given locality. However, because the Mercalli scale is based on observations of earthquake effects in specific locations, assigning an intensity value requires considerable time. A copy of the Modified Mercalli intensity scale, which ranges from I to XII, is presented in Fig. 17. The lower intensities on the scale are based primarily on human and structural responses to shaking; the higher intensities involve permanent distortion of the ground. Damage to structures is expressed in terms of low-rise masonry and wood-frame buildings. Plotting earthquake intensities on an isoseismal map can provide an overall picture of the geographical distribution of earthquake damage. An example is shown in Fig. 18. 


\section{THE RICHTER SCALE}

To determine the magnitude of an earthquake we connect on the chart

A. the maximum amplitude recorded by a standard setsmometer, and

B. the distance of that seismomerer from the epicenter of the earthquake (or the difference in times of arrival of the $P$ and 5 waves) by a straight line, which crosses the center scale at the magnitude.

- A unit change in magnitude corre. sponds to a decrease in seismogram amplitude by a factor of ten.

.... Definition of a magnitude 3 earthquake.
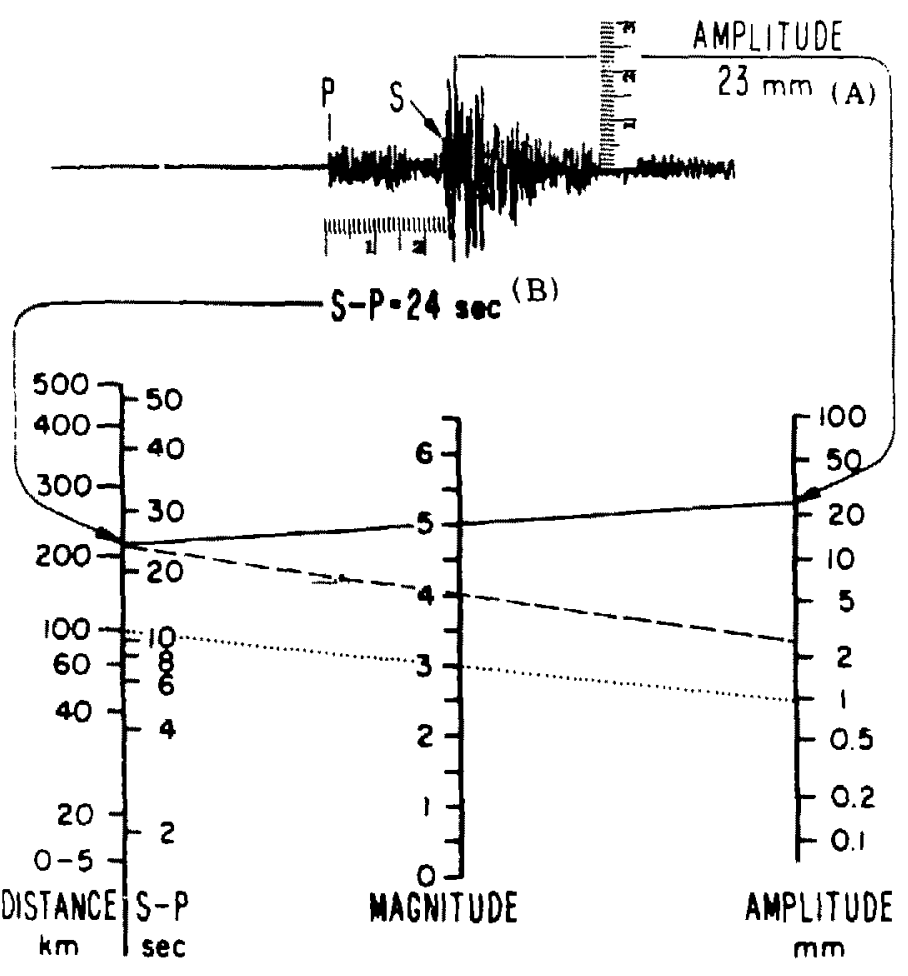

Fig. 15 - Determination of Richter magnitude using a Wood-Anderson seismograph (California Geology, February 1979, California Division of Mines and Geology.) 

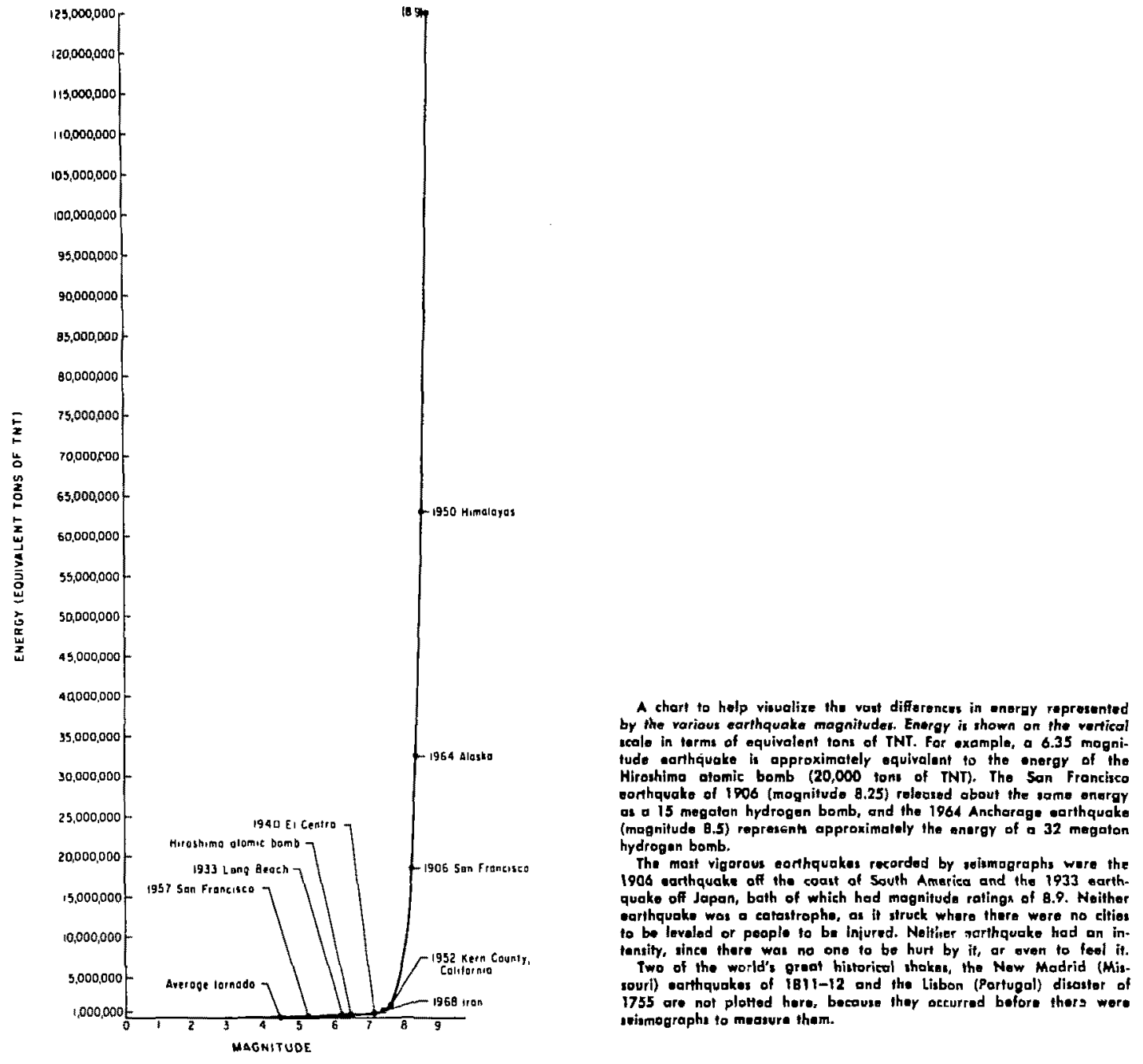

Fig. 16 - Chart comparing magnitude with energy released (California Geology, May 1969, California Division of Mines and Geology.) 


\section{Modified Mercalli Intensity Scale of 1931}

Not lelt by people, except under especially fayorable circumstances. However, dizziness or nausea may be experienced. Somelimes bids dro drimals dte inediy or disturoed Fiees sliuctures liquids bodies ol waler may swav genliy and doors mav swing very slowly

Felt indoors by a few people, especially on upper floors of multi-slory buildings, and by sensitive or nervous persons.

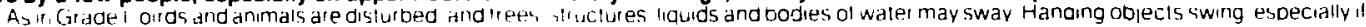
thev dre delicalely suspended

Felt indoors by several people, usually as a rapid vibration that may not be recognized as an earthquake at first. Vibration is similar to that of a light, or lightly loaded trucks, or heavy trucks some distance away. Duration may be eslimated in some cases. Movenents may de cipprecidale on wpoel levels of lall slluclures Standing molor cars may rock shghtly

Felt indoors by many, outdoors by tew. Awakens a few individuals, particularly light sleepers, but frightens no ono except those apprehensive from previous experience. Vibration like that due to passing of heavy, or heavily loaded trucks. Sensalion iike a heavy body striking building. or the falling of heavy objecis inside.

Lishes windows and doors rathle glassware and crockerv clink and clash walls ano house trames creak esperially it intensity is in the uppe range of this grade Hanging objects otlen swing Liquids in open vessels are disturbed slignlly Stationary automodies rock noliceably

Felt indoors by practically everyone, outdoors by most people. Direction can often be estimated by those outdoors. Awakens many, or most sleepers. Frightens a few people, with slight excitement; some persons run outdoors.

Buidings tremble inrougnoul Dishes and glassware break to some extent Windows crack in some cases bul nol generally Vases and small or unstaole objects overtum in many inslances and tew tall Hanging objects and doors swing generally or considerably Piciut es knock against walls or swing out ol place Doors and snulters oden or ciose abruptly Pendulum clocks stop or run fasi or slow Small obiecis move and

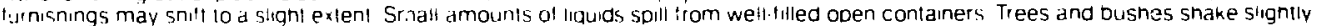

Falt by everyone, indoors and outdoors. Awakens all sleepers. Frightens many people; general excitement, and some persons run ouldoors. Peri, ons move unsleacily Trees and busnes shake shightly to modetately Liquids are sel in sirong molıon Small bells in churches and schools ing Poorlv Dutl Duldings may be damaged Plaster talls in small amounts Other blaster cracks somewhat Many dishes and giasses and a tew windows bitak Knick knacks books and Diclures fal; Furniture overturns in manvinstances Heavy turnisnıngs move

Frightens everyone. Goneral alarm, and everyone runs outdoors.

People find if difficult 10 stand Persons driving cars notice snakıng Trees and busnes snake moderalely to strongly Waves torm on ponds idk itnd st eams Water 15 muddied Gravel or sand stream banks cave in Large church bellj ing Suspended objecis quiver Damage is hegligibie in buldings ol good design and constructior slight to moderate in well-Duilt ordinary buildings considerade in poorly Duilt or Dadly dpighed buildings ddobe houses old walls iespecirilly where laid up without mortar spires elc Plaster and some stuccolall Many windows and some turnture break Loosened drickwork and illes shike down weak chimneys oreak al ine ioofine Cornices tali trom lowers and nign Duthings Brıcks and stones are disiodged Heavy lurnilure overturns Concrete mrigalıon diches are considerably damaged

\section{General fright, and alarm approaches panic.}

Persons driving cars are disturbed Trees shake strongly and branches and trunks break oft cespecially palm 1 reesi Sand and mud erupls in smdil amounts Flow of spings and wells is temporarily and sometimes permanently changed Dry wells renew tlow Temperatures of spring ind well waters vartes Damage slight in bick structures bull especially to withstand earthquakes considerable in ordinary substantial Duidings with some partial collapse heavy in sc me wooden houses wilh some lumbling down Panel walls break away in frame siructures Decayed pilings break of Wa!ls lall Solıd stone walls crack and break seriously Wel grounds and steed slopes crack to some eutent

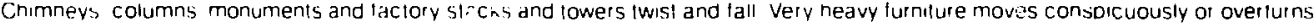

Panic is general.

Ground cracks conspicuously Damage is consıderable in masonty sliuclutes Dult especially to wilnstand eatthauakes great in otheı Mation v bulldings - some collapse in large pall Some wood Irame houses butl especially lo withstand earthauakes are inrown oul oi plumb others are sníted wrolly olt loundations Reservort s are ser lously damaged and underground pides somelımes break

\section{$X \quad$ Panic is general.}

Ground especirlly when loose and wel cracks uo to widins of several inches fissures up to a yard in widin run parallei to canal and stream bank 4 Landsiding ic considelable from rivet banks and steep coasts Sand and mud shilis horizontally on beaches and tlal land V/ater level changes in wells Wales is inrown on Danks ol canals lakes rivers ptc Dams dikes embankments are seriousiv damaged Well-bull wooden siructures and bidges ate severety damaged and some collapse Dangerous cracks develop in excellent brick walls Mast masonrvand trame struclures and ineir foundations dit destroyed Railroadidls Dend slightiv Pide ines buried in earth lear apart c: are cruslied endvise Open cracks and biodd wavv tolds oden in cumient Datvements and asphall road surlaces

Panic is general.

Disturbances in groundar math dind videspetad varying with the ground materat Broad issures earth slumps and land slips develop in soll wet qround Water chaged with satid and mud is ejecled in large amounts Sea waves ol signilicant miagnilude may deveiod Damage is severe to wood trame structure esDecirtly nedr shoch centef's qreat lo dams diker and embankments even at long distances Few il any Tidsonr siluclures remain slanding Supporting Dieis of pillits of large well-bult hidges are wrecked Wooden bridges inat give are less Hllected Ratiroad idis bend grealiv dind some thrust endwise Pibe lines biried in earih are put comoletely out of service

Panic is general.

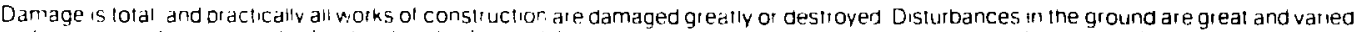

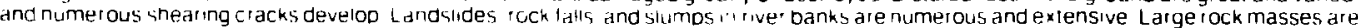

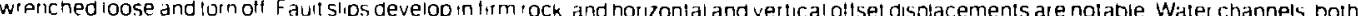
surlace and underground dre dislurbed und modilied grealiv Lakes dre dammed new watertalls are oroduced rivers are deflecled elc Surtace waves ale seen on giound surlaces Lines of sight and level are distorted Objects are thrown ubward into lhe air 


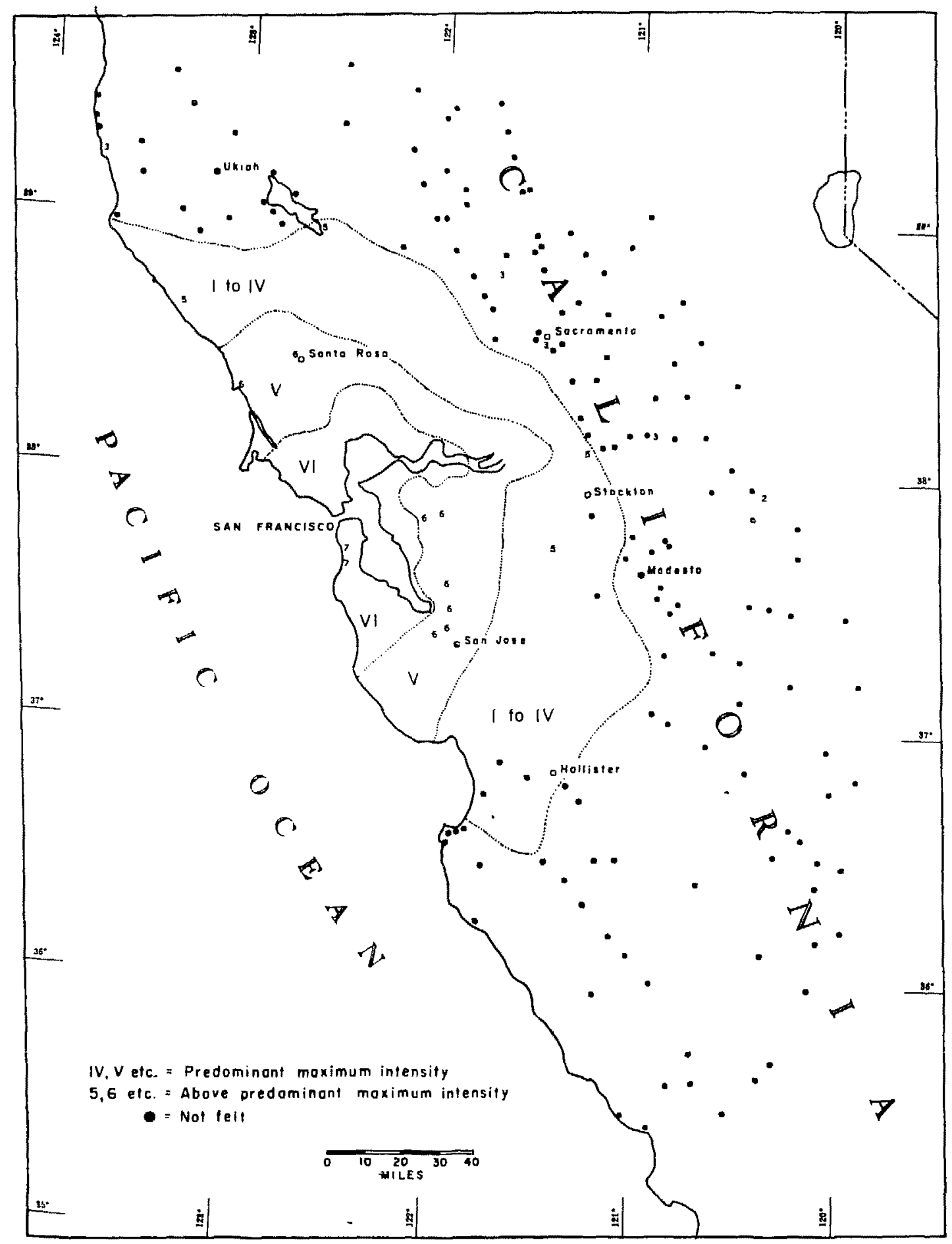

Fig. 18 - Isoseismal map of the March 22, 1957, earthquake, San Francisco, California (California Division of Mines and Geology Special Report 57.) 


\section{Chapter 4}

\section{AFPENDIX B}

\section{MAXIMUM CREDIBLE AND MAXIMUM PROBABLE EARTHQUAKES}

According to the California Division of Mines and Geology (February, 1975), the maximum credible earthquake for a site is the maximum earthquake that appears possible within the presently known tectonic framework. It is a believable event that is related to known geologic and seismologic facts. In determining the maximum credible earthquake, little regard is given to its probability of occurrence, except that probability is great enough to be of concern.

The following should be considered in determining the maximum credible earthquake for a particular site:

(a) seismic history of the site vicinity and the geologic province

(b) length of the significant fault or faults that can affect the site within a radius of 100 kilometers

(c) types of faults involved

(d) tectonic framework and structural history

(e) regional geologic setting.

Time intervals do not enter into the determination of maximum credible earthquakes.

The maximum probable (functional-basis) earthquake is the maximum earthquake that is likely to occur during a given time interval, usually 100 years. It is a probable occurrence and not an assured event that will occur at a specific time.

The following should be considered when determining the maximum probable earthquake for a particular site:

(a) regional seismicity, including recorded seismic activity

(b) fault or faults within a 100 -kilometer radius that have been or may be active within the next 100 years.

(c) types of faults invoived

(d) seismic recurrence (or frequency of occurrence) for the area

(e) mathematical probability or statistical analysis of seismic activity associated with the faults within the 100 -kilometer radius.

(f) active and potentially active faults within a 100 kilometer radius of the site. According to the Alquist-Priolo Geologic Hazard Zones Act (Chapter 7.5, Division 2, Public Resources Code, State of California), the State Mining Geology Board regards faults which have had surface displacement within Holocene time (about the last 11,000 years) as active and hence as constituting a potential hazard. Any fault considered to have been active during Quaternary time (last 3 million years) is considered by the State to be potentially active. The definition of active fault is intended to represent minimum criteria only for all structures; jurisdictional agencies may wish to impose more restrictive definitions requiring a longer time period of demonstrated absence of displacements for critical structures such as highrise buildings, hospitals, power plants, dams and schools.

The magnitude of the maximum probable earthquake will not be lower than the maximum that has occurred within historic time. It can be the same as the maximum credible earthquake. 


\section{Chapter 4}

\section{APPENDIX C}

\section{SEISMICITY OF THE UNITED STATES}

The following briefly describes the seismicity of the various regions of the United States.' The earthquake map, Fig. 19, shows the locations of historic earthquakes by intensity.

Northeastern Region: The northeastern region of the country contains zones of relatively high seismic activity. New York and Massachusetts have experienced numerous shocks; several have been quite severe. This region also is affected by large earthquakes originating in adjacent Canada, principally in the St. Lawrence River Valley.

Eastern Region: With the exception of the 1886 Charleston, South Carolina, earthquake, this region has experienced a moderate amount of low-level earthquake activity. Earthquakes occur throughout the region, and the axis of the principal activity roughly parallels the coast. The occurrence of earthquakes in the mountainous areas of the eastern region is not surprising because a process of adjustment is generally continuing in these regions; however, the occurrence of the Charleston shock in a sandy plain is more difficult to explain.

Central Region: The Upper Mississippi and Ohio Valleys are regions of relatively frequent earthquakes. Three of the great earthquakes of record occurred in the Upper Mississippi region in 1811 and 1812. The area was sparsely settled, so grave damage was not experienced. The extent and severity of landform changes from these shocks have not been equaled by any other earthquake in the contiguous United States.

Western Mountain Region: Montana, Utah, and Nevada have been subjected to earthquakes of considerable severity, and there is a region in Mexico, just south of the border between the United States and Mexico, that has had one major earthquake and many minor ones. A quake-related danger of considerable importance surfaced in the 1959 Montana earthquake, when a great avalanche claimed 28 lives and formed a barrier that blocked the Madison River and created Hebgen Lake.

\footnotetext{
"Learning from Earthquakes; Planning and Field Guide, p. 13, Earthquake En-
} gineering Institute, Berkeley, Califomin, 1977.
Washington and Oregon: Many earthquakes of intensity $V$ or greater centered in Washington and Oregon between 1841 and 1970. Other quakes were felt, but they were centered either offshore in the Pacific, in British Columbia to the north, or in neighboring states. Most of the earthquake activity occurred in the western part of the region, with the stronger shocks in the neighborhood of Puget Sound. The heaviest recent activity occurred in Washington: in 1946 a few miles west of Tacoma; in 1949 near Olympia; and in 1965 near Seattle. A few of the earlier shocks may have equaled or possibly exceeded those of 1946 in intensity, but the lack of detailed information prevents satisfactory comparison.

Alaska: Few of the Alaska shocks have caused severe damage because of the absence of large population centers. Seismic activity is separated into two zones. One zone, approximately 200 miles wide, extends from Fairbanks through the Kenai Peninsula to the Near Islands. The second zone begins north of Yakutat Bay and extends southeastward to the west coast of Vancouver Island.

In 1899 the Yakutat Bay area experienced one of the notable carthquakes of the nineteenth century. The shore was raised over a considerable length, and at one point there was a vertical fault slip of $47-1 / 2$ leet one of the greatest fault movements known. On March 27, 1964, one of the greatest gevtectonic events of our time occurred in southern Alaskil. In minutes. thousands of people were made homeless, 125 lives were lost. and the economy of the entire state was disrupted. Tsunamis swept the Pacific Ocean from the Gulf of Alaska to Artarctica and caused extensive damage along coastal Alaskil. British Columbia, and Californii.

Hawaii: Seismic activity centers on the island of Hawaii, and much of it is associated with volcanic processes. However, the stronger shocks that are sometimes felt throughout the islands are of tectonic origin. The greatest known carthquake. which occurred in 1968, was extremely violent and destructive considering the sparsely settled nature of the island. Shocks north of Hawaii are often felt strongly on the islands of Maui, Lanai, and Molokai. 
California and Western Verada: Earthquakes in California and "sestern Vevada represent approximately 90 pereent of the seismic activity in the contiguous Linited Slates. The majority of these shocks oceur at relatively shallow focal depths: this accounts, in part, for the greater violence of earlhyuakes in this region as compared with those occurring in the central or castern linited States. The principal fault in this area … the Siln Andreas fault extends over 600 miles through Californiat it runs from near the Sittun Sea in southern California northwest la Shelter cove in Humboldt
County. Movement along this fault was responsible for the greal earthquake in 1857 near Fort Tejon and for the 1906 San Francisco shock, as well as for many shocks of lesser magnitudes.

Pluerto Rice Region: Geologic and topographic evidence indicate that carthquakes have been of relatively frequent occurrence in the region of Puerto Rico for thousands of years. Many earthquakes have been recorded there, and several of the shocks have resulted in severe properly damige.

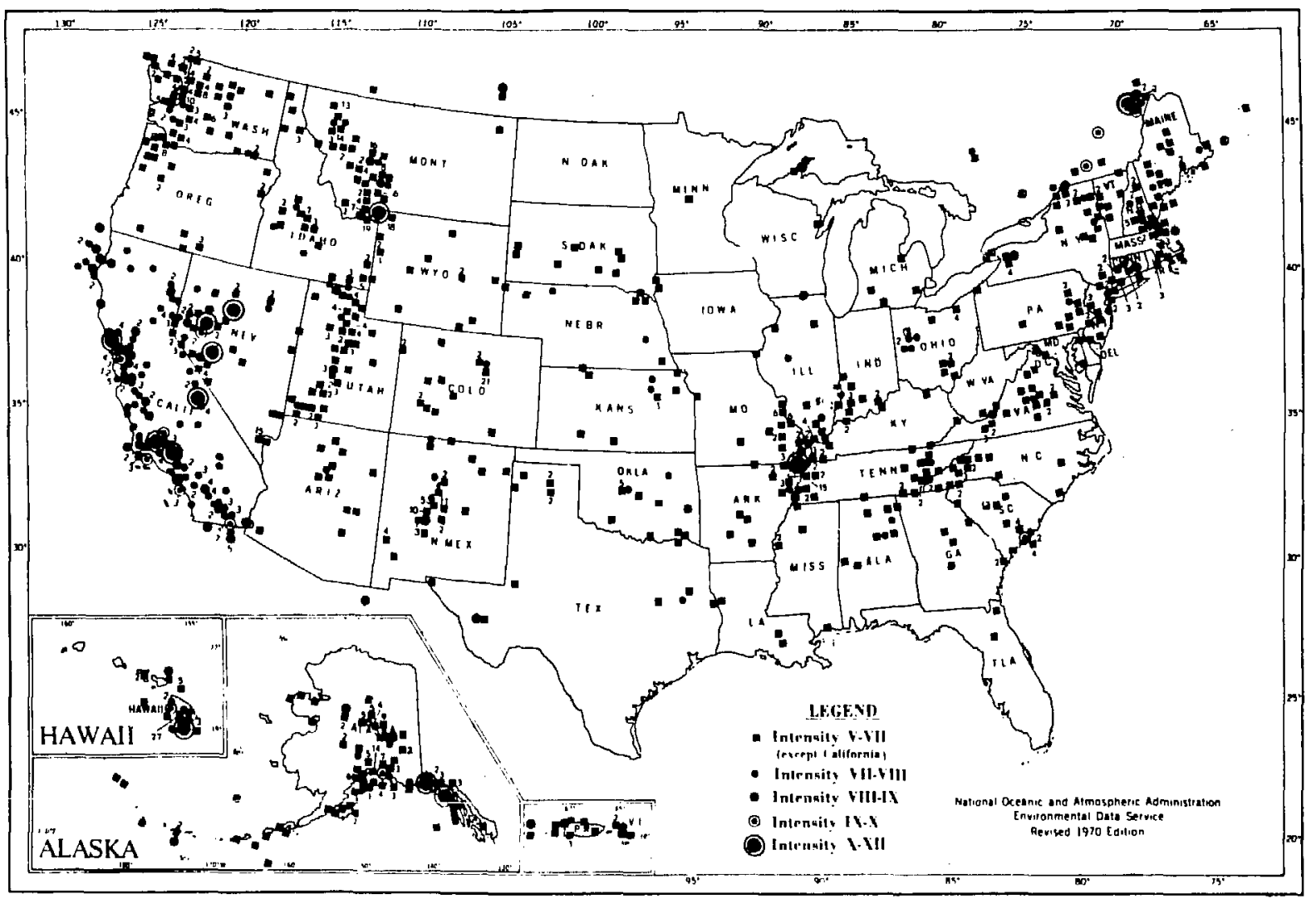

Fig. 19 - Earthquakes in the United States through 1970 (Earthquake History of the United States, U.S. Department of Commerce Publication 41-1.) 


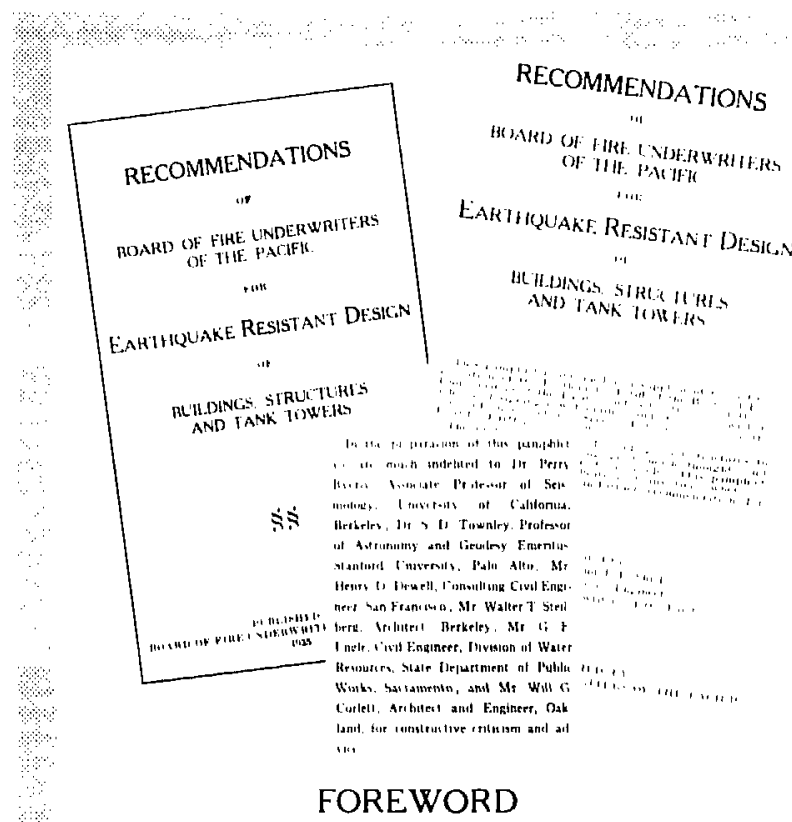

We live on an unstable coast. It is is regiun of greal topographic extremes, where mountain peaks reach elevaliuns of $14,000 \mathrm{ft}$. and over, within 75 miles of a depression whose floor is $275 \mathrm{ft}$. below the level of the sea; where the huge range of the Sierra Nevada lies in fairly close proximity (1) the Pacilic Ocean and the depths beyond the Continental Shelf; where the Sacramento and San Joaquin Rivers year ly year move vast tonnages of silt through the great central valleys from the mountains to the scil. Pent up behind the rampart of the Sierra Nevada lies the central plattau, with it 5 alterniting mountain ranges and valleys extending far to the East. Much of this p'itteau is $4,000 \mathrm{ft}$, above sea level. with the mountitin ranges reaching elevations of more than $10.000 \mathrm{ft}$

Although this region appears solid and substantial, it is often shaken by tiny tremors, and at not infrequent intervals by stronger vibrations, which, when felt by people are called earthquakes. This whole area seems to be in a state of unbalance, with readjustments constantly taking place. What causes these cannot be gone into here. For the present purpose it is enough to know that they do take place, as evidenced by the records of the seismographs, and that earth vibrations are felt strongly in various places from time to time. The readjustments generally occur on definite planes of weakness in the earth's crust, called faults, which in reality are long though not open cracks along which the movement takes place. When this movement is great it is sometimes visible at the surface, showing horizontal and vertical displacements of many feet in some cases. A considerable number of these faults are now well located, ind many more approximately so.

The San Andreas Fault is the best known and one of the 1. Meest active faults in the world. 1 It comes into the Pacific Coast at Point Arena in Mendocino County, runs to the south through Tomales and Bolinas Bays, crosses outsitle the Ciolden Gate, again reaches the Const at Mussel Rock, traverses the Spring Valley lakes, follows tha Coast Range to the south, passes to the E: at of Los Angeles and San Bernardino and within 8 miles of tne latter, curves casterly along the shore of the Salton Sea and possibly extends to the Mexican Border. A great fault runs along the east base of the Sierra Nevada, past Mt. Whitncy, and curves westerly toward the Coast. The Hayward Fault follows the base of the Berkeley Hills, passes to the east of San Jose, and appears

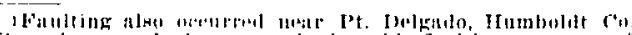

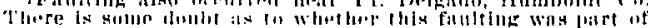

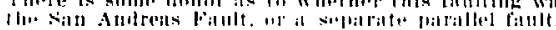

A booklet entitled "Recommendations of (the) Board of Fire Underwriters of the Pacific, for Earthquake Resistant Design of Buildings, Structures and Tank Towers" was prepared by H. M. Engle and J. E. Shield, Civil and Structural Engineers, in 1935. The Foreword from this publication, which is reproduced here, still provides a valid philosophy for today's earthquake engineers.

10 join the San Andreas system to the south. The Inglewood Fault, on which two strong movements have occurred in recent years, lies southerly from Los Angeles allong the coast line, and passes through Lone Beach. Thesc faults are only a few of those known to exist.

A condition must be faced from which there is no escape Earthquakes have occurred as far back as records have been kept; they will continue through our lifetime and far inte the future. They are dangerous solely because we make them 50 by erecting bui'dings and houses which can be shattered or shaken down. In themselies earthquakic have little hazard for us. They are dingerous only when we build things so weakly that they can be damaged or wrecked. It is just as casy to build them so they will not be shaken down. We have had aniple jroof in the past that it can be done and is economically feasible. The decision rests with us. If we choose, an earthquake can be made an interesting but not dangerous occurrence. If we choo-s: otherwise it will always be a thint of terror, somethine to $b$ : dreaded, something which may kill us. and cause misery and suffering. The choice is our own. Linfortunately. up to the present a course leading to terror and misery has largely been followed. The San Francises disaler of 1000 , thi. shock of 1892 at Dixon, Vacaville and Winters, the Santa Barbara shock of 1925, and now the Long Beach shock of 10.33 are ample proofs of this. If we are to be classed as an intellipent people a new course muit be chosen. The past cannot he undnne in a monent, but the future can slowly be made briphter along the road toward safely. The choice is up to us, and better late than never we hail hest do something. It is no disgrace to admit past crrors in which nearly all have shared. Much has been learned since 100h. It will be an everlasting disgrace if from this time forward we do not actively take steps to safeguard ourselves.

The courage and foresight of the Jiranese, foliowine the terrible Tokyo shock of 1923 , in completely replanning and rebuilding their city with rigid adherence to earthquake resistive construction affords an object lesson worthy of thoughtful consideration.

The late shock at Lone Beach is very definitely the handwriting on the wall, giving notice that a public altiture of indifference must give way to one of realization and constructive endeavor Nature has been kind to us on this Coast in the times of occurrence of our nolable shocks. Instead of trying to push our luck too firr, the time has come when we must do somethine positive for our own safeguard. On our decision rests the lives and happiness of many people in the future. We believe that the following recommendations, when intellizently carried oul, will result in struclures which will adequately safeguard life in severe shocks, and in which damage will be minimized and held to rather moderate proportions. 


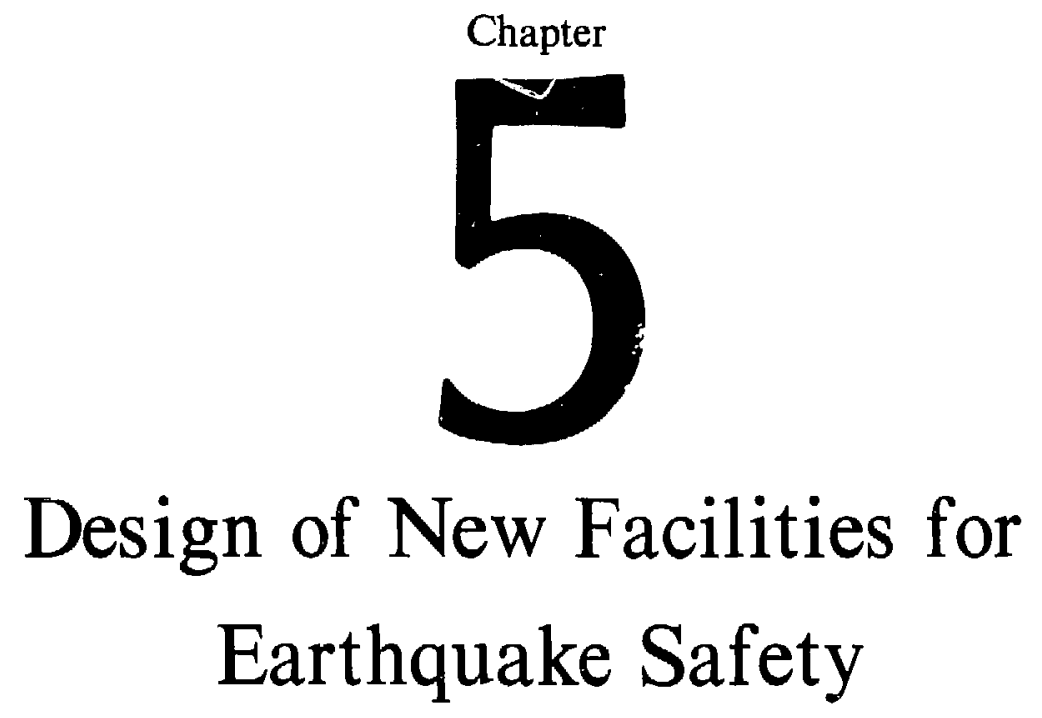

FOREWORD: Operator-Manager's Point of View (Donald G. Eagling)

The process of setting seismic criteria for a given site is an inexact science. Earthquakes, being unpredictable in nature, continue to bring surprises to engineers and seismologists as they attempt to correlate earthquake magnitude with earthquake ground motion and damage. The 1971 San Fernando and the 1979 Imperial Valley earthquakes in California produced ground accelerations which were recorded at higher levels than most researchers believed reasonable for "moderate" earthquakes. The startling effects on freeway structures, dams, and lifelines (e.g. utilities, roads) in the San Fernando earthquake stimulated many changes in seismic codes including the introduction of a soilstructure interaction factor. On the other hand, the damage during the Imperial Valley earthquake was relatively light, when one considers the recorded peak ground accelerations of $0.8 \mathrm{~g}$ and higher. In 1980 three relatively small earthquakes near Livermore, California took place within one minute producing a duration of heavy shaking previously associated only with major earthquakes. Although the effects were still very localized, the surprisingly long duration caused considerably more damage than one would expect from the instrumental magnitude of these events. This unpredictable nature is an important characteristic of earthquakes. For many structures, spending much time or money trying to improve the estimate of maximum ground acceleration or duration of shaking may not be cost effective. The results of an in-depth study might be considered to constitute "complete and accurate" input criteria and all parties involved might be lulled into a sense of false security. The ultimate test will be applied to the structure during an earthquake, not to the prediction.

In the analysis and design of special or essential facilities such as reactors or major hospitals, it is essential that detailed investigations and the best techniques be used to ensure that the worst possible ground shaking is taken into account. The risk of facility failure must be reduced to a minimum in the process of setting seismic criteria for design and construction as well as for dynamic analysis. For ordinary structures, however, it is impractical to spend limited resources to try to accurately predict the degree of ground shaking. It is a better use of time and money to concentrate effort on the structural design of the building.

For many buildings the lateral force coefficient to be used for the equivalent static force analysis can be sclected from an appropriate seismic risk map and building code. It is of utmost importance to focus on the design of the lateral-force-resisting system to ensure its continuity, ductility and completeness. That is, the system should provide a continuous path to transfer all forces from their point of application to the final point of resistance. The system must not have missing links, inadequate joints or anchorages, or britthe elements. The nagnitude of seismic forces may be unpredictable, but they can be counted upon to seek out weak spots or missing links in a lateral-force-resisting system. Experience has shown that inadequate structural performance in earthquakes can usually be attributed to neglect of this simple concept. 
If the level of shaking is so unpredictable, how can we design for earthquakes? A practical approach is to envelope the problem by designing for some appropriate lower level of resistance that can be achieved elastically and economically, and at the same time make provisions for inelastic behavior without sudden or brittle failure at the upper level of forces that could occur. It is important to recognize that intense shaking may stress the materials in the lateral-force system beyond yield and cause stress reversal as well. Therefore, yiclding of members must not result in sudden collapse. The structural sistem should be ductile. It is important to real$i z{ }^{\prime}$ that regardless of how sophisticated the analysis may be. earthquake resistance whimately is achieved by proper selection, designing, detailing and construction of the lateral-force-resisting system.

Among the lessons learned from accurate analysis of the effects of prior earthquakes on various facilities is the importance of detailing and the need for the engineer to remain responsible for ensuring that the constructed details actually carry out the design philosophy. Experience with California earthquakes has also established the importance of plan-check procedures and the so-called "third-party review." The requirement that plans and calculations must be submitted for formal review to the Structural Safety Section of the California Office of the State Architect has been a prime factor in the excellent performance of modern California public school buildings (elementary, high school, and community colleges).

The "third-party review" is often referred to as an "independent review" and questions are often raised about whether a consulting engineer can be truly independent if he is hired by an Operator-Manager. The answer is no, because the Operator-Manager can't relinquish his institutional responsibility as "Building Official" for the facility to a "third-party". The object of the third-party review is to provide both the Operator-Manager and the designer with technical protection against errors, omissions, lack of experience and other problems which plague structural design.

Often the reviewer will make use of simplistic analytical processes to detect gross error and those arising at the interfaces between disciplines. Except for certain construction types (particularly precast concrete) building redundancy usually prevents collapse until there are gross overloads or unless there are gross calculational errors. A gross error is more likely to occur when sophistication obscures an understanding of the overall physical process. The simplistic analysis or approximate check is a very valuable element of the third-party review.

Frequently the third-party review will raise technical differences of opinion and questions of code interpretation or application. The resolution of such issues is, of course, vital to the performance of the structure.
Finaily, the mere fact that the design engineer's work will receive peer review has a very positive effect on the quality of the design.

Earthquake engineering has developed rapidly and effectively in "earthquake country" because the lessons have been taught by actual earthquakes. Most structural engineers in California are convinced that their designs will in fact be subjected to the test during their professional careers. From the Operator-Manager's point of view, it is most important that the engineer selected for design of the lateral-force-resisting sysiem have such awareness. If he or she is not experienced in earthquake engineering, it is strongly recommended that the plan-check or third-party review be performed by a qualified structural earthquake engineer.

It is further recommended that the procedures of design and construction of earthquake-resistant structures include the following:

1. Submission of complete structural calculations, with lateral force analysis and design, signed by the engineer responsible and including:

a) statement of design criteria, lateral-force levels and design stresses;

b) clear description of the lateral-force-resisting system and the functional philosophy of the design.

2. A plan-check by a third-party professional, preferably one experienced in earthquake engineering.

3. Field inspection of the construction, with special attention being given to the lateral-force-resisting system by the engineer responsible for the design. The filing of a statement by the engineer at the project's completion, certifying that construction complies with construction documents.

The cost premium to provide good earthquake resistance in new buildings in the United States varies with the area of the country and the building type. Table 1, opposite, was prepared in 1970 by the Structural Engineers Association of California for the Task Force on Earthquake Hazard Reduction chaired by Karl Steinbrugge. Although too generalized for specific proposals, it is useful as a guide and to put the cost premium for seismic resistant design in proper perspective. The original intent for this table was to compare cost premiums for similar type buildings located in different seismicity zones. Although the table does not reflect code changes made during the last decade, those changes have little effect, except for buildings with concrete frames and precast steel or concrete elements.

The cost to rehabilitate existing buildings for improved seismic resistance varies considerably, primarily with the quality of design and the construction materials used and the type of lateral-force-resisting system inccrporated. The subject is discusscid extensively in Chapter 6. 
TABLE 1

ESTIMATED INCREASED COSTS

TO PROVIDE

EARTHQUAKE RESISTANCE IN BUILDINGS

Prepared by the Structural Engineers Association of California

\begin{tabular}{|c|c|c|c|c|}
\hline $\begin{array}{l}\text { AREA } \\
\text { (ZONE) } \\
\text { BUILDING } \\
\text { TYPE }\end{array}$ & $\begin{array}{l}\text { Areas where earth- } \\
\text { quake regulations } \\
\text { are now enforced }\end{array}$ & $\begin{array}{l}\text { Areas which now } \\
\text { enforce design for } \\
\text { hurricane, cyclone, } \\
\text { tornado or abnormally } \\
\text { high winds }\end{array}$ & $\begin{array}{l}\text { Other areas to } \\
\text { meet Zone } 3 \\
\text { requirements }\end{array}$ & $\begin{array}{l}\text { Other areas } \\
\text { located in Zones } \\
0,1 \text { \& } 2 \text { to bring up } \\
\text { to Zone } 2 \text { requirements } \\
\text { as a minimum }\end{array}$ \\
\hline $\begin{array}{l}1 \& 2 \text { story } \\
\text { wood frame }\end{array}$ & 0 & $1 / 2 \%$ & $2 \%$ & $1 \%$ \\
\hline $\begin{array}{l}\text { 1, } 2,3 \text { story } \\
\text { brick or } \\
\text { conc. block }\end{array}$ & 0 & $4 \%$ & $8 \%$ & $4 \%$ \\
\hline $\begin{array}{l}4 \text { story \& up } \\
\text { brick or } \\
\text { conc. block }\end{array}$ & 0 & $5 \%$ & $10 \%$ & $5 \%$ \\
\hline Concrete & 0 & $2 \%$ & $5 \%$ & $2 \%$ \\
\hline Steel frame & 0 & $1 / 2 \%$ & $3 \%$ & $1 \%$ \\
\hline
\end{tabular}

1. Zones afe those shown in Fig. I of the Task Force report on Program.'

2. Percent increase includes design, inspection, and construction cost.

3. Table assumes:

A. Basic design requirements of the Uniform Building Code (or equivalent) for wind forces are recognized and enforced at present in the area where the building is located.

B. Inciudes extra architect and engineer design and inspection costs.

C. Compared construction is of same quality, consiruction material and fire resistance.

"As shown in the 1970 Edition of the Uniform Building Code. 


\title{
Chapter
}

\author{
5 \\ Design of New Facilities for \\ Earthquake Safety \\ Roland L. Sharpe \\ Civil Engineer \\ Structural Engineer
}

\begin{abstract}
A leading authority in the field of seismic safety. Mr. Sharpe has 35 years experience in structural and earthquake enginecring design. He was the project director lor the Vational Seience Foundation/National Bureau of Standards project to develop comprehensive seismic design recommendations which can be adapted by jurisdictions throughout the Lnited States. He was also a principal consultant to the United States Alomic Energy Commission on the seismic safety of nuclear power plants, and he directed and administered planning. criteria determination and structural engineering design for the Stanford Linear Accelerator. He has investigated damage that occurred in several earthquakes.
\end{abstract}

Mr. Sharpe has authored numerous publications and engineering analyses and research reports on: reconmendations concerning the behavior of structural systems under dynamic loading: recommendations trape of earthquake response spectra: seismic design of structures: and on the need for seismic design of mechanical and electrical equipment.

$\mathrm{He}$ is active in a number of professional organizations and has served the Structural Engineers Association of California (SEAOC) on the board of directors and as chairman of the SEAOC Seismology Commillee. Currently he is chairman of the American Suciety of Civil Engineers Struet'ra' Division Executive Committec. He also served on the board of directors of the Earthqu $\mathrm{k}$ : Engineering Research Institute. He is chairman of the board and President of Engrnereri,g Decision Analysis Company. Inc., Palo Alto, Callifornia and Friankfurt. W. Germany.

This chapter treats the analysis and design of new buildings and facilities and briefly reviews pertinent building code provisions. The following subjects are discussed:

Determination of Criterial for the Facility

Construction Matcrials

Design Stcps and Design Considerations - Structural

Design Consideration:s - Nonstructural

Design Considerations - Lifelines

Plan Check Procedures
Dynamic Analysis -- Applications and Limitations

The chapter closes with a list of references and several appendices presenting excerpts of codr provisions, and some design details.

The basis for most seismic codes is the Structural Engineers Association of California (SEAOC) Bluebook. ${ }^{1}$ The Bluebook provisions are largely incorporated in the two best-known codes: the Uniform Building Code, ${ }^{2}$ and the Tri-Services Manual, Seismic 
Design for Buildings. ${ }^{3}$ A fourth publication, Tentative Provisions for the Development of Seismic Regulations for $B u$ dings, ${ }^{4}$ prepared by the Applied Technology Council, provides tentative but updated scismic provisions including requirements for nonstructural systems and components.

When designing structures for scismic resistance, it is important to recognize that design forces derived from code formulas represent the best judgments of competent groups of professional engineers. However. the scismic deformations to which the building may be subjected are really unknown and in nost cases may greatly exceed the design deformations obtained using the code formulas. In such cases the building structure could be severely overstressed as compared to stresses calculated for code seismic design loads.

The structure and its appendages must remain stable when undergoing horizontal deformations which could considerably exceed yield deflections. It is therefore basic to gond design that, together with providing the minimum design strength, the performance of the structural system at very large overloads a id deformations be carefully considered. To ensure adequate performance, the detailing of joints and members must be done to ensure that the structure will remain as a unit, cven while subjected to these very large deformations. It is also important that some redundancy be provided and that structural elenents be designed so less eritical clements fail first, thus absorbing and dissipating energy and providing protection for more critical members. A building or structure having this capability is said to have ductility, which will be discussed later. Finally. it is essential that a continuous load path (or paths) having adequate strength and stilfness be provided so that all forces will be transferred from the point oi application to the final point of resistance.

\section{DETERMINATION OF CRITERIA FOR FACILITY}

Several factors should be considered in developing scismic criteria for a site. the most important being general site characteristics, site seismicity, expected peak ground motions, structure or facility category use, type of structural system, and applicability of building code formulas. Each is discussed in the following sections.

\section{General Site Characteristics}

When selecting a new site, an investigation should be made to determine the existence of any active earthquake faults. The potential for landslides, liquefaction, or consolidation of foundation soils when subjected to vibratory ground motion should be determined. For an existing site, all available foundation investigations and geological reports should be reviewed for such information. Large differences in elevations should also be studied. Soils-foundation reports should be reviewed with the assistance of a qualified professional to determine the possible liquefaction potential of underlying soils during a seismic event. Similarly, the data should be reviewed for potential soil consolidation when subjected to vibratory motion. Detailed field investigations could be necessary to determine existence and extent of any of the above possible hazards. The extent to which such investigations are employed will depend on the size and importance of the proposed facility, probability of safety-related or large economic risks, and the possibility of or suspicion of potential site hazards.

\section{Site Seismicity}

For a normal-usage facility, it may be appropriate to select design coefficients based upon the seismic zoning shown in the building code. The importance of the proposed facility and/or the potential risks involved may warrant a special study of the site seismicity. If so, it should include a review of the historical seismicity within the surrounding area to a 50 mile radius. Probable frequencies of earthquake occurrence and probable ground motions at the site should be determined. An important factor in determining site seismicity is the degree of acceptable risk: should the facility be able to function after the occurrence of the naximum earthquake predicted to occur within 50 years. 100 years. or 500 years, or should the facility be designed to sustain only minimum damage and maintain functionability if any of these occur? This decision should be made by management, not left to the seismic consultant or cnginecr.

\section{Peak Ground Motion}

A facility that must be able to function during and after a majur earthquake. or still be functional only after a major event. should have its peak ground motions (PGM) for design deternined as a part of the study. For most sites the possible PGM could be several times more than the building code coefficient. Therefore, the PGM amplitude used in design should depend on the degrec of risk considered aceeptable for the facility. i.e., the PGM for a 50-year return period would be much less than for 500-year return period. After the PGM is determined, response spectra would be developed considering the soil and foundation conditions at the site and the distances to potential carthquake sources. 


\section{Category of Structure or Facility}

The structure or facility usage or importance and its potential safety-related or economic risks should be considered when establishing an acceptable degree of seismic-damage risk. A laboratory or a process facility handling potentially hazardous materials (such as plutonium or other toxic or radioactive materials) should be planned with more restrictive seismic design criteria than a normal office building or a warehouse. If special treatment is not warranted, the appropriate building code design provisions can be followed. The Uniform Builuing Code has a provision for increasing the seismic design coeflicient for structures of special importance or occupied by large numbers of pcople; for the highest categories, the seismic coefficient is multiplied by 1.5 .

\section{Type of Structural System}

The structural system used for the building, wuch as a momeni space frame, shear wall, or bearing wall systcm, largely governs the type of response a building will exhibit during an earthquake. A frame structure is usually the most flexible and dissipates energy by deforming in bending or nexure. Because a flexible structure tends to "give" when subjected to vibratory motion. less seismic energy is imparted to it. If the frame structure is ductile, i.e., has redundancy and capability to remain stable when stressed beyond yield levels, then a lower total seismic force coefficient can bc used in the design. However, it should be remembered that the nonstructural components and systems must be designed to accommodate the expected building frame deformations. Such accommodation would include providing connection and support details so that the frame could move without damaging exterior walls, windows, or interior partitions. Similarly, provisions to accommodate building deformations must be provided in the design of mechanical and electrical systems in a frame structure. These provisions can add to construction costs; however, a moment space frame may be the best solution, based on building function and use, if the building deformations can be accommodated.

A shear wall structure on the other hand, is quite rigid and deflects less than a comparable mument frame. Therefore, more energy is imparted to the structure and a higher total seismic force cuefficient in used. Most of the seismic-induced energy is dissipated by shearing distortion and less ductility is available. Since shear wall structures deform considerably less than comparable frame tructures, savings on connection of exterior walls. windiws, and interior partitions to the building structure can result. Shear wat! st klures may have a structural frame for sup ring gravity loads.

A bearing wall system has many characteristics of at shear wall system; however, some of the bearing walls in the building must be designed as shear walls to withstand or resist the lateral earthquake forces. In a bearing wall structure the gravity loads are largely carried by the walls; a high total seismic force coeflicient. similar to that used for shear wall buildings, is also used in the design of bearing wall structures.

The choice of a moment frame versus shear wall or bearing wall system can also be affected by functional and other design considerations.

\section{Applicability of Code Formulas}

Seismic design formulas given in building codes apply to typical buildings; they are not intended for towers, processing equipment or structures, danns, and special facilities such as those involved with high risk processes. In all such cases. special consideration should be given to the individual highly irregular building (in plan or vertically) structure's dynamic characteristics.

\section{CONSTRUCTION MATERIALS}

Four basic structural matcrials are used for seismicresistant building construction: structural steel, reinforced concrete. reinforced masonry, and wood or timber. Buildings constructed of any of the four materials can be designed to withstand major seismic motions. Each of these materials has physical characteristics that lend themselves to certain types of buildings and functions, and this section will discuss their pros and cons from a seismic design vicwpoint.

Structural stecl is a homogeneous matcrial with excellent stress-strain characteristics. Steel has excellent ductility and can deform many times its yield punt before failure. Structural steel frames generally deform more when subjected to earthquake motions than other types of structural framing systems. Of coursc. unless proper precautions are taken in the design to allow for this deformation. considerable damage can occur to nonstructural elements such as partitions, exterior walls, windows, ceilings, and mechanical and electrical systems. Structural stcel framing systcms cain be stiffened by using cross bracing or some other type of bracing, or shear walls to reduce deformation induced by seismic motion. For such systems. nonstructural components are less likely to be danaged. However. braced stecl framing has much less ductility than a structural stecl frame. Bracing members act primarily 
in tension: when lailure occurs it is somewhat abrupt. Unlike a moment frame system, a braced system has litthe capability to dissipate energy by continued deformation. A recent development is the eccentric-braced frame, which does allow some ductile deformation.

Reinforced concrete construction, either as a frame or as a shear wall structure, does not have as much ductility as steel frames. However, reinforced concretc frames can be designed and constructed to exhibit excellent ductility. Because these frames generally have larger nomber sizes than corresponding steel frame nembers, they are normally more rigid and deflect less when subjected to earthquake ground motions. As a result, the smaller deformations should cause less damage to nonstructural components. When subjected to major carthquake motions, concrete frames tend to crack and, in some cases, the concrete cover over the reinforcing steel spalls'. However, if properly designed, detailed, and constructed, reinforced concrete frames perform well during earthquakes.

Reinforced concrete buildings constructed with shear walls, and with the building components well tied tugether, generally exhibit good seismic performance. Since these structures are usually quite rigid, nonstructural components that are properly anchored to the structure suffer little dimage.
Reinforced masonry structures (either concrete block or clay brick) can be designed to function satisfactorily during a major earthquake. In UBC Seismic Zones 2, 3 and 4 , masonry must be reinforced with steel reinforcing. If properly detailed and constructed, these structures perform well during major seismic motions.

Wood or timber structures generally have cxhibited excellent performance when subjected to major earthquakes. However, fire and other safety requirements often limit their size and height. Wood construction has substantial interent energy-dissipating capability and. when shear panels and wood diaphragns arc properly utilized. makes very good structures. The floor and/or roof deck are designed to distribute horizontal seismic forces to vertical load-resisting panels. The floor or roof deck then acts as a diaphragm which may be considered analogous to a plate girder laid in a horizontal plane, where the floor or roof deck acts as the girder web. the beams or joists function as web stiffeners, and the peripheral beams act as flanges.

Shear walls or panels are used to resist and transmit the lateral seisnic forces to the foundation in the plane of the wall. A shear wall acts similar to a cantilevered plate girder standing on end; the wall acts as the web and vertical boundary members functions as the flanges. Shear walls may be constructed of wood, reinforced concrete, reinforced masonry, or structural stcel.

\section{DESIGN STEPS AND DESIGN CONEIDERATIONS - STRUCTURAL}

Some general design factors to be considered are building shape and geometry, framing type, basic construction materials. arrangement and type of so-called nonstructural components, and adequacy of connections of various building parts and components. To construct an efficient. cconomical, seismic-resistant building, it is essential that the architect and engineers collaborate as a team during the conceptual design stage. Too often the architect working alone develops the cunceptual plan. arrangement. and aesthetic design. and then presents the cuncept to the structural, mechanical and clectrical engineers for design of the appropriate systems. By involving the engincers in the conceptual design stage. the design team can often avoid expensive and sonetimes inadequatc solutions to effective scismic resistance. ${ }^{17}$

During the conceptual design phase the design team should consider certain factors:

I. A building's inherent resistance to seismic forces is determined to a large extent by the basic layout. It is desirable that the building be symmetrical or have symmetry about each axis, The symmetry should be considered in the arrangement of wall openings. location of shear walls, size and spacing of columns and other potential lateral force- resisting elements. If seismic force eflects are considered in the initial layout, significant cost savings can be made without detracting materially from the building's function or appearance.

2. Re-entrant corners, such as those concurring in L, T, or U-shaped plans, are locations of great stress and should be avoided or reinforeed appropriately.

3. The effect of components. such as interior partitions, filler walls, exterior glazing. or exterior wall panels should be considered in the initial layout. For example, filler walls not symmetrically located could interact with the framing system inducing torsional rotational moments in the structure. resulting in excessive stresses in colunns or other shear-resisting elements. Such stresses may not have been considered in the design. In addition. nonstructural components can stiffen a building and thus induce higher seismic forces in the building than may have been contemplated in the design.

4. Relative stiffnesses of the various stories in the building should be considered. Often the first story is made taller than the others with many of the interior walls deleted to give a more open appearance. As a result, the first story could be 
considerably more flexible than the others and excessive deformations could occur with accompanying adverse affects. An example of this situation was vividly demonstrated by the Olive View Hospital during the 1971 San Fernando earthquake. The upper stories were stiffened with shear walls, but the first story depended on columns in flexure to resist seismic forces. The large deflections of the first story caused excessive damage and almost total loss of the carrying capacity of the columns. Although only four months old, the structure had to be razed and a new facility designed and constructed.

5. Once building layout is determined. the type of construction material should be evaluated. Many factors other than seismic resistance affect selection of the particular construction material including total construction cost and requirements for fire resistance. The architect and the engineer should examine various framing systems and construction materials to deternine what will provide the required function at the lowest cost.

6. The use of a moment-resisting space frame (MRSF) versus a shear wall system should be evaluated. For buildings which have no brittle finishes, such as a warehouse or shop, either a MRSF or a shear wall system will work equally: well. Where there will be many relatively brittle elements such as interior partitions, stairwells, and cxterior glazing. the cost of stiffening the MRSF and/or designing connections to accommodate relative movement between the structural frame and these elements should be considered. Often, shear walls can be utilized to stiffen a structure without sacrificing function.

After all the foregoing factors have been considered, seismic design criteria applicable to the selected structural system should be established. If a building code is used, appropriate zone and seismic design factors should be selected from the code provisions. Codes normally provide minimum requirements for life safety. If the facility, because of its size and importance and/or potential safety-related or economic risks, demands more detailed criteria. the required detailed studies should be performed by qualified professional consullants.

These steps should be followed in the detailed design:

1. Select the site.

2. Determine the facilitys function. importance, and potential safety-related or econonic risk.

3. Determine the site seismicity (from either building code or special studies).

4. Determine the degree of acceptable risk (amount of property damage acceptable. necessity for nuaintaining function, potential hazard if function is lost, and potential hazard to occupants/public).

5. Establish the geometry and layout of the facility (in plan and vertically; see prior discussion).
6. Determine type of framing system and construction materials to be used.

7. Determine specific seismic design criteria to be followed (depending on building usage. importance, size, and type of framing system used). These factors may be taken from the building code, or determined by independent investigation..

8. Select the K-factor from the building code.

9. Make preliminary design of the structural framing system to determine preliminary sizes of beams. columns, walls, foundations, etc.

10. Calculate a preliminary value for the fundamental period. $T$, of the building.

11. Calculate the seismic coefficient C (In LBC, $\left.C=\frac{1}{15 \sqrt{T}}\right)$.

12. Calculate the base shear (for the LBC, $V=$ ZIKCSW, where $Z=$ the seismic zone factor, and varies from 3/16 for Zone 1 to 1.0 for Zone 4:

$I$ is an Occupancy Importance Factor which varies from 1 to 1.5 , depending on the usage of the building (see Appendix A):

$\mathrm{C}$ is the seismic coefficient calculated above;

$\mathrm{K}$ is the horizontal force factor selected from Table 23-I, Appendix A:

$\mathrm{S}$ is the site-structure resonance factor calculated as shown in Appendix A: and

$W$ is the total gravity load of the building which includes the total weight of the structure and applicable portions of other componenis (as defined in Appendix A).

13. Distribute base shear over the height. The LBC formula:

$$
F_{x}=\frac{\left(V-F_{i}\right) w_{x} h_{x}}{\sum_{i=1}^{n} w_{i} h_{i}}
$$

can be used (sce Appendix A). Lising the gravity loads and the seismic shear forces calculated it each level. recalculate the vertical and horizontal member sizes. The seismic shear force and torsional shear forces are distributed to the seismic resisting system with consideration given to the relative stiffnesses of the vertical components and the floor or roof diaphragn. In addition to any calculated torsional moment. an accidental torsional moment equal to the story shear times a distance equat to not less than $5 \%$ of the maximum dimension of the building at that level shall be distributed to the vertical lateral-force-resisting system. (See Sec. 2312 c 4. 1982 L'BC).

14. The building should be designed 10 resist verturning effects caused by wind or earthquake forces. Using the calculated seismic shear forces, the vicrturning moment at each floor should be calculated and the moment distributed to the various resisting elements (colunins or walls).

15. The design should ve reviewed to see if there is adequate redundancy in the structural framing sys- 
tem. There are many uncertainties in the amplitude and frequency characteristics of the earthquake ground motions, in the detailed behavior of materials and systems as they resist seismic loadings, and in the methods of analysis. Therefore, it is considered good earthquake engineering to provide as much redundancy as possible in the building's seismic resisting system. In a structural system without redundant components, every component must remain operative to preserve the integrity of the building structure. On the other hand, in a system that has considerable redundancy, one or more redundant components may fail and yet the structural system will retain its integrity and continue to resist lateral forces, although perhaps with some reduced effectiveness. In a frame system, redundancy can be obtained by making all of the joints of the load-carrying frame not only moment resisting, but also part of the seismic resisting system. A moment-resisting space frame has considerable load carrying ability even when stressed beyond yield deformations. Redundancy can also be provided by using several different types of seismic resisting systems in any one building; thus a back-up sysiem can prevent catastrophic effects if the primary resisting system undergoes excessive deformations.

16. The design should be checked to determine if there are significant discontinuities in strength between adjacent stories, which can cause adverse response in a building. Normal practice is to determine the size. length. or strength requirement of a resisting member. If more than the required strength is provided, so much the better. The extra strength in a story, if significantly different than the strengths in adjacent stories, can produce responses which vary greatly from those calculated. One approach for considering this problem is given in Appendix B.

17. The drift in each story should be calculated. Story drift is defined as the displacement of one floor relative to the floor immediately below. The lateral displacement or deflection of the building relative to the base is not story drift, and should be not used for drift control or stability considerations because it could give a false impression of the effects of critizal stories. However, the total building deflection is important when considering seismic separation between adjacent buildings. Story drift should be controlled so as to ensure building stability under maximum earthquake conditions. Large horizontal deflections can cause secondary stress effects due to eccentricity of the gravity load inducing moments and forces in the members. Moments and stresses due to gravity loads are augmented by the stresses induced by bending moments equal to the lateral drift times the total weight of the structure above the level under consideration. The Commentary of Reference 4 . Section 3.7, summarizes recent work in this area. Generally, in areas of high seismicity, seismic-drift considerations will control for buildings up to medium height. In areas having 'ow seismicity and for very tall buildings in high risk seismic zones, wind loadings can control, at least in the lower stories.

18. Member sizes and seismic resisting elements on each floor should be reviewed for conformance with the initial design assumptions. If they do not conform, the procedure described above should be repeated, using the new sizes. If significant differences in mass and stiffnesses of adjacent stories exist, a dynamic analysis should be made (see section on dynamic analysis). The general design approach for each basic material follows:

\section{Structural Steel Frames}

In general, the requirements of the American Institute of Steel Construction (AISC) specifications Part: 1 and 2, for the Design, Fabrication and Erection of Structural Steel for Buildings ${ }^{5}$ can be used for the structural steel design. Limitations provided in the Uniform Building Code on story drift (0.005 times the story height) should be followed. For structural steel buildings in Seismic Zones 3 and 4, moment frames should be ductile moment frames designed in accordance with Part 2 of the AISC specifications. Modifications listed in the Uniform Building Code should be followed, including connections of beams to columns, developing full plastic capacity of the beam, and special consideration of possible local buckling in members when stressed beyond yield.

\section{Reinforced Concrete}

Reinforced concrete buildings designed to resist significant seismic forces usually have moment resisting frames, shear walls, or combined moment-resistingframe shear-wall construction. Because actual seismic forces may greatly exceed design forces, buildings may be deformed beyond the elastic limit to dissipate input energy. Therefore, ductility is necessary for the rtructures to sustain gravity and other loads without catastrophic failure. Even though a structure's energy dissipation capacity (work done in deforming the structure) is related to its ductility capabilities. overreliance on ductility could be inappropriate. Excessive structure deformations can cause significant damage to both structural and nonstructural elements. Either the deformations must be limited. or structural and nonstructural components must be designed to iolerate large deformations per story without significant damage.

Concrete without steel reinforcing is a relatively britthe material and when overstressed, fails suddenly and sometimes catastrophically. Therefore, concrete siructures should be designed to be reinforced and have minimum possibility of concrete compressive failure. concrete shearing failure, or loss of reinforcing 
anchorage. Compression failures can be controlled by requiring confinement or special transverse reinforcing of longitudinal reinforcing bars. Continement increases the strain capacity, and compressive, shear, and bond strengths of concrete. Maximum confinement should be provided near beam and column connections. Shear failures can be controlled by providing sufficient shear reinforcement and stirrup-ties or hoops. Anchorage failures can be controlled by following the special anchorage requirements given in the building code.

The Uniform Buiiding Code provides ductile conerete design and detailing provisions intended to inhibit failures from compression, shear, or loss of anchorage. References 6 and 7 give detailed discussions of seismic resistance design requirements for reinforced concrele structures. Appendix $C$ includes figures showing limitations on dimensions for ductile concrete frames, rebar splices, longitudinal steel, girder web reinforcement, and column transverse reinforcement, girder column joint analysis, and reinforeement details for ductile conerete frames Appendix $C$ also contains recommenditions concerning design of shear walls and their reinforcement. and concrete floor and roof diaphragms.

\section{Reinforced Masonry Construction}

Where seismic resistance is required. buildings constructed of masonry should be reinforced. This applies to reinforced concrete block masonry as well as to reinforced grouted brick masonry. Numerous publications deal with these two t!pes of masonry and References 3 and 8 contain information regarding design details for reinforced masonry construction. Masonry walls should be firm!y anchored to the building's floors and roofs. There should be extra reinforcing at the tops and bottoms of openings. at changes of direction in building geometry, and att points where excessive stress might occur when the building is subjected to earthquake motions.

\section{Wood or Timber Buildings}

Fire safety requirements usually limit wood or timber buildings in size and height: however, as noted previously, they generally perform well when subjected to major earthquake ground motions. Wood construction practices have not been coditied in a standardized form in the United States. Heavy timber design practices generally follow the National Design Specifications for Stress-Grade Lumber and Its Fastenings (NDS). ${ }^{9}$ Unfortunately, this document does not specify either simple or critical construction practices. No single code of practice exists for lightweight wood franing: however. there is a general similarily of construction throughout the United States. Chapter 25 of the LBC contains some excellent details and is a good document to follow. Wood has inherent energy absorbing capacity and. especially for small structures. has performed well in earthquakes when all conponents are adequately tied together and the structure is anchored to the foundation.

\section{General Design Requirements}

Building codes do not give all design requirements necessary to make a structure fully carthquake-resistant and therefore considerable engineering judgment based on experience is needed to ensure adequate resistance. The following discussion of special requirenents should be helpful when it is not feasible to retain experienced carthquake engineers:

1. The building components should be lied together to act as a unit. This not only aids in carthquake resistance, but also adds to the capability to resist high winds, floods. explosion, progressive faiture. and foundation settlement. As a general requirement. a section passed through any part of a structure should be tied to the rest of the structure so as to resist at force at least equal to 5 pereent gratity and, in higher seisnoic zones for at least 10 percent gravity times the weight of the portion of the building being connected. In addition. beams should be tied together, to their supports or columns, and columns tied to the footings for a minimum of 5 percent of the dead and live load reaction.

2. Concrete and masonry walls should be anchored to all floors and roofs for lateral support. A common event noted during major earthquakes is the pulling away of heavy masonry or concrete walls from floors or roofs. As a minimum. such walls should be anchored for a foree equal to at least 200 pounds per lineal foot or the appropriate building code requirement. whichever is larger.

3. Shear walls or other bracing elements in buildings are often not uniformly spaced around the floor or roof diaphragms. Collector or drag bars should be provided to collect the shear forces and trinsmit them to the shear resisting elements. These collector or drag bars are composed of reinforced concrete beams in concrete slabs, steel members in steel diaphragms. and continuous wooden members in timber structures.

4. Diaphragms, mentioned previously, act as horizontal deep beams or trusses. They distribute the lateral loads to the vertical resisting elements. and are subject to shears. bending moments, direct stresses, and deformations. In some cases deformations must be controlled because they could overstress the walls to which they are connected. Diaphragm deflection must not cxeed the ability of the walls that are normal to the direction being analyzed to deflect without fiilure. Wall anchorages tend 10 tear off diaphragm edges and therefore ties must be extended into the diaphragm to develop adequate anchorage. For upenings in shear walls and diaphragms. chord stresses must be provided for, and the chord members anchored (to 
develop chord stresses) by cmbedment. A diaphragm should be tied together so it will act as a unit.

5. Bearing walıs, like concrete and masonry walls, should be anchored to floor and roof diaphragms. It is important that the wall elements and interconnections have sufficient ductility or rotational capacity or strength to remain as a unit. Consideration should be given to shrinkage or settlement effects on this capability.

6. Walkways into buildings or interconnections between buildings are of ten constructed with a roof slab and a single row of columns. These are referred to as inverted pendulum-type structures because a large portion of their mass is concentrated near the top. Where such structures incorporate heavy concrete slabs, lateral seismic motion may cause a rotation of the slab that can result in vertical accelerations acting in opposite directions on the slab overhang. Hence, a bending moment is induced at the top of the column. One way to cope with this is to apply one-half of the calculated foundation bending moment at the top and vary the moments along the column from 1.5 times the base moment at the base to 0.5 times the base moment at the top. This recommendation is based on background work performed during the develop menl of Reference 4.

\section{DESIGN CONSIDERATIONS - NONSTRUCTURAL}

Seisnic design requirements contained in most building codes are only for the structural framing system. Recent earthquakes have demonstrated that damage to architectural components and systems and to mechanical and electrical systems and components can, in some instances, exceed the total structural system cost; furthermore, significant damage can occur without major damage to the structural framing system. Enclosure systems (such as infill walls, curtain walls, spandrel beam covers and precast panels). finish systems (such as partitions. ceilings and veneers), and service systems (such as heating, lighting, air conditioning. communications and transportation) all can affect and possibly alter the response of a building and its components during an earthquake. Any of the components may act structurally: whether designed as part of the structural framing system or not. These systems are traditionally referred to as nonstructural components, but can behave structurally and improve or impair the building's ability to endure an earthquake without damage.

The degree to which any structural or permanent nonstructural component may interact with any other or all of the building's component parts should be considered in determining whether a given component can be incorporated into the lateral force-resisting system. If so, this could reduce the initial cost of the structural system and enhance building performance during an earthquake. The architect should collaborate with the engineers during the conceptual design stage so that such components can be incorporated into the traditional structural system to improve the building's response to earthquakes and help all components to better endure the induced forces and deformations.

Several categories of building components are typically not incorporated into the structural systems of most buildings. These categories include:

- components that are not considered permanent:

- permanent or major componsnts for which structural incorporation would be too expensive;

- components having mass, stiffness or configurations that would probably have a detrimental effect on the building response, or would cause unacceplable problems in the building's functional layout or aesthetic concepts.

Nevertheless, some of the components in the above categories, present in a given building, will interact with others and affect the building's earthquake response. As in most aspects of providing a high degree of seismic safety in building design. the architect should work closely with the structural engineers when designing and detailing such systems.

Regardless of whether the component is part of the structural system or not, consideration should be given in its design to improved capability for earthquakeresistance. For example, a partition which is connected to the floor and ceiling must be able to accommodate the differential motions between the slab or floor above and the floor on which it is supported, as well as be compatible with motions that may be induced in the ceiling, or in mechanical or electrical equipment sy'stems. References 10 and 11 contain discussions regarding interaction of building components during carthquakes and architectural seismic design of such conrponents.

As a minimum. architectural components and mechanical and electrical systems and components should be designed to resist seismic forces to which they may be subjected: this is especially true in UBC seismic zones 3 and 4 .

Generally, the component's anchorage or attachment should be designed in accordance with the formula:

$$
F_{p}=Z_{\text {I C }} W_{p} \text {. }
$$

where $F_{p}$ is the seismic force applied to the component at its center of gravity, $C_{p}$ is the seismic coefficient for 
the component, and $Z, I$, are the seismic zone coefficient and occupancy importance factors, respectively, as specified in the Uniform Building Code.

Reference 4 presents more detailed requirements for the design of architectural, mechanical, and electrical systems. The basic formulas used are of the same type. However, factors are included for required performance, amplification of force with increased height in the building (earthquake response varies with height), and type of attachment system for mechanical and electrical systems (see Appendix D).

In the design of architectural, mechanical and electrical components and systems, design consideration should be given to the differential motion in each story (or story drift) during the earthquake. Since story drifts are relatively small in a shear wall or braced frame building, they probably do not need to be con- sidered except in seismic zones 3 and 4 . However, for most frame structures, provisions should be made 10 accommodate the story drift. As noted previously, consideration should also be given to possible interaction between architectural, mechanical, and electrical systems when the building deforms.

Partitions, ceilings, and filler walls should be designed to resist seismic forces normal to their plane. The Uniform Building Code gives minimum factors for which these elements should be designed; Sections $1807(\mathrm{k})$ and $2312(\mathrm{~g}$ and $\mathrm{k})$ give minimum design requirements for architectural, mechanical, and electrical systems. Reference 12 discusses design of attachments for mechanical and electrical systems; Reference 4, Chapter 8 and corresponding commentary discusses seismic design of architectural, mechanical, and electrical composients.

\section{DESIGN CONSIDERATIONS — LIFELINES}

Facility lifelines include means of ingress and egress such as stairways and elevator systems; critical mechanical and electrical systems; and systems external to the facility, such as utilities, road access, bridges, and fire protection. Seismic design of such lifelines should consider the means for building occupants to evacuate safely during and after earthquake emergencies. Ltilities such as natural gas could be ruptured and fires ignited. Liquid fuels or other flammables may leak from broken lines, or electrical short-circuit currents in excess of the normal protective device's capabilities may occur. Consideration should be given to devices that will automatically stop fuel flows or safely interrupt electrical currents in the event that severc earthquake motions occur; this recommendation is especially applicable to scismic zones 3 and 4. Gas or high temperature energy supplies to buildings can be interrupted by installing seismic valves at service connections. Interruption in electrical service can be accomplished by shunt-tripping the main circuit breakers when activated by a sensor that can detect excessive ground motion. This means of electrical service shutdown should be carefully evaluated for any adverse effects to the electrical system.

The overall site electrical distribution network should be reviewed to ensure that the fault current potential which existed when the site was first developed has not increased sufficiently to exceed the capability of supply and distribution equipment to adequately handle such loads. This problem is of concern because phase-tophase or phase-to-ground faults can develop during a seismic event and equipment may not be adequately designed to prevent destruction of service entrance equipment, service protection equipment, or distribution equipment, and could represent a significant source of fire. Consideration should be given to this problem to avoid a potential safety hazard. The commentary provides further discussion in Section 8.3.5 of Reference 4.

Generally, utility piping systems should avoid unstable ground and not traverse soil conditions with widely varying compaction or consolidation. Care should be taken when piping systems pass from natural ground onto an unstable fill area. In seismic zones 2 through 4, consideration should be given to providing two independent sources of water supply for major facilities. If a public utility company is providing the service, there is a good chance that little or no consideration has been given to the system's seismic resistance. A dependable water supply is essential to combat fires that might occur during or after major earthquakes. For critical processes requiring continued functioning, an alternative gas supply such as liquid petroleum gas or an emergency power supply (diesel powered generator) system should be provided.

It is essential that fire fighting equipment have ready access to any facility that might be damiaged by an earthquake. If access is by bridges or at the edge of steep slopes that might landslide during an carthquake. consideration should be given to rerouting access. or improving the seismic resistance of road structures.

Chapter 10 in Reference 3 gives seismic details for various site utility systems. 


\section{PLAN CHECK PROCEDURES}

The proliferation of activities and associated equipment now employed in almost any building, as compared with a few decades ago when such was the exception, has greatly complicated the problems of architectural and mechanical design for seismic safety. Many facilities today are composed of complex systems or the construction procedures may be innovative or untried. Designers are experiencing increasing pressure to producc work on accelerated schedules and for low fees. This makes it very difficult for them to devote as much attention to design as they might like. Because of the low fee criteria the most qualified designer may not be selected. Therefore it is important to have the structural and seismic designs reviewed by an independent consultant. Some practical plan check procedures have been developed and employed to help assure good design and construction, and also to facilitate the reviews themselves, as well as inspections and approvals.

Independent seismic reviews should be made at two stuges for major facilities, facilities having a potential risk to life safety due to the process contained therein, or facilities with a potentially large economic loss. The first review should be made at the end of the preliminary design or Title l services, and the second, separate review when the final design is completed, but before bids are taken.

The structural/seismic design reviews should include design philosophy. framing system, construction materials, criteria used, and any other factors pertinent to the seismic capability of the proposed facility. Particularly important in the review is the check for a continuous load path, or paths, and for the adequacy of their strength and stiffness to transfer seismic forces from point of application to final point of resistance. Also important is a check of the foundation plan to verify that it has been designed to accommodate forces developed or movements induced in the building by design ground motions. In sum, peer review by an independent consultant or peer group need not provide a detailed check of the spacing of reinforcing bars, but rather an overview to help identify oversights, errors. conceptual deficiencies, and other elements likely to cause problems during and after construction.

Examples of peer review procedures include those employed by the United States Corps of Engineers advisory boards reviews of dam designs (either performed in-house or by engincering firms), and by the Bureau of Reclamation, which recently developed similar procedures. The United States Nuclear Regulatory Commission has a staff and an advisory committee on reactor safety that perform certain independent peer review functions for nuclear power plants. Many utilities involved with major facilities have independent design reviews made. These may seem unnecessary expenses, but peer reviews can catch costly design mistakes in judgment, calculations, or philosophy. For a major facility, an independent peer review could more than pay for itself by uncovering design deficiencies before they are cast in concrete or constructed in steel.

Another important requirement is that the architectengineer submit a complete set of structural calculations, as-built drawings and specifications, an explanation of the lateral force resisting system, and a listing of the design loads and criteria. It is extremely helpful, after a facility has been constructed for some time. to be able to utilize as-built drawings to determine how a proposed change in the building structure would affect its lateral force resistance. Design loads and criteria should be listed either on the drawing cover sheet or on a sheet near the front of each set because calculations are sometimes separated or misfiled separately from the plans. Similarly, an explanation of the lateral force-resisting system should be listed on an early sheet of the drawings.

When required, calculations for seismic resistance of mechanical and electrical systems should also be submitted, and a listing of design loads and criteria given on the mechanical and electrical drawings. Lastly, the architect-engineer should certify that calculations and drawings have been checked by his staff. These requirements should be part of fee negotiation becausc cursory checks or spot checks of calculations and drawings may result from competitive fee negotiation.

\section{DYNAMIC ANALYSIS - APPLICATIONS AND LIMITATIONS}

Earthquake-induced ground motions are dynamic. transient. and quite erratic, coming from all directions. both horizontal and vertical. A structure behaves as a dynamic system when vibrating under the influence of these seismic motions. Without the aid of a large computer it is impractical, if not impossible, to determine the detailed dynamic behavior of most structures. Thus, in the past, engineers, while recognizing the dynamic nature of the problem, have sought to simplify and reduce it to a static one: dynamic forces are represented by code-prescribed cquivalent static horizontal forces. Criteria are based largely on uniform 
structures with symmetrical luadings. and on building performance during past earthquakes. As a result, the seismic force coefficients given in the building cotes are considerably less than the forces which might occur during an earthquake. Factors such as structural damping. ductility, participation of nonstructural elements. and the customary safety factors used in design are relied upon to ensure survival of structures during seisnic events.

Dynamic analysis is an alternative to the static code analysis becuuse it considers the structure's dynamic characteristics when subjected to earthyuake ground motions. An analysis is considered dynamic if it recognizes that both loading and response are time-dependent and employs a suitable method capable of simulating and monitoring such lime-dependent behavior. ${ }^{14}$ Complex structures, structures that have signiticant irregularities vertically in stiflness, mass, or geometry, or have significant eccentricities in plan. should be subjected to dynamic analysis to bette estimate probable structural response when subjected to strong earihquake motions.

In this type of analysis, the dynamic characteristics of the structure are represented by a mathematical model and input motion can be represented as a response spectrum. or an acceleration-lince histury. The dynamic characteristics of a lincarly elastic structure are commonly represented by its natural frequencies and mode shapes. For every degree of freedom in a linearly elastic structure. there exists a unique natural frequency of vibration and an associated mode shape. It is necessary to obtain these dynamic characteristice if the modal superposition method is used to compute the dynamic response. The structure's fundamental frequency (or period) mily be estimated by the use of code-prescribed approximate formulas, where the period is usually expressed ats a function of building dimensions. When more accuracy is required, computer programs that provide for the automated calculation of natural frequencies and mode shapes must be used. (Calculation by hand usually is practical for only snall buildings.) The model can be fairly simple to very complex. depending on degree of precision desired and complexity of the structural framing system.

Dynamic modal analysis is useful for calculating the linear response of complex. multidegrce-of-frecdom structures. It is based on the fact that the rcsponse of portions of the structure can be superimposed on the responses of the individual natural modes of vibration. each mode responding with its own particular pattern of deformation. the mode shape with its own frequency. the modal frequency with its own mudal damping.

Dynamic analysis makes it possible 10 introduce the concept of structural damping. A structure's response can. therefore, be modeled by the respunse of a number of single-degree-of-freedom oscillaturs with pruperties chosen to be representative of the modes and the degrec to which the mode is excited by the earthquake motion.

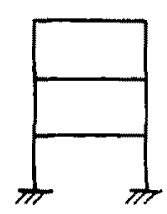

Planar structure
Mathemotical model

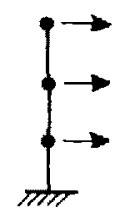

Fig. I Example two-dimensional mathematical model.

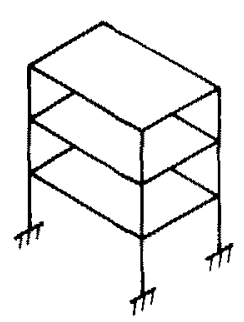

3-D structure

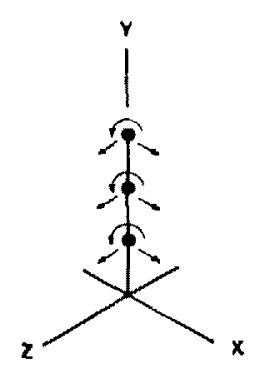

Mothematical model
Fig. 2. -. Example three-dimensionial mathemalical model.

Vumerous full-scale testh and anilyes of carthquake response have shown that use of at dynamic modal analysis with vincously damped single-degree-of freedon oscillators deseribing the response of the structural modes is an accurate approximation of a linear response. A somewhat simplitied mudal analysis prot cedure is presented in Chapter 5 of Reference 4.

In a dynamic analysis, a structure may be modeled as a two-dimensional structure when the structural framing is relatively uniform in one direction. or by a more complex three-dinensional model tsee examples in Figs. I and 2). Regardless of which model is used. the structure's geometry (story heights, biy widths. arrangement of lateral force resisting elements): the properties of the beams, girders, and wills (elatitic moduli, monent of inertia and areits): the distribution of weight in the structure foften lumped an a matss at each story level): and the appropriate damping values must be considered. ${ }^{14,16}$ Damping is a mathematical representation of the energy absorption charateteristics of the building clements and components. Damping results from a number of factors. including sistem damping. which is energy dissipation due to movement of the joint connections in a structure, damping charateleristics of malterials used. and enerey dissipation into supporting soils.

When a dynamic analysis is used. the earthquake input motion must be selected. the mathematical madel developed, and the fundamental matural period of the structure calculated. Most dynamic analyses atssume that the structure is fixed all the base. The etfects of 
the underlying soil on the response of the building should be included when the foundation material is not rock or well-compacted or cemented materials, and if the building structure is relatively stiff in comparison 10 the foundation materials.

After the mathematical model has been formulated, the next step is to apply the specified ground motion by using a digitized accelcration timc history record (one or more) or a response spectrum. A response spectrun is a plot of the peak responses of a family of damped single-degrec-of-freedom oscillators when subjected to a given input motion. The spectrun can be given in acceleration, velocity, or displacement values. However, for must structural design, the acceleration spectrum is used. The analytical techniques used in dynamic analysis are summarized in References 13 through 16.

For all but small buildings, the volume of calculations required makes it mandatory that a computer be used to make the dynamic analysis. Many computer routines are available; however, most of the programs are restricted to elastic problems, i.e., analysis of a building while it is responding linearly and is stressed below yield.

For some structures or facilities it might be beneficial to make an inclastic or nonlinear analysis. Inelastic or nonlinear procedures have bcen developed which can be useful for many buildings. Such analyses require use of acceleration time histories and are quite timeconsuming and expensive to make. (Reference 15 presents one approximate procedurc.) The use of inelastic or nonlinear analysis is generally justified only for

\section{REFERENCES}

\section{Chapter 5}

1. Recommended Lateral Force Requirements and Commentary. Seismology Committee, Structural Engineers Association of California, 1980 ed.

2. Uniform Building Code, International Conference of Building Officials, 1982 ed.

3. Seismic Design for Buildings, ARMY TM 5-809-10, NAVY NAVFAC P-355, AIR FORCE AFM 88-3, Chapter 13, U.S. Departments of the Army, Navy and Air Force, February 1982 ed.

4. Tentative Provisions for the Developmem of Seismic Regulations for Buildings, ATC-3-06, Applied Technology Council, Palo Alto, CA, June 1978.

5. Specification for the Design. Fabrication, and Erection of Structural Steel for Buildings, American Institute of Steel Construction, Inc., Chicago, IL, November 1978.

6. Evolution of Codes and Standards for Earthquake-Resistant Reinforced Concrete Building structures of critical importance.

Dynamic analysis is not a panacea or cure-all, but an extremely powerful tool to estimate the response of a complex structure to dyramic input motion. Its use is generally not justified for the simpler, smaller buildings or for symmetrical buildings, except for those that are multistory, say four or five stories or more. When a dynamic analysis is proposed, an approximate check should be made of structural stresses and moments using manual calculations and equivalent lateral force procedures. Any significant differences between the results of manual calculations and the computer dynamic analysis should be examined; and if the results of the dynamic analysis cannot be explained, the analysis should be reviewed in detail.

Generally the outputs from a dynamic analysis are the seismic shears, overturning moments, and deflections at each floor. After the dynamic analysis is completed, the values of story shear, moment, and deflection for the various modes must be combined. A generally accepted method is to take the squarc root of the sum of the squares of the modal quantitics. This method generally gives satisfactory results; however. it is not always conservative, inasmuch as more adverse combinations of modal quantities could occur than are given by this method. This is particularly true when two modes have very nearly the same natural period. The values from analyses can be employed in the design, following the same methods applied in the equivalent lateral force procedure, using appropriate allowable stresses based on ultimatc-strength design procedures.

Construction, Sharpe, Roland L., Procecdings of Workshop on Earthquake-Resistant Reinforced Concrete Building Construction, University of California, Berkeley, CA 1977.

7. ACI Workshop - Seismic Design of Concrete, by Sharpe, R. L., and E. Elsesser, American Concrete Institute Annual Convention, San Dicgo. CA, April 1977.

8. An Evaluation of Seismic Design Provisions for Masonry in the United States, University of California Earthquake Engincering Research Center, Report 81-10.

9. National Design Specification of Stress-Grade Lumber and Its Fastenings. National Forest Products Association, 1977.

10. The Interaction of Building Components Durin Earthquakes, McCue Boone Tomsick and Engii. $\because$ ing Decision Analysis Company, Inc., National Scr. ence Foundation Grant Research Report, January 1978.

11. Architectural Design of Building Components for Earthquakes, MBT Associates, National Science 
Foundation Research Grant Report, San Francisco, CA, 1978.

12. "Needed: Seismic Design of Mechanical and Electrical Equipment," Sharpe, R. L., and R. Gallagher, Building Standards, September-October, 1972.

13. Earthquake Engineering, Wiegel, R. L. (ed.), Prentice-Hall, Inc., 1970.

14. "Behavior of Structural Systems Under Dynamic Loads," Sharpe, Roland L.; G. Kost, and J. Lord, Building Practices for Disaster Mitigation, Building Science Series 46, National Bureau of Standards,
February 1973.

15. "Procedures and Criteria for Earthquake-Resistant Design (Part II)," Newmark, N. M., and W. J. Hall, Jr., Building Practices for Disaster Mitigation, Building Science Series 46, National Bureau of Standards, February 1973.

16. Dynamics of Structures, Clough, R. W. and J. Penzien, McGraw-Hill Book Company, 1975.

17. Building Configuration and Seismic Design. Arnold, C. and Reitherman, Robert, John Wiley \& Sons, New York, 1982.

\section{APPENDICES}

\section{CONTENTS}

A Excerpts from the Uniform Building Code UBC), 1982 Edition; Contents

B "Discontinuities in Strength of Vertical

Resisting System," Sec 3.7.3, Tentative

Provisions for the Development of Seismic

Regulations for Buildings, ATC-3-06,

Applied Technolngy Council, Palo Alto.

CA, June 1978.

C "Ductile Concrete Space Frames," Part

VII-A, Seismic Design of Concrete.

American Concrete Institute (ACI) Workshop

Report. San Diego, CA, April 1977.

D “Architectural Design Requirements,"

Sec. 8.2, Tentative Provisions for the

Development of Seismic Regulations for

Buildings, ATC-3-06, Applied Technology

Council, Palo Alto, CA, June 1978. 
Chapter 5

\title{
APPENDIX A
}

\author{
Excerpts from \\ Uniform Building Code (UBC) \\ 1982 Edition \\ Published by: International Conference of Building \\ Oflicials (ICBO)
}

$\begin{aligned} \begin{array}{c}\text { Chapter } 18 \\ \text { Section }\end{array} & \\ 1807 & \text { (a), (k) } \\ \text { Chapter } 23 & \\ \text { Section } & \\ 2303 & \text { (a) through (f) } \\ 2308 & \text { (b) } \\ 2310 & \\ 2312 & \text { (a) through (k) } \\ & \text { Tables 23-I, 23-J } \\ & \text { Table 23-K } \\ & \text { Seismic Zone Maps }\end{aligned}$ 


\title{
Chapter 5
}

\section{APPENDIX A}

\author{
Excerpts \\ from \\ Uniform Building Code (UBC) \\ 1982 Edition
}

\section{Special Provisions for Group B, Diviaion 2 Otfice Buildings and Group R, Divlaion 1 Occupancies}

Sec. 1807. (a) Scop.. This section shall apply to all Group B, Division 2 office buildings and Groun R. Diviswn 1 Occupancies, each having foors uxed for human necupancy locited more than 75 feet atoove the lowest level of firs department vehicle access. Such buildings shull be provided with either un approved uutomatic sprinkler system in accordance with Section IBO7 (c), or safe areas of refuge (compartmentation) in accordance with Section $18(07$ (1).

(k) Seismic Considerations. In Susmuc Zones No, 2, No. 3 and No, 4, the anchorage of mechanical and electrical equipment tequired for life safely sys tems, including fire pumps and elevaltor drive and suspension systems, shall be designed in atcordante with the requirements of Section 2312

\section{Dealgn Methods}

Sec. 2303. (a) General. All buildings and portions thereof shall he designed and constructed to sustuin, within the stress limitations specified in this code, ill dead lrads and all other loads specified in this chapter or elsewhere in this code. Impact loads shall te considered in the design of uny structure where impact loads oceur.

EXCEPTION: Unless otherwise required by the builung official, buildings or portions thereof which are constructed in accordance with the conventional framing requarements specified in Chapte: 25 of this code shall be decmed to neet the requirements of this stetion

(b) Rafionality. Any system or metiod of construction to be used shatl be bused on a rational analysis in accordance with well-eslablished principles of mechanics. Such analysis shall result in a system which provides a complete load patb capable of transferring all loads and forces from their point of origin to the lond-resisting elements. The analysis shall include but not be limited to the following:

1. Distribution of horizonlat shear. The total titeral forec shall be distributed to the various vertical elements of the lateral force-resisting system in proportion to their rigiditics considering the rigidity of the horizontal bracing system or diaphragm. Rigid elements that are assumed not to be part of the lateral forceresisting system may be incorporated into buildings, provided that their effect on the astion of the system is considered and provided for in the design.

2. Forizontal torsional moments. Provision shall be made for the inereased forces induced on resisting clements of the struclurul system resulting from torsion due to eccentricity between the center of application of the lateral forces and the center of rigidity of the lateral force-rcsisting system. Forces shall not be decreased due to torsional $\mathrm{c}$ ffects. For accidental torsion requirements for seismic design, see Section 2312 (e) 4 .

3. Stability against overturning. Every building or structure shall bo designed to resist the overturning effects caused by the lateral forces specified in this chapter. Sec Section 2311 (c) for wind and Section 2312 if for seismic

4. Anchorage. Anchorage of the roof to walls und columns, and of walls and columns to foundations, shall be provided to resist the uplift and sliding forces which result from the application of the prescribed forces. For additional requirements for masonry or concrete walls, see Section 2310.

(c) Critical Distribution of Live Loads. Where strueturial members are arranged so as to creute continuity. the loading conditions which would cause muximum shear and bending moments along the member shall be investigated

(d) Stress Increases. All allowible stresses and soil bearing values specified in this code for working stress design may he increased one-third when considering wind or earthquake forees either acting alone or when combined with vertical loads. No increase will be allowed for vericical loads actıng alone

(c) Load Factors. Load factors for ultımate strength design of concretc and plastic design of stecl shall be is indicated in the appropriate chapters on the matcrials.

(f) Load Combinations. Every building eomponent shall he provided with strength adequate to resist the most critical effect resulting from the following combination of loads fller live load shall not be included where its inclusion results in lower stresses in the memher under investigation):
1. Dead plus tloor live plus roof live (or snou ).

2. Dead plus foror live plus wind rer seismic)

3. Dead plus rind live plus wind plus anew/2 ।

4. Dead plus 17su lave plus snou plus tind/2 1

5. Dead plus 'he at live plus snow' plus semmic

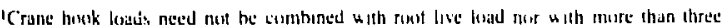

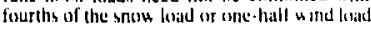

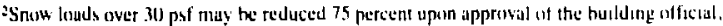

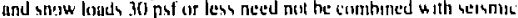

\section{Special Design}

Sec. 2308.

(b) Retaining Walls. Retaining walls shall be designed to resst the laterat pressure of the retained material in accordance with accepted engineering pric tice. Walls retaining drained earth may be designed for pressure equivalent to that exerted by a fluid weighing not less than 30 pounds per cubic foot and having a depth equal to that of the retuined earth. Any surcharge shall be in addition to the equivalent fluid pressure.

\section{Anchorage of Concrete or Masonry Walls}

Sec. 2310. Conirece or masunry walls shall be anchored wall thanr and routs which provide lateral support for the wall. Such anchorage thall proside a positive diret connection capable of resisting the horizontal forces spectited it

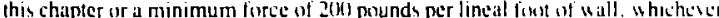
is greater. Walls shall be designed to renst bending between anchors where the anchor spicing exceeds 4 feet. Requared anchors in masonrs $H_{\text {all }}$ af hollow unt or cavity walls shall be emtedded in at reintenced grouled structural clement th the wall. See Sections 2312 (j) $2 \mathrm{C}$ and 2312 (1) $3 \mathrm{~A}$

\section{Earthquake Regulations}

Sec. 2312. (a) General. Every building or structure and every portion thereof shall be designed and constructed to resist stresses produced by lateral forces at provided in this section. Stresses shall be calculated as the effect of a force applied horizontally at each floor or roof level above the base. The force shall be assumed to come from any horizontal direction.

Structural concepts other than set forth in this section may be approved by the building official when evidence is submitted showing that equivalent ductility and energy absorption are provided.

Where prescribed wind loads produce higher stresses, such loads shall be used in lieu of the loads resulting from carthquake forces

(b) Definitions. The following definitions apply only to the provisions of this section

BASE is the level at which the earthyuake motions are considered to be imparted to the structure or the level at which the structure as a dy namic vibrator is supported.

BOX SYSTEM is a structural system without a complete vertical louscarrying space frame. In this system the required lateral forces are resisted by shear walls or braced frames as hereinafter defined.

BRACED FRAME is a truss system or its equivalent which is provided to resist lateral forces in the frame system and in which the members are subjected pimurily to axial stresses.

DUCTILE MOMENT-RESISTING SPACE FRAME is a moment-resisting space frame complying with the requirements for a ductile moment-resisting space frame as given in Section 2312 (j)

ESSENTIAL FACILITIES-Sec Section $2312(k)$

LATERAL FORCE-RESISTING SYSTEM is that part of the structural system assigned to resist the lateral forces prescribed in Section 2312 (d)

MOMENT-RESIST ING SPACE FRAME is a vertical load-cartying space frame in which the members and joints are capable of resisting forces primarily by flexure 
SHEAR WALL is a wall designed to resist lateral forces parallel to the wall. SPACE FRAME is a threc-dimensional structural system without bearing walls, composed of interconnected members laterally supported so us to function as a complete self-contained unit with or without the aid of horizontal diaphragms or floor-bracing systems.

VERTICAL. LOAD-CARRY ING SPACE FRAME is a space frame designed to carry all vertical loads

(c) Symbols and Notations. The following symbols and notations apply only (i) the provisions of thic section:

c. - Numerical coteficient as specilied an Sectim 2312 ad

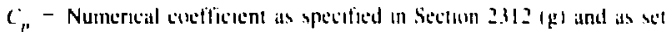
forth in Titble No. 21. 1

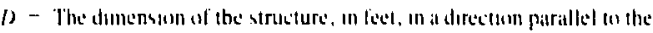
applica forces

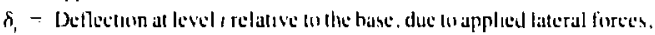
Y f, fur use in formula (I2-3).

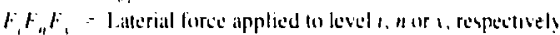

$f_{p}-$ Lateral fiesces an at part of the strucitere and an the derectem under Limsuderillmul.

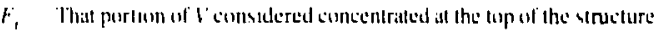
In indition to $\%$ "

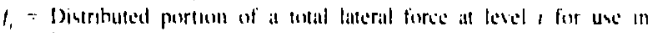
Firmula $(12-3)$

g - Acceleration due to gravity

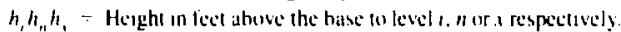

1. Occupaniv Importance Fuctor as sct lorth in Table No. $23 \cdot \mathrm{K}$

$K$ - Nimerical coneflicient as set torth in Tible $\mathrm{N}_{0} 23.1$.

Level,

1 level al the structure refierred to by the suhscript

1.- 1 desengates the first level ahove the base

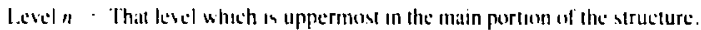

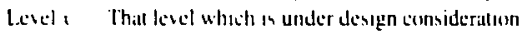

1 - I dengenales the first level abuve the hase.

$v$ - The tutal number of vteries above the base to level $n$

s. Numerscal coreflicent for ste-structure resonance

$T=$ Fundamental elastic period of vibration of the building or structure in seconds in the direction under consideration.

$T_{1}=$ Characteristic sitc period.

$V=$ The total lateral force or shear at the base.

$W=$ The total dead load as defined in Section 2302 including the partition loading specified in Section 2304 (d) where applicable.

EXCEPTION: $W$ shall be equal to the total dead load plus 25 percent of the floor live load in storage and warebouse oceupancies. Where the design snow load is 30 psf or less, no part nead be included in the value of $W$. Where the snow load is greater than 30 psf, the snow load shall be included; however, where the snow load duration warsants, the truilding official may altow the snow load to be reduced up to 75 percent.

$w_{1} w_{1}=$ That portion of $W$ which is located at or is assigned to tevel $i$ or $x$ respectively.

$W_{p}=$ The weight of a portion of a structure or nonstructural component.

$Z=$ Numerical coefficient dependent upon the zone as determined by Figures No. 1, No. 2 and No. 3 in this chapter. For locations in Zone No. $1, Z=1 / 16$. For locations in $Z$ one No. $2, Z=3 / 8$. For locations in Zone No. $, Z, Z=1 / 4$. For locitiuns in Zone No. $4, Z=1$

(d) Minimum Earthquake Forces for Structures. Except as provided in Section 2312 (g) and ( $i)$, every structure shall be designed and constructed to resist minimum total lateral seismic forces assumed to act nonconcurrently in the direction of each of the main axes of the structure in accordance with the following formula:

$$
V=z I K \operatorname{cs} W
$$

The value of $K$ shall be not less than that set forth in Table No. 23-1. The value of $C$ and $S$ are as indicated hereafter except that the product of $C S$ need not exceed 0.14 .

The valuc of $C$ shall be determined in accordance with the following formula:

$$
C=\frac{1}{15 \sqrt{T}}
$$

The value of $C$ need not exceed 0.12 .

The period $T$ shall be established using the structural properties and deformational characteristics of the resisting elements in a properly substantialcd analysis such as the following formula:

$$
T=2 \pi \sqrt{\left(\sum_{i=1}^{n} w_{1} d_{i}^{2}\right) \div\left(g \sum_{i=1}^{n} f_{i} \delta_{i}\right)}
$$

where the values of $f_{i}$ represent any lateral force distributed approximately in accordance with the principles of Fonnulas (12-5), (12-6) and (12-7) or any other rational distribution. The elastic deflections, $\delta_{1}$, shall be calculated using the applied lateral forces, $f_{t}$.

In the absence of a determination as indicated above, the value of $T$ for buildings may be determined by the following formula:

$$
T=\frac{0.05 h_{n}}{\sqrt{D}}
$$

Or in huildings in which the buteral forct-resisting systen consists of ductile moment-resisting space frames capable of resisting 160 percent of the required laseral fores and such system is not enclosed by or adjoined by more rigid elements tending to prevent the frame from resisting lateral forces:

$$
T=0.10 \mathrm{~N} \text {. }
$$

The value of $S$ shall be determined by the following formulas, but shall be not less than 1.0:

$$
\text { for } T / T_{1}=1.0 \text { or less } S=1.0+\frac{T}{T_{A}}-0.5\left[\frac{T}{T_{1}}\right]^{2}
$$

for $T / T_{1}$ greater than 1.0 or less $S=1.2+0.6 \frac{T}{T_{1}}-0.3\left[\frac{T}{T_{1}}\right]^{2} \ldots(12-4 \mathrm{~A})$

WHERE:

$T$ in Enrmulas (12-4; axi (12-4A) shall be established by a properly substuntiated analysis out $T$ suall be not less than 0.3 second.

The range of values of $T$, may be established from properly substantiated geotechnical data, in accordance with U.B.C. Standard No. 23-1, except that $T$, shall not be taken as less than 0.5 second nor more than 2.5 seconds. $T$, shall be that value within the range of site periods, as determined above. that is nearest to $\tau$.

When $T_{s}$ is not properly established, the value of $S$ shall be 1.5 .

EXCEPTION: Where $T$ has been established hy a properly substantiated anuly. sis and exceeds 2.5 seconds, the value of $S$ may be determined by assuming i value uf 2.5 seconds for $T$.

(e) Distribution of Lateral Forces. 1. Structures having regular shapes or framing systems. The total lateral force $V$ shall be distributed over the height of the structure in accordance with Formulas (12-5), (12-6) and (12-7).

$$
r=F_{1}+\sum_{1}^{n} F_{1}
$$

The concentrated force at the top shall be detcrmined according to the following formula:

$$
F_{i}=0.07 \pi
$$

$F$, need not exced $0.25 \mathrm{~V}$ and may be considered as 0 where $T$ is 0.7 second or less. The remaining portion of the total hase shear $V$ shall be distribuled over the height of the structure including level $n$ according to the following formula

$$
\text { r. } \sum_{i=1}^{n}\|,\|, h,
$$

At each level designited as $x$, the force $F$, shall twe applied over the area of the bulding in accordance with the mass distribution on that level

2. Setbacks. Buildings having serbacks wherein the plan dimension of the tower in each direction is at least 75 percent of the corresponding plan diniension of the lower part may be considered as uniform buildings without setbacks. provided other irregularities as defined in this section do not exist.

1. Structures having irregular shapes or fram.ing systems. The distrihution of the lateral forces in structures which have highly irregular shapes, large differences in lateral resistance or stiffness between adjacent stories, or other unusual structural feutures, shall be determined considering the dynamie characteristics of the structure.

4. Accidental torsion. In additinn to the requirements of Section 2303 (b) 2. where the vertical resisting elements depend on diaphragm actinn for shear distribution at any level, the shear-resisting elements shall be capable of resisting a torsional moment assumed to he equivalent to the story shear acting with an cecentricity of not less than 5 percent of the miximum building dimension at that level. 
(f) Overturning. Al any level the increncental changew of the desyn werturning monent, in the story under consideration, shall be destrthuted to the varsous resisting elements in the same proportion an the distributen of the shear in the resisting systent. Where other vertical members are provided which are capalnde of purtially resisting the wyerluming moments. a redistribution may be mide to

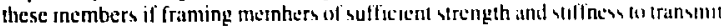
the required loads are provicled

Where a vertical reststing clement is discontinusus, the werturmang moment

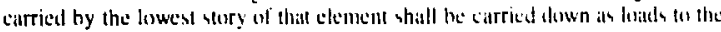
foundation

(g) Lateral Forcc on Elements of Siructures and Nonstructural Components. Parts or portions of structures, nonstructural components and thetr anchorage to the main structural system shall be deaigned for lateral forees in uceordante with the following formula.

$$
F_{r}=Z I C_{r} W_{r}
$$

The values of $C_{p}$ are set forth in Table Na. 23-J. The value of the / coefficient shall be the value used for the huilding.

EXCEPTIONS: 1. The value of $I$ for punel connectors shull be us given in Section 2312 (j) $3 \mathrm{C}$

2. The value of $/$ for anchoruge of inachnery and equipment required for life safety systems shall be 1.5

The distribution of these forces shalt be according to the gravity loads pertaining thereto.

For applicable forces on diuphragms and connections for exterior panels, refer to Sections 2312 (j) $2 \mathrm{C}$ and 2312 (j) $3 \mathrm{C}$

(h) Drift and Building Separations, Luteral deflections or drift of a story relative to its adjacent stories shall not exceed 0.005 times the story height unless it can be demonstrated that greater drift can be tolerated. The displacement calculated from the application of the required lateral forces shall be multiplicd by $(1.0 / K)$ to obtain the drift. The ratio $(1.0 / K)$ shall be not less than 1.0

All portions of structures shall be designed and constructed to act as an integral unit in resisting horizontal forces unless sepurated structurally by a distance sufficicnt to avoid contact under deflection from seismic action or wind foress

(i) Alternate Determination and Distribution of Seismic Forces. Nothing in Section 2312 shall be decmed to prohibit the submission of properly substantiated technical data for establishing the lateral forces and distribution hy dynamic analyses. In such analyses the dynamic characteristics of the structure must be considered.

(j) Structurai Systems. I. Ductility requirements. A. All buildings designed with a horizontal force factor $K=0.67$ or 0.80 shall have ductile moment resisting space frames.

B. Buildings more than 160 feet in height shall have ductile moment-resisting space frames capable of resisting not less than 25 percent of the required seismic fnrees for the structurc as a whole.

EXCEPTION: Buildings more than 160 feet in height in Seismic Zones Nos. and $\mathbf{2}$ may have concrete shear walls designed in uccordance with Section 2627 or braced frames designed in conformance with Section 2312 (j) $1 \mathrm{G}$ of this code in liu: of a ductile moment-resisting space frame, provided a $K$ value of $I .00$ or $I 33$ is utilized in the design.

C. In Seismic Zones No. 2, No. 3 and No. 4 all concrete spuce frumes required by design to be part of the lateral force-tesisting system und all concrete frumes located in the perimeter line nf vertical support shall be duetile moment-resisting space frames.

EXCEPTION: Frames in the perimeter line of the vertical support of building designed with shear walls taking 100 percent of the design lateral forces need only conform with Section 2312 (j) iD.

D. In Seismic Zones No. 2, No. 3 and No. 4 all framing elements not required by design to be part of the lateral force-resisting system shall be investigated and shown to be adequate for vertical load-carrying capacity and induced noment due to $3 / K$ times the distortions resulting from the code-required lateral forces. The rigidity of other elements shall be considered in accordance with Section 2303 (b) 1 .

E. Moment-resisting space frames and ductile moment-resisting space frames

may be enclosed by or adisined by more rigid elements which would tend to prevent the space frame f $r^{\prime}$, m resisting lateral forces where it can be shown that the action or failure of the more rigid elements will not impuir the vertical and lateral load-resisting ability of the space frame.

F. Necessary ductility for a ductile moment-resisting space frame shall be provided by a frame of structural stee) with moment-resisting connections (complying with Section 2722 for buildings in Seismic Zones No. 3 and No, 4 or Section 2723 for buildings in Seismic Zones No. 1 and No. 2) or by a reinforced concrete frame (complying with Section 2625 for buildings in Seismic Zones No.

3 and No. 4 or Section 2626 for buildings in Seismic Zones No. 1 and No. 2).

EXCEPTION: Buildings with ductile moment-resisting space frames in Seismic Zones No. 1 and No. 2 having an importance factor $/$ greater than 1.0 shall comply with Section 2625 or 2722

G. In Scismic Zones No. 3 and No. 4 and for buildings having an importance fuctor / greater than 1.0 located in Seismic Zone No. 2, all members in hraced frames shall be designed for 1.25 times the force determined in accordance with Section 2312 (d). Connections shall be designed to develop the full capacity of the members or shall be based on the above forces without the one-third increast usually permitted for stresses resulting from earthquake forces.

Braced frames in buildings shall be composed of axially loaded bracing members of A.36, A441, A.500) Grades $B$ and C. A.50), A.572 (Grudes 42, 45, 50 and 55) or A588 structural stecl, or reinforced concretc members conforming to the requirements of Section 2627

H. Reinforced concrete shear walls for all buiddings shall conform to the requirements of Section 2627

I. In structures where $K=0.67$ and $K=0.8()$, the special ductlity require ments for structural stecl or reinfored concrete specified in Sectun 2312 ij $/ \mathrm{F}$, shall apply to all struclural elements below the base which are required to transmit to the foundation the forces resulting from lattral louds.

2. Design requirements. A. Minor alterations. Minor structurul alteration may be made in existing buildings and other structures, but the resistance to lateral fores shall be not less than before such alterations were made, unless the hutding us altered mets the requirements of this section.

B. Reinforced masonry or concrete. All elements withın struclures loculed in Seismic Zones No. 2, No. 3 and No, 4 which are of masonry or eoricrete whall bx reinforced so as to qualify as reinforeed musonry or cunstete under the provisums of Chapters 24 and 26. Prineipal reinforeement in musunry shall be spaced 2 feet maximum on center in buildings using a moment-resisting space frame

C. Diaphragms. Floor und roof diaphragms and collectors shall to designed to resist the forces determinc $:$ in accordance with the following formula:

$$
F_{p t}=\frac{\sum_{i=x}^{n} F_{i}}{\sum_{i=x}^{n} w_{i}}
$$

WHERE:

$F_{1}=$ the lateral force applicd to level $l$.

$w_{1}=$ the portion of $W$ at level $l$

$w^{\prime}=$ the weight of the diaphragm and the elements tributary thereto at level $x$. including 25 percent of the floor live load in storage and wirchousc occupancics.

The force $F_{m}$ determined from Formula $(12.9)$ need not exceed $0.30 Z / \mathrm{m}$,

When the diaphragm is required to tuansfer lateral forces from the vertical resisting elements above the diaphragm to other vertical resisting clements belou the diaphragm due to offsets in the placement of the elements or to changes in stiffness in the vertical elenents. these forces shall be added to those determined from Formula (12-9).

However, in no case shall lateral forec on the diaphragen he lest than $0.14 Z / w_{p r}$

Diaphragms supporting concrete or masonry walls shall have continuous ties between diaphragm chords to distribute, into the diaphragm, the anchorage forces specified in this chapter. Added chords muy be used to form suhdiaphragms to transmit the anchorage forces to the main cross ties. Diaphragm deformations shall be consideted in the design of the supported walls. See Section 2312 (j) 3 A for special anchorage requitements of wood diuphragms.

3. Special requirements. A. Wood diaphragms providing lateral support for concrete or masonry walls. Where wood diaphragms are used to laterally support concrete or masonry walls the anchorage shall conform to Section 2310 In Zones No. 2. No. 3 and No. 4 anchorage shall not be accomplished by use of toenails or nails subjected to withdrawal; nor shall wood framing be used in crossgrain bending or cross-grain tension.

B. Pile caps and caissons. Individual pile caps and caissons of every huilding or structure shall be interconnected by ties, each of which can carry by tension and compression a minimum horizontal foree equal to 10 percent of the larger pile cap or caisson loading, unless it can te demonstrated that equivalent restruint can be provided by other approved methods.

C. Exterior elements. Prccast or prefabricuted nonbsaring, nonshear wall panels or similar elcments which are attached to or enclose the exterior shall be designed to resist the forces determined from Fomula $(12-k)$ and shall accommo. date movements of the structure resulting from lateral forces or temperature changes. The concrete panels or other similar elements shall be supported by menns of cast-in-place concretc or mechanical connections and fasteners in accordance with the following provisions

Connections and panel joints shall allow for a relative movement hetween stories of not less than two times story drift caused by wind or $(3.0 / K)$ times the calculated elastic story displacement caused by required scismic forces. or $1 / 2$ inch, whichever is greater. Connections to permit moventent in the plane of the panel for story drift shall be properly designed sliding connections using slotied or oversized holes or may be connections which permit movement by bending of stecl or other connections providing equivalent sliding and ductility capacity 
Bodies of connectors shall have sufficient ductility and rotation capacity so as to preclude fracture of the concrete or brittle failures at or near welds.

The body of the connector shall be designed for one and one-third times the force determined by Formula $(12-8)$. Fasteners attaching the connector to the panel or the structure such as bolts, inserts, welds, dowels, tetc , shall be designed to ensure ductile behavior of the connector or shall be designed for four times the load determined from Formula (12-8),

Fasteners embedded in concrete shall be attached to or hooked around reinforeing steel or otherwise terminated so as to effectively transfer forces to the reinforcing steel.

The value of the coefficient / shall be 1.0 for the entire connector assembly in Formula (12-8)

(k) Essential Facilities. Essential facilities ure those stnuctures or buyldings which must be safe and usable for emergency purposes after an earthquake in order to preserve the health and safety of the general public. Such facilities shall include but not be limited to:

1. Hospitals and other medical facilities having surgery or emergency treatment areas.

2. Fire and police stations.

3. Municipal government disaster operation and communication centers deemed to be vitul in emergencies.

The design and detailing of equipment which must remain in place and be functional following a major earthquake shall be based upon the requirements of Section $2312(\mathrm{~g})$ and Table No. 23-J. In addition, their design und detailing shull consider effects induced by structure drifts of not less than $(2.1) / K)$ tumes the story drift caused by required seismic forces nor less than the story drift caused by wind. Special consideration shall $\$$ !so be given to relative movements at separation joints.
TAELE NO. 23--HORIZONTAL FORCE FACTOR K FOR BUILDINGS OH OTHEA STRUCTURES

\begin{tabular}{|c|c|}
\hline TY?E OR ARAANGEMENT OF RESISTING ELEMENTS & $\begin{array}{c}\text { VALUE } \\
K\end{array}$ \\
\hline I All butlding framing systems except as herenatter classified & 100 \\
\hline 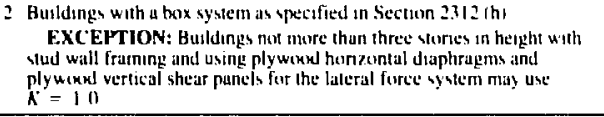 & 133 \\
\hline 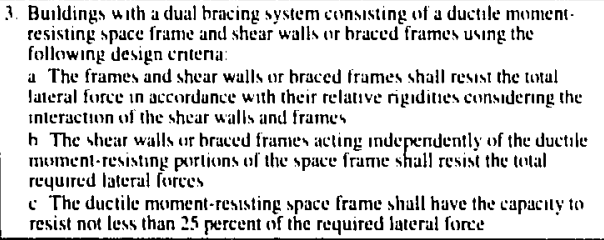 & 1180 \\
\hline 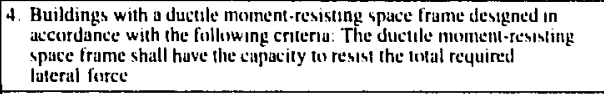 & 1167 \\
\hline $\begin{array}{l}\text { 5. Eleveted lanks plus full conlents. on fout or more cross-bruced legs and } \\
\text { nut supporled by a building }\end{array}$ & $2.5^{4}$ \\
\hline $\begin{array}{l}\text { 6. Structures other than hulluings and other than those set forth in Tible } \\
\text { No. 23 J }\end{array}$ & $2 .(x)$ \\
\hline
\end{tabular}

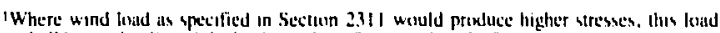

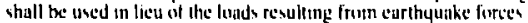

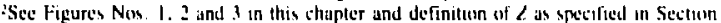
2., 2 (c).

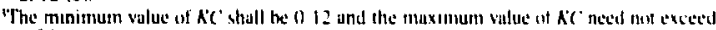
0,25

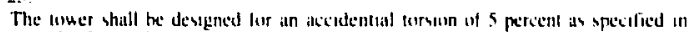

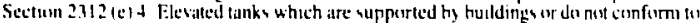
ivpe ir arrangement al supporting elements is descrited atweve thall he designed in accordince with Sectum ? 31 ? $(2)$ using $c^{\circ}=$;

TABLE NO. 23-K-VALUES FOA OCCUPANCY IMPOATANCE FACTOA 1

\begin{tabular}{|l|c|}
\hline \multicolumn{1}{|c|}{ TYPE of OCcupancy } & 1 \\
\hline Essential facilities' & 1.5 \\
\hline $\begin{array}{l}\text { Any butlding where the primary (xcupancy is for assembly use } \\
\text { for more than } 300 \text { persons (in one rom) }\end{array}$ & 125 \\
\hline All others & 1.0 \\
\hline
\end{tabular}

'See Section 2312 ( $k$ ) for definition and udditional requirements for essential tacilicies
TABLE NO 23-J-HOAIZONTAL FORCE FACTOR $c_{p}$ FOA ELEMENTS OF STRUCTURES AND NONSTRUCTURAL COMPONENTS

\begin{tabular}{|c|c|c|}
\hline PART OR PORTION OF BUILDWAS & $\begin{array}{l}\text { DAECTION OF } \\
\text { HORLONTAL } \\
\text { FOACE }\end{array}$ & of $c_{g}^{1}$ \\
\hline $\begin{array}{l}\text { 1. Exterior bearing and nonbearing walls, interior } \\
\text { bearing walls and partitions, interior nonbearing } \\
\text { walls and partitions-see also Section } 2312 \text { (j) } 3 \mathrm{C} \text {. } \\
\text { Masonry or concrete fences over } 6 \text { feet high }\end{array}$ & $\begin{array}{l}\text { Normal to } \\
\text { flat } \\
\text { surface }\end{array}$ & 0.36 \\
\hline $\begin{array}{l}\text { 2. Cantilever elements: } \\
\text { a. Parapets }\end{array}$ & $\begin{array}{l}\text { Nomal to } \\
\text { flat } \\
\text { surfaces }\end{array}$ & \multirow{2}{*}{0.8} \\
\hline b. Chimneys or stacks & $\begin{array}{c}\text { Any } \\
\text { direction }\end{array}$ & \\
\hline $\begin{array}{l}3 \text { Exlerior and interior omnmentations and } \\
\text { appendages }\end{array}$ & $\begin{array}{c}\text { Any } \\
\text { direcrion }\end{array}$ & 0.8 \\
\hline $\begin{array}{l}\text { 4. When connected to, part of, or housed within } 4 \\
\text { building: } \\
\text { a. Penthouses, anchorage and supports for } \\
\text { chimneys, stacks and tanks, including contents } \\
\text { h. Storage racks with upper storage level at more } \\
\text { than } 8 \text { feet in height, plus contents } \\
\text { c. All equipment or machinery }\end{array}$ & $\begin{array}{c}\text { Any } \\
\text { direction }\end{array}$ & 0.321 \\
\hline $\begin{array}{l}\text { 5. Suspended ceiling framing systems (upplies in } \\
\text { Seismic Zones Nos. 2, } 3 \text { and } 4 \text { only)-see alco } \\
\text { Section } 4701 \text { (c) }\end{array}$ & $\begin{array}{c}\text { Any } \\
\text { direction }\end{array}$ & $0.3^{47}$ \\
\hline $\begin{array}{l}\text { 6. Connections for prefubricated structural elements } \\
\text { other than walls, with forec applied al center of } \\
\text { gravity of assembly }\end{array}$ & $\begin{array}{c}\text { Any } \\
\text { direclion }\end{array}$ & $0.3^{5}$ \\
\hline
\end{tabular}

${ }^{\prime} C_{p}$, for elements laterally self-supporte: only at the ground level may to lwo therds of value shisun

: $W_{n}$ for sforage racks shall he the weight of the racks ples comtents The value of $C_{n}$ for facks over two storage support levels on height shall he 0 24 for the levels hetow the lop (wo levels In lieu of the tahulated values steel storage racks may he designed in accordance Hith U.B C. Standard No1 27.11

Where a numiber of storage rack units are intereonnected so that there are a minimum of feur vertical clements in each direcitun on sach column line designed in resist horizontal forecs, the design cerefficients muy be is for $a$ huilding with $K$ yalues from Table No. 21-1. $C S=0.2$ for use in the formula $V=2 I K C S W^{\prime}$ and $W$ equal an the unal dead losd plus 50 percent of the rack-rated capacity Where the despen and rack configuratinns are in accordance with thes paragraph. the design provesions in L: B.C Standard No 27.11 do not apply.

For flexible and flexibly mounted eyurpment and machinery. the approprate values of $C_{0}$ shall be detemuned with consideratun given wo hoth the dynamic properties of the eyuipment and machenery and lot the huldong or structure in which it is placed but shall be not less than the listed values. The design ot the eyusmient and machinery and their ancherage is att entegral part of the design and apecificatton of such eyupment and masionry

For essential facilities and life sufety sysems, the design and detuling af eyupment which must remain in place and te funclitinal follewing a majur earthyuake shall eomsider Jnfts in accordinte with Section $2312(k)$

Ceiling weight shall include alt light fixtures and other equipment which is laterally supported by the ceiling For purposes of determining the lateral force, a ceiling weight of nok less than 4 pounds per squarc fool shall be used

sThe force shall be resisted by positive anchorage ard not hy friction

oSee also Scction 2.309 (b) for minimum load and callection criteria for intenor partitions.

'Dres not apply to ceilings constructed of lath and plastet or gypsum board screw ot nal! attached to suspended members that support a celling at one level extending from watl to wall 
Chapter 5, Appendix A (Continued)

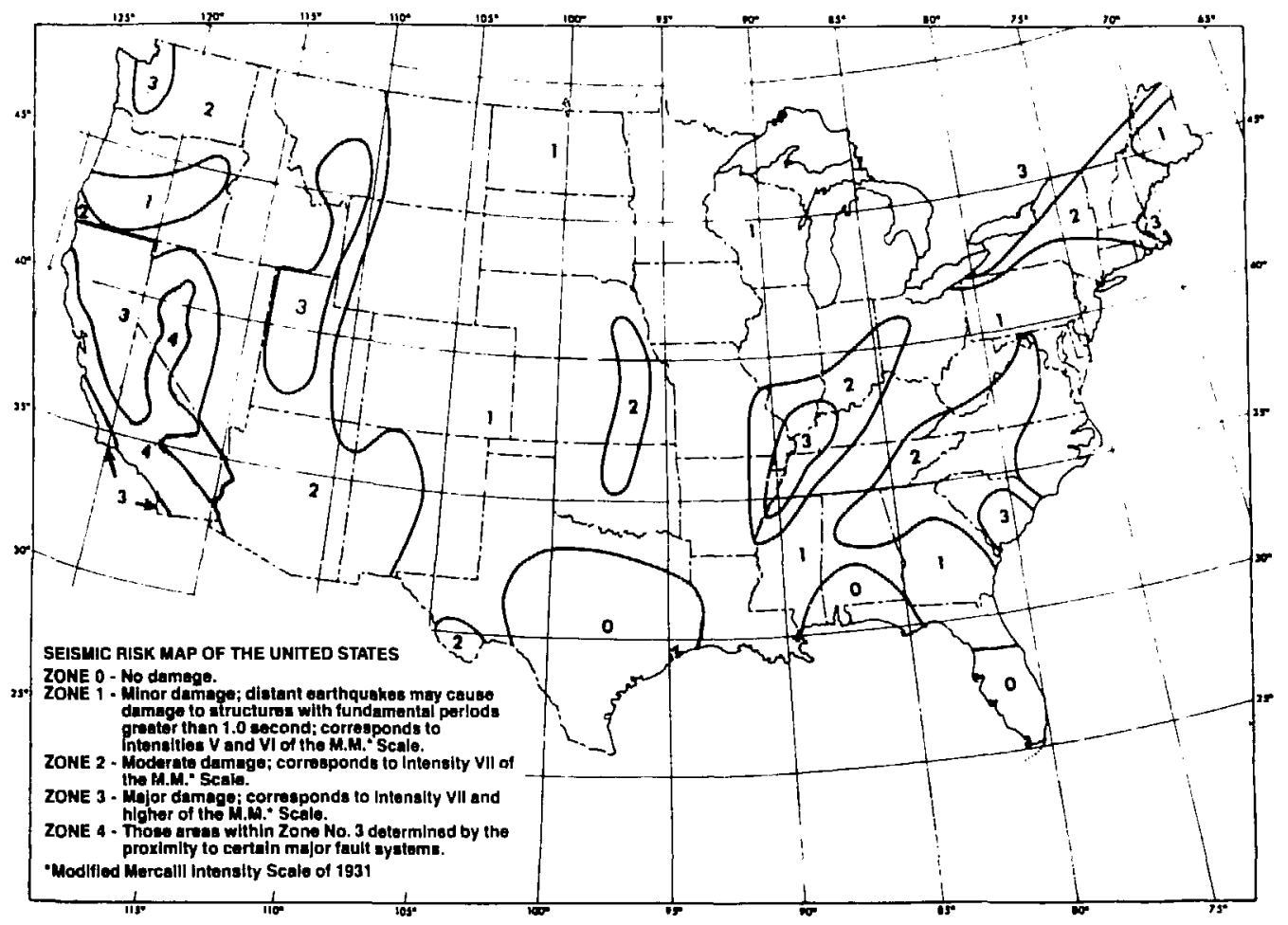

Fig. 3 - Seismic Zone Map of the Cnited States mainland -.. Uniform Building Code (UCB) 1982 - International Conference of Building Officials.

Fig. 4-Seismic Zone Map of Alaska.

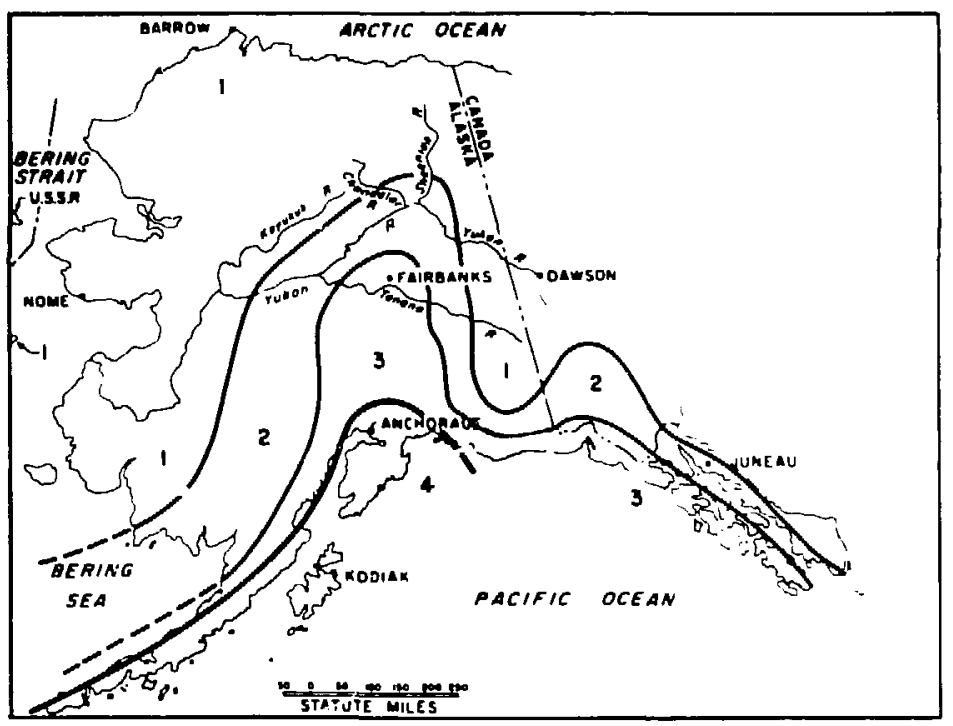


Chapter 5, Appendix A (Concluded)

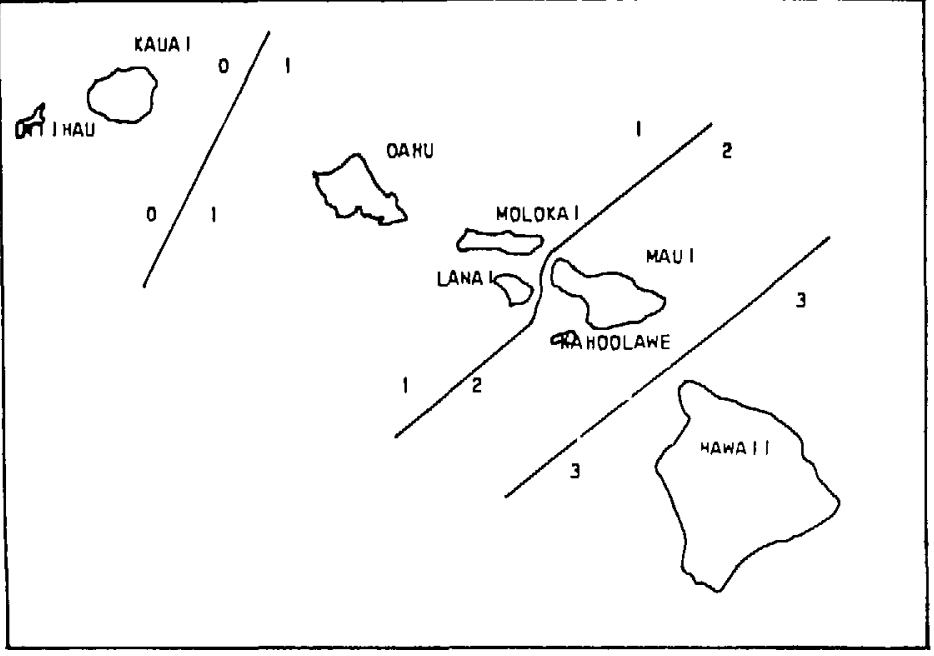

Fig. 5 - Seismic Zone Map of Hawaii.

Fig. 6- Basic Wind Speeds (mpin), of the L'nited States mainland (map).

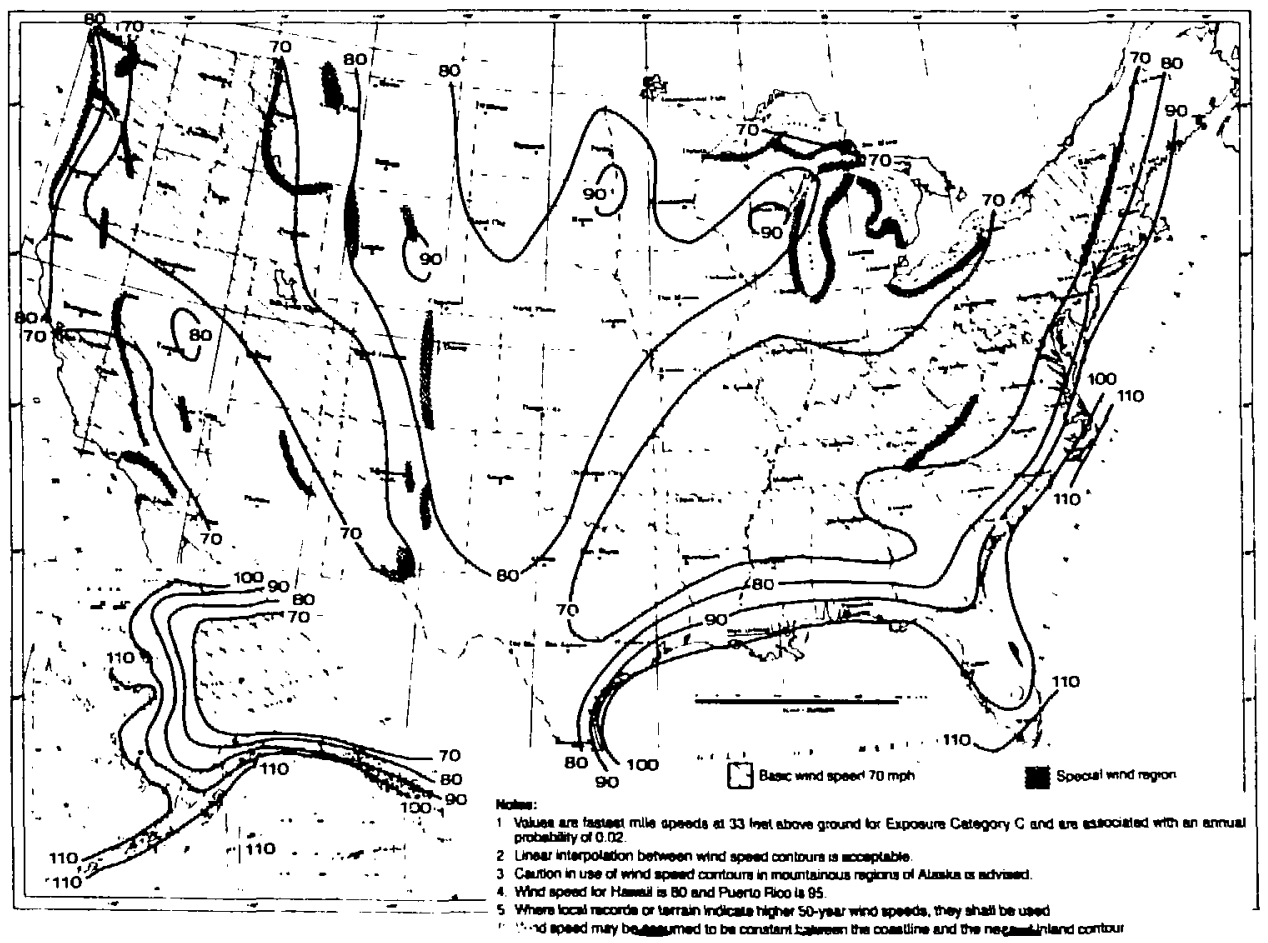




\section{Chapter 5}

\section{APPENDIX B}

Excerpt From Reference 4:

ATC-3-06 "Tentative Provisions For The Development

Of Seismic Regulaticns For Buildings"

Section 3.7.3 and Commentary

\subsubsection{DISCONTINUITIES IN STRENGTH OF VERTICAL RESISTING SYSTEM}

The design of a building shall consider the potential adverse effects when the ratio of the strength provided in any story to the strength required is significantly less than that ratio for the story immediately above a: 1 the strengths shall be adjusted to compensate for this effect.

\section{Commentary}

\subsubsection{DISCONTINUITIES IN STRENGTH OF VERTICAL RESISTING SYSTEM}

This Section requires consideration of discontinuities in strength. It is not generally recognized that large discontinuities in story strength can cause adverse response effects in a building. Usual practice is to determine what size, length, or strength of a resisting element is required; if more than the required strength is provided, so much the better. Unfortunately the extra strength in a story, if significantly different than that in adjacent stories, can produce responses which vary greatly from liose calculated by using the procedures in Chapter 4 or 5.

The committee considered the following approach to this problem:

1. Compute the ratio of shear capacity to the design shear for usch story. Denote this ratio for story $n$ by $r$.

2. Compute $r$, the average of $r_{n}$ over all stories.

3. If for any story $r_{\mathrm{f}}$ is less than $(2 / 3) r$, modify $R$ and $C_{d}$ for the building as given by Table $3-B$ to $R$ and and $\widetilde{C_{d}}$

where

$$
\begin{gathered}
\widetilde{C_{d}}=1+\frac{C_{d}-1}{2} \\
\dot{R}=\frac{\widetilde{C_{1}}}{C_{d}} R
\end{gathered}
$$

4. Use $\mathrm{R}$ instead of $\mathrm{R}$ to recompute the lateral forces. and $C_{d}$ instead of $C_{d}$ in computing story drifts.

The committee feels that further study should be given to this problem. 


\title{
APPENDIX C
}

\author{
PART VII-A \\ DUCTILE CONCRETE SPACE FRAMES"
}

(See also Figs. 7 thru 14)

\section{Design Criteria}

A. General: The criteria used in design of a concrete ductile moment-resisting space frame is ACI 318-77, except that $\mathrm{ACl}$ 318, Appendix $A^{\prime}$ is modified by SEAOC Recommended Lateral Force Requirements, 1974 and 1980.

B. SEAOC Modifications

1. General Modifications: The SEAOC recommendations modify the ACI 318-71 rcquirements so that an appropriate amount of ductility will be provided in concrete frames in Seismic Zones 2, 3. and 4 . The requirements which have been modified are as follows:

a. Cast-in-place monolithic beam and slab construction or precast concrete frame members may be used. Prestressed, post-tension. flat-slab systems are not to be used.

b. The design load factors have been revised from those in $\mathrm{ACl} 318$ :

$$
\begin{gathered}
\mathrm{U}=1.4(\mathrm{D}+\mathrm{L})+1.4 \mathrm{E} \\
\mathrm{L}=0.9 \mathrm{D}+1.4 \mathrm{E}
\end{gathered}
$$

c. All longitudinal reinforcing steel in columns and beams shall comply with ASTM A615, Grade 40 or 60 , or ASTM A706. The actual yield stress, based on mill tests, shall not exceed the minimum specified yield stress, $f_{y}$, by more than 18,000 psi. Retests shall not exceed this value by more than an additional 3,000 psi. In addition, the ultimate tensile stress shall be not less than 1.33 times the actual yield stress, based on mill tests. Grades other than these specified for design shall not be used.

d. Limitations are placed on percentage of reinforcing which can be used:

\author{
Vertical Reinforcement Ratio, "p" \\ Minimum $p=0.01$ \\ Maximum $p=0.06$ \\ Horizontal Reinforcement (Flexural \\ Members) Ratio, " $p$ " \\ Maximum, $p=0.025$
}

e. Special requirements are given on splices, anchorages, beam stirrups, column ties and hoops, and joint reinforcement.

f. Special requirements are given to provide the formation of inelastic hinges in beams rather than in columns.

2. Special Modifications

a. All Buildings in Seismic Zones 2, 3, and 4 (as defined by Uniform Building Code, 1982) which have moment-resisting frames shall be designed as ductile moment space frames.

b. All buildings in Seismic Zones 2, 3, and 4 with concrete space frames required by design to be part of the lateral force resisting system and all concrete frames located in the perimeter line of vertical support shall be ductile moment space frames.

c. All buildings in which shear walls are used as part of the lateral force sisting system and where " $K$ " of less than 1.33 is used, the concrete or masonry shear walls shall have boundary elements conforming to Section 3D of the SEAOC Recommendations.

d. Column ties shall be at least No. 3 bars for longitudinal bars No. 10 or smaller, and at least No. 4 bars for No. 11 or larger and bundled bars. 

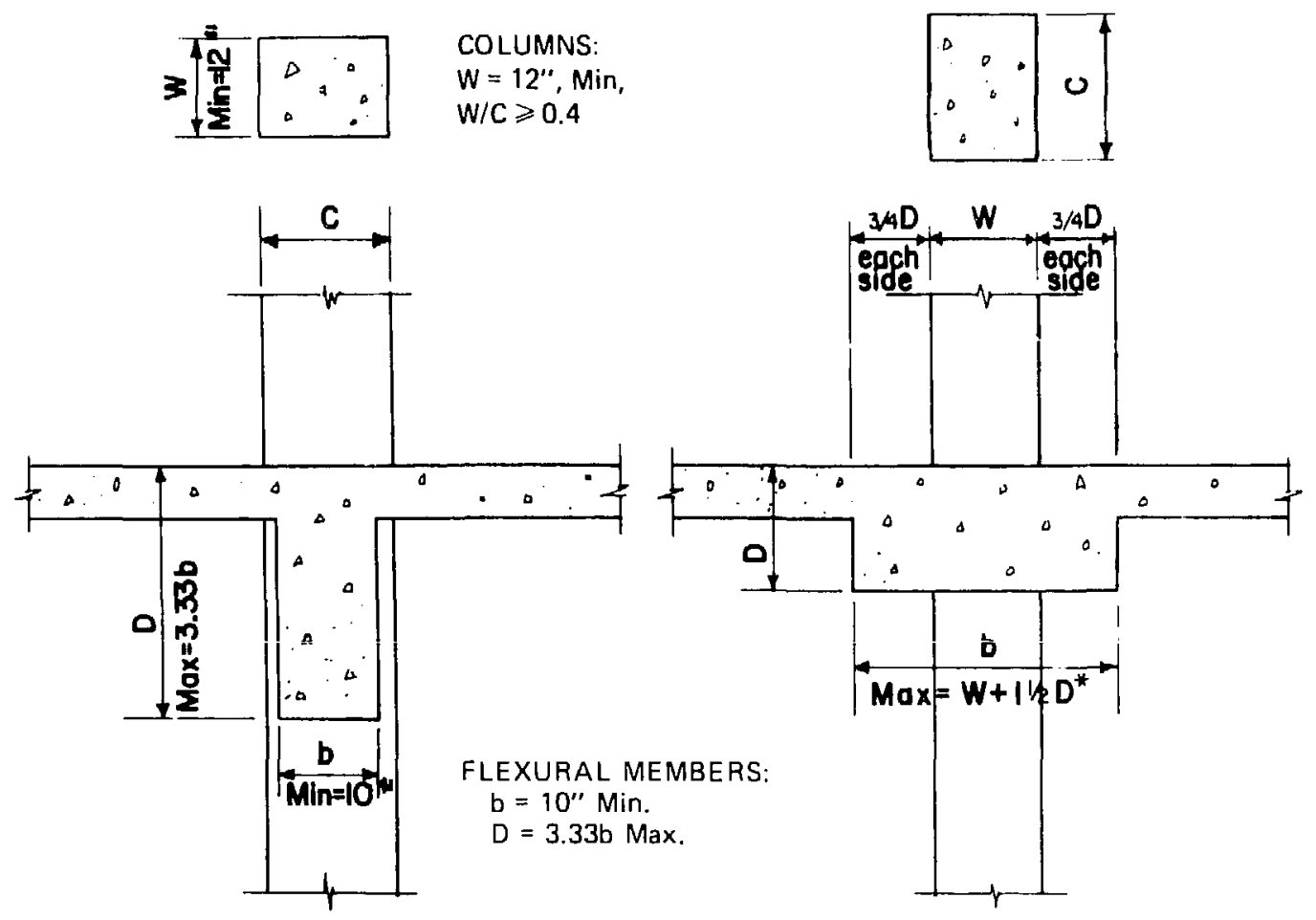

DEEP BEAM

SHALLOW BEAM

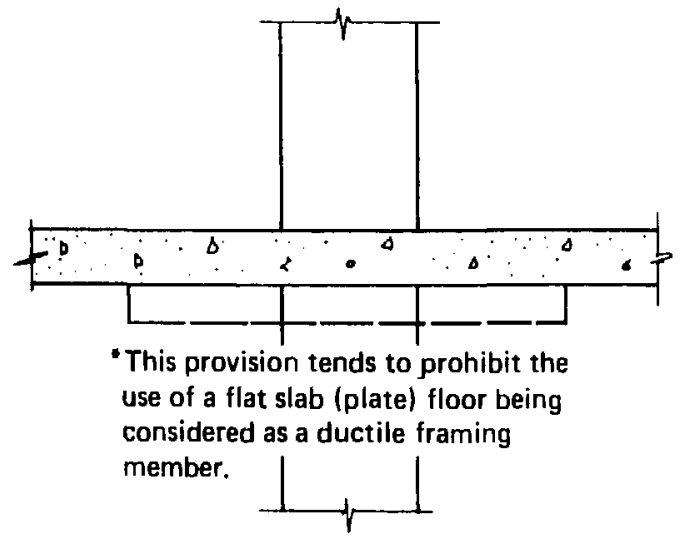

THIN MEMBERS

(Not Permitted)
DUCTILE CONCRETE FRAMES

LIMITATIONS ON DIMENSIONS

Fig. 7 


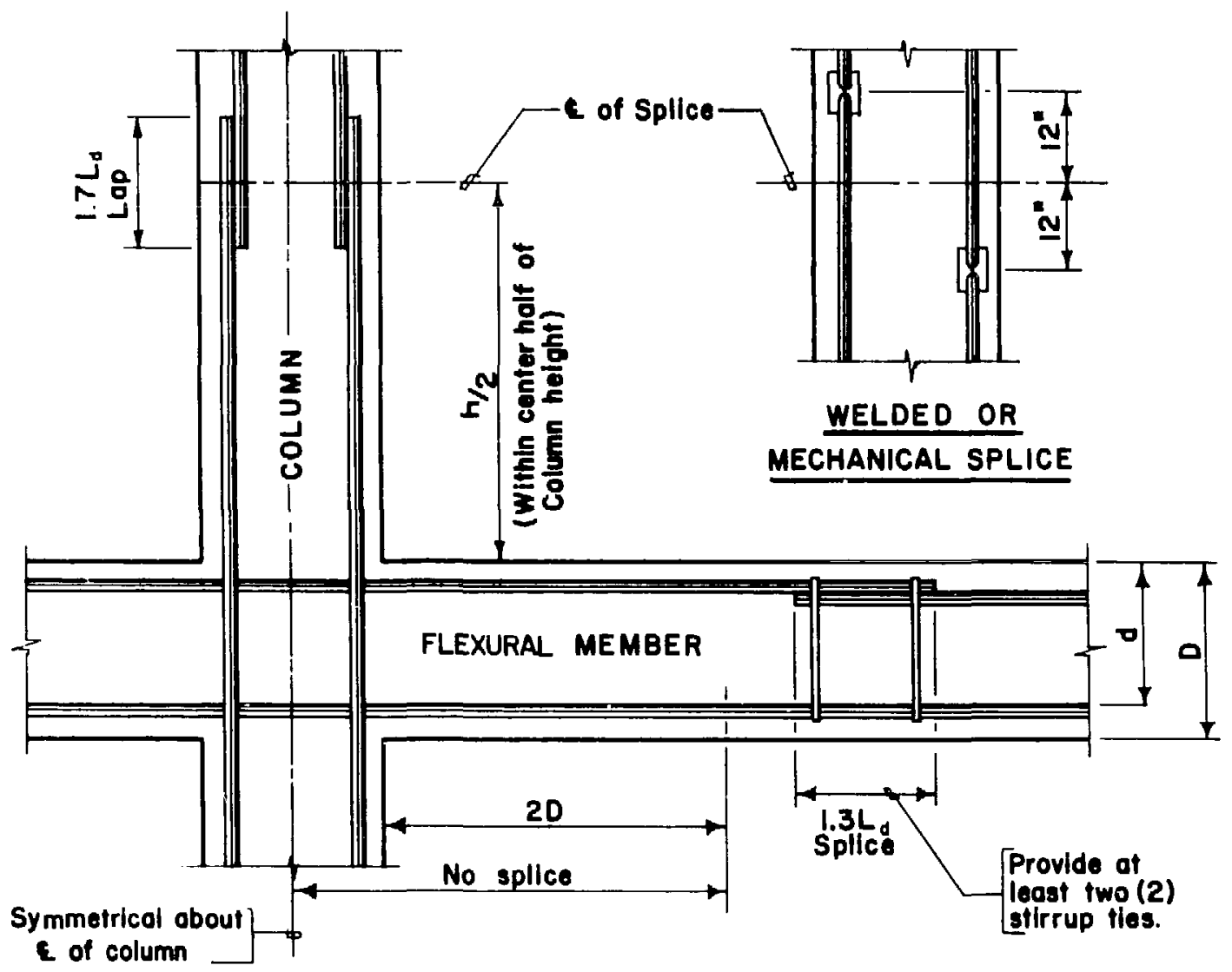

\section{FLEXURAL MEMBER:}

Tensile steel will not be spliced by lapping in a region of tension or reversing stress unless the region is confined by stirrup-ties. Splices will not be located within the column or within a distance of twice the member depth from the face of the column. At least two stirrup-ties will be provided at all splices.

\section{COLUMN:}

$L_{d}$ is the tension development length.

At any level, not more than alternate bars will be welded or mechanical spliced. Minimum distance between two adjacent bar splices - 24".

For \#145 \& \#18S bars, welded splices are

DUCTILE CONCRETF FRAMES

recommended. Lap splices will not be used. 


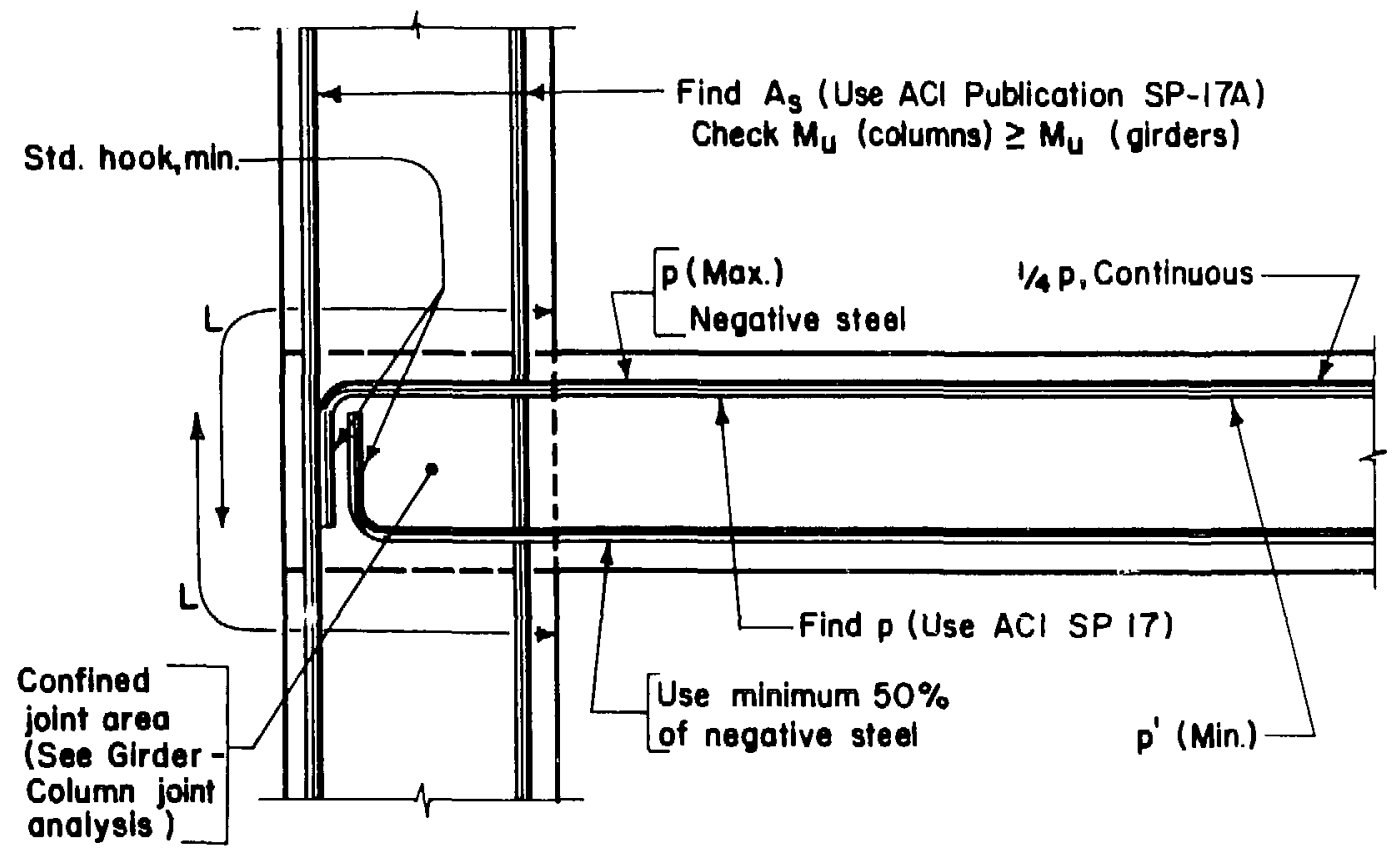

DESIGN:

Use

ACI 318-77 with load modified

FLEXURAL MEMBER:

$\mathrm{f}_{\mathrm{C}}=3,000$ p.s.i. at zó úāys min.

to:

$$
\begin{aligned}
& U=1.40(D+L+E) \\
& U=0.90 D+1.4 E
\end{aligned}
$$

$f_{y}=60$ k.s.i. (ASTM A615-60) Max. or ASTM A706

$p^{\prime}$ (Min., top and bottom) $=\frac{200}{f_{y}}$ AND 2-bars, Continuous

$p-($ Max. Neg. Reinf. $)=0.025$

$L$ (Anchorage) $=0.6 L_{d}^{*} \underline{O R}$ Min. 24"

" $L=L_{d}$ for Top Member (without column above)

\title{
COLUMN:
}

$f^{\prime}{ }_{c}=3,000$ p.s.i. at 28 days Min.

$f_{y}=60$ k.s.i. (ASTM A615-60) Max.

Reinforcement ratio, $p$ (for tied columns)

$$
\geqslant 0.01 \text { and } \leqslant 0.06 \text {. }
$$

\author{
DUCTILE CONCRETE FRAMES
}

LONGITUDINAL REINFORCEMFNT

Fig. 9 


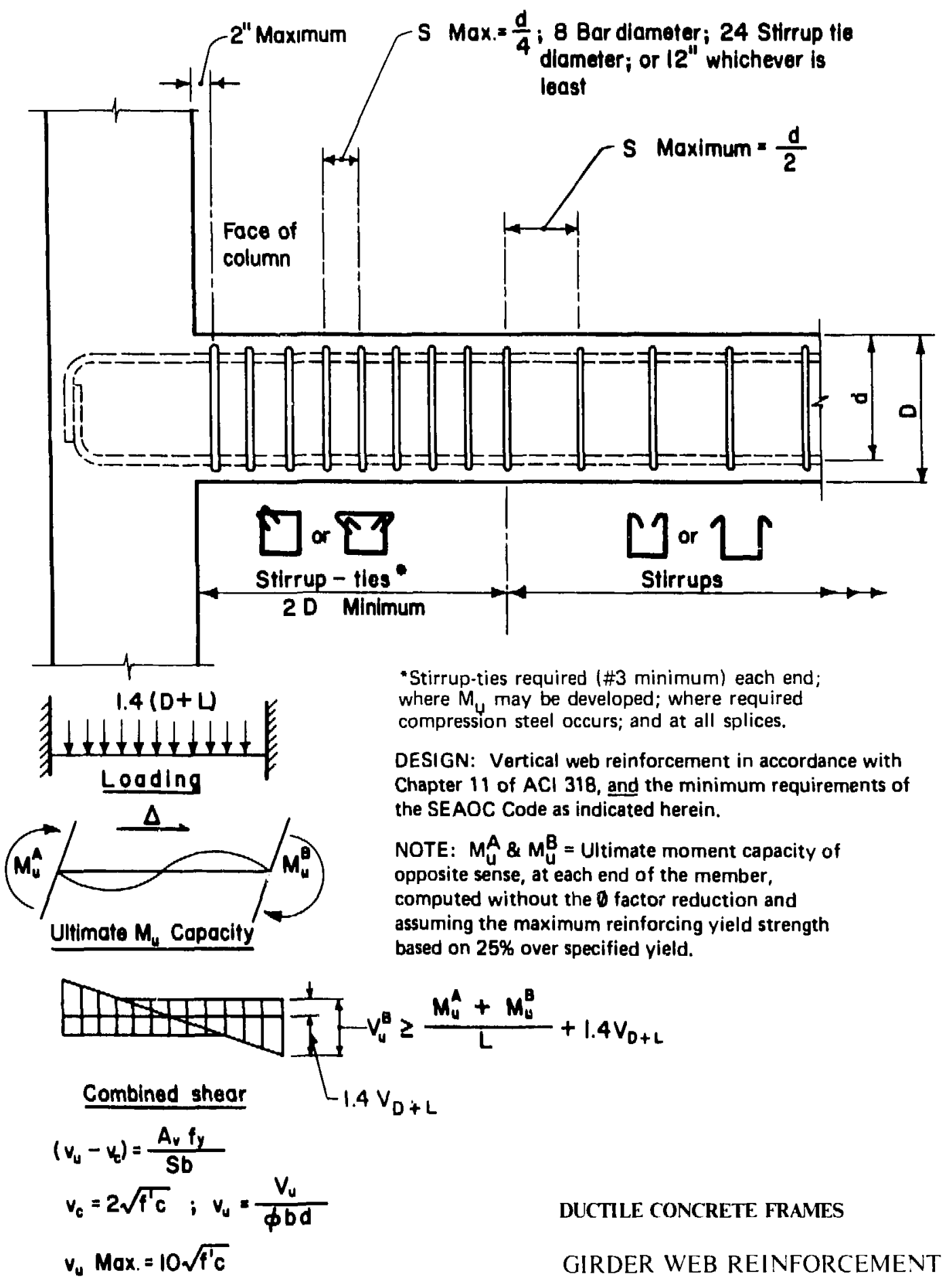

Fig. 10 


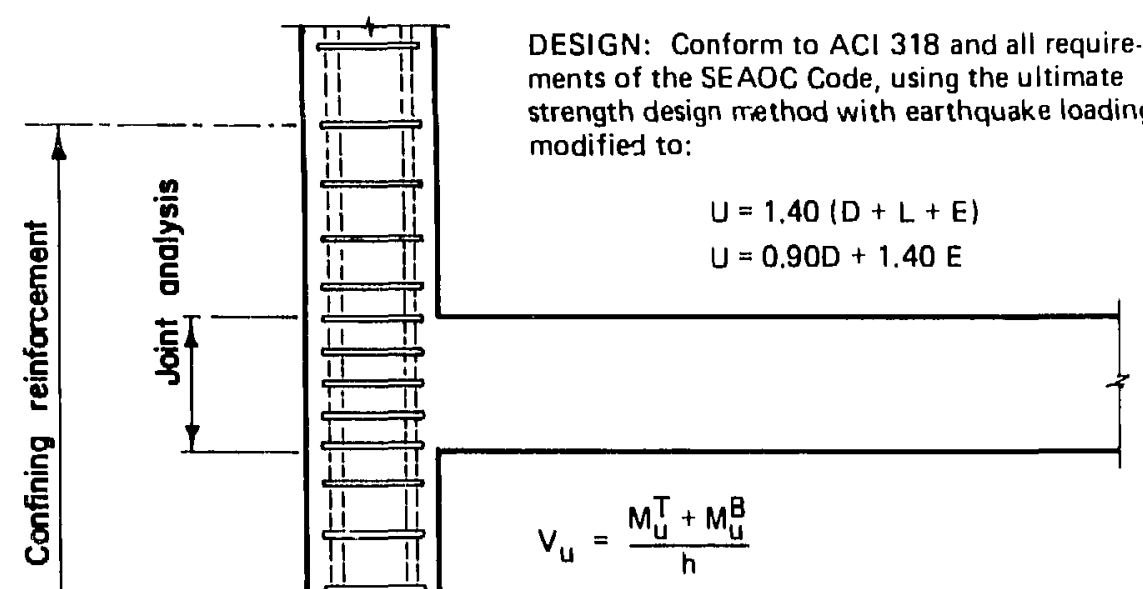

NOTE: $M_{u}^{\top}$ and $M_{u}^{B}=$ smaller ultimate moment capacity of beam or column at top and bottom of column computed without $\emptyset$ factor reduction and assuming the maximum reinforcing yield strength based on $25 \%$ over specified yield.

If $\frac{P}{A_{g}}>0.12 f^{\prime}$ deduct $v_{c}$

$\left(v_{u}-v_{c}\right) b=\frac{A_{v} f_{y}}{S}$

$v_{c}=2 \sqrt{f_{c}^{\prime}}$

$v_{u}=\frac{v_{u}}{\partial b d}$

$S$ Max. $=1 / 2$ Min. Col. dimension. Use $2 / 3 A_{v}$ for spirals.

\section{DUCTILE CONCRETE FRAMES}

COLUMN TRANSVERSE REINFORCEMENT

Fig. 11 


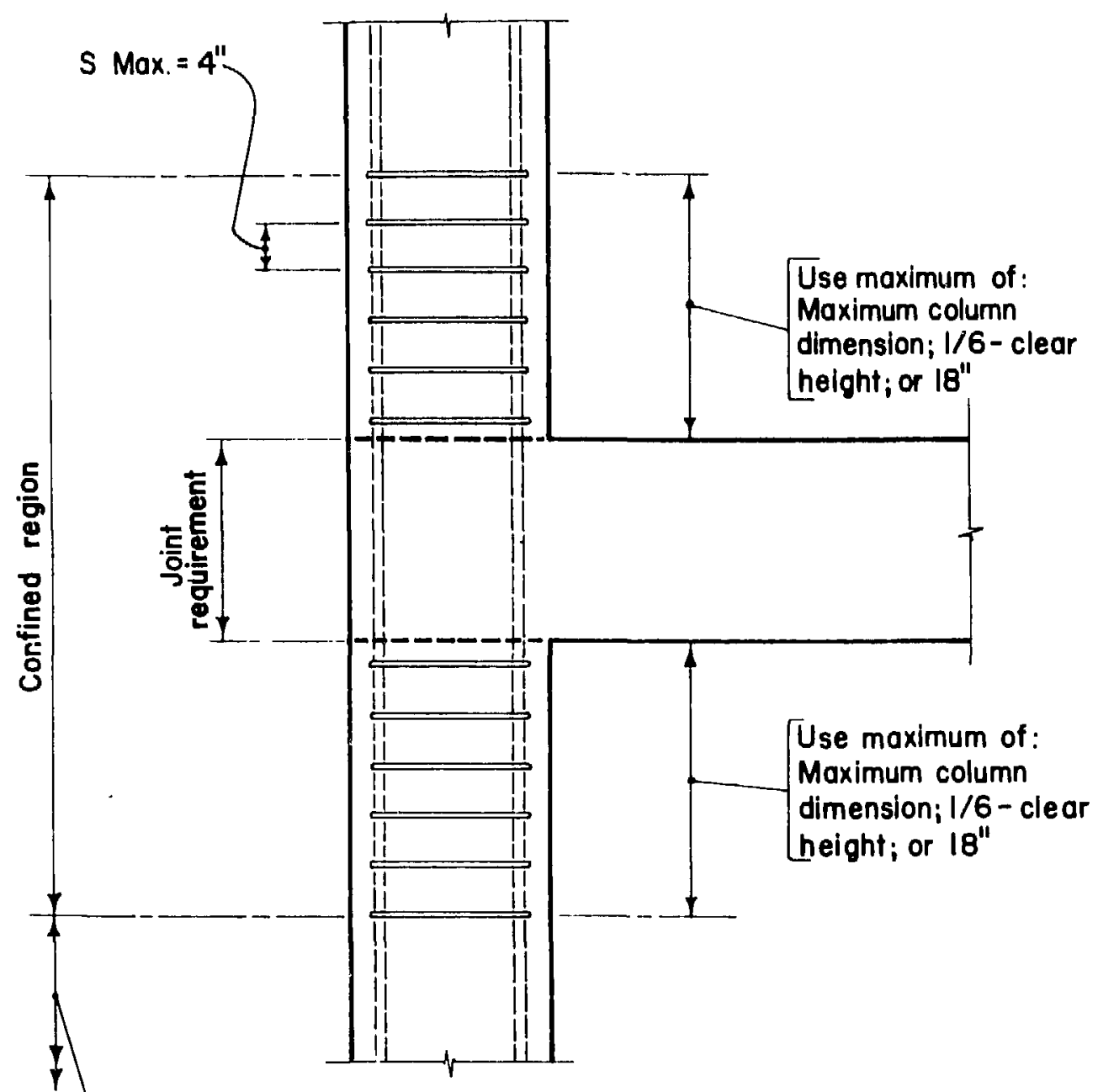

At any section where the ultimate capacity of the column $\left(P_{u}\right)$ is less than the sum of the shears $\left(\Sigma V_{u}\right)$ computed by

$$
V_{u}=\frac{M_{u}^{A}+M_{u}^{B}}{L}+1.1 V_{D+L}
$$

for all the beams above the level under consideration, confining reinforcement shall be provided.

DUCTILE CONCRETE FRAMES 


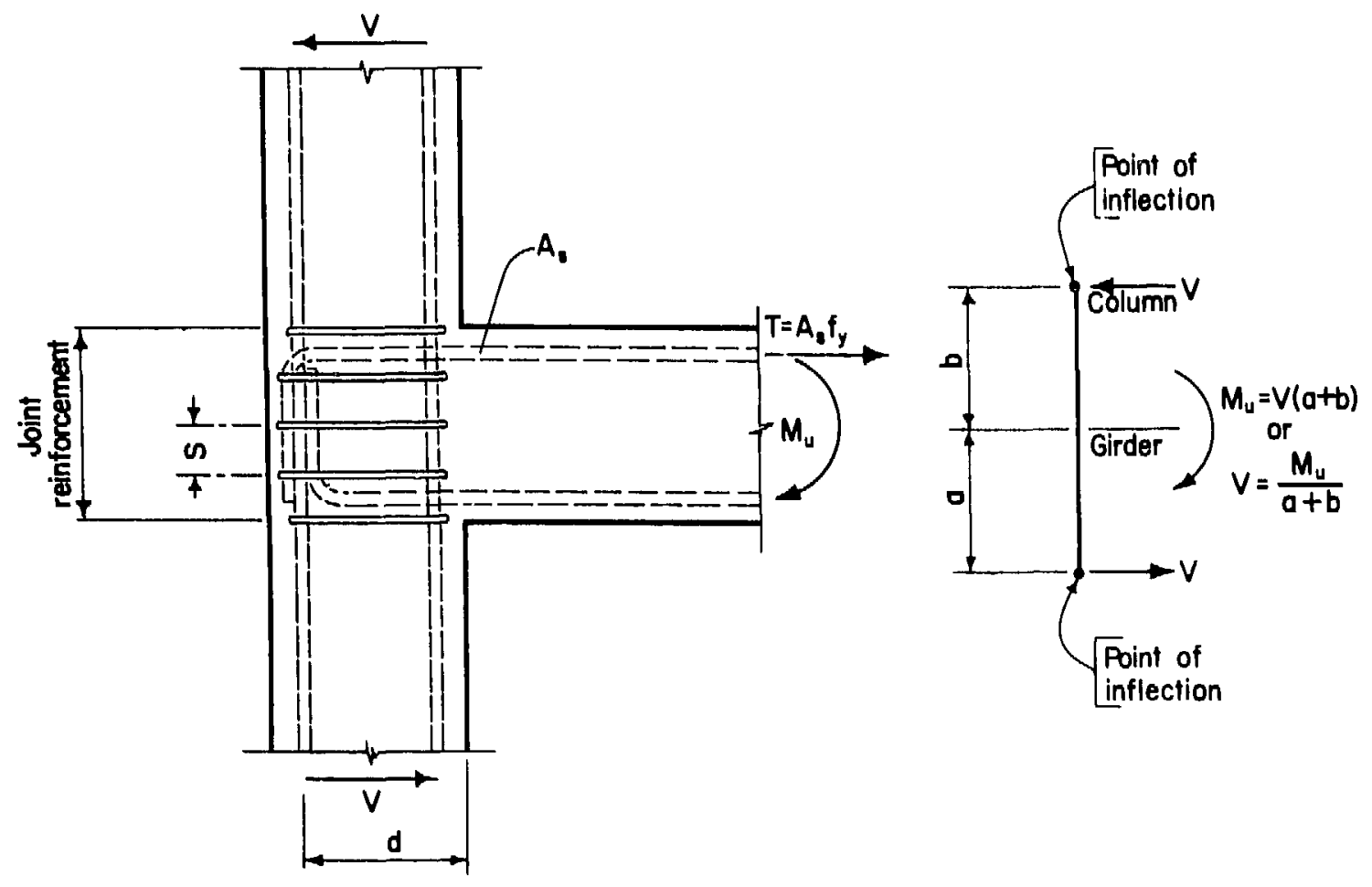

$V_{u}=T-V=A_{s} f_{y}-\frac{M_{u}}{a+b} \quad V_{u}=\frac{V_{u}}{\phi b d}$

$s=\frac{A_{v} f_{y}}{\left(v_{u}-v_{c}\right) b}$ where $v_{c}=2 \sqrt{f_{c}}$ except when P/Ag $<0.12 \mathrm{fc}$
then $v_{c}=0$

$s=4^{\prime \prime} \max$.

Only $1 / 2$ the special transverse reinforcement is required for columns where girders frame into all four sides.

NOTE: Column Confining Reinforcement is a minimum and may govern.

DUCTILE CONCRETE FRAMES

GIRDER-COLUMN JOINT ANALYSIS

Fig. 13 


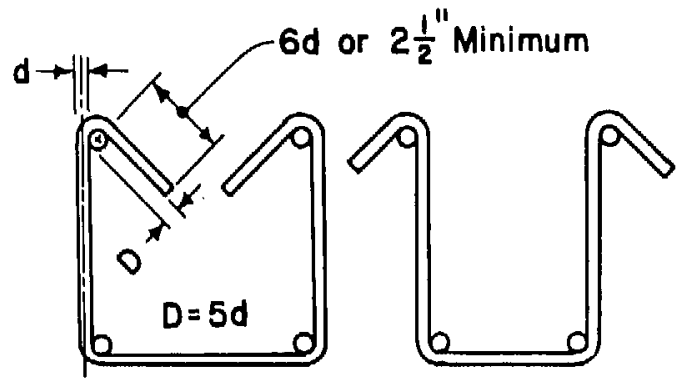

STIRRUPS

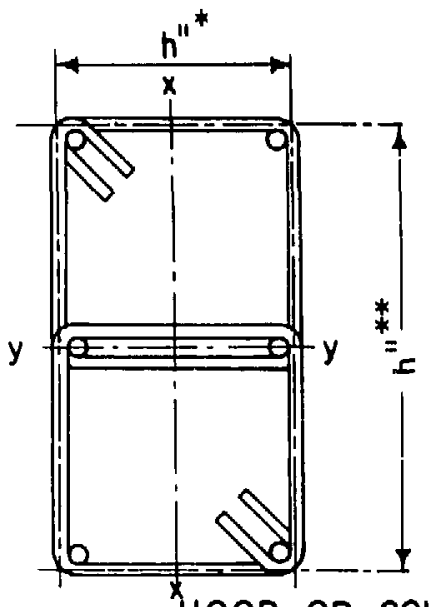

HOOP OR COLUMN TIE

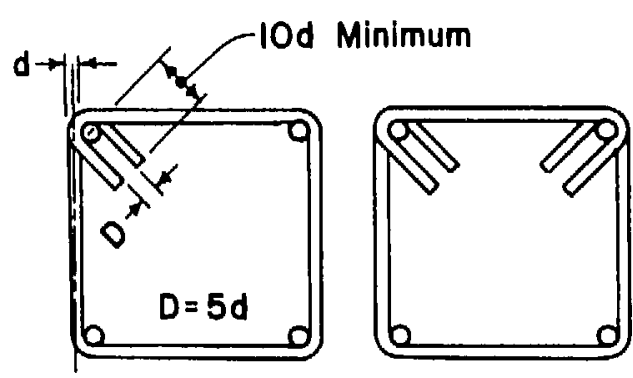

ST IRRUP-TIES

- USED IN BEAMS -

- USED IN COLUMNS -

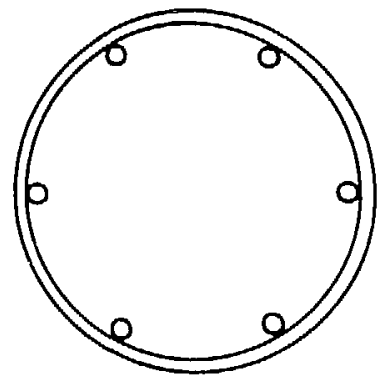

SPIRAL
SPIRAL RATIO:

ps $=0.45 \frac{{ }^{\prime}{ }_{c}}{f_{y}}\left(\frac{A_{g}}{A_{c}}-1\right)$ or $0.12 \frac{f^{\prime}}{f^{\prime \prime}{ }_{y}}$,

whichever is greater.

HOOP REQUIREMENTS - TOTAL TIE AREA:

$A^{\prime \prime}{ }_{s h}=0.30 a h^{\prime \prime} \frac{f^{\prime}{ }_{c}}{f^{\prime \prime}{ }_{y h}}\left(\frac{A_{g}}{A_{c}}-1\right)$ or

$0.12 a^{\prime \prime} \frac{\prime^{\prime c}}{f^{\prime \prime} y h}$, whichever is greater.

¥3 Bars Minimum.

DUCTILE CONCRETE FRAMES

TRANSVERSE REINFORCEMENT DETAILS

Fig. 14
* $h$ " for $A_{y h}^{\prime \prime}$ crossing $y-y$ axis ** $h$ "for $A_{\text {mh }}^{\prime \prime}$ crossing $x-x$ axis 


\section{PART VII-B}

\section{CONCRETE SHEAR WALLS'}

(See atso Figs. 15 and 16 )

\section{Design Criteria}

A. General: The criteria used in design of a concrete shear wall (or walls) is $\mathrm{ACI} 318-77$, except that $\mathrm{ACI}$ 318. Appendix $A^{\prime}$ is modified by SEAOC Recommended Lateral Force Requirements, 1974 and 1980.

B. SEAOC Modifications

1. The design load facturs have been modified:

$$
\begin{aligned}
& \mathrm{U}=1.4(\mathrm{D}+\mathrm{L})+1.4 \mathrm{E}^{+} \\
& \mathrm{U}=0.9 \mathrm{D}+1.4 \mathrm{E}^{\dagger} \\
& \text { 'Use } 2.0 \mathrm{E} \text { for calculating shear and diagonal } \\
& \text { tension in buildings other than those comply. } \\
& \text { ing with requirements for buildings with } \mathrm{K}= \\
& 0.67 \text {. }
\end{aligned}
$$

2. Special boundary elements reinforced as columns are required in some cases at ends of walls, openings, and column locations. These elements are to provide confined flanges for the shear wall. The wall reinforcing is required to be anchored to the elements in order to maintain the shear capacity. The requirements for the special boundary elements apply only to Scismic Zones 2, 3, and 4.

3. Minimum areas and spacings of wall reinforcement have been modified:

Minimum ratio " $p$ " is 0.0025 , each way.

Maximum spacing is $D / 3$ or 18 inches, where

$D$ is the wall length.

4. Maximum total design stresses have been modified:

Ultimate shear stress: $v_{u}=2 \sqrt{f^{\prime} \mathrm{c}}+p f_{y}$.

Average horizontal shear $v_{u}$ for all wall piers: not to exceed $8 \sqrt{\mathrm{f}^{\prime}} \mathrm{c}$.

\footnotetext{
"From American Concrete Institute ( $\mathrm{ACI}$ ) Workshop, San Diego, $\mathrm{CA}$ March 15. 1977.

'Appendix A was not revised for the ACl $318-77$ edition.
}

Horizontal shear $v_{u}$ in an individual picr: not to exceed $10 \sqrt{\mathrm{f}^{\prime} \mathrm{c}}$.

\section{General Criteria}

1. Wall Deflections: The deflection of a concrete shear wall can be determined from the sum of the shear and moment deflections. In the case of a solid wall with no openings, the computation of deflection is quite simple. However, where the shear wall has openings in it, as for doors and windows, the computations for deflection and rigidity are much more complex. An exact analysis, considering angular rotation of elements, rib shortening, etc. is very time consuming. For this reason, several short-cut approximate methods involving more or less valid assumptions have been developed. These do not always give consistent or satisfactory results.

2. Shear Distribution: Where several independent shear walls are resisting forces from a rigid diaphragm in any one-story structure, the relative rigidity of the various walls must be determined. This is necessary so that a logical and consistent distribution of story shears to each wall can be made. The total height of wall from diaphragm level above to diaphragm or foundation level below frequently must be considered. Exact determination of stiffness is very difficult and is not necessary. Approximate methods in which the deflections of portions of walls are combined usually are adequate.

3. Assumptions: The usual analysis assumes that the foundation is unyiclding or that soil pressures will vary as a straight line under a wall when subjected to overturning. These may not be realistic assumptions. Where the openings in a shear wall are so large that the resulting wall approaches an assembly similar to a rigid frame. the wall shall be analyzed as a rigid frame. 


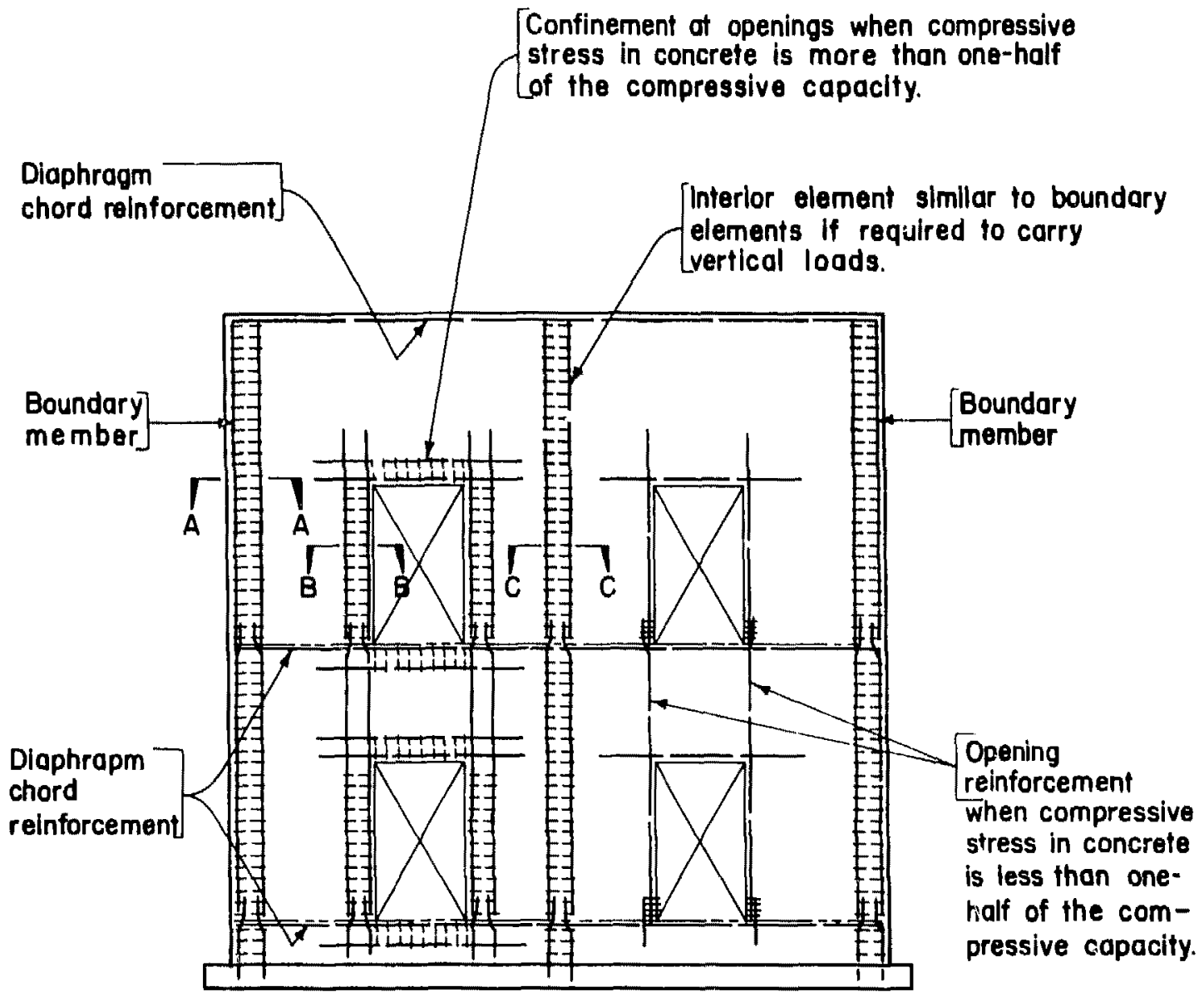

NOTES:

Special vertical boundary elements, as shown above, shall be provided at the edges uf concrete shear walls in buildings with $25 \%$ moment.resisting space trame $K=0.80$.

CONCRETE SHEAR WALLS

SPECIAL BOLNDRY ELEMENTS

Fig. 15 


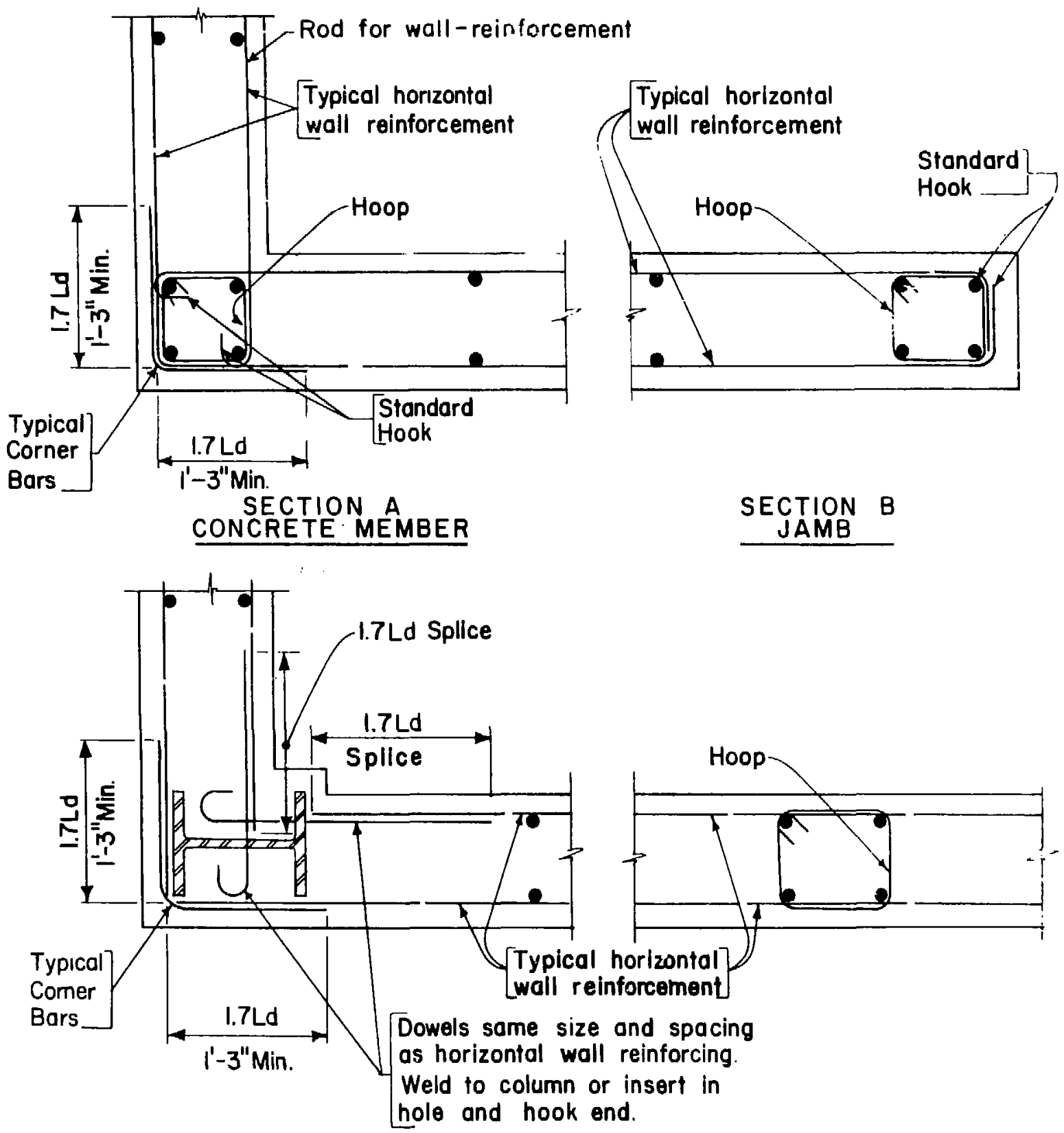

SECTION A

STEEL MEMBER
SECTION C INTERIOR MEMBER

Notes:

Steel boundary members shall be ASTM A36,

A 500 (Grades B and C), A 501, A 572 (Grades

$42,45,50$ and 55$)$ or $A 588$.

For location of sections, see Fig. 15.

$\mathrm{L}_{\mathrm{d}}=$ development length in tension.

CONCRETE SHEAR WALLS

SPECIAL BOLNDARY ELEMENTS 
PART VII-C

\section{CONCRETE FLOOR AND ROOF DIAPHRAGMS}

\section{Design Criteria}

A. General: The criteria used in the design of a concrete diaphragm is $\mathrm{ACl} 318-77$, except that $\mathrm{ACI}$ 318, Appendix $A{ }^{\prime}$ is modified by SEAOC Recommended Lateral Force Requirements, 1974 and 1980.

The equations for use in determining the strength and stiffness capabilities of various diaphragm materials have in most cases only been published in the literature of the companies supplying these materials; moreover, very little data is available relative to design and analysis of concrete diaphragms. The published equations have been based on a limited number of tests and havi been derived empirically to fit the test data available to them. The equations indicated herein are those available from the publication "Seismic Design for Buildings," Tri-Services Micinual.

B. Specific Criteria

1. Concrete diaphragm webs will be designed as concrete slabs which may be designed to support vertical loads between the framing members or rest on other vertical load-carrying elements such as precast concrete eleinents or steel decks.

2. The formula for $U$ should be $1.4(D+L)+2.0 E$

3. If the slab itself is supporting vertical loads, the span $\left(\mathrm{L}_{y}\right)$ must not be greater than $3 t$. The shear capacity will be as determined by the requirements of $\mathrm{ACl} 318-77$, but should he limited to the value determined by the formula ${ }^{2}$

$$
q_{u d}=\frac{6 f^{\prime}{ }^{\prime} t}{1+\frac{3 L_{v} 2}{t^{2}}}
$$

where

$$
\begin{aligned}
\mathrm{q}_{u d}= & \text { Shear capacity in pounds per foot. } \\
\mathrm{f}_{\mathrm{c}}^{\prime}= & \text { Compressive strength of concrete } \\
& \text { but limiter o a maximum of } \\
& ? \text { noo pounds per square inch for } \\
& \text { setermination of } \mathrm{q}_{\mathrm{ud}} \text { : } \\
\mathrm{L}_{v}= & \text { Clear span in feet between framing } \\
& \text { members. } \\
\mathrm{t}= & \text { Thickness of slab in inches. }
\end{aligned}
$$

4. When cast diaphragm slabs are not monolithic with the supporting framing members, the slab will be anchored by mechanical means at frequent intervals to the framing members.

\footnotetext{
"From American Concrete Instïute (ACl) Workshop. San Dicgo, CA, March 15. $197 \%$

'Appendix A was not revised for the ACI3/0.77 edition.

${ }^{2}$ The formula indicated is from the Tri-Services Manual, "Seismic Design for Buildings." 1982.
}

5. If the diaphragm slab is not supporting vertical loads but is supported by other vertical loadcarrying elements, the same restrictions as to span and shear will apply. In this case, however, $\mathrm{L}_{v}$ is the distance between mechanical anchorage between the diaphragm slab and the vertical load-carrying members. This mechanical anchorage can be provided by steel insirts or reinforcement or by bonded cast-in-place concrete lugs. Typical anchorage of precast units when used to support a concrete diaphragm is required. These anchorage details may require modification in some cases in order to provide for shrinkage and creep of precast units.

6. If precast units are continuously bonded trgether, they may be considered as concrete diaphragms and designed accordingly as described herein before. Intermittent bonded precast units should not be used as a diaphragm.

7. Special diagonal reinforcement should be placed in corners of diaphragms.

8. Concrete diaphragms are generally calegorized as rigid and are usually limited only by the appropriate deflection limitations. The deflections of this type of diaphragm will be determined using the unfactored loads.

9. Deflection Limitations; Diaphragm span-width ratios should be limited to $3: 1$ to insure reasonable diaphragm lateral deflections under seismic loading.

\section{References}

1. "Recommended Lateral Force Requiremenis and Commentary," Structural Engineers Association of California, 1980.

2. "Building Code Requirements for Reinforced Concrete, ACI 318-77," American Concrete Institu:." Detroit, Michigan.

3. "Recommendations for Design of Beam-Column Joints in Monolithic Reinforced Concrete Structures," ACI-ASCE Committee 352, American Concrete Institute, July 1976.

4. "Design of Multistory Reinforced Concrete Building for Earthquake Motions," Blume, J. A., Newmark, N. M., and Corning, L. M., Portland Cement Association, 1961 .

5. "Seismic Design for Buildings," Departments of the Army, The Navy, and the Air Force, February 1982. 


\section{APPENDIX D}

Excerpt From Reference 4:

ATC-3-06"Tentative Provisions for the

Development of Seismic Regulations for Buildings"

\section{Sec. 8.2 ARCHITECTURAL. DESIGN \\ REQUIREMENTS}

\subsection{GENERAL}

Systems or components listed in Tuble 8-B and their attachments shall be designed and detailed in accordance with the requirements of this Chapter. The designs or criteria for systems or components shall be included as part of the design documents.

\subsubsection{FORCES}

Architectural systems and components and their attachments shall be designed to resist seismic forces determined in accordance with the following formula:

$$
F_{p}=A_{v} C_{c} P W_{c}
$$

where

$F_{p}=$ The seismic force applied to a component of a building or equipment al its center of gravity.

$C_{c}=$ The seismic coefficient for components of architectural systems as given in Table 8-B (dimensionless).

$W_{c}=$ The weight of a component of a building or equipment.

$\Lambda_{\mathrm{v}}=$ The seismic coefficient representing the Effective Peak Velocity-Related Acceleration as determined in Sec. 1.4."

$\mathrm{P}=$ Performance criteria factor as given in Table 8-A (dimensionless).

\section{EXCEPTIONS:}

When positive and negative wind loads exceed $F_{p}$ for nonbearing exterior walls, these loads shall govern the design. Similarly, when the code horizontal loads exceed $F_{p}$ for interior partitions, these loads shall govern the design.

TABLE 8-A

\section{PERFORMANCE CRITERIA}

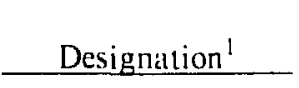

$\mathrm{S}$

G

L

'See Tables 8-B and $8-C$.
Performance

Characteristic Level P

$\begin{array}{cc}\text { Superior } & 1.5 \\ \text { Good } & 1.0 \\ \text { Low } & 0.5\end{array}$

"See Reference 4. 


\section{TABLE 8-B}

\section{SEISMIC COEFFICIENT (C) AND PERFORMANCE CHARACTERISTIC LEVELS REQUIRED FOR ARCHITECTURAL SYSTEMS OR COMPONENTS}

(See Table $8 \mathrm{~A}$ for $\mathrm{S}, \mathrm{G}$ and $\mathrm{L}$ Designations)

\begin{tabular}{|c|c|c|c|c|}
\hline \multirow[b]{3}{*}{ Architectural Components } & \multirow{3}{*}{$\underset{\text { Factor }}{\mathrm{C}_{\mathrm{c}}}$} & \multicolumn{3}{|c|}{$\begin{array}{c}\text { Required Performance } \\
\text { Characteristic Levels }\end{array}$} \\
\hline & & \multicolumn{3}{|c|}{ Seismic Hazard Exposure Group } \\
\hline & & III & II & $\mathrm{I}$ \\
\hline \multicolumn{5}{|l|}{ Appendages } \\
\hline Exterior Nonbearing Walls & .9 & $\mathrm{~S}$ & $\mathrm{G}^{2}$ & $\mathrm{~L}^{4}$ \\
\hline Wall Attachments & 3.0 & $\mathrm{~S}$ & $\mathrm{G}^{2}$ & $\mathrm{~L}^{4}$ \\
\hline Veneers & 3.0 & $G$ & $G^{1}$ & $\mathrm{~L}$ \\
\hline Roofing Units &.$\dot{0}$ & $G$ & $G^{2}$ & NR \\
\hline \multicolumn{5}{|l|}{ Containers and Miscellaneous } \\
\hline Components (free standing) & 1.5 & $\mathrm{G}$ & $G$ & NR \\
\hline \multicolumn{5}{|l|}{ Partitions } \\
\hline Stairs and Shafts & 1.5 & $\mathrm{~S}$ & $\mathrm{G}^{3}$ & $\mathrm{G}$ \\
\hline Elevators and Shafts & 1.5 & $\mathrm{~S}$ & $\mathrm{~L}^{3}$ & $\mathrm{~L}^{5}$ \\
\hline Vertical Shafts & .9 & $\mathrm{~S}$ & $\mathrm{~L}^{3}$ & $\mathrm{~L}^{6}$ \\
\hline Horizontal Exits including Ceilings & .9 & $\mathrm{~S}$ & $\mathbf{S}$ & G \\
\hline Public Corridors & .9 & $\mathrm{~S}$ & $\mathrm{G}$ & $\mathrm{L}$ \\
\hline Private Corridors & .6 & $\mathrm{~S}$ & $\mathrm{~L}$ & NR \\
\hline Full-height Area Separation Partitions & 9 & $\mathrm{~S}$ & G & G \\
\hline Full-height Other Partitions & 6 & $\mathrm{~S}$ & $\mathrm{~L}$ & $\mathrm{~L}$ \\
\hline Partial-height Partitions & 6 & $\mathrm{G}$ & $\mathrm{L}$ & NR \\
\hline Structural Fireproofing & 9 & $\mathbf{S}$ & $\mathrm{G}^{3}$ & $\mathrm{~L}^{6}$ \\
\hline Ceilings - Fire-rated Membrane & .9 & $\mathrm{~S}$ & $\mathrm{G}^{3}$ & $\mathrm{G}$ \\
\hline Ceilings - Nonfire-rated Membrane & .6 & $\mathrm{G}$ & $\mathrm{G}$ & $\mathbf{L}$ \\
\hline \multicolumn{5}{|l|}{ Architectural Equipment - Ceiling, } \\
\hline Walls, or Floor Mounted & .9 & $\mathbf{S}$ & G & $\mathrm{L}$ \\
\hline
\end{tabular}

$N R=$ Not required.

\footnotetext{
${ }^{1}$ May be reduced one performance level if the arca facing the exterior wall is nominally inaccessible for a distance of 10 feel plus one fool for each floor of height.

2May be reduced one performance level if the urea facing the exterior wall is nominally inacecssible for a distance of 10 feet and building is only one story.

${ }^{3}$ Shall be raised one performance level if building is more than four stories or 40 feet in height.

${ }^{4}$ Shall be raised one performance level if building is in an urban area.

${ }^{5}$ May be reduced to NR if building is less than 40 fect in height.

${ }^{6}$ Shall be raised one periormance level for an occupancy containing flammable gases, liquids, or dust.
} 
Sec. 8.3 MECHANICAL AND ELECTRICAL DESIGN REQUIREMENTS

\subsubsection{GENERAL}

Systems or components listed in Table 8-C and their attachments shall be designed and detailed in accordance with the requirements of this Chapter. The designs or critcria for systems or components shall be included as part of the design documents.

An analysis of a component supporting mechanism based on established principles of structural dynamics may be performed to justify reducing the forces determined in Sec. 8.3.2.

Combined states of stress, such as tension and shear in anchor bolts, shall be investigated in accordance with established principles of mechanics.

\subsubsection{FORCES}

Mechanical and electrical components and their attachments shall be designed for seismic forces determined in accordance with the following formula:

$$
F_{p}=A_{v} a_{c} a_{x} C_{c} P W_{c}
$$

where

$\mathrm{F}_{\mathrm{f}}, \mathrm{A}_{v}, \mathrm{P}$, and $\mathrm{W}_{\mathrm{c}}$ are as defined previously in Sec. 8.2.2.

$\mathrm{C}_{\mathrm{c}} \stackrel{\mathrm{v}^{\prime}}{=}$ The seismic coefficient for components of mechanical or electrical systems as given in Table 8-C (dimensionless).

$a_{c}=$ The amplification factor related to the response of a system or component as affected by the type of the attachment, determined in Sec. 8.3.2(A).

$a_{x}=$ The amplification factor at level $x$ related to the variation of the response in height of the building.

The amplification factor, $a_{x}$, shall be determined in accordance with the following formula:

$$
a_{x}=1.0+\left(h_{x} / h_{n}\right)
$$

where $h_{\mathrm{x}}=$ The height above the base to level $\mathrm{x}$ where $h_{n}=$ The height above the base to level $n$

\section{(A) ATTACHMENT AMPLIFICATION}

The attachment amplification factor. $a_{c}$. shall be determined as follows:

For fixed or direct attachment to buildings: $a_{c}=1$.

For resilient mounting system:

with seismic activated restraining device: $a_{c}=1$.

with elastic restraining device:

$$
\begin{aligned}
& \text { if } T_{c} / T<0.6 \text { or } T_{c} / T>1.4 \quad a_{c}=1 . \\
& \text { if } T_{c} / T \geq 0.6 \text { or } \leq 1.4 \quad a_{c}=2 \text { minimum. } \\
& \text { if mounted on the ground or on a slab } \quad a_{c}=2 . \\
& \text { in direct contact with the ground }
\end{aligned}
$$

The value of the fundamental period, $T$, shall be the value used in the design of the building as determined in accordance with Sec. 4.2 or Sec. 5.4.

The fundamental period of the component and its attachment, $T_{\text {. }}$ shall be determined in accordance with the following forminla:

$$
\mathrm{T}_{\mathrm{c}}=0.32 \sqrt{\mathrm{W}_{\mathrm{c}} / \mathrm{K}}
$$

where

$K=$ The stiffness of the equipment support attachment determined in terms of load per unit deflection of the center of gravity (lbs./in.) as follows:

For stable resilient attachments, $\mathrm{K}=$ spring constant.

For other resilient attachments, $K=$ slope of the load/deflection curve at the point of loading.

In lieu of Formula 8-4, properly substantiated values for $T_{c}$ derived using experimental data or any generally accepted analytical procedure may be used. 
TABLE 8-C

\section{SEISMIC COEFFICIENT $\left(C_{c}\right)$ AND PERFORMANCE CHARACTERISTIC LEVELS REQUIRED FOR MECHANICAL/ELECTRICAL COMPCNENTS}

(See Table 8-A for S, G, and L Designations)

\begin{tabular}{|c|c|c|c|c|}
\hline \multirow[b]{2}{*}{ Mechanical/Electrical Components } & \multirow[b]{2}{*}{$\begin{array}{l}\mathrm{C}_{\mathrm{c}} \\
\text { Factor }\end{array}$} & \multicolumn{3}{|c|}{$\begin{array}{l}\text { Required Performance } \\
\text { Characteristic Levels }\end{array}$} \\
\hline & & $\begin{array}{c}\text { Seisn } \\
\text { III }\end{array}$ & $\begin{array}{l}\text { ard } \\
\text { II }\end{array}$ & Group \\
\hline $\begin{array}{l}\text { Emergency Electrical Systems (code required) } \\
\text { Fire and Smoke Detection Systems (code required) } \\
\text { Fire Suppression Systems (code required) } \\
\text { Life Safety System Components }\end{array}$ & 2.00 & $S$ & S & $\mathrm{S}$ \\
\hline $\begin{array}{l}\text { Boilers, Furnaces, Incinerators, } \\
\text { Water Heaters, and Other Equipment } \\
\text { Using Combustible Energy Sources or } \\
\text { High Temperature Energy Sources, } \\
\text { Chimneys, Flues, Smokestacks, and Vents } \\
\text { Communication Systems } \\
\text { Electrical Bus Ducts and Primary Cable Systems } \\
\text { Electrical Motor Control Centers, } \\
\text { Motor Control Devices, Switchgear, } \\
\text { Transformers, and Unit Substations } \\
\text { Reciprocating or Rotating Equipment } \\
\text { Tanks, Heat Exchangers, and Pressure Vessels } \\
\text { Utility and Service Interfaces }\end{array}$ & 2.00 & $S$ & G & $\mathrm{L}$ \\
\hline $\begin{array}{l}\text { Machinery (Manufacturing and Process) } \\
\text { Lighting Fixtures }\end{array}$ & $\begin{array}{l}.67 \\
.67^{3}\end{array}$ & $\begin{array}{l}S \\
S\end{array}$ & $\begin{array}{l}G \\
G\end{array}$ & $\begin{array}{l}\mathrm{L} \\
\mathrm{L}\end{array}$ \\
\hline $\begin{array}{l}\text { Ducts and Piping Distribution Systems } \\
\text {-Resiliently Supported } \\
\text {-Rigidly Supported } \\
\text { Electrical Panelboards and Dimmers }\end{array}$ & $\begin{array}{l}2.00 \\
.67^{4} \\
.67\end{array}$ & $\begin{array}{l}S \\
S \\
S\end{array}$ & $\begin{array}{l}G \\
G \\
G\end{array}$ & $\begin{array}{l}\text { NR } \\
\text { NR } \\
\text { NR }\end{array}$ \\
\hline Conveyor Systems (non-personnel) & .67 & $\mathbf{S}$ & NR & NR \\
\hline
\end{tabular}

$\mathrm{NR}=$ Not Required.

'Where mechanical or electrical comnenents are not specifically listed in Table 8-C, the designer shall select a similarly listed component, subject to the approval of the authority having jurisdiction, and shall base the design on the performance and $C_{c}$ values for the similar componen!.

${ }^{2} C_{c}$ values listed are for horizonta! forces. $C_{c}$ values for vertical forces shall be taken as $1 / 3$ of the horizontal values.

${ }^{3}$ Hanging- or swinging-type fixtures shall use a $C_{c}$ value of 1.5 and shall have a safety cable attached to the structure and the fixture a: cach support point capable of supporting 4 times the vertical load.

${ }^{4}$ Seismic restraints may be omilled from the following installations:

a. Gas piping less than 1 -inch inside diameter.

b. Piping in boiler and mechanical rooms less than $1-1 / 4$ inches inside diameter.

c. Al other piping less than $2-1 / 2$ inches inside diameter.

d. All electrical conduit less than $2 \cdot 1 / 2$ inches $i$.sside diameter

c. All rectangular air-handling ducts less than 6 square feet in cross sectional area.

f. All round air-handling ducts less than 28 inches in diameter.

g. All piping suspended by individual hangers 12 inches or less in length from the top of the pipe to the bottom of the support for the hanger.

h. All ducts suspended by hangers 12 inches or less in length from the top of the duct to the bottom of the support of the hanger. 


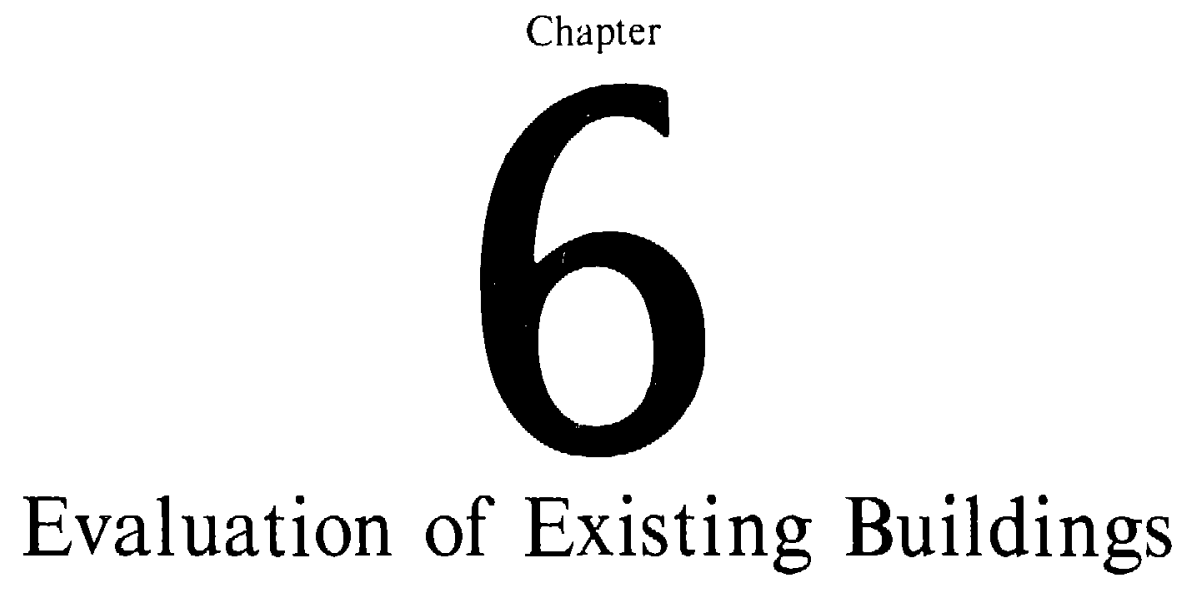

FOREWORD: Operator-Manager's Point of View (Donald G. Eagling)

When existing facilities are revicwed for earthyuake safety. it is not unusual to find scrious structural deficiencies in a signilicant percentage of the buildings reviewed. This has been the experience in both public and private sectors. Unfortunately, relatively new buildings, presumably designed to comply with modern seismic design codes, are sometimes found to be huzardous. At times, earlier codes have been more or less permissive with respect to seisnic design. Also. many buildings were legalistically designed to barely neet the minimum requirements of the seismic code to keep construction costs as low as possible. Lisually these buildings lack the ductility or redundance that is generally obtained if the designer carrics out the fundamental intent of the code. Sometimes important elements of the lateral-force-resisting system were constructed of brittle material. A good example is the non-ductile reinforced concrete frame which was permitted by cude until relatively recently.

As previous!y stated, it is important for the operator-manager to recognize that a building of recent vintage may be unsafe even if it was "designed to code". This is always an important consideration and particularly when a number of buildings must be reviewed for earthquake safety and a priority system is to be established for the sequence of review.

The term "designed to code" is a relative matter depending upon the year it was designed and built. Structural engineers learn from every new earthquake and from time-to-time this information is reflected in major changes in the earthquake provisions of the Uniform Building Code. In the saine manner, research leads to changes. Almost invariably these changes lead to code "improvements." Looked at from the opposite point of vicw, each seismic code change increases the inventory of "non-conforming" buildings which some view as "unsafe" buildings. At times structural provisions of the code have been weakened and sometimes new types of construction were allowed for short periods before the design was properly' codified. "Designed to code" should not be taken as assurance that a building is well designed for earthquake safety.

It should not be taken for granted that just hesause a building was designed at a particular time it was actually designed to comply with the code in effect at that time. A determination should be made whether or not it was in fact "designed to code." The foregoing are good reasons to ut.: ze a structural engineering consultant who has haa significant experience in observing earthquake damage to buildings and in evaluating their anticipated seismic performance, to make a seismic evaluation of existing facilities.

The subject of modern hazardous buildings has been a sensitive one for the engineering profession to deal with publicly. The legal aspects of the problem - tie liabilities involved, pressures from materials suppliers, heavy investments. uccupancy considerations and techntical limitations of code enforcement all tend to cloud the issue and suppress public discussion. Even in those cases where public buildings have suffercd serious structural seismic damage because of poor design. the profession of ten has been unable to deal with the problcm clearly and effectively. These buildings in general have only marginally met the legal minimum requirements of the code while missing the broader, more basic "motherhood" provisions of the code which define intent. Many knowledgeable earthquake engineers who are convinced of the hazards inherent in such buildings 
cannot point fingers specifically without considerable personal liability. The usual appreach therefore is 10 modify the code to solve future problems rather than to mitigate existing hazards.

Fortunately, the State of California Seismic Safety Commission is making good progress in dealing with the hazardous buildings problem. Recently a Subcommittee of the Seismic Safety Commission presented a report entitled, "Other Major Kinds of Potentially Hazardous Buildings," in which it addresses the identification of building types it considers to be potentially hazardous, excluding unreinforced masonry structures. The subject of unreinforced masonry buildings has been extensively' studied by others and steps have been taken by several California cities to abate the hazard presented.

The Subcommittee's report which deals directly and effectively with potentially hazardous modern buildings is reproduced below to give the Operator-Manager good insight into the problem.

\section{"General}

\section{“OTHER MAJOR KINDS OF POTENTIALLY HAZARDOUS BIILDINGS"}

"This Subcommittee has identified several general calegories of buildings which can be considered as being hazardous during seismic disturbances. This is with recognition that it is extremely difficult and perhaps even improper to categorically classify different lypes of construction as being hazardous. There are many factors contributing to the manner in which a specific building will perform during a severe earthquake. Nevertheless, there is general agreement within the Subcommittee that the categories identified include many hazardous buildings. The identification has been in broad but recognizable terms, but these categories will need to be reasonably well defined in order to enable anyone to cite a particular building as hazardous. Even with precise definitions, the classification of the degree of hazard of a specific building will be largely subjective.

"As with all subjective evaluations, there will be a broad range of risk included in each category, probably ranging from zero to maximum risk. One of the major problems in attempting any abatement program wili be to evaluate the risk of each building in order to determine a course of action. Some of the important clcments of risk that this Subcommittee should consider are:

- What is the seismicity of the particular area? For example, a building that is hazardous in Los Angeles may not be hazardous in Modesto.

- What is the life safety exposure'? What is the nature of the occupancy, and do a large or small number of people occupy the building?

- What is the importance of the function of the building during and immediately after an earthquake? Is it essential to be operative after an earthquake?

- What performance do we anticipate during an earthquake? Do we expect complete collapse or other extreme life safety hazards?

- How does the quality of the particular design and construction affect the risk? Is the building better or worse than the average in its category?

"The definitions of the categories of hazardous buildings should include consideration of these elements of risk.

"Assuming that the general categories can be adequately defined, the next step would be to establish some system to identify individual hazardous buildings. This presumes, of coursi, that the total concept of abatement of hazardous buildings nas teen accepted by the general public and their governing political bodies. The Subcommittee did not attempt to address that issue, other than to state that an extensive efucational process undoubtedly would be réi:ired, and any program would have to consider the overail aconomic impact on the community, with a reasonabie time period for implementation.

"The Subcommittee feels that the system used by the City of Santa Rosa appears to have a great deal of merit. In general, that system entails a review by the City Building Department to generally identify those buildings that may be considered to be hazardous, and requires the owners of the buildings to submit engineering reports in sufficient detail to classify the buildings as hazardous or nonhazardous. If the building is found to be hazardous, then srme abatement program is required, varying from demolition to minor repair."

The charge to the Subcommittee also included a number of questions that are difficult to answer in detail without a great deal of research. Pertinent comments on those questions are included in the following discussions of the various building categories covered by the Subcommittee's report.

\section{"Non-Ductile Concrete Frame Buildings}

"Throughout the State of California, there exists a large number of "non-ductile concrete frame buildings." Included are buildings from the very early days of reinforced concrete structures, up to the time when building codes required that any moment-resisting frame which was part of the carthquake resisting system, had to be a ductile moment-resisting frame (1968 - San Francisco, 1973 - Uniform Building Code). Non-ductile concrete frame buildings have suffered badly in all recent earthquakes. In general, this type of building does not have a shear wall system, and the lateral-force resistance is expected to be provided through frame action. Many of these buildings were designed and constructed prior to the adoption of earthquake codes and they have some, but very little. 
calculable seismic resistance. Those buildings that were designed and built under a building code requiring earthquake resistant design can probably show more calculated resistance, but that resistance is generally not sufficient to withstand earthquake forces which will stress the building beyond its elastic limit. The details of construction of the non-ductile concrete frame building are such that severe damage and possible collapse can be expected in areas of exposure to strong earthquakes.

"There are a large aumber of these buildings in the older, relatively large cities such as San Francisco, Los Angeles and Oakland. Of the older buildings, there are many in the medium height range of 4 to 8 stories. In the 1950's and 1960's some taller buildings were built, up to twenty stories. Many of the older buildings were occupied as manufacturing or warehouse buildings as well as office buildings. With the current interest in the rehabilitition of older buildings, many of these buildings are candidates for conversion to a new use, such as some form of housing. Such rehabilitation is an excellent opportunity to provide an adequate earthuquake-resisting system for the building.

"Non-ductile concrete building frames can be found in one-story parking garages or similar structures, with relatively heavy concrete roof systems, ostensibly braced by slender non-ductile concrete columns which often cantilever out of the foundations.

Current building (seismic) codes will not allow further construction of this type of building. although this presumes adequate code enforcement.

"Strergthening of existing buildings of this type can best be accomplished through the use of a concrete shear wall or braced frame system. The cost of these systems would depend upon the nature of the specific building, but would protably be relatively expensive, say 24-50\% of the cost of new construction. (Some examples of failure and damage to non-ductile frames are: VA Hospital, San Fernando, California; the ambulance structure, Olive Vie'N Hospital, San Fernando; Petunia Building. Caracas, Venezuela; and Cypress Gardens, Caracas.

\section{"Precast Concrete Buildings}

"While most of these buildings are of tilt-up concrete construction, they fall into two basic subcategories: Pre-1973 tilt-up buildings, and recent and current tilt-up precast buildings.

"Pre-1973 Tilt-up Buildings: Following the extensive drarage to tilt-up buildings in the 1971 San Fernando Earthquake, changes were made in the building codes requiring positive anchorage of the precast wall panels to floor and roof diaphragms, as well as other specific diaphragm details. It is presumed that buildings constructed since that time are adequate in this respect: however, there are many buildings throughout the State that were constructed with details similar to those used in damaged San Fernando buildings. Buildings in this category were of masonry wall construction as well as tilt-up concrete. While some owners have taken steps to correct these deficiencies, it is the judgment of this
Subcommittee that most have not. (An example given of this type of construction is the Vector Electronics Building which suffered severe damage in the 1971 Sin Fernando Earthquake.)

"Those pre-1973 tilt-up concrete buildings could be reinforced at relatively low cost to provide anchorage sufficient to prevent wall collapse during a severe earthquake since the roof to wall interface is usually: exposed and accessible.

"Recent and Current Tilt-up Precast Buildings: While wall-diaphragm connections and diaphragn details have improved since 1973, other aspects of tiltup and precast concrete construction have deteriorated. The use of tilt-up construction has expanded beyond the original industrial warehouse type of building with mostly solid wall panels, into light industrial, commercial, retail, and housing uses, with much more attention to "architecture." This trend has lead to precast tilt-up buildings with many large openings, that in the extreme become simply spandrels with very narrow integral columns. In general, adjacent panels are no longer connected together except for chord reinforcing at the diaphragm and the panels are not adequately connected to the foundation system. Whereas tilt-up construction was originally used primarily for one-story construction, two-story buildings are now quite common and taller buildings are occasionally observed. This new generation of tilt-up building does not have the characteristics of ductility, toughness and redundancy which are necessary for good earthquake performance. These buildings have not yet been tested by a real earthquake. but it is the opinion of this Subcommittee that they will prove to be collapse hazards.

"Casual observation of a number of these precast concrete buildings currently being constructed makes it quite clear that the designers of these buildings either do not understand the primary elements of earthquake resistant design or they choose to ignore them. Of equal significance is the fact that these designs are being approved by the local building departments. The Subcommittee feels that this issue is of extreme importance.

"These precast buildings are being constructed in large numbers throughout the State, particularly in areas of rapid growth of light industry, which in many cases also happen to be in areas of high seismicity.

"A program of education for architects, engineers and building officials should be given to avoid this type of hazard in the future. It may well be necessary to effect code changes which would require very specific details and configurations, such as is done in ATC-306. Strengthening this type of existing building would probably vary deperding on the nature of the building. but should probably include a well distributed system of concrete shear walls or braced frames. It is anticipated that repair of such buildings would be relatively expensive.

\footnotetext{
" "Tenta.ıve Provisions for the Development of Seismic Regulations for Buildings," ATC-3.06, Applied Technology Council, Palo Alto, California, June 1978.
} 


\section{"Soft Story Buildings}

"The soft-story building is much more difficult to identify because the structural system is often obscured by cladding. There are many such buildings, but we have no idea how many or where they are located. We think the scope of the problem is significantly less than for non-ductile concrete frame buildings or precast concrete buildings. Nevertheless, these buildings should be identified, as they can present a very great hazard. The most hazardous of these buildings also fall under the non-ductile concrete frame category. (Examples given of soft-story buildings are the Olive View Hospital and the Imperial County Service Building).

"Future hazardous buildings of the soft-story variety might be avoided by enacting code changes outlawing this type of construction. There are numerous building configurations, however, that can have a negative influence on building performance under seismic loading. Requiring "special analysis" and ductile performance for "irregular" buildings is considered to be a better solution, but it depends on knowledgeable engineers, architects and a good plan-review procedure,

"The correction of existing hazards posed by the soft-story building can probably be done most effectively through the addition of concrete shear walls or braced frames.

\section{"Other Identified Hazards}

"Prestressed Concrete Buildings: Buildings with prestressed elements, some cast-in-place and some precast. have suffered significant distress due to high stress concentrations resulting from creep, shrinkage, and temperature shortening. Volume change of this type is not compatible with the philosophy of providing ductility, toughness and redundancy by tying together an earthquake resistant building.

"The long-term creep-shortening of the prestressed double tees was the basic problem behind the Artioch High School roof failure, which resulted in an evaluation of similar systems in other schools throughout $\mathrm{Cal}$ ifornia.

"Many post-tensioned structures have been observed to suffer significant cracks and structural deterioration due to the creep-shortening effect of the post-tensioning forces. Many of these structures are undergoing scrutiny by knowledgeable owners, and this type of construction will certainly bear watching.

"Pre-1934 Unreinforced Masonry Buildings having less than five dwelling units: These buildings are now exempted by the Los Angeles ordinance, but there is still a potential for a large loss of life throughout the State of California in this type of building. Research is required to better analyze, evaluate and reduce the earthquake hazards in these buildings.

"Theaters and Auditoriums with Long-Span Roof Structures built prior to 1933: This class of structure presents a potential hazard to a relatively large number of occupants due to the wide span of the roof structure and the lack of a lateral force-resisting system. Further hazards are created by high stage walls and scenery as well as other materials in the Hy lofis.

"Exterior Cladding and Glazing: Many buildings are clad with heavy precast concrete or masonry panels which are attached to the basic frame. The strength of these connections is vitally important to prevent the panels from breaking loosc as a result of building distortions in a severe earthquake. Buildings constructed before the advent of current code anchorage requirements are particularly suspect.

"These systems should be the subject of continuing research, as should glazing practices and details to prevent shattering of glass.

"Parapets: This list would not be complete without parapets. Although Los Angeies long ago completed a hazardous parapet abatement program and San Francisco is doing so now, other cities with similar seismic exposure should follow suit.

\section{"Summary}

"This report has presented several categories of buildings which the Subcommittee considers to be hazardous to a reasonably significant degree. Several other categories, considered to be of lesser importance have also been discussed.

"The following policies are recommended for consideration by the Seismic Safety Commissioni.

- Tentatively establish a list of "Other Major Kinds of Potentially Hazardous Buildings."

- Develop reasonably precise definitions for those categories.

- Prepare a system for evaluating the risks involved for individual buildings, including consideration of:

Local Seismicity

Degree of Life Safety Exposure

Importance of Building Function

Nature of Hazard

Quality of Design and Construction

- Compile an Inventory of Buildings to be Considered.

- Consider Recommended Code Changes for Certain Problem Areas.

- Consider the Economic Impact of Enacting an Abatement Program and the Political Reality of doing so.

- Evaluate the Total Abatement Program."

The subject report by the California Seismic Safety Conmmission's Subcommittee marks an important step forward in public recognition of problems inherent in many modern hazardous buildings. The Subcommittee's summary recommends broad policy to the Commission and provides an excellent outline for a systematic approach to prioritize the evaluation of existing buildings with respect to hazard abatement. It also provides a logical background for this Chapter, which describes a practical methodology for carrying out a seismic safety survey of existing buildings. 


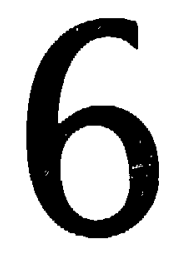

\section{Evaluation of Existing Buildings}

Harold M. Engle, Jr.

Engle \& Engle were the lead structural engineers of the seismic safety program at Lawrence Berkeley Laboratory. In addition both Harold M. Engle, Sr. (1898-1977) and Harold M. Engle, Jr. played a principal role in many aspects of writing and producing this publication.

Mr. Engle, Sr.'s 58-year career in civil and structural engineering included 19 years on the Field Act Advisory Buard to the State Architect (California) for the design of public school buildings. Additionally, he was the Consulting Structural engineer for the Pacitic Fire Rating Bureau and Factory Insurance Association, responsible for review of seismic risks. He also developed procedures for rating buildings for earthquake insurance rates. A charter member of the Earthquake Engineering Research Institute, Consulting Engineers Association of California, and the Structural Engineers Association of Northern California, he was also a member of the American Society of Civil Engineers and the Seismological Society of America. Mr. Engle was the author of numerous publications and. throughout his career, gave more than 100 talks on earthquakes and earthquake-resistant structural design before various technical sucieties and service clubs.

H. M. Engle, Jr., a University of Southern California graduate, has worked more than 20 years in the Engle \& Engle partnership and is now sole technical partner in the firm. He is a member of the Structural Engineers Association of Northern California, Consulting Engineers Association of California, Earthquake Engineering Research Institute, and the Seismolagical Society of America. To his work in the field of seismic analysis and design. Mr. Engle has brought a thoroughly professional methodology for surveying existing buildings and facilities for earthquake-related hazards and providing seismic strengthening recommendations. Engle \& Engle is located in San Rafael, California.

\section{Introduction}

In order to evaluate structures for seismic resistance the investigator must have a concept of what structural systems provide assured earthquake resistance. This concept can best be developed by observing the performance of structures in past easthquakes. Prior to embarking on an earthquake safety program, the project manager should request a statement from the structural engineer consultant performing the evaluation regarding review criteria.
The awareness and concern of design professionals regarding earthquake hazard has not followed a smooth path. In California, the period between 1906 and 1933 was one of reconstruction and rapid growth, with the large majority of the design profession (architects and engineers) not addressing the seismic design problem. The Long Beach earthquake of 1933, with the subsequent passage of the Field Act governing public school design in California, altered this to some degree. From 
1933 to 1971 seismic design provisions became incorporated into the Uniform Building Code used throughout the West. Unfortunately, outside of public school design in California, the efficacy of all aspects of the Code lateral force provisions, their enforcement, and the attention and judgment given the provisions by many design professionals were not conducive to achieving a consistent result.

Outside of California the majority of the design profession was either ignorant of, or ignored seismic design. During this period many buildings were constructed which can be classified as earthquake resistant. Earthquake resistance was accomplished either by accident or by designers who had studied past building performance and used judgment in applying Code provisions, realizing that Code provisions were minimum and sometimes fallible, and that adherence to them did not guarantee earthquake-resistant structures.

The spectacular freeway-overpass, hospital-building, and other structure collapses produced by the 1971 San Fernando, California earthquake have made the entire design profession, code writing bodies and regulatory agencies suddenly aware of earthquake hazards. News media coverage of seismic design adequacy in nuclearpower-plant, liquid natural gas, dam, and other potentially hazardous facilities, has intensified interest and concern. The pendulum has swung from ignorance and apathy in some quarters to awareness. Unfortunately this has resulted in extreme conservatism in design parameters used by some designers and regulatory agencies. This over-conservatism does not correspond with past building performances. An example of this is the 8-inch concrete shear wall buildings at the Veteran Administration Hospital that withstood the San Fernando earthquake without si"uctural damage. Seismic design criteria for the new, post-earthquake, Olive View Hospital, were so stringent that the VA buildings would not satisfy them. ${ }^{1}$

The intent of the seismic design evaluation is to identify real seismic hazards, not to make blanket condemnations based on unrealistic seismic design criteria.

The following sections offer brief descriptions of construction types, with comments on their earthquake resistance. $^{2}$

\section{Concrete Construction}

Cast-in-place, moment-resisting concrete frames: This type of construction has produced numerous total collapse failures in past earthquakes. The four building collapses in the 1967 Caracas quake, and collapse of the Olive View Psychiatric Unit (San Fernando, 1971) are among the most notable. Concrete frames in both cases were non-ductile and illustrated the need for continuity of longitudinal top and bottom steel in horizontal members, adequate confinement of vertical column bars, design consideration of the effects on "non-structural" elements, and the use of realistis lateral-force coefficients. Both ductile and non-ductile concrete frames are subject to relatively large displacements, with non-elastic energy dissipation occurring after fairly high velocities are reached. In the case of the Olive View Psychiatric Unit there is doubt that even if the frame had been designed as a ductile frame, that collapse of the structure would have been prevented without the use of higher lateral force coefficients. For this reason, existing buildings with moment resisting concrete frames, non-ductile and ductile, should be carefully investigated for earthquake safety.

Many concrete frame buildings have unreinforced masonry infill walls. The relatively flexible frames often provide inadequate deflection (drift) control, resulting in excessive damage to these brittle elenents. In most cases where hollow tile or unreinforced concrete block infill walls have been used, no consideration has been given to interaction of the frame and infill wall. The result is that actual forces transmitted to the frames where masonry infill walls occur are considerably greater than the design forces. This type of construction is particularly hazardous and generally requires rehabilitation for earthquake safety.

Cast-in-place reinforced concrete shear wall lbox system): This type of construction, when adequate attention has been given to design detail, has an excellent performance record in past earthquakes. When the term "shear wall" is used it should be assigned to walls in which the principal resisting vertical elements, when stressed beyond the elastic limit, will provide nonelastic energy absorption without collapse hazard. Shear wall action occurs when wall elements have a $H / D$ ratio $\leq 1$, and wall grid reir.forcing is sufficiently anchored to edge trim bars and foundations so that diagonal cracking occurs before flexure or overturning failure. A series of short, closely spaced columns confined by deep spandrel beams similar to the longitudinal walls of the Hakodate University classroom building (Fig. 1) should not be construed as shear wall construction.

The failures of the Four Seasons Apartment (Anchorage, Alaska, 1964) and the Olive View Hospital stair towers (San Fernando, 1971) were overturning failures and not failure of shear walls per se. Shear wall construction in low rise buildings (approximately 160 feet or less) can provide truly earthquake resistant construction. Shear wall construction is capable of limiting non-structural damage and precluding the possibility of ground-vibration induced collapse. Figures 2 (Industrial Bank of Japan, Tokyo, 1923); 3 (Stanford Avenue School, Southgate, CA, Long Beach, 1933); 4 (Knik Arms Apartment Building, Anchorage, Alaska, 1964); and 5 (Veterans Administration Hospital, San Fernando, 1971) are representative of sound concrete

\footnotetext{
"H is height of wall elcment. D is width of wall element.
} 
Fig. I - Hakodate University classroom building, Tokachi-Oki earthquake, Japan, May 1968.
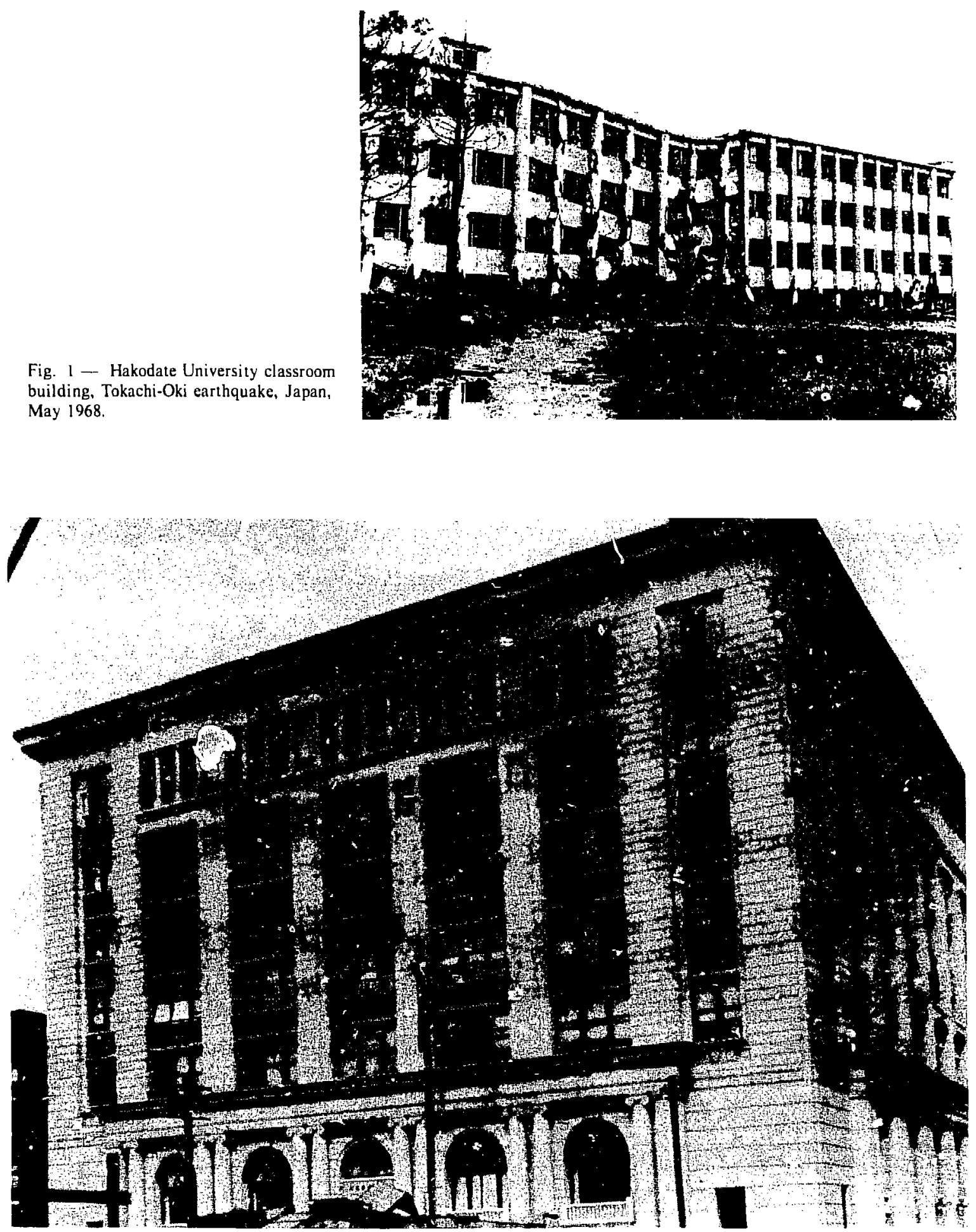

Fig. 2 - Industrial Bank of Japan, Tokyo, 1923. 


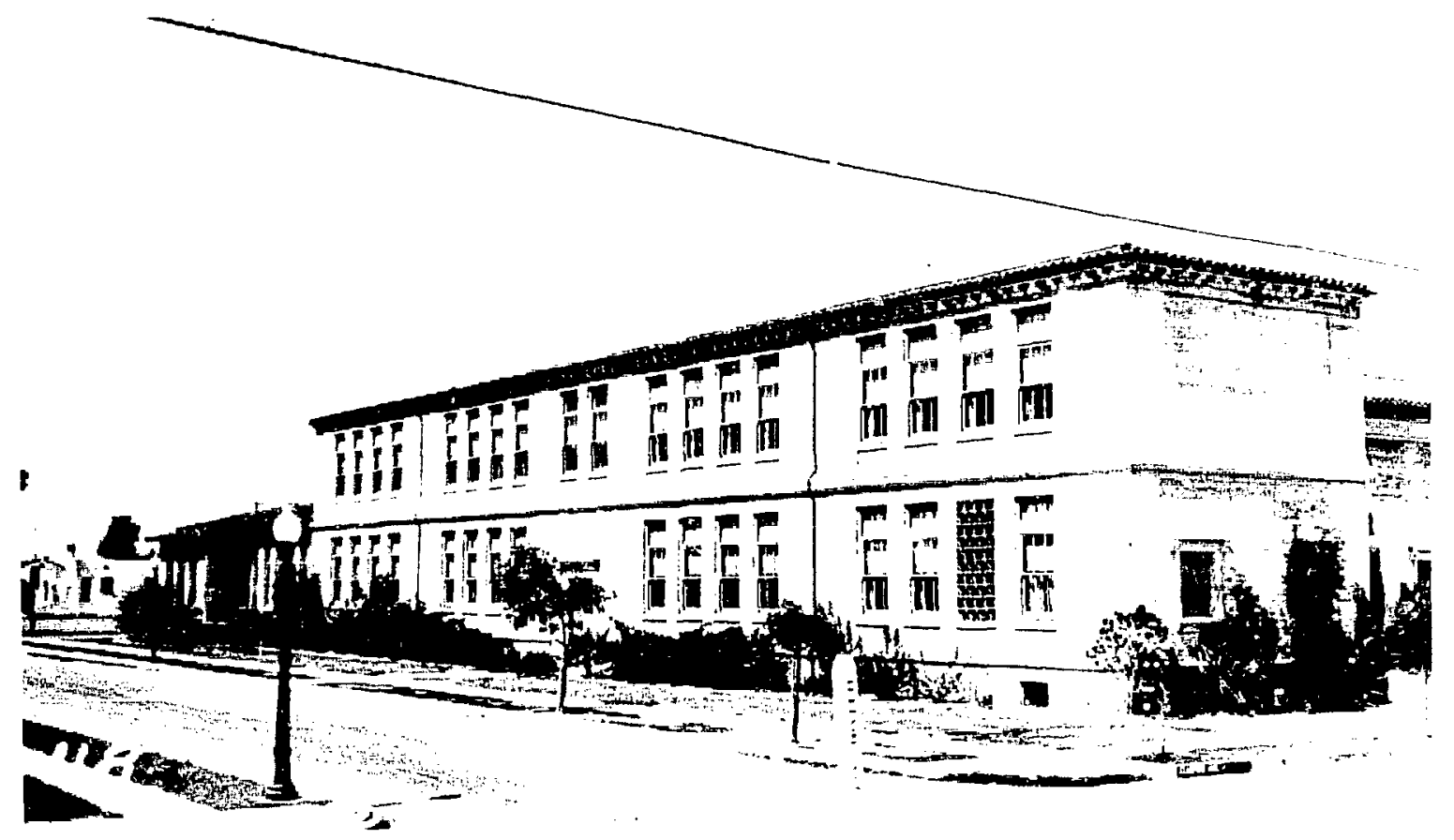

Fig. 3 - Stanford Avenue School, Southgate, California; Long Beach earthquaks, 1933.

shear wall construction. All of these structures survived the major quakes noted with little or no damage. The Industrial Bank of Japan had numerous interior concrete shear walls, exterior concrete walls and a complete vertical load-carrying structural steel frame. This building was designed, by Dr. Naito in 1920 , to resist earthquake forces (base shear) equal to $10 \%$ of the weight of the building.

Precast-prestressed and post-tensioned concrete construction: The greatest inherent problem with precastprestressed construction is obtaining adequate strength in the connection of components. Economic pressure influences connection detail. When the decision is made to use precast-prestressed components many designers, in order to justify the alleged economy, feel obligated to keep the number of connections to a minimum and let convenience and speed of erection become the dominant design criteria. It is difficult for a few weld plates with anchors embedded 3 to 4 inches into the edge of a component member to equal the strength and toughness of a connection made with conventional reinforcing spaced 12 inches on center and properly embedded in a cast-in-place closure pour. Both precast-prestressed and cast-in-place, posttensioned construction are subject to elastic strain and inelastic (creep) strain due to prestress forces. When this type of construction is used for floor and roof systems which frame into relatively stiff columns or walls, problems associated with thice strins can develop. Both the elastic and cieep shortenting can cause high moments and shears in columns, and high shear stresses in walls. There are numerous cases where buildings have literally been destroyed by this action. This ccndition severely limits the capacity of a structure to resist earthquake forces.

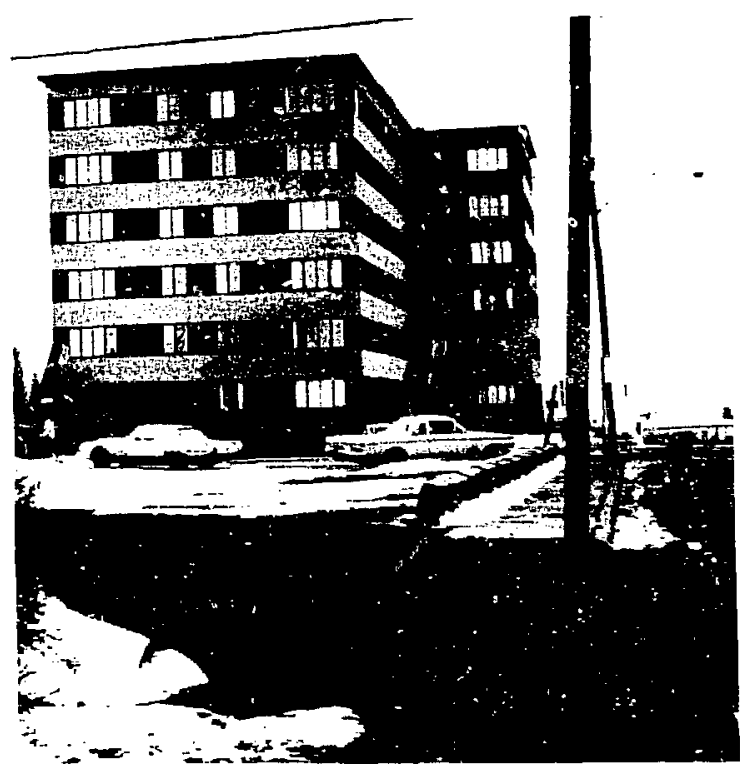

Fig. 4-Knik Arms apartment building, Anchorage, Alaska, 1964. 


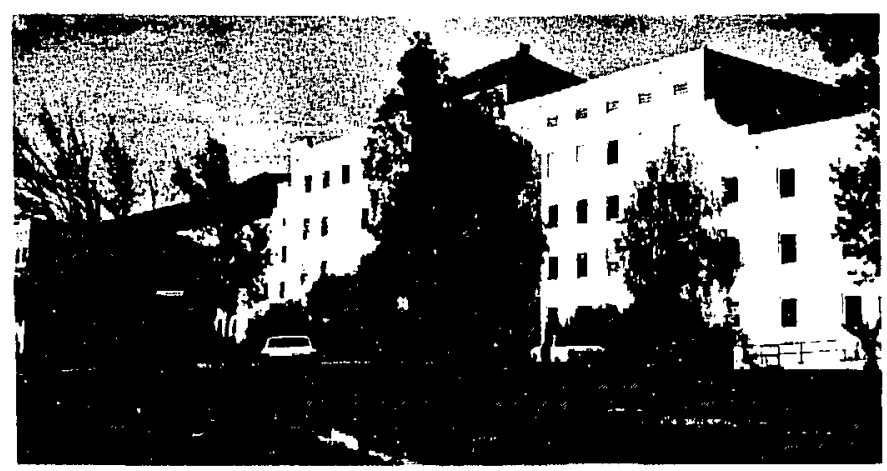

Fig. S - Two concrete shear-wall buildings of the Veterans Administration Hospital, San Fernando, California, 1971.
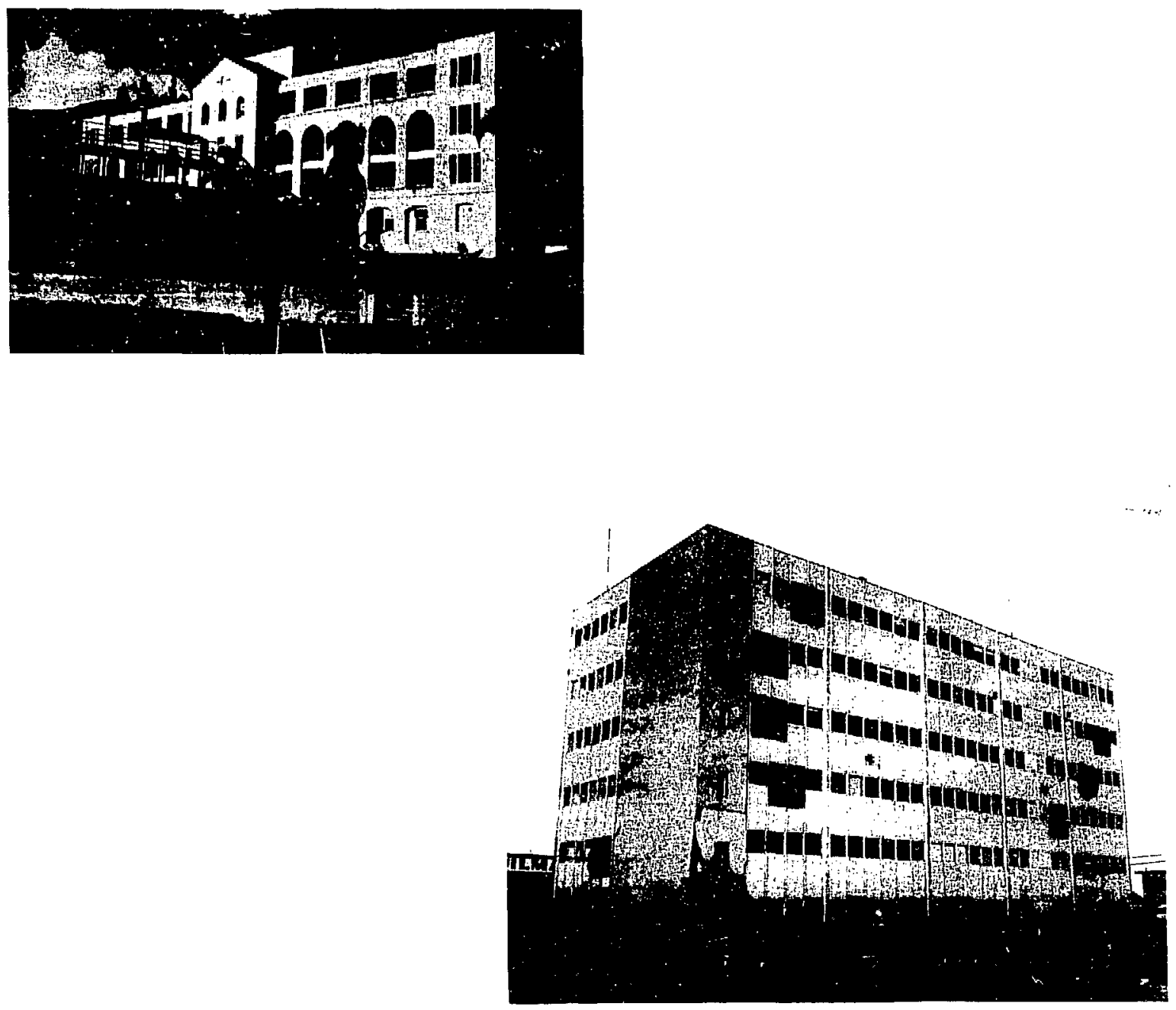

Fig. 6 - Cordova Building, Anchorage, Alaska, 1964. 

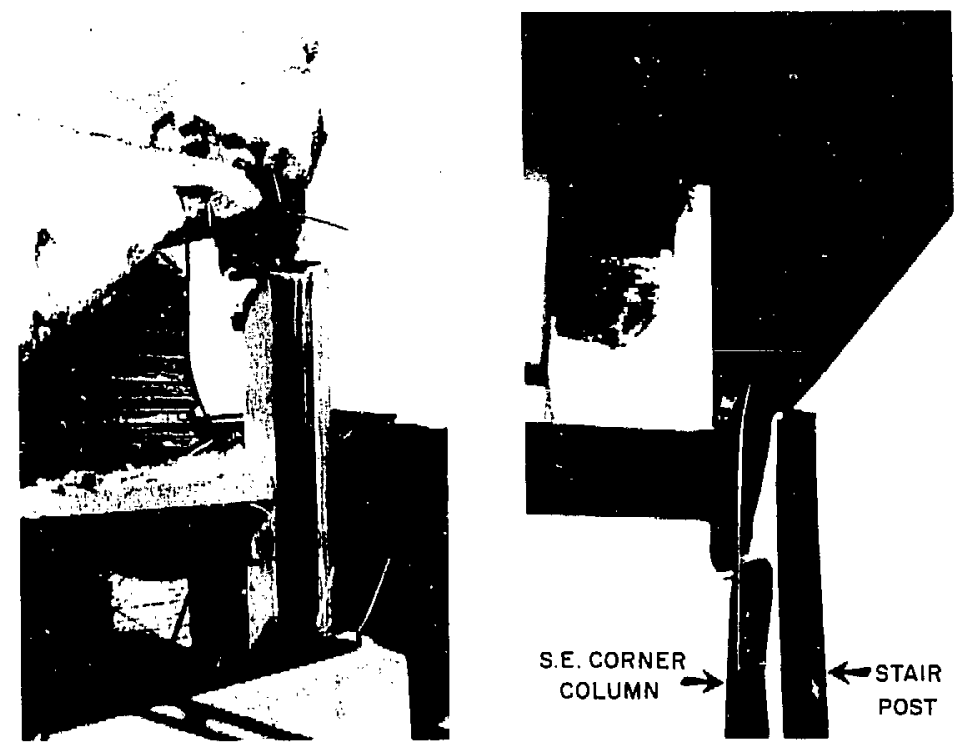

Fig. 7 - Construction detail, Cordova Building, 1964.

\section{Steel Frame Construction}

Numerous framing and bracing schemes associated with steel frame construction have been devised. Five general categories are: 1) ductile moment-resisting space frames, 2) proprietary type steel buildings, 3) braced frames using steel diagonal bracing, 4) steel frames using concrete or masonry shear walls, and 5) frames having a dual bracing system comprised of moment-resisting space frames in conjunction with shear walls or diagonal bracing (Uniform Building Code $\mathrm{K}=0.8$ ).

Relatively few ductile moment-resisting steel frame structures have been subjected to major shocks. No total collapses have occurred. The heaviest damage to this construction type occurred in the Cordova Building (Anchorage, 1964), in which a column failed at the southeast exterior wall corner (Figs. 6 and 7). This damage appears to have been caused by lack of consideration of frame, rigid-curtain-wall, and stairframing interaction, and the torsional effects of unsymmetrical core walls. The cast-in-place concrete stairway curtain walls contained minimum reinforcement. In reviewing this type of construction, particular attention should be given to the type and adequacy of attachment of exterior curtain walls and the possible adverse effects of stif, non-structural elements.

Single story, all-metal proprietary type buildings with braced and moment-resisting frames normally present minimal earthquake hazard. Wind forces generally govern. However, this type of construction can be susceptible to seismic damage when tension rod bracing is loose or has been removed.
Conventional buildings with diagonally braced steel frames can provide adequate seismic resistance if the bracing members and their connections arc conservatively designed for large seismic forces. Bracing members must be designed to act as tension and compression members. Braced frames not so designed and without back-up shear wall or frame action bracing, are subject to collapse if a bracing meriber buckles or fails in tension.

Steel frames braced with reinforced concrete shear walls should be classed as concrete shear wall construction. See "Cast-in-Place Reinforced Concrete Shear Wall (Box System)" for comments.

Frames braced with reinforced masonry walls should be classed as masonry shear wall structures. Frames that depend on unreinforced unit masonry infill walls jor lateral stability' are patently damage-prone and in many cases collapse hazards. See "Masonry Construction-Reinforced Masonry Shear Wall."

Steel frames with dual bracing systems (ductile moment-resisting space frames with shear walls or braced frames) can provide assured earthquake resistance if careful attention has been given to design detail and an adequate lateral force coefficient has been used.

The term "steel frame structure" is often interpreted as being automatically earthquake resistant. As noted above, steel frames are associated with a variety of iracing systems. Some of these systems can provide assured seismic bracing while others without earthquake design provisions can be collapse hazards. Each building must be considered on an individual basis. 


\section{Masonry Construction}

The term "reinforced masonry." used herein, means masonry reinforced with deformed reinforcing bars completely embedded in grout. For earthquake resistant design, masonry reinforced with proprictary wire mesh devices in the mortar joints should not be classified as reinforced masonry.

Reinforced masonry shear wall construction, when properly designed, has performed well in past earthquakes in low rise structures. Grout core brick and hollow concrete block units both can be adequately reinforced. In concrete block shear walls, it is good praclice to fill all cells with grout and use a common-bond pattern. Stacked bond is nol recommended. Figure 8 shows earthquake damage to a concrete block watl. This picture originally appeared in a report on the San Fernando earthquake with the erroneous caption, "Damage to well-reinforced hollow concrete block wall." This wall was completely devoid of horizontal reinforcing and the blocks were laid with stacked bond.

Reinforced masonry walls can perform as well as reinforced concrete walls. Reinforced masonry is more subject to human error during construction than concrete and therefore requires continuous construction inspection.

Unreinforced masonry shear wall construction, whether brick, concrete block, hollow tile, dry rubble masonry or adobe has proven extremely damage-prone worldwide. There are some exceptions. Unreinforced brick masonry well laid in cement mortar, with minimal wall openings and roof and floor diaphragms adequately anchored to walls, has surviver heavy shaking with minor or no damage. Each structure of this type of construction should be independently evaluated.

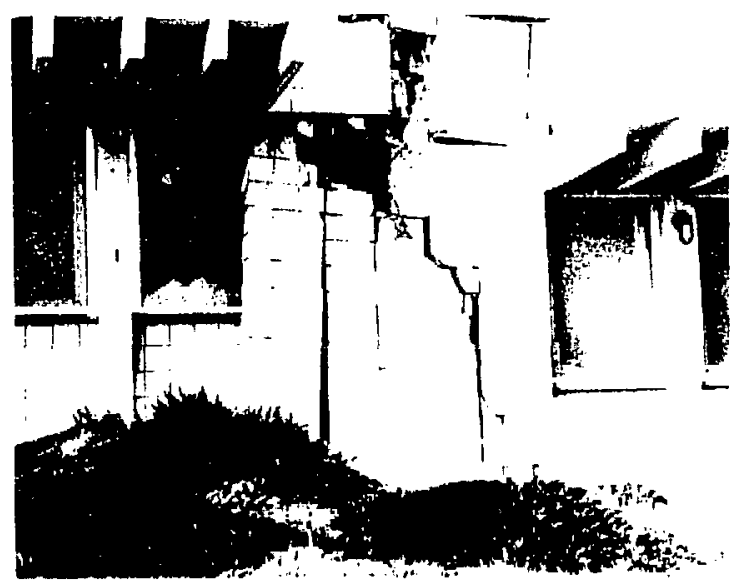

Fig. 8 - Stacked-bond laid, hollow concrete, block wall with no reinforcing; San Fernando earthquake, 1971.

\section{Wood Frame Construction}

As in the case of steel frame construction the inclination is to interpret wood frame construction as "earthquake safe". Due to its relatively light weight, the lateral stability of many wood frame structures is of ten governed by wind, not earthquake forces. However, there are numerous examples of collapse or partial collapse of wood frame buildings due to ground vibration not associated with ground subsidence or building site fault breakage (Fig. 9 - Dwelling, Long Beach, 1933). Wood frame structures are less susceptible to damage caused by design errors than concrete or masonry con-

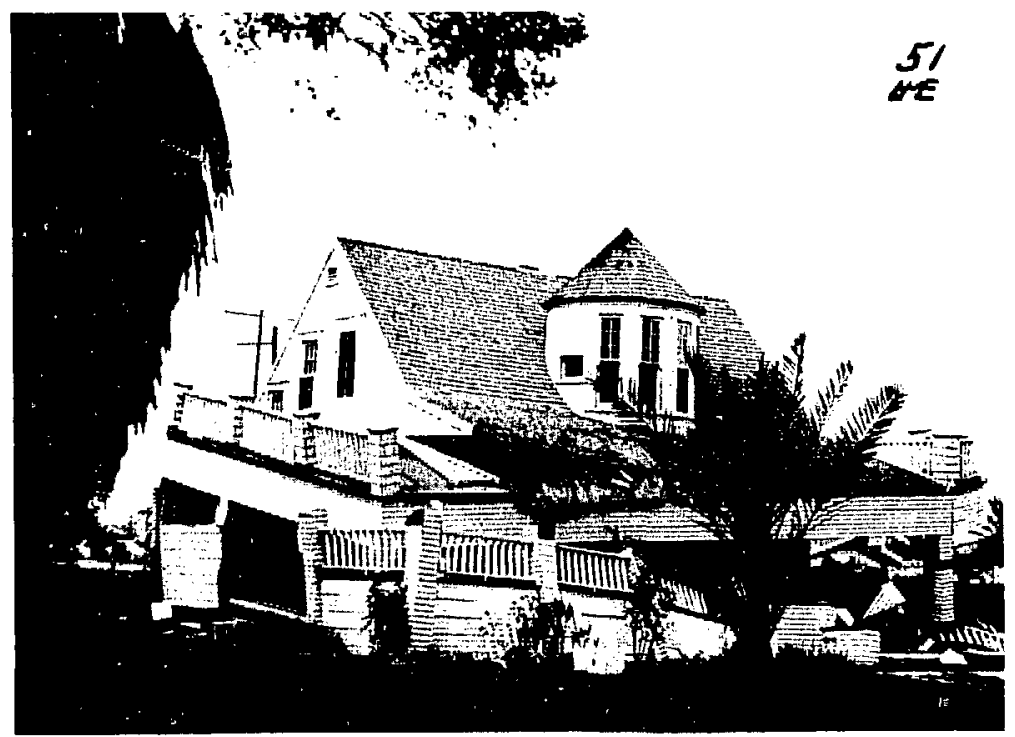


struction. However, they are definitely not immune. Poor performance of wood frame structures can be attributed to the absence of a rational lateral-force-resisting system.

Well designed wood frame construction can be made life-safe against earthquake ground vibration. This fact has been demonstrated by the performance of wood frame schools in California designed in accordance with State of California Administrative Code Title 21, administered by the Office of the State Architect. Many otner wood frame structures designed for industrial, commercial and residential uses have also performed well in past earthquakes.

\section{Building Evaluation}

Optimum information for evaluating existing buildings includes the following:

1. Complete architectural, structural, mechanical, and electrical plans, including construction change orders and complete plans of all subsequent alteration work.

2. Soils reports, including soil boring logs.

3. Construction inspection reports and laboratory reports on materials tests and inspections.

4. Original structural design calculations.

The information is listed in the order of importance. The complete plan record, including architectural plans, gives the reviewer an overall picture which the structural plans alone do not convey. In many instances socalled nonstructural curtain and infill walls not shown on structural plans have a major adverse impact on structural behavior. Mechanical and electrical plans can often provide information on anchorage of major equipment items and locations of embedded piping and conduit which may affect structural performance.

The importance of change orders and alteration plans is self evident. Aл original sound design can be seriously impaired by "snap" decisions rendered during the construction process. Alterations to an existing structure by a new group (other than the original design professionals) can result in impairment of the original seismic bracing scheme. This point is illustrated by a building at the Lawrence Berkeley Laboratory. The original structure was a diagonally braced circular structural steel frame. The design was adequate with no discontinuities in the lateral force resisting system. Additions to the structure required removal of some diagonal bracing in the plane of the walls and addition of structural tees to the weak axis of the eight existing columns to compensate for the removal of the bracing. The new built-up column sections were intended to resist lateral forces by column bending. Close inspection of the plans for modification showed no specific detail on connection of the tees to the truss gusset plates at the top of the columns. Subsequent field inspection revealed that the "T" reinforcing members extended to within 6 inches of the gusset plates and then terminated. The lack of connection between " $T$ " reinforcing and gusset produced a hinge at the point of maximum bending in the column. The tees as installed were completely useless in replacing the original diagonal bracing. The above example illustrates the necessity for carefully reviewing all documented alterations and the need for follow-up field inspection to insure that the alterations were properly implemented. The care taken in the oiginal design-construction process of ten is not manifest in subsequent alterations.

The soils report and borings give an insight into potential differential settlement problems and slope stability on hillside sites. Earthquakes can produce differential settlements which, under normal static conditions, would take years to achieve. Investigation at the Lawrence Berkeley Laboratory usually showed good coordination between the soils engineers and the design structural engineer. However, this has not always been the case in buildings investigated at other locations. In many instances, carefully prepared soils reports pointing out soils defects and giving specific foundation design recommendations, were completely ignored by the structural engineer. This lack of coordination produced conditions causing major structural-differentialsettlement damage under static load conditions. Earthquakes can turn such conditions into potential life hazards.

Construction inspection reports and laboratory test results provide insight into construction problems and also indicate the care taken to fully implement the intent of the design. Earthquakes act as the ultimate inspector in that they usually reveal construction defects, sometimes with disastrous results.

The design calculations, if available, can aid in the evaluation of the design. However, they are the least important of the information chain. They should not be used as substitute for making check calculations on important structural items vital to the performance of the bracing system.

\section{Information Gaps}

Many older structures have either no design record or an incomplete record. This lack of information should not preciude an evaluation. The evaluation process will be more costly; however, adequate information can be developed without literally' tearing the structure apart. At the Lawrence Berkeley Laboratory the information records were excellent and only a few minor buildings had incomplete records. Many California pre-Field Act (1933) schools without plan records have been evaluated and rehabilitated. The evaluation and rehabilitation have been economically feasible and effective as demonstrated by the performance of these rehabilitated schools in the San Fernando earthquake.

The following lists, with comments, give the general procedures for determining existing structural detail. 


\section{Wood Frame Investigation}

1. Remove adequate areas of interior and exterior finish 10 determine: stud size and spacing: top plate configuration and top plate splice detail and corner interconnection; sill plate size and anchorage to foundation: type of wall and roof sheathing. Gypsum board, gypsum lath and plaster, portland-cement plaster over paper-backed wire lath on line wire, and "straight" (face grain perpendicular to studs) one-inch nominal lumber sheathing, all can be considered ats structural diaphragm sheathing within rather narrow limits. Gypsum board and stuceo are brittle matterials -..- once fractured, they provide minimal shear resistance. "Straighi" lumber sheathing has limited shear capacity. Shear resistance of "straight" sheathing depends on the resistance of the nail couples. When diaphragms of this type are exposed to the weather the nails tend to loosen as the wood weathers.

Diaphragms of the above materials should not be considered as structural diaphragns except for small arca, one-story wood frame structures. If the brittle diaphragm materials show evidence of existing cracks due to differential settement or diffcrential wood shrinkage, they should not be considered as structural diaphragms. The same prohibition applies to exposed straight sheathed wood diaphragms with loose nailing.

Diaphragms sheathed with diagonal one-inch nominal lumber sheathing or plywood can perform as dependable diaphragms for any size wood frame structure. Diagonal shcathing should be checked for minimum code nailing. Diagonally sheathed and plywood sheathed exterior walls with stucco extcrior should have sufficient stucco removed to determine the existence of "dry rot" in the wood sheathing. Walls without roof eave overhangs are particularly vulnerable to leaks and subsequent "dry rot". Plywood sheathed diaphragms should be checked for ply'wood grade, thickness, nail size and spacing and edge blocking at unsupported joints.

Wall vertical boundary members should be checked for hold-down anchors to the foundation where the dead load of the wood frame superstructure is insufficient to counteract overturning forces.

2. Inspect attic and sub-floor areas to determine floor, roof member sizes and connection details. Determine the connection detail between roof framing members and walls. The connection should be checked for forces normal to the wall and shear transfer in the plane of the wall. The connection between wood frame floor and roof diaphragms and concrete and masonry walls is critical. The failure of this connection is onc of the major causes of building collapse or partial collapse where wood-floor-or-roof construction is supported by concrete or masonry walls. The connection should conform to all the provisions of the 1982 Uniform Building Code. These provisions prohibit the restraint of masonry and concrete walls by wood members subject to cross grain bending and cross grain tension.
3. Wood frame structures with masonry veneers: Special care should be taken to determine the adequacy of the veneer attachment. Sections of veneer should be removed to determire the type and condition of the anchorage. Wood frame construction with masonry veneer is subject to dry rot conditions similar to wood frame with stucco exteriors.

\section{Concrete Construction Investigation}

1. Remove sufficient finish to determine member sizes and provide access for cutting for cores and chasing.

2. Reinforcing size and spacing can be determined by cutting chases. "Typical" members of a given group can be chased to determine exact sizes and spacing of reinforcing, with other members of the group checked with magnetic detection devices to determine if the reinforcing pattern is consistent.

3. Cores for compression tests should be cut from slabs, walls, columns and beams. Each member category should have sufficient cores cut so that representative average compression strengths can be determined. In many older concrete buildings (circa 1900 to 1930) the concrete walls have the lowest compressive strengths. In shear wall type buildings of this vintage particular care should be taken to determine areas of concrete unsuitable for structural purposes. Concrete average compressive strengths should be greate: than 1500 psi for the concrete to be considered adecuate for structural purposes.

\section{Steel Frame Construction Investigation}

1. Remove sufficient finish to determine member size and connection detail.

2. Cut coupons from typical members for ultimate tensile and yield strength tests.

3. If frame has bolted joints, bolts should be checked for material type and torque, if high strength bolts.

4. Critical welded joints should be checked using nondestructive testing devices. Particular attention should be made to the inspection of bracing members and bracing connection detail in braced frames.

\section{Masonry Construction Investigation}

1. The investigation of reinforced masonry construction is similar to the procedures used for concrete construction, i.e., chasing and core cutting and testing. Grout core masonry should have some cores cut to determine the shear strength of the joint between the masonry unit and the grout core. All cores cut from both grout core and filled cell masonry should be subject to visual examination to ascertain if all joints and/or cells are completely grout-filled.

2. Unreinforced masonry: in general, unreinforced masonry should not be used for earthquake bracing purposes (i.e., shear walls). Cores should be cut from 
unreinforced masonry to determine the compressive strength. Masonry with compressive strengths less than 900 psi. should not be used for structural purposes (vertical load support).

\section{Seismic-Design-Check Parameters}

The question arises, upon what code will the structural evaluation be based? Will the evaluation be a "code" static design evaluation or will it be a dynamic design evaluation? The seismic design provisions of the Uniform Building Code ${ }^{3}$ have been considered a model in many other countries. As mentioned in the chapter introduction, the UBC provides minimum standards and is not infallible. In 1967 the Code regressed with the introduction of the " $\mathrm{J}$ " factor to reduce seismic overturning moments. The " $\mathrm{J}$ " factor was removed in the 1973 edition of the UBC, after the experience of the 1967 Caracas earthquake. Also, prior to 1973 there were no provisions in the Code that specifically prevented the use of wood diaphragm ledgers in cross grain bending and cross grain ties for the restraint of masonry and concrete walls. There were also no code provisions governing diaphragm cross ties. These provisions were added as a result of the 1971 San Fernando earthquake.

The 1982 edition of the UBC provides adequate seismic design check parameters for most structures, with the following exceptions:

1. It is recommended that only Zone 3 or 4 seismic provisions be used for facilities which should be earthquake resistant.

2. All concrete structures where frame action is the only means of seismic bracing should meet the requirements for ductile concrete frames. The " $K "$ factor for these frames should not be less than 1.

Since 1971, Title 21 governing California public school construction has required that all concrete frame buildings should be designed as ductile frames. Where ductile concrete frames are the only lateral force bracing, both static and dynamic design checks should be made.

The code static load design should be checked with the view that the building will be subjected to forces greater than the code forces. The following questions should be careful.y considered:

1. Does the building have a rational lateral forceresisting system? Is the system carefully detailed to avoid discontinuities in the load path?

2. Will the members and joints that are critical for stability deform without undergoing sudden brittle failure when stressed beyond yield?

Realistic seismic hazard evaluations of existing structures can be made using the above criteria. Life hazards can be identified and the necessary rehabilitation measures can be implemented to correct the hazardous conditions. The demonstrited performance of California public schools in past earthquakes of damaging intensity is a testimonial to this.

\section{Methodology}

The format used for the Lawrence Berkeley Laboratory inspection reports is shown on the sheets in the Appendices, 6 A-E. This format provides an overview of salient features affecting the seismic design of the structure.

Upon completion of the form sheets, A througf $D$, check calculations were made. Sheet $E$ (Notes on Design-Summary) was then completed. In our opinion, independent check calculations are preferable to a review of the original design calculations.

A thorough field inspection of the structure should never be omitted even if complete records are available. The inspection will not require the core cutting, chasing or testing as noted under "Concrete Construction Investigation," but should entail some removal of finishes at critical structural connections to corroborate that in situ conditions conform with plan detail.

\section{REFERENCES}

Chapter 6

1. Earthquake Design Criteria, Housne.r, G. W., and Jennings, P. C., Division of Engineering and Applied Science, California Institute of Technology; a monograph published by the Earthquake Engineering Research Institute, September 1982.

2. Learning from Earthquakes - Planning and Field Guides, Earthquake Engineering Research Institute, Berkeley, California, 1977.

3. Recommendec Lateral Force Requirements and Commentaries, Seismology Committee, Structural Engineers Association of California, San Francisco, Calif., 1980. 
Chapter 6

\section{APPENDICES}

A-D

Inspection Reports

Design Summary
6-16

6-20 


\section{APPENDIX A}

ENGLE \& ENGLE

STRUCTORAL ENGTIEHERS

EARTHEUAKE TNSPECTION REPORT

F11e No.

519

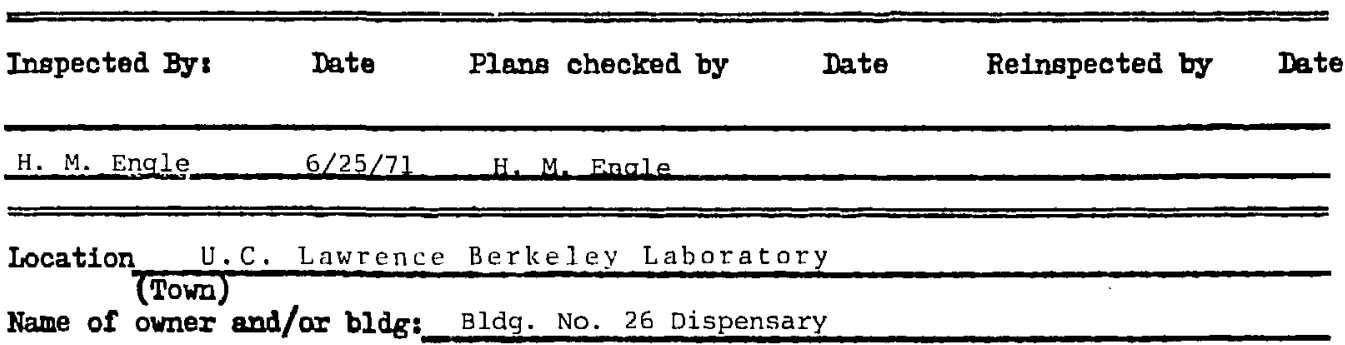

Occupancy and contents:

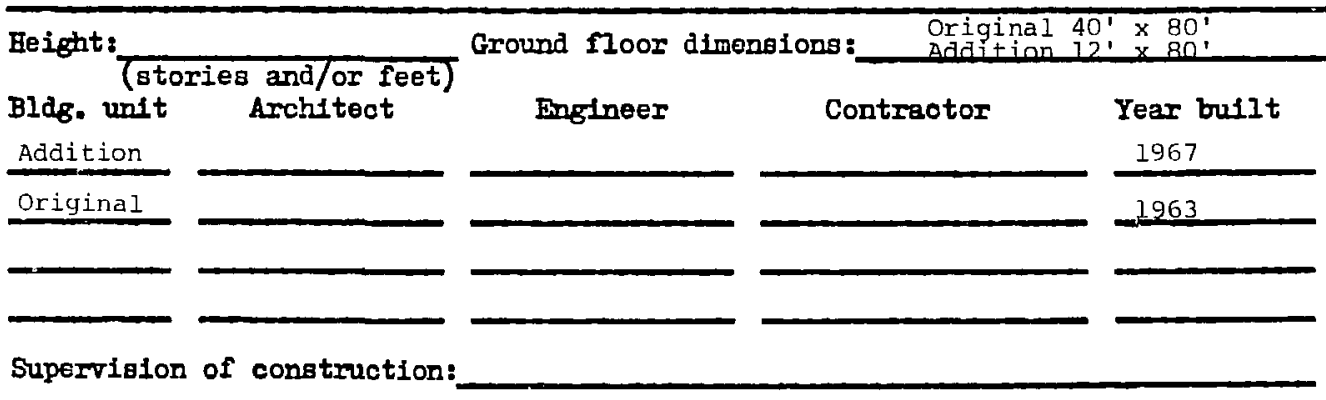

EXPOSURE -

Overhanging untt masonry or other large mase:

Side:

Side:

Side: Height

He1ght Helght
Material

Material

Material

Pounding againat adjointing atructure:

Side:

Side: Height of Contaot: Height of Contact:

Side? Height of Contact:
Separation between bldgr: Separation between bldgr: Separation between bld 8 :

ROOF STRUCTURDS

Chimeys, roof tanks, eigns, equipment, penthouses, eto: 


\section{APPENDIX B}

Foundation material and soll tests: Three test holes bored and logged. Material to about 7' depth, brown silty clay moderately firm, wet Material to about 7 I' shown as silty clay, moderately firm, moist or wet.

Footings and excavation depth: Addition and Original 24" or more below finish grade. Soil bearing noted as $2000 \#$ per $\mathrm{sg}$. ft.

\section{BASEMERNT}

HALU: Thtolness: Material:

FLOOR: Thtcleness: Material:

FRAITE

Steel frame - window wall structure - original and addition. Second floor slab loads (Line A of plans), are carried on 8" conc. wall - one plane of steel.

\section{FIOORS AND ROOF}

\section{Floor Thickness}

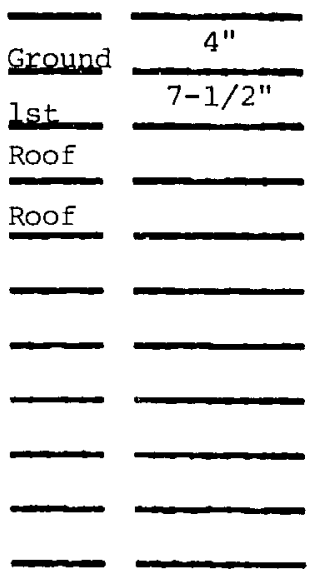

Material

Concrete

Rein. Conc.

Metal deck

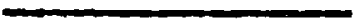

Metal deck on steel

\section{Slab on grade}

Slabs 20' span max.

Labs 20 span max.

steel deck

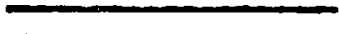

oists

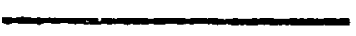

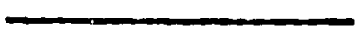
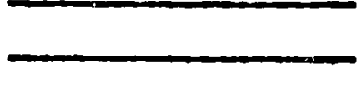
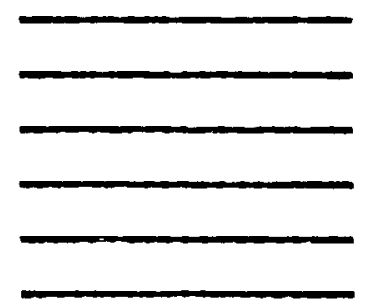

Original and Addition

Original

Adition Roof at

Qriginal ist floor level

Original 
APPENDIX C

$$
\text { File No. } 519
$$

\section{EXTERIOR WALLS}

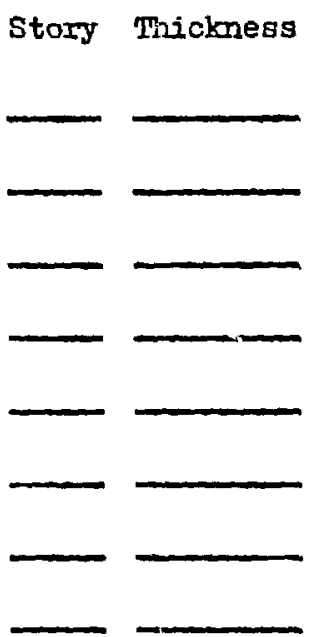

\section{Material}

Type

\section{Remarks}

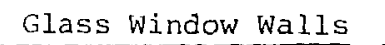

\section{Some sections filled}

with solid rement
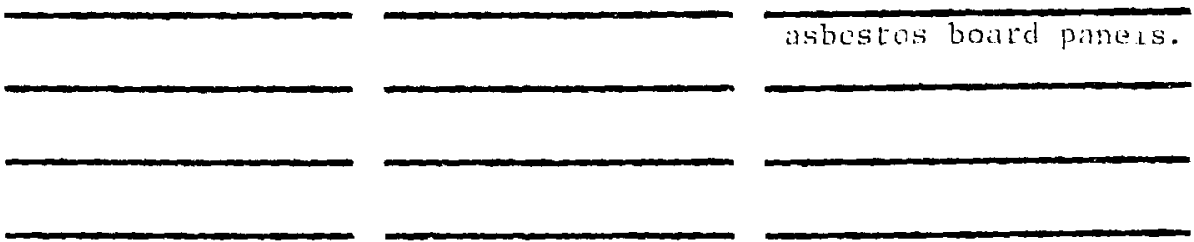

PARAPET: none

Height: Thichness: Material

Secured by:

Cornice and other projections: none

Material: Width of overhang:

Secured by:

Approximate percentage of wall opening: North 90: East 90: South 90\% West $90 \%$

Remarks

\section{INTERTOR PARTITIONS}

Quantity, type, material and thickness: Numerous non-bearing partitions - metal studs with gypsum board. 


\section{APPENDIX D}

File No.

519

ORNAWEITI:.TION

Exterior: none

Interior:

MISCEITANEOUS

Eridence of settlement: none noted

Exterior cracks: none noted

Interior cracks: few noted

Defective materials or workmanship: none noted

Previous earthquake damage:

none as far as could be ascertained

Fault. Approximate J sation of known nearby major faults: about $3 / 4$ miles east of Haywarai/

Unusual Structural conditions: Lack of bracing in transverse direction 


\section{APPENDIX E}

\section{NOTES ON DESIGN-SUMMARY}

File No. 519

The original building, 40' $\times 80^{\prime}$ in size, was one story, with the sub flcor space open, built in 1963. In 1967 an addition was made, consisting of closing in the sub floor area, and subdividing the area, and adding a shed addition, $12^{\prime} \times 80^{\prime}$ on the east side, with roor below original concrete floor slab level (Fig. 1). This addition does not increase or decrease the earthquake hazard to the structure.

The bldg. is located on a slope. The underlying soils are noted on the boring logs as moderately firm, moist or wet. The original ground surface dropped off sharp?y to the east.

The present building ground floor, Fig. 2, is a 4" slab on grade. The 1st (ground floor) story height is 14'-6". The 2nd floor (original floor) is a $71 / 2^{\prime \prime}$ reinforced concrete slab over the whole bldg. area. Slab spans, framing into the wall on Line A, are 16'-0". Slabs spannirg parallel to lines B and Al and between B and $A \perp$ have 20'-0" spans. The 8" concrete walls on lines Al and A below the second floor level are load bearing walls. Columns on Line B, 1st floor to roof are 8" W.F. 31非 columns, with webs parallel to the walls. Columns on line A start at 2nd floor and go to roof ( $8 \mathrm{~W} . \mathrm{F}$. 31 \# cols.). There are no structural steel columns in the end walls on lines 1 and 5 . These walls are open between lines $A$ and Al. All other exterior walls, both floors, are window walls or cement asbestos panels. The eave beam at roof, completely around the roof, is a continuous 10" W.F. 21 k beam with welded splices, and welded to the tops of columns. The connections to column tops are not symmetrical with respect to the columns and are poor as far as joint fixity is concerned. Corner columns are particularly poor (Fig. 3). Column bases are partially fixed by four $1 "$ round anchor bolts, all within the column (Fig. 3). The roof is spanned by 20 inch steel joists, span 40', resting on the $10^{\prime \prime}$ eave beams on lines $A$ and $B$. Roof joists are spaced at 8'-0" ctrs. The roof is steel deck, but plans show no detail of joints or welding. The end walls on lines 1 and 5 are devoid of bracing.

Longitudinal shears would be taken thru the $71 / 2 "$ 2nd floor slab to the 8 " concrete walls on lines $A I$ and $A$, most of the shear going to wall on Line Al. There is no steel tie between cols. on line $B$ at 2nd floor. The edge of the $71 / 2^{\prime \prime}$ slab being the fixity in a longitudinal direction. A 9 " channel was welded to columns on line $B$ to take the addition roof, and this could act as a tie. The channel spans 20' between columns. Shed addition has a steel deck roof. The concrete walls are good for longitudinal shears in excess of $131 / 3 \%$. Roof shears in a longitudinal direction would have to be transferred to the 2 nd floor slab by bending in the steel wall frames on lines $A$ and $B$. While the fixity detail at tops and bottoms of columns is somehwat deficient, it should be enough to give reasonable behavior in a severe

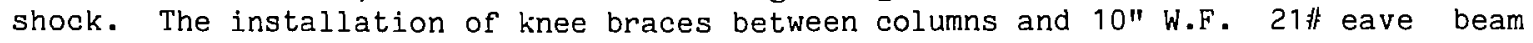
would be desirable however.

In the transverse direction (E-W) the building is practically devoid of any dependable lateral force resistance (see Fig. 2). The connection between roof joists and eave beams on Lines $A$ and $B$ provides no joint fixity. The joints between 2nd floor slab and walls on lines A and Al are hinged. Walls have only one plane of steel in center of wall ( $\# 4$ bars 9 10" ctrs. each way). (Continued) 
NOTES ON DESIGN-SUMMARY

File No. 519

(Concluded)

In a severer shock the 2nd floor slab could move downhill, toward the east with resultant collapse.

The soils at the site are classed as silty clay, moderately firm, moist or wet.

\section{RECOMMENDATIONS :}

1. Add three 8" reinforced concrete bracing walls between lines A and Al. Anchor to walls $A$ and $A I$, and to 2nd floor slab with thru bolts. (No cinch anchors allowed). Carry wall ftg. level at elevation $923^{\circ}$ and urder walls on $A$ and $A$. Dry pack solid under existing wall footin's. New walls to be slotted thru 8" block wall of addition. Reasonable sleeves shoui... be left in new walls to accommodate existing piping. A wall should be placed within $15^{\prime}$ of lines 1 and 5 , with the 3rd wall between. A wing wall below existing ftgs. should be used to transmit shears from bracing walls to soil. Note new walls between 1 and 2 , and 4 and 5 do not hit 8 " conc. wall on line Al.

2. Add tension and compression braces in 2nd story on Lines 1 and 5. Provide detail to transfer shears from roof to these braces, and from braces to slab. New vertical members from slab to roof will be necessary. This bracing could be placed on outside of wall.

3. Add one bracing wall between 2nd floor slab and roof near line 3 if possible. This wall should be about 20' long.

4. Provide new slab for equipment at south end of line A. Anchor equipment to slab.

5. Check equipment and contents for anchorage. One piece of equipment set on a table could be thrown to floor. Some of cases and shelves for bottle storage have sliding doors. This is desirable. Open shelves for bottle storage should have face bars to keep bottles from sliding off. All cases, shelves, and book cases should be anchored to walls or partitions. Heavy machines, $x$-ray etc. should be individually checked. 


\section{Bldg. \#26}

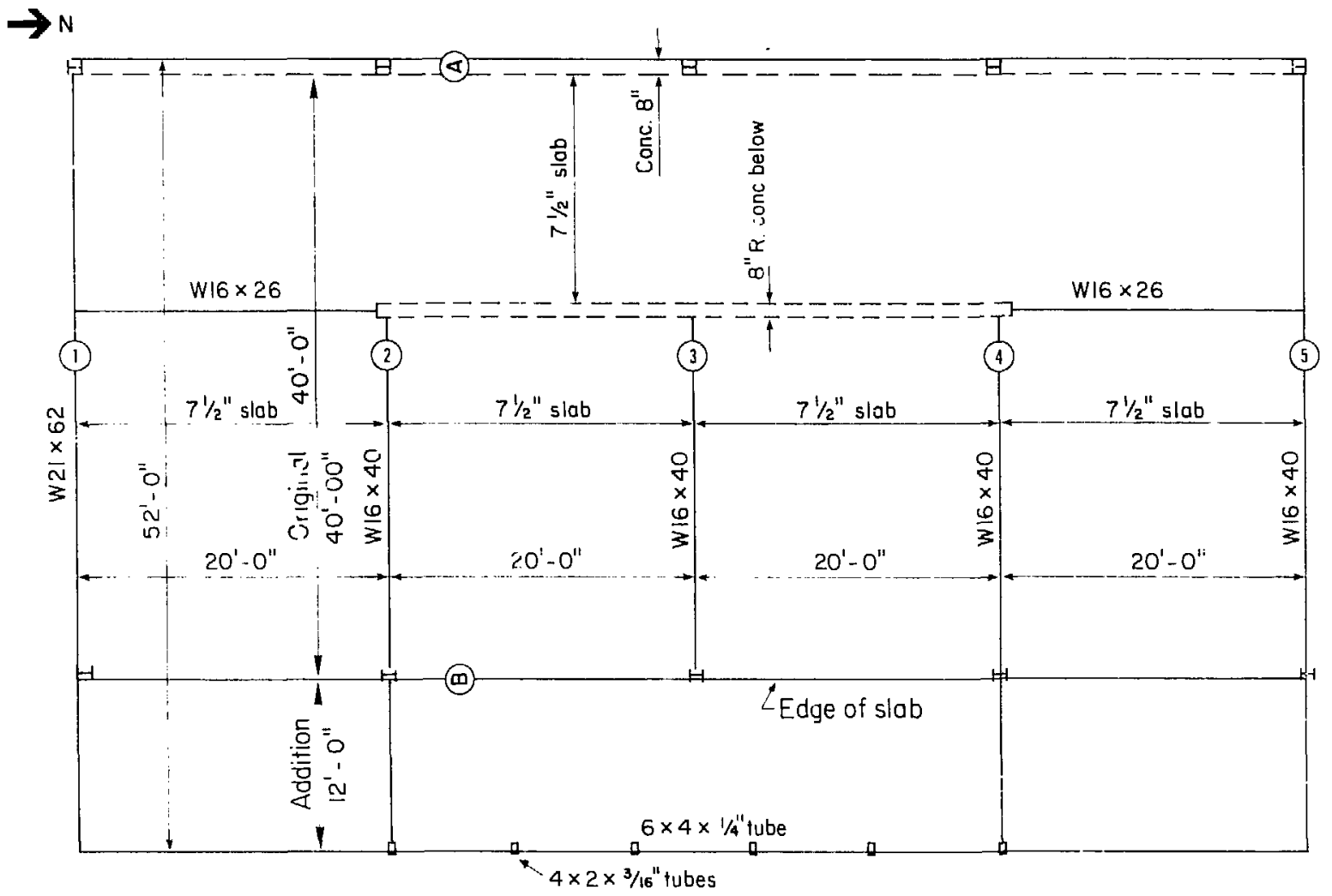

Fig. 1 - Building 26 concrete slab, plan view. 
Bldg. \#26

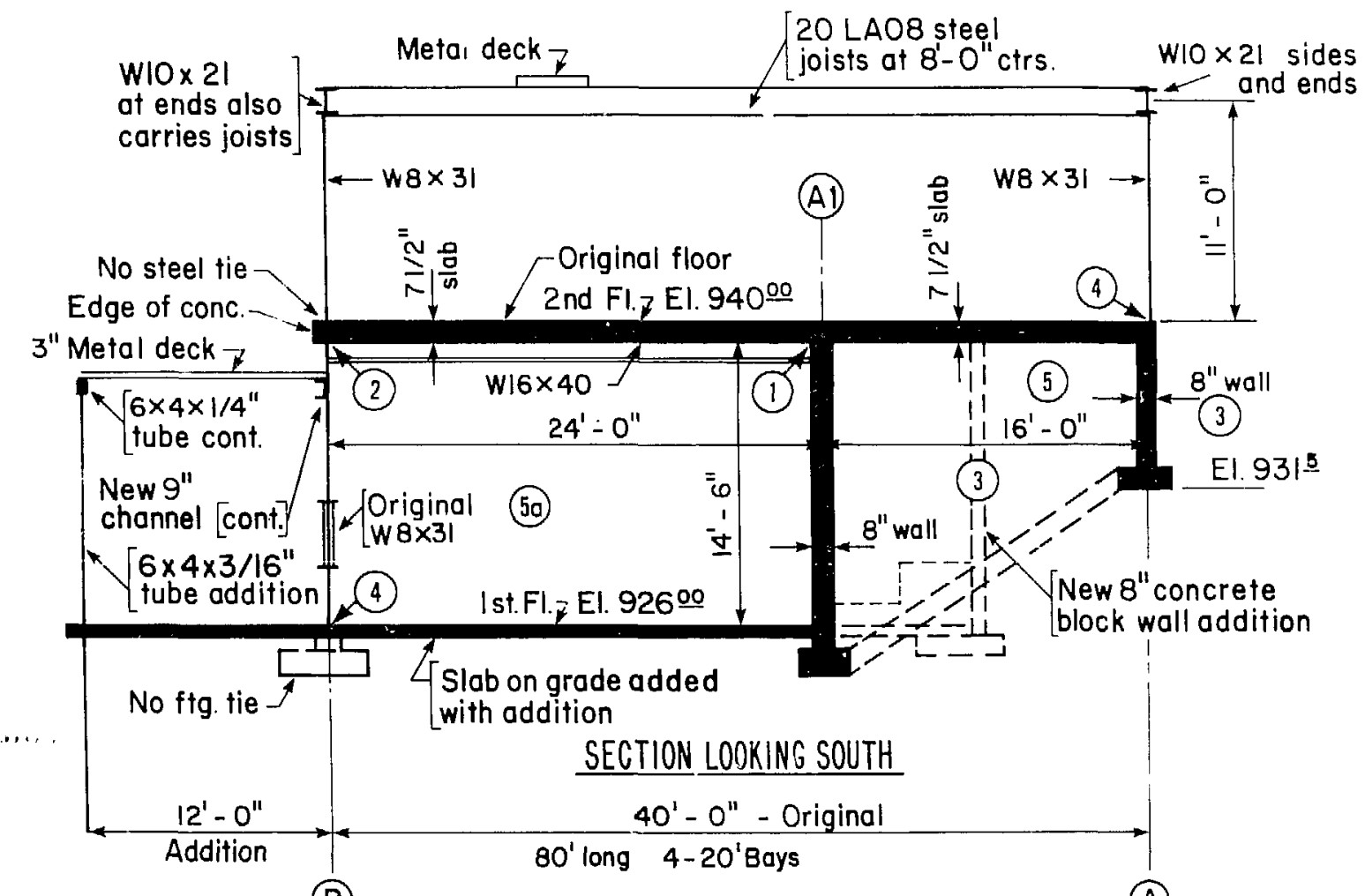

(B)

(1) Connection of steel beams to 8 " wall poor.

(2) Connection of steel beams to $W 8 \times 31$ cols. poor. Beam frames to column web. Detail light. No steel longitudinal tie. Edge of slab only.

(3) One plane of reinforcing in center. Should have two planes. Bars \#4 at 10 "ctrs each way in center of wall. Wall in good shape.

(4) W8 $\times 31$ column base has $4-I^{\prime \prime}$ round $\times 1$ '- 0 " bolts, all located inside of flanges. Poor detail. \#8 bars welded to bottom of bolts. (See illustration at right)

(5) Open south end and north end. Breezeway. At south end, poorly $\mid$\begin{tabular}{ll|l}
0 & 0
\end{tabular} anchored transforiner on undermined slab. Anchored at north side only.

(50) Open in original construction. Window walls added at time of addition, both ends. 
Bldg. \#26 - Dispensary.

Photographic equipment in Rm 006 - on floor in E.Q. microscopes on floor.

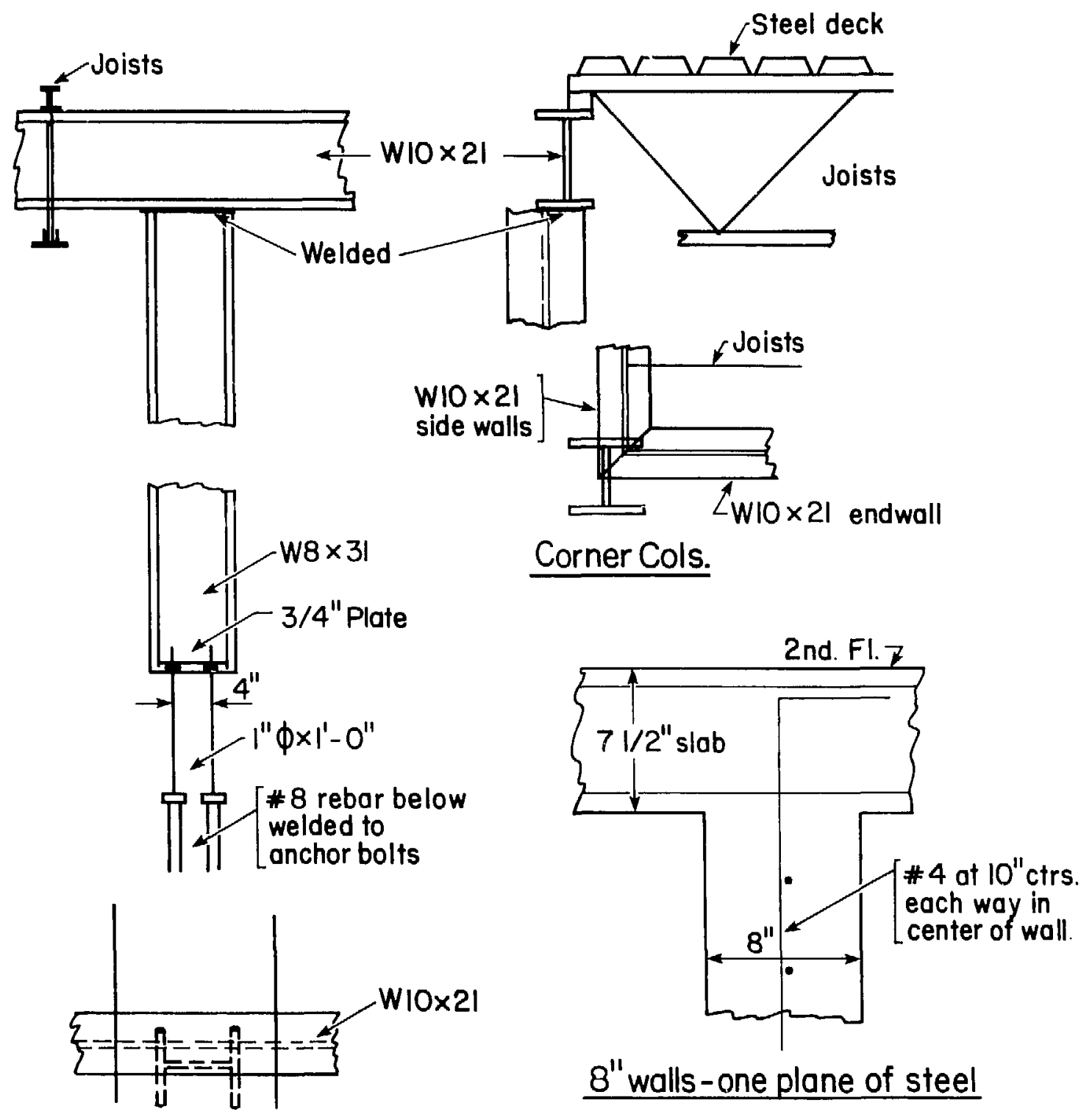

Fig. 3-Building 26, Details. 


\section{Chapter \\ 7 \\ Rehabilitation of Buildings For Earthquake Resistance}

\section{FOREWORD: Operator-Manager's Point of View (Donald G. Eagling)}

In essence the principles that apply to good seismic design for new buildings are equally applicable to the design of projects to improve the earthquake resistance of existing buildings. The difierence is that one doesn 1 have the opportunity to design the existing structure from scratch. Analyses and design solutions arc apt to be Icss straightforward and rehabilitation construction more complicated.

When a structure is to be rehabilitated to improve its seismic safety, the prime objective is to establish a formal lateral-force-resisting system that will perform in a predictable manner. Usually the problem building will have other seismic hazards as well as the lack of a predictable lateral-force-resisting system. For example. access corridors and room partitions were sometimes constructed of unreinforced hollow tile blocks in older buildings, a brittle material not allowed by modern codes. Often non-structural elements - hung ccilings. light fixtures, mechanical equipment, etc. - are not anchored properly.

The combination of problems may add up to a total rehabilitation cost that is overwhelming. A legalistic attitude sometimes prevails which dictates that nothing should be done unless the building can be completely brought up to current code compliance. This of coursc is not good risk management. It is important to separate the deficiencies on a priority basis. then take the best-first-step to improve the situation. Try to get the most cost-effective and risk-reduction effective program. Sometimes obvious deficiencies exist which can be remedied so easily and economically that correction should be accomplished immediately. Such would be the case where, for example. it is discovered that rod cross-bracing is not tight and shaking would cause the bracing to hammer or allow unsafe defiections to take place. Obviously, the bracing can be tightened without delay to abate the hazard. Also if a brace is missing, it can usually be replaced rather easily. $A$ sophisticated analysis is not required and it is not necessary to process the correction through an elaborate priority system. The solution is obvious.

The course of action may be much more complicated when serious fundamental deficiencies exist. It may take considerable time to develop an acceptable solution and fund a project for correction. If a deficiencs represents an imminent hazard to life safety, action should be taken immediately to reduce the risk even though the hazard may not be completely eliminated by the action. In some situations. the hazard can be significantiy reduced by adding partial bracing or simply increasing the strength of the weakest elcment. Improving the building's resistance to withstand minor carthquakes reduces the statistical probability of serious damage or injury. even if the building is not capable of resisting a major earthquake. The exposure of humun life can be reduced either by decreasing the number of people using the facility or the daily hours of occupancy. Risk management, which plays a very important role in the process of building rehabilitation, is covered in depth in Chapter 10.

A common stumbling block in rehabilitation projects is the problem of setting criteria for analysis and 
design. Sometimes older buildings were constructed of materials that are not acceptable under modern standards and codes. Such materials may be brittle or their earthquake performance unpredictable: allowable stresses may not be published. In spite of this situation it is normally not feasible to abandon a hazardous building on short notice unless the activities within can be moved to another safe usable space already available. Usually a building can be strengthened more economically and quickly than it can be replaced if a predictable lateral force-resisting system can be established for the structure. For the operator-manager the key consideration is predictability. If the older building does not have a clearly defined and predictable lateral force-resisting system, it cannot be considered safe. If such a system can be established by modifying and strengthening the existing structure or by integrating an entirely new lateral force-resisting system into the existing structure, then rehabilitation is generally practical and economical. Always the key consideration is predictability. The performance of the rehabilitated building should be predictable and attainable. Another important consideration is whether the rehabilitation can be accomplished without seriously disrupting the process or research activities within the building. Sometimes a building can be strengthened or buttressed from the outside to avoid this disruption.

Lateral-force criteria for rehabilitation projects can be established rather easily when the equivalent-staticlateral-force method of design analysis is used. If the lateral force-resisting system for an ordinary building is designed for a base shear of $0.2 \mathrm{~g}$, it should perform in an earthquake as well as if it were designed for $0.8 \mathrm{~g}$ in a dynamic analysis. In those areas where the earthquake hazard is minimal, an analysis using $0.1 \mathrm{~g}$ equivalent static base shear coupled with a ductile design is a reasonable and economical lateral force criteria for rehabilitation projects. A lateral force factor $0.1 \mathrm{~g}$ is large enough to analyze and easily trace through a lateral force-resisting system and highlight connections that should be carefully detailed for earthquake resistance. For most buildings and locations it's large enough so wind does not control the design and the earthquake vs. wind premium in construction cost is very small. If one then ensures that the lateral force system will act in a ductile way when over-stressed, the situation becomes predictable even if the size of the earthquake is not.

In many areas of the United States damaging earthquakes are rare events and it is difficult for engineers to take them seriously in the design of conventional structures. Extremely few buildings in the mid-west and east have been designed for carthquakes, even in those areas where it is known that damaging earthquakes have occurred in the historic past. A great many buildings are constructed of unreinforced unit masonry (usually brick or concrete block), one of the brittle building systems particulwi, susceptible to abrupt collapse in damaging carthquakes. Significant progress could be made by simply avoiding the use of unreinforeed unit masonry in future construction. Unfortunately, all of the hazardous brick buildings which now exist cannot be readily replaced. It his been estimated that over 20,000 fatalities could occur in such buildings should a major earthquake occur near the congested areas of Los Angeles. In 1974 Los Angeles began work to develop an ordinance to review and evaluate existing unreinforced brick buildings in such a way as to "codify" their future existence and reliability. The work leading up to the proposed ordinance should be very valuable to the Operator-Manager who has a large inventory of such hazardous buildings. The report on this work is entitled "A Case Study in Hazard Abatement for Older" Masonry Buildings", and was presented in September 1980 by Earl Schwartz. Senior Structural Enginecr, of the Department of Building and Safety. City of Los Angeles. It provides a methodology for testing, cvaluating and upgrading such buildings even though they cannot meet today's code for earthquake safety. The report is highly recommended for use in those are's of the country where unreinforced masonry buildings will undoubtedly be used until a moderate or major earthquake causes disaster for thousands of occupants of buildings of this construction.

Chapter 7 lays substantial emphasis on wood in spite of the fact that wood frame structures have performed admirably even when constructed with practices no longer considered acceptable by codc. Generally. good performance under such conditions did not conform to theory in the sense it could be predicted by calculation. The techniques illustrated in the wood-fratule drawings in this chapter provide solid basis for predictable performance and, even more important. provide easy-tofollow principles which apply to other building types.

Building codes and regulations lay the basis for determination and application of seismic loads. but they are generally intended for new buildings, not older. hazardous buildings. The building code can still scrve as a vital resource, but it is essential that design for rehabilitation be carried out by an experienced earthquake engineer. Effective rehabilitation will be very dependent on professional judgment and insight that is not provided in the Code or textbook. Usually, it is neither feasible nur sensible to correct all the deliciencies in an older hazardous building. but it is usually practical to provide a structural solution for the life safety of the occupants. This then is the focus of this chapter. 


\title{
Chapter
}

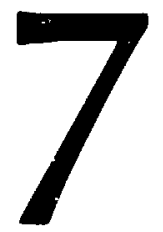

\section{Rehabilitation of Buildings For Earthquake Resistance}

\author{
John J, Earle \\ Civil Engineer \\ Structural Engineer
}

\begin{abstract}
Mr. Earle has extensive structural analysis and design experience and is widely active in seismic code and educational work. He was the principal contact and project engineer for all work done by Shapiro, Okino, Hom and Associates involving structural analysis and design of the earthquake-resisting systems incorporated into existing buildings, radiation shielding blocks, and other facilities and equipment at Lawrence Berkeley Laboratory. Much of his work includes seismic design of schools, laboratories and other facilities. He is currently chairman of both the Structural Technical Group and the Professional Development Committee of the San Francisco Section of the American Society of Civil Engineers. $\mathrm{He}$ is also chairman of the Continuing Education Committee of the Structural Engineers Association of Northern California. He has organized several seminars on seismic code and design. Mr. Earle is a Registered Civil and Structural Engineer in California, with Shapiro, Okino, Hom and Associates, Engineers, San Francisco, California, which was founded for the practice of structural engineering by Daniel Shapiro in 1965.
\end{abstract}

\section{Introduction}

Earthquake-induced phenomena such as shaking, tilting, sliding, and shifting have long been observed and recorded. Builders and engineers have investigated and reviewed each disaster with the hope that development of new and effective construction methods will mitigate future destruction. Earthquake response and damage is illogical; it does not conform to easily discernible patterns. Impressions and observations from many seismic events had to be catalogued to begin to understand building reaction to a vibratory environment and to determine which principles of mechanics are applicable to the total structure, rather than individual parts. Gradually, researchers and engineers have pinpointed certain of the elements essential for structural integrity during earthquake motion.

This pinpointing was difficult because certain building materials or methods were found extremely hazardous and not adaptable to construction in seismically active areas. For example, unreinforced brick performed well under gravity and wind load effects, but ended up in rubble when severely shaken. Unreinforced structures of concrete block or of precast or preformed concrete elements, or of similar elements having reinforcement improperly connected, exhibited marked susceptibility to seismic damage. Steel structures and wood framed buildings showed better endurance and resistance; most survived major earthquakes.

As with all young sciences, knowledge and ideas accumulated rapidly, but were accepted slowly by 
engineers and building authorities. Therefore, even modern buildings contain flaws and critical weaknesses, although they conform with the latest code regulations. Once their weaknesses are discovered and defined, corrective measures should be taken to provide a new external bracing system; restore or strengthen an existing system; install supplemental bracing; alleviate local weaknesses; insert new primary elements such as shear walls where existing elements are found to be inadequate; or completely rehabilitate the structure with incorporation of new lateral load resisting system.

Each solution must be evaluated regarding degree of risk to life, safety of experimental programs, anticipated useful life of the structure, importance of continued occupancy after a major earthquake, economic expediency of permanent abandonment due to severe damage, protection of irreplaceable records and computer storage, or other criteria. Engineering solutions can differ depending on the assessment and resolution of one or all of these problems. Managers and administrators must recognize that full compliance with building codes and accepted earthquake engineering principles does not guarantee resistance of structures to major seismic events without possibility of damage.

Building codes and regulations emphasize the magnitude and application of loads, but provide little information on the design of the system for load resistance. Since the system and its components are strictly within the engineer's province, it is necessary that experienced engineers be employed to provide design service and it is absolutely essential that the professional-in-charge understands the client's intentions.

One further problem arises in corrective work. Certain restraints may be imposed because of inability to interrupt an experimental program or production process or because occupancy or equipment location precludes providing the optimum solution. Compromises can react adversely on the degree of protection provided and an otherwise sound and effective structural system can be weakened materially if certain structural elements have to be offset, penetrated, reduced in size or otherwise modified. Furthermore, subsequent experimental program changes may disrupt a lateral bracing system which appears expendable because of a long prior history of satisfactory structural performance without the bracing. One must remember that earthquake bracing is anticipatory and can be absolutely useless until the occurrence of the earthquake (unless the same bracing system is used for wind resistance). It is easy to forget that earthquake timing is unpredictable and can occur any time even though seismic activity has been dormant for long periods.

Once the deficiency has been isolated, corrective work can generally be classified as follows:

1) Temporary abatement of collapse or failure;

2) Restoration or reconstruction to a level of compliance to minimum building code or facility regulations; and
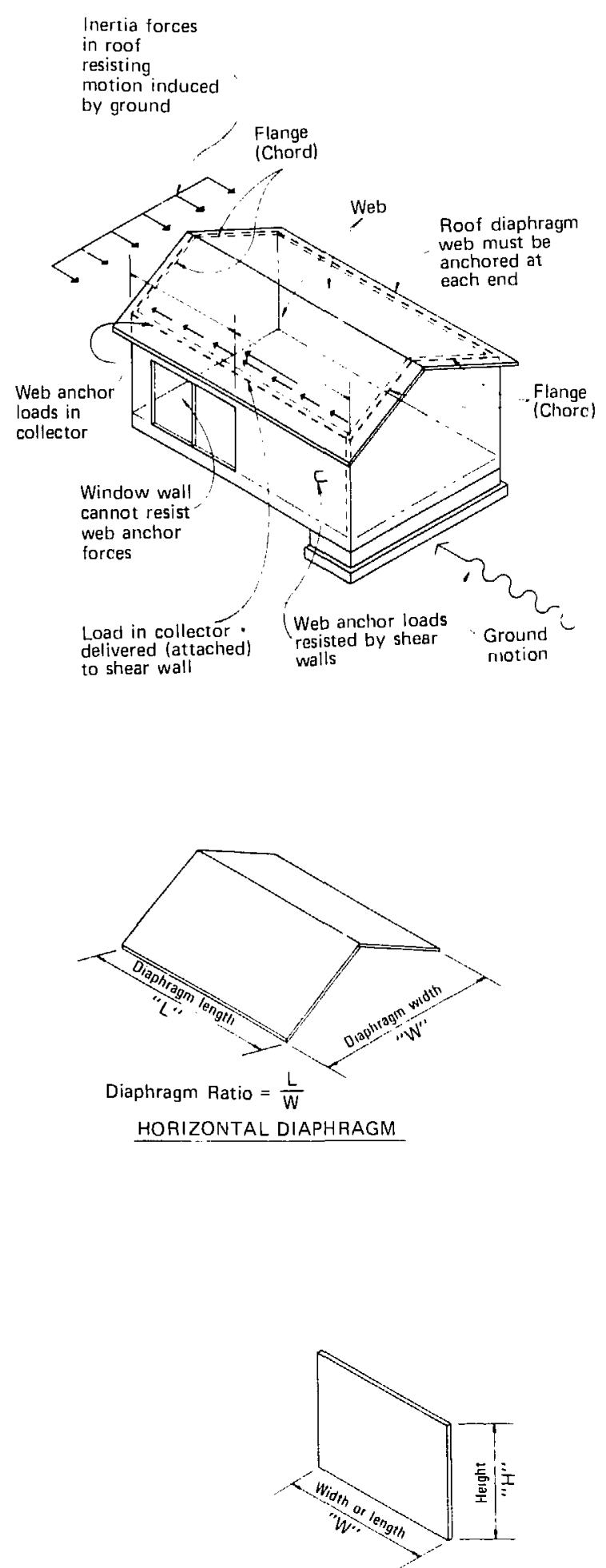

Diaphragm Ratio $=\frac{H}{W}$

SHEAR WALL 

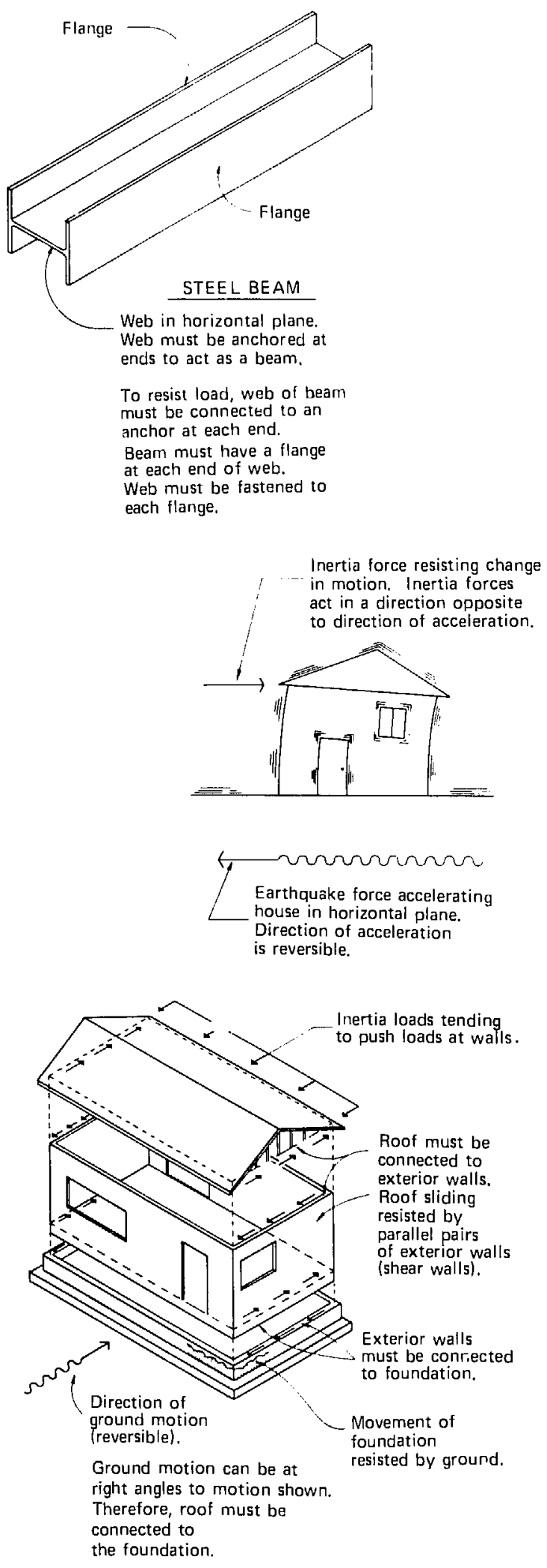

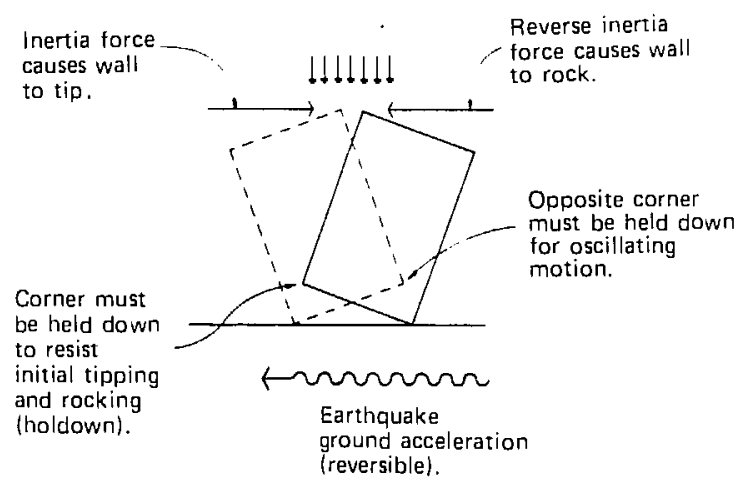

3) Rehabilitation of the earthquake lateral load resistive system. This latter category assumes complete protection to life safety and some degree of property damage prevention. Steps 1 and 2 assure life safety only, and must not be assumed to preclude property damage (even to the level of no further utility) after an earthquake.

\section{Temporary Abatement}

Vacating a hazardous building is not always expedient, but temporary occupancy can be accommodated by reducing principal hizards to a level of risk consistent with protection of life safety only. No consideration should be given to the survival of the building as a useful structure after the earthquake. However, the building must survive as an integral structure long enough to evacuate the occupants either during or after an earthquake.

Where a building is isolated from other structures, property damage can be tolerated consistent with the basic requirement of life safety. However, property damage would have to be limited if adjacent improvements had to be protected.

Sudden local failure, shifting of the building off its foundation, and partial or complete collapse should be regarded as the major hazards. Any expedient and inexpensive method of bracing or reconstruction that improves protection can be used if it sufficiently mitigates principal hazards. Any combination of resisting systems can be used, whether they are integrated or external to the main structure. Local or general strengthening of existing components such as floors. walls, stairwells, bare stud basement walls, etc., can be used to keep the structure functional until evacuation.

It is not mandatory for the temporary lateral loadcarrying system to conform to building code regulations or standards. However, code formulas can be useful in det-imining what loads the system should be designed to resist. Crude approximations can be used to arrive at lateral force coefficients. Amplification factors, such as soil-structure interaction mandated by the code, 
could be ignored for this purpose. Nail and fastener values tabulated in the codes can be exceeded by a factor of two and working stresses for the various building materials can be increased by a factor of 1.7. Nail spacings and plywood thicknesses recommended for roof and wall diaphragms should be adhered to but can be exceeded for temporary facilities. Odd plywood sheet layouts may be used, as diaphragm deflections are not critical. Steel bracing can be designed for inelastic yielding, but tie rods or struts should be large enough in cross sectional areas to limit deflections to prescribed code values. Deflection limitations would be especially significant in brick walls or brick or masonry veneer. A valid deflection check of all bracing systems should be part of the aralysis.

All new structural elements, restraints and connections incorporated in the temporary earthquake bracing system may be considered expendable after the first earthquake of any significant magnitude. The designer should not attempt to differentiate temporary abatement procedures (as is done in some codes and regulations) for different earthquake magnitudes, such as minor shaking with no damage, major shaking with moderate damage, and severe shaking with significant damage but not collapse. The goal should be to design to force levels associated with the worst probable anticipated event during the structure's limited, remaining, useful life. The designer should be aware that any significant earthquake could destroy further effectiveness of the temporary system. An evaluation will have to be made after the quake but in all likelihood, except for very minor tremors, the building probably will have to be evacuated and abandoned. This must be considered when making an economic comparison of saving the structure for a short period or moving personnel elsewhere.

For temporary abatement the designer may rely on ultimate or real strength of construction materials, rather than on stress values factored down to provide safety against overload. Certain physical phenomena can be tolerated which would be totally unacceptable under the usual earthquake resistant design standards, i.e., rupture of main bracing elements or their connections to the foundation; tearing of wall finish materials and exterior roof and wall sheathing or flooring; and splitting of wood sections. All these eventualities absorb energy generated by earthquakes, and must be anticipated.

The easiest way to take corrective steps is to determine methods of reinforcing the structural elements (walis, floors, etc.) of existing structures. This is usually possible in wood framed buildings since they generally have significant inherent strength. The designer must invent ways of strengthening roof and floor diaphragms by renailing existing sheathing to supporting joists. If there is a linoleum or asphalt tile finished floor, renailing can be done directly through the floor coverings. Roofing materials may prevent direct access to roof sheathing, but gypsum board ceiling panels can
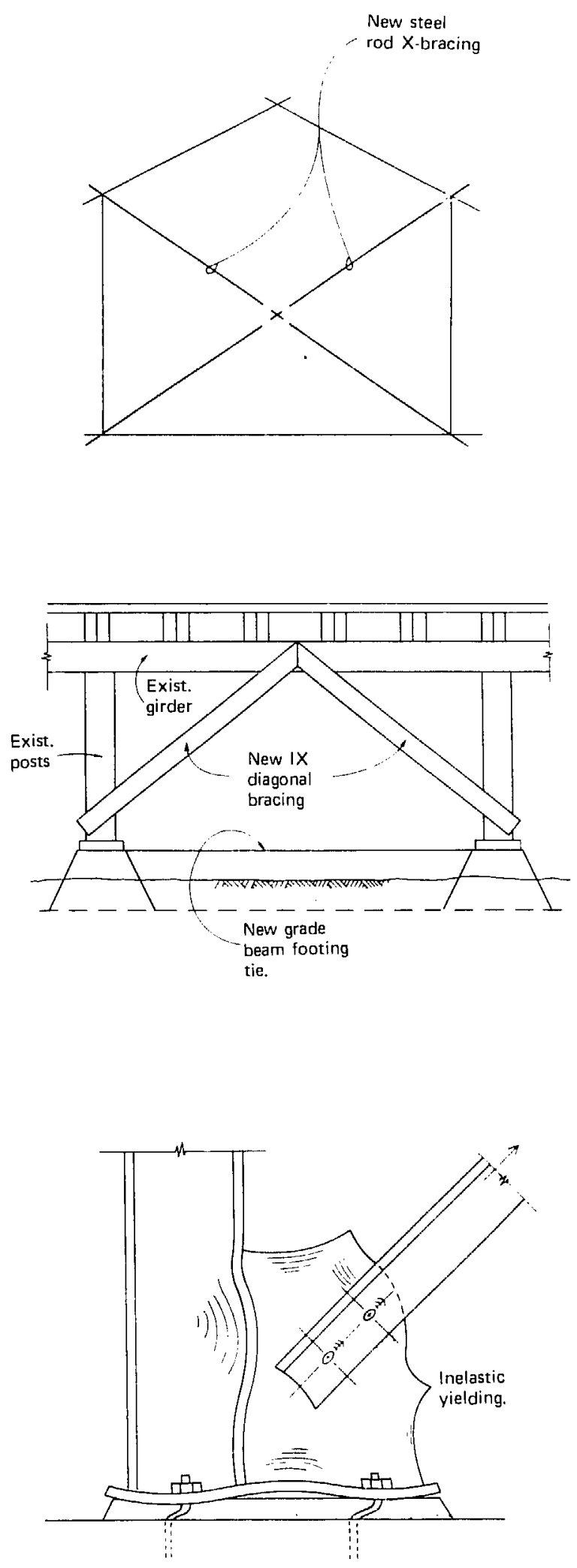

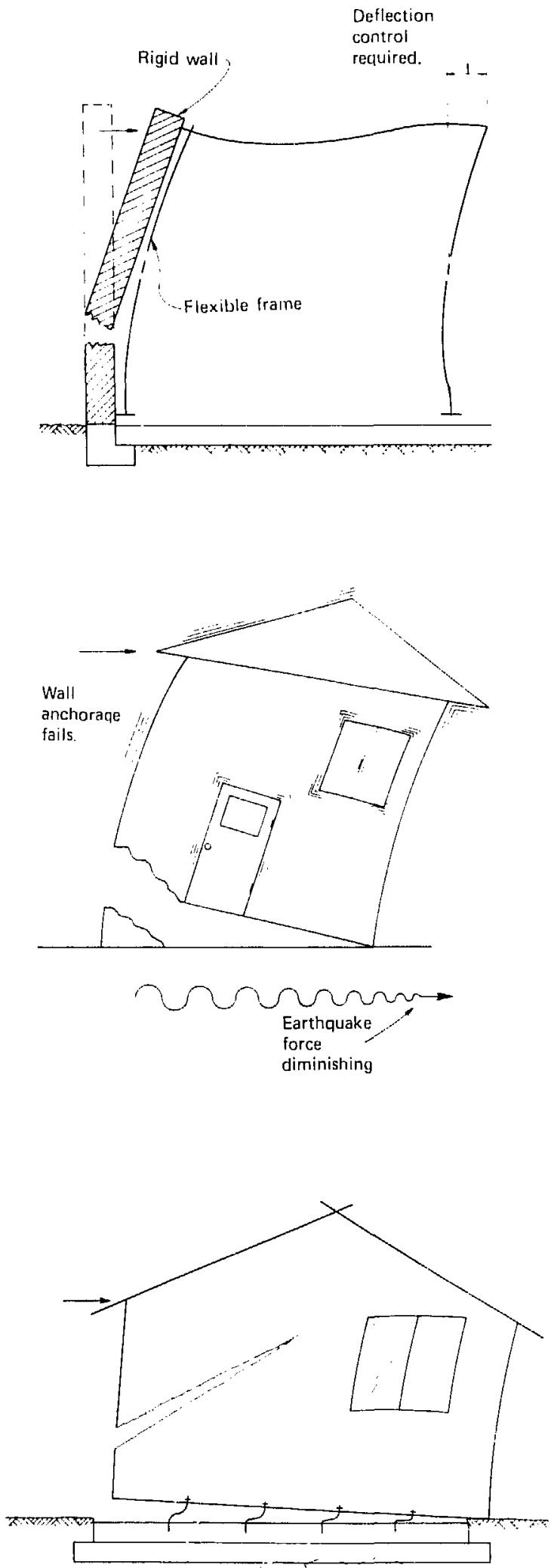

be nailed to the underside of the roof or ceiling joists to create an effective diaphragm. The most critical point for renailing is at the outside wall boundaries and interior continuous walls, such as corridors. At the outside wall boundaries the floor and roof sheathing should be nailed to solid blocking which can usually be inserted from the inside by removing access strips of wall finishes at wall top plates.

Horizontal (floor and ioof) diaphragms must have flanges (chords) at bondaries to take tensile and/or compressive bending stresses. Wall top plates can scrve this function; however, such wall top plates must be continuous and are rarely adequately spliced. Renailing of these plates can be accomplished by exposing them from the inside. This extra nailing must be done where the top plates have been spliced. The actual location of the splice points must be determined by investigation. Pre-manufactured sheet metal straps can be used effectively in splicing existing top plates.

Gypsum-waltboard-sheathed walls can be utilized as shear walls. It is best to use walls that are in line or nearly in line with one another and that are at least four feet ir. length. Here again, conventional gypsum board nails and nail spacing are usually inadequate for earthquake resistance and the wallboard panels must be renailed. Walls are most of ten sheathed on each side and, to be effective, each side should be renailed. Critical nailing lines are at the top and bottom plates and end studs. Additional shearwall/panel strength can be accomplished by stripping off the gypsum wallboard and applying plywood to the bare studs. Sill plates of walls should be renailed to existing blocking or new blocking inserted in the floor framing to which the sill plates are nailed.

Basement areas or crawl space offer the best opportunity for access to strengthen the base of a wood framed building. Oftentimes the studs and wall plates are exposed, as is the underside of the first floor framing. Mud sills on foundation walls can be reanchored by using drilled-in-place concrete anchors. Blocking can be inserted at plate lines and plywood sheathing applied to the inside face of studs. This plywood should be nailed to mud sills and new or existing blocking as stipulated in the Code. Force collectors can be created by applying new framing members to the face of the plywood overlay and nailing through the side piece and the plywood to plates or blocking behind Lengths as long as possible should be used for collectors and the individual lengths must be spliced at butt joints throughout its length.

Wood structures are flexible and thus can be enclosed by a flexible support system that is external to the building itself. Cantilevered poles, anchored in the ground and attached to the building, fit this criteria. Poles must be inserted on each face of the structure and tied together at the top with a steel rod tensioned with a turnbuckle. The bottom of the poles should be inserted in oversized holes drilled in the ground and the 
More substantial and heavier structures, especially brick and reinforced concrete, are not so easily remedied by temporary measures. When steel or wood bracing is used, it is usually less stiff than the concrete structure it attempts to support. Thus the bracing will probably become effective only after the braced structure has failed. This becomes significant in terms of column compressive failure which can be sudden, and any bracing system or shoring system must be designed to support the column loads temporarily. Such bracing or shoring systems must take the load to new foundations directly through axial load delivered by diagonal struts. The bracing system must be anchored for shear and overturning loads. A framing system designed to resist loads through shear and bending, such as rigid frames, should not be used.

Temporary abatement serves the purpose when a short building life is assumed and temporarily exterided. One should not forget the original assumption and continue to occupy the building in the belief that temporary abatement continues to offer protection if no seismic activity has occurred in the interim. One should not continue to rely on temporary abatement. The building should either be abandoned as originally scheduled or permanently rehabilitated.

\section{Reconstruction to Compliance With Minimum Code or Laboratory Regulations}

Most building code regulations establish earthquake standards just sufficient to offer protection against bodily harm by relying on the judicious application of design principles and experience to achieve these minimum standards. Protection of the building itself is generally limited to the preservation of the structure's integrity and components (such as ceilings and mechanical fixtures) so that occupants are not endangered. Emphasis should be on the minimum effort needed to bring the building into full structural compliance with codes. If the distinction is clearly made between minimum as against temporary, one should expect better buil.ng performance and less destruction for buildings brought up to minimum structural compliance than for buildings rehabilitated for temporary occupancy.

Reconstruction to minimum standards involves less work than full rehabilitation of the lateral force resisting system, and therefore less disruption to the building and surrounding environment. Indeed, the remedial work should be completed with as little interruption and dislocation to ongoing operations as possible. With this in mind, the designer should determine methods of improving the existing but weak or inadequate earthquake-resistive systems. There may be additional hazards present. Resistive systems may have to be developed to prevent the release of hazardous radioactive or chemical emissions or protect delicate and valu-
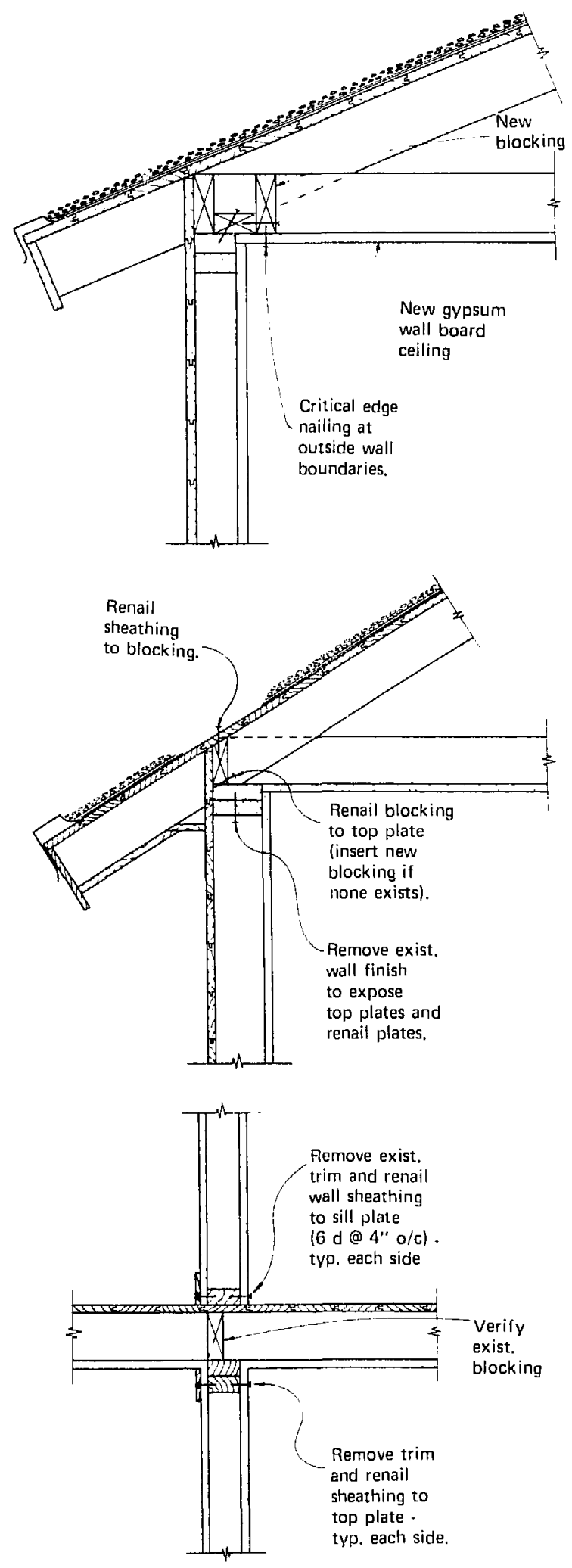


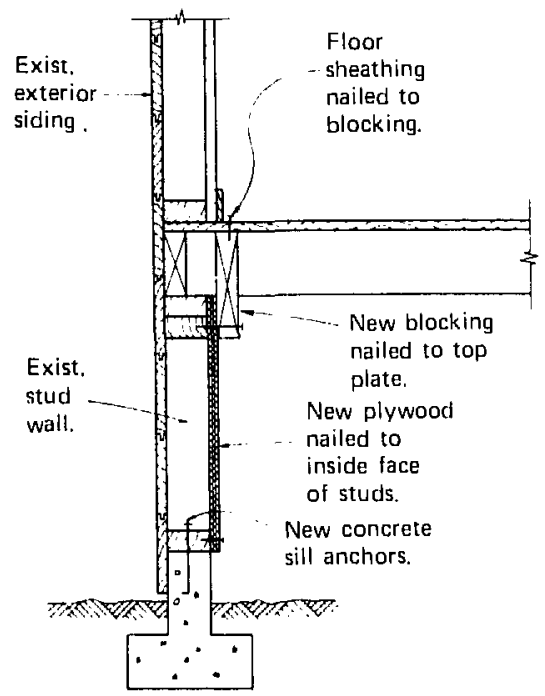

able equipment.

The prudent designer will not want to proceed without adequate background information such as geologic and soils data, slide potential, slope instability and other geophysical characteristics. Any maps or charts that provide clues to earthquake hazards in the vicinity should be reviewed. (USGS geologic maps are very useful in this regard.) New geological hazards reports, initiated solely for the rehabilitation work contemplated in this section, are probably not warranted unless the work involves a major or essential facility.

Soils information is likely to be available as such reports are generally prepared for original construction. Allowable soil bearing values can be taken directly from them. However, the designer may want verification from the professionals who prepared the report that the new loads to be superimposed on the bearing stratum are close enough to allowable or permissible values recognized by the original report. The need for new boring requirements should be considered. Soils and geologic information should be limited to instability problems and bearing failures. Ground acceleration coefficients related to theoretical site periods developed from geophysical tests are not warranted, but amplification factors for soil structure interaction computed from formulas in building codes should be included in the base shear formulas.

Building codes allow earthquake analyses to use equivalent loads based on dynamic considerations. The principal parameter is the structure's period; the earthquake coefficient is related inversely to this function. The insertion of additional bracing or walls and the strengthening or redesign of diaphragm or bracing trusses (all of which are made to interact with existing elements) could vary the period and completely change the response of the structure to earthquakes. The code
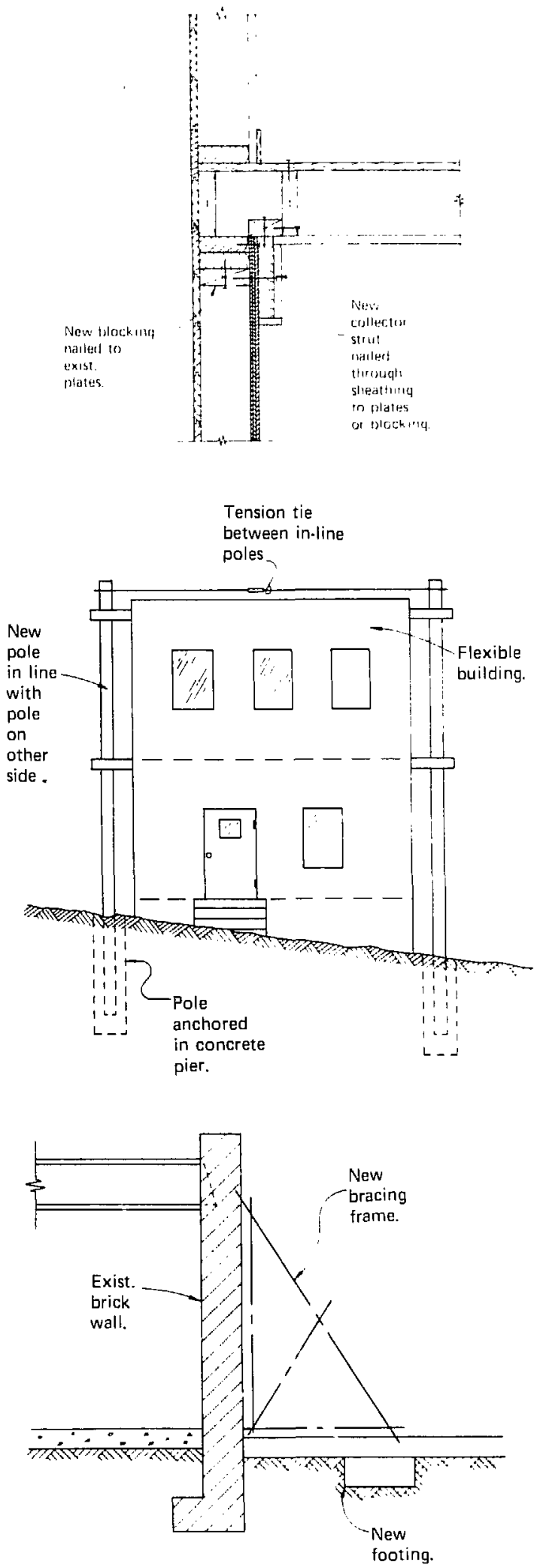
formula does not necessarily reflect this change in response. Because the period may become a less dependable variable, it is best to arbitrarily elect a little larger coefficient to accommodate all variables, and apply it directly to the base shear calculation. Whether the calculation of the base shear is based on code formula coefficients or on the arbitrary standards depends on which is the larger of the two values. The latest codes require inclusion of an importance factor when calculating base shear. For most buildings $I=1$, but for emergency facilities which must be operable during and after an earthquake the factor adjusts to $\mathrm{I}=1.5$. For fire stations, police communications centers, firstaid stations and garages housing emergency vehicles, the factor $\mathbf{I}=1.5$ should be incorporated in the base shear formula both for the code procedure and arbitrary coefficient method. For shear-wall type buildings of one- or two-story construction, the base shear works out to be 0.186 times the dead load of the structure assuming the worst soil-structure interaction and the area zone of highest seismic risk. A general or arbitrary

UNIFORM BUILDING CODE LATERAL SEISMIC LOAD (BASE SHEAR)

$$
\begin{aligned}
& \mathrm{V}=\mathrm{ZIKCSW}=\text { BASE SHEAR } \\
& Z=1 \text { (WORST CASE) } \\
& \mathrm{K}=1.33 \\
& C=\frac{1}{15 \sqrt{T}} \\
& \mathrm{I}=1.0 \text { (except } \\
& \text { emergency } \\
& \text { facilities) }
\end{aligned}
$$

\section{$\mathrm{S}=$ STRUCTURE-SOIL INTERACTION \\ COEFFICIENT}

$$
\begin{aligned}
& \mathrm{CS}=0.14 \text { Max. } \\
& \mathrm{W}=\text { DEAD WT. OF STRUCTURE } \\
& \mathrm{v}=(1)(1.33)(0.14) \mathrm{W} \\
& \mathrm{V}=0.186 \mathrm{~W}
\end{aligned}
$$

\section{ALTERNATE}

$$
\begin{aligned}
\text { ZIKCS } & =0.2 \text { Max. } \\
v & =0.2 \text { Max. }
\end{aligned}
$$
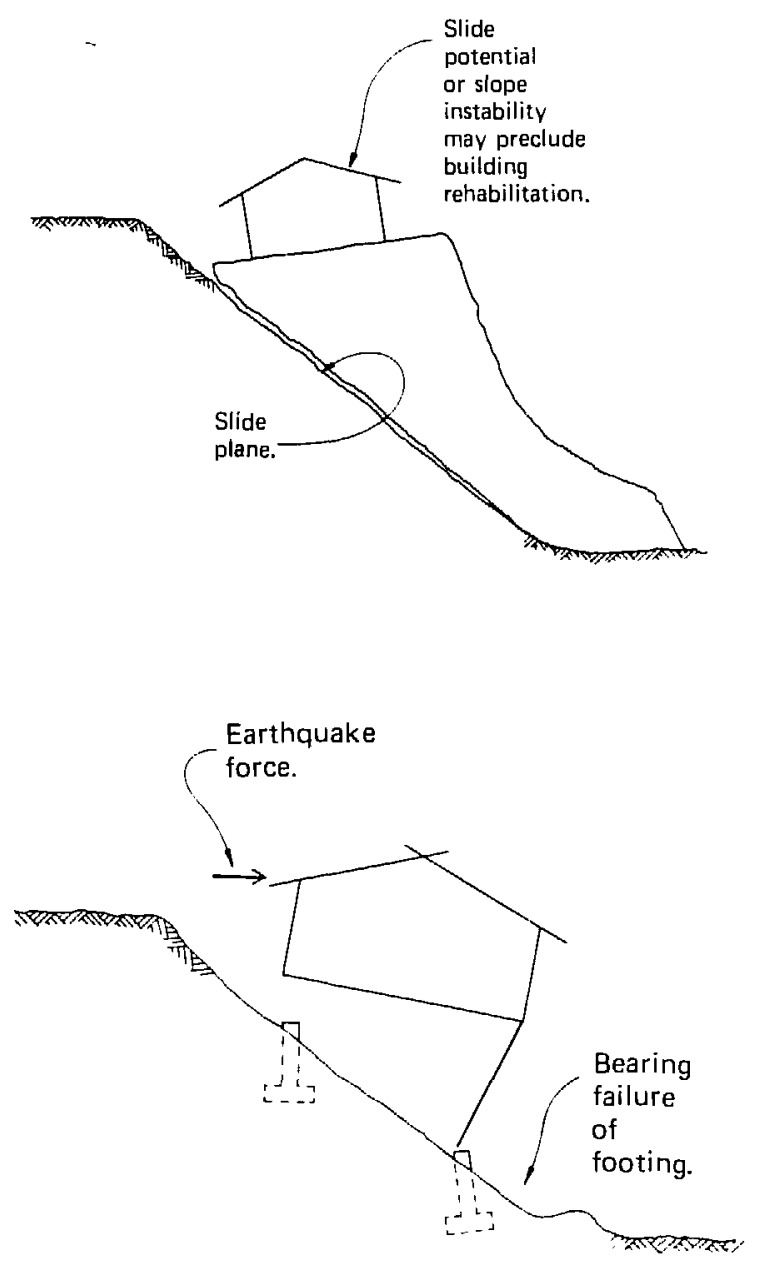

Earthquake

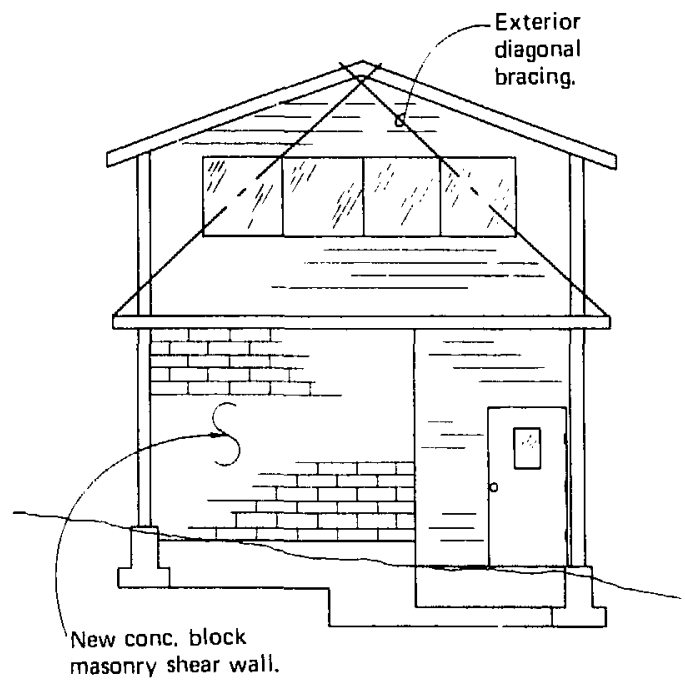



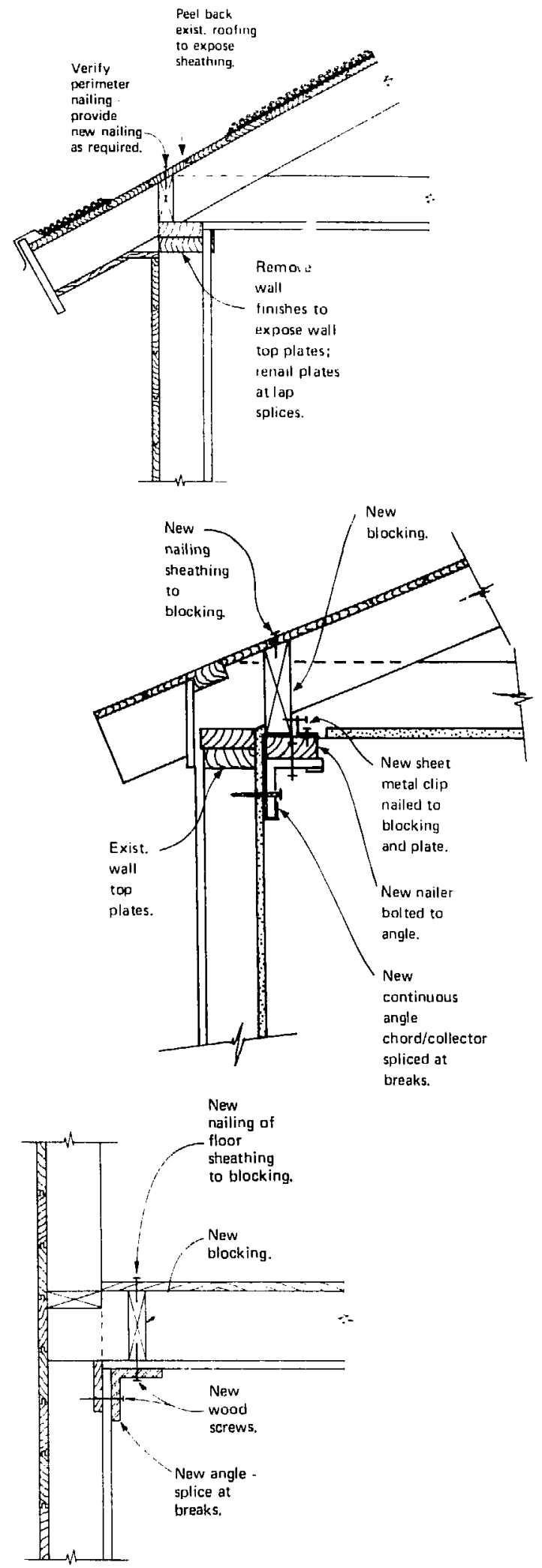

earthquake coefficient of 0.2 applied to the gravity load is, therefore, a reasonable and easily applied requirement. This arbitrary coefficient of 0.2 probably reflects our knowledge of earthquake engineering more realistically than the implied cuefficient expressed to three decimal places.

Bracing carrying only axial load (tension or compression) is an effective and direct method of supporting earthquake lateral loads, especially for use in a new system that is introduced into an existing building. However, the connections of bracing elements can exhibit brittle qualities and cause failure before the strength of the bracing member is developed. The Uniform Building Code recognizes this weakness and introduces an adjustment factor to the lateral loads introduced by the earthquake into the bracing. The bracing members have to be designed for 1.25 times the axial force but the allowable stresses used to size the member may be increased 1/3. The connections, however, are not allowed the $1 / 3$ stress increase and must be designed to resist the factored $(1.25 \mathrm{x})$ loads in the bracing member without increases in allowable working stresses. Members in connections other than the principal earthquake bracing may be designed on the basis of working stresses with the one-third increase.

All the usual building materials can be used to develop a lateral force resisting system. Each material has its advantages. Structural steel is relatively light and easily altered on the site. It can also be welded during construction, an important consideration when having to cut and fit members into unusual situations. Wood has some of the flexible qualities of steel, but can only be joined together by limited types of connectors. and is not fireproof. Reinforced concrete is especially useful because its heavy weight can be used in dead man anchors, buttresses, drilled piers, and walls. Reinforced concrete block masonry can be useful when adding new shear walls because individual block units are easy to work with and easily transportable. Block walls also require no forming. Reinforced brick masonry has some of these advantages.

Whenever possible, it is best to restore or replace the primary bracing elemants already existing in a structure. One begins at the roof level by assessing the capability of the roof diaphragm. Most older wood framed roofs were built with diagonal sheathing that has considerable strength as a diaphragm. However, it is necessary to uncover the sheathing boards and verify the nailing at the perimeter exterior walls. If greater diaphragm strength is required or straight laid sheathing exists, a plywood overlay can be placed on top of the existing sheathing and nailed according to code regulations. New nailing of the plywood to the sheathing and the sheathing to joist and/or blocking will be needed. This is especially important at the perimeter exterior walls. Because old wood is hard, it may require pre-drilling for proper instaliation of nails. If the existing sheathing is deteriorated badly (dry rot. 
termites, etc.) it may be necessary to strip it off and replace it with plywood. Diagonal truss bracing can also be used on the underside of the roof joists with some effective way fourd to transfer the roof loads into the truss and the truss loads into the wall bracing elements.

Care must be exercised to assure the new diaphragm decking is properly anchored to chord members at the diaphragm boundaries (usually the exterior walls). Existing wall top plates (in wood construction) can be used as chords and collectors but plate internailing will be required, with special attention given to plate splices. The diaphragm loads have to be transferred to the plates through blocking or joists. Sheet metal clip angles are useful in connecting the blocking or joists to the plates. Where top plates are inaccessible or inadequate, steel angles or channels can be inserted at the roof ceiling level and the diaphragm loads delivared to these cloord members by nailing or screwing to wnod nailers. Although wood screw values for diaphragn: loads have to be developed from individual fastener values rather than code tables, screws are a very effective and positive way of making the shear transfer at diaphragm boundaries.

Steel-framed structures withoul a proper diaphragm can be corrected by removing the existing decking and renewing it with corrugated or hat-shaped metal decking. The metal decking is easily welded to the existing steel framing. If supplemental framing members are needed they can be inserted in the framework before applying the metal deck. If heavy sheathing materials are being removed (such as concrete precast elements) they should be replaced wherever feasible with lighter materials such as metal deck.

In steel framed buildings, existing struts and purlins may not be spliced for continuity. At the diaphragm boundaries then, the members selected as flanges (chords) should be spliced so that the member becomes continuous for the full length or width of the building. Purlins or struts selected as collectors must be similarly spliced.

Floor diaphragms are similar to roof diaphragms and the same type of remedial measures are required.

Shear walls or diagonal bracing can be used to transfer the floor and roof diaphragm loads to the foundation. Diagonal bracing is usually the simplest and least expensive solution. For exterior walls the diagonals can go on the outside face of the wall, but the effects of eccentricities must be considered and resolved. For light loads, knee braced solumns can be used, but generally the diagonals siould continue directly to the foundation. They can tl.sn be anchored to existing footings or attached to new concrete footings. The use of diagonals results in large uplift loads and the members taking the vertical component of the diagonal must be anchored into a drilled concrete-filled friction pier. (Friction values should be obtained from the soils engineers.) The diagonal must also be
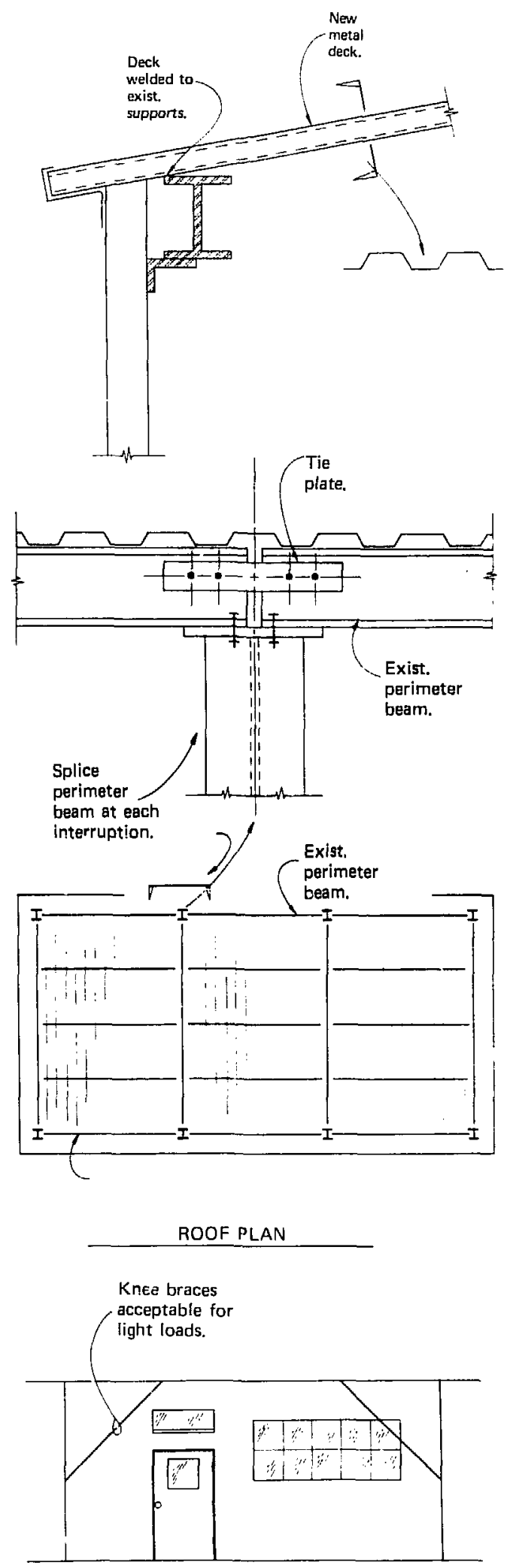

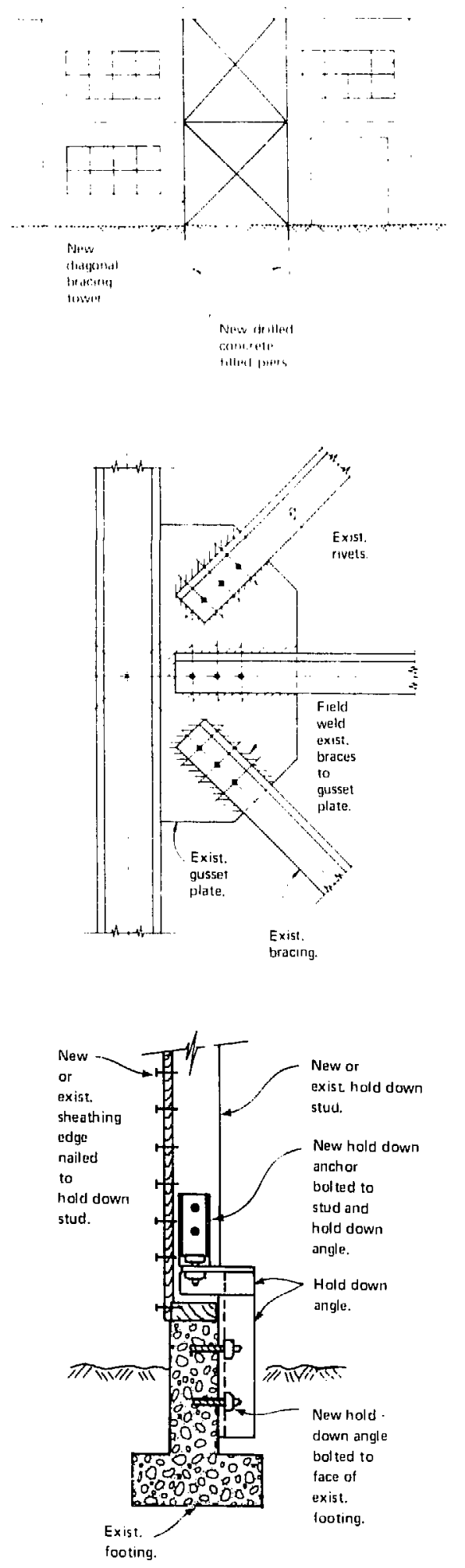

anchored for the horizontal cumponent.

Older structures have generally been designed for wind load or seismic loads that are much less than ought to be anticipated. As compression load members are usually designed on a conservative basis because of buckling criteria, existing bracing members may be adequate for earthquake bracing with a one-third allowable stress increase. Existing bracing members should be checked for compression. They were probably designed only for tension originally but will be subjected to both tension and compression during an earthquake. The rivets or bolts at the connections will probably be found inadequate, but the individual bracing members can be welded to the gusset connection plates, thus enhancing the connection's strength.

If walls are available to act as vertical shear elements or panels, they can be tied together through the use of collectors. Steel angles can be used effectively as collectors for both concrete and wood walls. At a concrete wall, collectors can be delivered to the wall by bolting the angle to the wall face. Drilled-in-place concrete anchors can be placed in the wall to receive the bolts. Allowable anchor values should be selected from code tables or manufacturers' recommended working load values. Diagonally braced bays spaced intermittently along a wall must also be tied together by collectors attached to the building walls.

Where existing sheathing materials on shear wall elements are not able to carry the earthquake shears, wood frame walls can be resheathed with plywood; or they can be strengthened by closing up window or door openings and the wall resheathed; or additional wall elements can be created through architectural rearrangement. Uplift can be resisted by using hold-downs anchored to the face of existing footings. If the available footing is not heavy or strong enough to resist overturning effects, the wall hold-downs used can be rods anchored in new drilled, concrete-filled piers.

Existing concrete and unreinforced masonry walls can be strengthened by placing a new wall adjacent to the existing wall and creating composite action by chipping slots or keyways in the face of the old wall. This will usually involve enlarging the existing footing. In lieu of forming and placing concrete against the old wall. the new concrete thickness can be applied by a pneumatic process (air blown concrete) such as Gunite or Shotcrete. The new concrete placed against the old wall must be reinforced for seismic loads perpendicular to and in the plane of the wall. Keyways can also be used with drilled-in anchors, with anchor rods projecting froni the keyed area into the new work. Longer shear walls can sometimes be gencrated by filling in openings between columns or closing up windows. Reinforced concrete block masonry is an acceptable alternate when the greater shear strength or weight of reinforced concrete is not a design requirement. Concrete block is a versatile builouing material which eliminates forming and can be cut to fit into and around 
openings. Reinforced concrete or concrete block masonry walls must be tied at the floor and roof lines for seismic loads perpendicular to the face of the wall.

Generaliy speaking, the lightest building materials should be employed when forming new or reconstructing old vertical shear resisting elements (shear walls). Heavier elements add to the earthquake incrtia load carried by the floor and roof diaphragms. This increased weight must also be considered in review of existing columns and foundations.

Buildings on sloping sites can become a problem especially if the slope is unstable and is not able to support new shear wall elements. Depending upon the position of the building relative to the top of the slope, it may be possible to anchor the building or individual wall lines to a dead man anchor placed in more stable soil formations. Tension ties can be used to anchor shear wall lines to the dead man anchor. These ties can be reinforced concrete beams cast in trenches dug in the ground. Or, the tie rod can be installed in slanturilled cased holes and the whole assembly filled with concrete. These rods must also be securely anchored at the building end to the shear walls or framing. These tie rods should pass through recesses cast in the dead man. After the dead man anchor concrete has reached design strength, the tie rods should be prestressed. The dead man anchor must be designed to withstand the load by passive resistance of the soil. In analyzing the bending and shear stresses in the dead man, consideration should be given to the distribution of passive soil pressure which may vary along the length of the dead man.

Bracing of retaining, enclosure, or basement walls can be accommodated either externally by shoring the inside face or by tying the wall back into the soil behind the wall and utilizing the soil's cohesive strength. Rock anchors or tie-backs can be used if the drilling crews have sufficient space to set up their drilling equipment. Anchorage of the tie-back must be behind the theoretical failure plane in the soil. The location of the failure plane and the capacity of the anchor tie must be established from data furnished by a soils engineer. If a tie back is to be a permanent installation, it should be grouted along its full length to prevent corrosion.

\section{Rehabilitation of Earthquake Lateral Load System}

In the major rehabilitation of a lateral load resisting system, the goal is protection of property as well as life. Limiting property damage entails more effort, time, and cost than is usually required to bring buildings into code conformance. Rehabilitation work can cause possible disruption to operations or require evacuation of all or part of a building in order to do the work. Design should comply with applicable building codes and
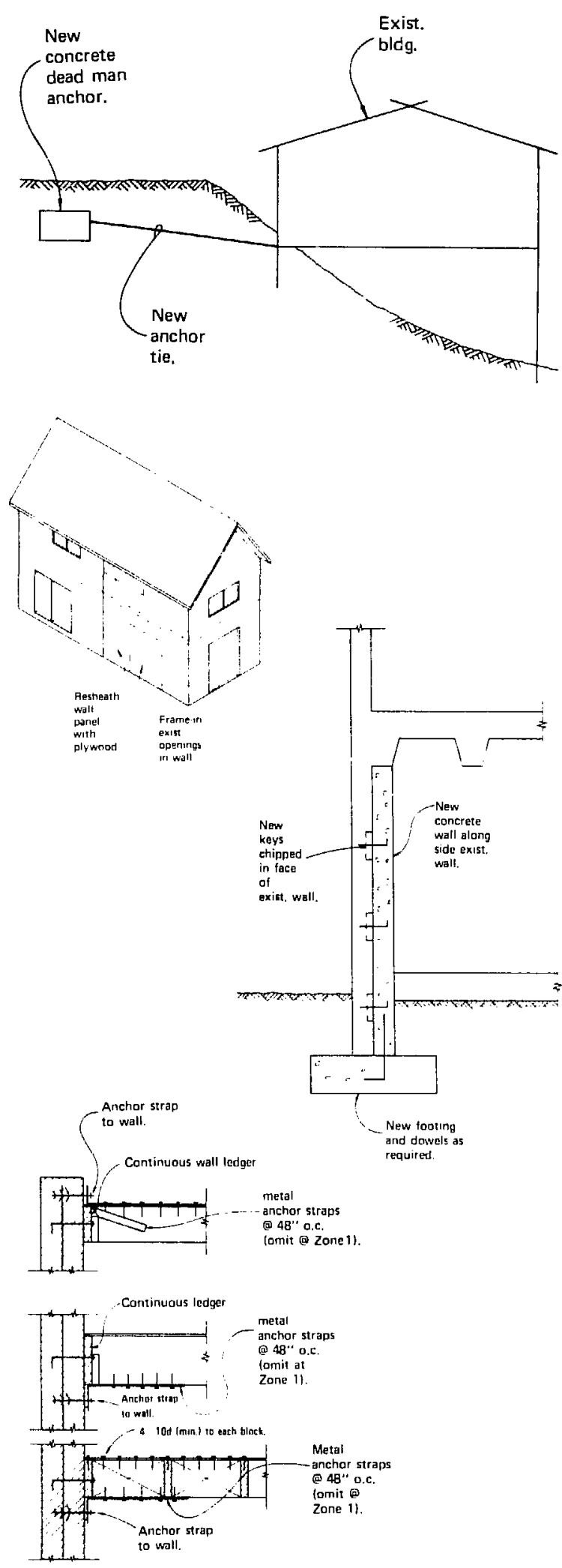

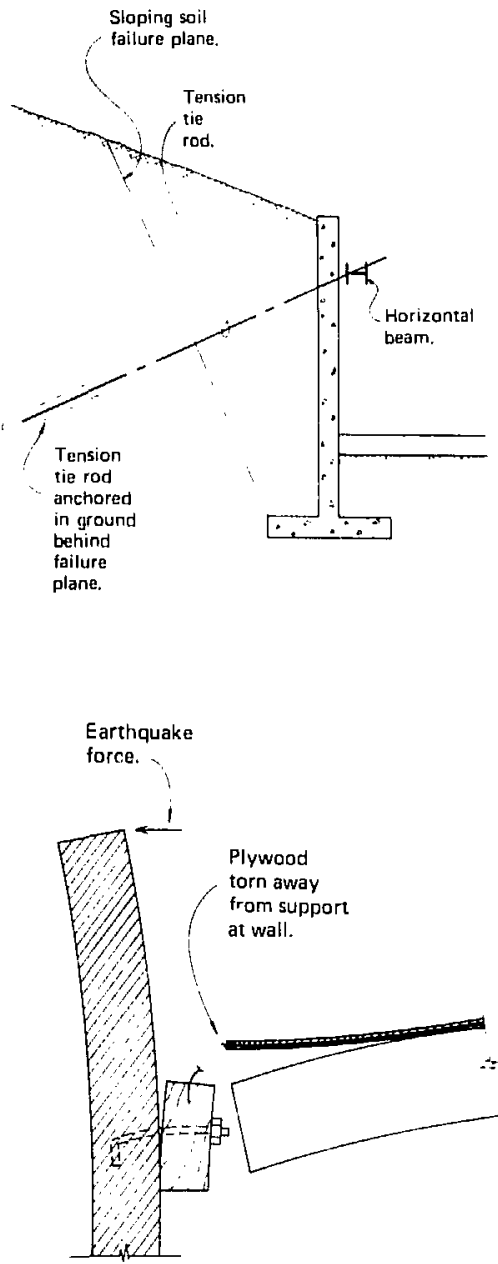

General practice pre-San Fernando earthquake.

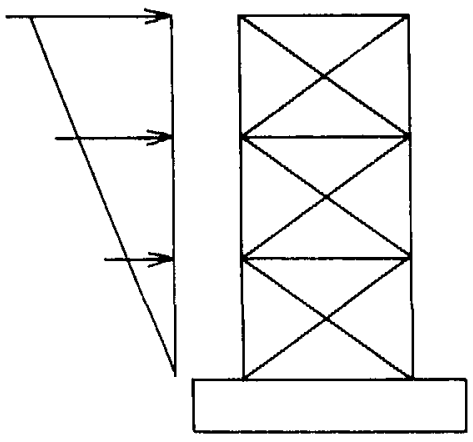

STATIC FORCE ANALYSIS recommendations of the Structural Engineers Association of California. For special cases where a higher level of damage control is sought, the California Administrative Code, Title 19 (Hospitals) and Title 21 (Public Schools) can serve as guides. The lateral force system ultimately used should be carefully reviewed by management and staff, the operations personnel affected by the disruption, and any plan check process involved. The project cost will probably be over $10 \%$ higher than for minimum compliance. This should be anticipated in budget estimates so protection will not be compromised.

Earthquake design and code requirements are being improved. Thus it becomes necessary to review an existing lateral load resisting system to compare it with the latest design developments. Knowledge gained from earthquakes may lead to conflicts with the original assumptions, which may no longer be valid or in agreement with current practice. Therefore, the reviewer should look carefully at his original design to uncover critical weaknesses.

The latest codes emphasize the dynamic properties of the structure, with the fundamental period of vibration as the most useful parameter, and also the stiffness characteristics of the building with which to approximate deflection or lateral drift.

Because of the extensive nature of the review and redesign, current information about local soil conditions and geologic hazards should be verified by new boring logs or test pits, and ground water level variations should be recorded. Known unstable soil conditions must be reconsidered and any new movement recorded. Any recent investigation and conclusions about activity on nearby faults must be heeded.

In some instances, where warranted, the designer should not rely on the equivalent static force method of ana:ysis. If the building is such that it can be realistically modeled by mathematical formulation and the dynamic properties of its materials adequately defined, a dynamic analysis may be undertaken.

It is well to emphasize that the new design should incorporate all the latest procedures and theory. Ductility should be introduced by using steel, ductile, moment-resisting frames. Concrete frames must comply

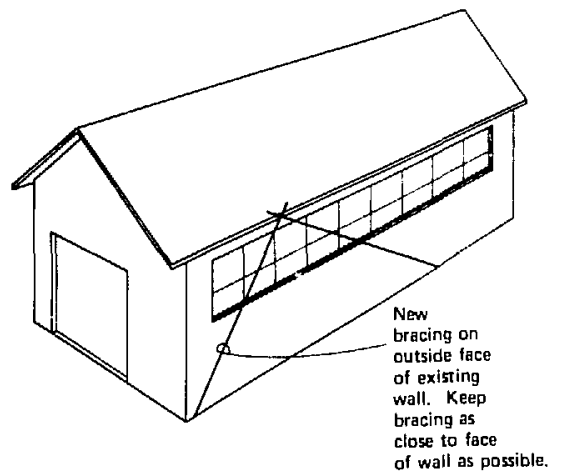


with the requirements for concrete, ductile, momentresisting frames. New concrete shear walls and resisting members should be designed by ultimate load concents using the requisite reduction and amplification factors for actual and allowable shear stress values. Compatibility of new and old framing must be carefully considered. Also, deflections of elements not a part of the lateral resisting system, but required to resist gravity loads, must be limited to code prescription.

Insertion of new moment or braced frames and/or shear wall elements may require cxtensive foundation work. Shear walls normally have edge members that carry large axial loads. These direct loads must be carried down to firm foundation-bearing materials. Shoring will be necessary if existing footings have to be enlarged; and underpinning of existing walls and columns may be required where existing footings have to be deepened and/or reconstructed. If possible. drilled concrete filled piers or caissons can be placed adjacent to existing footings and wall axial loads delivered to the caissons through transfer grade beams. In order to avoid undesirable eccentricities the shear walls may have to be thickened to the extent that they project beyond the former limits of the face of the building. In general, it is desirable to avoid any offset between the center of gravity of the load and gravity axis of the foundation. In reality some eccentricity can be tolerated in earthquake design if the effects on the structure are accounted for. In any event, for major rehabilitation work, the designer should not hesitate to shore the existing construction, remove undersized or inadequate footings, and reconstruct new foundations in

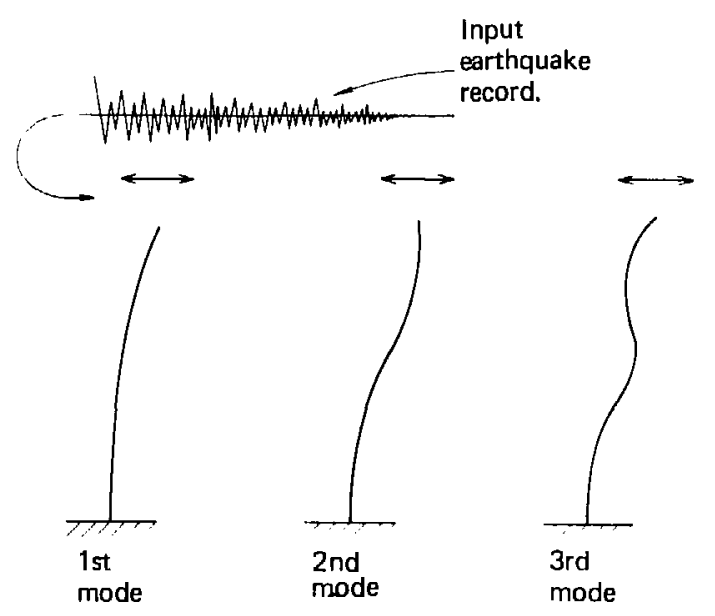

Final Results Obtained By Superposition

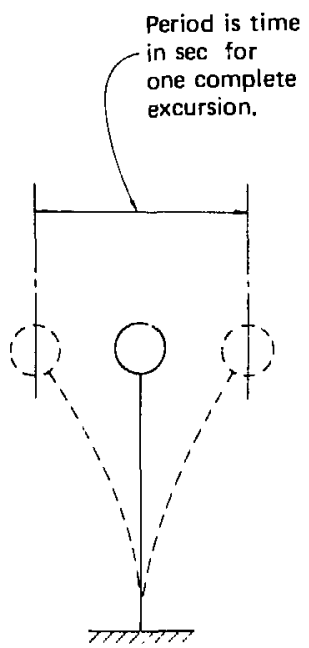

FREE VIBRATION
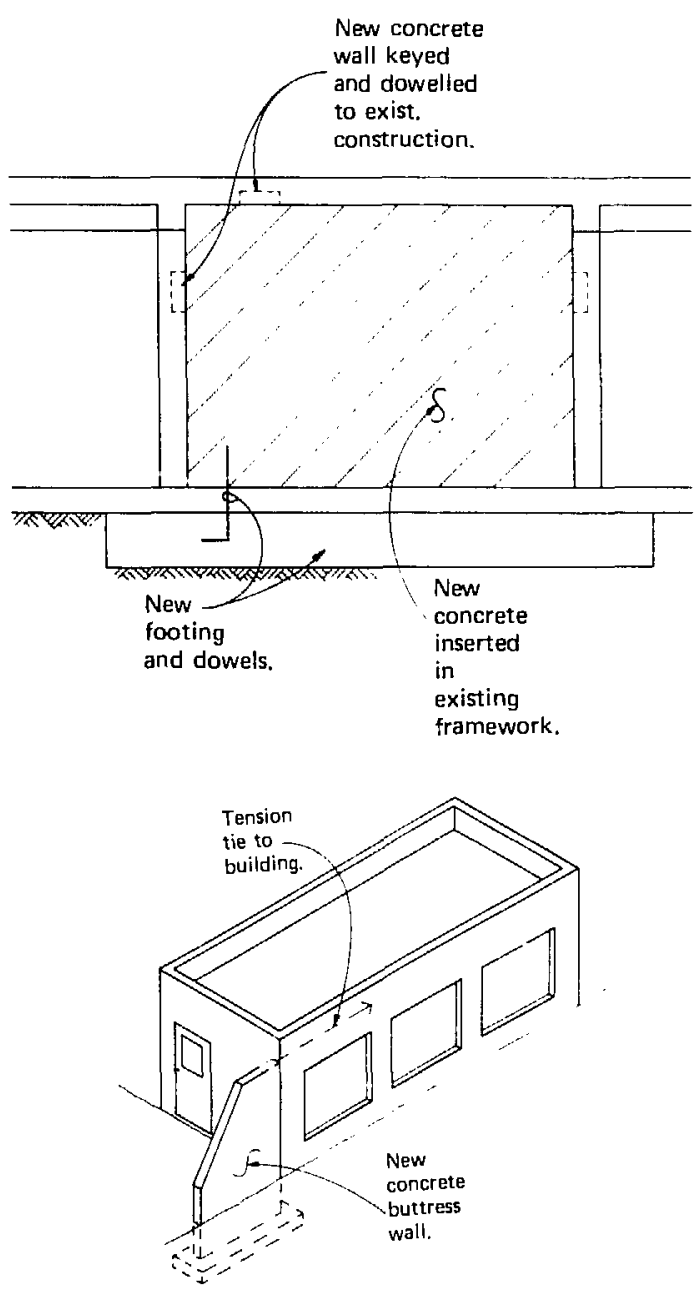

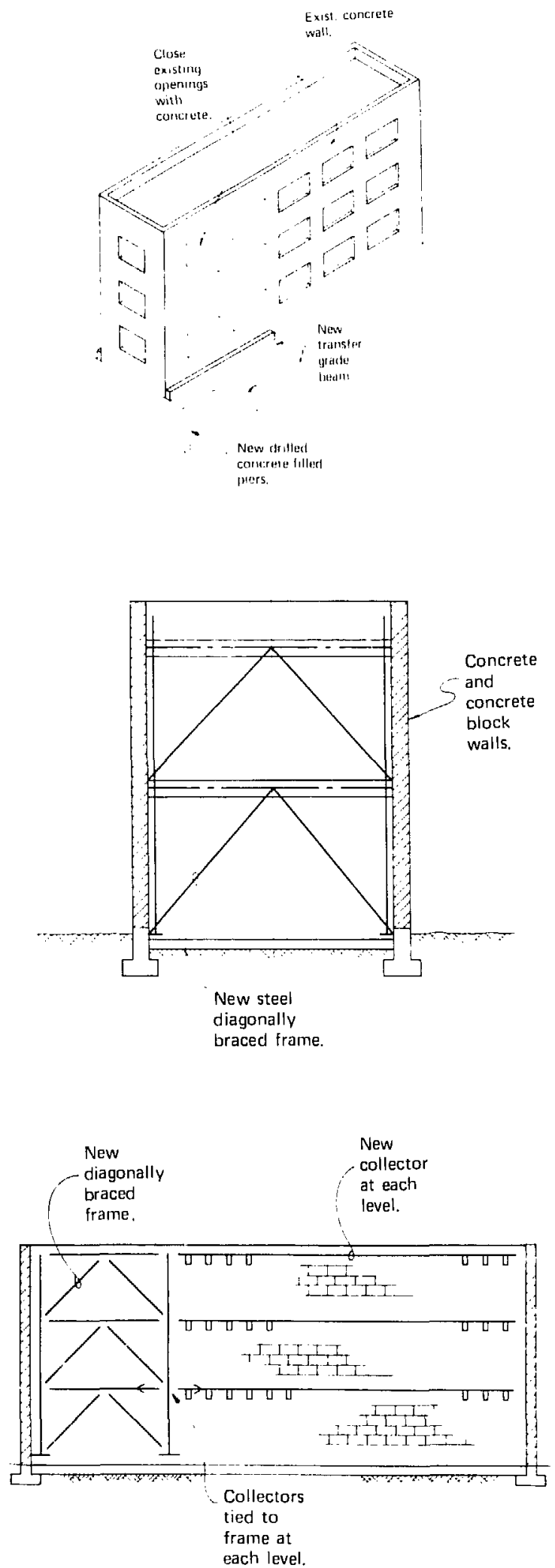

accordance with design requirements. Mass concrete footings can be placed outside the limits of the existing foundation with ties and/or grade beams employed for interaction between the new and old foundation. Battered caissons or piers (piles) can be used to resist axial loads from diagonal bracing. Critical soil values for friction and/or passive resistance must be obtained from the soils consultant. Prestressed ties are very effective where the anchorage load is ii tension.

Incorporating shear walls is usually the simplest and most direct method of handling earthquake loads. Shear walls are most easily located in exterior wall lines provided that floor and roof diaphragm ratios and shear strengths are adequate to span between exterior walls. If diaphragm ratios need correction, or if openings impair the strength and stiffness of the diaphragm, shear wal!s can be located on interior wall lines. Corridor walls are most convenient as interior shear elements. Since shear walls become permanent parts of the structure, their location must be coordinated with architectural considerations.

Closely akin to shear walls are abutments or fins. Such abutments can be placed at the ends of the structure, in line with existing shear or enclosure walls. Abutments must be adequately tied to the existing structure to prevent the building from tearing away from the abutment. Ties should function in tension where possible. When anchoring ties to the face of concrete walls, drilled-in anchors can be inserted into the existing wall face with hooked rods projecting from the anchor. Concrete in the form of a band can then be placed against the existing wall face.

Moment-resisting frames should be avoided in concrete or masonry buildings; they can be utilized for steel framed structures. Frame elements should be kept within exterior wall lines and in line with the wall. Struts and ties must be used to collect and deliver loads

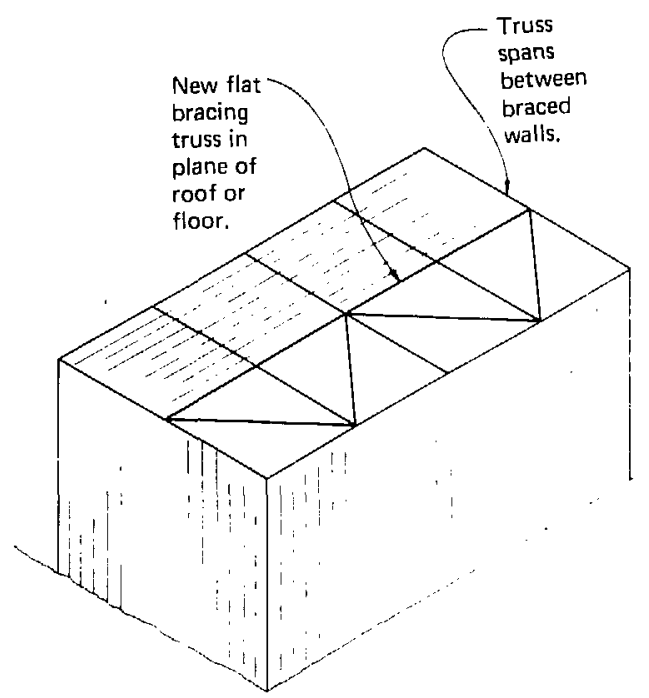




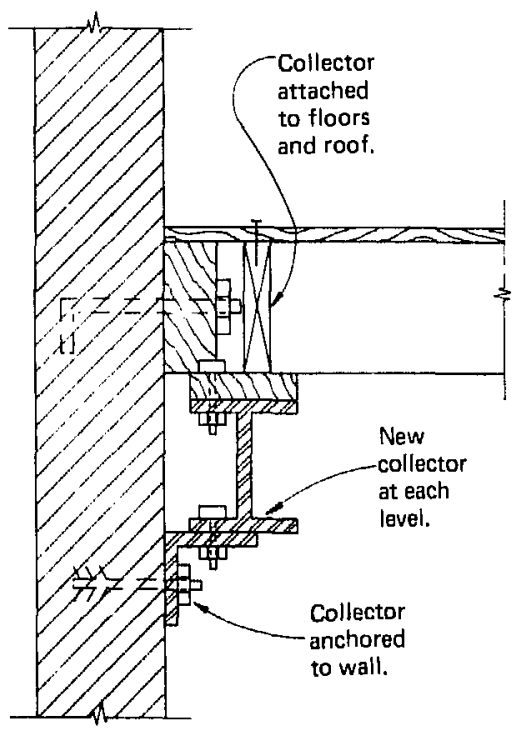

to the frame. Floor and roof diaphragms must be secured to the collector struts. Because of interferences with existing windows, utilities framing, etc., the designer is tempted to place frames outside the plane of the wall. Such eccentricities should be avoided wherever possible in rehabilitation; existing architectural facades must be adjusted to accommodate new framing. Generally, moment frames should not be combined with more rigid bracing, such as diagonal bracing or shear walls; nor should any system be employed which will introduce significant torsion.

Diagunally braced frames can be utilized for wood, steel, masonry or concrete structures. Diagonal bracing lines should be in the exterior wall lines and on interior lines as required. As diagonal bracing resistance is generated totally by axial or direct forces, it is even more imperative that bracing lines be in the plane of existing building lines and foundations. Wood structures are inherently flexible and thus, not totally compatible with diagonal bracing characteristics. For wood buildings, plywood shear walls are a preferable solution. Bracing must be tied to the structure it supports, and a
Long, narrow diaphragm characteristics improved with new shear wall.

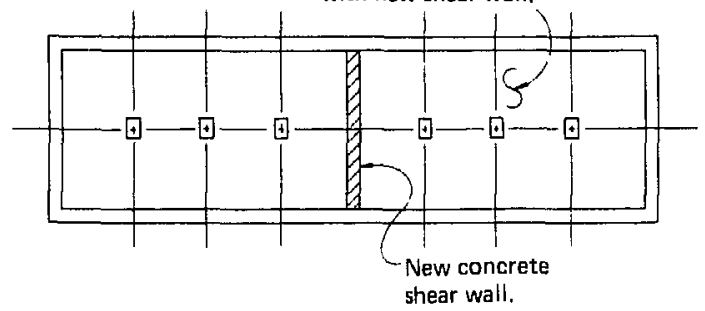

FLOOR PLAN

complete system of collector ties and struts should be provided.

Roof and floor diaphragms may have to be reconstructed, In wood structures existing finish and subfloor can be removed and new plywood nailed to joists. Partition walls will have to be shored, the sill plate removed, and the studs cut as required to permit plywood sheets to continue through under the partition. Plywood could be applied to the underside of joists with proper details, but existing light fixtures and duct penetrations may preclude this.

Concrete floors can be strengthened by adding a topping slab keyed or otherwise bonded to the existing slab. Lightweight concrete should be used for this topping slab (even if its shear properties are somewhat less than regular concrete). Diaphragm shears can be reduced by altering the existing floor area tributary to the diaphragms by inserting new shear walls or bracing lines, thus reducing diaphragm lengths. New chords and collectors can be introduced by threading and splicing reinforcing bars for the required lengths. The bar must be covered with concrete by guniting.

Light-gage metal deck sections are the easiest and quickest way to reconstructing a floor or roof diaphragm in steel buildings. New framing can be added as required for chords and collectors. Another alternative is to construct a horizontal bracing truss in the plane of the roof and/or floor using some of the existing framing as chords and diagonals. 


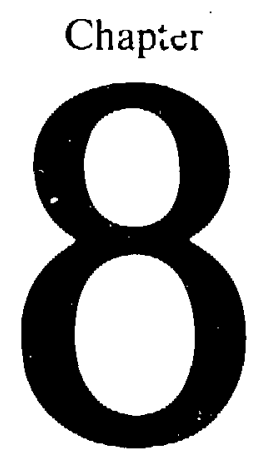

\section{Evaluation of Operations and}

\section{Building Contents}

\section{FOREWORD: Operator-Manager's Point of View (Donald G. Eagling)}

During recent years there has been an increasing awareness of those seismic hazards posed by nonstructural elements in buildings, such as suspended ceilings. ducts and piping, mechanical and clectrical equipment, elevators, file cabinets, book cases, partitions, glazing. architectural ornamentation, and misccilaneous movable objects. Damage to building mechanical, electrical and plumbing equipment received particular attention following the Alaska (1964), San Fernando (1971), and Managua (1972) earthquakes and significant codification has since developed although somewhat slowly. More recent earthquakes in California (Santa Barbara (1978) and Livermorc (1980)) have demonstrated the extreme hazards to life-safety and property damage, posed by non-structural elements and contents in buildings. In both of these carthquakes, structural damage was overshadowed by damage and costs related to non-structural elements, and by secondary effects which made emergency response very difficult. In both cases damage was very localized. Although the extent of perscnal injury was minimal, it was obvious that good luck rather than preparation saved many feople from serious injury. In each of the quakes, public institutions - Lawrence Livermore National Laboratory and the University of California at Santa Barbara - werc situated in the area of heavy shaking and the lessons learned fell upon responsive management. In each case the carthquake experience was well documented and the earthquake safety improvement programs that followed combine to provide excellent reference material for those OperatorManagers in charge of similar facilities.
This chapter covers earthquake safety as it relates "N the contents and operatiuns that are carried on inside buildings with the realization that non-structural elements which are part of existing buildings generally were not designed or installed with earthquakes in mind. For example, mechanical and electrical equipment are often installed in buildings without being adequately fastened to their foundations. Although this chapter does not treat non-structural elements of buildings comprehensively, several recommended references covering the subject are listed at the end of the chapter.

Shops, laboratories and production facilities contain many heavy objects which will travel. rock. topple. or break during earthquake shaking. This action may induce secondary effects which can be even more hazardous, such as breakage of containers holding toxic chemicals or explosive gases. Normal office equipment and furniture also pose significant hazards for injury. Heavy file drawers supported on low friction bearings usually arc cjected during an earthquake if the cabinets dn not have positive latches. Wide drawers in flat trasing files similarly become massive and multiple missiles when accelerated out of cabinets. Book cases and storage shelving which are not properly restrained. topple or discharge their contents to clutter and block nearby space.

Examples of common seismic hazards posed by building contents are shown throughout this chapter. The approach to mitigate these hazards is relatively simple. One has only to observe a building space and carefully: 


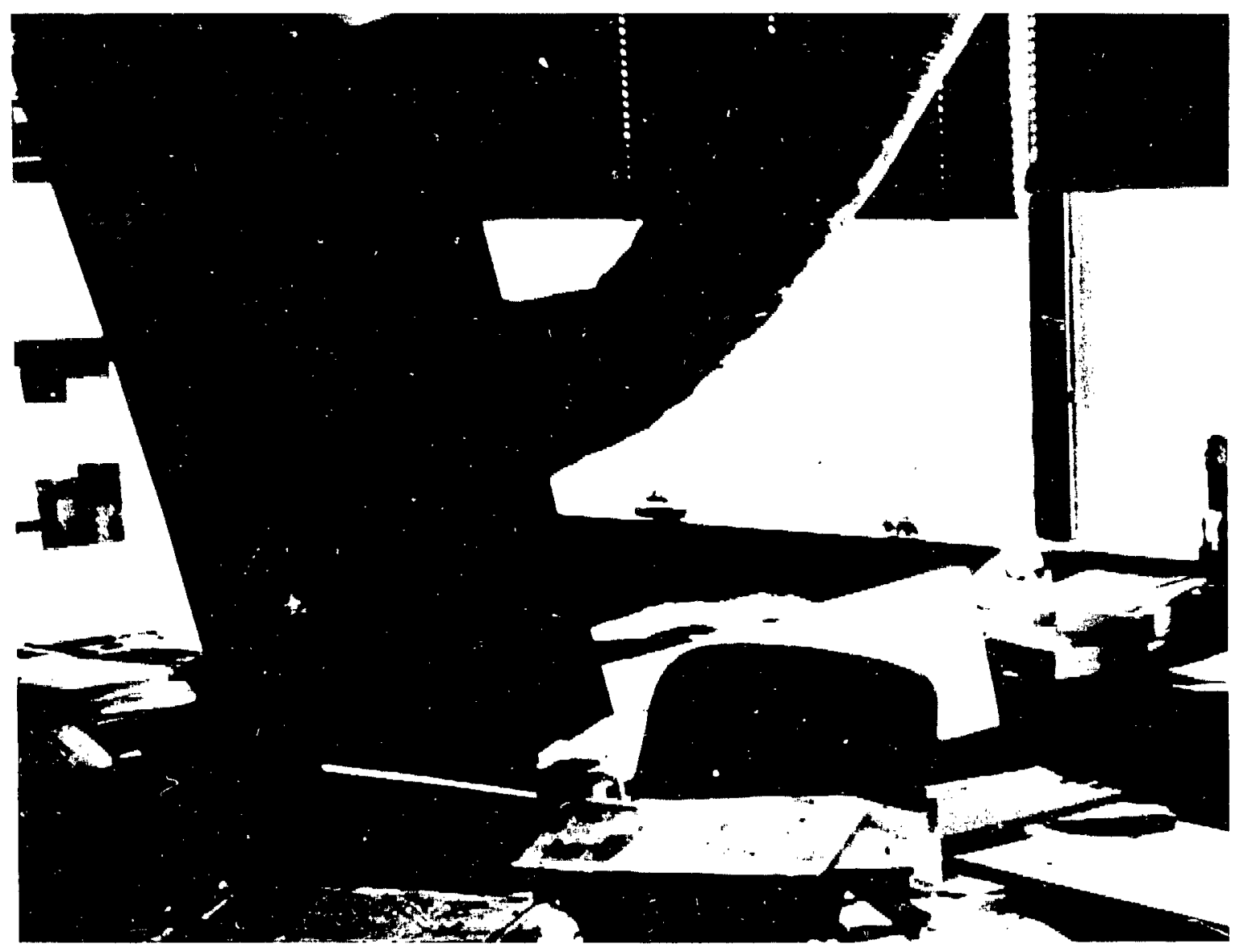

Fig. 1 - Failure of heating and ventilating system components over work station.

consider what will probably happen to the contents if the building is violently shaken. Consider the working stations of the occupants, Fig. 1 , in relation to the imagined action of hazardous contents. Will a tall book case fall over a desk chair"? (Fig. 2) Are the cabinet file drawcrs aimed at the occupant? Are heavy objects stored above the work station? Will the exit door be blocked by fallen debris? Renember, when violent shaking takes place an occupant may not be able to maneuver quickly. Instead, a person can be very helpless in this situation. The "cure" has to take place before the shaking starts, to make escape from injury more than a matter of luck. A well organized Building Manager system, coupled with a program to educate building occupants and their supervisors about carthquake safety. can be quite effective if supported by a systematic inspection program. The overall success of this combination will be dependent on the following principles:

- Building Managers must be supported with authority in order to carry out their rather difficult responsibil- ities. Usually, this can be achieves by appointing the person with the highest supervisory responsibility in the building as Building Manager. Most of the time-consuming work associated with the responsibility can then be delegated. but the Building Manager must be accountable to Management for the safety of occupants.

- An educational progran will be most effective if the occupants, supervisors and Building Managers have some real understanding of how building contents react to damaging earthquakes. This is best achieved by showing photographs of actual earthquake damage. backed up if possible by open discussion with an earthquake engineer who has observed such damage.

- Scismic safety inspections should be scheduled and carried out in conjunction with other routine inspections, such as fire safety and industry safety, so the economic burden is minimized. Although the inspector should be trained to visualize the effects of heavy shaking on building contents, one docs not have to be a civil-structural engineer to get the job dras. Of 


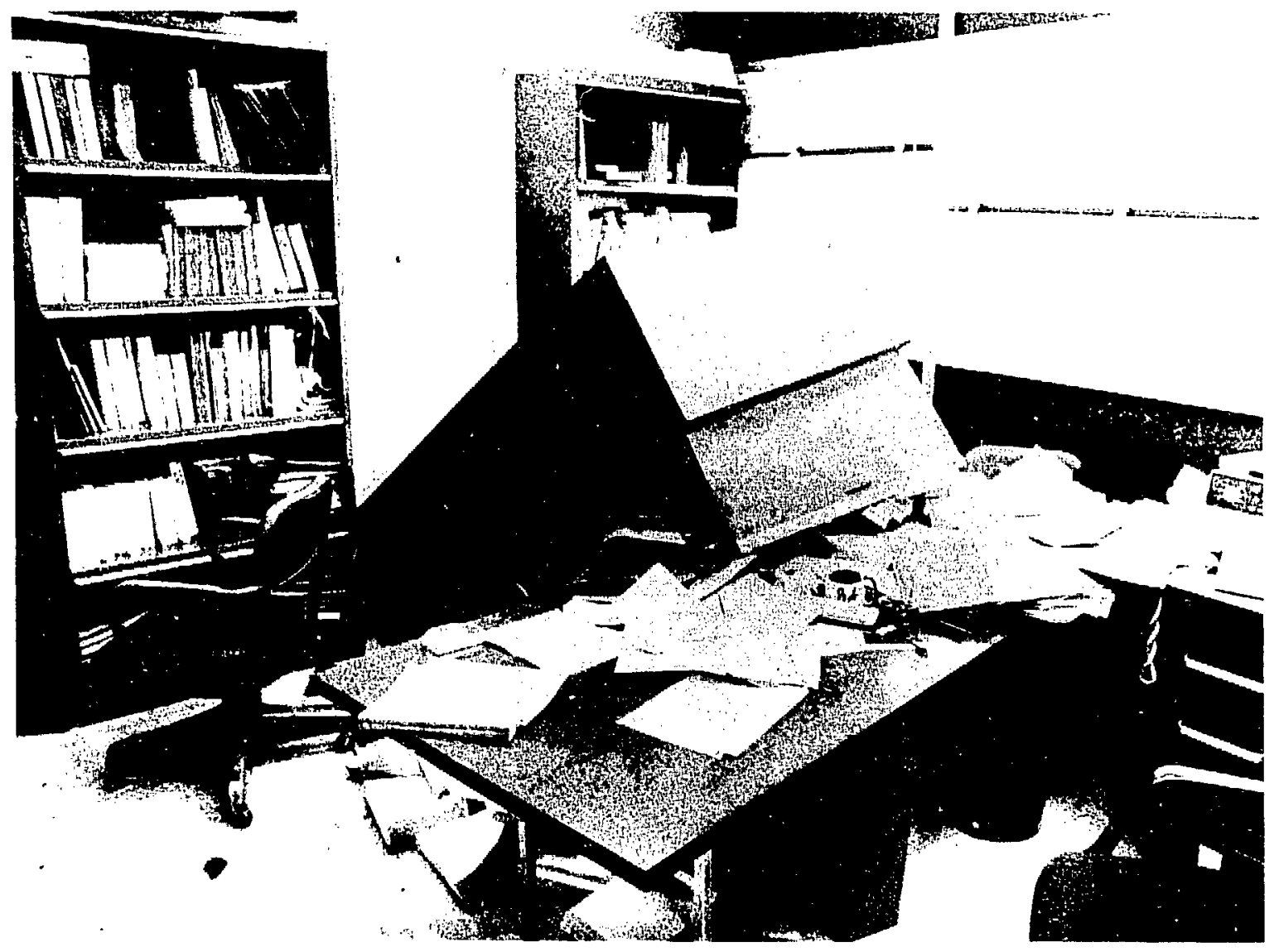

Fig. 2 - Unanchored bookcase overturned upon work station.

course common sense must be used. For example. when heavy book cases are tied together and finally braced or boltcd into a wall, the wall must provide adecjuate strength for anchorage. Gypsum wall board will not provide sufficient strength, and the wall framing itsclf. particularly if it is a partition that terminates at a hung ceiling. must be adequatcly braced. It is of prime importance to arrange for an individual to focus on earthquake preparedness related specifically to building contents and operations.

- Finally, the results of seirmic safety inspections must be communicated to someone who can arrange for corrective action. If the Building Manager accompanies the inspection party, this first-hand experience will usually provide increased motivation for correction. Of course, there must be an avenue for the Building Manager to pay for those corrective measures that require labor and materials, such as equipment tie downs, and bracing for storage racks or library shelving, Fig. 3 The costs of operational corrections, such as relocating storage facilities or moving furniture, are sometime assigned to the users to provide motivation for "seismic" housekeeping. 


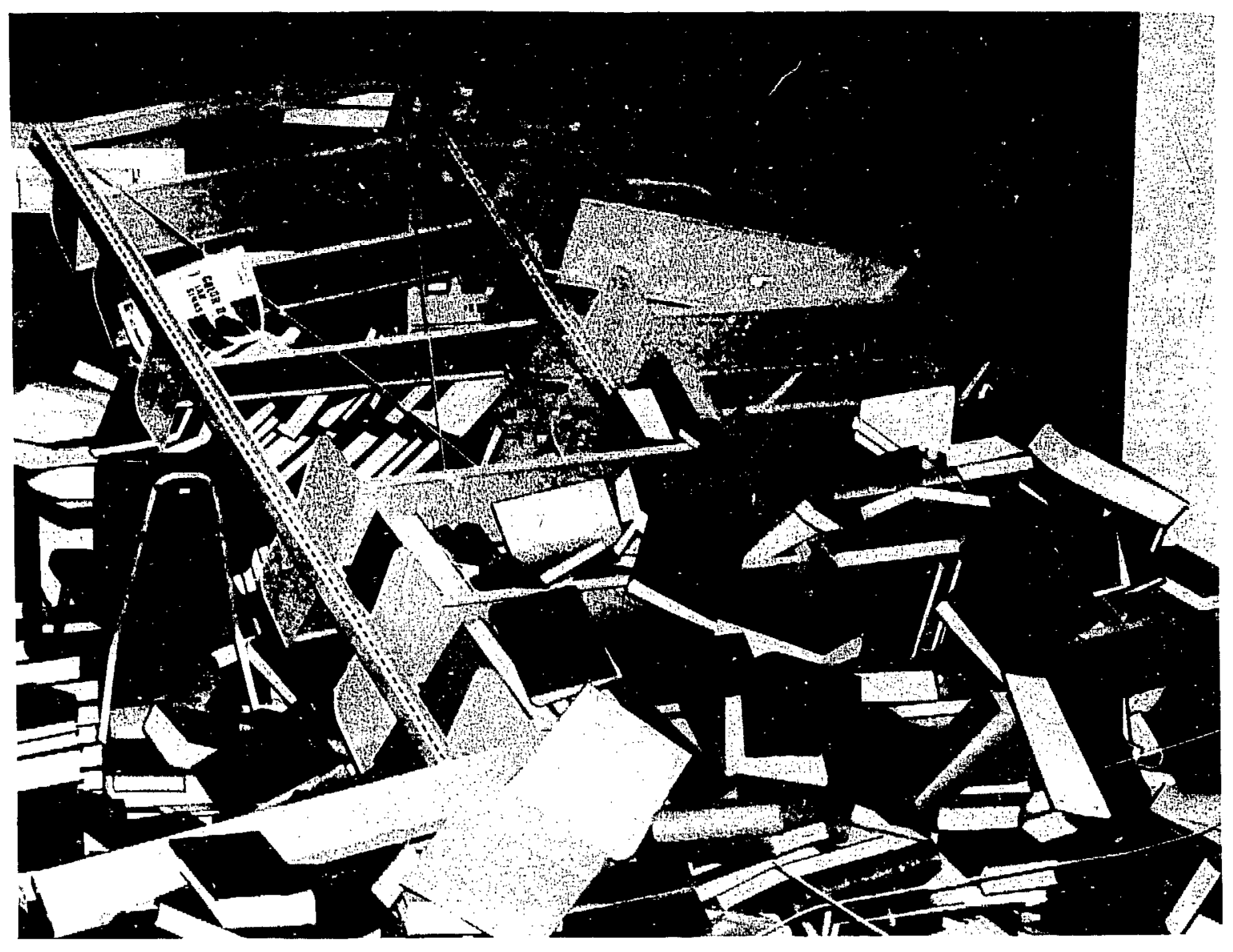

Fig. 3 - Failure of library shelving at work station. 


\title{
Chapter
}

\author{
8 \\ Evaluation of Operations and \\ Building Contents \\ James L. Stratta \\ Civil Engineer \\ Structural Engineer
}

Mr. Stratta has w:en a consulting civil and structural engineer since his graduation from the University of California at Berkeley in 1943. In 1952 he joined a partnership for architecture and engineering, with special empnasis on seismic analysis and design. He began his private consulting practice in 1978.

Mr. Stratta served in 1962 as president of the Structural Engineers Association of Northern California, and in 1967 as president of the Consulting Engineers Association of California. He was a director of the American Consulting Engineers Council, 1968, and is a member of the Earthquake Engineering Research Institute. He is a fellow of both the American Society of Civil Engineers, and the American Consulting Engineers Council. He has taken part in world-wide earthquake conferences and surveyed numerous quake sites. James L. Stratta is located in Menlo Park, California.

Mr. Stratta has co-authored reports on the following seismic events:

$\begin{array}{ll}1964 & \text { Anchorage, Alaska Earthquake. } \\ 1970 \text { \& } 1974 & \begin{array}{l}\text { Peru Earthquakes. } \\ \text { Interaction of Infill Walls and Concrete } \\ 1971\end{array} \\ \begin{array}{l}\text { Frames During Earthquakes. } \\ 1976\end{array} & \text { Rotation of Footings Due to Surface Waves. } \\ 1977 & \text { Mindanao, Philippines Earthquakes. } \\ 1979 & \text { Friuli Earthquake, Italy. } \\ 1980 & \text { Compania-Basilicota Earthquake, Italy. }\end{array}$

\section{Inspection of Contents}

In the aftermath of an earthquake, the number of injuries, loss of life, and amount of property damage due to causes other than structural failures will be inversely proportional to the quality of the inspection, and the precautions taken to reduce hazards in facilities prior to the earthquake. Expiosions, fires, toxic fumes, falling objects, sliding objects, and other serious sunditions of ten occur during seismic activity. An awareness of how such poteritially disastrous events (often triggered and/or intensified by sequential collisions) can happen will facilitate development of means to minimize injury or damage, or chances of their occurrence Some steps which can be taken to prevent or mitigate such problems are described in this chapter. These are 
summarized below, then discussed in more detail in the sections that follow.

Explosions can occur in several ways. Whenever hazardous compounds, liquids, or gases are to be stored, expert advice should be sought regarding both the physical facilities and operational procedures to be utilized with respect to seismic safety. The compatibility and proximity of adjacent materials to be stored in a given space, suitability of containers, ambient temperatures and pressures, presence of electrical devices, and location of the storage areas should be considered. The basic objective is to protect occupants and facilities from the effects of impact, spiliage and/or mixing of such materials in the event of an earthquake.

Gases stored in containers or distributed in building piping, including heating fuels or any other material which could be ignited by a spark or elevated temperatures, should be monitored and, where advisable, seismic shutoff valves installed to reduce the hazard. Electrical equipment and conduit should be securely anchored and provided with expansion joints or flexible connections at points most likely to be heavily stressed in an earthquake. Seismic disconnect devices should be considered for electrical service where arcing could lead to fires or explosions.

Dangerous fumes are normally exhausted, neutralized, or absorbed by special ventilation systems. Consideration should be given to installation of an earthquake-resistant system which would continue 10 exhaust or contain such fumes in the event of an earthquake. An unusually insidious situation exists, however, where backup emergency power is normally supplied to an environment in which explosive gases could be present in the aftermath of an earthquake. For example, emergency power may be required to ensure continuity of ventilation of a space in the event of a normal power outage. If, as the result of an earthquake, explosive gases are released in that space and power is lost, emergency power may still cause sparking and possibly an explosion. In this situation, an earthquake-resistant, explosion-proof electrical system may be necessary,

Falling objects often create very serious problems ruring earthquakes. In addition to injuring people,

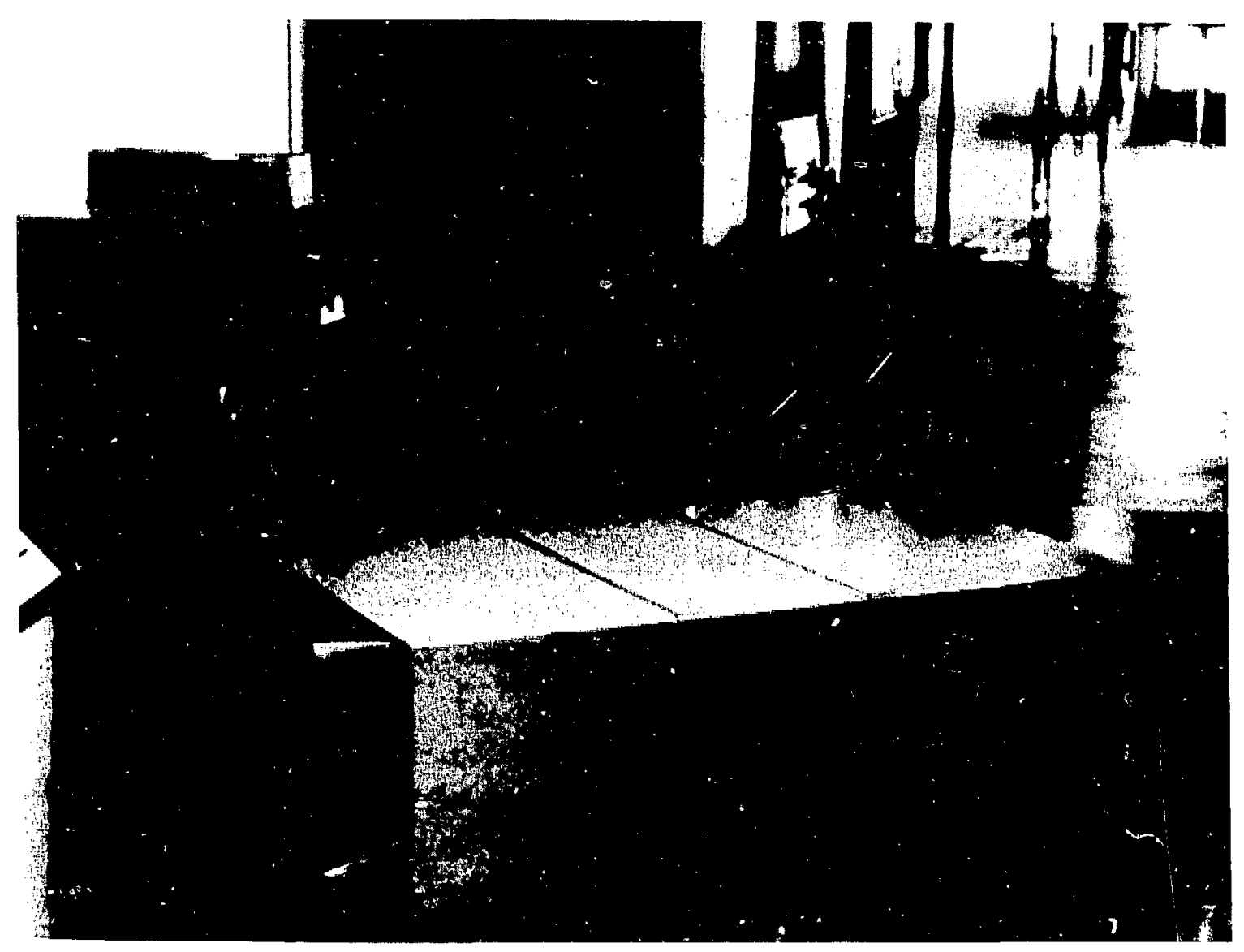

Fig. 4-Overturned vending machine in access corridor. 
they may create obstructions to egress from buildings. For example, free-standing or inadequately anchored lockers or vending machines in hallways often slide or topple, blocking exit paths, Fig. 4. Such obstructions may stimulate panic in an already stressful emergency condition.

Sliding objects, particularly heavy, unanchored equipment or partitions, may travel across the floor, creating one or more of a variety of serious problems, examples of which will be given later. Intense shaking can also cause other equipment-related problems. For example, heavy compressed gas containers may fall over and slide or roll with considerable velocity. If the tank valve is broken off, the gas will escape precipitously and the container will react like a missile. Also research equipment, housing other hazardous dispersible materials, such as radioactive substances, carcinogens, or virus may overturn and rupture, releasing their contents.

Non-structural building components and tquipment are some of the more typical seismic hazards which may be present in research facilities. The potential dangers provide ample justification for carrying out systematic building-content inspections for earthquake safety. Practical means for preventing or mitigating such possible problems and property damage are discussed in the following sections relating to the four modes of equipment displacement and failure, as depicted in Fig. 5.

\section{Explosions}

In the storage of explosives, particular care must be taken to prevent the types of moving and rupturing failure represented in Fig. 5. Expert consultation should be employed. Typically, chemical storage cabinets are not designed or constructed to prevent spillage or breakage of chemical containers during an earthquake. However, in a seismic area an earthquake may cause the various bottles containing chemicals to slide off the shelf or out of cabinets, fall to the tabletop or floor, Fig. 6, and break. If any mixture of these spilled chemicals can cause an explosion or other potentially dangerous event, precautions to avoid such problems should be taken to mitigate the hazard.

Typically, chemical storage cabinets are not designed or constructed to prevent spillage or breakage of chemical containers during an earthquake, ar 1 modification may be necessary.

Good seismic safety practice dictates the use of spillproof, unbreakable containers that are not subject to attack by acids or solvents. Providing a lip or guardrail for each shelf is suitable only where relatively small amounts of low-hazard materials are involved. Unfortunately, a railing may not prevent containers from overturning on a partially-filled shelf, even if it will restrain them from falling off the shelf during an earthquake. Sturdy storage cabinets with positive spring clo-
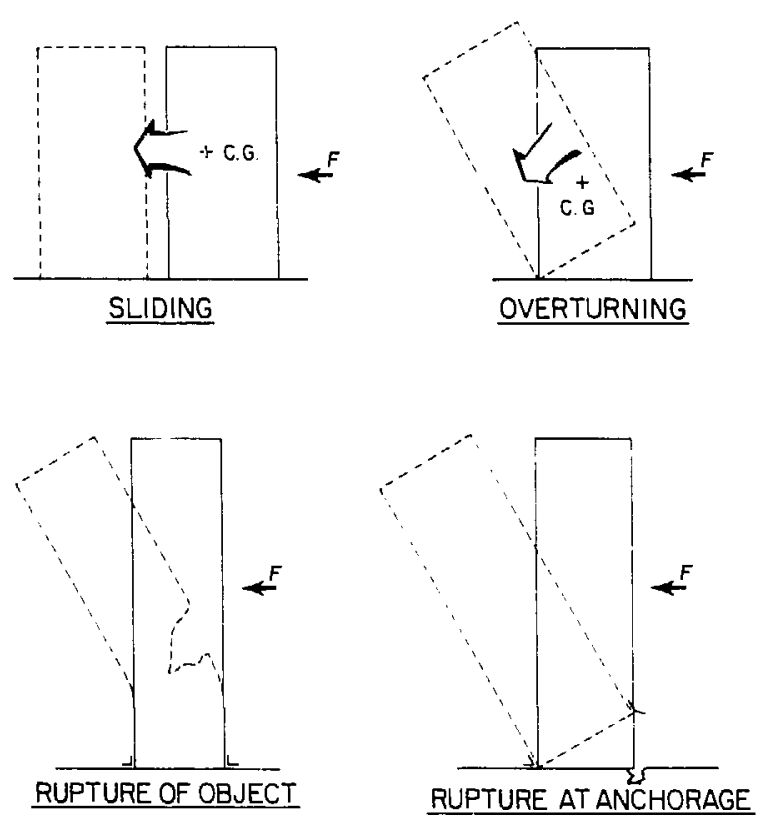

Fig. 5- Four modes of equipment displacement and failure.

sures and catches on the doors offer better protection than open shelves. Proper workability of the closures and catches should be verified at each building inspection and/or by users. If visibility of cabinet contents is desired, wire-reinforced glass can be securely fitted in the door frames. Full shelves and only compatible materials in each cabinet are recommended. In building areas containing significant amounts of gases which can combine to cause hazardous mixtures, provisions should be made to preclude accidental mixing. For example, seismic shut-off valves may be installed at main gas supply points, or at appropriate distribution line locations, as best suits the situation. Explosionproof electrical fixtures and switches should always be used where sparking could cause a problem.

\section{Fires}

Gencrally explosions will also result in fires. The same precautions as previously outlined for explosions should be exercised for fire prevention.

The storage of flammable chemicals should be very carefully monitored. Cabinets containing hazardous chemicals should be securely anchored to prevent overturning, falling, or sliding. Doors need positive latches to prevent opening due to shaking. Rooms how:ing flammables should have properly rated firewalls, ceilings and doors. Curbs, drains, mechanical equipment, and electric fixtures should also comply with fire protection codes. Operating procedures for the storage and use of flammable chemicals should comply with good practice for seismic safety. 


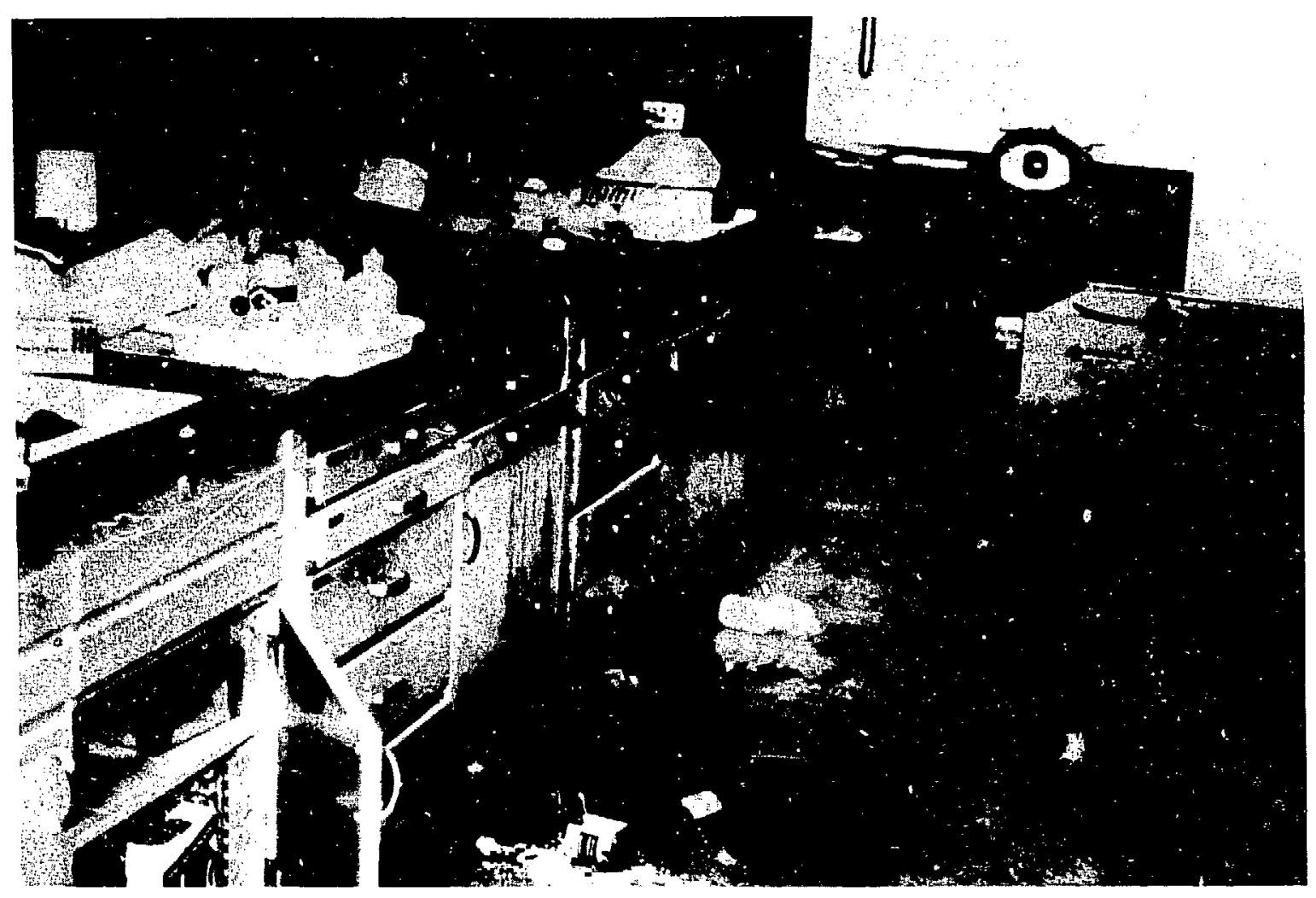

Fig. 6 - Spilled chemicals in "wet" laboratory.

Electrical fires can result from several causes. Short circuiting is probably the greatest hazard and also the most difficult to control. Because short circuits may occur due to structural failure or building collapse, seismic safety evaluation of existing buildings should include inspection of electrical devices and building wiring.

A number of essential conditions must be met to reduce electrical hazards related to operations and building contents during an earthquake. Proper anchoring can prevent the overturning of switchgear, transformers, motor control units and similar equipment. Figure 7 shows a damaged panel at the Olive View Hospital after the San Fernando Earthquake. As a rule of thumb, this type of equipnent should be anchored for a static force equal to one-half of the weight of the equipment acting horizontally at the center of gravity. Energy and water supply lines of various types should also be protected.

Electrical ovens, boilers, and other high-amperage units should be securely anchored to prevent motion and tearing of electrical feeder lines which could short and start fires. Outdoor tanks storing volatile flammable gases or liquids such as propane must be anchored to prevent loss of contents and a possible holocaust. Fire sprinkler systems should be periodically checked to ensure that materials are not stored adjacent to lines or mains where their collapse onto the sprinkler system could cause a rupture in the lines during seismic motion. It is of course vital that a water supply for fire protection is indeed available in the aftermath of an earthquake. On-site storage with emergency pumping facilities may be necessary for proper risk management.

\section{Toxic Fumes}

The two major sources of fumes are those generated as a result of an earthquake and those which were generated prior to the earthquake and were being exhausted. In some laboratories toxic fumes may be evolved as a result of processes used in research or other routıne operations. Research processes generally are conducted in hoods which exhaust the gases. Such gases may pass through high efficiency filters or scrubbers prior to emission to the outside atmosphere. For some hazardous operations it is imperative that filter and scrubber systems are designed to resist earthquakes and that the exhaust and scrubber fans are connected to an emergency generator so that continued 
operation is assured even though a puwer failure may occur. Hoods or benches where these gases are generated should also be carefully anchored to prevent the aforementioned modes of failures.

Most fumes originated due to seismic motion result from a mixture of chemicals or gases used or stored in the facility. When observing a storage area, a few simplc questions will help determine the presence of a seismic safety problem. Ask what will happen if any two of these chemicals stored here come into contact with one another. What will happen if they mix with water? Or if they come into contact with acids or solvents which may be stored nearby - what then? If the answer to any of these questions indicates hazardous consequences, positive means should be made to prevent such contact in the aftermath of an earthquake.

Toxic gases may be piped in, but more likely equipment will be connected to cylinders, canister, or dewars. Whatever the source, hazardous gas must be prevented from creating a serious problem as the result of heavy shaking. Where large amounts of gases are maintained or supplied, use of earthquake valves should be considered. Plating facilities should be carefully observed also, with the same questions in mind. Tanks are likely to overflow so the mixtures of these liquids should be analyzed. Sliding and overturning of tanks should te prevented with properly designed anchorage.

\section{Falling Objects}

Objects may fall from shelves, bins or tables. A rather innocuous appearing object is the locker or cabinet, multiples of which may line corridors or other access ways. During seismic motion, tall cabinets or shelves, unless anchored to the walls, will tip over. If they fall in a corridor, injury to personnel who are in the passageway may be minimal, but the resultant blockage of egress, Fig. 8, from the building may greatly amplify the panic felt by those trying to escape the building. Large volumes of heavy books or files stored on shelves along corridors are also extremely hazardous. Exits and tributary corridors should be inspected regularly for objects that block or congest these areas. Nothing should be allowed to impede prompt exiting of personnel from the building. Personnel should be instructed not to panic and run from buildings, but restraint during an intense earthquake is almost impossible to achieve.

Areas where materials or objects are stored in high places, such as storage rooms, warehouses, shipping and receiving rooms, libraries, etc., should be inspected, keeping in mind the four modes of equipment failure previously illustrated (Fig. 5). Computer rooms where raised floors are neither braced nor anchored will be hazardous if floors collapse due to seismic motion. Tall computers will then almost certainly overturn, possibly injuring personnel and blocking exits. Short circuiting from electrical connections may also occur. Generally.

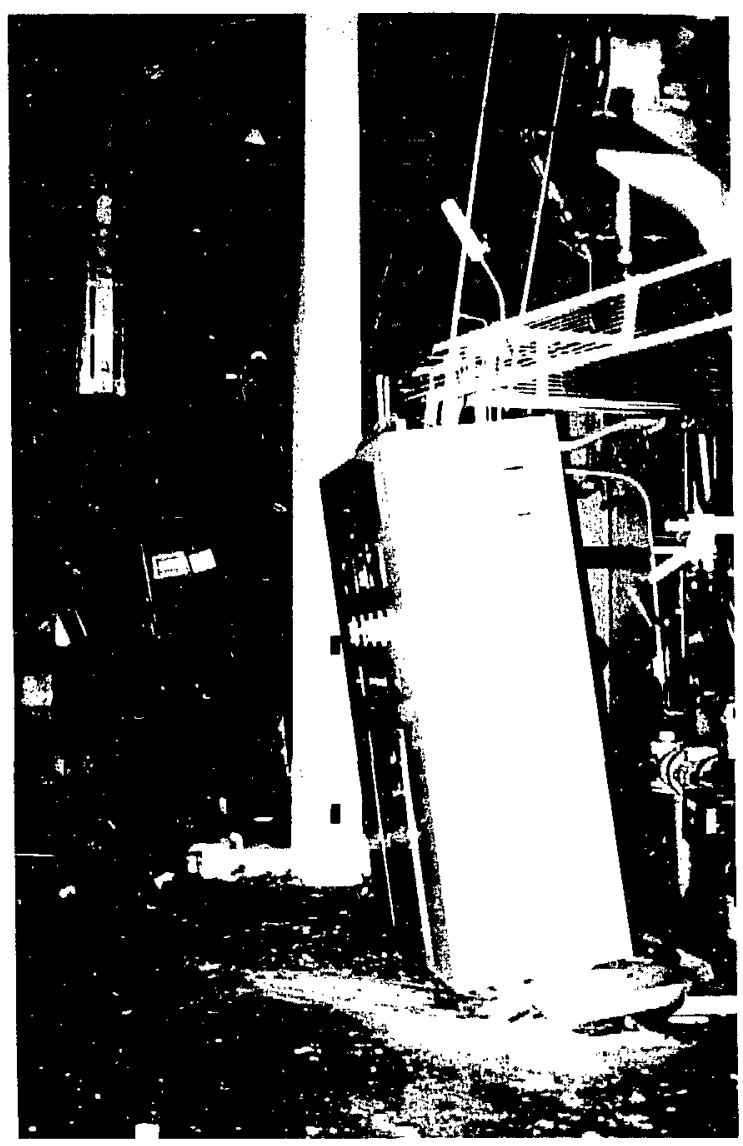

Fig. 7 - Failure of damaged motor control panel.

cabling will restrain equipment if the computer floor itself survives the shaking.

Process or research equipment placed on table tops will be particularly vulnerable to falling to the floor. Usually such equipment is very expensive and difficult to replace. Aside from the loss, dire secondary consequences may result. If the shattered equipment spills hot, toxic, flammable or dispersible radioactive materials, spilling could create serious situations. Anything containing highly dangerous material should be carefully designed to prevent spillage of its contents and anchored to a stable surface, regardless of its location.

\section{Sliding Objects}

The effects of sliding objects are somewhat similar to those of falling objects. However, the sliding components of buildings sometimes have unique characteristics and therefore are given special attention in this discussion.

The principal building components to be considered in most cases are those of the mechanical and electrical 


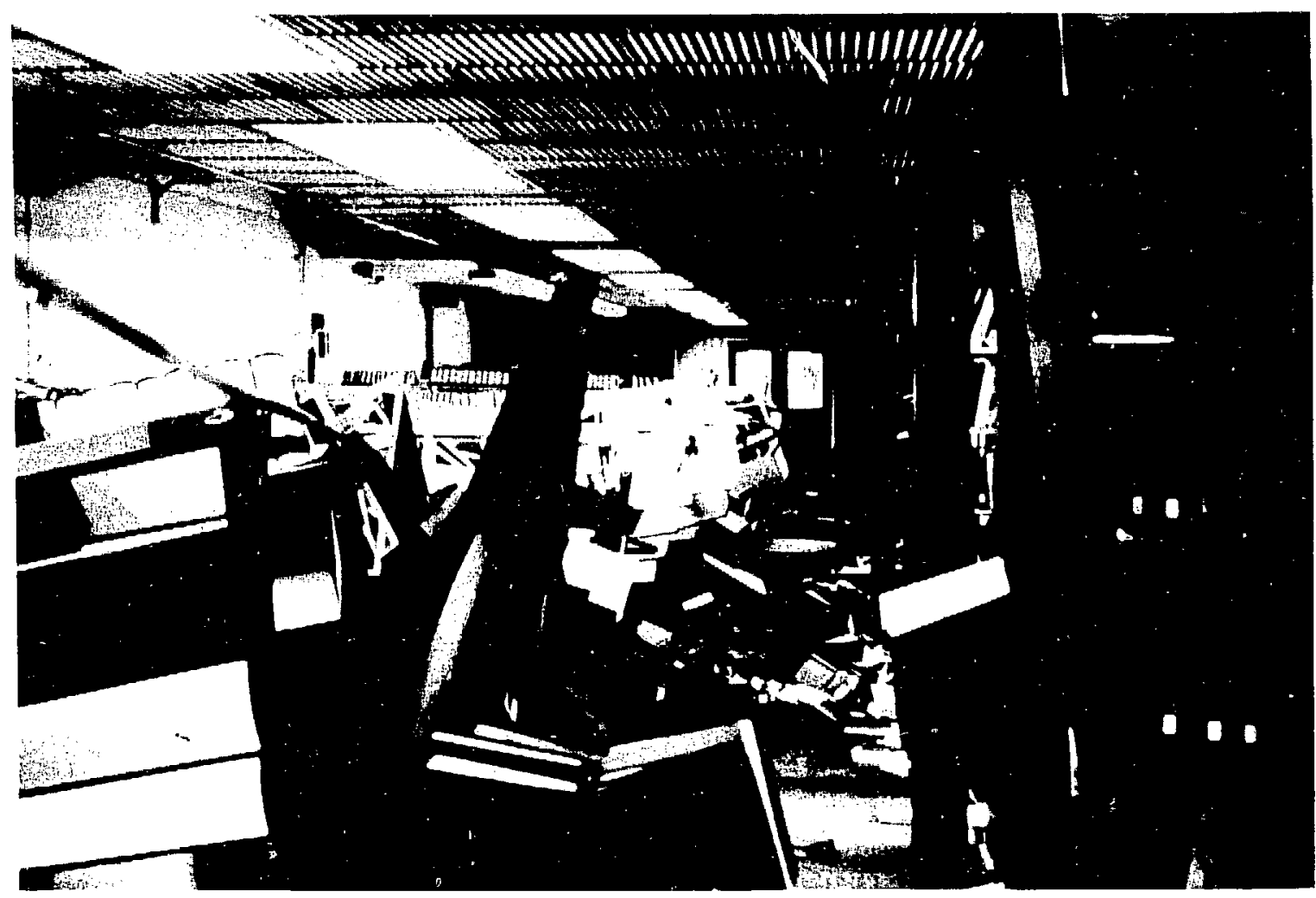

Figs. 8 - Failure of inadequately braced library stacks.

systems. Such mechanical system components are chillers, Fig. 9, pumps, boilers, cooling towers, and air handling units require anchoring in a manner that will minimize damage or, for units of critical systems, permit operation after an earthquake. The movement of any of these components, or the breakage of lines leading to and from them, will cause the systems to shut down and result in costly property damage. Even in relatively minor earthquakes, property damage to building mechanical systems has been very expensive. The fact that some of these units are on mounted springs to eliminate vibration further complicates the problem. Although expert advice should be sought in such cases, the references at the end of this chapter provide good guidance and methodology for design solutions.

In order to keep this subject in proper perspective, it should be pointed out that anchoring such equipment is usually required only if it is desired to keep the building in operation or to reduce remedial expenses. The motion of these elements and resulting damage will result in expensive repair but it is unlikely to cause personal injury or serious structural damage to the building.

In the electrical system, anchorage of sub-stations, switchgear, motor control centers, panel boards, and emergency generator is required. Again, as in the case of the mechanical system, the extent and sophistication of earthquake resistance and anchorage will be dictated by the use and contents of the building. It should be pointed out, however, that it would be a very rare case where an emergency generator need not be securely anchored. When a power outage occurs in an earthquake, emergency power is usually needed.

In summary, contents of buildings which should be prevented from sliding are those which could make the equipment unusable or which can create other problems. Heavy X-ray machines should be anchored so that they will be usable in the aftermath of an earthquake. Equipment which is piped to hazardous gases should be securely anchored to prevent breakage of gas lines with resulting leakage. Similarly, unanchored equipment connected with electrical feeders could break the line resulting in sparking and possible short circuiting. Overhead cranes present special hazards for buildings and occupants, Fig. 10. Generally, over-running cranes can be equipped with "keepers" to prevent derailing or falling from the crane runway rail during an intense earthquake. 


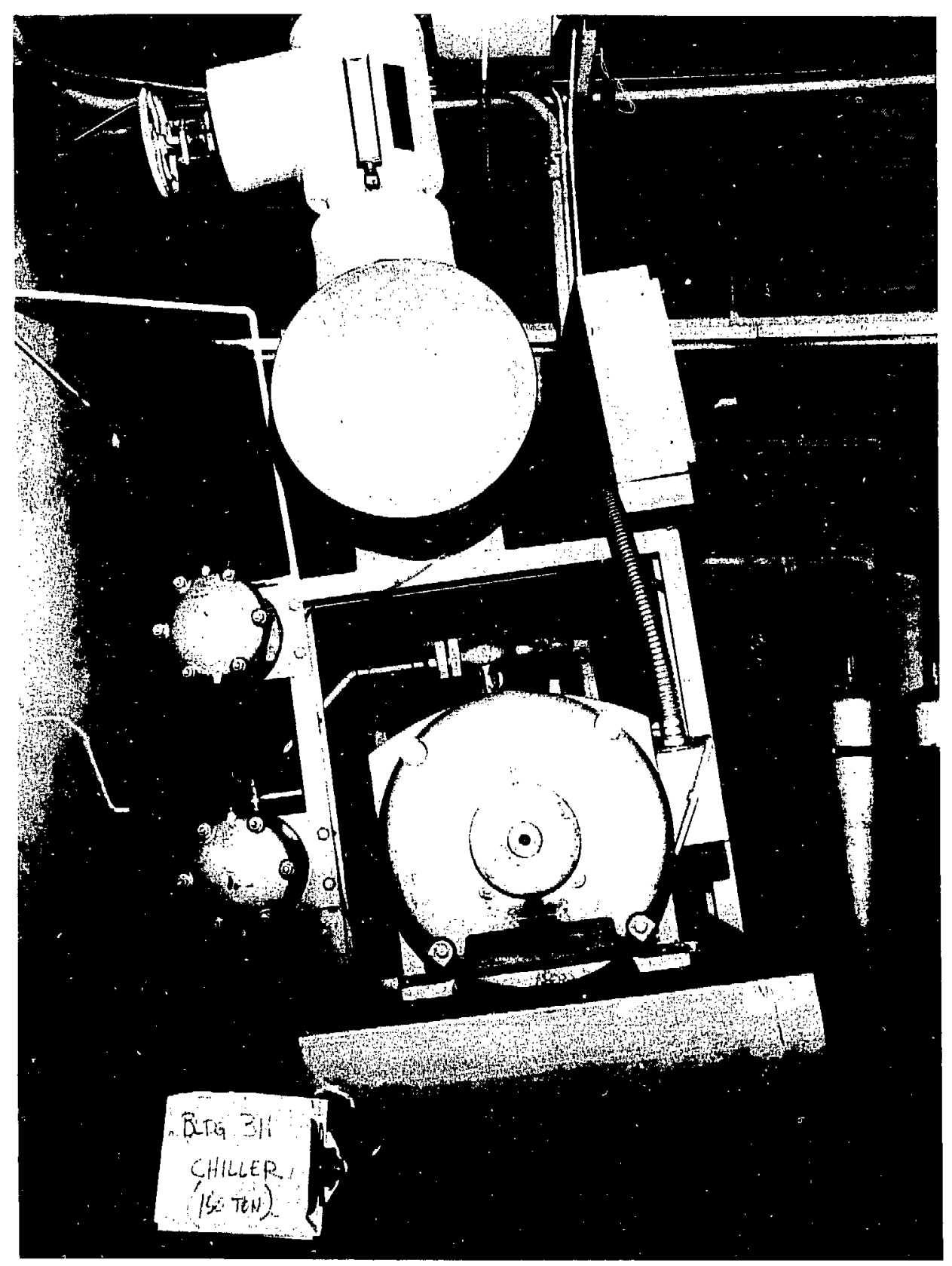

Fig. 9- Failure of anchorage for 150 ton chiller unit.

Generally, anchor bolts for mechanical equipment installations have been too small for adequate anchorage in concrete. It is simply good practice to use large bolts because most of the cost is in the labor and anchor bolts in concrete have little ductility.

\section{Miscellaneous Problems}

In large, older buildings certain items should be updated. Ceilings and lighting fixtures over work stations, Fig. 11, and exit corridors should be well braced 


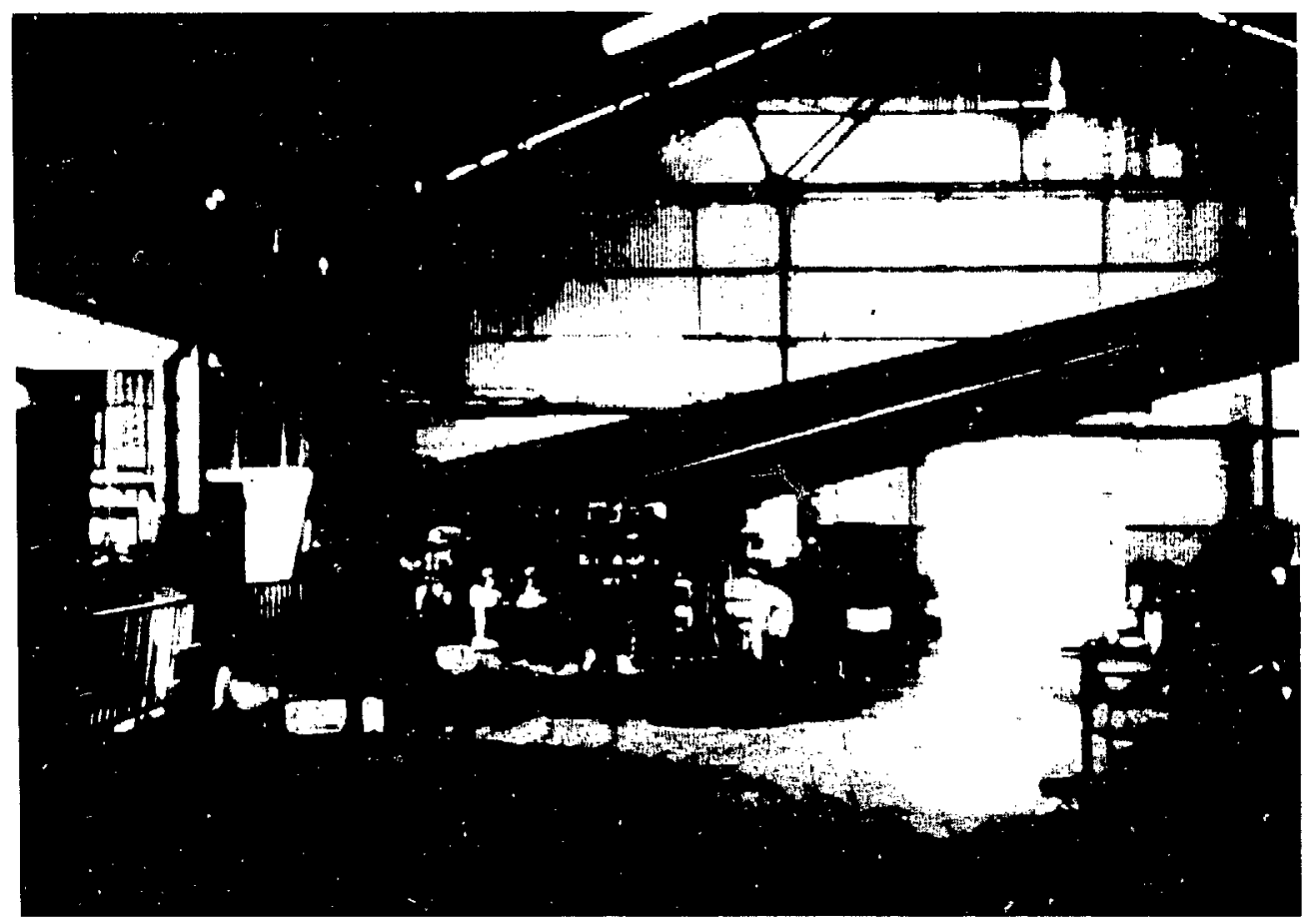

Fig. 10 - One end of a bridge crane fell from its runway rail (upper phe.c.) during the December 23, 1972 earthquake in Managua Nicaragua; in the same quake, another overhead crane in a turbine room (lower photo) remained operational.

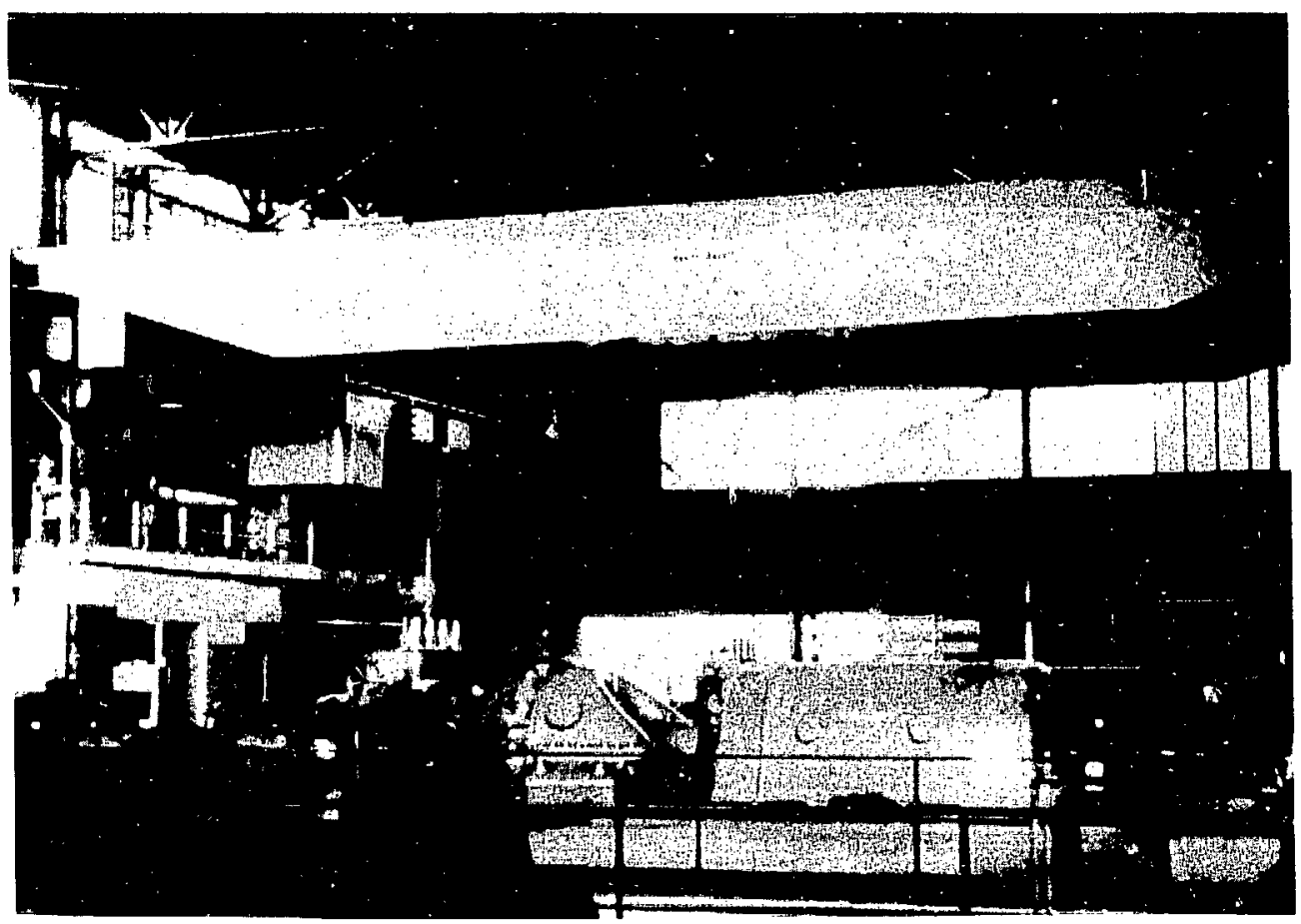




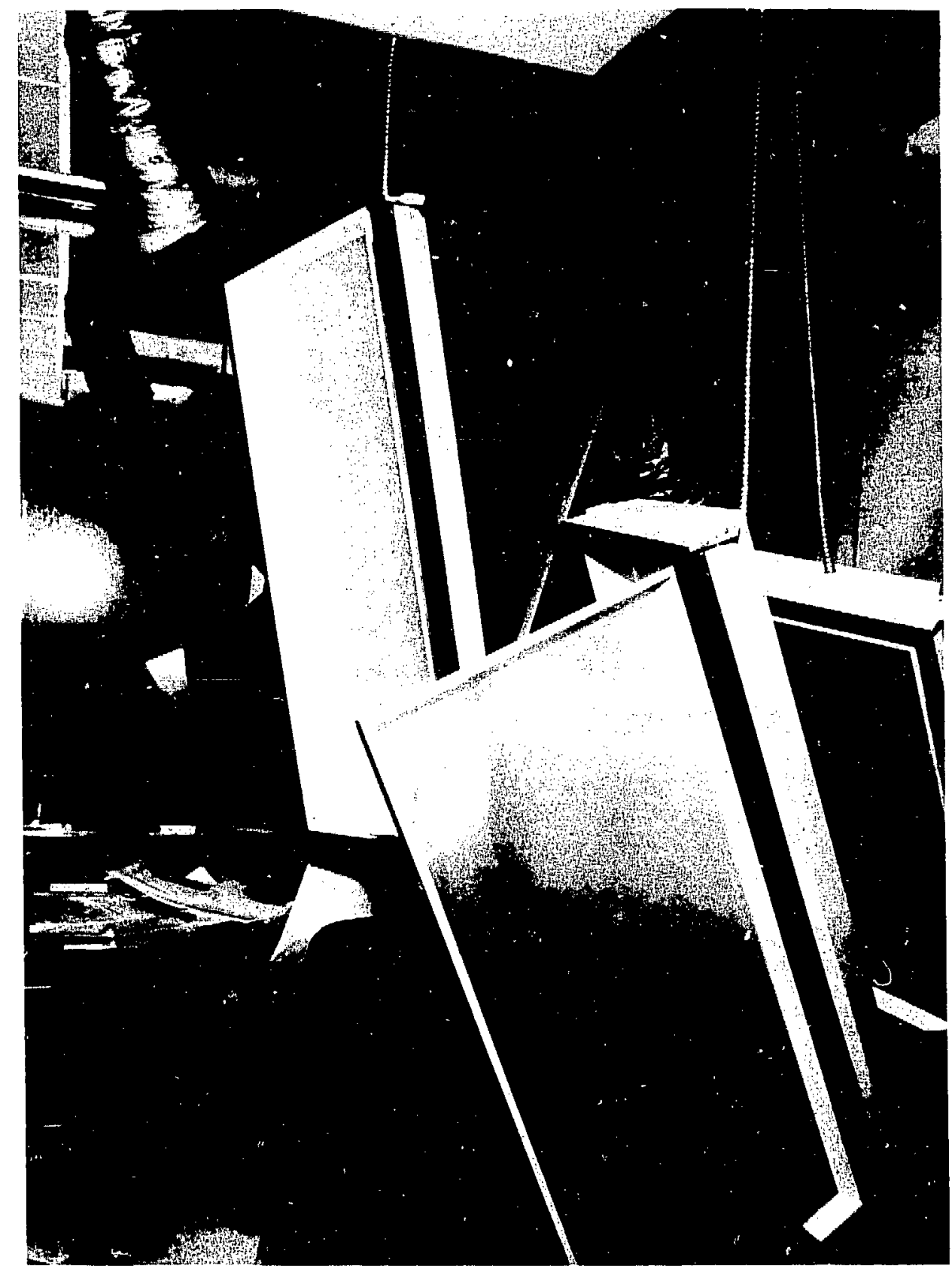

Fig. 11 - Failure of hung ceiling, light fixtures, and ductwork over work station.

and anchored to prevent collapse. The exterior facade over exits should be checked to ensure that there can be no falling objects, such as masonry or other heavy veneers, parapet walls, or potted plants to rain down on people leaving the building.

Up to this point the discussion has been concerned primarily with problems relating to harm to personnel. Another very important factor is financial loss. For example, major pieces of electronic equipment may cost hundreds of thousands of dollars. In "earthquake country" some effective preventive program to reduce the possibility of heavy financial loss is simply good risk management. The cost premium is usually 
insignificant. The most difficult problems relate to operational procedures and the need for mobility.

\section{Inspections}

When inspecting a facility, one should take sufficient time to walk around the interior and exterior of each building, while visualizing a scenario of the aftermath of an intense earthquake. One should imagine how objects would be moved about and the problems they would create. All doors should be opened and all rooms inspected; closets and cabinets included. Spaces above hung ceilings of ten contain potential falling hazards. Any space may hold potentially dangerous materials or situations. Many conditions that are entirely adequate for efficient daily operation may be inappropriate from a seismic safety point of view. In particular, special attention should be given to those spaces and facilities which will be used for emergency recovery.

The frequency of inspections should be related to the usage of buildings. Laboratories and chemistry rooms certainly need more frequent inspection than office complexes.

\section{GENERAL REFERENCES}

\section{Chapter 8}

Earthquake Protection of Essential Building Equipment, Design Engineering and Installation, Gary L.
McGavin, John Wiley \& Sons, Inc., 1981.

"Architectural Design of Building Components for Earthquakes," MBT Associates for National Science Foundation Research Report, San Francisco, CA, 1978.

"A Report on Non-Structural Damage to Buildings, Alaska Earthquake, March 27, 1964," J. Marx Ayres, Tseng-Yao Sun and Fredrick Brown of Ayres \& Hayakawa, Consulting Engineers, Los Angeles, CA, 1967.

"Earthquake Resistive Construction for Mechanical Systems, Light Fixtures and Ceilings," prepared for Los Angeles Unified School System, J. Marx Ayres and Tseng-Yao Sun of Ayres \& Hayakawa, Consulting Engineers, Los Angeles, CA. 1972.

"Basis for Seismic-Resistant Design of Mechanical and Electrical Service Systems," G. M. and T. R. Simonson, Consulting Engineers, San Francisco, California, and Engineering Decision Analysis Company, Inc., Palo Alto, California, 1976.

"The Great Alaska Earthquake of 1964," Engineering Division, National Academy of Science, Washington, D.C. 1973.

"Tentative Provisions for the Development of Seismic Regulations for Buildings," ATC 3-06, Applied Technology Council, Palo Alto, California, June 1978.

"Study to Establish Seismic Protection Provisions for Furniture, Equipment and Supplies for VA Hospitals," Research Staff Office of Construction, Veterans Administration, Washington, D.C., 1976. 


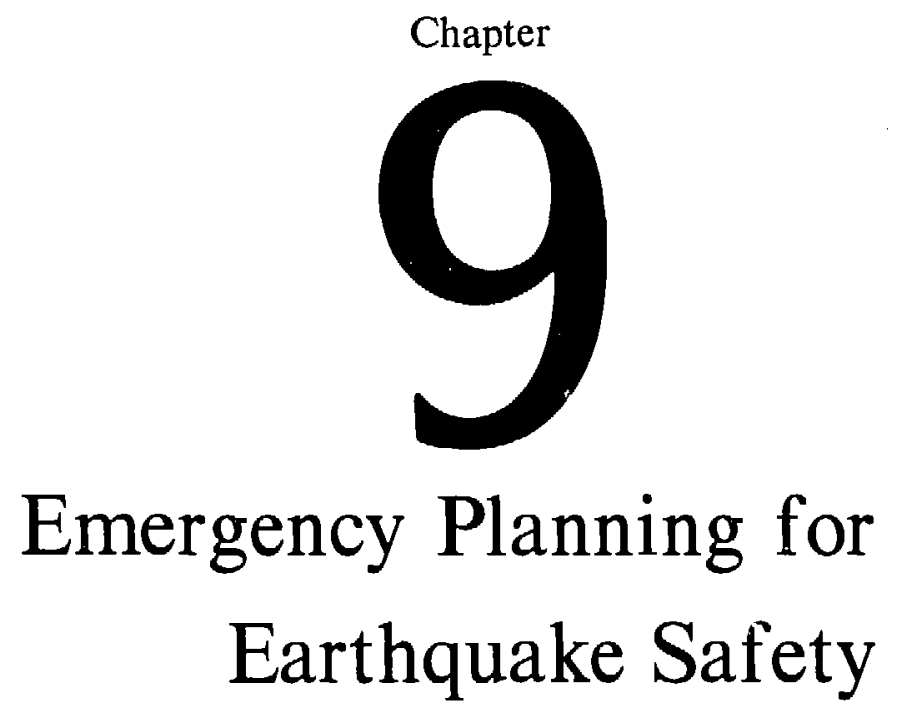

Donald G. Eagling

Most DOE sites have emergency organizations with well trained professionals and specialized equipment to handle any type of accident, injury or hazard on very short notice. Often immediate communication with medical professionals is available within the organization. Limited medical facilities are normally situated un-site, available within minutes for the treatment of personal injuries. In a major disaster such as a large earthquake, however, the multiplicity of emergencies and injuries to be dealt with simultaneously would overwhelm these special capabilities. In a destructive earthquake, lifelines such as communications systems, energy and transportation arteries, water and fire protection systems may be damaged or disrupted. Buildings will sustain structural damage. Non-structural building elements such as partitions, hung ceilings, light fixtures, heating ducts and overhead pipes may fall into building corridors and impede access and egress. Flammable gases, chemicals and other hazardous materials may leak or spill. Fires may develop.

The aftermath of a major earthquake presenis a very different situation than most emergency teams generally face. It calls for a different approach to emergency planning. Self help is a key element in large-scale emergency response, and preparedness is the "preventative medicine" that reduces the magnitude of the problem.

The most effective stimulus to produce an earthquake preparedness program is a visit by the "master inspector," the real earthquake. Obviously. this approach can be very costly and is not recommended. A much more practical technique is to develop a model or scenario for the situation that will probably exist in the aftermath of a damaging earthquake.

In the early 1970's the National Oceanic and Atmuspheric Administration studied the Los Angeles and San Francisco regions to provide earthquake scenarios for cmergency planning. The exercise was cye opening and alarming. As a consequence many major improvements have taken place which will save the lives of thousands of people when the "big one" takes place. The "scenario" technique, to be effective, must be a practical exercise. The approach involves utilizing the professional judgment of experienced earthquake engineers to produce a likely model of the aftermalh of a damaging earthquake.

Detailed analysis and time consuming research is not recommended. The idea is to assume that the cntirc region is heavily shaken by an earthquake of long durittion and then systematically consider what will probably happen to lifelines; transportation systems such as roads, railroads, bridges, and airports: utility systems such as watcr. natural gas and power supplies: communication systens such as radio and telephone facilities: emergency recovery facilities such as hospitals, clinics. fire stations, police stations and associated equipment.

Locally, the probable condition of on-site buildings and support facilities, roads. emergency equipment. water supply tanks. etc.. can be predicted on a judgment basis. The probable condition of the site can also be anticipated. Is fault movement likely"? Are there areas of poorly compacted granular soil deposits which may subside during heavy shaking or become subject to liquefaction? Are hillside areas likely to fail in 
landslides? What is the potential for flooding from water storage facilities? What is the potential for offsite contamination by hazardous materials? Where are personal injuries likely to occur. Will certain areas of the site be isolated from others? How safe are garage facilities for ambulances and fire engines'?

The object is to make an educated estimate of the multiplicity of conditions and obstacles that emergency response teams may face in the aftermath of an earthquake. The task must be simplified by the heavy use of judgment or the development of the scenario will become overwhelming and too time consuming and costly to be practical. Fortunately, there are a number of experienced "earthquake chasers"; structural engineers, soils engincers, geologists and seismologists, who can supply this type of service effectively and cconomically, provided they are properly directed to keep the process simplified.

The scenario technique more clearly defines the problems and usually adds new perspective to emergency response planning. The results are often surprising. The need to focus on self-help becomes more realistic. Many new problems become evident. Some have simple solutions. Other hazards can be mitigated, but not eliminated. Priorities are easier to resolve.

Unanticipated events occur in almost every destructive earthquake. Seismic performance of individual buildings and other facilitics can be stated only in a probabilistic sense. Time of day, weather, and scason have significant affects on vulnerability, injuries and emergency response capability. Detail and accuracy are not so important in the process as is the insight gained for the emergency organizations that will be called upon in the aftermath of the earthquake.

Generally, effective response to widespread damage and injury will require considerable coordination of the usual emergency resources such as environmental health and safety erews, police, firemen, medical personnel, mechanics and craftsmen, equipment operators, communications technicians, plant facilitics engineers and management. The necessity for broad interaction is one of the special problems proposed by earthquake emergencics. Once a reasonable scenario is developed, one good approach is to appoint an emergency preparcdness committce made up of those line managers responsiblc for these various emergency organizations. These people have the special expertise, the resources and the will to cause preparedness to happen. They will be practical because they will be in the "trenches" when recovery" from disaster is required and they must coordinate in response.

When an earthquake strikes. the multiplicity of problems that results is widespread and sudden. The need to know what has happened is of paramount importance and time is of essence. Generally, communications systems have serious problems, just when they are needed most. Telephone lines become overloaded and unavailable for emergency use. Relay transmitters for radio pages often tip over or become disconnected from their power sources. Public address systems of ten lose house power and become useless if emergency generator or standby battery systems are also damaged and fail to function. Usually people run out of buildings so the normal internal public address systems cannot reach them.

Many of these problems can be remedied by modifying existing systems. The local telephone company often has lineload control that can be instituted to free certain predesignated telephones from the overload condition. Generally, by working with the telephone company arrangements can be made 10 institute lineload control locally. but it is essential to settle exactly who will make the decision when it's needed. Obviously the telephone center on site and its standby battery racks must be tied down to ensure that it will not be damaged and made inoperative by the earthquake. If underground telephone service lines cross an active fault, precautions can be taken to provide slack and fexibility at the crossing to prevent damage.

Transmitters and antennas may be inadequately tied down or poorly braced against overturning. It is generally a very simple matter to correct this weak link.

Emergency generator circuits should be reviewed to ensure that lifeline communications will stay online when public power supplies are lost. The fucl used in emergency generation must not be susceptible to loss. For example. natural gas systems should not be relied upon as a back-up system. The generators themselves must be tied down and emergency fuels stored handily' nearby.

Public address system speakers can be strategically located outside buildings to reach predetermined gathering spots. "Bull horns" and radios can be made available to Building Managers and other key personnel who may be an important part of the emergency response communication chain. When other means are not available, the use of "runners" to carry information becomes necessary.

Of course it is essential to harden the usual emergency communication centers availabje at most sites. The police or security command center and the fire station command center are obvious examples. When a widespread emergency exists, time is of essence, so the predesignation of a principal command center with adequate conference roon facilities, technical filcs, maps, and emergency plans is nost important. Generally. needs will be grcater than resources. Coordination of available resources for recovery is highly dependent on priority control by responsible and knowledgeable management.

Sclf-help planning, preparation and training should be a key element in any emergency responsc plan for carthquake safety. Although it is essential that the framework for self-help organization is established by management, ultimate success will depend on the participation of those having local authority and responsibil- 
ity for well-defined areas of activity and/or locations. It is most important that these individuals are clearly designated and they are fully involved in all development work associated with self-help plans; alternates should be designated for each individual "authority."

Emergency Plans must be kept very simple and concise to be effective. People will not read or use long, complex plans. Where possible, reference documents for use during an emergency should be written in the form of checklists. Each designated responsibility or authority should be identified by a generic or functional term rather than a person's name; c.g., Building Managcr. Checklists should be tailored to each role, not generalized to encompass divergent roles. Each checklist should clearly identify responsibilities and locations of necessary tools and supplies. As mentioned above, more than one individual should be designated for each functional role established in the emergency plan. Also, the equipment to be utilized by these individuals should be sinilarly identified, i.c., a helmet for the Building Manager should clearly identify his title and the building for which he is responsible. In action, the helmet identifies functional authority and unfamiliar faces will not confuse the players.

Communications will be difficult immediately after an earthquake. Just kceping track of information will be a problem. Often the noise level is so great that communication in command centers becomes very difficult. This should be carefully considered in the layout and organization of the functions which must take place. Radios, telephones, speakers and the individuals who must communicate within the comnand center need some sound isolation or separation. Information boards and maps need similar consideration. These interactions should be tested in realistic drills to work out the bugs; if possible, liefore the command center plan is solidified.

Test drills, like the scenario technique for modeling the aftermath of an earthquake, are very effective in bringing a plan for emergency response to a realistic and practical level.

Often professional emergency aranizations are reluctant to use volunteers for back-up. ienerally, this attitude is a valid one for most individual amergency situations, but in a widespread earthquake extra help is essential. The energency plan shouid! include designated response teams as a source to the professional organizattions. Individuals trained in first aid, strong people who can become stretcher bearers, traffic coordinators, runners to assist in communications, "ham" operators, individuals trained in the use of fire fighting equipment and people capable of hard physical labor will be needed. Predesignated individuals and locations for reporting should be part of the emergency plan. along with at least minimal training for the job.

Inevitably a major earthquake will be followed by aftershocks which can be a serious hazard for buildings structurally damaged by the main shock. A quick assessment of building safety is always a high priority task immediately after the earthquake. In addition to predesignating responsibilities for structural review. simplified key plans should be developed for each building to identify its lateral force resisting system. In this way, if structural engineers cannot make the first quick assessment of quake damage, less qualified individuals can be used to flag damage which seems critical for earthquake resistance.

Generally, the main emergency command center will be separately located from the communication centers for the professional emergency organizations such as the fire department, security or plant protection, safety services, medical clinic, craft shops, facilities engineering, and transportation. This will necessitate a great deal of communication at the main command center to coordinate the overall emergency response.

The number of individuals designated to operate within the emergency command center should be kept to a minimum to reduce confusion and facilitate communication and ccordination among the participants who must make command decisions. On the other hand people in the inner circle have a strong need for staff support. For example, the heavy flow of communication from various and widespread sources will create a need to funnel information into the center without causing a bottleneck. Two or three people may be continuously needed to write down messages delivered by runners and provide carbon copies to those who need them and for file. Other persons must be available to record on display boards such incoming information as the locations of injuries, fires, water and gas leaks, building damage and other problems which may require action. Display maps with clear acetate covers for grease pencils may be used with a color code to categorize the problem, i.e., red for fire and blue for water leaks.

A communication board or message center will be needed to list those who have been called or contacted. Communicators will be needed to send messages out of the center after decisions are made. Walkie talkies and ham radio operators with portable equipment and rechargeable batteries are another very useful resource for communication.

Support personnel will also be needed to handle public information interaction. Invariably after a damaging earthquake many visitors show up at the scene of damage; reporters, engineers, geologists, seismologists, representatives of public agencies, politicians and interested citizens. It is important that this hervy influx does not interfere with the operations of the Emergency Command Center. The facility for interaction with visitors should be located somewhere else. Many of the early visitors will be professionals who are capable and willing to assist in support activities. In particular, structural engineers can be extremely useful in assessing building damage and ustally they are well organized professionally to respond to this need. If 
utilized properly, this assistance is both invaluable and economical in the early stages of response and recovery.

The Earthquake Engineering Research Institute (EERI), 2620 Telegraph Avenue, Berkeley, CA 94704; phone (415) 843-0972, is probably' the best resource for pre-planning the use of outside help after an earthquake. The institule is a non-profit organization which is devoted to finding better ways to protect people and property from earlhquake hazards. It is best known for its field investigations of destructive earthquakes. Included in its membership are most of the leading U.S. earthquake investigators from all relevant ficlds, The Institute has set up volunteer response teams and pre-arranged a methodology for coordination of assistance and investigations in the immediate aftermath of earthquakes.

In 1977 the EERI published a document entitled "Learning from Earthquakes, 1977. Planning and Ficld Guides." The intent of the publication was to provide plans, procedures and checklists for filed investigations by intcrdisciplinary professionals to maximize the opportunity for learning in the immediate aftermath of future earthquakes. It covers engineering, geoscience, and social science aspects of earthquakes. The format consists of short commentaries under most specific subjects followed by checklists. The commentries summarize lessons learned from past earthquakes and the checklists provide guidance for investigating new earthquakes. This document is a rich source of information upon which to plan for emergency recovery from earthquakes. In particular, the checklists are recommended for reference in the mitigation of seismic hazards before an earthyuake takes place.

Serious preparation for widespread emergencies should include the acquisition and strategic storage of special tools. equipment, fucls and supplies that may be needed in early recovery operations. For example breaks in water supply and distribution lines will require emergency repairs or temporary by-passes to get fire protection systems back in service. This can be quickly accomplished if emergency cross-over connections with adapter fittings for "plain-end" water pipe and hose risers to fit standard fire hose are on hand. These emergency cross-over connections can be casily prefabricated using standard rod and socket clamps 10 fit all sizes of water mains and stored with 2-1/2 in. standard fire hose in 50 foot lengths to provide flexibility to quickly reconnect across breaks of any span up to 600 fect. Similarly, emergency cross-over connections can be prefabricated for natural gas mains.

Those tools generally needed in earthquakes (such as shovels, axes, crowbars, "jaws-ol-life" cutters, saws. insulated gloves) can be stored in multiple locations in keeping with the need for "sclf help" when widesprcad damages occur. Similarly, first aid and medical supplies can be located in facilities that are safe and suited for use as alternate Medical Centers.

Natural gas and LPG systems pose special explosion hazards after damaging earthquakes. The nost effective measure to mitigate the hazard is to install earthquake shut-off valves in the main distribution lines. Placing a single such valve in the main is important but still leaves too much potential for explosion in the distribution system. Similar valves should also be installed at other strategic points.

Also it is important to look at the potential for loss of water supplies including those from external sources. Fire protection sprinkler systems are of little value if water service or storage is lost. In those cases where the potential for loss of outside service is significant, the installation of on site water storage and emergency pumping stations should be seriously considered.

Realistic drills to test earthquake emergency planning are very important. One of the best ways to assure that such a drill will be effective is to utilize an experienced carthquake investigator to review the site and plant and develop a damage and injury scenario by which to test the plan. Again one of the best sources to contact for a recommendation for a list of such consultants is the Earthquake Engineering Rescarch Institutc. 


\section{Chapter
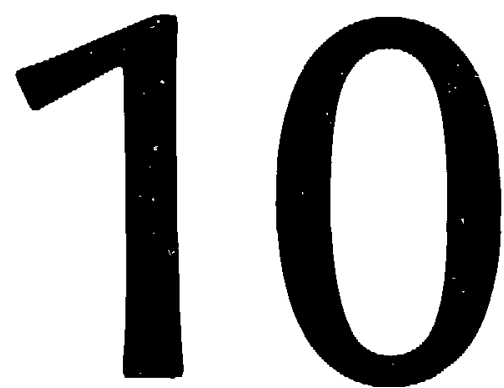 \\ Risk Management}

\section{FOREWORD: Operator-Manager's Point of View (Donald G. Eagling)}

Risk management from the operator-minager's point of view is an impurtant part of a comprehensive earthquake salfety program. It is, of course. inherent in the establishment of lateral force criteria for the design of buildings and equipment including research facilitics and experimental set-ups. Earthquake codes establish minimum requirements for life safety and essentially provide protection against collapsc. Damage control is not the prime objective. Many code provisions, such as the prescribed limitations on "drift" (deflection based upon prescribed lateral forces), have the effect of reducing damage, but one must realize that the real earthquake will cause deflections much greater than "code deflections." When damage control is an important consideration, the design must account for these larger deflections. This protection is not inherent in the Code. One approach is to analyze a structure with the objective of predicting or estimating the location and extent of damage that will probably result from a major carthquake. In this way. additional attentiom to design detail can be applied specifically in the area of concern to "buy insturance" against damage for little extra cost, an example of good risk management.

Liability is certainly a legitimate coneern in risk management. Often. however, this concern is translated into a legalistic solution. rather than al practical solution which actually mitigates the scismic hazard. For example, the Code is generally not retroactive so it is not legally incumbent upon the "responsible official" to upgrade an existing building 10 current standards. Nevertheless, some earlier editions of the Code made it "legally" possible to design and construct a hazardous building. A non-ductile reinforced concrete frame building is a good cxample. $A$ decision not to review an existing building because it wals once designed to Code is a legalistic solution to aroid liability, but it does nothing to mitigate any seismic hazard that may exist. This legalistic position under the protective umbrella of the Code is beconing more difficult to assume because the engineering profession is now much more aware of hazardous buildings which have becn "built to Code." One cannot be certain to avoid liability by remaining ignorant of the hazard. The legal issue nay well be whether or not such a building is commonly known to be hazardous by the profession.

On the other hand the risk of liability should be managed carefully when structural hazards are revealed as a result of seismic safety surveys and reports. For example, if $\mathrm{a}$ building is reported to be a collapse hazard, the official responsible for the safety of the occupants would take steps to mitigate the hazard. It is important to actively seek funds to abate the hazard and to inform the occupants that the building is deficient. While these steps will not guarantee inmunity, failure to take them certainly increases liability.

The problems of funding rehabilitation work are usually difficult and the solutions time consuming. The period during which the hazard may continue to exist increases the risk of liability.

A public agency cannot legally go out of business: therefore. it cannot spend its available funds so hcavily for rehabilitation that it cannot fulfill its prescribed mission. This fact weighs against liability, but does not provide immunity. In the event that a damaging earthquake results in litigation. the pertinent issue is: what funds were available to the responsible official and what were they used for"? With this in mind. one approach to managing the risk of liability is to take the basic risk-reducing steps which can be identified immediately 
(assuming the hazard cannot be easily abated in a short time), then follow due process to find a permanent solution to the problem. Examples of emergency steps are: adding temporary supports, reinforcing structural joints, installing epoxy grouting, removing potential hazards, or even reducing the occupancy loading. Normally, some emergency funding can be found for such purposes while the more time-consuming tasks of evolving a permanent solution and developing adequate funding takc place. The important point is that responsible action (within constraints) must take place if liability is to be minimized.

It is likely that a seismic safety survey will turn up a number of structurally deficient buildings and facilities. This has been the common result where such reviews have been carried out. For years many buildings were designed with non-ductile, reinforced-concrete frames that were then permitted by Code, but are now known to have poor scismic resistance. Many older buildings have no formal or predictable lateral force resisting system. Sometimes building alterations have reduced or destroyed the resistance incorporated in the original design. The point is, a seismic safety survey will likely present the responsible official with a multiplicity of hazards and risks to manage.

It is important to mitigate the risks on the basis of priority, but it is even more important not $10 \mathrm{get}$ bogged down in a complex series of studies or a methodology which slows the process of abatement. A simplistic priority system based upon some due process and responsible professional judgment is sufticient. As with the Richter scale for measuring the magnitude of earthquakes. it is not as important that the result is accurate as it is that relative size (or priority) is easily and quickly established.

The same selection principle should be applied when seismic safety surveys are initially carried out. That is, the priority system for the sequence in which buildings and facilities are surveyed should be simplistic and direct. Obvious problems, possible collapse hazards and high risk facilities such as those with toxic dispersible contents, should be reviewed early. High occupancy buildings and lifeline facilities should also be early on the list. It is important that the survey should not be held back by an academic approach to the multiplicity of potential hazards and the complexity of the problem. The recommendation is to keep the approach simplistic, rely on good professional judgment and move forward.

One stumbling block to seismic safety is the ever present concern for accurately estimating the intensity of the potential earthquake that a given site night experience. For various reasons, political, acadenic and psychological, the immediate. basic need to find out whether a brace is indeed missing unfortunately too often becomes secondary to guessing how big the earthquake is going to be. Commonly, the problems uncovered in a seismic survey have less to do with lateral force criteria to be applied than with other design deficiencies such as missing links, brittle members or connections, lack of continuity or just poor construction. When a building or facility is found deficient, the size of potential seismic input is only one of the considerations which may be brought to bear on the corrective measure. Usually there will be ample time to develop detailed lateral force criteria after the real problem is revealed.

The recommendation is: don't delay the seismic survey in order to study the potential seismicity of the site. Experience show's that this approach is not good risk management.

The design sriteria for new buildings are rather well established in the latest Codes, but this is not true for rehabilitation work. Here good risk management requires more careful consideration. The lateral force provisions in the Code provide good guidelines for rehabilitation design, but often, lateral force resistance is only part of the problem. As discussed, brittleness, lack of continuity or redundancy, deflections, poor detailing, poor workmanship, and many other possible deficiencies may exist. From the standpoint of risk management, it is even more important than in the design of new facilities that the designer of rehabilitatim work give particular attention to a complete seismic diagnosis and criteria development.

Once it is determined that a building has a serious structural deficiency that must be corrected, another kind of problem is often present. The building muy have other Code deficiencies by current standards that are not central to the main hazard. That is, the main structural deficiency may be a collapse hazard, but the other Code deficiencies may not present life safety hazards. The question may then arise: will the responsible official (or the engineer who designs the rehabilitation work) be put in a position of liability if the design does not correct all the deficiencies by current Code standards? Often it is not economically feasibie or even good risk management to correct everything. For example, funding may be used to correct two collapse hazards rather than spend it all on one building to bring everything up to Code.

The recommendation is to achieve the most life safety for the flutding available, but mitigate possible liabilities for the design professional by careful due process. For example: a "criteria board" can be established consisting of professionally knowledgeable members such as the rehabilitation designer, the plan checker (preferably an independent consultant), and the "building official" (the in-house person responsible for design and conseruction).

The authority to set seismic criteria should then be officially delegated to this "expert" group. Court jidgments have held that the responsible authority will be immune from liability for acting in a discretionary manner if this person has the authority and knowledge to do so. The authority must be properly delegated and 
"knowledge" implies professional judgment in the practice involved. The rehabilitation design engineer will be reasonably protected by the due process involved assuming he fulfills his design responsibilities satisfactorily.

High on the list of effective risk management techniques related to seismic safety is the so-called "third party plan check" that has been described elsewhere in this manual. This independent plan check, together with proper field inspection of construction (whether new or rehabilitation work), is most highly recommended as one of the best ways of assuring seismic safety in structural design and construction.

California engineers generally believe the buildings they design will be subjected to a damaging earthquake during the lifetime of the structure. They don't consider the hazard to be one that in all likelihood will not occur. They are also aware that the earthquake is the real master inspector. If there is a gap in the lateralforce-resisting system, the consequences will be more serious than statistical. This point of view has a very positive effect upon risk management as applied to design.

In areas of the country where earthquakes are very rare events, it is difficult for engineers to take them seriously, particularly in the design of conventional structures. It is a fact that extremely few buildings in the mid-west and east have been designed for earthquake safety, even in those areas where it is well known that damaging earthquakes have occurred in the historic past. Many buildings are constructed of unreinforced unit masonry, one of the building types particularly susceptible to earthquake damage and collapse. A great deal of progress could be made by simply avoiding the use of unreinforced unit masonry in new construction.

In "earthquake country" the choice of criteria for seismic design can be a relatively simple matter, if one believes the great earthquake is imminent. In this case, the design earthquake can be taken relatively close to the maximum credible earthquake. This might correspond to $0.2 \mathrm{~g}$ base shear using the static equivalent design approach or to $0.8 \mathrm{~g}$ using ground spectra acceleration for an inelastic dynamic analysis. This design approach is based on what is known as the "minimax decision," since it minimizes the maximum losses in the future.

In areas of the country where the potential for a great earthquake exists, but the probability is extremely low, the choice of criteria can be very difficult. The maximum credible earthquake is not a practical choice for the design of most conventional structures in such areas. A more fundamental consideration relates to the decision whether or not to design for seismic forces at all. However, considerable seismic resistance can be achieved for very little extra cost by simply applying the principles of equivalent static lateral force design and making sure that the system is continuous and ductile. The insurance available in such a minimal approach is a true bargain in risk management. The lateral-force factor to be utilized is of secondary importance. However, if the Uniform Building Code values are used, one has some assurance that this choice is properly coordinated with other provisions of the Code.

Risk management as discussed in this foreword to Dr. Benjamin's chapter has dealt primarily with a varicty of non-technical issues which must be carefully managed in a comprehensive earthquake safety program. The intent of this discussion is 10 provide the operatormanager with practical guidance through the maze of socio-political. legal, and economic risks that may impede the progress and success of such a program.

In the chapter that follows, Dr. Benjamin discusses both practical and technical issues of risk management. providing techniques for dealing with the probabilistic nature of earthquakes, and illustrating methods of relating hazards, mitigation costs, and probability to management decisions. 


\section{Chapter}

\section{0}

\section{Risk Management}

Jack R. Benjamin, Ph. D.

Civil Engineer

Dr. Benjamin is a leader in the application of probabilistic methods and decision theory in civil engineering. He is Professor Eneritus of Civil Engineering at Stanford University. Dr. Benjamin is author of the book Statically Indeterminate Structures, one of the McGraw-Hill Engineering Series, and is co-author of the book Probability, Statistics, and Decision for Civil Engineers, the standard text and reference on probabilistic methods in civil engineering.

Much of his work has dealt with extreme and unusual (high-hazard) loading conditions, the development of rational, probability-based design criteria, and safety analyses using decision, event, and fault tree techniques. In addition, he has had extensive structural engineering experience for more than 30 years, both as a consultant and in his own design practice. A registered engineer in California, Dr. Benjamin is chairman of the board of Jack R. Benjamin and Associates, Inc., Consulting Engineets, ralo Alto, California.

\section{Introduction}

Risk management from the technical point of view is the formal process by which hazards are mitigated under the constraint that ail acceptable mitigation measures cannot be accomplished instantaneously. In the simplest case, risk management may determine that an acceptable mitigation measure involves only following a check list to ensure that an important item in operation or maintenance is not forgotten. At the other extreme there are important facilities which may be of questionable structural integrity - - yet ve subject to diverse human and natural hazards - and for which resources for hazard mitigation are not only limited but become available as a function of time. The problem in this latter case is that of obtaining the best allocation and expenditure of scarce resources at each instant of time.

Major technical concerns in the risk management of important facilities include the uncertainties inherent in the hazards and the effectiveness of any mitigation effort. It is common for hazards to be described in probabilistic terms by level and occurrence over a period of time. For example, the earthquake hazard may be described by an effective peak acceleration level that has a 10 percent probability of being exceeded in 50 years, or a wind hazard may be described in terms of a velocity with a return period of 100 years. On the other hand, the effectiveness of any mitigation effort is traditionally described in deterministic terms. For example, the structure designed by the Code should not collapse even under severe earthquake load, and should sustain only minor structural damage during moderate ground shaking. These estimates of behavior are deterministic since there is no estimate of the probability of different damage levels. Risk management, therefore. requires the combining of diverse types of forecasts. both deterministic and probabilistic.

\section{The Decision Tree}

The decision tree provides a useful device for diagramming and systematically keeping track of isk 
management decisions. The tree is the framework for evaluating alternative mitigation plans, and since the tree can be updated, it can continuously model the decision situation as a function of time.

A simple decision tree for two earthquake related hazards is shown in Fig. I. Assume that the responsible official or panel of professionals is to decide on the risk management program. This "decision maker" is considered to be at Apex 1. With an available $\$ 100,000$ expenditure it is further assumed that only two different mitigation plans are acceptable. With Action $A$, all resources go to major structura! modification of the building. while with Action B all resources go to stabilizing critical equipment in the building. The equipment can be severely damaged by a low level earthquake which the building will survive. If the earthquake ground motion is very severe, the building structural system will fail and the building will collapse, destroying the critical equipment, even if it is stabilized. The earthquake that could cause the building to fail is a very rare event, while low level earthquake ground motions frequently occur.

Now, if the decision maker takes Action $A$ io repair the building and the future (one year) includes the small carthquake, the equipment loss is shown to be $\$ 200,000$. Similarly, if Action $\mathrm{A}$ is taken and there is a great earthquake, the total loss is $\$ 300,000$ consisting of pa. ial-building and complete-equipment damage. If no

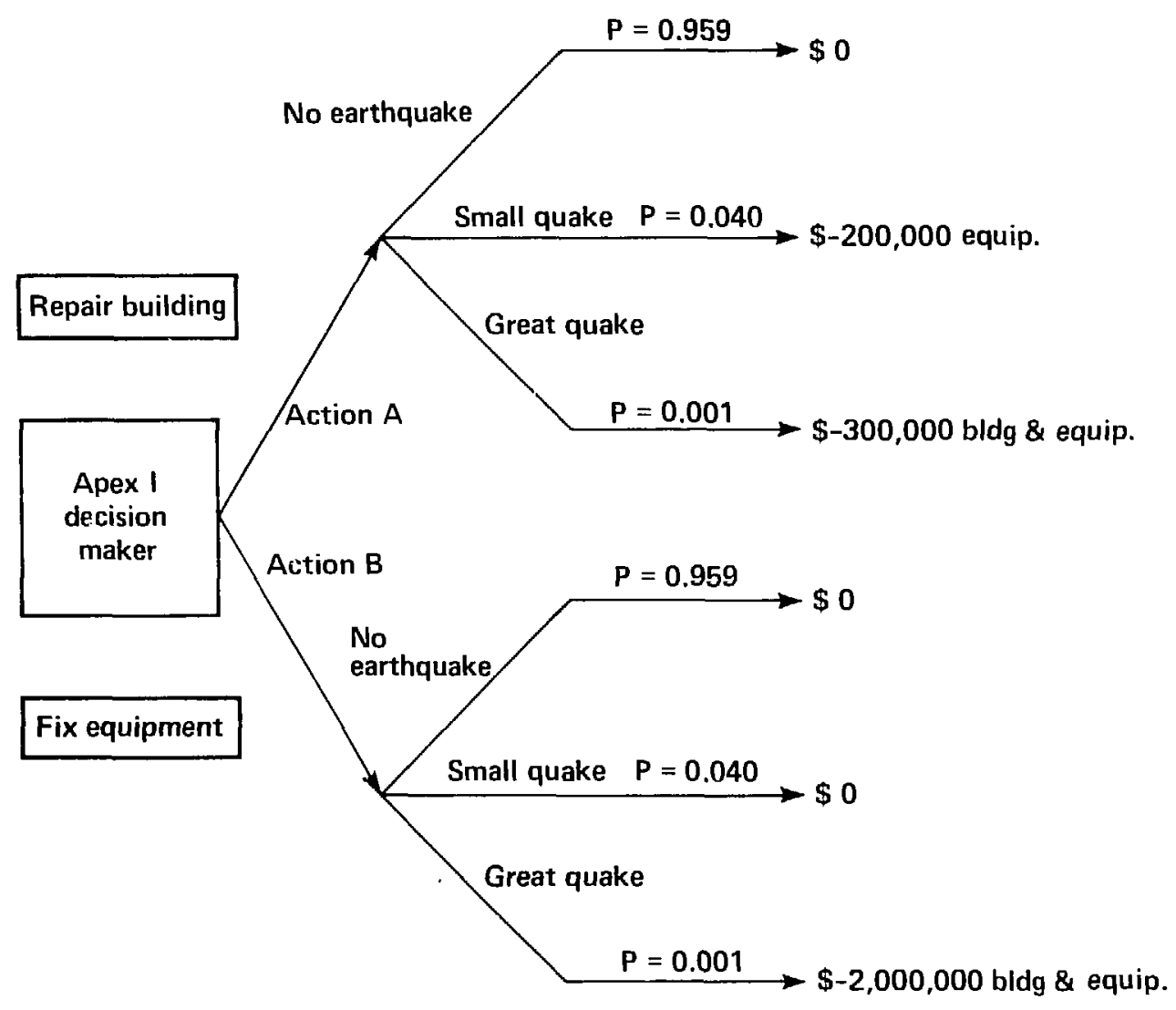

\begin{tabular}{|c|c|c|c|}
\hline Action & Future & Probability & Value Received \\
\hline $\begin{array}{l}\text { Decision } \\
\text { maker } \\
\text { chooses } \\
\text { A or B cost } \\
\$ 100,000\end{array}$ & Uncertain & $\begin{array}{l}\text { Measure of } \\
\text { uncertainty }\end{array}$ & \\
\hline
\end{tabular}

Fig. 1 - Risk Management Decision Tree 
earthquake occlirs, there is no loss or gain except that the $\$ 100,000$ expenditure is a sunk cost." In contrast, if the available funds are expended to stabilize the equipment (Action B), there will be no loss with a small event but a $\$ 2,000,000$ loss (total loss of building and equipment) is estimated to be the consequence of very severe ground motion from a great earthquake.

Thus, the decision tree contains the consequence of taking an action and finding the future. The probabilities of occurrence of the hazard is noted on the tree so that the diagram contains all of the basic ingredients for the decision. The units of the consequence may be dollars or any other convenient and consistent measure of preference.

For simplicity, the "decision maker" in Fig. I must choose either A or B. Action B reduces the possible loss from the occurrence of a frequent but small earthquake, while Action $\mathrm{A}$ reduces the worst possible loss from a great event. The optimum action, A or B, depends on the probabilities of occurrence of earthquake levels in any one year in the life of the facility. Two contrasting viewpoints exist in choosing Action A or B. First, if the $\$ 2,000,000$ loss with a great earthquake is so large as to be completely unacceptable, the optimum action is A. This type of decision is called a "minimax decision" since it minimizes the maximum possible loss that can be experienced in the future. This tlye of decision rule fits the case where one of the possible losses is not acceptable, or the probability. of occurrence of the level of hazard does not effectively infuence the decision.

In contrast, if the losses shown are severe but not catastrophic. the optimum decision can be determined by weighting the losses by the probabilities of occurrence and summing for each action. The optimum decision is then the one with the smallest weighted loss. This is known as the "expected value" decision rule. Using this decision rule the expected loss per year with Action $\mathrm{A}$ is $0.040 \times \$ 200,000=\$ 8,000$ for the small earthquake and $0.001 \times \$ 300,000=\$ 300$ for the great earthquake. The sum is $\$ 8,300$ per year. With Action B, the expected loss is $\$ 2,000$ per year, so that the optimum action is to stabilize the equipment and accept the small risk that the entire building with equipment could be a total loss in a great earthquake.

In most practical problems, a combination of the minimax and expected value rules is employed. For example, if a third Action $C$ is also possible with intermediate loss characteristics, the minimax rule could be used to eliminate Action $B$. and then the expected value rule used to choose between Actions $A$ and $C$. The choice of decision rules is obviously' at the discretion of the "decision maker".

\footnotetext{
"Note that in order to compare Actions A and B with the "do nothing" Action, in which the \$100.000 expenditure is not made, requires that a future longer than one year be considered. It is assumed in this example that in the long-run both Actions $A$ and $B$ are preferable to the "do nothing" Action.
}

\section{Forecasting Rare Events}

The most common frequency statistic employed with rare events is the return period, T. The return period is the average long-run time between events of the same description. That is, if the return period of the 1906 San Francisco earthquake is 200 years, over a million or so years, on the average one such earthquake has occurred each 200 years. The actual record would show considerable variability in the time between events, but the average time between events is 200 years. This does not mean that the next event is forecast for 1906 $+200=2106$.

If the return period is 200 years and the event is equally likely to occur any year, the probability of occurrence in any one year is approximately $1 / T=1 / 200=0.005$. If the probability of occurrence in any one year is 0.005 , the probability of non-occurrence is obviously $1-0.005=0.995$. The probability of non-occurrence in any two years is then $0.995 \times 0.995=0.990$. Thus, the probability of at least one occurrence in these same two years is 1 $0.990=0.010$. The probability of non-occurrence in 200 years of the 200-year event is $(0.995)^{200}=0.37$, so that the probability of at least one occurrence is 1 $0.37=0.63$. Thus the probability of occurrence of an event with a return period of $T$ years in a time span of $T$ years is approximately two-thirds.

The results of calculations of this type are given in Table 1, in which return periods are related to the probability of occurrence in a given time span. nonoccurrence in the same time span, and the probability that the largest event in a given time span will be the event with a return period of $T$ years. The latter follows directly by defining the T-year event as the largest event of interest.

These same basic procedures for calculating occurrence probabilities apply to fires, high winds. accidents of all types including automobiles, and all other rare events which can only be classed and counted in a time reference.

\section{Multiple Earthquake Hazards}

One of the more common combinations of hazard events is that of earthquake followed by fire. However, it is not satisfactory to assume that fire is certain after a major earthquake. since historic evidence shows that this combination, although more common than other combinations of events, is relatively rare. The actuarial data on the occurrence of fires do not apply to fires associated with earthquakes, since the latter are either too rare to materially influence the statistics or simply not treated as a separate class. However. a good physical knowledge of a facility will aid in subjectively estimating the fire hazard related to earthquakes.

The simplest way to analyze possible multiple hazard events is to use an event tree, which is really the subset 
TABLE 1

RETURN PERIOD DATA

Return Period in Years, $T$

\begin{tabular}{|c|c|c|c|c|c|c|}
\hline 10 & 20 & 50 & 100 & 200 & 500 & 1000 \\
\hline 0.1 & 0.05 & 0.02 & 0.01 & 0.005 & 0.002 & 0.001 \\
\hline 0.63 & 0.63 & 0.63 & 0.63 & 0.63 & 0.63 & 0.63 \\
\hline
\end{tabular}

Approximate Annual

Probability of

Occurrence, $p$

rence in $T$ years

Number of Years, $n$, for

which there is a $10 \%$

probability that the

$\mathrm{T}$ Year event will be exceeded ( $90 \%$ probability of nonexceedance)

Number of Years, $\mathrm{n}$, for which there is a $20 \%$ probability that the $\mathrm{T}$ Year event will be exceeded ( $80 \%$ probability of nonexceedance)

Number of Years, $\mathrm{n}$, for which there is a $50 \%$ probability that the $\mathrm{T}$ Year event will be exceeded ( $50 \%$ probability of nonexceedance)

$$
\begin{aligned}
& \begin{array}{llllll}
7 & 14 & 34 & 69 & 138 & 346
\end{array} \\
& \text { Equation: Probability of Exceedance }=1-(1-p)^{n} \\
& \mathrm{n}=\frac{\log \text { (Probability of Nonexceedance) }}{\log (1-\mathrm{p})}
\end{aligned}
$$

Note: The event with a return period of 475 years has a probability of exceedance of $10 \%$ (nonexceedance of $90 \%$ ) in 50 years. 
of the decision tree dealing with the uncertain future. An example of an event tree of the occurrence of fire and earthquake is shown in Fig. 2. Beginning at the left apex and moving to the right the branching shows the sequence of events which are possible in the time period of interest.

For the example of fire and earthquake hazards, the possible events are:"

1. No fire and no earthquake

2. Fire without earthquake

3. Earthquake with subsequent fire

4. Earthquake without subsequent fire

Because fires and earthquakes are rare events, the most likely probability is that of no earthquake and no fire. Assuming that the fire of concern, without earthquake, occurs on an average of one time a year per 1.000 laboratory buildings, the probability of occurrence in any given year is 0.001 for a specific laboratory building. If the earthquake of concern is the 100-year event, the probability of occurrence in a given year is 0.01 . If there is an earthquake, it is subjectively estimated by a knowledgeable professional that

\footnotetext{
"Nece that it is possible to have a fire occur at one time and and earthquake occt!t al a different time during the same year. However the probability of this lype of multiple hazard actually occurring is assumed to be so small that it can be neglected in the analysis.
}

the probability of a subsequent fire is 0.2 . Thus, the probability of earthquake and subsequent fire is then $0.01 \times 0.2=0.002$ so that the probability of earthquake and no subsequent fire is 0.008 (i.e., $0.01 \mathrm{x}$ 0.08).

Assuming losses associated with each event are estimated by analysis or judgment, the annual expected loss of earthquake and fire can be calculated. For example, if the loss due to fire without earthquake is $\$ 1,000$, the loss due to earthquake without fire is $\$ 10,000$, and the loss due to earthquake with fire is $\$ 20,000$, the total expected annual exposure for consideration in the mitigation plan (or for purchase of insurance) is:

$$
\begin{aligned}
& \text { Fire (No Earthquake) } \\
& \text { Earthquake, No Subsequent Fire } \\
& \text { Earthquake, Subsequent Fire } \\
& 0.001 \times 0.99 \times 1.000=\$ 1 \\
& 0.008 \times 10,000=80 \\
& 0.002 \times 20,000=-40 \\
& \text { Total Annual Exposure per Building \$121 }
\end{aligned}
$$

It is important to note that this weighting procedure assumes that the loss levels are within normal operational bounds and are acceptable. That is, if earthquake plus fire would result in total destruction (an abnormal and unacceptable outcome to some decision makers), while fire or earthquake by themselves do not eliminate long-range functional survival, the mitigation plan should take steps to prevent the possible losses resulting from total destruction.

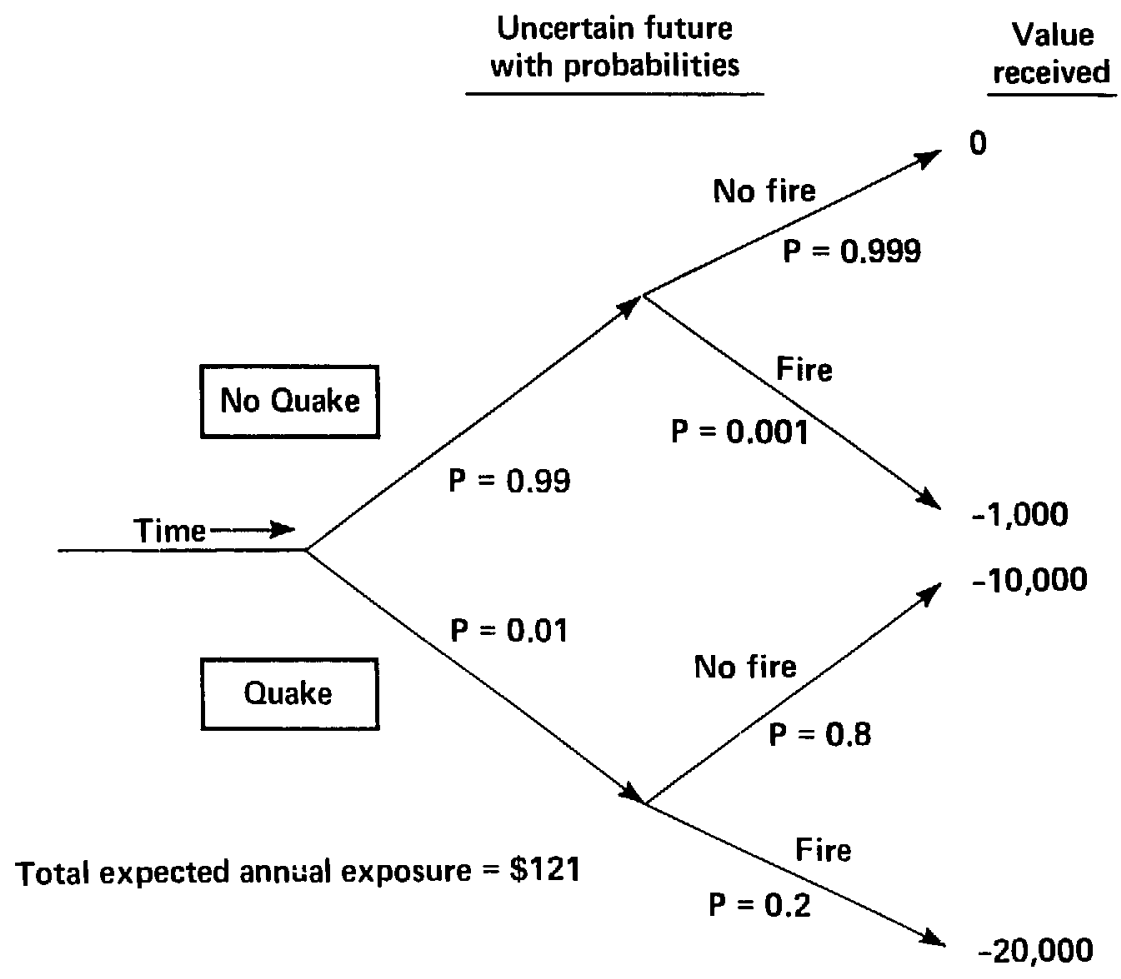

Fig. 2 - Event Tree for Fire and Earthquake Hazards 


\section{Example of Technical Risk Management}

As an example of multiple hazard risk management, assume that a risk management program is developed for a laboratory complex consisting of three buildings.

Building $A$ is an old masonry warehouse used to store laboratory supplies and spare equipment. It is likely to sustain total collapse in a major earthquake, and moderate to total damage in a moderate earthquakc. There is no fire hazard, unless the usage changes.

Building $B$ is a modern one-story steel frame structure housing very fragile laboratory equipment. There is low level human occupancy, but the fire hazard is high. There is a sprinkler system to prevent fire damage. In a major earthquake the structure will sustain light damage with light to severe equipment damage. A fire is certain to start; however, the sprinkler system was not originally designed to displace the same amount as was the building without breaking. Thus, it is estimated that the chance of the sprinkler system's working following a major earthquake is only $25 \%$. If the sprinklers do not work then the equipment will be further damaged and the chance of building collapse is $50 \%$. In a moderate earthquake the types of hazards are similar to those in a major earthquake; however, the extent of possible damage is less and the estimated probabilities of the possible damage states are different. For example, the probability of the sprinklers' functioning is estimated to be $50 \%$ (this probability could be increased if periodic maintenance were performed). If the sprinklers do not work, the chance of building collapse is estimated to be $20 \%$ since it is more likely that the fire department will be able to control the fire before collapse.

Building $C$ is a two-story unreinforced concrete block masonry structure with timber framing. It is used for offices and has a high level of human occupancy. The building has no sprinklers, but has a moderate fire hazard due to gas leak or inadvertent trash fire, etc. In a major earthquake there would be moderate to heavy structural damage, but collapses would be localized as a consequence of the presence of many closely spaced partitions. If a fire should follow the earthquake due to a break in a gas line, there would be time for evacuation with minimum human injury, but further structural damage would very likely occur to the point of total loss. During a moderate earthquake, structural damage would be light to moderate. The chance of fire following the earthquake is much less; however, the consequences could be either heavy or total structural damage. If a fire starts in Building $\mathrm{C}$ without an earthquake, the possible damage levels range from light to total depending on the arrival time of the fire department.

The return period of major earthquakes at the site is estimated at 200 years, while for moderate earthquakes it is 20 years. It is further estimated that a fire level causing damage to Building $B$ occurs on an average of one time a year per 50 laboratory buildings of this type, and important fire losses in office buildings such as Building $C$ have a return period of 100 years. The other conditional fire probabilities are estimated by the responsible professional either subjectively or by analysis. Costs of the different possible damage levels to the three buildings and their contents are listed in Table 2.

TABLE 2

\section{ESTIMATED COSTS OF POSSIBLE DAMAGE LEVELS}

\section{Building A}

Total Building $\mathbf{A}$

Collapse $\left(\mathrm{TB}_{\mathrm{A}} \mathrm{C}\right)$

Moderate Building $A$

Damage $\left(\mathrm{MB}_{\mathrm{A}} \mathrm{D}\right)$

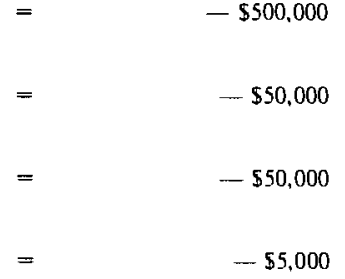

Total Content Loss

( $\mathrm{TC}_{\mathrm{A}} \mathrm{L}$ )

Moderate Content

Loss (MC $\mathrm{A}_{\mathrm{A}} \mathrm{L}$

$-\$ 5,000$

\section{Building B}

Total Building $\mathbf{B}$

Collapse $\left(\mathrm{TB}_{\mathrm{B}} \mathrm{C}\right)$

Light Building $\mathrm{B}$

Damage $\left(\mathrm{LB}_{\mathrm{B}} \mathrm{D}\right)$

Severe Eruipment

Damage $\left(S E_{B} D\right)$

Moderate Equipment

Damnge ( $\left.M E_{B} D\right)$

Light Equipment

Damage $\left(\mathrm{LE}_{\mathrm{B}} \mathrm{D}\right)$

\section{Building C}

Total Building $\mathrm{C}$
Damage $\left(\mathrm{TB}_{\mathrm{C}} \mathrm{D}\right)$
Moderate Building
Damage ( $\left.\mathrm{MB}_{\mathrm{C}} \mathrm{D}\right)$
Light Building $\mathrm{C}$
Damage ( $\mathrm{LB}_{\mathrm{C}} \mathrm{D}$ )
Law Suits for
Injuries

$=$

$=$

$$
\begin{array}{r}
-\$ 1,000,000 \\
-\$ 10,000 \\
-\$ 1,000,000 \\
-\$ 100,000
\end{array}
$$$$
=\quad-\$ 5.000
$$

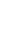

$-\$ 200,000$

$$
\begin{array}{r}
-\$ 20,000 \\
-\$ 1,000,000
\end{array}
$$

The first step in setting up the decision tree for the risk management program is to construct the event trees for each of the three buildings, realizing that these event trees will ultimately be merged to combine the hazard effects and consequences for all three buildings. Figures 3, 4, and 5 show the event trees for each building respectively along with the estimated costs of damage and estimated probabilities for each possible event. 
Multiplying the estimated loss for each possible event branch by the probabilities along that branch and summing the products gives the expected annual loss for each building. These expected annual exposures are the basis for determining the cost effectiveness of different mitigation alternatives.

For example, considering no mitigation effort, the expected annual exposure for Building $B$ from fire and earthquake hazards is $\$ 53,700$. By providing a more aggressive maintenance and repair program for the sprinkler system in the building, the probabilities that the sprinkler system will function are increased to $80 \%$ for a fire following a moderate earthquake and $50 \%$ for a fire following a major earthquake. The expected annual exposure with the improved maintenance and repair is thus $\$ 41,200$, which is an expected annual sav- ings of $\$ 12,500$. If the annual cost of this maintenance and repair program is more than $\$ 12,500$, then the mitigation is not cost effective.

A second mitigation effort might be the modification of the equipment supports to lower the chance of damage during an earthquake.

Suppose that it is possible to lower the equipment damage level to moderate or light during an earthquake in which a fire does not start or the sprinkler system functions. Assuming that there is a $60 \%$ chance of moderate equipment damage during a major earthquake after which the sprinkler system functions, and a $40 \%$ chance of moderate damage following a moderate earthquake after which no fire starts or the sprinklers work, the expected annual exposure is reduced to $\$ 36,900$, or an expected savings of $\$ 16,800$. If equipment supports

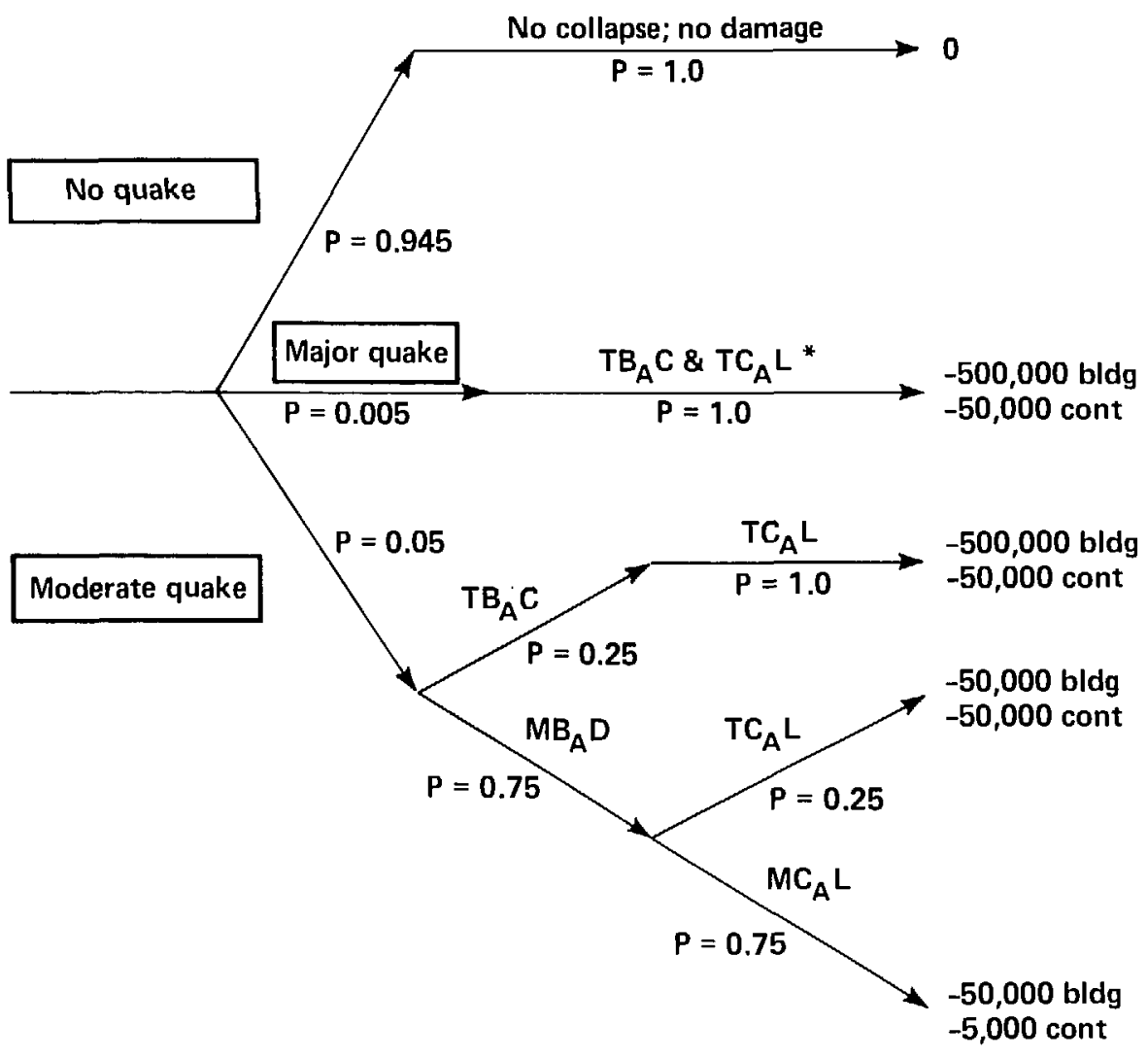

Expected annual exposure from earthquake $=\$ 12,100$

* See Table 3 for damage nomenclature

Fig. $3 \rightarrow$ Event Tree for Building A - No Mitigation 


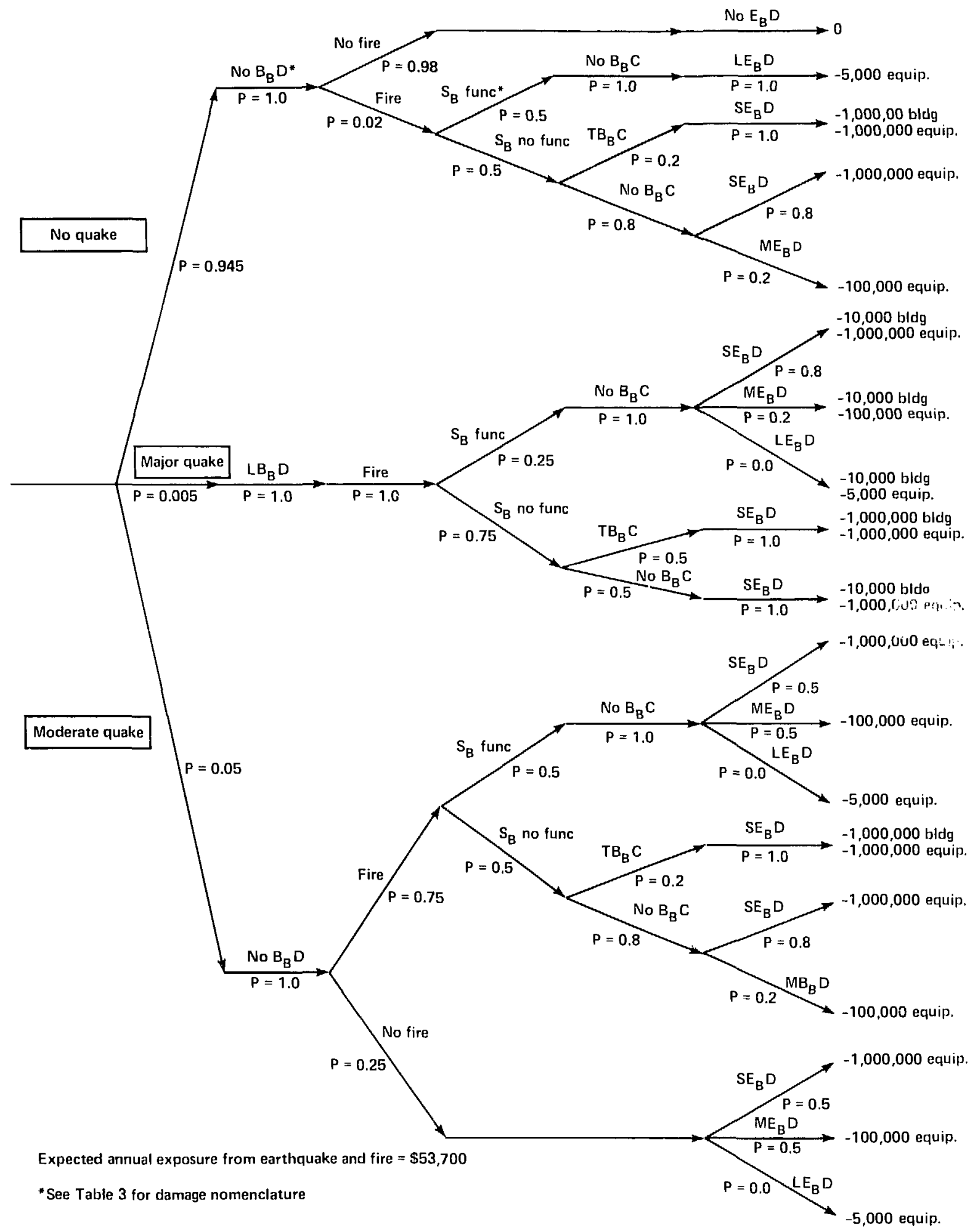

Fig. 4 - Event Tree for Building B - No Mitigation 


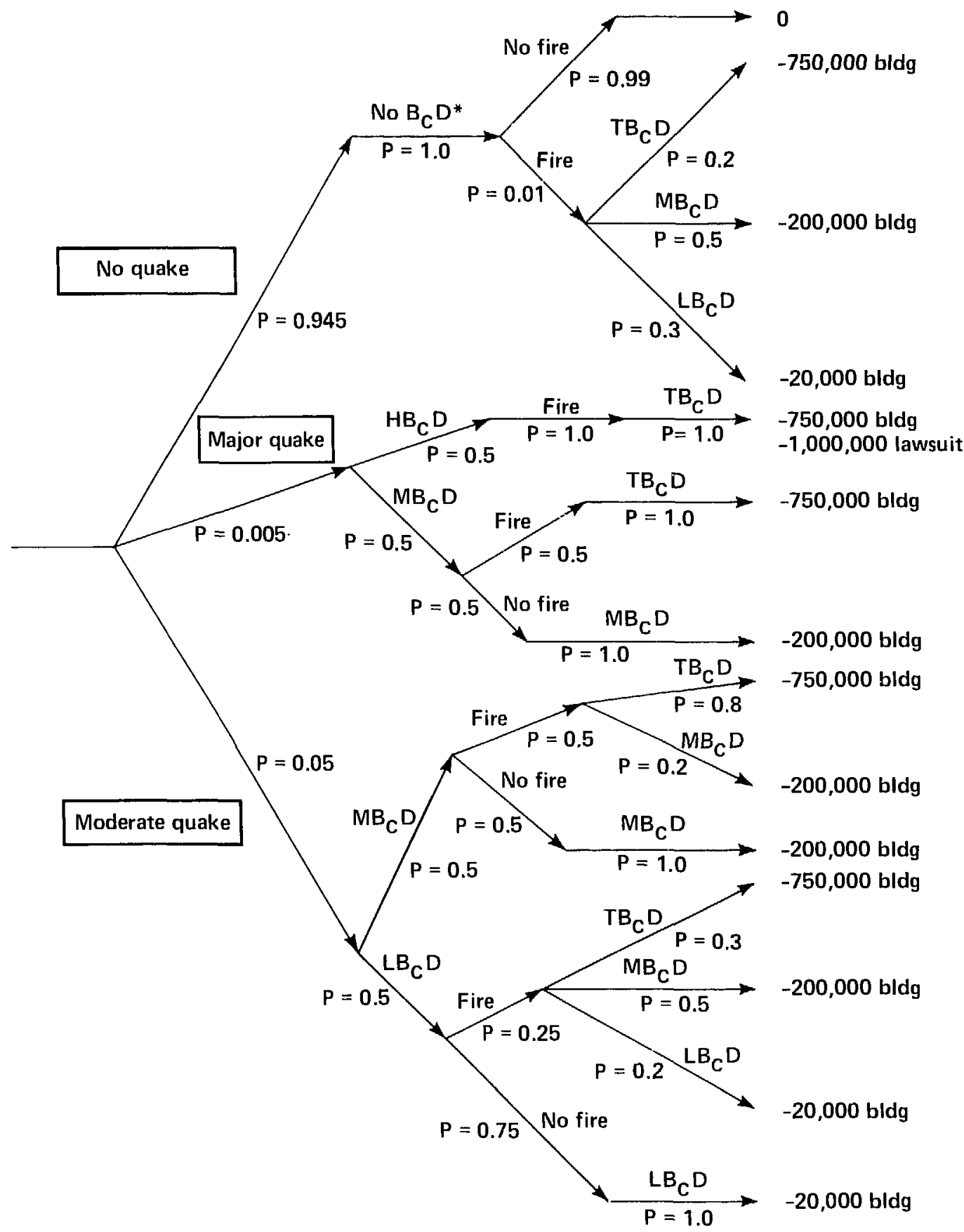

Expected annual exposure from earthquake and fire $=\$ 21,000$

${ }^{*}$ See Table 3 for damage nomenclature

Fig. 5 Event Tree for Building C Vo Mitigation 
can be modified for less than $\$ 16,800$ /year, then this alternative becomes cost effective. It may be, however, that modifications to the equipment supports reduce the functional value of the equipment, rendering this alternative unacceptable, in which case a high-priced insurance premium may be the only acceptable alternative. It is interesting to note that if both the sprinkler r.xintenance program and the support modification program are implemented, the expected annual exposure is $\$ 17,800$ or an expected savings of $\$ 35,900 /$ year, which is greater than the sum of the savings considered independently.

Each of the three building hazard event trees can be used separately in the preceding manner, if each has an

TABLE 3

\section{DAMAGE NOMENCLATURE}

\section{Building A}

$$
\begin{aligned}
& \mathrm{TB}_{\mathrm{A}} \mathrm{C} \\
& \mathrm{MB}_{\mathrm{A}} \mathrm{D} \\
& \mathrm{TC}_{\mathrm{A}} \mathrm{L} \\
& \mathrm{MC}_{\mathrm{A}} \mathrm{L}
\end{aligned}
$$

Bldg.

Cont.

\section{Building B}

$$
\begin{aligned}
& \mathrm{TB}_{\mathrm{B}} \mathrm{C} \\
& \mathrm{NoB}_{\mathrm{B}} \mathrm{C} \\
& \mathrm{LB}_{\mathrm{B}} \mathrm{D} \\
& \mathrm{NoB}_{B} \mathrm{D} \\
& \mathrm{S}_{\mathrm{B}} \\
& \text { Func. } \\
& \mathrm{SB}_{\mathrm{B}} \\
& \text { No Func. } \\
& S E_{B} D \\
& \mathrm{ME}_{\mathrm{B}} \mathrm{D} \\
& \mathrm{LE}_{\mathrm{B}} \mathrm{D}
\end{aligned}
$$

Ept.

\section{Building C}

$$
\begin{aligned}
& \mathrm{TB}_{\mathrm{C}} \mathrm{D} \\
& \mathrm{HB}_{\mathrm{C}} \mathrm{D} \\
& \mathrm{MB}_{\mathrm{C}} \mathrm{D} \\
& \mathrm{LB}_{\mathrm{C}} \mathrm{D} \\
& \mathrm{NoB}_{\mathrm{C}} \mathrm{D}
\end{aligned}
$$

Total Building A Collapse

Moderate Building A Damage

Tota! Content Loss, Building A

Moderate Content Loss,

Building A

Building

Content

Total Building B Collapse

No Building B Collapse

Light Buslding B Damage

No Building B Damage

Sprinkler System

Functions, Building B

Sprinkler System Does

Not Function, Building B

Severe Equipment Damage, Building B

Moderate Equipment Damage, Building B

Lighı Equipment

Damage. Building B

Equipment

\author{
Total Building C Damage \\ Heavy Building C Damage \\ Moderate Building C Damage \\ Light Building C Damage \\ No Building C Damage
}

annual mitigation budget of its own. However, if mitigation alternatives for the three buildings are in competition for the funding available, then the event trees must be combined into a single event tree which encompasses all possible outcomes for all three buildings on an annual basis. Only in this manner can mitigation alternatives for one building be compared with those for another building, or with composite mitigation efforts for all three buildings.

The preceding example illustrates both the complexities inherent .1 earthquake related risk management problems and the systematic methodology for rationally evaluating and selecting mitigation alternatives that optimize the use of available funds. 


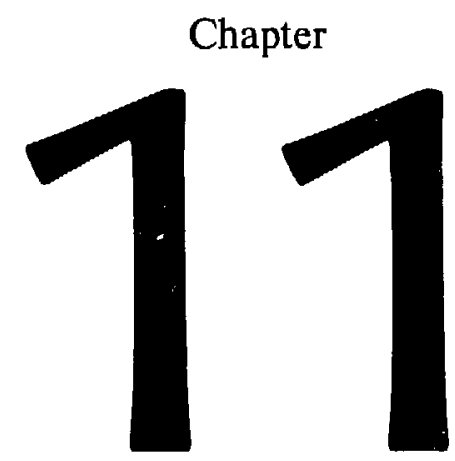

\section{Design of Concrete Shielding Blocks} for Earthquake Safety

\section{FOREWORD: Operator-Manager's Point of View (D̄onald G. Eagling)}

Massive concrete shielding blocks pose a very special problem in earthquake safety. In 1975, full-sized shielding blocks were subjected to realistic earthquake motions for the first time utilizing the University of California's 100 ton shaking table at the Earthquake Engineering Research Center, Richmond, California. Until then only theoretical studies were available for reference and these primarily concerned rocking action and overturning. In those instances where earthquakes were actually taken into consideration, design was usually predicated primarily on the aspect ratio (height-towidth) of the block. The idea was to prevent toppling. Little consideration was given to sliding thus the proximity of heavy shielding blocks to building columns, experimental equipment, or habitable shelters was usually ignored. Experiments on the shaking table clearly demonstrated the sliding hazard. After the static friction between the block and the concrete surface of the shaking table was overcome, the table moved almost freely beneath the block. Imagine what would happen if a huge stack of concrete shielding blocks impacted a vital building column, located in close proximity, with an acceleration of $0.5 \mathrm{~g}$. The anchor bolts in the column base plate would yrovide little shear resistance against this enormous force.

The simplest way of avoiding this potential hazard is to design the configuration of massive shielding with adequate clearance provided between the shielding and building columns so that contact will not be made during an earthquake. If the column must penetrate the shielding stack, fill the space between the shielding and the column with non-rigid shielding materials that will net trap the column in the event of differential motion.

Anl ai:ernate method involves anchoring the shielding blocks against movement and designing the stack of blocks to incorporate a ductile lateral-force-resisting system. The important thing to recognize in this approach is that most of the dynamic forces induced by an earthquake must be dissipated by the deformational ductility of the lateral-force-resisting-system. Unlike a building, there will be little energy absorbed in deforming the very rigid blocks and relatively little molecular damping within individual blocks. The redundancy available in most building framing systems is not available in the individual block. The seismic ground motion will transfer almost directly into the lateralforce-resisting system. The resisting system should be designed as a minimum for a static lateral force coefficient equivalent to the peak ground acceleration. If the stack is quite high with respect to its depth, consideration should be given to amplification with height of the induced motion at the base.

A third alternative method involves a more sophisticated design based upon a soft restraint such as a "dash pot" or shock absorber. This approach has been demonstrated on the shaking table by a person moving a massive block around the table by hand after it has broken friction with the table. It has also been demonstrated many times during testing of instrumentation packages designed to resist explosive impact loads.

Usually the specific situation dictates the right 
approach. It is important to ensure that the designer analyzes shielding restraints as a complete lateralforce-resisting system, including the interaction between the ground, the foundation, and the shielding. A set of calculations covering the complete system including a narrative description of how the system is expected to function should be made. The best way to ensure this will happen is to require a design review by an independent experienced earthquake engineer. There is small likelihood that the person responsible for designing the experimental apparatus will give the seismic restraint realistic consideration.

Restraints for massive equipment, important experimental apparatus and vital research or production facilities should be treated similarly. Usually, state-of-theart experimental apparatus is designed and fabricated with little consideration for the forces induced by earthquakes. When it is necessary to protect the internals, it is usually feasible to design the equipment base to dissipate some or most of the seismic motion at the base so that the sensitive apparatus will not be subjected to the full ground motion. This can be accomplished by providing shock absorbers between the foundation and the equipment so that the apparatus will see less acceleration than do the foundation and the ground.

The chapter that follows deals primarily with the restraint of shielding block assemblies. The methods described have been utilized in the field without the benefit of a test by the "master inspector," the real earthquake. However, the emphasis is placed on design rather than analysis with the objective that failure will be limited to inelastic behavior rather than collapse even if the size of the earthquake is misjudged. 


\title{
Chapter
}

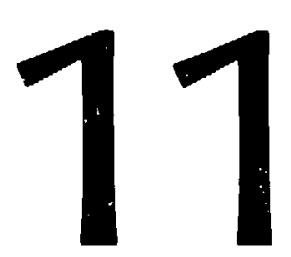

\section{Design of Concrete Shielding Blocks for Earthquake Safety}

Jchri J. Earle

Civil Engineer

Structural Engineer

\begin{abstract}
Mr. Earle has extensive structural analysis and design experience and is widely active in seismic code and educational work. He was the principal contact and project engineer for all work on the structural analysis and design of the earthquake-resisting systems incorporated into existing buildings, radiation shielding blocks, and other facilities and equipment at Lawrence Berkeley Laboratory. Much of his work includes seismic design of schools, laboratories and other facilities.

He currently is chairman both of the Structural Technical Group and the Professional Development Committee of the American Society of Civil Engineers. He aiso is chairman of the Continuing Education Committee of the Structural Engineers Association of Northern California. He has organized several seminars on seismic code and design.

Mr. Earle is a Registered Civil and Structural Engineer in California, working on the staff of Shapiro, Okino, Hom and Associates, Engineers, San Francisco, California, which was founded for the practice of structural engineering by Daniel Shapiro in 1965.
\end{abstract}

\section{Introduction}

When ionizing radiation is profuced from particle accelerators, it is necessary to shield the workers as well as surrounding environment from harmful radiation. For this purpose, concrete blocks are often used as modular shielding elements. Concrete blocks are massive items and are potential hazards in the event of earthquake shaking. Restraint systems for blocks should be devised so that a safe environment is maintained for life safety and property damage is minimized. A practical code for designing concrete shielding block assemblies does not exist at present. Little is known from actual earthquakes about how massive items similar to shielding blocks behave, particularly when restrained. However, experiments with shielding blocks on the 100 ton shaking table at UC Berkeley's Earthquake Engineering Research Center have been carried out to investigate both rocking and sliding motions. This research has been documented in two references which are recommended to the reader: "Sliding Response of Rigid Bodies to Earthquake Motions" by M. Aslam, W. G. Godden, \& D. T. Scalise, LBL3868, September 1975 and "Rocking and Overturning Response of Rigid Bodies to Earthquake Motions," M. Aslam, W. G. Godden \& D. T. Scalise, LBL-7539, November 1978.

This chapter provides background and recommendations for the design of shielding blocks for earthquakes 
based upon the reference research and recent design applications at the Lawrence Berkeley Laboratory. To date these designs have not been tested by an actual earthquake. The concepts proposed for shielding design are explained under the following headings:

- Basic Configurations of Shielding Block Assemblies

- Effects of Earthquakes on Shielding Blocks

- Building Code Analogy for Design

- Ultimate Strength Analogy for Design

- Applications to Isolated Blocks

- Prevention of Dislocation and Overturning

- Design of Wall Shielding and Tunnels for Earthquakes

- Design of Shielding Caves for Earthquakes

- Summary of Proposed Earthquake Design Criteria

\section{Basic Configurations of Shielding Block Assemblies}

Individual block sizes are usually limited by the capacity of the handling equipment available to move them, such as overhead cranes and forklifts. On the other hand, thickness and height requirements for the shielding vary, so it is necessary to accommodate the blocks to these requirements by stacking them or placing units side by side. Thus, entire shielded areas are formed by assembling individual blocks in some required pattern. The blocks may be arranged in many different configurations depending on the degree of shielding required and the physical area available.

Concrete blocks are durable, expensive, heavy and bulky. This makes re-use attractive, and storage expensive. For these reasons, blocks constructed for one project are usually adapted to subsequent layouts not always compatible with their sizes or configurations.

The most common block configurations, Fig. 1, arı:

1. isolated blocks in line with or at right angles to one another and without a ceiling cover.

2. "tunnels" with two parallel lines of wall blocks with or without ceiling or roof blocks.

3. "caves" which form enclosures with a roof and four mutually perpendicular walls similar to a box.

Usually the vertical load of blocks is carried directly by the ground or by a slab on grade. Naturally, such heavy loads should not be placed on unstable ground formations or porential landslide areas. Where supported by a slab or structure, the capacity of the supporting structure must be verified.

Blocks are heavy and usually have a relatively low profile; therefore, wind load becomes a problem only in areas subject to extreme conditions (such as a hurricane or tornado). Wind loading should not be ignored, but it is unusual where wind considerations will control.

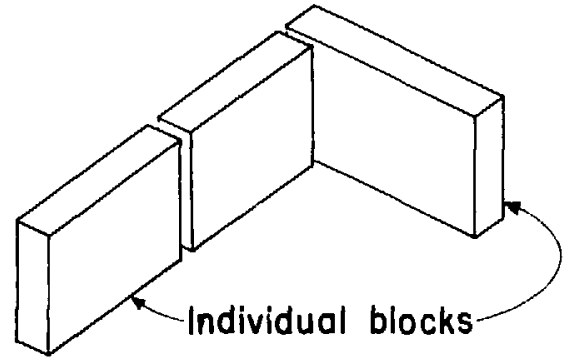

\section{ISOLATED BLOCKS}

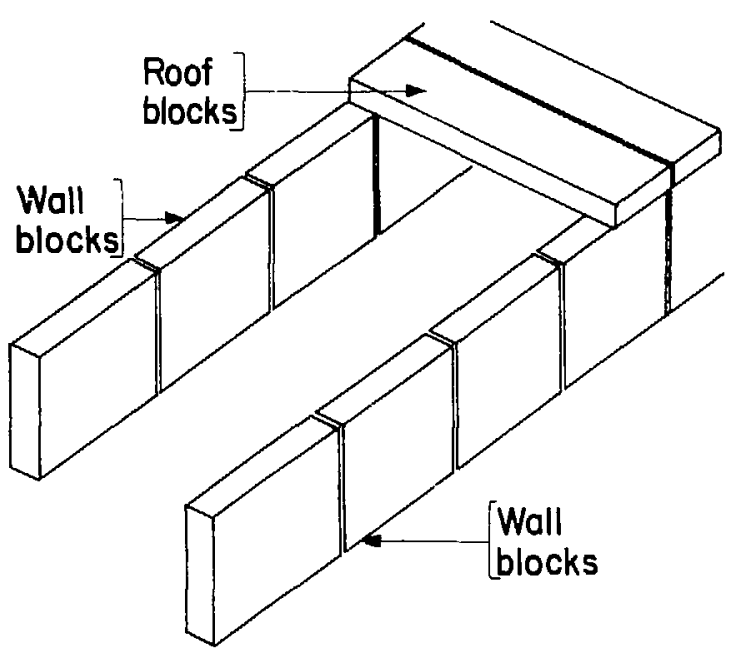

TUNNELS

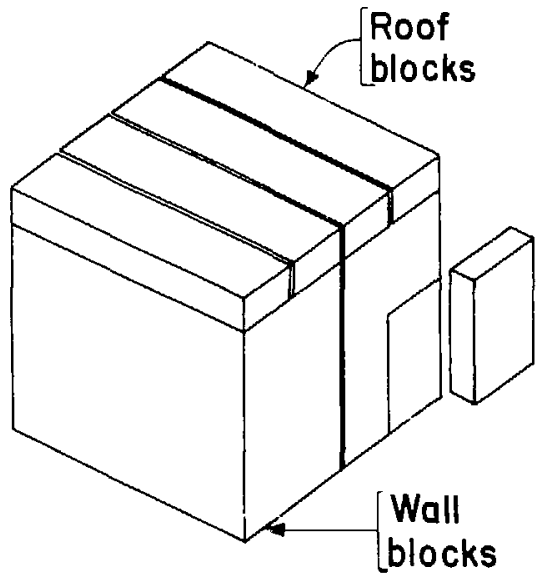

CAVE

Fig. 1 


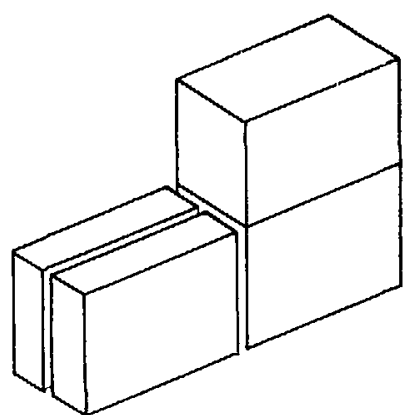

\section{BLOCK STACKS}

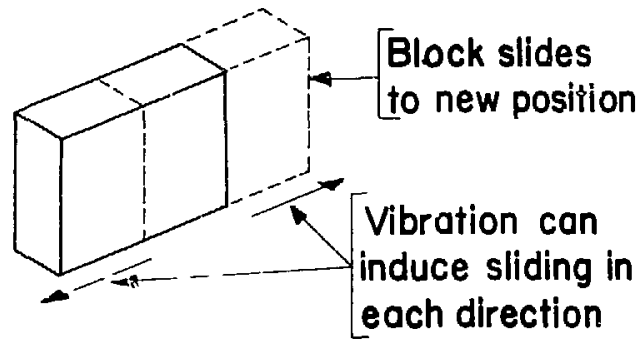

SLIDING

Rocking motion or wobble

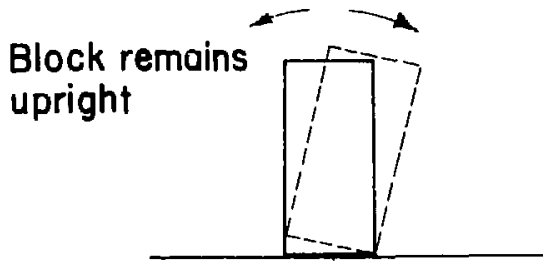

\section{ROCKING}

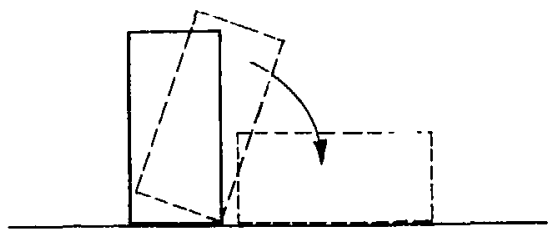

OVERTURNING

\section{The Effects of Earthquakes on Shielding Blocks}

Because of the massive character of blocks, resistance to ea: thquake shaking involves different considerations than normal structures. Earthquakes induce vibratory loads in block structures that can cause the following principal hazards (Fig. 2):

1. sliding or lateral movement;

2. rocking, wobbling, or random movement;

3. overturning;

4. shifting and misalignment;

5. roof collapse;

6. collision with adjacent equipment, buildings or other obstacles.

Unfortinately, principles of earthquake design of shielding block assemblies are not set rorth in a building code. Codes are oriented towards buildings which have $r^{r}$ ponse characteristics and alctural properties not generally available in block st. .ctures. Provisions against seismic damage are based upon the observation of behavior in previous earthquakes, and research and experimentation. As data from each of these sources is limited, the designer must rely heavily upon experience, judgment, and ingenuity.

Earthquake effects are not fully predictable in advance and it is not possible to duplicate all possibilities with mechanical test devices. Therefore, rules extrapolated from the principles of mechanics or test information should be used with care, especially in a situation where the natural response of shielding blocks may be changed by a restraint system that dissipates the energy effects of earthquake disturbances. The designer should also understand that lateral-force-

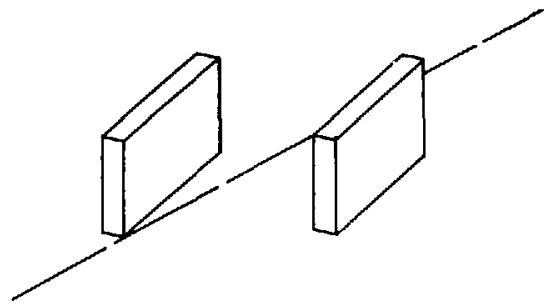

SHIFTING-MISALIGNMENT

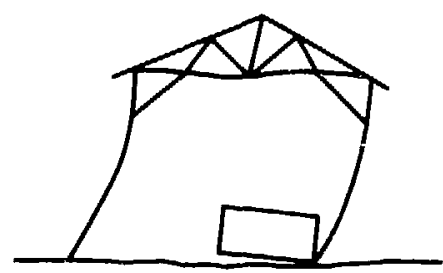

Fig. 2 
resisting systems used to restrain blocks are not the same as the restraint sy'stems contemplated by those who developed the building code regulations.

Formulas for deriving equivalent static lateral forces by relying on an evaluation of dynamic characteristics (such as the fundamental period of vibration of a building) or a formula that incorporates reduction constants for systems providing good ductility must be modified conservatively so that they more accurately reflect actual peak ground accelerations with only minor system damping.

\section{Building Code Analogy}

Building code regulations which have been formulated specifically for buildings, are not applicable directly to shielding blocks. The documents most widely used for seismic design are the L'niform Building Code (UBC), and the Recommended Lateral Forc'e Requirements of the Structural Engineers Arsuciation of California. Both of these recognize the dynamic nature of earthquake loads, but allow an equivalent static analysis to represent the dynamic effects. These codes have been based upon extensive study of the performance of buildings subjected to earthquakes. The equivalent static load is defined as a base shear that is the summation of the maximum lateral loads acting on the structure during any single time interval or during any one single event. The base shear, Fig. 3 , is distributed throughout the structure in a fashion also prescribed by the code.

The base shear as formulated by the Code, is the product of several factors, the two most important being a coefficient, $C$, for dynamic force and a coeflicient, $K$. for type of framing response. The coeflicient $C$ is dependent on the natural period, height, plan dimensions, and damping property of the structure. Shaking table tests have shown that various natural rocking periods can be induced into a single unrestrained block. Fig. 4. Restraining a single shielding block against displacement will have a significant influence on the $C$ value because a restrained block will have a very short fundamental period. Since the $\mathrm{C}$ value is inversely proportional to the fundamental period, a large $C$ coefficient will result from the calculation. The $\mathrm{C}$ value for assembled blocks should be arbitrarily selected, because period calculations for block assemblies are probably meaningless.

The $K$ value will reduce or magnify the base shear depending on the structural system selected and its ductility or energy dissipation capacity. Therefore, by Cirte systems with a good experience record. the abili:adergo stress reversal without undue distress deform without rupture, are assigned a $\mathrm{K}$ factor less than I. Less effective, non-ductile systems are penalized with a $K$ value iarger than 1 . Since there has been so little experience with shielding block assemblies in earthquakes it seems reasonable to combine the two

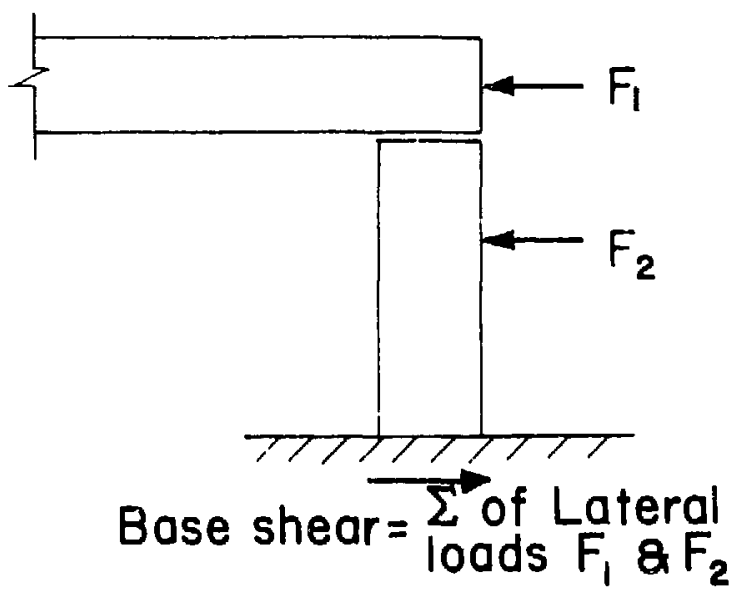

Fig. 3

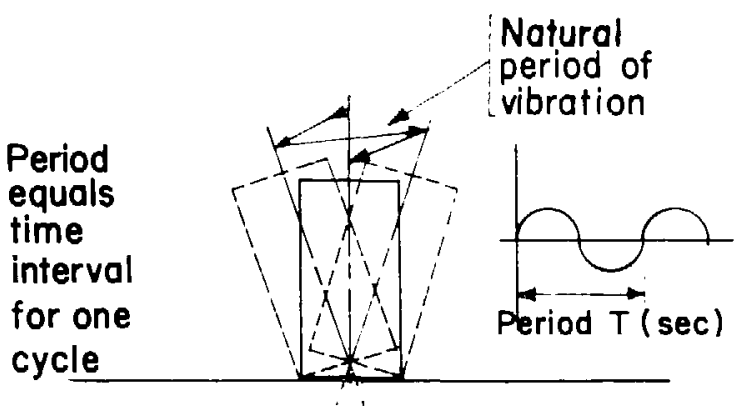

FREE VIBRATION

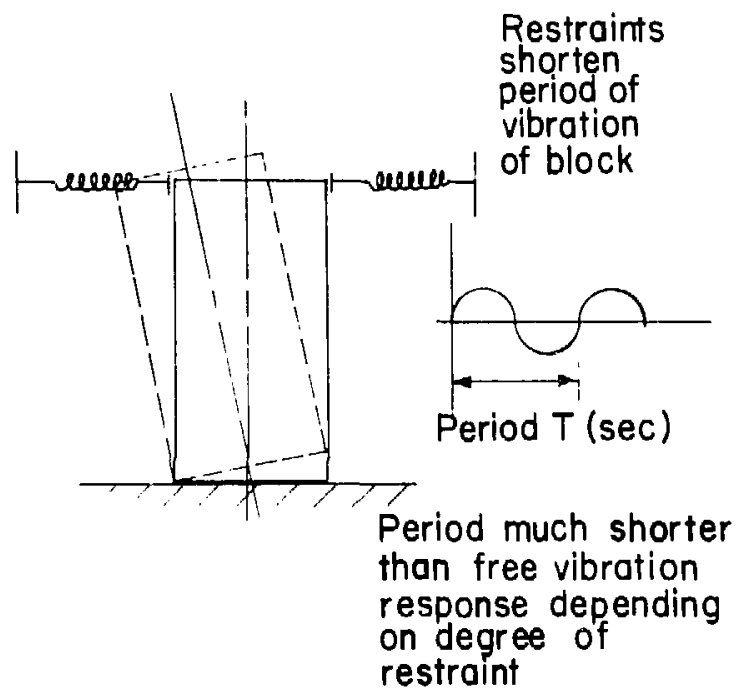

Fig. 4 


\section{BUILDING CODE ANALOGY}

$$
\begin{aligned}
\mathrm{V}= & \text { Base Shear } \\
\mathrm{V}= & \mathrm{ZIKCSW} \\
& \mathrm{Z}=1.0, \mathrm{I}=1.0, \\
& \mathrm{~K}=\begin{array}{r}
\text { varies with the } \\
\text { framing system }
\end{array} \\
\mathrm{C}= & \frac{1}{15 \sqrt{\mathrm{T}^{*}}} \\
& \mathrm{C} \text { not exceed } 0.12, \\
& \mathrm{~S} \text { not exceed } 1.5, \\
& \mathrm{CS} \text { not exceed } 0.14
\end{aligned}
$$

\section{SIMPLIFIED FORM:}

$$
\begin{aligned}
C_{p} & =Z \text { ZIKCS } \\
& =0.2 \text { arbitrary determination } \\
V & =C_{p} W \\
& =0.2 W
\end{aligned}
$$

\footnotetext{
"Building code formula for T (fundamental period of building vibration) not applicable to conerete block assemblies.
}

Fig. 5

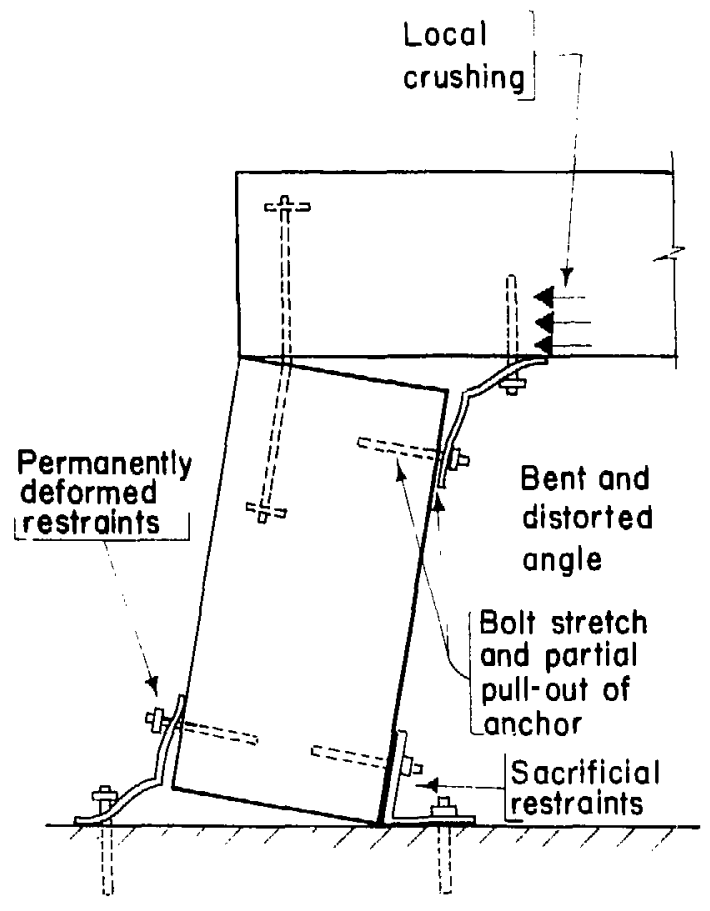

Fig. 6 coefficients, $K$ and $C$, into a single coefficient, $C_{p}$, and to assign arbitrary values to this coefficient consistent with the dynamic ground motion generated by the design earthquake, Fig. 5.

Three other factors enter into the building code calculation for base shear; the first being a seismic risk factor, $Z$, which adjusts the magnitude of the base shear for frequency of occurrence, seve ' $y$, and damage for geographical locations. The $Z$ factor is readily available from seismic risk maps in the Uniform Building Code. An I factor has been added to amplify the base shear for critical facilities such as fire houses and hospitals. In most cases, I $=1.0$ is appropriate for block assemblies. The $\mathrm{S}$ factor which takes account of the interaction of soil and structure depends on the ratio of the structure's fundamental period to the characteristic site period of the supporting geologic formation. The product " $\mathrm{KC}$ " must be amplified by the soil/structure resonance factor, S. Assuming the worst possible combination of factors, the base shear resulting from building code calculations would be approximately 0.2 times the building's gravitational load (weight). Thus it seems easiest to combine all the factors into a single earthquake-design coefficient, called $C_{p^{*}}$ and arbitrarily assign a value of 0.2 to this coefficient.

Building codes specify the maximum allowable design stresses to be used. The UBC allows working stresses $i v$ be increased one-third for earthquakes and wind loads. However, the designer must anticipate excursions of stress well beyond the elastic range into plastic yield, Fig. 6.

Thus when the building code analogy is used, one must design to the elastic state but expect inelastic behavior.

\section{Ultimate Strength Analogy}

For concrete block lateral restraining systems, it may be better to adopt a philosophy of s. iticial restraints and rely on the yield or ultimate strength (short of rupture) of the restraining members (Fig. 7) rather than on code stipulated stresses and allowable increases.

In this analogy more realistic earthquake forces must be used rather than code prescribed forces. The problem is primarily one of reliability and cconomics. Code-prescribed forces are based upon historical information and damage documentation related to buildings and unusual features, such as parapet or curtain walls. Experience shows that a low rise building properly designed to code for a static lateral load of $0.13 \mathrm{~g}$ will resist earthquakes with ground accelerations in excess of $0.6 \mathrm{~g}$. The code stipulated force is designed to allowable working stresses, but the actual force is resisted by stress excursions into plastic yielding short of ultimate strength. Shielding block configurations, on the other hand, have no historical counterpart. Lateral load coefficients should be conservatively estimated but the problem involves economics as well as reliability. 
Yield stress for steel is 1.65 to 2 times working stress. If a coefficient of $0.2 \mathrm{~g}$ is selected to derive seismic loads for working stress design, a coefficient of $0.5 \mathrm{~g}$ is a conservative choice of seismic loads for yield stress design. For ultimate strength design $0.7 \mathrm{~g}$ is a reasonable coefficient since ultimate stresses are 3 to 4 times working stresses (Fig. 8).

The relationship between the response acceleration (expressed as a percentage of gravitational acceleration) and period of vibration can be shown by a response spectrum. Curves can be developed showing the relationship between a response spectrum for a real earthquake, the spectrum stipulated by the Uniform Building Code, and the static carthquake factors suggested here. For three spectra shown in the diagram. Fig. 9, period is shown on the horizontal axis and corresponding maximum response acceleration is depicted on the vertical axis. The highest spectrum curve represents one actual ground vibration component out of many which radiate from the source of disturbance, but is defined here as the maximum. For the curves generated from the ground accelerations or the Uniform Building Code formula, the response accelerations diminish as the period lengthens. However, the $0.5 \mathrm{~g}$ factor as recommended does not vary with per:ods so its spectrum line remains constant. As shielding block assemblies have a high frequency response (or short period) one should utilize the high plateau part of the ground acceleration spectrum. In the figure the area above the $0.5 \mathrm{~g}$ line or area abcd represents the approximate energy demand of the block restraint system beyond yield. This is provided by the plastic yielding of the base connections as the input motion exceeds the accelerations associated with the $0.5 \mathrm{~g}$ curve. In order to ensure that plastic yielding will absorb the energy demand, the base clip angle must be allowed to deform. The designer should not use heavy full depth stiffeners that will not permit distortion. If the clip angle is too stiff all the energy will go to shearing the brittle concrete into which the bolts are anchored. This excess energy demand can be five to six times that represented by the Uniform Building Code spectral values (UBC curve) or several times that represented by the $0.5 \mathrm{~g}$ line.

It can be seen that as the earthquake response level spectrum approaches the ground acceleration, less reliance (safety factor) can be placed on the reserve strength of the restraints. Crucial elements such as floor anchors should be designed for a force value depending on an assessment of the risk to safety should the part fail. Since the method is empirical and not related directly to measurable loads, the designer must utilize the ultimate strength and deformational capacity of materials along with proper detailing to impart necessary toughness to restraints.

\section{Applications to Isolated Blocks}

In anchoring individual concrete blocks for lateral stability, a suitable lateral force coefficient is needed

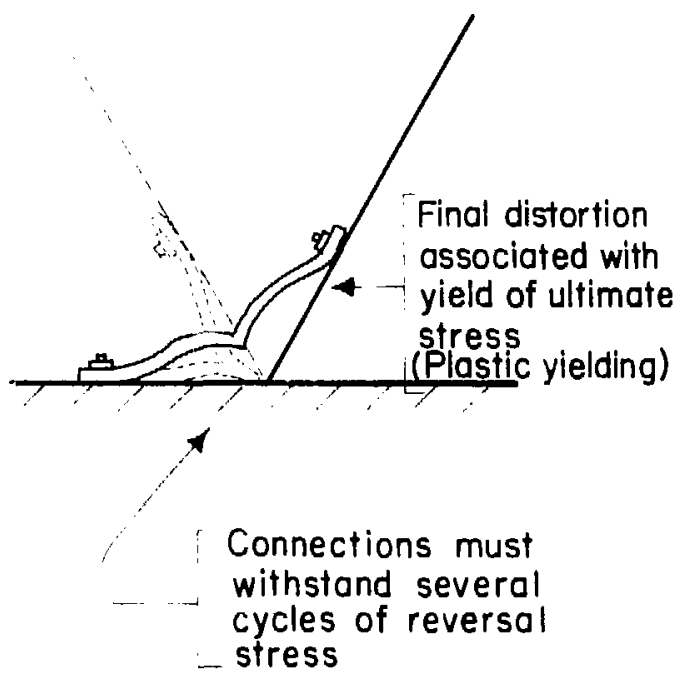

Fig. 7

\section{YIELD OR ULTIMATE DESIGN}

For working stress design

$$
C_{p}=0.2
$$

For yield stress design

$$
c_{p}=0.5
$$

For ultimate stress

$$
C_{p}=0.7
$$

Fig. 8

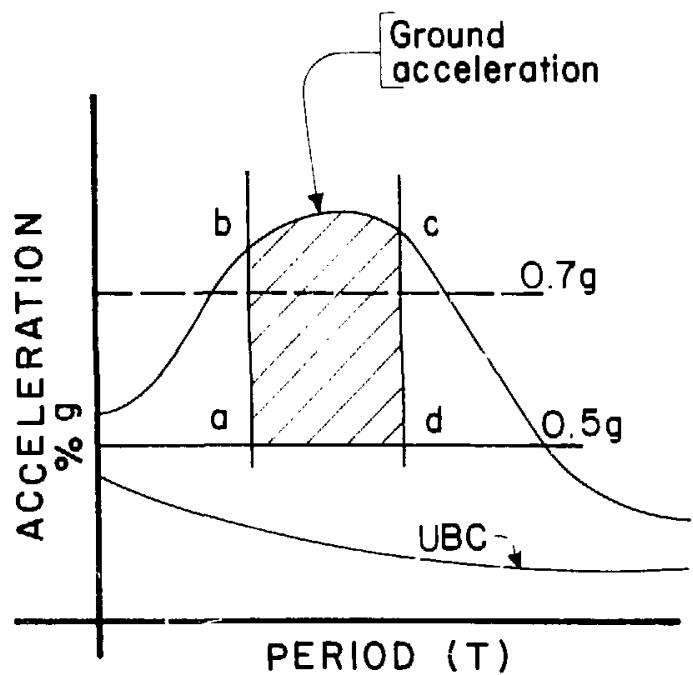

Fig. 9 


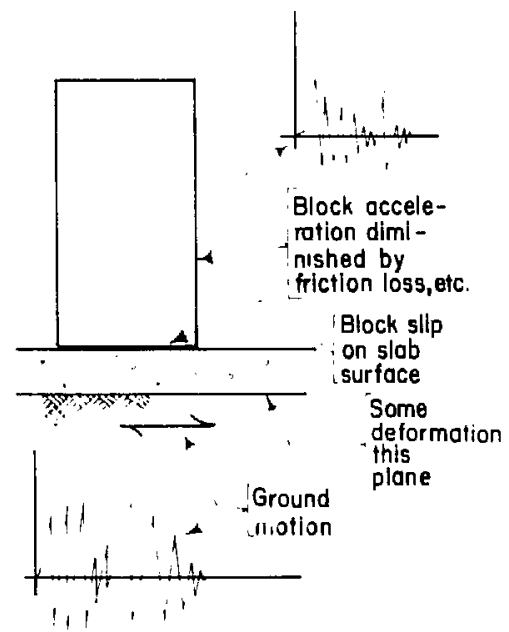

Fig. 10

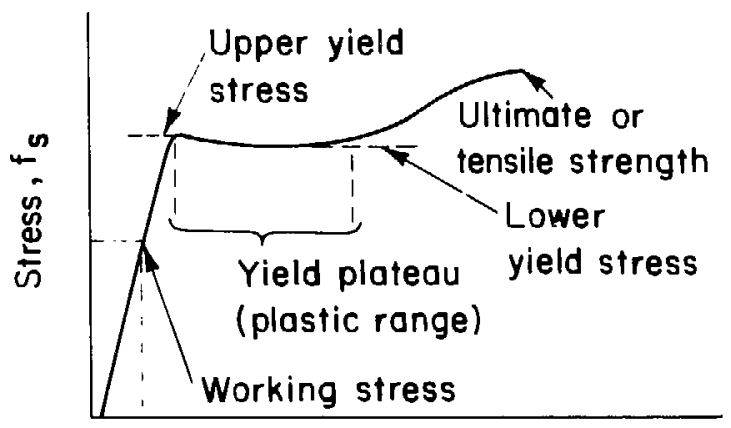

Strain, $\epsilon$

Fig. $11-$ Structural steel stress-strain curve.

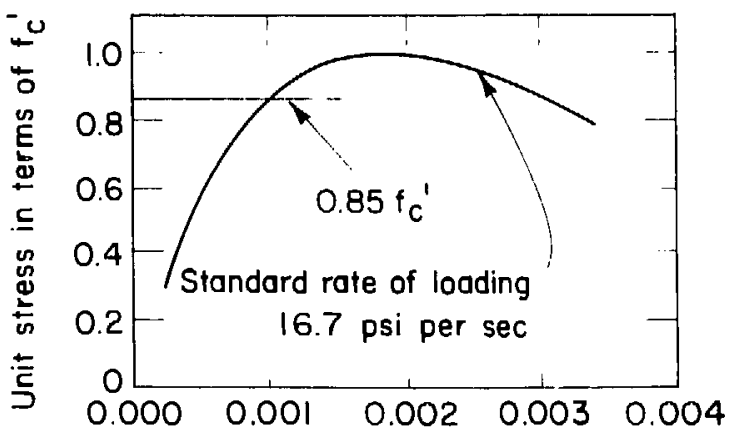

Unit strain in concrete

Fig. 12 - Typical stress-strain curve for concrete cylinders. for computing equivalent static loads that correspond reasonably to the actual earthquake dynamic forces. As most blocks rest on a slab-on-grade there is some energy dissipated in mobilizing the slab, Fig. 10, resulting in some attenuation of the actual ground acceleration. Conversely, when blocks rest on structural framing which is integral with a building frame, there may be amplification of the ground motion. Of greater concern is the possibility of resonance between the forcing frequencies or ground vibrations and the fundamental period of the anchored block. An anchored block has a short fundamental period so an installation supported on a base condition having a short site period (rock) must be designed for a larger force coefficient than one on a softer foundation.

Of equal concern is the fact that an isolated block does not benefit from continuity or redundancy inherent in a unitized system. Also, the base connections which transmit the ground motions to the block may break or tear away due to their brittle nature. Based upon these considerations earthquake coefficients of $0.5 \mathrm{~g}$ at yield stresses for ductile systems, and $0.7 \mathrm{~g}$ at ultimate stresses for non-ductile systems are recommended for the severest anticipated seismic event in the highest risk zone.

After selecting the lateral coefficient an assessment must be made of the real strength of the materials used to resist the loads. If economics dictate, restraint systems should be expendable for the maximum seismic event and materials stressed into the plastic or ultimate region. However, overturning should be prevented. The bending, breaking-up and distorting of anchors is an important source of energy dissipation. Mechanisms can be consiciered as having been fully effective even if during the earthquake they are deformed to the point of uselessness for subsequent events. Structural steel yield stresses can be taken as 1.65 times the corresponding working stress values. At the yield stress value, with a flat yield plateau (Fig. 11), there is ample reserve strain capacity available before the steel strains migrate to the ultimate value and rupture.

Concrete does not exhibit the same type of yield plateau as steel; therefore, yield values are not as easy to define (Fig. 12). Some reserve capacity before ultimate strength should be retained so a factor of 0.85 should be applied to the ultimate values assumed and a factor of 1.33 times the applicable working stress level for yield values. Since concrete is a brittle material, susceptible to sudden failure or deterioration; it is best to be conservative when relying on its reserve strength properties.

Anchors usually employed will be expansion type anchor bolts drilled into existing concrete work or embedded in new work, Fig. 13. Tabulated data usually list working loads as a percentage of ultimate test loads, $25 \%$ being the most common. Therefore ultimate values for anchor bolts and proprietary items like expansion anchors could theoretically be accepted at 
four times their tabulated working loads. Considering failure is abrupt, one should use ultimate values at three times working load values, reserving the excess capacity for very short-lived surges or pulses.

In summary, when anchoring shielding blocks, the basic idea is to provide just enough restraint to prevent dislocation and/or toppling of the block. The restraint system should be designed for stresses or strain conditions approaching yield. For example the ductile steel base clip angle itself should be designed to yield before the brittle concrete holding the anchor bolt can possibly fail. This allows the designer to build energy absorption into a rigid restraining system.

\section{Anchorage Design}

The clip angle should be large enough to provide enough metal to absorb significant energy in bending after yielding. Sizing the angle for $.5 \mathrm{~g}$ base shear at yield stress should accomplish this objective. The angle should not be so heavily stiffened that it rigidly transmits the design shear directly into the anchor bolts without deforming the clip angle. It is also very important that the bolts which anchor the angle to the concrete floor slab and to the concrete shielding block have proper embedment in each and adequate edge distance. The basir philosophy of anchorage requirements is consistent with the ultimate strength design philosophy of reinforced concrete. The failure mechanism is controlled by requiring yielding of the steel anchorage prior to brittle failure of the concrete.

The distance from an anchor bolt to a free edge of the concrete is a very important consideration in anchorage design. If possible anchor bolts siould be located and embedded so that concrete reinforcing steel will intercept potential cracking planes. If sufficient embedment depth and edge-cover distance to develop the strength of anchor steel cannot be achieved in design, then the allowable values for shear and pull out should be reduced appropriately. If several bolts are parallel to a free edge, the effect of overlapping planes on the lateral concrete design strength must be taken into account. For these important considerations the reader is referred to the article, "Guide to the Design of Anchor Bolts and Other Steel Imbedments" by R. W. Cannon, D. A. Godfrey and F. 1. Moreadith which was published in Concrete International, July 1981.

\section{Prevention of Dislocation and Overturning}

One of the easiest and cheapest ways to minimize block dislocation is to key blocks together at coplanar surfaces, Fig. 14, and to the floor. Where blocks in line abut each other, continuous tongue and groove keyways along the contact surfaces are a good solution. Floor keys can be cast in new construction where block locations have been predetermined but chipping or casting keyways in existing construction is not always feasi-
Allowable tension equals

$3 / 4 \times$ manufac-

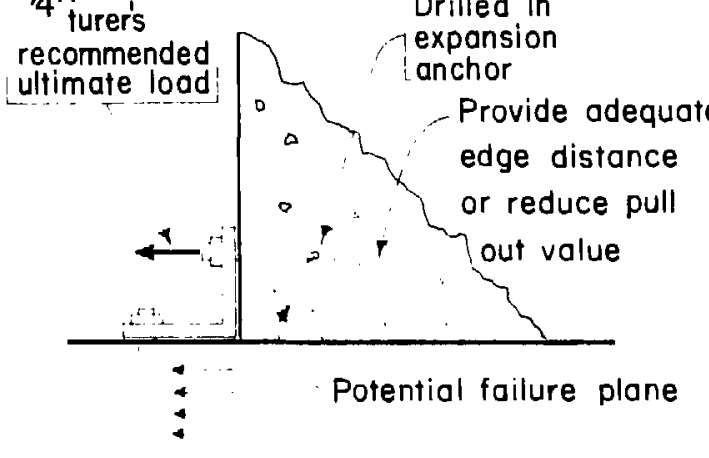

Fig. 13

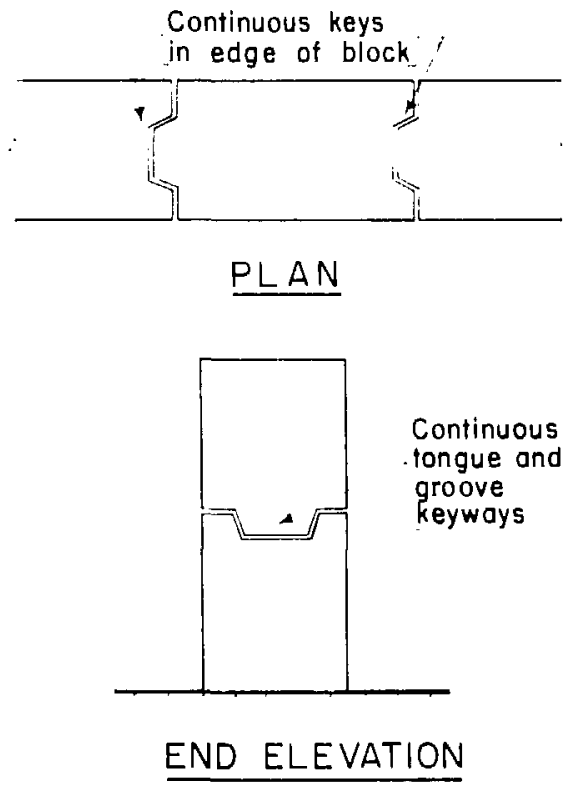

Fig. 14

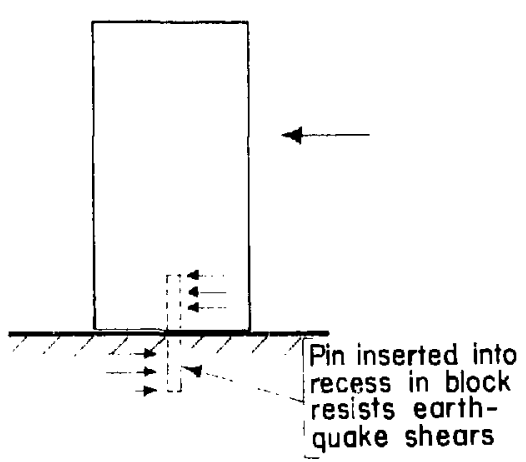

Fig. 15 

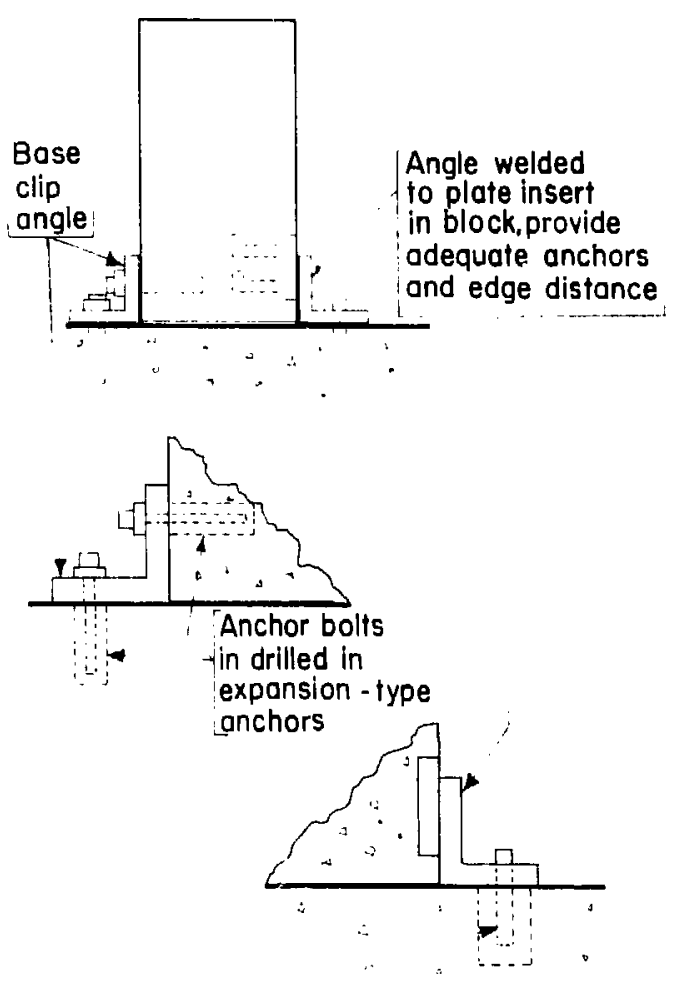

Steel pin grouted inio oversized hole drilled into slab or ground

Fig. 16

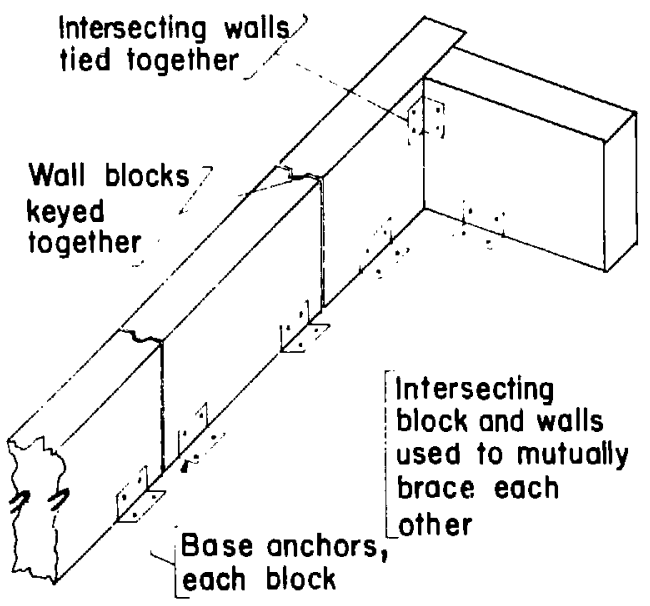

Fig. 17 ble. Heavy pins can be drilled and placed in existing slabs, Fig. 15. The pins can protrude up into voids (formed in the bottom of the block) as the block is set in position on the floor. Lateral loads are transferred by shear in the pin and bearing of the pin on the concrete; and through shear and bearing at the keyway edges. In lieu of pins at the base, angle clips can be attached to the block and secured to the floor with pins or anchor bolts, Fig. 16. Flat steel plate inserts with substantial anchors into the concrete can be cast in the face of the base of the block, and base angle clips can be welded to these plates; or stud anchors can be welded perpendicular to the flat face of the plate and used to bolt (clamp) the base angle to the face of the block. Other anchoring systems can be devised with the function of keeping the ground or slab from shearing away from the blocks as the ground (or slab) induces motion in the block from the earthquake ground motion.

Blocks with a low profile will tend to slide without overturning when put in motion. If the block can slide without causing damage, precautions such as keyways and base anchors can be omitted, and in fact a slide enhancing material might be inserted under the block to keep the block from overturning. Inert anti-friction materials such as Teflon are very expensive. Materials such as plywood or masonite are more suitable - they have the desirable property of reducing friction initially, but deteriorating in efficiency as the earthquake motion fades out. The thickness of the slide bearing materials should be controlled carefully, because if it is crushed by the rocking motion of the block, overturning will be more likely.

Whenever existing anchored shielding block installations are available, their ability to resist movement of other blocks or assemblies may be utilized. Intersecting blocks or walls can also be erected to resist displacement. In these instances, the designer can consider the blocks as a system and provide base anchors. keys, pins and ties as necessary to maintain elements in place. Generally, building framing members should not be used to resist heavy shielding block lateral loads. The blocks and their restraints should be free and adequately clear of building support components. A structural analysis is mandatory if the building framing system is used, and framing elements used should not be part of the vertical load carrying building frame.

Base anchors, Fig. 17, are an effective remedy against sliding and the possibility of differential displacement, but are probably not a satisfactory safeguard against overturning under severe $\sigma_{i}$ sustained rocking motion. Overturning restraints, Fig. 18, can be incorporated with base anchors in the form of tie-down rods or straps attached to block framing systems, foundations or other ballast with sufficient resistance or dead weight to counteract uplift loads. Diagonal bracing struts are a good method of maintaining block stability; the bracing strut should rest or react against the top third of the block height. The principal drawback of 
struts is the encroachment on space around the blocks. To overcume this hindrance, cantilevered steel column sections can be connected to horizontal beams which engage the facss of the blocks such that the beams span horizontally between columns and deliver the block load to the cantilever column. Cantilever action is obtained by anchoring the bottom of the column in a shaft drilled into the ground and filled with concrete, Fig. 19. Formulas are available in the Uniform Building cad' i define the drilled shaft's depth and diameter, and wo bearing values can be interpolated from previuusly available information or assumed from visual site inspection, geologic maps or code tables.

\section{Design of Shielding Walls and Tunnels for Earthquakes}

Often. shielding blocks are assembled in a longitudiral tunnel configuration without transverse walls and with roof blocks sitting directly on wall blocks. It is imperative that a support and anchorage system for the component parts (blocks) be provided in order to prevent misalignment or shifting of tunnel wa!l blocks which would cause the collapse of roof blocks. Assumptions made in evaluating the earthquake coefficient for a unique case should be reviewed first and justifiable adjustments made.

The premise that the base anchorage should be designed to prevent brittle failure yet provide ductility in the angle remains as valid for tunnel configurations as for isolated blocks. However, it is possible to take advantage of additional energy-dissipating phenomena at the interface of wall and roof. As will be described later. connections can be devised that allow for distortion and stress reversal, which along with friction and damping, relieve the effects of dynamic loading. The actual forces could be the same as at the base: however. the superstructure can be designed for reduced forces and still meet the energy demands through inelastic deformation. It is necessary merely to allow the connection or restraining device to yield and let the strain energy of yielding absorb the overload without rupture. Therefore, it is acceptable to use a lower earthquake coefficient of $0.5 \mathrm{~g}$ in determining the equivalent static loads that are to be factored into calculations for the restraining structural features that maintain roof and wall block integrity.

To prevent premature or brittle failure of a ductile connection, one should differentiate between the ductile and brittle features of the same connection. While the ductile or steel portion can be designed for the $0.5 \mathrm{~g}$ coefficient, the concrete anchorage, which is brittle, should be capable of safely withstanding stresses based on the $0.7 \mathrm{~g}$ coefficient. In most instances, the steel parts, i.e., angles, plates, pins, bolts, can be designed for $0.5 \mathrm{~g}$ using the yield strength of the material. But where the steel member relies on the strength of the concrete for effectiveness, such as anchor bolts and pins
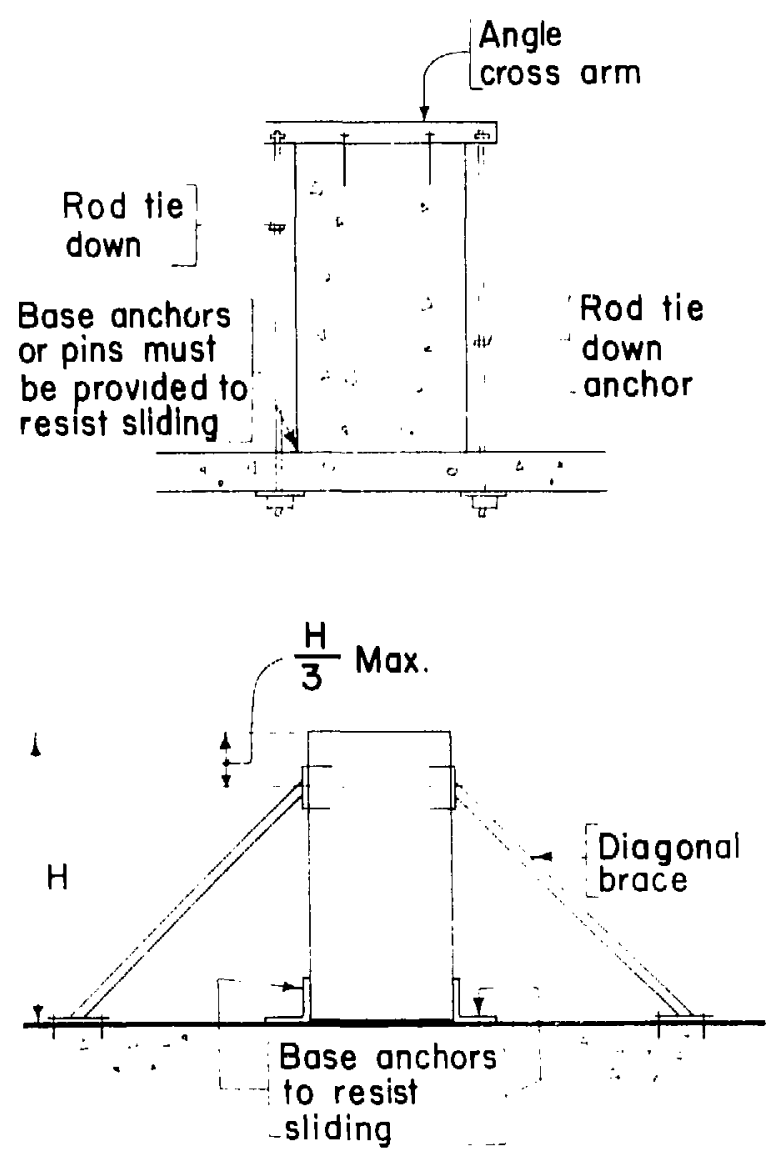

Fig. 18

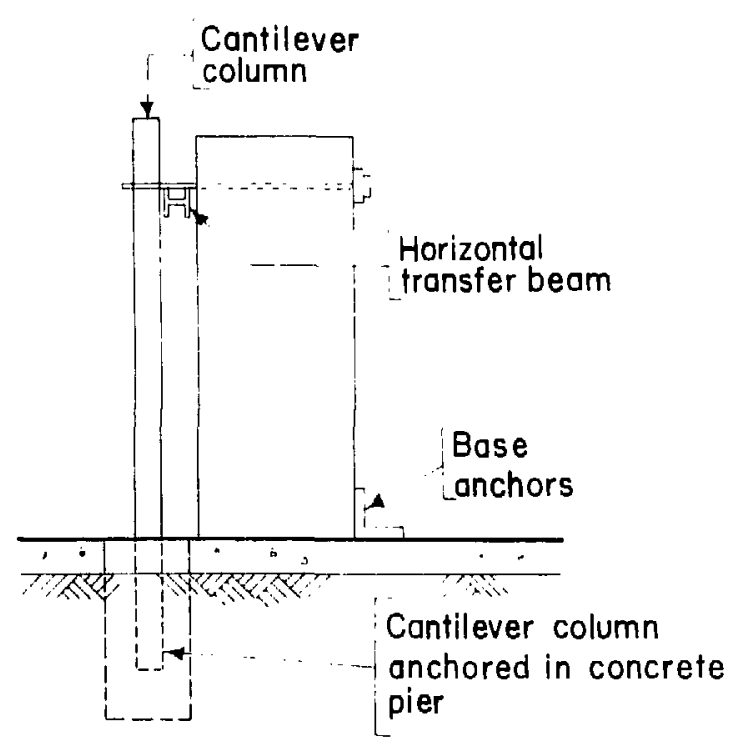

Fig. 19 


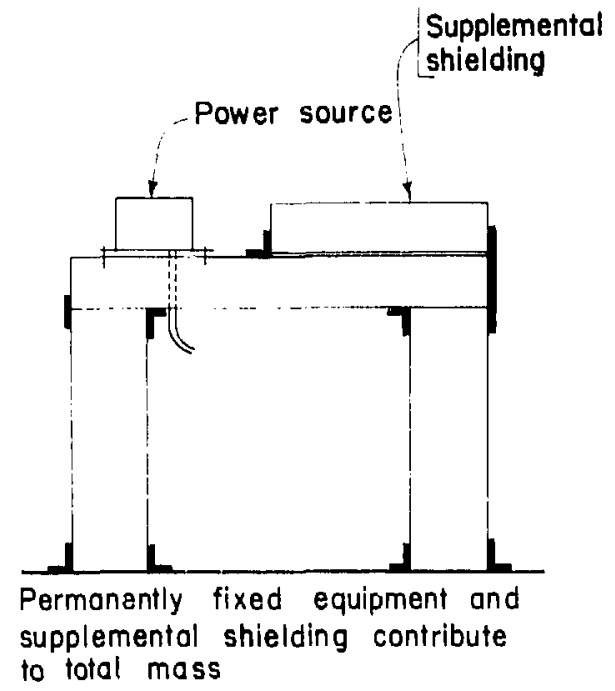

TUNNEL

Fig. 20
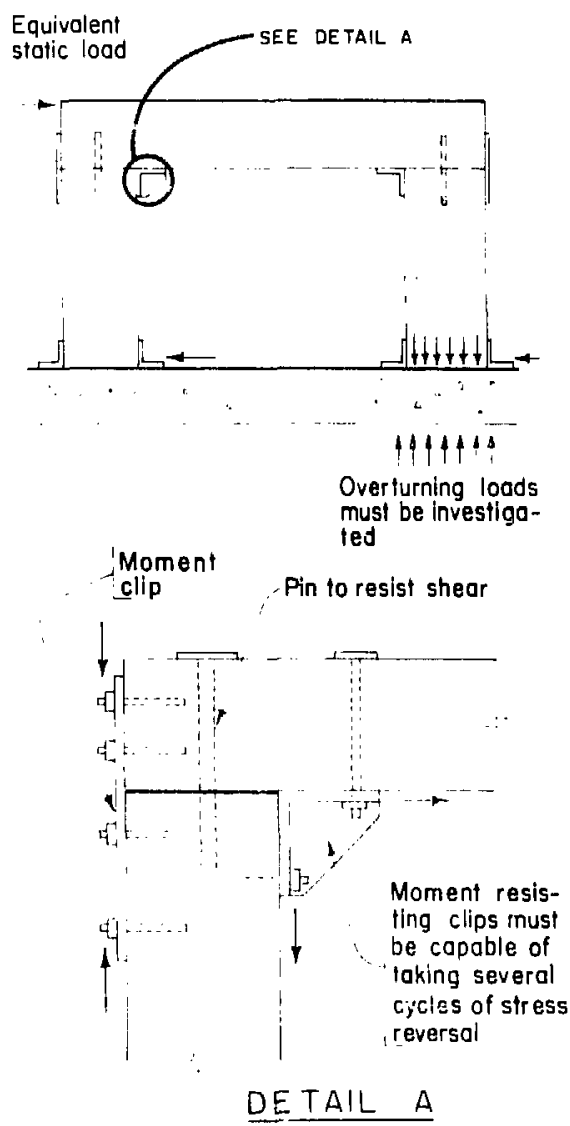

Fig. 21 bearing against concrete, the individual part of the connection anchored in concrete should be sized using the $0.7 \mathrm{~g}$ coefficient and stresses of 0.85 times the ultimate strength of the concrete. Thus, concrete anchorages will be strong enough to allow the beneficial dissi ation of energy by the distortion of the ductile materials in the connection.

With block structures having roofs, the problem arises as to what gravity loads to use with the earthquake coefficient $\left(C_{p}\right)$ to develop the lateral design force. Normally, one would only consides the dead weight of the wall and roof blocks. However, heavy experimental equipment, supplemental shielding, and power sources are frequently placed permanently on the roof, Fig. 20. Unless these accessory weights are effectively isolated, they (or some proportion) must be included in the dead load calculation. This effective dead weight multiplier by the earthquake coefficient $\left(C_{p}\right)$ results in the base shear which becomes the "equivalent" static force applied to the tunnel formation.

As before with isolated blocks, a primary tenet is isolation of the tunnel and its components from building supports or adjacent structures. Wall blocks should be keyed to adjacent blocks and roof blocks keyed or mechanically interlocked to prevent movement relative to their base block, Fig. 21. Base angle clips and pins can be incorporated to preclude sliding. Frame action can be utilized by incorporating angles and brackets to develop moment capacity at roof block and wall block interface. In this situation the clip angles transfer seismic energy directly into this interlocked "frame" for dissipation rather than relying upon the clip angle itself to dissipate energy. For this reason the clip angle should be sufficiently stiffened to transfer several cycles of stress reversal to the "frame" established by the connections. Because it is virtually impossible to develop inflection points in thick blocks, it is wise to assume the walls pinned at the base when calculating frame moments. The tunnel frame overturning loads will add substantially to the dead load; thus the available bearing strata, including the slab and soil, must be investigated for this condition. A soils report should be carefully considered in this instance. Ductility and reserve strength without fetigue failure are primary considerations for all connections and all anchors that have the capability for frequent stress reversal. Tiedowns to resist overturning or harmful uplift are part of the design effort.

In tunnel construction the underside of the roof may be a convenient place to put horizontal diagonal bracing. This location is sometimes preferred when the roof blocks must be occasionally removed. A horizontal truss system, Fig. 22, can then be developed to receive lateral loads from the blocks. Truss reactions must be transferred to the foundation through frame action of the wall and roof blocks or via extra framing, i.e., " $\mathrm{A}$ " frames or struts at the ends of the tunnel or spaced 
intermittently along the length of the tunnel. Diagonal bracing is generally regarded as having less desirable ductile qualities than less rigid framing techniques because of compressive bi:ckling possibilities and tensile hammering tendencies. As a result the building code mandates a design load modifier of 1.25 at working stresses. To maintain the same concept of resistance for the truss system, one should apply the 1.25 factor for the yield analysis advocated in this chapter by modifying the earthquakc coefficient to $1.25 \times 0.5 \mathrm{~g}$ or $0.625 \mathrm{~g}$. First yield stresses should be utilized for the diagonal bracing (rather than ultimate stresses) with this greater coefficient.

If truss reactions at the ends of the tunnel or reaction points are to be transferred to the foundation by moment frame action of the wall and roof block assembly, these reactions in the mornent frame need not include the 1.25 load modification factor when designing the moment frame connections and base anchorages. Design of truss member connections to block assemblies (moment frame) should use reactions derived with the 1.25 modifier. When diagonal braces in a vertical plane are employed to hold the truss (in the roof plane) the modified reactions $(1.25 \mathrm{x})$ should continue to control sizes and details. Foundation bearing pressures can be evaluated on the basis of reactions calculated without the 1.25 factor.

Diagonal bracing can also be located on top of the roof blocks where the exposure of the framing poses no hazard to personnel and does not interfere with process equipment or temporary dismantling. Depending on design loads, connection of the truss diagonals to the blocks, Fig. 22, may be accomplished with anchor bolts; drilled-in-place concrete anchors, i.e., Wej-Its, Parabolts, welded studs or pins. Most support techniques used for individual blocks or blocks in line are equally adaptable to tunnel-like or roofed-over configurations. Diagonal struts can be used to brace each wall; or a system of walers and cantilevered columns can be integrated to support the walls. Since the inertia loads to be resisted are large, the problem of flexibility is encountered when resorting to cantilevers. A check of deflections must be completed and an evaluation made of potential effects of translations and rotations on the stability of the cell unit. Elastic properties of the ground must be considered in determining deflections; the modulus of subgrade reaction could be a useful parameter in this regard.

\section{Design of Shielding Caves for Earthquakes}

Cave facilities may resemble buildings more than other shielding configurations investigated, particularly when the shielding can be accomplished with thin concrete blocks as in the case of precast concrete buildings, Fig. 23. If so, one should reassess the earthquake coefficient of such caves with respect to experience with similar buildings that have successfully withstood seismic forces. If the lateral force resisting system for

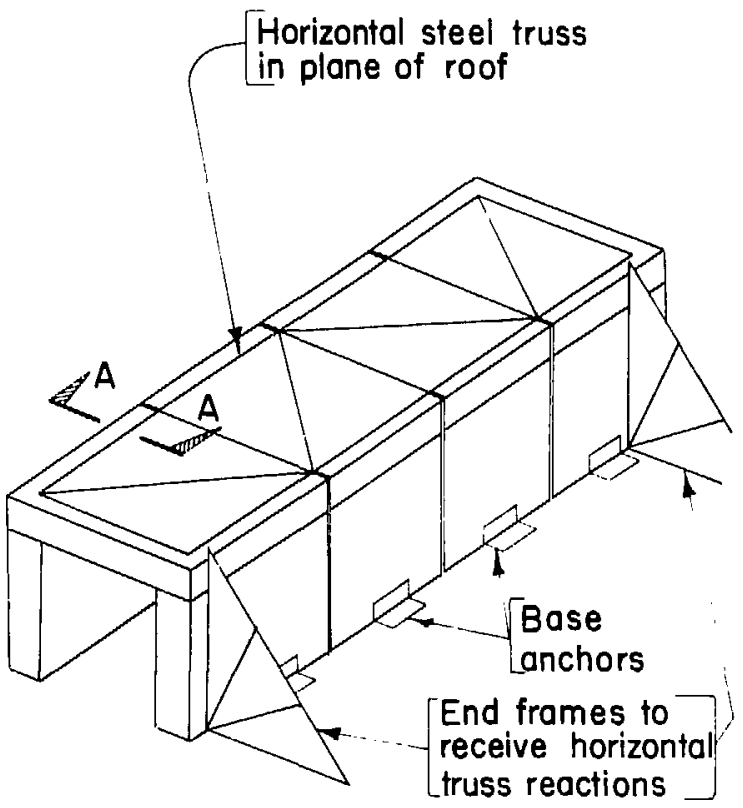

Fig. 22
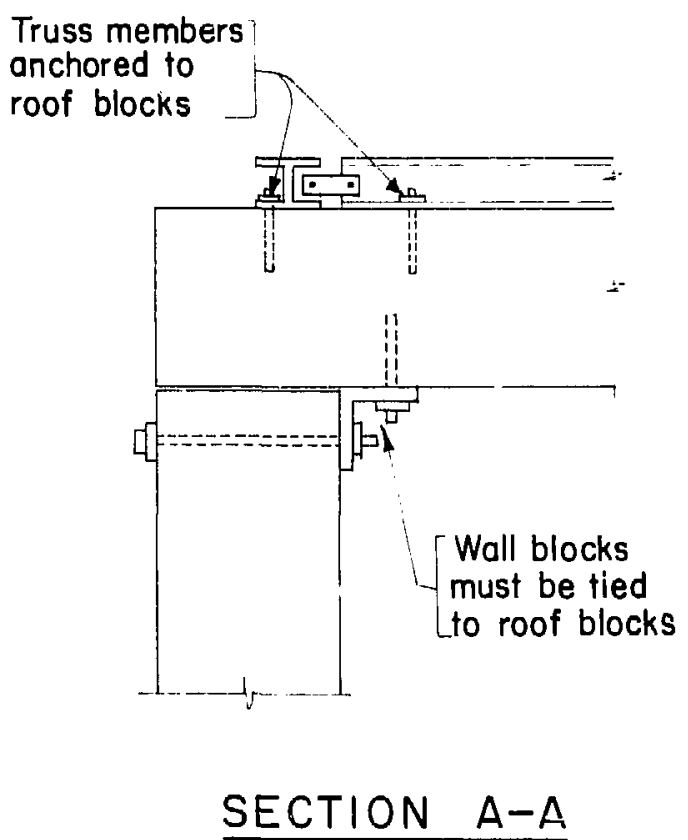

Fig. 22 (Continued) 
Wall top plates acting

as flanges (chords)

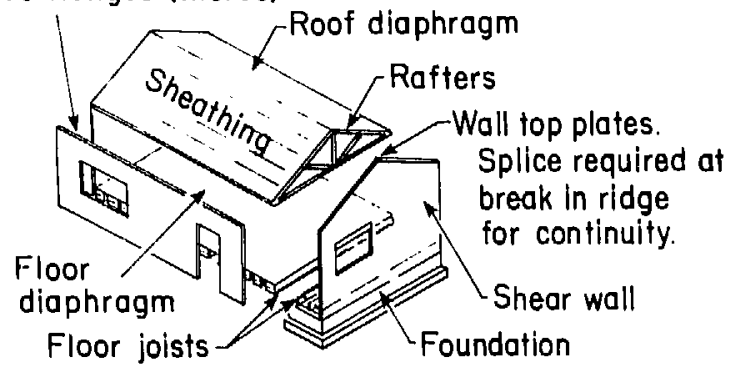

BUILDING

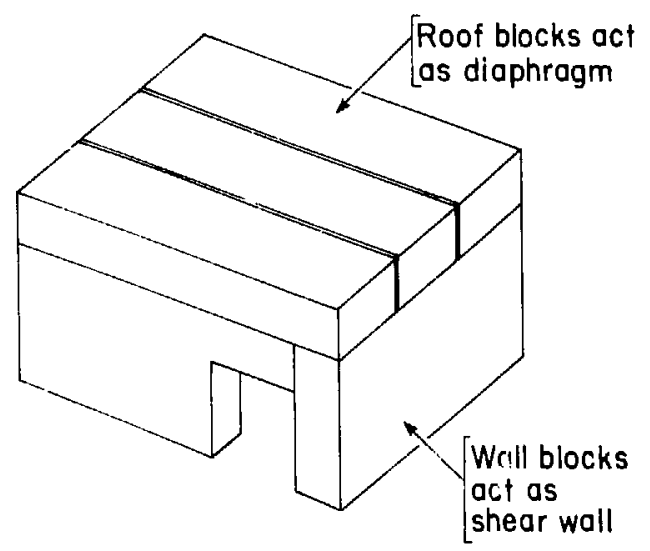

CAVE

Fig. 23

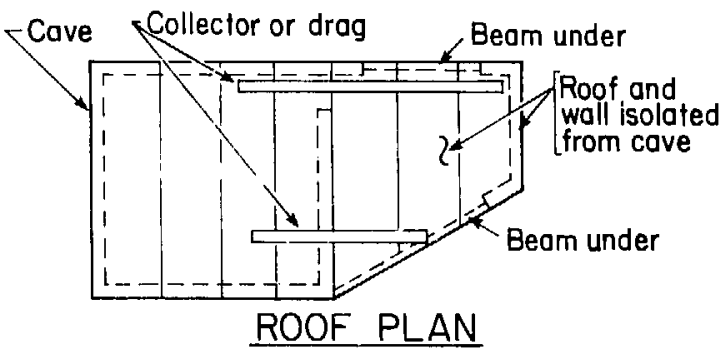

Fig. 24 the cave has the ductility and redundancy of a building the designer can logically use building code criteria for analysis and design. Rather small coefficients can be used, provided one adheres to curtain design and construction principles. For single mass systems, $0.2 \mathrm{~g}$ should be used as a minimum regardless of values computed from code formulas. Allowable stresses can then be predicated upon working stresses increased by onethird. Generally, however, the author continues to favor the use of higher coefficients and yield stresses that are more in keeping with the primary response of a very rigid structure such as a cave of shielding blocks.

In the conceptual design of an earthquake resistant bracing system, the designer must make provision for an uninterrupted path for transferring loads in the bracing members to the ground or bearing medium. Collectors can be used to drag loads from areas tributary to the bracing elements (Fig. 24). Connections and splices must be strong enough to prevent collected loads from breaking the connecting link to the bracing members and isolating part of the cave, thus leaving it without lateral support and immediately susceptible to distress. Caves by nati re usually have four walls mutually perpendicular to each sther; these walls can be used to counteract loncis concentrated by collectors. Internal stresses within the block are seldom critical, but connections of bracing elements or collectors to the blocks must be strong enough to prevent premature breaking away, Fig. 25. Resisting loads by members in tension and bolts in shear are the preferred approaches. When employed, bolts should be high strength fasteners (except A490) tightened in accordance with standard recommended procedures. Good welding has better ductile characteristics than bolting, but quality control is less reliable and welding is more expensive. Drilledin-place proprietary anchors (i.e., Parabolts, Wej-Its) should not be used in tension. Cast-in-place anchors or bolts epoxied into drilled holes are recommended for applications in tension.

Other conventional design techniques are useful in caves, the most expedient being the use of the cave roof as a diaphragm. Shear plates can be used to transfer seismic shears from block to block and structural steel shapes can form flanges (chords) for the diaphragm and load transfer elements, Fig. 26. Individual wall blocks can be anchored together and to the floor to complete the path to the ground for the dynamically induced forces. Where walls can be unitized, tie-downs at the ends to resist uplift are seldom necessary. Interior cross walls, if permanently located, are useful as additional resisting elements and must be anchored to the roof for their proportionate load. Maintaining integrity and alignment are necessary adjuncts to a satisfactory system; previous emphasis on keys, pins, and mechanical interlocks apply.

A supplemental bracing scheme external to the shielding blocks is often an attractive alternative. Here the lateral loads calculated by code formulas can be 
delivered to the supporting framework and the frame members, Fig. 27, designed to function within code allowable stress limits. Diagonally braced or moment frames can be used although some caution is necessary when relying on ductile moment resisting frames. The code allows a reduction ( $\mathrm{K}$ factor) on the load-carrying capacity of these moment frames because of the good ductile performance expected and because of the defor* mation characteristics and ductile qualities of the joints. However, reducing the design moments and shears also may result in lighter and less stiff frames with larger deflections that could be incompatible with tolerable movement of the blocks. If the blocks are unyielding and resist movement, they cannot adapt to the distortions of the frame. This may lead to failure of the frame or frame anchorages, because the frame will not be able to absorb the required energy through plastic yielding. This accumulation of energy may lead to failure of the frame becausr the premise that this energy would be dissipated by distorions of the frame proves invalid. A careful and detailed compatibility analysis must be attempted and a stiffer frame may be required than indicated from the design for moments and shears only.

Since the $K$ factor allows primarily for the ductile qualities of the frame, it must be factored from the computations of moments and shears used to compute deflections. Therefore, the loads should be multiplied by $1 / K$ ( $K$ not greater than l) to determine the deflections. Because of the incongruous nature of the combination of blocks with a moment frame, multiplying the internal forces by some multiple of $1 / K$, say $3 / K$, should be done when verifying deflections. Application of this procedure will result in a stiffer frame.

It can be argued that under such severe restrictions ductile frames should be abandoned both from the standpoint of economics and function. But, if one forcgoes the beneficial qualities of ductility as afforded by a moment frame, a substitute for ductility must be provided by adding more strength and toughness. A concentric diagonally braced steel frame (Figs. 27 and 28), if properly designed and detailed, can provide the toughness. The diagonal bracing system must have sufficient strength to undergo several sudden load reversals during any seismic event; the members and connections must be tough enough to resist severe impulse loading. Strength $r, n$ best be achieved by designing the system to carry as much of the load as possible by member's in tension. Toughness can be attained by making the connections of members strong and durable and more than adequate to develop the full plastic strength of the connected members. Regardless of the direction of load (tension or compression) indicated by the analysis, connections should be designed to develop the most critical strength of the member used, be it tension or compression so that severe stress reversals can be accommodated. Thus, the connections must be able to transfer member forces without failing before

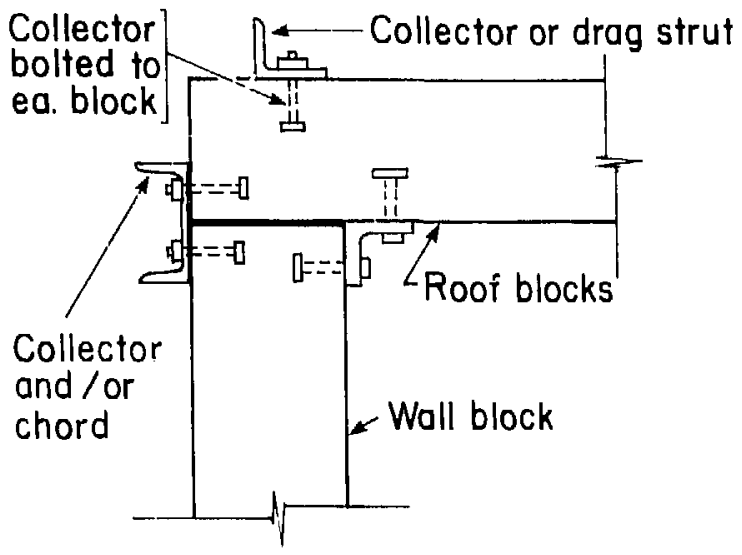

Fig. 25

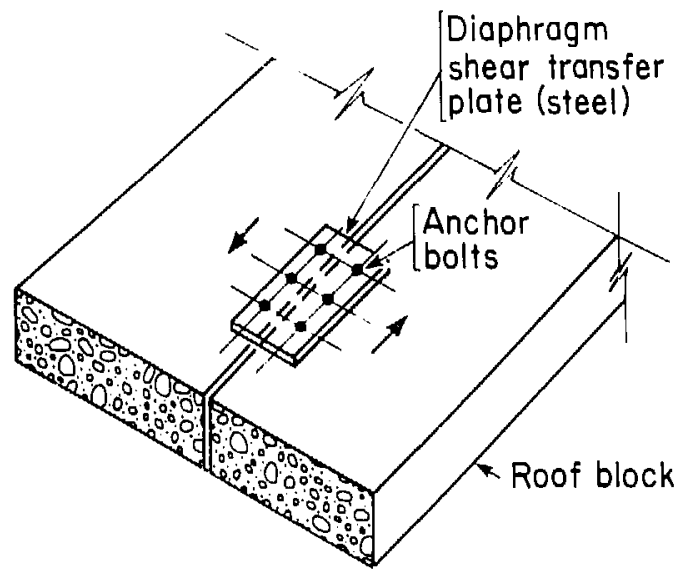

Steei section acts as

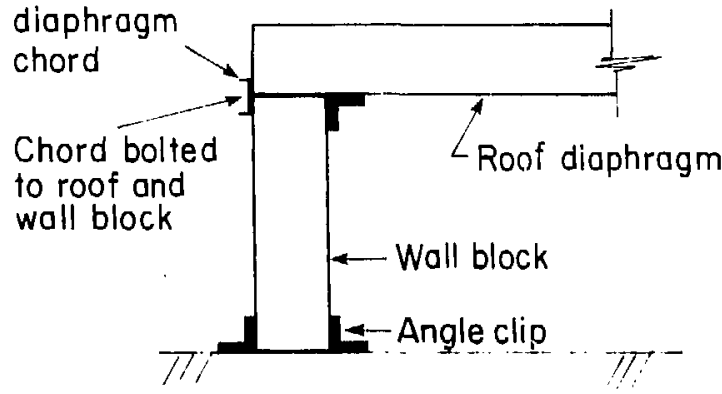

Fig. 26 

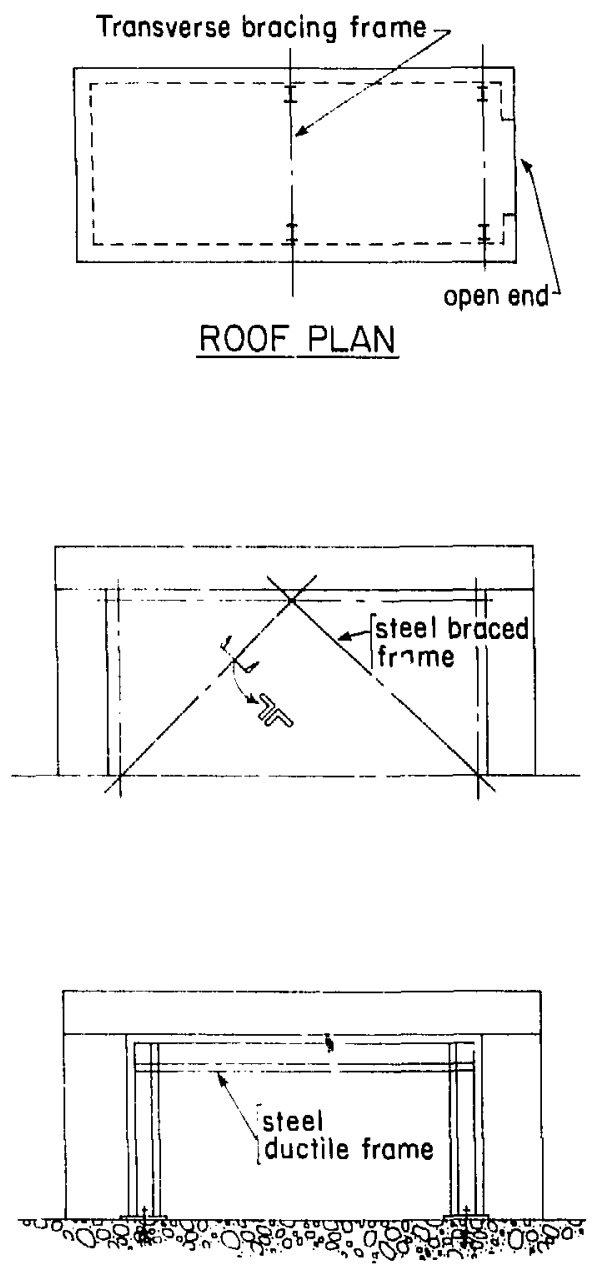

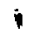

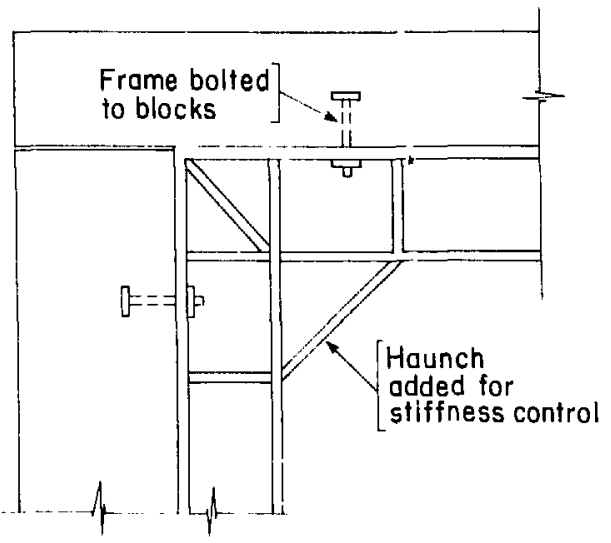

Fig. 27 the member does. It must be assumed that a tension member could accidentally be stressed in compression and vice versa, and the connections designed for the actual plastic strength of the member in either mode. Such strength may exceed the load values used in the design of the member. Finally, strength is best achieved by eliminating eccentricities both in the loading (symmetry) and in the joints, Fig. 28.

\section{Summary of Proposed Earthquake- Design Criteria}

The earthquake design criteria for the bracing of concrete shielding blocks must take into consideration the seismicity of the site location of the blocks and the type of bracing system used to brace the shielding blocks against earthquake ground motions.

The following criteria are recommended for the severest anticipated seismic event in the highest risk zone, Zone 4, Figure No. I Seismic Zone Map of the United States, 1982 Uniform Building Code.

The design base shear, $V=C_{p} \times W$, varies with the type of bracing system. For ductile bracing systems and connections that are constructed of structural materials, like structural steel, that exhibit ductile non-linear behavior at stresses beyond their yield points, a value of $C_{p}=0.5$ is recommended with appropriate yield stress values equal to 1.65 to 2.0 times the allowable working stress values. Diagonal bracing members and their connections shall be designed to resist forces resulting from a base shear increased by a load mooification factor of 1.25 times 0.50 or a $C_{p}=$ 0.625 to insure ductile behavior in the bracing members

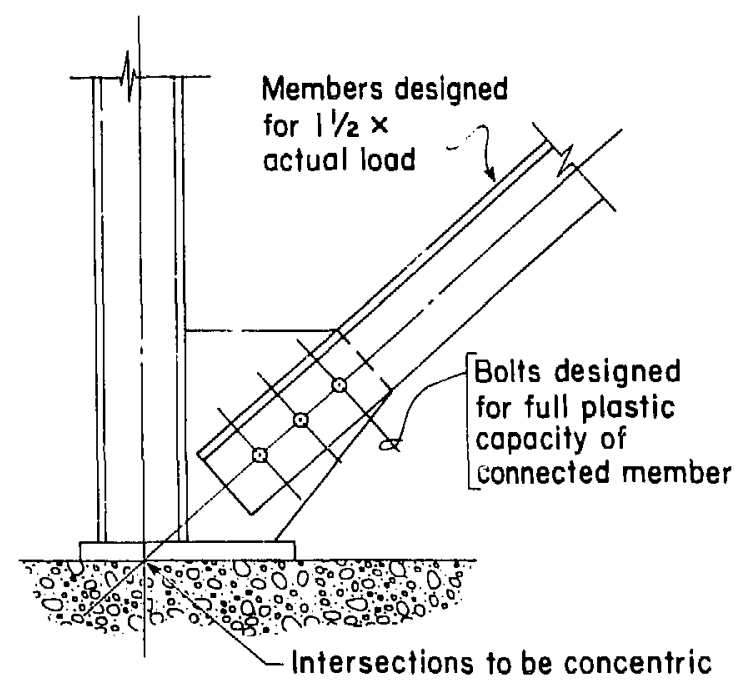

Fig. 28 
and their connections. Diagonal bracing members shall be designed utilizing allowable yield stresses rather than ultimate stresses.

For non-cuctile systems and connections constructed of structural materials that do not exhibit reserve strain energy capacity resulting from non-linear behavior, like non-ductile reinforced concrete, a value of $C_{p}=0.7$ is recommended with appropriate ultimate stress values depending on the type of connection. For reinforced concrete it is recommended that a capacity reduction factor be used such as 0.85 times the ultimate compressive strength of concrete for bearing and compressive stresses. For the design of the anchor bolts or proprietary expansion anchors which depend on concrete for their ultimate load capacity, use $3 / 4$ the manufacturer's ultimate load values, with proper consideration of edge distance and embedment of the anchors. The anchor bolts and shear pins shall be designed strong enough to allow the beneficial dissipation of energy by the distortion of the ductile materials, structural steel, in the connection. 


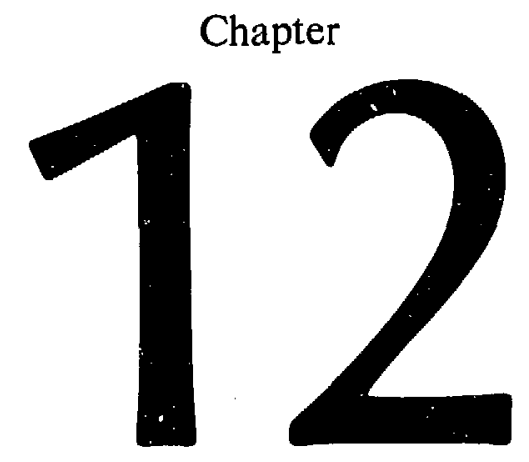

\section{Model Code and Related Services}

\section{FOREWORD: Operaior-Manager's Point of View (Donald G. Eagling)}

The Uniform Building Code (UBC), a widely recognized "model code," is prescribed by the Department of Energy (DOE) for seismic design of buildings. It includes well-developed provisions for designing buildings for lateral-force-resistance to dynamic loads produced by both wind and earthquakes. Not everything one needs to know for seismic design is in the UBC, but in the hands of a competent seismic engineer it is very good.

The UBC is published by the Interr tional Conference of Building Officials (ICBO), a nrofit organization owned and controlled by its . A members. They are "building officials" from UBC member cities, counties, states, or any governmental unit which has jurisdiction over building construction. Operators or managers of DOE facilities who are responsible for seeing that the UBC requirements are met in the design, construction and modification of buildings and facilities may become Class A ambers of the ICBO, providing they have a 'population' to protect. Class A membership automaiically entitles the member to one vote in the code-change process.

In addition to UBC, the ICBO publishes the $U B C$ Standards (similar to ASTM Standards); the Uniform Mechanical Code (UMC) Siandards; the Uniform Plumbing Code (UPC) Standards; the Uniform Fire Code (UFC); Building Standards Magazine; ICBO Research Recommendations; and many other useful documents.

An expert technical staff is maintained by the ICBO to provide plan-checking and code-interpretation services for members desiring such assistance. The ICBO does not control nor does it have jurisdiction. The
"Building Official" (the Class A member) who has jurisdiction also has the legal responsibility for enforcing the code. The ICBO does not. The ICBO serves and supports the Building Official.

Suppliers and vendors who wish to have their prot ducts or systems (such as metal decking) approved by the ICBO must have their products tested and certinied by quality control agencies as meeting ICBO Standards. Products must be re-examined annually to maintain this approval.

ICBO Research Recommendations, a publication which reports product tests and specifies how they must be applied and what values can be used in a given design, is sent to Class A members monthly. Designer and managers who do not have direct or at - indirect access to these Recommendations do no! . .. the proper allowable values to use in seismic designi; similarly, neither do they have current listings of the products which are approved by the ICBO. Manufacturers offering approved products for sale in periodical advertising and other sales literature must include the ICBO-approved design values. Products which have not been approved by the ICBO obviously have no such restriction.

If the ICBO s*aff is used for plan checking, the Class A member doing so will receive a marked-up set of plans, plus a report setting forth the specific ICBO recommendations. It is up to the Class $\mathrm{A}$ member having jurisdiction whether or not the advice is acted upon. The ICBO does a thorough job of "plan checking," covering all aspects of code application.

Currently (1983) the cost to join the ICBO and receive the Uniform Building Code, Building Standards 
Magazine, and the ICBO Research Recommendations would be $\$ 60$ per year for most Department of Energy (DOE) sites. The fee depends on the population of the facility. Advice and interpretations (by phone or letter) are free. Plan checking is reasonable; for example, the ICBO fee was about $\$ 1500$ in 1983 for a million dollar construction contract, with a sliding scale producing proportionately lower fees as project cost increases (e.g., for a 10 million dollar construction contract, the plan check fee in 1983 was $\$ 8763$ ). If one is responsible for enforcing the use of the UBC and is not a Class A member, one simply does not have all the data needed to do the job properly. The Research Recommendations and other published material provided by the "Conference" (ICBO) are of great technical importance to the "Building Official" as wcll as to the designer.

Often provisions of the UBC are necessarily generalized. For example, the code does not provide a direct interpretation for the height to be used in seismic calculations for a building that is taller on one end than on the other. The formulae provided by the code apply generally to flat building sites. As mentioned, advice and code interpretation are available from the technical staff of the ICBO, to assist the Building OfTicial in such special situations. Consulting with the Staff is, of course, not mandatory but may prove extremely helpful.

One last point. The so-called third-party plan check. an independent design review, is a highly effective and inexpensive tool for seismic safety. It is not necessary to use ICBO for this purpose, although they do an excellent job. For fast turnaround, milestone reviews, and close-coupled interaction, it may be more practical to use an independent consulting engineer. However, it is most important to employ a competent, experienced earthquake engineer, not one who is inexperienced or must rely entirely upon the Code for direction. At best the plan check should be performed by an engineer who has had actual experience in earthquake damage surveys. If this is not practical, then it is advisable to choose a professional who has carefully studied earthquake damage reports and is also competent in structural engineering for lateral force design. In any case, the engineer should be thoroughly familiar with the socalled "Bluebuok," the Recommended Lateral Force
Requirements and Commentary, published by the Structural Engineers Association of California. This is the reference document used by the ICBO to interpret the lateral force provisions of the UBC.

The Uniform Building Code (LBC) is only one of several good "model codes" published by non-profit organizations engaged in the study and advancement of standards and criteria for safe building construction throughout the United States. The primary reason the UBC is described in this Chapter is that it is the particular building code prescribed for construction by the Department of Energy. The home office of the International Conference of Building Officials (ICBO) is located in southern California in "earthquake country" so the UBC is particularly sensitive to lateral force design. Those structural and soils engineers who seek to produce a positive effect upon seismic safety have generally pursued this goal through the advancement of the lateral force provisions of the UBC.

It is important to understand that the ICBO has no jurisdiction per se. They only publish the LBC and provide technical support services. The LBC becomes a "legal" document only after it is adopted in a statute or regulation by a governmental agency such as a state, county, municipality or special district having legal jurisdiction. Often the agency having jurisdiction will adopt the code with exceptions or modifications. DOE has not made changes.

Generaily. most operator-managers are not sufficiently familiar with the use of model codes, how they are changed, how to interpret code provisions and how to use the consulting services of code bodies. In particular, they need to know more about the ICBO simply because the Uniform Building Code is the model code specified for their use for the design and construction of DOE buildings. For this reason the Chapter that follows provides a detailed description of the ICBO and its goals and services as viewed by the ICBO itself.

Another nationally recognized code which is generally used for a given area of the United States in which a DOE facility or project is located, may be used by the manager-operator of the DOE facility for general building design, other than seismic. Normally the other nationally recognized codes offer services similar to those offered by the ICBO. 


\title{
Chapter
}

\author{
12

\section{Model Code and Related Services}

Wendell S. Bril

\begin{abstract}
Mr. Bril has more than 35 years' experience in management, technical, and educational aspects of building regulation, including plan review, field inspection, supervision, and training. He served the City of Santa Monica, California as Building Inspector for 13 years and Santa Ana, California as Director of Building Safety for 19 years. In the latter post he was responsible for management of the Department of Building Safety and Housing.

Ile is a past president of both the Orange-Empire (California) and the California State chapters of the International Conference of Building Officials (ICBO) and has long been involved in ICBO research, fire, life safety and other activities.

Mr. Bril recently retired as Training and Development Specialist for the ICBO, working on educational and training programs. He is a lieutenant colonel, Corps of Engineers, U.S. Army Reserve, Retired.
\end{abstract}

\section{Introduction}

To administer a comprehensive earthquake safety program, the operator-manager of a Department of Energy facility must establish policy, make decisions, offer guidance, and take specific actions to insure seismic safety in buildings and other structures. The International Conference of Building Officials (ICBO) offers general and technical services to assist him in meeting that objective.

\section{Organization and Objectives}

The ICBO is a non-profit service organization, owned and controlled by its meinber cities, counties, states, and other governmental units. The Conference's objectives are:

1. Publication, maintenance, and promotion of the Uniform Building Code and its related documents;

2. Investigation and research on principles and techniques that involve life and property safety in the construction, use, and location of buildings and related structures;

3. Development and promulgation of uniformity in regulations pertaining to building construction;

4. Education and certification of the building official, plan examiners, and inspectors; and

5. Formulation of guidelines for the administration of building and inspection departments.

Since it was founded in 1922, expansion of the Conference and adoption of the Uniform Building Code by more governmental bodies in ever-widening areas of the nation have led to the establishment of regional offices in Kansas City, Missouri, and Columbus, Ohio.

The primary operating control of the International Conference of Building Officials is vested in its Class A Members, the governmental units or departments engaged in the administration or formulation of laws and ordinances relating to building construction. Each Class A Member is required to designate a representa- 
tive to act for the member in Conference affairs. For most cities and counties, the designee is that individual who has the legal responsibility for the administration of the adopted building codes, laws, and ordinances; usually, this is the building official. For other governmental units, the designee is the person responsible for administration of the code compliance program. These representatives act for their jurisdictions in matters of code revisions and maintenance, and they are the members eligible to vote, hold office, and serve on committees of the Conference.

The organization is directed through a Board of Directors and Officers elected from the Class A membership. It operates through a staff based in Whittier, California, and its ficld offices in Kansas City, Missouri, and Columbus. Ohio. These field offices arc designed to provide full services in the realms of research, plan checking, code consultation and interpretation, education, and participation in regional activities. Each Class A Mcmber, regardless of population. has equal voting privileges on changes to the Uniform Codes and all corporate operations of the Conference. The Uniform Building Code and its related documents are maintained current through an annual review process with new editions published every three years. All code and related activities of the Conference are conducted in an open forum that permits all segments of the industry the full opportunity to be heard and participate in the processes.

\section{Membership}

Membership in the conference is open to all governmental units as well as all other segments of the building construction industry. There are eight classifications of members. In many instances, Department of Energy (DOE) operating agencies qualify for Class A Membership. Classes of membership are as follows:

1. Class A - Governmental units or departments engaged in the administration or formulation of laws or ordinances relating to building construction, and any such unit which has adopted the Uniform Building Code or used it as a basis in the promulgation of a building code.

2. Class B - Individuals representing such governmental units or departments.

3. Chapter - Associates or groups of city or county officials engaged in the administration or formulation of laws or ordinanres related to building construction.

4. Professional - Engineering-architectural societies or associations interested in the practice of architecture or engineering.

5. Professional - Individuals engaged in the practice of architecture, engineering, applicable types of inspection, construction, research, or other related activities.
6. Associate - Firms interested in the objectives of the Conference.

7. Subscribing - Trade associations or groups of firms interested in the objectives of the Conference.

8. Honorary - Bestowed upon an individual or organization who has rendered outstanding and meritorious service :o further the objectives of ICBO.

\section{Services}

A full-time research staff of registered civil, structural, and fire-protection engineers is maintaincd for the purpose of evaluating and formulating recommendations on new materials, products, and construction systems. Many of the research recommendations deal with lateral-force-resisting systems and other seismic safetyoriented determinations (shear and tension values of anchor bolts for anchoring structures or machinery, for example). Class A Members receive a complete file of the current recommendations and monthly supplements keeping the file up to date.

A plan-checking, or plan-examination, service is provided by a staff of registered civil, structural, and fireprotection engineers. When used, this service provides a third-party review by an engineering staff with experience in earthquake engineering, assuring that the calculations, plans, and specifications will fulfill the objectives of the earthquake safety program and other requirements of the Code.

A staff of engineers and experienced construction experts is available to assist members in the interpretation and application of the Uniform Building Code and other regulations. This assistance is available by letter, or, in urgent situations, by telephone consultation. Interpretations of unusual or common interest are published in each issue of the Building Standards magazine.

Educational courses, including college credit courses as well as seminars, are sponsored in various universities and colleges throughout the country for training and development of building officials, plan examiners. and inspectors. All members are kept fully informed on vital issues affecting their work through a constant flow of information disseminated primarily through the bimonthly Building Standards magazine and the alternate monthly newsletters.

\section{Publications}

One of the primary functions of ICBO is the publica tion and maintenance of the Uniform Building Code (UBC) and its related documents. From its early and continuing recognition of the importance of proper seismic safety design, the UBC has established a posi- 
tion of leadership across the nation for its maintenance of objective and responsive regulations which address this problem. A companion publication, the Uniform Building Code Standards, presents in a compact and concise manner all of the national test material and special design standards referred to in the Uniform Building Code.

The seismic design requirements of the UBC are based upon studies made by the Seismology Committee of the Structural Engineers Association of California (SEAOC) over the years, but most specifically since 1957. In that year, the Board of Directors of SEAOC gave specific direction to the Seismology Committee to initiate studies leading to code provisions which would be available to ICBO or any other code writing body which desired to use them. They are based upon the observed fact that earthquake ground motion and the response of buildings and structures thereto is a problem in structural dynamics even though the actual provisions in the code are expressed as so-called "equivalent" static forces.

These provisions have evolved and changed through the years based upon actual experience during earthquakes. The resulting studies of damage and the interpretations and conclusions drawn therefrom hav: led to revised code provisions. Furthermore, the provisions are based upon research carried on at universities specializing in studying earthquake resistant design and specifically the ductility of structural framing systems.

At the present time, the UBC seismic design provisions are based upon a preference for ductile framing systems that can absorb large amounts of energy within acceptable limits of inelastic deformation as the primary seismic resistance. However, the provisions also recognize that for low and intermediate height buildings, shear walls and braced frames may provide the primary resistance, and furthermore, give a slight bonus to those systems by using a ductile structural frame as a "back-up" system, or second line of resistance. The code also provides for possible effects due to depth and type of soil at the site, the importance of the building as related to its function, and the geographical location of the structure as it relates to the exposure to earthquake damage.

In addition to recognizing the dynamic nature of the earthquake problem and desirability of ductility in the framing system, the seismic design provisions of the UBC require that the building structure and all of its components be tied together in one cohesive unit and that a logical load-resistance path be maintained continuously through the structure, so that all loads in the structure can be adequately resisted and delivered to the ground.

Every three years a new edition of each of the various ICBO codes is published, incorporating advances in seismic, structural, fire, and life safety design and keeping pace with changes in building construction technology. In each of the two intervening years, a supple- ment is issued containing all changes approved at the most recent annual business meeting, plus an analysis of these changes. In this manner, the codes are maintained as a "living document."

As mentioned in the Foreword of this chapter, in addition to the Uniform Building Code and the UBC Standards, the Conference publishes the Uniform Mechanical Code, Uniform Code for the Abatement of Dangerous Buildings, Uniform Fire Code, Solar Energy Code, and additional educational and technical reference materials.

Short courses, textbooks, and manuals on building department administration, field inspection of buildings and structures, and plan review are also available. Building construction and design offices frequently use these services for a variety of routine work, and when there is a need for supplemental training of personnel on the building construction or related staffs.

\section{Potential Benefits}

The manager of a DOE facility should consider individual or agency membership in the International Conference of Building Officials as an integral part of an overall seismic safety program so that the "inhouse" staff may receive the benefits of the available ICBO services. When dealing with the design of new facilities, evaluation or rehabilitation of existing facilities, and other aspects of a professional seismic safety program, there is a continuing need for an "on-call" technical service capability for plan review, research, and interpretation, which is offered by the Conference.

Experience has shown that merely establishing a level of lateral-force resistance for structures is not effective without making certain that the load-resisting system is continuous, adequately connected, and anchored, to perform properly during a seismic incident. In recognition of this important fact, the UBC incorporates provisions to insure the integrity of related features in the structure, such as fire protection elements, building exits, storage racks, machinery and other equipment. The ICBO also studies what is necessary in these features to maintain life safety systems and assure the continued operation of essential facilities.

\section{Applying for ICBO Membership}

A copy of the ICBO Membership Application form, complete with descriptions of the Classes of Membership and benefits, is presented on the next two pages.

Persons wishing to discuss eligibility requirements and other details may contact ICBO directly. The telephone number is (213) 699-0541. ICBO's complete address is:

International Conference of Building Officials

5360 South Workman Mill Road

Whittier, California 90601 


\section{International Conference of Building Officials}

5360 SOUTH WORKMAN MILL ROAD • WHITTIER, CALIFORNIA 90601 • (213) 699-0541

\section{MEMBERSHIP APPLICATION}

\section{PROVISIONS OF THE BYLAWS REGARDING OBJECTIVES}

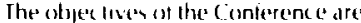

1 Io inveshigale and promote the principles underlying satcty in the. construction. ox c upancy and loc atton of buildings and struc lures

2. To research, develop, recommend and foromote untiorm regulationh,

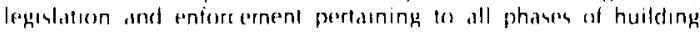
construction.

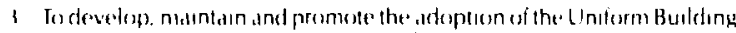
codte and other unifors coder and relised documents which are designed to advance the catuse of uniformity in regulations for the construction, alleration, conservation, mainlenance, preservation or repatr of huildings and structures, and equipment and fixtures in either of the foregoing. in the extent regulation of any said matters is consid. ered destrable.

\pm To advise and assist in the administration of huilding laws and urdinances, the development of management and entorcement programs and related activitien.

5. To research, develop and publish educadional matertals relating to uniform building construction procedures and practices

6. Toradvance the professionat sills of those engaged in the administration and eninrcement of building laws.

7. To do all such other things as are incidental to or destrable for the attanment of the above objectives.

DATE

\section{BYLAWS PROVISION \\ ANNUAL MEMBERSHIP DUES \\ FOA FOLLOWING CLASSIFICATIONS}

(See reverse side for more delailed membership intormation.)

(1) CLASS A dues are based upon population as follows

Lems than 10,000

Dues

Over 10,000

$\$ 60.00$

(designated by $C$ lass $A$ representative) ......... None

(3) CLASS C (for nonvoling government individuals) . . . 45.00*

(4) CHAPTER (as a group) None

(5) PROFESSIONAL ............. $45.00^{*}$

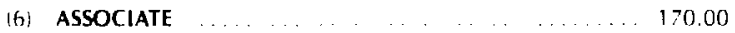

(7) SUBSCRIBING . . . . . . . . . . . . . 345.00

(8) HONORARY None

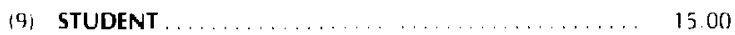

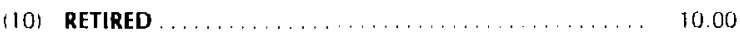

-With research reports, $\$ 110.00$ additional per year.

I hereby apply for a membership in the International Conference of Building Officials Classitication on behalf of 


\section{MEMBERSHIP CLASSES}

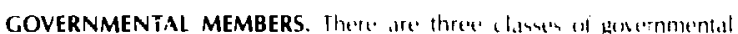
numbership

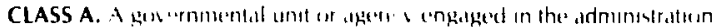

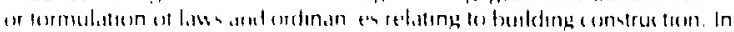

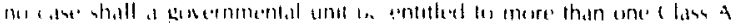

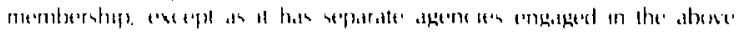

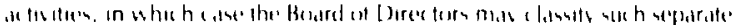
.

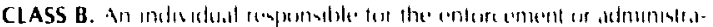

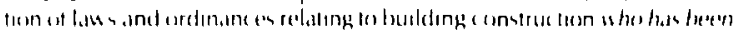

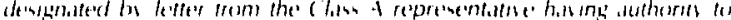

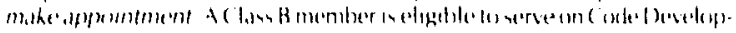

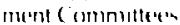

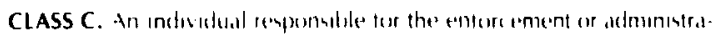

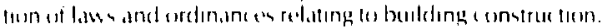

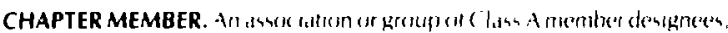

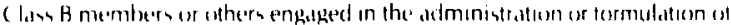

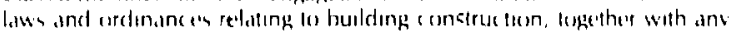

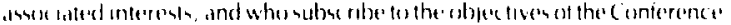
PROFESSIONAL MEMBER. An Individual ur tirm. Inc orpurated or un.,incom-

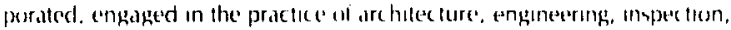
resesirch or tersing.

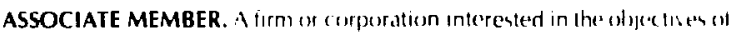
the cunterence

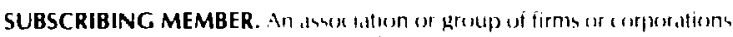
interested in the whjectiven of the conterence.

HONORARY MEMBER. An indw idusl who has rendeterd orutstatoding and meriterious servic as in the furtherinces of the ohler tiven of the Conference, and who shall be proposed by the Board of Directors and confirmed by a majority vote at the Annual Conterence

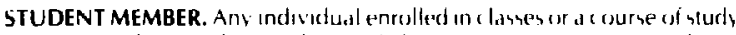

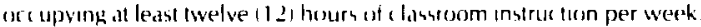

RETIRED MEMBER. Any fornier remghaded representativer of a Clase A member who is rellired.

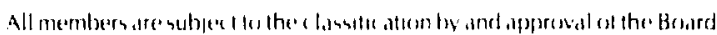
ai Directors.

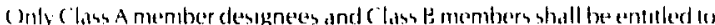
wote on any matter, whethes as a commitlee memiber or otherwise. Gach Clase A memizer shall have une vote and one vote only on any given matter However, for the purpose af bringing up matters for disc ussion, ali members nuay niake and uecond motions. Al! members shall be entitled to particupate in meetings and disc ussions. Excepl as otherwise provided by the Bylaws, any member mas be appointed to a committee as a nonvoting member.

Clas A members thall, when admitted to membership, designate in writing the individual who is (o) act an offor al representative for the purposes of voling, exerulıng written consents, and for committee membership. Class $A$ members may, in addition, designate, in writıng, individuals to do as Class B members to serve on standing committees, and vote on other matters of business which may be assigned by the Board of Directors. Said designations may be changed in writing from time to time. The Class A member may also designate in writing an individual from his own govern. mental unit or agency thereof to attend and acl as a substitute proxy in the place and stead of the Class $A$ designee or Class B members in all resperts as set iorth ahove

\section{MEMBERSHIP BENEFITS}

CLASS A MEMBERS initially rec ewe all Conference services, inc luding al gratis subscription to the Cinference periodical. Building Standards, and one cupy of each of the following: Uniform Building Code lisuse ledit, Uniform Building Code Standards, Uniform Mechanical Code. Uniform Housing Curle, Unifurm Plumbing Conde. Uniform Cude for the Abutement of Dangerous Buildıngs. Unitorm Sign Codes. Dwelling Construc tuen Under the Uniform Building Corle, Uniorm Fire Code, Uniform Fire Cude Standards, Uniform Building Securaly Code. Uniform Administrative Code and

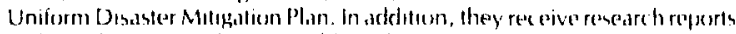
and supplements at they are published, a copy of each new edition of the Uniform Building Code lowse leati) and annuat supplements in the vears between republicaltion, a cops of the Membership Roster and annital uphlate, and meeting nulle es.

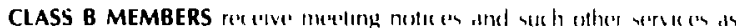
authorized by the Bonded of Dircetors

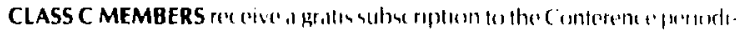

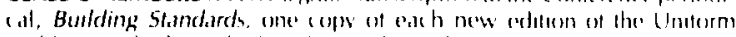

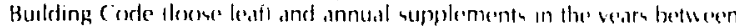

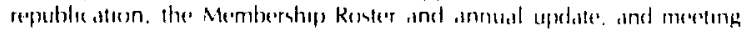
nutro's.

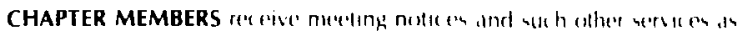
wuthorted by the Bosird of I Irex (or

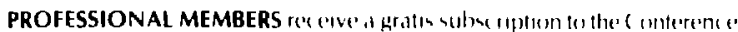

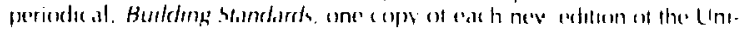

furm Bulding (ode floose leafi) and annual suppiements in the years between republication, the Membership Roster and annual update, and meeting nolices.

ASSOCIATE MEMBERS reccive a gratis subscription to the Conference periodical, Building Standards, une copv of unch new edition of the Uniform Building Code (loose leafi) and annual supplements in the years between republication, research reports and supplements as they are published, the Menbership Roster and annuil update, and meeting notices.

SUBSCRIBING MEMBERS receive Iwo gratis copies of the following: ench issue of the Conference periodic al, Building Standirds, each new edition oi the Uniform Building Code (louse leaff) and annual supplements in the vears between republication, research repurts and supplenents as thev are published, the Me'mbership Roster and annual update, and meeting notices.

HONORARY MEMBERS recilve a gratis subsoription to the Conterence peroudical. Building Strandards, one copy of each new edition of the Uniform Builting Code lloose leafil and annual supplements in the vears between republication, the Memlership Roster and annual update, and meering nuslic s's.

STUDENT MEMBERS recese d gratis subscriptum to the Conference pertodrcal, Buildeng standird,

RETIRED MEMBERS recente a gralls subse ription to the Conference periodical. Bulding Shandards the Menbership Roster and annual update, and meating notices 
This report was done with support from the Department of Energy. Any conclusions or opinions expressed in this report represent solely those of the author(s) and not necessarily those of The Regents of the University of California, the Lawrence Berkeley Laboratory or the Department of Energy.

Reference to a company or product name does not imply approval or recommendation of the product by the University of California or the U.S. Deparment of Energy to the exclusion of others that may be suitable. 